



\section{LA MANCOMUNIDAD DE LOS CANALES DEL TAIBILLA EN LA PROVINCIA DE ALICANTE}

Análisis de la implantación y evolución de la Mancomunidad de los Canales del Taibilla en la provincia de Alicante y sus repercusiones.

Joaquín Melgarejo Moreno

Andrés Molina Giménez

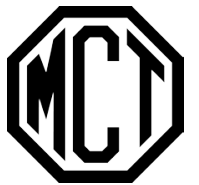

Instituto Universitario del Agua y de las Ciencias Ambientales 


\section{LA MANCOMUNIDAD DE LOS CANALES DEL TAIBILLA EN LA PROVINCIA DE ALICANTE}

\section{Edición:}

Mancomunidad de los Canales del Taibilla

Instituto del Agua y las Ciencias Ambientales

Universidad de Alicante

\section{Dirección:}

Joaquín Melgarejo Moreno

\section{Autores: \\ Joaquín Melgarejo Moreno \\ Andrés Molina Giménez}

\section{Ilustraciones:}

Ana Melgarejo López

Martín Noguerol Bertomeu

Silvia Valero Rodríguez

Rafael Zarza García

\section{Imagen de portada:}

Martín Noguerol Bertomeu

Silvia Valero Rodríguez

Diseño editorial y maquetación:

Martín Noguerol Bertomeu

Silvia Valero Rodríguez

(C) Editor, Autores e Ilustradores

\section{Impresión:}

Imprenta QdH - Cartagena

Primera edición: Marzo, 2017

ISBN: 798-84-16724-40-6

Depósito legal: A76-2017

*Las bases de los mapas y planos utilizados han sido extraídas de las siguientes fuentes: PENOA cedido por (C) Instituto Geográfico Nacional de España.

SIOSE cedido por ( I Instituto Geográfico Nacional de España

Reservados todos los derechos.

Los derechos de explotación de esta obra están amparados por la Ley de Propiedad Intelectual. Ninguna de las partes de la misma puede ser reproducida, almacenada ni transmitida en ninguna forma ni por medio alguno, electrónico, mecánico o de grabación, incluido fotocopias, o por cualquier otra forma, sin permiso previo, expreso y por escrito de los titulares del @ Copyright

Impreso en España 


\section{LA MANCOMUNIDAD DE LOS CANALES DEL TAIBILLA EN LA PROVINCIA DE ALICANTE}

Análisis de la implantación y evolución de la Mancomunidad de los Canales del Taibilla en la provincia de Alicante y sus repercusiones.

Joaquín Melgarejo Moreno

Andrés Molina Giménez 
1. DESCRIPCIÓN GEOFÍSICA DEL ÁREA ABASTECIDA POR LA MCT

\section{LA MCT COMO MODELO DE GOBERNANZA INTEGRAL DEL AGUA}

3. MARCO JURÍDICO Y ESTRUCTURA ORGANIZATIVA DE LA MCT

3.1. El proceso de construcción jurídica de la MCT.

3.2. Principales normas reguladoras.

3.3. Naturaleza jurídica de la MCT.

3.4. Organización: especial referencia a la representación de la provincia de Alicante en los órganos de gobierno de la MCT.

\section{INCORPORACIÓN DE MUNICIPIOS Y LLEGADA DE CAUDALES DE LA MCT A LOS MUNICIPIOS ALICANTINOS}

4.1. Incorporación formal de los municipios alicantinos.

4.2. Llegada de los caudales de la MCT a los municipios alicantinos.

\section{LOS RECURSOS HIDRAÚLICOS SUMINISTRADOS POR LA MANCOMUNIDAD EN LA PROVINCIA DE ALICANTE}

5.1. Integración de caudales de diversa naturaleza y procedencia en el sistema de la MCT.

5.2. Caudales procedentes del río Taibilla.

5.3. Caudales procedentes del trasvase Tajo Segura.

5.4. Caudales procedentes de contratos de cesión a través del Acueducto TajoSegura (ATS).

5.5. Caudales procedentes de la Cuenca del Júcar (embalse de Alarcón) para los municipios alicantinos integrados en dicha Demarcación.

5.5.1. MCT - Municipios abastecidos por el Consorcio de Aguas de la Marina Baja (CAMB)

5.5.2. MCT - Otros municipios alicantinos de la Demarcación del Júcar. 5.6. Caudales propios de los municipios alicantinos integrados en el Organismo. 5.7.Recursos subterráneos extraordinarios.

5.8. Recursos procedentes de la desalinización con aprovechamiento en la provincia de Alicante. 
6. POBLACIÓN ABASTECIDA Y VOLÚMENES SUMINISTRADOS POR LA MCT EN LA PROVINCIA DE ALICANTE

6.1. Datos generales.

6.2. Evolución de los consumos en los municipios alicantinos del sistema MCT.

6.2.1. Grandes municipios.

6.2.2. Municipios del litoral.

6.2.3. Municipios del área pre-litoral.

6.2.4. Municipios del interior.

6.2.5. Municipios del Medio Vinalopó: Aspe, Hondón de las Nieves y Hondón de los Frailes.

6.2.6. Aeropuerto de Alicante.

6.2.7. Otros suministros en la Zona 6 de la MCT (Alicante).

7. INFRAESTRUCTURAS DE DISTRIBUCIÓN Y POTABILIZACIÓN DEL AGUA EN ALTA DE LA MCT EN LA PROVINCIA DE ALICANTE

7.1. Transporte del agua: canales.

7.2. Infraestructuras de almacenamiento.

7.3. Infraestructuras de potabilización.

8. PRECIOS DEL AGUA

8.1. Cuestiones generales.

8.2. Tarifa de la MCT.

9. REPERCUSIONES SOCIOECONÓMICAS DE LA MCT EN LA PROVINCIA DE ALICANTE

9.1. Salud pública.

9.2. Turismo.

9.3. Construcción inmobiliaria.

9.4. Actividades industriales.

9.5. Comercio.

10. CONCLUSIONES

\section{BIBLIOGRAFÍA}





\section{ÍNDICE DE FIGURAS Y TABLAS}

\section{FIGURAS}

Fig 01. Demarcaciones Hidrográficas Europeas. Precipitación Media Anual. [Elaboración propia.]

Fig 02. Precipitación Media Anual en España (mm). [Aemet. Elaboración propia.]

Fig 03. Sistemas de escasez estructural y coyuntural, por demarcaciones hidrográficas.

Fig 04. Sistemas de escasez estructural y coyuntural, por subcuencas.

Fig 05. Dirección de flujos hídricos en el área de influencia de la MCT.

[Elaboración propia.]

Fig 06. Mapa de alturas en el ámbito de la MCT.

[Elaboración propia.]

Fig 07. Mapa de la provincia de Alicante. Precipitaciones medias anuales. [Gil Olcina, 2000.]

Fig 08. Evapotranspiración potencial en la provincia de Alicante. [Gil Olcina, 2000.]

Fig 09. Origen y procedencia de los recursos suministrados $\left(\mathrm{m}^{3}\right)$ a abastecimientos urbanos en la provincia de Alicante. 2004. [Diputación de Alicante, 2007. Elaboración propia.]

Fig 10. Recursos hídricos en España ( $\left.\mathrm{m}^{3} / \mathrm{hab} / \mathrm{año}\right)$. [Elaboración Propia.]

Fig 11. Red básica de infraestructuras de la MCT [Elaboración propia.]

Fig 12. Relación entre los caudales suministrados y la población abastecida en serie histórica (1945-2015) [Elaboración propia.]

Fig 13. Organigrama MCT. [MCT. Elaboración propia.]

Fig 14. Estructura del Consejo de Administración. [MCT. Elaboración propia.]

Fig 15. Estructura del Consejo Ejecutivo. [MCT. Elaboración propia.]

Fig 16. Mapa MCT, 1929 [MCT. Elaboración propia.]

Fig 17. Mapa de los 17 municipios de Alicante integrados en la MCT en 1946

Fig 18. Toma de agua en el río Segura, Ojós (Murcia) [MCT.] 78

Fig 19. Inauguración de fuente pública en la Vega Baja, julio 1969 [MCT. 61 Archivo histórico.] 
Fig 20. Nuevos Canales de Murcia, Cartagena y Alicante [Memoria MCT, 1976. Elaboración propia.]

Fig 21. Incorporación de los municipios de la provincia de Alicante a la MCT [MCT. Memoria 2009. Elaboración propia.]

Fig 22. Evolución de la población abastecida por la MCT en la provincia de Alicante [MCT. Elaboración propia.]

Fig 23. Evolución de la población abastecida por la MCT en la provincia de Alicante (1960-2013) [MCT. Elaboración propia.]

Fig 24. Síntesis del proceso de integración de los municipios en la MCT (19282015) [MCT. Elaboración propia.]

Fig 25. Proceso de llegada de las aguas a los municipios alicantinos integrados en la MCT (1958-2015) [MCT. Elaboración propia.]

Fig 26. Inauguración de depósito de la MCT en la Vega Baja, julio 1969. [MCT. Archivo histórico.]

Fig 27. Incorporación de los primeros municipios alicantinos a la MCT (19581959) [MCT. Elaboración propia.]

Fig 28. Entidades de población del término municipal de Alicante [Ayuntamiento de Alicante.]

Fig 29. Fotografía de aguadores en Alicante finales del S. XIX [Archivo Municipal de Alicante (AMA). (AMAEM, 2009).]

Fig 30. Fuente de la Plaza del Puente, 1952 (Alicante) [Francisco Sánchez, AMA. (AMAEM, 2009).]

Fig 31. "A por agua", 1944. Alicante [Francisco Sánchez, AMA. (AMAEM, 2009).]

Fig 32. Evolución del urbanismo residencial turístico en la Playa de San Juan (Alicante). Principios s.XX, años 40, años 60. [http://arquitecturadirecta.blogspot. com.es/2011/04/algunas-fotos-antiguas-de-la-playa-de.html]

Fig 33. Plaza del Mar, 1960 [Francisco Sánchez, AMA. (AMAEM, 2009).]

Fig 34. Aljibe público Tabarca. Años 50 (Alicante) [http://lafogueradetabarca. blogspot.com.es/2014/06/el-historico-problema-del-agua-y-la.html]

Fig 35. Fuente de la Glorieta en Elche [Cátedra Pedro Ibarra Ruiz. Universidad Miguel Hernández http://www.elche.me/taxonomy/] 
Fig 36. Certificación de titularidad del capital social de la compañía por acciones: The Elche Waterworks Company [Cátedra Pedro Ibarra Ruiz. Universidad Miguel Hernández http://www.elche.me/taxonomy/

Fig 37. Inauguración llegada de las aguas de la MCT a Elche [Diario Información, 25/6/1958]

Fig 38. Depósitos de agua de Massapa, Santa Pola. [Rafael Zarza García]

Fig 39. Llegada de las aguas de la MCT a los municipios de Alicante hasta 1972

[MCT. Elaboración propia.]

Fig 40. Pozos de Cremós (Orihuela) [Jesús García Molina. Archivero de Orihuela.]

Fig 41. Documento histórico de devolución de los pozos de Cremós (1938)

[Archivo Histórico de Orihuela.]

Fig 42. Documento histórico de devolución de los pozos de Cremós (1938)

[Archivo Histórico de Orihuela.]

Fig 43. Carros de aguadores en Orihuela [Diario Información 16/6/1963.] 89

Fig 44. Carro de aguador (1948) [Aguadores Orihuela http://www.minutocero.es/ galeria.php?tipo $=$ foto\&id $=342]$

Fig 45. "Aguaores" en Torrevieja, 1960

Fig 46. Conexión de Hondón de los Frailes con la MCT [MCT, Proyecto 12/13 de Abastecimiento a Hondón de los Frailes (AC/Hondón de los Frailes). 2014] 93

Fig 47. Dinámica de llegada de los caudales de la MCT a los municipios alicantinos [MCT. Elaboración propia.]

Fig 48. Clasificación de los municipios alicantinos abastecidos por la MCT en función del número de habitantes [MCT. Elaboración propia.]

Fig 49. Urbanización residencial Ciudad de las Comunicaciones (San Miguel de Salinas) [Google Maps]

Fig 50. Situación del Embalse del Taibilla a 3 de septiembre de 2003 (Nerpio) [Memoria MCT, 2003.]

Fig 51. Esquema previsto producción-consumo [MCT. Elaboración propia.]

Fig 52. Procedencia de los recursos suministrados por la MCT en diferentes años [MCT. Elaboración propia.]

Fig 53. Procedencia de los recursos y población abastecida por la MCT.

Evolución histórica [MCT. Elaboración propia.] 
Fig 54. Certificación de calidad del agua del río Taibilla (1930) [Memoria MCT, 1945.]

Fig 55. Caudales procedentes del río Taibilla y su posición relativa en el conjunto del sistema MCT [MCT. Elaboración propia]

Fig 56. Relación trasvase Tajo-Segura. Regadío-secano [MCT. Elaboración propia]

Fig 57. Mapas geofísicos cuencas del Tajo, Segura, acueducto y área de la MCT [Elaboración propia]

Fig 58. Trazado del trasvase Tajo-Segura y zona de influencia de la MCT [Elaboración propia]

Fig 59. Destino del agua del Tajo-Segura (1979-2014) [Sindicato Central de Regantes del Acueducto Tajo-Segura. Elaboración propia.]

Fig 60. Regla de Gestión del TTS (1997-2014) [Melgarejo, 2009. Elaboración propia.]

Fig 61. Reglas de Explotación del Trasvase Tajo-Segura, 2014 [Melgarejo et al., 2014. Elaboración propia.]

Fig 62. Aportaciones del ATS y peso relativo en el sistema MCT [MCT. Elaboración propia.]

Fig 63. Conducción Rabassa-Fenollar-Amadorio (Alicante-Benidorm) [MCT. Elaboración propia.]

Fig 64. Poblaciones que cuentan con recursos propios en el ámbito de la MCT en la provincia de Alicante [MCT. Elaboración propia.]

Fig 65. Recursos propios en volumen y porcentaje (2004) [MCT. Elaboración propia.]

Fig 66. Recursos propios de la ciudad de Alicante (1984-2015) [MCT. Elaboración propia.]

Fig 67. Recursos propios de Elche (1984-2015) [MCT. Elaboración propia.]

Fig 68. Recursos extraordinarios utilizados por la MCT [MCT. Elaboración propia.]

Fig 69. Caudales desalinizados por la MCT, 2003-2015 [MCT. Elaboración propia.]

Fig 70. Aportación de caudales desalinizados en el conjunto de la MCT [MCT. Elaboración propia.] 
Fig 71. Aportación de aguas desaladas al sistema de la MCT por la IDAM Alicante I [MCT. Elaboración propia.]

Fig 72. Aportación de aguas desalinizadas al sistema de la MCT por la IDAM Alicante II [MCT. Elaboración propia.]

Fig 73. Desalinizadoras de Alicante I y II [MCT.]

Fig 74. Aportación de aguas desaladas al sistema de la MCT por la IDAM San Pedro del Pinatar [MCT. Elaboración propia.]

Fig 75. Aportación de aguas desaladas al sistema de la MCT por la IDAM San Pedro II [MCT. Elaboración propia.]

Fig 76. Desalación en el ámbito de la MCT [MCT. Elaboración propia.]

Fig 77. Tarifas del agua desalinizada $2005\left(\mathrm{c} € / \mathrm{m}^{2}\right)$ [Memoria MCT, 2006.]

Fig 78. Tarifas del agua desalinizada $2006\left(\mathrm{c} € / \mathrm{m}^{2}\right)$ [Memoria MCT, 2007.]

Fig 79. Tarifas del agua desalinizada $2007\left(\mathrm{c} € / \mathrm{m}^{2}\right)$ [Memoria MCT, 2008.]

Fig 80. Tarifas del agua desalinizada $2008\left(\mathrm{c} € / \mathrm{m}^{2}\right)$ [Memoria MCT, 2009.]

Fig 81. Dinámica de crecimiento de la población en la provincia de Alicante [Diputación de Alicante. Elaboración propia.]

Fig 82. Dotación real (1/h/día) año 2004 [Diputación de Alicante. Elaboración propia.]

Fig 83. Municipios abastecidos por la MCT por provincias [MCT. Elaboración propia.]

Fig 84. Población de Derecho abastecida en Alicante según suministrador en alta en número de habitantes y porcentaje sobre el total [INE. 2015. Elaboración propia.]

Fig 85. Sistemas Generales de Abastecimiento de Agua Potable en alta en la provincia de Alicante (2004) [Elaboración propia.]

Fig 86. Agua suministrada históricamente para abastecimiento urbano en la provincia de Alicante en relación al conjunto de la MCT [Elaboración propia.]

Fig 87. Evolución del agua distribuida por la MCT a los municipios abastecidos de la provincia de Alicante [MCT. Elaboración propia.]

Fig 88. Volúmenes demandados por año a la MCT en la provincia de Alicante [MCT. Elaboración propia.] 
Fig 89. Consumos agregados por municipios desde la llegada de caudales en la provincia de Alicante [MCT. Elaboración propia.]

Fig 90. Relación población y viviendas abastecidas en MCT, provincia de Alicante y Comunidad Valenciana [Elaboración propia.]

Fig 91. Evolución anual del consumo doméstico (1/hab/día) en la ciudad de Alicante, 2000-2013 [Albiol et al., 2014.]

Fig 92. Evolución porcentual del consumo de Alicante en relación con el total de la MCT [MCT. Elaboración propia.]

Fig 93. Evolución del consumo de agua potable en Alicante [MCT. Elaboración propia.]

Fig 94. Distribución mensual del consumo de agua potable en Alicante (1975, 1985, 1995, 2005, 2015) [MCT. Elaboración propia.]

Fig 95. Volúmenes según procedencia en Alicante 2011 [AMAEM. Elaboración propia.]

Fig 96. Volúmenes según procedencia en Alicante 2015 [AMAEM. Elaboración propia.]

Fig 98. Volúmenes según procedencia en San Vicente 2011 [AMAEM. Elaboración propia.]

Fig 99. Volúmenes según procedencia en San Vicente 2015 [AMAEM. Elaboración propia.]

Fig 97. Agua suministrada por la MCT a San Vicente del Raspeig (1993-2015) [MCT. Elaboración propia.]

Fig 101. Volúmenes según procedencia en Alicante + San Vicente 2011. [AMAEM. Elaboración propia.]

Fig 102. Volúmenes según procedencia en Alicante + San Vicente 2015. [AMAEM. Elaboración propia.]

Fig 100. Caudales agregados de Alicante y San Vicente del Raspeig [MCT. Elaboración propia.]

Fig 103. Evolución porcentual del consumo de Elche en relación con el total de la MCT [MCT. Elaboración propia.]

Fig 104. Evolución del consumo de agua potable en Elche (1958-2015) [MCT. Elaboración propia.]

Fig 105. Distribución mensual del consumo de agua potable en Elche (1975, 
Fig 106. Término municipal de Orihuela y sus pedanías [Ayuntamiento de Orihuela. Elaboración propia.]

Fig 107. Evolución del consumo de agua potable en Orihuela [MCT. Elaboración propia.]

Fig 108. Distribución mensual del consumo de agua potable en Orihuela (1975, 1985, 1995, 2005, 2015) [MCT. Elaboración propia.]

Fig 109. Consumo de agua potable en Torrevieja (1972-2015) [MCT. Elaboración propia.]

Fig 110. Distribución mensual del consumo de agua potable en Torrevieja (1975, 1985, 1995, 2005, 2015) [MCT. Elaboración propia.]

Fig 111. Consumo de agua potable en Santa Pola (1958-2015) [MCT. Elaboración propia.]

Fig 112. Distribución mensual del consumo de agua potable en Santa Pola (1975, 1985, 1995, 2005, 2015) [MCT. Elaboración propia.]

Fig 113. Consumos de agua de Guardamar (1969-2015) [MCT. Elaboración propia.]

Fig 114. Distribución mensual del consumo de agua potable en Guardamar del Segura $(1975,1985,1995,2005,2015)$ [MCT. Elaboración propia.]

Fig 115. Consumo de agua potable en Pilar de la Horadada (1987-2015) [MCT. Elaboración propia.]

Fig 116. Distribución mensual del consumo de agua potable en Pilar de la Horadada (1995, 2005, 2015) [MCT. Elaboración propia.]

Fig 117. Consumo de agua potable en Rojales (1979-2015) [MCT. Elaboración propia.]

Fig 118. Consumo de agua potable en San Fulgencio (1979-2015) [MCT. Elaboración propia.]

Fig 119. Distribución mensual del consumo de agua potable en San Fulgencio (1985, 1995, 2005, 2015) [MCT. Elaboración propia.]

Fig 121. Consumo de agua potable en Algorfa (1979-2015) [MCT. Elaboración propia.]

Fig 120. Consumo de agua potable en San Miguel de Salinas (1979-2015) [MCT. Elaboración propia.]

Fig 122. Consumo de agua potable en Callosa del Segura (1966-2015) [MCT. 
Fig 123. Consumo de agua potable en Catral (1966-2015) [MCT. Elaboración propia.]

Fig 124. Consumo de agua potable en Daya Nueva (1979-2015) [MCT. Elaboración propia.]

Fig 125. Consumo de agua potable en Daya Vieja (1979-2015) [MCT. Elaboración propia.]

Fig 126. Consumo de agua potable en Benferri (1966-2015) [MCT. Elaboración propia.]

Fig 127. Consumo de agua potable en Albatera (1966-2015) [MCT. Elaboración propia.]

Fig 128. Consumo de agua potable en San Isidro (1995-2015) [MCT. Elaboración propia.]

Fig 129. Consumo de agua potable en Redován (1965-2015) [MCT. Elaboración propia.]

Fig 130. Consumo de agua potable en Rafal (1979-2015) [MCT. Elaboración propia.]

Fig 131. Consumo de agua potable en Los Montesinos (1991-2015) [MCT. Elaboración propia.]

Fig 132. Consumo de agua potable en Jacarilla (1966-2015) [MCT. Elaboración propia.]

Fig 133. Consumo de agua potable en Granja de Rocamora (1979-2015) [MCT. Elaboración propia.]

Fig 134. Consumo de agua potable en Formentera (1979-2015) [MCT. Elaboración propia.]

Fig 135. Consumo de agua potable en Dolores (1966-2015) [MCT. Elaboración propia.]

Fig 136. Consumo de agua potable en Crevillente (1958-2015) [MCT. Elaboración propia.]

Fig 137. Consumo de agua potable en Cox (1979-2015) [MCT. Elaboración propia.]

Fig 138. Consumo de agua potable en Bigastro (1969-2015) [MCT. Elaboración propia.]

Fig 139. Consumo de agua potable en Benijófar (1979-2015) [MCT. Elaboración propia.] 
Fig 140. Consumo de agua potable en Benejúzar (1969-2015) [MCT. Elaboración propia.]

Fig 141. Consumo de agua potable en Almoradí (1979-2015) [MCT. Elaboración propia.]

Fig 142. Consumo de agua potable en Aspe y Hondón de las Nieves (1989-2015) [MCT. Elaboración propia.]

Fig 143. Consumo de agua del Aeropuerto de Alicante-Elche (1979-2008) [MCT. Elaboración propia.]

Fig 144. Suministro a Entidades Civiles [MCT. Elaboración propia.]

Fig 145. Elevación de San Miguel de Salinas [Memoria MCT, 1976.]

Fig 146. Nuevos Canales de Alicante y Cartagena [Memoria MCT, 1976. Elaboración propia.]

Fig 147. Redes de canales de la MCT [MCT. Elaboración propia]

Fig 148. Nuevas elevaciones y canales de la MCT [MCT. Elaboración propia]

Fig 149. Red de Canales principales en la MCT y canales del postrasvase, sobre los que se han instalado potabilizadoras de agua [MCT. Elaboración propia.]

Fig 150. Canales y desalinizadoras en el área de la MCT [MCT. Elaboración propia.]

Fig 151. Depósitos y embalses del sistema MCT [MCT. Elaboración propia.]

Fig 152. Depósito de cabecera de distribución de la ciudad de Alicante [Memoria MCT, 2007.]

Fig 153. Localización de las ETAP del sistema de la MCT [MCT. Elaboración propia.]

Fig 154. ETAP Sierra de la Espada (Molina del Segura, Murcia) [MCT.]

Fig 155. ETAP La Pedrera [MCT.]

Fig 156. Potabilizadora de Torrealta [Memoria MCT, 2007.]

Fig 157. Diagrama instalaciones ETAP Torrealta, (Orihuela, Alicante) [MCT.]

Fig 158. Precio del agua $\left(€ / \mathrm{m}^{3}\right)$ de uso doméstico en España por provincias [AEAS-AGA (2013). Elaboración propia.]

Fig 159. Precio del agua $\left(€ / \mathrm{m}^{3}\right)$ de uso doméstico en España por Comunidades Autónomas [AEAS-AGA (2013). Elaboración propia.] 
Fig 160. Tarifas del agua de la MCT desde 1945 hasta 2015 [MCT. Elaboración propia.]

Fig 161. Tarifas del agua de la MCT desde 2006 hasta 2015 [MCT. Elaboración propia.]

Fig 162. Distribución de plazas turísticas en la provincia de Alicante [Elaboración propia.]

Fig 163. Playa de San Juan (Alicante), años 70 [http://arquitecturadirecta. blogspot.com.es/2011/04/algunas-fotos-antiguas-de-la-playa-de.html]

Fig 164. Oferta de alojamiento turístico MCTA vs. resto provincia de Alicante (2015) [Conselleria de Turismo. Elaboración propia]

Fig 166. Comparativa oferta de alojamiento reglado en el área de la MCTA vs. resto de la provincia de Alicante (2015) [Conselleria de Turismo. Elaboración propia.] 243

Fig 165. Mapa de tipologías de municipios turísticos en el área alicantina de la MCT [MCT. Elaboración propia.]

Fig 167. Planta hotelera [Conselleria de Turismo. Elaboración propia.]

Fig 169. Evolución de la planta hotelera en el ámbito de la MCT (1986-2015) [Conselleria de Turismo. Elaboración propia.]

Fig 168. Planta hotelera (2015) [Conselleria de Turismo. Elaboración propia.]

Fig 170. Oferta de plazas extrahoteleras en el área alicantina de la MCT [Conselleria de Turismo. Elaboración propia.]

Fig 171. Arenales del Sol, años 70, Elche [http://www.carabassi.net/fotografias/ antiguas.html]

Fig 172. Peso de la Vivienda de Potencial Uso Turístico (VPUT) en el área abastecida por la MCT [INE y Observatorio Valenciano de la Vivienda. Elaboración propia.]

Fig 173. Situación urbanística (tipos de suelo) de la costa de Orihuela en 1970 [Plan General de Ordenación Urbana de Orihuela.Elaboración propia.]

Fig 174. Situación urbanística (tipos de suelo) de la costa de Orihuela en 1988 [Plan General de Ordenación Urbana de Orihuela.Elaboración propia.]

Fig 175. Situación urbanística (tipos de suelo) de la costa de Orihuela en 1995 [Plan General de Ordenación Urbana de Orihuela.Elaboración propia.] 
Fig 176. Situación urbanística (tipos de suelo) de la costa de Orihuela en 1988 [Plan General de Ordenación Urbana de Orihuela.Elaboración propia.]

Fig 177. Actividades industriales en los municipios de la MCT [Elaboración propia.]

Fig 178. Fotografía aérea de Elche Parque Industrial [Diario La Verdad 7/2/2015]

Fig 179. Importancia de las actividades comerciales en el área suministrada por la MCT [Conselleria de Economía Sostenible, Sectores Productivos, Comercio y Trabajo. Elaboración propia.]

Fig 180. Evaluación de las variables físicas y socioeconómicas de la MCT. [MCT. Elaboración propia.]

Fig 181. Inversiones reales 1929 - 1975 [Memoria MCT, 1979. Elaboración propia.]

Fig 182. Inversiones reales 1975 - 2005 [Memoria MCT, 2005. Elaboración propia.] 


\section{TABLAS}

Tabla 01. Relación entre los caudales suministrados y la población abastecida en serie histórica (1945-2015) [MCT. Elaboración propia.]

Tabla 02. Datos básicos municipales de la provincia de Alicante [Memoria MCT 2009.1

Tabla 03. Incorporación de municipios de la Vega Baja en 1978 a la MCT [MCT. Elaboración propia.]

Tabla 04. Producción máxima anual de las desalinizadoras que aportan caudales a la MCT [MCT. Elaboración propia.]

Tabla 05. Indicadores de valores mínimos para Nivel 3 [MCT. Elaboración propia.]

Tabla 06. Contratos de cesión inter-cuencas entre la MCT y la CR. Canal de las Aves [Calatrava et al., 2016]

Tabla 07. Tarifa de utilización de agua de los pozos de reserva del Sinclinal de Calasparra (2000-2011) [CHS.]

Tabla 08. Características principales de la desalinizadora Alicante I [MCT.]

Tabla 09. Datos planta desalinizadora Alicante II [MCT. Elaboración propia.]

Tabla 10. Datos desalinizadora San Pedro I (Antonio León Martínez Campos) [MCT. Elaboración propia.]

Tabla 11. Datos desalinizadora San Pedro II [MCT. Elaboración propia.]

Tabla 12. Tarifas de las desalinizadoras gestionadas por la MCT, 2015 [MCT. Elaboración propia.]

Tabla 13. Consumos $\left(\mathrm{kWh} / \mathrm{m}^{3}\right)$ en desalinizadoras del área de influencia MCT [MCT. Elaboración propia.]

Tabla 14. Recursos según procedencia de la MCT años hidrológicos de 2004-2005 [MCT. Elaboración propia.]

Tabla 15. Recursos según procedencia de la MCT años hidrológicos de 2005-2006 [MCT. Elaboración propia.]

Tabla 16. Evolución del consumo de agua potable en los municipios de la 
Tabla 17. Datos técnicos del Canal de Alicante [MCT. Elaboración propia.]

Tabla 18. Datos técnicos del Nuevo Canal de Alicante [MCT. Elaboración propia.]

Tabla 19. Datos técnicos de la conexión entre las potabilizadoras de La Pedrera y Torrealta [MCT. Elaboración propia.]

Tabla 20. Datos técnicos ETAP Sierra de la Espada [MCT.]

Tabla 21. Características técnicas de la potabilizadora de La Pedrera [MCT.]

Tabla 22. Datos técnicos ETAP de Torrealta [MCT.]

Tabla 23. Aportaciones al sistema de la Mancomunidad de los Canales del Taibilla, según procedencia (2005-2013) [Memorias MCT (Varios años).

Elaboración propia.]

Tabla 24. Evolución de la construcción de viviendas en las provincias abastecidas por la MCT (2000 y 2006) [Ministerio de Fomento, 2007.] 



\section{INTRODUCCIÓN.}

La política de gestión del agua debe jugar un papel instrumental, orientado a la provisión de un conjunto de servicios que bien son esenciales para la vida o bien tienen un carácter estratégico para la economía. En términos generales, el objetivo de la gestión hídrica debe consistir en hacer compatible el crecimiento económico y la mejora del bienestar de la sociedad con la reducción de la escasez y, en consecuencia, con la protección del medio hídrico. Este objetivo obliga a quienes se enfrentan a la gestión de este recurso natural a considerarlo como un activo económico, con profundas implicaciones sociales y ambientales.

Entre las demandas actuales, se incluye la que está destinada a satisfacer las necesidades del consumo humano, una demanda esencial que debe proveerse en condiciones de seguridad para la salud, y con una elevada garantía de provisión cualesquiera que sean las condiciones climáticas y económicas. También debe tenerse en cuenta que los recursos hídricos son indispensables para el normal funcionamiento de los procesos de creación de riqueza en actividades tales como la agricultura de regadío, la generación de energía, la fabricación de bienes en la industria y la oferta de servicios turísticos y de oportunidades de recreo.

La "crisis del agua", las polémicas interregionales en torno a la asignación del recurso, las dificultades del abastecimiento y las restricciones que periódicamente padecen determinadas poblaciones, junto con la existencia de una fragmentada regulación, provocan que el agua se nos presente, cada día más, como un verdadero problema nacional, que enfrenta a sectores de la economía del país y determina las condiciones esenciales de vida de la población. Así, qué duda cabe de que el sector del agua se enfrenta a un conjunto de importantes y urgentes retos medioambientales, escasez de agua e incumplimiento de la normativa europea, y económicos, déficit de inversiones y tarifas insuficientes para recuperar los costes incurridos en los servicios de agua y acometer las nuevas inversiones. A estos retos hay que añadir las deficiencias que presenta el marco regulatorio actual: elevado número de Administraciones Públicas con competencias, y ausencia de una regulación lo suficientemente estable y predecible (Melgarejo, et al., 2015).

El ciclo integral del abastecimiento urbano de agua se compone de dos fases. En suma, el agua hay que captarla y transportarla hasta las redes urbanas, lo que denominamos fase de "alta", para luego distribuirla hasta los domicilios, lo que se corresponde con la fase de "baja"; en esta segunda fase el protagonismo es casi exclusivo de los entes locales, y en particular, de los municipios. El punto de conexión se situaría en los depósitos de 
cabecera de distribución, una vez el agua ha pasado por la potabilización y es apta para el consumo humano.

En la fase de alta cobra protagonismo el régimen jurídico que regula el uso y aprovechamiento de agua, y por tanto la Ley de Aguas (TRLA). La autoridad competente es la de demarcación, y en particular, la confederación hidrográfica que corresponda según la demarcación hidrográfica. Entre la Confederación y el Municipio aparecen entidades públicas interpuestas que son los protagonistas en el transporte y potabilización. En este trabajo veremos cómo interviene la Mancomunidad de Canales del Taibilla (MCT).

El consumo medio de agua para uso doméstico de los europeos durante 2013 ha fluctuado en términos medios entre los 100 y los 320 litros. El consumo doméstico representa aproximadamente el $15 \%$ del uso total que se hace del agua en Europa. De esta cantidad, sólo se utiliza para beber entorno al 3\%, mientras que el resto se gasta en el inodoro, lavar, fregar, duchas, jardín y otros consumos domésticos. En España, en 2013, el consumo medio de agua de los hogares se situó en 130 litros por habitante y día, con un descenso del 3,7\% respecto a los 135 litros registrados el año anterior (INE, 2015). En cuanto al origen de los caudales que se destinan al abastecimiento urbano, el 77\% corresponde a aguas superficiales, el 18\% son aguas subterráneas y el $5 \%$ procede de aguas desaladas (AEAS, 2014). Según el INE, en 2013, el 66,4\% del volumen captado por las empresas y los entes públicos suministradores de agua procedió de aguas superficiales, mientras que el 30,1\% tuvo su origen en aguas subterráneas. El 3,5\% restante provino de otro tipo de aguas, desaladas del mar o salobres (INE, 2015).

En este trabajo se analizará un modelo de éxito de sobrada eficacia en el terreno de la gobernanza del agua, que ha permitido a la provincia de Alicante, en el sureste de España, superar las dificultades derivadas de una extraordinaria limitación de recursos hídricos propios (precipitaciones de $300-500 \mathrm{~mm} / \mathrm{año}$ ), en un contexto de elevadas demandas derivadas de la población endógena, alrededor de 2.000.000 habitantes, junto con un gran crecimiento industrial, turístico y de segundas residencias.

La gestión de los recursos naturales, cada día más, ocupa una posición privilegiada en el panorama de las preocupaciones que afectan a una sociedad evolucionada y a los agentes responsables de la gestión pública. En el caso de uno tan básico como es el agua, ocioso resultaría admitir que cualquier intento de analizar la situación actual de los abastecimientos urbanos alicantinos sería vano si no es contemplado dentro del decisivo proceso de readaptación a que se está viendo sometida la política hidráulica. Es precisamente en el terreno de los usos urbanos donde se materializa una de las señas de cambio más expresivas y de mayor envergadura socioeconómica (Morales, 2002). 
Según Gil Olcina (1987), la Mancomunidad de los Canales del Taibilla "es, sin ningún género de dudas, una de las mayores realizaciones de la historia hidráulica española, aunque curiosamente pasa bastante inadvertida incluso para sus propios beneficiarios, que parecen haber olvidado el tradicional y angustioso problema, preñado de penuria y restricciones del abastecimiento de agua potable, resuelto con su integración en dicho organismo. El desarrollo urbano, turístico, industrial y hasta agrícola de la extensa área beneficiada es impensable sin la Mancomunidad de Canales del Taibilla”. Este olvido de su existencia por parte de la sociedad es la muestra más palpable de su eficiencia, pues, en caso contrario, había sido objeto de una crítica feroz por parte de los diferentes agentes sociales y de las administraciones municipales (Morales, 2002).

Un clima cálido y con escasas precipitaciones y una aridez elevada, junto con una oferta natural de recursos de agua muy pobre, convierte al territorio meridional alicantino en un espacio dependiente de aportes externos para garantizar unas demandas que han experimentado un crecimiento constante en los últimos cuarenta años. Las circunstancias demográficas y económicas, así como el despegue industrial y urbano del área afectada, ha traido consigo un incremento constante del gasto de agua en los municipios mancomunados, así como nuevas peticiones para extender la red de abastecimientos.

En este sentido, la Mancomunidad de los Canales del Taibilla se ha convertido en una entidad esencial para entender las dinámicas territoriales de las últimas décadas en la mitad meridional de la provincia de Alicante. Se trata del eslabón básico que, desde su creación, ha garantizado los abastecimientos urbanos de agua de una de las regiones naturales más secas de Europa. Sin su participación, no podría explicarse el desarrollo experimentado en esta parte de España, desde mediados del S. XX (Vera et al., 2009).

Las áreas abastecidas por la MCT en la provincia de Alicante se corresponden, con el sistema de explotación Vinalopó-Alacantí, con carácter ordinario, así como el Sistema Marina Baja, con carácter extraordinario mediante la conducción Rabasa Fenollar Amadorio, ambos del ámbito de planificación hidrológica de la Demarcación del Júcar. Junto a ello nos encontramos con el sistema del Segura, que comprende la comarca de la Vega Baja, correspondiente por tanto a la Demarcación Hidrográfica del Segura. 
En la provincia de Alicante conviven diversos Sistemas Generales de Abastecimiento de Agua Potable, aparte de aquellos municipios que gestionan el abastecimiento de forma autónoma:

- El Consorcio Aguas de la Marina Baja (7 Municipios).

- El Consorcio de Aguas de la Marina Alta (18 Municipios).

- Sociedad del Canal de la Huerta (4 Municipios).

- Canal del Cid, AMAEM (8 Municipios).

- Mancomunidad de Canales del Taibilla (35 Municipios).

En la actualidad, un total de 35 municipios, incluyendo a los tres mayores municipios de la provincia en cuanto a número de habitantes (Alicante, Elche y Torrevieja), además de numerosas poblaciones que superan los 20.000 habitantes, integran el área abastecida por la MCT en la provincia de Alicante. El área suministrada, por tanto, excede la propia delimitación de la demarcación del Segura, e incorpora a municipios pertenecientes a la del Júcar. Se ve afectada por consiguiente por dos ámbitos de planificación hidrológica de demarcación, así como por la normativa legal del trasvase Tajo-Segura.

No se concibe el despegue y consolidación de un modelo económico y territorial basado en gran medida en la construcción de nuevos asentamientos, que albergan miles de viviendas para uso vacacional y turístico, junto con el espectacular desarrollo del aparato de servicios comerciales, de ocio, restauración, asistenciales, hotelería, administración, entre otros, sin la dinámica de un sistema público de abastecimiento de aguas, que aporta recursos en cantidad y calidad, como clave de los abastecimientos a poblaciones. 


\section{1.- DESCRIPCIÓN GEOFÍ́SICA DEL ÁREA ABASTECIDA POR LA MCT.}

España es uno de los países de la Unión Europea con mayor superficie bajo estrés hídrico. El consumo de agua supera el $40 \%$ del total disponible en un $72 \%$ de la superficie nacional, dato que contrasta con el $26 \%$ de la superficie italiana o el $1 \%$ de la alemana. El estrés hídrico exige una mayor eficiencia en la utilización de los recursos disponibles. Este hecho conlleva, entre otras implicaciones, una mayor necesidad en la dotación de embalses y presas, así como una mayor inversión en mantenimiento y renovación para garantizar su correcto funcionamiento. También deben priorizarse las inversiones en la reducción y eliminación de las pérdidas en las redes de abastecimiento, que permitan el máximo aprovechamiento de los recursos disponibles.

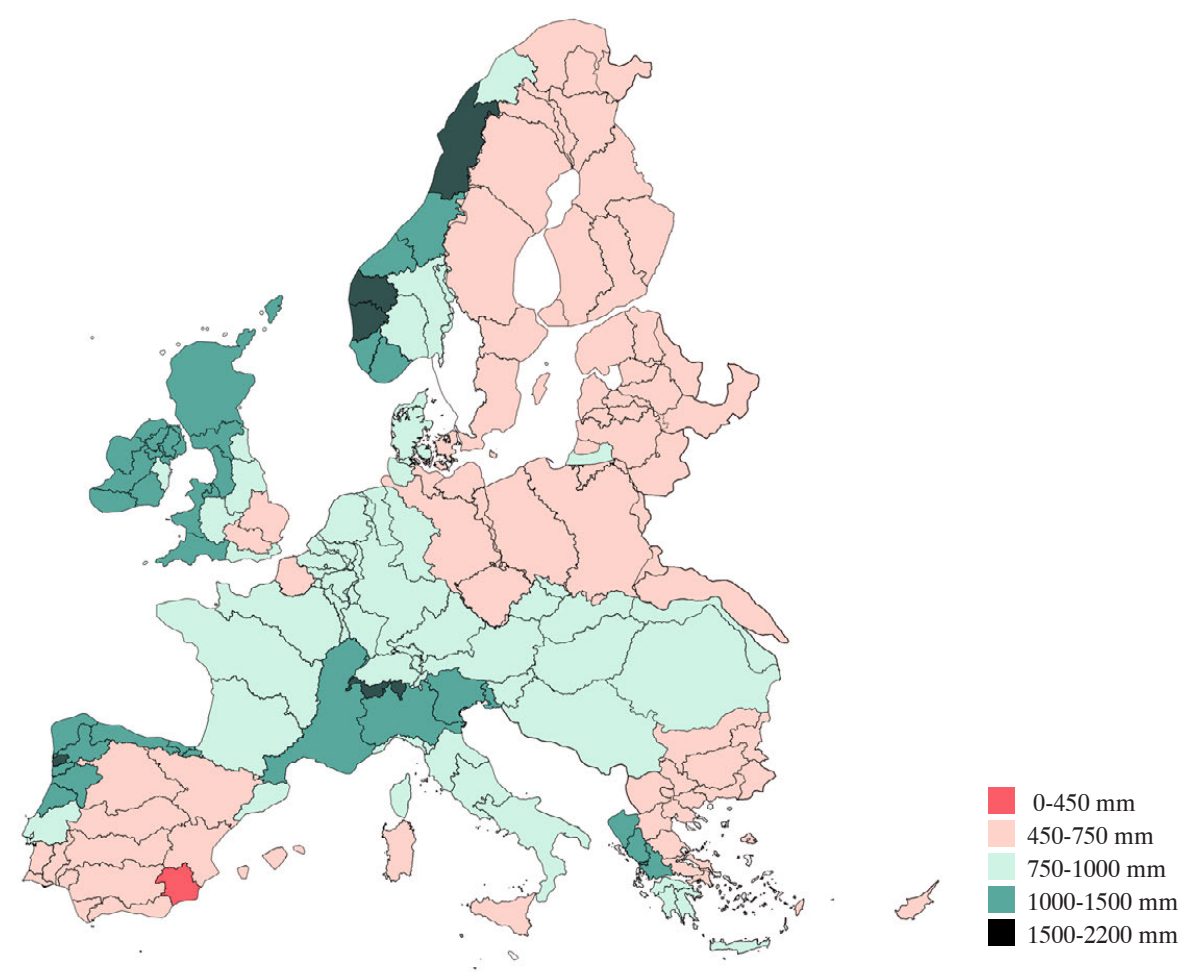

Fig 01. Demarcaciones Hidrográficas Europeas. Precipitación Media Anual. [Elaboración propia.] 
La endémica indigencia hídrica que ha sufrido el Sureste peninsular, ha conducido continuamente los esfuerzos hacia el aumento de las disponibilidades hídricas, presentes en el transcurso de la historia de estas tierras, generalmente, a partir de la necesidad de obtener recursos externos a su propio enclave o al acopio de los mismos desde diversos sistemas que, en cualquier caso, pasan por un concepto de planificación, desarrollo, explotación y gestión de infraestructuras hidráulicas bastante complejo (Melgarejo, 2009). En la figura 2 se observa que los niveles de precipitaciones medias anuales menores en la Península Ibérica se concentran precisamente en el Sureste.

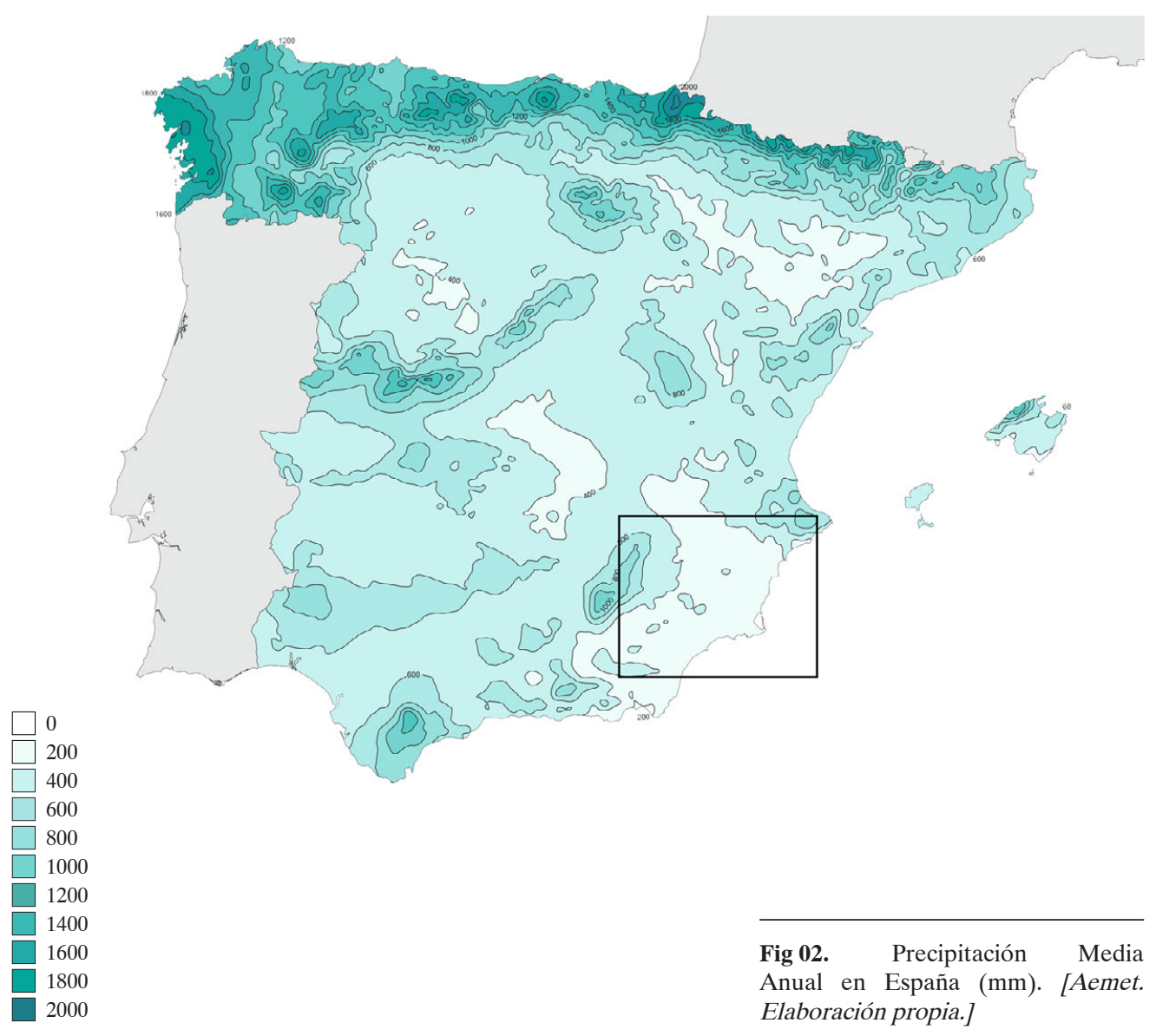

En el Libro Blanco del agua del año 2000 se establecieron por primera vez los espacios considerados con déficit estructural o coyuntural de recursos hídricos en España. En la figura 3 se aprecia cómo la cuenca del Segura es el único territorio peninsular con escasez estructural. Este espacio se encuentra entre dos demarcaciones con escasez coyuntural, lo cual acentúa las dificultades de resolución de los problemas que se generan en esta área geográfica. 
La situación de escasez estructural es más evidente si descendemos a la división por subcuencas hidrográficas que se representa en la figura 4, en la que junto al territorio de la demarcación del Segura nos encontramos con otras zonas adyacentes como la práctica totalidad de la provincia de Alicante, que pese a estar en la demarcación Júcar, presenta valores similares de déficit estructural.

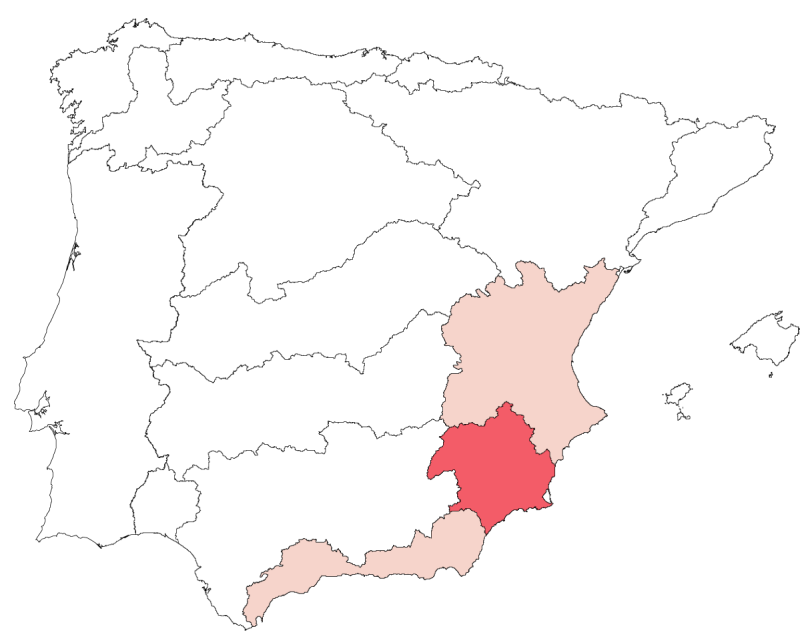

Baja utilización.

Escasez coyuntural.

Escasez estructural.

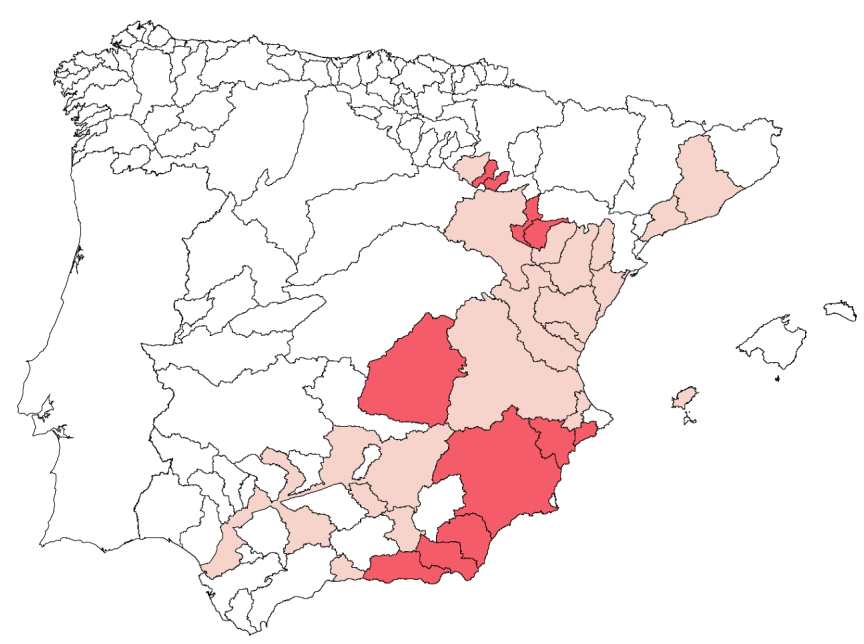

Fig 03. Sistemas de escasez estructural y coyuntural, por demarcaciones hidrográficas.

[MIMAM, Libro Blanco del Agua, 2000.]

Fig 04. Sistemas de escasez estructural y coyuntural, por subcuencas.

[MIMAM, Libro Blanco del Agua, 2000.] 
Las dirección de los flujos hídricos y el relieve en el ámbito de la MCT, que se observan en las figuras 5 y 6 , son coincidentes con los espacios de escasez estructural que se han comentado en las figuras anteriores.

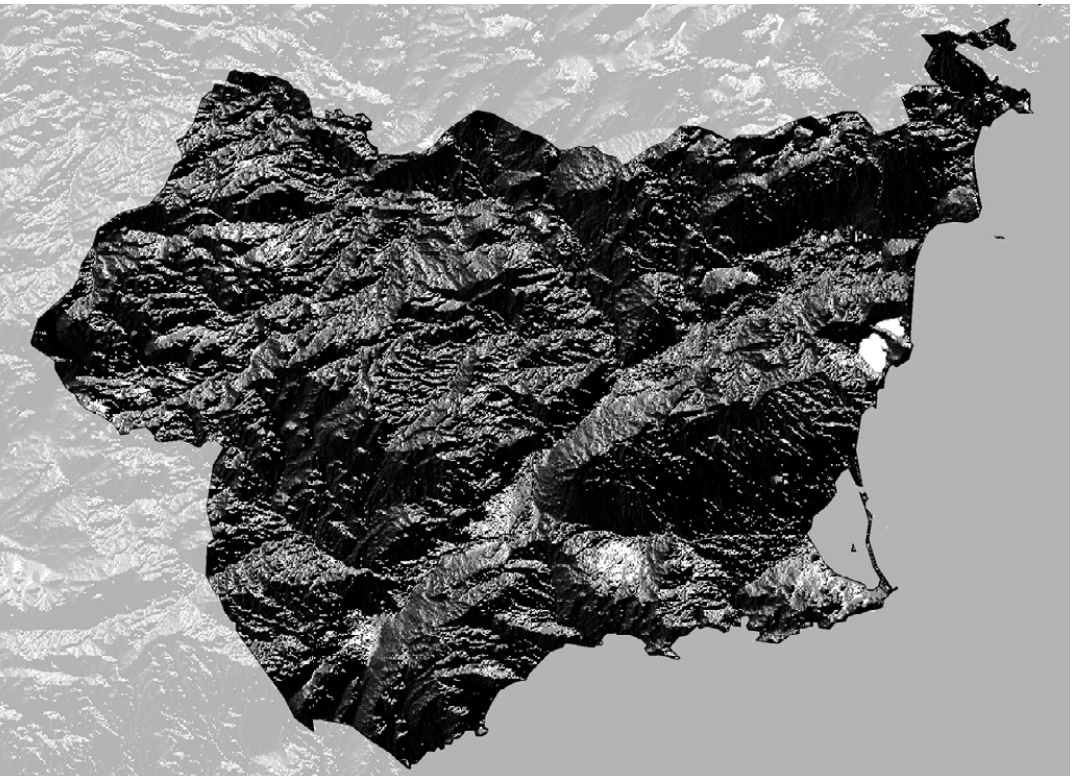

Fig 05. Dirección de flujos hídricos en el área de influencia de la MCT. [Elaboración propia.] Fig 06. Mapa de alturas en el ámbito de la MCT. [Elaboración propia.]

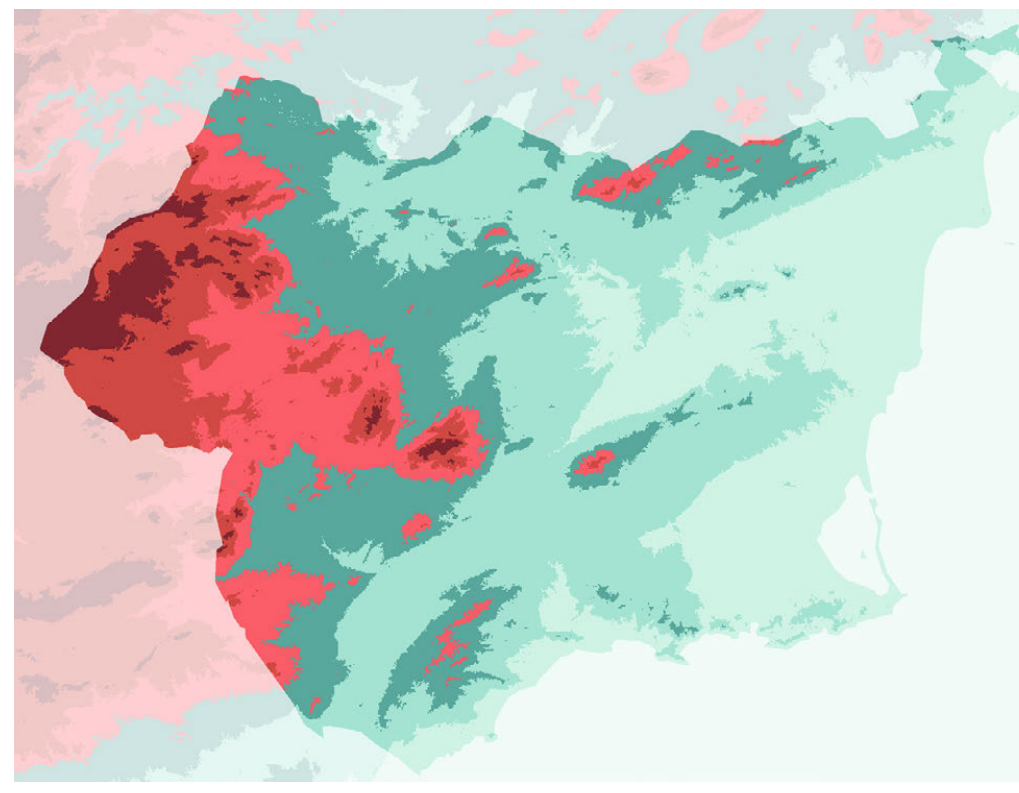

$0-150 \mathrm{~m}$

$151-400 \mathrm{~m}$

$401-700 \mathrm{~m}$

$701-950 \mathrm{~m}$

$951-1250 \mathrm{~m}$

$1251-2500 \mathrm{~m}$

La aridez define climatológicamente el Sureste peninsular. Las escasas precipitaciones registradas son además poco eficaces, dado que a menudo son de fuerte intensidad y las aguas circulan rápidamente hacia el mar. La insolación y la persistencia de los períodos de sequía favorecen una elevada evapotranspiración potencial. Todos estos factores hacen que la garantía del suministro, tanto para los usos agrarios como los urbanos, sea un reto de difícil consecución en estas tierras.

La falta de agua ha sido y en buena medida continúa siendo un factor limitante para el crecimiento y el desarrollo económico de la provincia de Alicante. En la figura 7 se observa como en los términos municipales suministrados por la MCT en la provincia de Alicante, la precipitación media anual oscila entre los 200-300 mm en su mayor parte, y 
Entre 200 y $300 \mathrm{~mm}$

Entre 300 y $400 \mathrm{~mm}$

Entre 400 y $500 \mathrm{~mm}$

Entre 500 y $600 \mathrm{~mm}$

Entre 600 y $700 \mathrm{~mm}$

Entre 700 y $800 \mathrm{~mm}$

Entre 800 y $900 \mathrm{~mm}$

Entre 900 y 1000 mm

Entre 70 y $75 \mathrm{~cm}$

Entre 75 y $80 \mathrm{~cm}$

Entre 80 y $85 \mathrm{~cm}$

Entre 85 y $80 \mathrm{~cm}$

Superior a $90 \mathrm{~cm}$
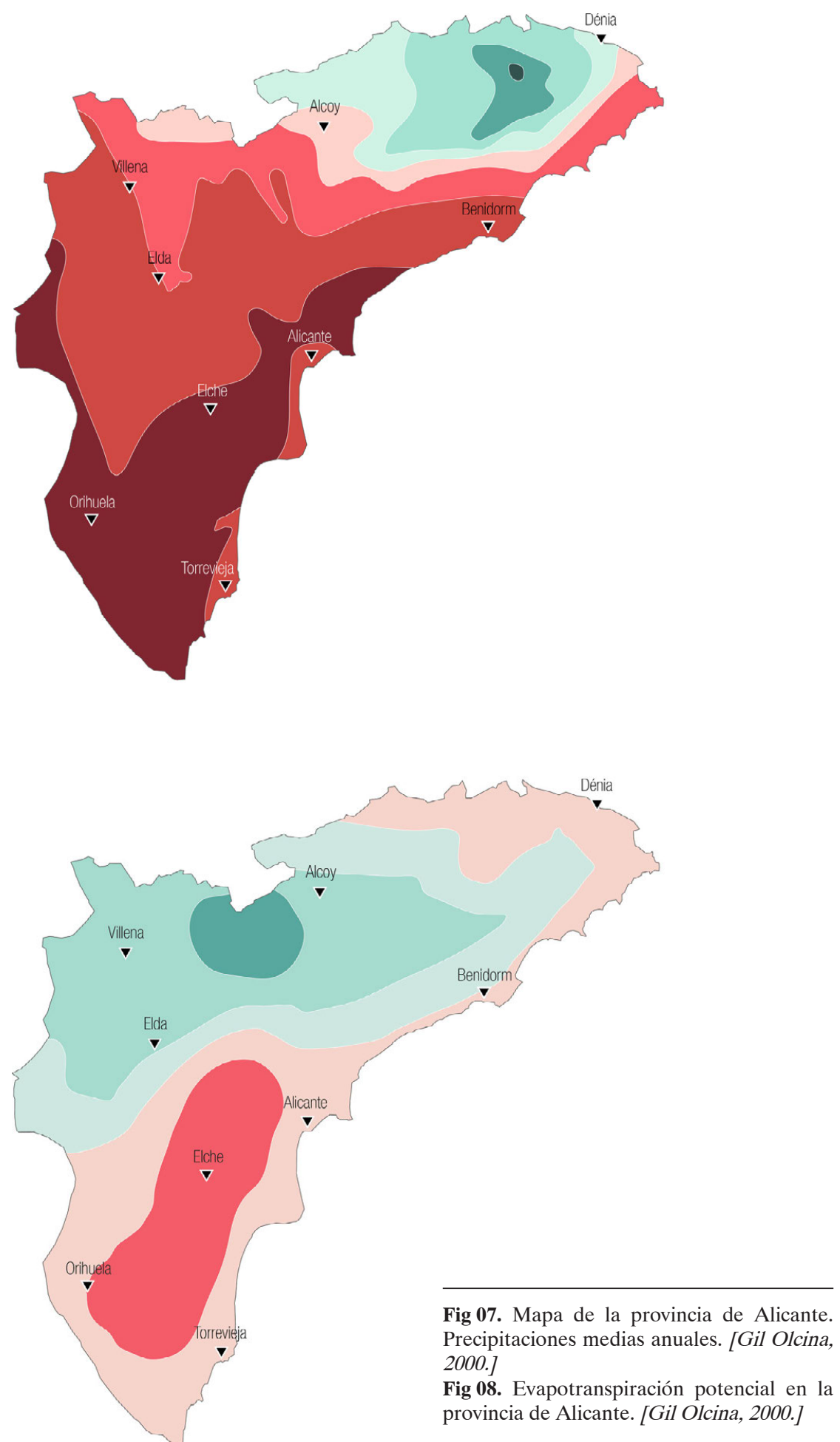
los 300-400 mm en algunos puntos. Lo que se corresponde con un clima semiárido con características subdesérticas.

A la escasa precipitación media anual se une la elevada evapotranspiración potencial en toda la zona suministrada. En la figura 8 se evidencia que todos los municipios receptores de recursos del sistema de la MCT en la provincia de Alicante tienen valores superiores a $\operatorname{los} 85 \mathrm{~cm}$.

Ambos condicionantes, baja precipitación y elevada evapotranspiración potencial, producen, junto a otros factores, que el área de suministro de la MCT se encuentre íntegramente bajo unas condiciones de escasez estructural.

En este contexto, la provincia de Alicante debe afrontar una demanda de recursos importante y creciente. En un año medio, como el 2004, el consumo de agua para abastecimiento urbano, según datos de la Diputación de Alicante (Mapa del Agua de la Provincia de Alicante, 2007), se elevó hasta los 203.4 hm³/año, a los que habría que sumar unos $3 \mathrm{hm}$ /año correspondientes a aprovechamientos independientes de la red municipal, que abastecen a urbanizaciones y diseminados mediante de captaciones privadas de aguas subterráneas. En ese mismo año, el 51,81\% del agua suministrada para consumo en la Provincia, habría sido aportada por aguas subterráneas provinciales, un 35,39 \% correspondería a recursos MCT, de diferentes orígenes, la desalación de agua del mar aportaría un 9,65 \% de los recursos captados, y finalmente, el 3,15 \% sería aportado por recursos superficiales provinciales.

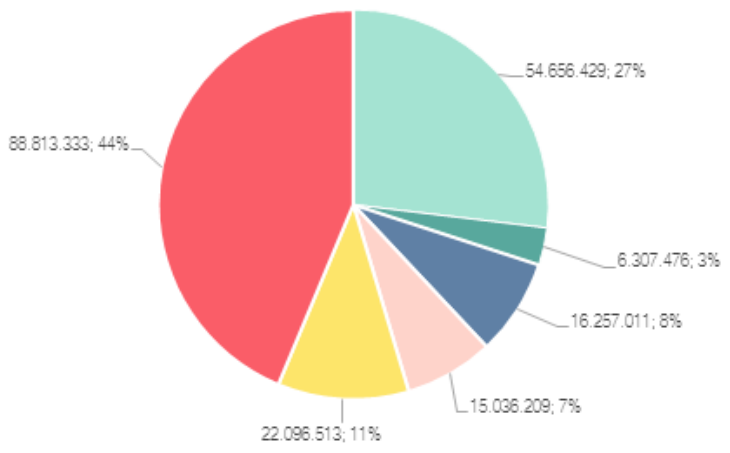

Fig 09. Origen y procedencia de los recursos suministrados $\left(\mathrm{m}^{3}\right)$ a abastecimientos urbanos en la provincia de Alicante. 2004. [Diputación de Alicante, 2007. Elaboración propia.]

Esta situación ha requerido constantes esfuerzos encaminados a incrementar las disponibilidades hídricas, sumando todas las fuentes de suministro posibles, endógenas o exógenas. A la escasez estructural del recurso se acompaña un continuo incremento 
de la presión sobre el mismo debido al desarrollo agrario, urbano, industrial, el turismo, tanto estacional como residencial, y al propio desarrollo demográfico y la mejora de las condiciones de vida. Estas presiones han acrecentado las demandas y con ello la necesidad de optimizar todos los recursos disponibles. Nada de esto hubiera sido posible sin una adecuada planificación del recurso y una explotación racional sobre la base de un modelo organizativo estable y eficiente.

La MCT se encuentra entre dos ámbitos de planificación hidrológica, Segura y Júcar, que en ambos casos se encuentran por debajo de lo que la ONU reconoce como dotación mínima de recursos por habitante y año (1000 m³/hab/año). Sólo las cuencas internas de Cataluña y Canarias se sitúan por debajo de los valores del área de la MCT.

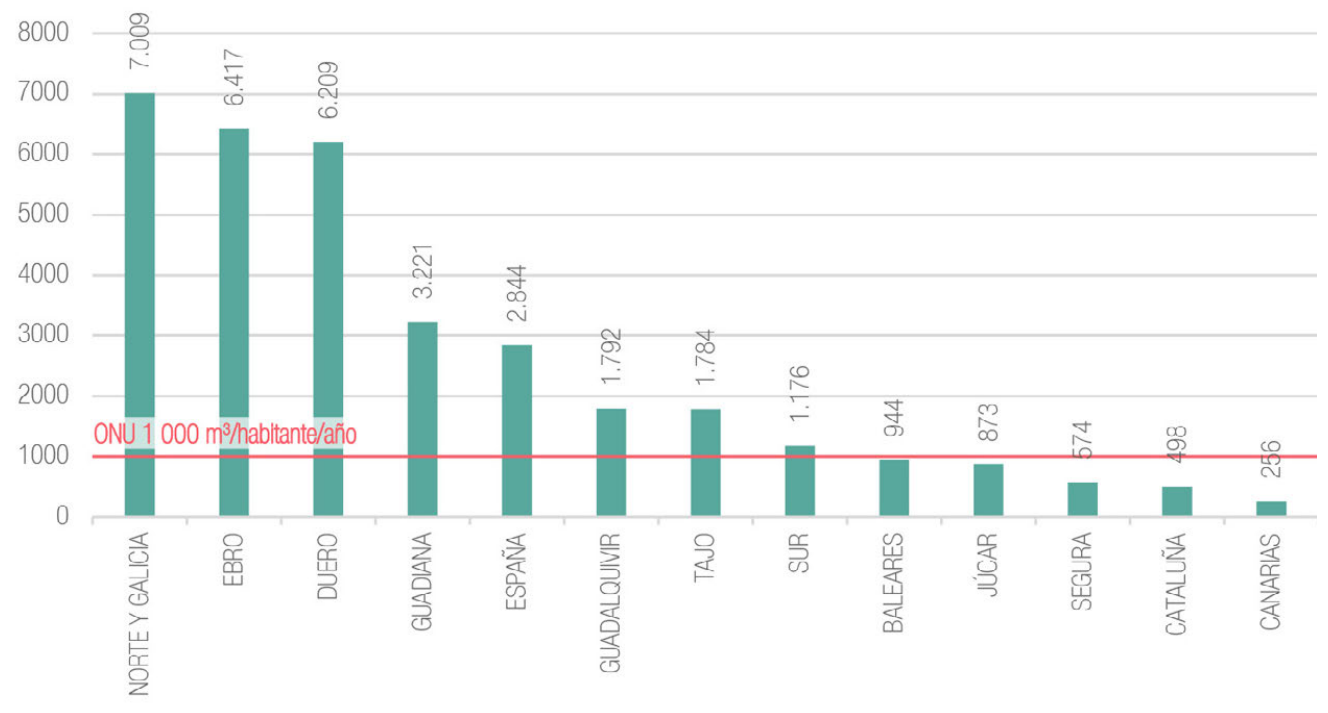

Fig 10. Recursos hídricos en España $\left(\mathrm{m}^{3} / \mathrm{hab} / \mathrm{año}\right)$. [Elaboración Propia.]

La red de infraestructuras que gestiona la MCT, que se aprecia en la figura 11, moviliza en la actualidad un gran volumen de caudales de distintas procedencias, lo que permite afrontar una demanda creciente en un entorno socioeconómico de gran desarrollo actual y potencial.

La acción de este Organismo ha permitido superar incluso las fases de extrema sequía. Así, por ejemplo, en los periodos secos de 1990-95, cuando en otras regiones más 
húmedas, como el Gran Bilbao y Madrid, tuvieron que soportar prolongados periodos de restricciones en el suministro, los murcianos y alicantinos superaron la etapa sin apenas incidencias sobre los abastecimientos (Morales, 2002).

El incremento de la población abastecida ha sido exponencial, no sólo por el propio crecimiento demográfico, sino también por la progresiva extensión del ámbito de la MCT a nuevos municipios que han encontrado en la entidad la garantía de sus suministros. En la figura 12 se aprecia la evolución tanto de los recursos suministrados como de la población abastecida, lo que demuestra la creciente complejidad del sistema de gobernanza del agua que desarrolla la MCT.

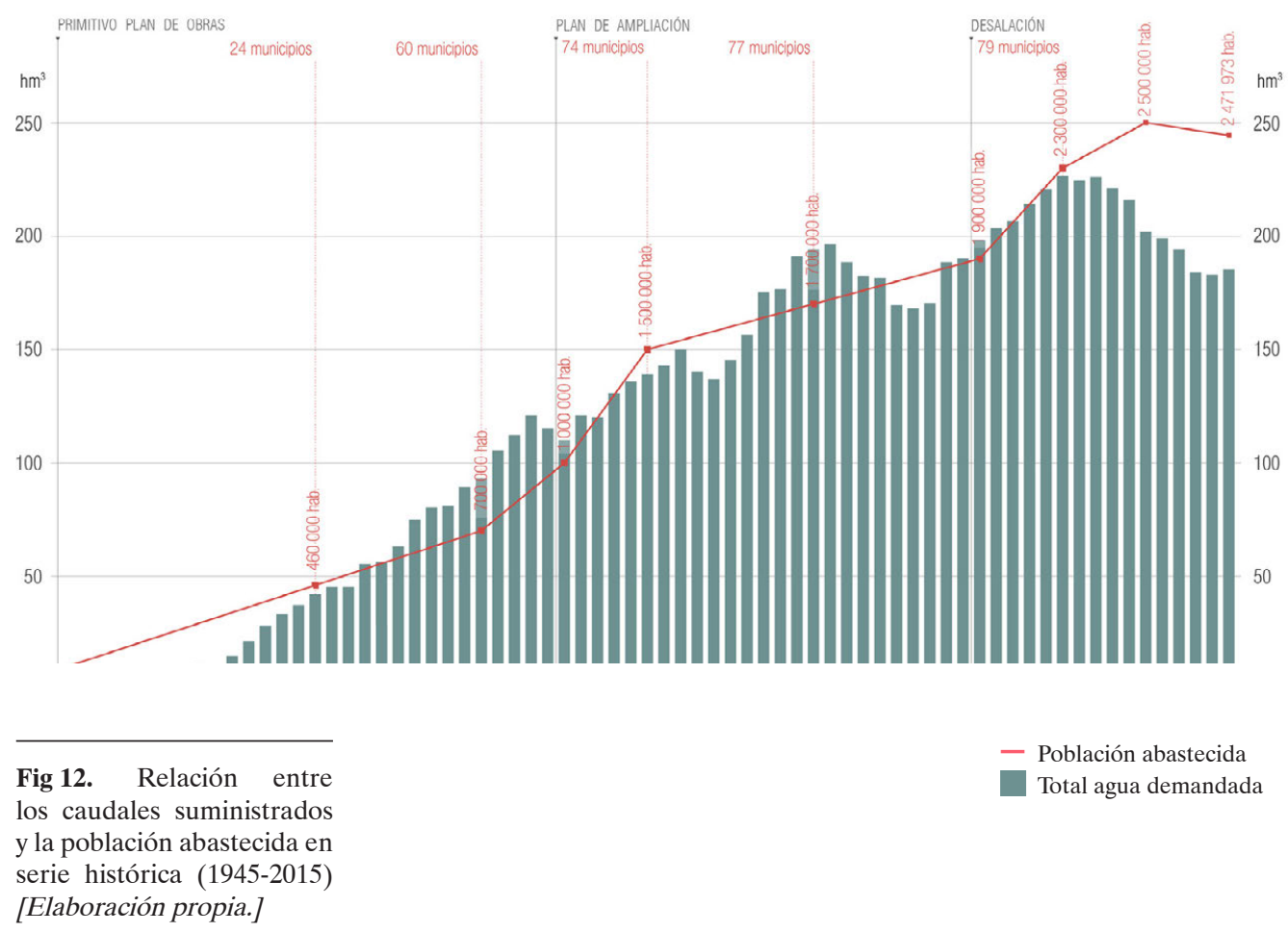

Desde los años 50 la población abastecida por la MCT ha pasado de 125.000 habitantes a más de 2 millones y medio en 2010, lo que representa un crecimiento extraordinario tanto en el número de personas como en el número de hectómetros cúbicos servidos. 


\begin{tabular}{|c|c|c|}
\hline Año & Habitantes & $\mathbf{H m}^{\mathbf{3}}$ \\
\hline $\mathbf{1 9 5 0}$ & 125.000 & 5 \\
\hline $\mathbf{1 9 6 0}$ & 460.000 & 42 \\
\hline $\mathbf{1 9 7 0}$ & 700.000 & 93 \\
\hline $\mathbf{1 9 7 5}$ & 1.000 .000 & 110 \\
\hline $\mathbf{1 9 8 0}$ & 1.500 .000 & 139 \\
\hline $\mathbf{1 9 9 0}$ & 1.700 .000 & 194 \\
\hline $\mathbf{2 0 0 0}$ & 1.900 .000 & 198 \\
\hline $\mathbf{2 0 0 5}$ & 2.300 .000 & 225 \\
\hline $\mathbf{2 0 1 0}$ & 2.500 .000 & 202 \\
\hline $\mathbf{2 0 1 5}$ & 2.471 .973 & 185 \\
\hline
\end{tabular}

Tabla 01. Relación entre los caudales suministrados y la población abastecida en serie histórica (1945-2015) [MCT.

Elaboración propia.]
En la tabla 02 se observan los datos de superficie, censo y densidad de población de los municipios alicantinos que reciben caudales de la MCT.

En los últimos años, en el conjunto de España, se ha constatado un descenso del consumo de agua doméstico (Saurí, 2003; March et al., 2014; Gil, et al., 2015). Este descenso se debe a un conjunto de causas: la mejora de la eficiencia del suministro, la instalación de dispositivos de ahorro en el hogar, la presencia de electrodomésticos que usan agua más eficientemente, una mayor sensibilización ambiental, el uso de aguas regeneradas depuradas y pluviales, el incremento del precio del agua, cambios socio-económicos, la crisis económica y las condiciones climáticas (Morote, 2016).

La progresiva y constante incorporación de municipios y entidades a la MCT, el crecimiento urbano y demográfico, y la influencia de nuevos tipos de demanda industrial y turística, han hecho preciso incrementar los recursos gestionados por la MCT. El fuerte crecimiento de la demanda desde la década de 1960 desbordó las previsiones en dotaciones por habitante y día, resultando insuficientes los caudales del río Taibilla para mantener los mínimos exigibles en las poblaciones abastecidas. Por tanto, desde los inicios de dicha

década, hay una auténtica lucha por conseguir nuevos recursos, que se cubrieron con aguas procedentes de pozos de la cuenca (recursos extraordinarios), trasvase Tajo-Segura, desalinización, y contratos de cesión de derechos. 


\begin{tabular}{|c|c|c|c|}
\hline Municipios & $\begin{array}{l}\text { Superficie } \\
\mathbf{K m}^{2}\end{array}$ & Censo 2009 & $\begin{array}{c}\text { Densidad hab/ } \\
\text { km }^{2}\end{array}$ \\
\hline 1. Albatera & 61,54 & 11.745 & 190,85 \\
\hline 2. Algorfa & 18,36 & 4.346 & 236,71 \\
\hline 3. Alicante & 201,27 & 334.757 & $1.663,22$ \\
\hline 4. Almoradí & 42,72 & 19.147 & 448,20 \\
\hline 5. Aspe & 70,90 & 20.180 & 284,63 \\
\hline 6. Benejúzar & 9,33 & 5.467 & 585,96 \\
\hline 7. Benferri & 12,36 & 1.876 & 151,78 \\
\hline 8. Benijófar & 4,36 & 3.976 & 911,93 \\
\hline 9. Bigastro & 4,10 & 6.744 & $1.644,88$ \\
\hline 10. Callosa de Segura & 24,77 & 17.924 & 723,62 \\
\hline 11. Catral & 20,01 & 8.745 & 437,03 \\
\hline 12. Crevillente & 104,55 & 28.609 & 273,64 \\
\hline 13. Cox & 16,76 & 6.826 & 407,28 \\
\hline 14. Daya Nueva & 7,09 & 1.942 & 237,91 \\
\hline 15. Daya Vieja & 3,14 & 674 & 214,65 \\
\hline 16. Dolores & 18,70 & 7.427 & 397,17 \\
\hline 17. Elche & 326,07 & 230.112 & 705,71 \\
\hline 18. Formentera del Segura & 4,33 & 4.285 & 989,61 \\
\hline
\end{tabular}




\begin{tabular}{|c|c|c|c|}
\hline 19. Granja de Rocamora & 7,17 & 2.362 & 329,43 \\
\hline 20. Guardamar del Segura & 35,58 & 16.329 & 458,94 \\
\hline 21. Hondón de las Nieves & 68,85 & 2.862 & 41,57 \\
\hline 22. Hondón de los Frailes & 12,6 & 1.214 & 96,35 \\
\hline 23. Jacarilla & 12,20 & 2.096 & 171,80 \\
\hline 24. Los Montesinos & 1,05 & 4.949 & 328,84 \\
\hline 25. Orihuela & 365,44 & 86.164 & 235,78 \\
\hline 26. Pilar de la Horadada & 77,91 & 22.050 & 283,02 \\
\hline 27. Rafal & 1,62 & 4.135 & $2.552,47$ \\
\hline 28. Redován & 9,45 & 7.335 & 776,19 \\
\hline 29. Rojales & 27,56 & 20.510 & 744,19 \\
\hline 30. San Fulgencio & 19,75 & 12.030 & 609,11 \\
\hline 31. San Isidro & 11,69 & 1.806 & 154,49 \\
\hline 32. San Miguel de Salinas & 54,85 & 8.135 & 148,31 \\
\hline 33. San Vicente del Raspeig & 40,55 & 53.126 & $1.310,14$ \\
\hline 34. Santa Pola & 58,16 & 31.760 & 546,08 \\
\hline 35. Torrevieja & 71,44 & 101.792 & $1.424,86$ \\
\hline
\end{tabular}

Tabla 02. Datos básicos municipales de la provincia de Alicante [Memoria MCT 2009.] 


\section{2.- LA MCT COMO MODELO DE GOBERNANZA INTEGRAL DEL AGUA.}

La gobernanza del agua puede definirse como el conjunto de sistemas políticos, sociales, administrativos y económicos que permiten una mejor organización y gestión del agua, y la más eficiente prestación de servicios asociados. La correcta gestión de los recursos hídricos permite cualificar las condiciones sanitarias de sus habitantes, el éxito de sus economías, y la sostenibilidad de sus recursos naturales. La noción de gobernanza aplicada al agua incluye el diseño de políticas públicas y marcos institucionales sostenibles, aceptados por la sociedad (Melgarejo et al. 2017).

Este concepto entronca también con las actividades locales y redes de influencia, incluyendo entre estas últimas al sector privado y a la sociedad civil. El gobierno del agua debe involucrar a los ciudadanos en la toma de decisiones, maximizando su participación en los asuntos públicos (Rogers, P. y Hall, A. W. 2003).

No existe un modelo único para la gobernanza del agua. Los sistemas de gobernabilidad deben ajustarse a las particularidades sociales, económicas y culturales de cada territorio. Sin embargo, existen algunos principios o atributos básicos esenciales para la buena gobernanza del agua. Así, las instituciones deben operar de manera abierta. Han de utilizar un lenguaje comprensible y accesible para que el conjunto de la población muestre una mayor confianza en las instituciones. Las decisiones políticas deben ser transparentes, de manera que los ciudadanos puedan seguir fácilmente los pasos adoptados en la formulación de las políticas.

La teoría económica clásica vincula la eficiencia al rendimiento económico, pero también hay que considerar los resultados de eficiencia política, social y ambiental, que han de armonizarse con el rendimiento económico. Es decir, no se deben emprender acciones sin la participación real de los usuarios y administradores locales del agua (en este caso gobiernos locales, organizaciones de cuenca, organizaciones de usuarios y otros). Para ello se debe contar con mecanismos reales de participación, de comunicación, de toma de decisiones y de rendición de cuentas (Aguilar, G. e Iza, A. 2006).

Los gestores del agua, tanto gubernamentales como del sector privado, se enfrentan a una oferta que disminuye frente a una demanda creciente. Factores como los cambios demográficos y climáticos incrementan la presión sobre los recursos hídricos. El tradicional enfoque fragmentado ya no resulta válido y se hace esencial un enfoque holístico para la gestión del agua. Éste es el fundamento de la Gestión Integrada de los Recursos Hídricos (GIRH), aceptado ahora internacionalmente como el camino hacia un desarrollo y gestión eficientes, equitativos y sostenibles de unos recursos hídricos cada vez más limitados, y para abordar unas demandas en competencia (Integrated Water Resources Management in Action, 2009). 
El cambio climático augura una crisis hídrica que previsiblemente afectará a muchos territorios en el planeta. Frente a ello es imprescindible desarrollar instrumentos de gobernanza que permitan gestionar de manera integral los recursos escasos. Escasez que además puede verse acentuada por la falta de calidad de los recursos como consecuencia de la acción humana. Frente a ello son necesarios mecanismos jurídico-institucionales y económicos que permitan ordenar de manera eficiente la actividad desarrollada por todos los actores implicados en la gestión del agua.

La tecnología también tiene un importante papel en la búsqueda de la sostenibilidad. Una buena gobernanza del agua supone que el entorno jurídico e institucional debe ser capaz de movilizar y poner en valor las mejores técnicas disponibles para alcanzar una gestión sostenible. Los trasvases, la desalación y la reutilización del agua residual regenerada son los principales factores tecnológicos, pero la política hidráulica es la que debe decidir cómo combinar todos esos factores de la manera más eficaz, teniendo en cuenta los costes y las derivadas medioambientales.

Definida así la gobernanza del agua, e identificados sus principales aspectos y retos de futuro, resulta evidente que la MCT ha supuesto y supone un modelo integral de gobernanza del agua, que ha permitido organizar de manera eficiente, ambiental y económicamente sostenible, la distribución de un recurso escaso mediante un modelo institucional estable, transparente y participativo. Un modelo que permite involucrar a todos los agentes implicados en la toma de decisiones, Ayuntamientos, Administración estatal, Comunidades Autónomas y usuarios singulares.

Sobre estas bases, la MCT viene garantizando los suministros de agua potable al Sureste peninsular, a pesar de tratarse de una de las zonas de España de mayor crecimiento, tanto demográfico como económico. Su buena gobernanza de los recursos escasos ha permitido afrontar el continuo aumento del consumo de las pasadas décadas. Para ello la MCT ha buscado nuevas fuentes de abastecimiento y ha realizado un loable esfuerzo en la mejora de su gestión, extremando el control de fugas, apostando por la tecnificación de las redes y sistemas de suministro, así como apoyando la realización de campañas publicitarias, de difusión y educación sobre la necesidad de ahorrar agua, fomentando con ello la cultura de un uso eficiente y respetuoso con el medio ambiente. 


\section{3.- MARCO JURÍDICO Y ESTRUCTURA ORGANIZATIVA DE LA MCT.}

\section{1.- El proceso de construcción jurídica de la MCT}

La creación de la MCT es una respuesta de auxilio del Estado ante la necesidad de asegurar el abastecimiento de agua a la Base Naval de Cartagena por razones de defensa nacional, así como a determinados municipios situados en la región de Murcia y en la provincia de Alicante. Así lo expresaba Rafael Benjumea y Burín, Ministro de Fomento de la época, en la exposición de motivos que encabeza el Real Decreto Ley no 1703 , de 4 de octubre de 1927, por el que se constituye la MCT.

Con un caudal de 2 metros por segundo, procedente del río Taibilla se pretendía dar solución a la escasez, presuponiendo que con dichos recursos se podría abastecer a la población existente en la época, que el Decreto cuantifica en unas 300.000 personas, y a su potencial incremento hasta el triple de ese número. Además, se preveía la posibilidad de ampliar dicho caudal al doble del volumen inicialmente previsto, en un futuro lejano, de resultar necesario y razonable.

El Decreto Ley de 4 de octubre de 1927, aun cuando en su artículo primero sólo menciona a los municipios de Murcia, Cartagena y Orihuela, como destinatarios iniciales de los suministros, tiene una clara vocación expansiva, al prever la futura incorporación de otras poblaciones en función de las disponibilidades económicas y presupuestarias. Es importante destacar que la adhesión de los municipios a la MCT fue siempre voluntaria, si bien una vez acordada su integración, quedaban sujetos a la normativa reguladora de la MCT.

Otro de los aspectos importantes es la participación financiera de los beneficiarios en los costes de construcción y explotación, algo que desde el primer momento queda claro en la normativa constitutiva. El Estado auxilia a la Base Naval y a los municipios en sus necesidades de abastecimiento, pero al mismo tiempo les exige contribuir a los costes. El artículo 4 del Decreto Ley obligaba para ello a las poblaciones abastecidas a formar una Mancomunidad antes del inicio de las obras correspondientes, con el fin de garantizar el reembolso de las cantidades anticipadas por el Estado para ejecutar las obras. Estos costes serían también repercutidos a la Base Naval a través del Ministerio de la Marina.

Las entidades citadas debían contribuir con las partes alícuotas del coste del pantano del Tabilla, así como a financiar el coste íntegro del canal de conducción, embalses compensadores y obras complementarias. La sanción en el supuesto de impago, en el caso de los Municipios, sería la pérdida del control del suministro en baja a favor de la MCT, y por tanto, de la facultad de cobrar las tarifas correspondientes hasta el completo 
cumplimiento de la deuda e intereses. También cabía la posibilidad de establecer recargos transitorios para compensar la tarifa impagada, e incluso suspender el suministro. La financiación de la MCT se articulaba mediante la suma de varios conceptos, incluidos el anticipo del Estado, las aportaciones de los Ayuntamientos, las tarifas del agua cedida a los Ayuntamientos, y la tarifa energética.

La MCT se configura, desde un principio, como un organismo de gestión del agua en alta, quedando claro que las obras de distribución en baja son a cargo de cada población, con fondos propios municipales. El destino del agua gestionada por la entidad es siempre el abastecimiento, si bien se prevé la posibilidad de utilizar sobrantes en regadíos, con el conocimiento y aprobación de la Confederación del Segura.

Desde un punto de vista orgánico, la administración de las obras de conducción y su posterior explotación se adjudicó en un principio a un órgano colegiado interadministrativo, como era la Junta Administrativa, donde estaban representados los Municipios integrados, la Confederación del Segura, y los representantes de los Ministerios de Hacienda, Marina y Fomento. Este último ministerio, además, tenía la potestad de nombrar al Presidente de la Junta. El funcionamiento de la Junta fue precisado por un reglamento aprobado por Real Decreto no 450 de 2 de marzo de 1928. De este texto se deduce que en el acto constitutivo de la Mancomunidad acordaron integrarse los Ayuntamientos de Orihuela, Elche y Alicante, junto a otros municipios murcianos, todos los cuales decidieron constituirse en Mancomunidad. Más tarde decidirán incorporarse también, de manera temprana, los municipios alicantinos de Crevillente, Benferri, Catral, Redován y Santa Pola.

De acuerdo con esta normativa, la Mancomunidad se conforma como una entidad de duración indefinida, y asume importantes funciones administrativas, entre las que destaca de manera especial la facultad reglamentaria, es decir, la capacidad de crear normas de rango reglamentario para organizar la explotación del sistema. Además, se le reconocen dos importantes potestades, la de autoorganización y la recaudatoria.

Se crea mediante este Decreto un importante órgano administrativo, la Junta General, que se configura como verdadero órgano rector de la Mancomunidad. Los municipios alicantinos obtienen en este órgano una representatividad de segundo orden, probablemente atendiendo a que la llegada de caudales, y por tanto, su plena integración efectiva, será más tardía, de acuerdo con la evolución de las obras. Así, mientras que los Municipios de Murcia y Cartagena se ven representados por sus más altas autoridades, sus alcaldes, bajo la condición de Vicepresidentes de la Junta, el resto de municipios asumen únicamente vocalías en el órgano. La presidencia, en esa época, le correspondía al Capitán General del Apostadero de Cartagena (Almirante en Jefe de la Base Naval). Una de las más importantes atribuciones de la Junta era decidir sobre los expedientes de 
admisión de municipios al sistema de la MCT. El marco organizativo interno de la MCT se completa con la creación de un Comité Ejecutivo, cuyas funciones quedan diferidas a a un reglamento especial que debía aprobar el Ministerio de Fomento.

Un año después de su constitución formal, el Estado aprobó el Real Decreto Ley no 1317 de 22 de Julio de 1928, en el que se calificaba a esta entidad como una "Mancomunidad de Municipios", concediéndole además personalidad jurídica propia. La Mancomunidad se define así como una entidad autónoma, sujeta únicamente a las limitaciones derivadas de la Alta Inspección del Estado. Los Ministerios de Fomento, Hacienda y Marina, serían los encargados de supervisar el cumplimiento de sus fines. Desde un punto de vista económico, el régimen de ingresos del Organismo se enriquece con dos recursos económicos adicionales, como es el valor de la energía cedida a la Confederación hidrográfica del Segura, y las aportaciones voluntarias convenidas con entidades o particulares interesados en mejoras inmediatas. En esta reglamentación se establecen, en el terreno organizativo, tres órganos principales, la Junta General, presidida por el Presidente de la Mancomunidad, el Comité ejecutivo, y la Dirección técnica.

En el terreno financiero, el Real Decreto Ley de 2 de agosto de 1930, aprueba el Proyecto de Bases del Plan General de Obras y la fórmula económica, ya que transforma la aportación del Estado en unas subvenciones fijas a fondo perdido abonables por anualidades por los Ministerios de Marina y Fomento.

Hasta aquí las bases normativas históricas de la Mancomunidad, que posteriormente evolucionan hacia una configuración distinta. La reorganización de la MCT tiene lugar mediante la aprobación de la Ley de 27 de abril de 1946, sobre reforma de la Mancomunidad de Canales del Taibilla. Esta disposición degrada a rango reglamentario toda la normativa arriba indicada, precisando además la derogación implícita de todas las previsiones contenidas en ella que pudieran resultar incompatibles con la nueva regulación.

La Mancomunidad se dota ahora de una nueva estructura organizativa, dado que pasa actuar bajo la dirección de un Consejo de Administración, que inicialmente se define como un organismo delegado del Ministerio de Obras Públicas. Se mantiene con ello la dualidad inicial que caracteriza al Organismo, ya que sigue apareciendo como una mancomunidad de municipios, a la que se superpone una organización administrativa de ámbito superior directamente vinculada con la Administración del Estado.

El artículo 1 de la Ley de 1946 no atribuye todavía a la Mancomunidad la calificación jurídica de organismo estatal, sino solamente al Consejo de Administración, que ejerce funciones delegadas del Ministerio de Obras Públicas. Ello se debe a que la 
hoy denominada "Administración institucional" o "Sector Público Estatal" no había adquirido todavía un marco jurídico claramente definido en esa época. Es a finales de los años 50 cuando se produce la modernización de la Administración pública española, con la aprobación de leyes tan importantes como la Ley reguladora de la Jurisdicción Contencioso-administrativa, de 27 de diciembre de 1956, la Ley de 20 de julio de 1957 sobre régimen jurídico de la Administración del Estado, y la Ley de 17 de julio de 1958, de Procedimiento Administrativo. Fechas, como puede observarse, bastante posteriores a la Ley de 1946.

El Consejo de Administración, como dispone el artículo 2 de la Ley, dispone personalidad jurídica propia e independiente del Estado, contando con autonomía administrativa y financiera. Siempre bajo la supervisión de los órganos estatales de intervención correspondientes, y la aprobación previa de sus acuerdos más importantes por parte de su Administración matriz, el Ministerio de Obras Públicas.

Los Ayuntamientos que habían venido formando parte de la Mancomunidad tuvieron, en virtud de lo establecido en el artículo 3 de la norma, que ratificar su voluntad de permanencia, o desistir de ello en un plazo de 4 meses desde la entrada en vigor de la Ley. También se abrió la posibilidad de solicitar nuevas incorporaciones en el citado plazo, para aquellos municipios que estuvieran dentro de la zona geográfica que pudiera ser abastecida por el organismo. Este precepto fue intensamente utilizado por la MCT a lo largo del tiempo, ya que muchos ayuntamientos utilizaron este cauce procedimental para solicitar su ingreso; a su vez, el Organismo utilizó el artículo para resolver favorable o desfavorablemente dichas peticiones según el caso.

En la nueva Ley se cambiaban totalmente las bases económicas que hasta entonces habían venido rigiendo, pues el dinero necesario para las obras ejecutadas lo venía facilitando el Estado, sin que los Ayuntamientos aportaran nada; al aprobarse la Ley, tendrían que ser los Municipios los que facilitaran, con sus aportaciones proporcionales de garantía, los fondos necesarios para continuar las obras ya que el Estado no daría más soporte económico. De ahí que se concediera un plazo para que los Ayuntamientos hasta entonces mancomunados pudieran continuar o separarse, del mismo modo que se posibilitaba a Municipios no mancomunados para que en un plazo prudencial solicitaran si así lo deseaban el ingreso en la Mancomunidad. (Acta del Consejo de Administración de 10/11/1945).

Por otra parte, se asignó a la Mancomunidad un caudal regulado de $2.500 \mathrm{~m}^{3}$ de agua por segundo del río Taibilla y de los manantiales afluentes al mismo; caudales que debían destinarse en exclusiva a abastecimientos, y a la producción de hidroelectricidad que pudiera obtenerse como consecuencia de las actuaciones relacionadas con el primer uso. Las asignaciones concretas se fijaron por el Ministerio de Obras Públicas, directamente en 
el caso de la Base Naval y el Puerto de Cartagena, y previo informe de la Mancomunidad en el resto de casos. Cabe destacar que las asignaciones a los establecimientos públicos son calificadas como derechos preferentes de suministro, quedando los sobrantes disponibles para su distribución a los municipios.

Los recursos financieros que este marco legal asigna a la Mancomunidad son los siguientes:

a.- Subvención del Estado hasta el límite del 50\% del coste de los trabajos de primer establecimiento. Los excesos de esta cantidad debían ser reintegrados de manera diferida por la Mancomunidad.

b.- Aportaciones directas de organismos oficiales estatales.

c.- Ingresos por explotación de sus servicios.

d.- Empréstitos emitidos y operaciones de crédito.

e.- Otros.

El Consejo de Administración quedaba integrado por el Capitán General del Departamento Marítimo de Cartagena, el Consejero Inspector Regional de la Demarcación dependiente del Ministerio de Obras Públicas, los Alcaldes de Murcia, Lorca, Alicante y Cartagena, y diversos altos cargos y funcionarios técnicos.

Con el objeto de descargar de asuntos del Consejo, se creó un Comité Ejecutivo con funciones delegadas del primero. En este órgano también estaban representados los intereses alicantinos, ya que el Alcalde de Alicante formaba parte del mismo. Formaban parte del órgano dos representantes del resto de municipios, elegidos por votación del Pleno para dos años, y sin posibilidad de reelección. El Capitán General asumía las funciones de Delegado del Gobierno y Presidente tanto del Consejo como del Comité. Cabe destacar que, a diferencia de la regulación anterior, el Alcalde de Alicante pasa a ostentar una de las vicepresidencias, en concreto, la vicepresidencia cuarta, junto a los Alcaldes de Murcia y Cartagena, que ostentan la segunda y tercera. La vicepresidencia primera quedaba reservada para el Consejero Inspector Regional de la Demarcación. El Ministro de Obras públicas retenía la competencia de convocar y presidir el Consejo cuando lo estimara conveniente.

Desde un punto de vista financiero, el artículo 8 de la Ley determina que los usuarios de la Mancomunidad quedan obligados a abonar el canon y la tarifa por metro cúbico de agua que se apruebe, cuyo importe agregado debía cubrir los costes de explotación, intereses y amortizaciones de empréstitos. Para garantizar la suficiencia de recursos, los Ayuntamientos debían contar con la aprobación previa de las tarifas giradas a sus 
usuarios por parte del Ministerio correspondiente, previo informe favorable de la Dirección Técnica y el Consejo de Administración de la Mancomunidad. Cabe destacar a este respecto que la MCT, de forma muy temprana, viene aplicando el principio de recuperación integral de costes, que mucho después recogerá la Directiva Marco del Agua en el año 2000.

La Ley establece definitivamente una formula económica para financiar las obras, consistente en que el Estado aportará el 50\% del coste total del Plan General. El otro 50\% deberá buscarlo el Organismo en el mercado de capitales con la garantía de sus propios ingresos y la mancomunada de los ayuntamientos. Por otra parte, la norma da entrada en el Organismo a lo que denomina Entidades Estatales, que independientemente de la Marina u otras entidades oficiales (Bases Aéreas del Mar Menor, Puerto de Cartagena), incorpora al suministro de agua a Empresas Nacionales que se ubican en el Valle de Escombreras, con lo que implícitamente se asume satisfacer las demandas industriales de gran consumo.

Hasta 1945, todas las obras habían sido financiadas íntegramente por el Estado como ya ha sido indicado, situación que modifica la Ley de 1946. Las dificultades para encontrar financiación eran notorias, especialmente por la desconfianza que las entidades de crédito muestran respecto a la solvencia de los ayuntamientos (Nieto Llobet, 2013). Para obviar las dificultades de financiación que ponían en peligro la continuación del Plan de Obras, se publicó el Decreto-Ley de 23 mayo 1947 donde, por parte del Estado, se establecía una subvención anual al Organismo de 2,4 millones de pesetas, durante 25 años. Esta subvención podía utilizarse directamente en la construcción de obras, o en garantía de los préstamos.

Igualmente, y con objeto de que en la cantidad que podía ofrecerse como garantía existiera una participación significativa de los municipios, el artículo 3o disponía: "Se establece un recargo del $15 \%$ sobre las cuotas del Tesoro de la contribución rústica y urbana, correspondiente a las fincas sitas en los términos de los municipios de la Mancomunidad. El importe de este recargo será abonado por la Delegación de Hacienda de Murcia, directamente al Consejo de Administración de la Mancomunidad”. El recargo sobre las contribuciones constituyó una pieza fundamental, no sólo para la financiación directa de las obras, sino también como garantía financiera para la obtención de los préstamos. El primer empréstito se contrae con el Banco de Crédito Local por importe de 60 millones de pesetas en 1948. A éste le seguirán dos más, uno en 1952 por importe de 27,2 millones de pesetas, y otro en 1954 por 100 millones. Después de 1956 se realizan dos operaciones más por importes de 90 y 80 millones respectivamente. En resumen, se obtuvieron 357,2 millones que aseguraron la continuidad de las obras en curso, y el comienzo de los canales del Segura, Murcia y Alicante. 
Para finalizar las actuaciones previstas en el Plan de Ampliaciones, el principal problema será buscar la financiación necesaria, pues se mantenía lo establecido en la Orden de 29 julio 1966 de que el plan cubriese, mediante tarifas, los costes de explotación y de amortización de las obras. El principio económico era claro: "los costes de ampliación del sistema de abastecimiento, ya en estado de madurez, debían ser soportados por los rendimientos del propio sistema". Para financiar el Plan se suscribieron tres empréstitos: 2.517 millones ptas para la 1a Etapa (obras principales), 3.995,0 millones ptas para la Segunda Modificación del Plan de Ampliaciones, redactado en marzo de 1974. Con estos recursos pudo iniciarse la contratación de las obras principales que esencialmente eran los nuevos canales de Murcia, Alicante y Cartagena, las plantas de tratamiento en origen de los respectivos canales, y las estaciones elevadoras o de captación para alimentar a dichas plantas desde los canales del postrasvase. Una vez esas obras fueran terminadas, quedaba asegurada la incorporación a las redes de la Mancomunidad de las aguas del Trasvase. No obstante, la necesidad de ampliar los ramales y depósitos según fuesen exigiéndolo las demandas de las poblaciones, dio lugar en 1974 a la redacción de la Tercera Modificación, aprobada por Decreto 497/75 de 6 marzo, cuyo total importe alcanzó los 4.741,8 millones ptas.

La estructura orgánica actual de la MCT viene establecida en el Real Decreto 2714/1976, de 30 de Octubre. De acuerdo con esta norma, la MCT está regida por un Delegado del Gobierno, el Consejo de Administración, y el Director. El Delegado del Gobierno, de acuerdo con lo que establece el Decreto ley de 10 de agosto de 1950, debe ser nombrado por Decreto, aprobado en Consejo de Ministros a propuesta del Ministerio competente en materia de obras públicas, y sus funciones siguen siendo las que se establecieron en la Ley de 27 de abril de 1946. Preside además el Consejo de Administración, que estará constituido de acuerdo con dicha Ley, con los cometidos que en ella se especifican. El Director mantiene igualmente las funciones que le fueron asignadas por la Ley de 1946.

Para terminar, resulta necesario mencionar un conjunto de importantes previsiones establecidas en la disposición adicional cuadragésima primera de la Ley 50/1998, de 30 de diciembre, de Medidas Fiscales, Administrativas y del Orden Social, ya que esta normativa flexibilizó el régimen de acceso a la MCT. Todos los municipios situados en la zona geográfica que pueda ser abastecida por la Mancomunidad pueden acogerse a esta norma para solicitar su ingreso en la MCT al Ministerio con competencias en medio ambiente, el cual, previo informe de aquélla, resolverá respecto a su admisión, determinando las condiciones a que han de someterse. Permite también, bajo determinadas condiciones, la incorporación de otros municipios, así como incrementar el suministro de agua potable a los municipios ya integrados con la finalidad de abastecer a instalaciones industriales y de servicios cuyas necesidades no se encuentren contempladas en sus dotaciones. Esta modificación legal fue posible por la incorporación de nuevos recursos hídricos 
procedentes de la desalinización, y facilitó a su vez la entrada de Aspe, Hondón de las Nieves (2005) y posteriormente de Hondón de los Frailes (2013).

El Comité Ejecutivo de la MCT, en su reunión de 24 de octubre de 2013, mostró su preocupación por la posible privatización de la actividad que realiza la MCT. Esta posibilidad se encontraba en fase de estudio en el Ministerio de Agricultura, donde se estaba elaborando un informe sobre el particular. Según consta en la memoria anual de 2013, varios Ayuntamientos mostraron su oposición a cambios en el status jurídico de la MCT, tanto en cuanto a su posible privatización, como por su posible fusión con ACUAMED (CEMCT 26/2/13 y 24/10/13). Los Plenos municipales de diversos Ayuntamientos aprobaron mociones en dicho sentido, que fueron debidamente comunicadas a la MCT (CEMCT 14/5/14). Entre dichos Ayuntamientos, figuran varios pertenecientes a la provincia de Alicante, como son los Ayuntamientos de Alicante, Aspe, Santa Pola, Guardamar del Segura, San Vicente del Raspeig, Bigastro, Crevillente, y Villajoyosa, este último no perteneciente a la MCT, pero sí al Consorcio de Aguas de la Marina Baja, que ha sido eventualmente receptor de caudales transferidos desde el embalse de Alarcón a través de las infraestructuras de la MCT. Esta iniciativa no prosperó debido a la oposición de los beneficiarios del sistema y del contexto social y político que se manifestó en contra, pero durante un tiempo produjo un importante nivel de incertidumbre en el Organismo.

\section{2.- Principales normas reguladoras.}

Al margen del régimen jurídico general que afecta a esta entidad, en su condición de organismo público estatal, y singularmente la Ley 40/2015, de 1 de octubre, de Régimen Jurídico del Sector Público, la Mancomunidad dispone de un cuerpo normativo propio que determina las peculiaridades de su régimen jurídico. Las fuentes normativas pueden clasificarse de acuerdo con la siguiente estructura:

a.- Instrumentos reguladores constitutivos:

- Decreto Ley 4 de Octubre 1927: Creación de la Mancomunidad.

- Decreto 2 de Marzo 1928: Constitución y Régimen.

- Decreto Ley 22 de Julio 1928: Reglamento.

- Real Decreto Ley de Agosto 1930: Reorganización.

b.- Reforma, ampliación y consolidación financiera de la Mancomunidad:

- Ley 27 de Abril de 1946: Reforma. 
- Decreto 28 de Junio 1946: Dotaciones de agua a Municipios.

- Orden 26 de Septiembre 1946: Municipios integrados.

- Decreto Ley 23 de Mayo 1947: Subvención Estado y establecimiento recargo sobre contribuciones rústica y urbana.

- Orden 23 de Febrero 1950: Amplía municipios integrados.

- Decreto Ley 10 Agosto 1950: Modificación nombramiento del Delegado del Gobierno-Presidente.

- Decreto 497/1975, de 6 de Marzo: Fija régimen de auxilios del Estado al coste de las obras del Plan de Ampliación de los Abastecimientos.

- Real Decreto 2714/1976, de 30 de Octubre: Establece estructura orgánica.

c.- Normativa del periodo post-constitucional

- Real Decreto 1654/1985, de 3 de Julio: Establece nivel orgánico de Subdirector General para el Director del Organismo.

- Ley 39/1988, de 28 de diciembre, de Haciendas Locales.- Desaparece el recargo a favor de Mancomunidad sobre las contribuciones rústicas y urbanas.

- Ley 50/1998, de 30 de Diciembre: Adapta su naturaleza jurídica a Organismo autónomo (LOFAGE), amplía sus funciones al suministro industrial y de servicios, y posibilita la incorporación de nuevos municipios.

- Ley 33/2003, de 3 de Noviembre: Establece régimen de incorporación de bienes al patrimonio del Estado.

- Ley 62/2003, de 30 de Diciembre: Establece las tasas que constituyen recursos propios del Organismo.

La Mancomunidad, por otra parte, debe aplicar el régimen presupuestario, económico-financiero, de contabilidad, y de control establecido por la Ley 47/2003, de 26 de noviembre, General presupuestaria. 


\section{3.- Naturaleza jurídica de la MCT.}

Aunque la MCT se configura tempranamente como un organismo público estatal, adopta en origen una denominación que no resulta casual o irrelevante: "Mancomunidad". Las mancomunidades son instituciones de honda tradición histórica en España. Las primeras se remontan a la Edad Media, y son entidades creadas para la gestión y explotación de recursos forestales. No obstante, los primeros intentos de regular esta figura se producen a mediados del siglo XIX (Font y Parrado, 2000).

Ya el siglo XX, esta institución se reguló en el Estatuto Municipal de 8 de marzo de 1924, bajo cuya normativa se constituyó la MCT. El Reglamento que regula la Junta Administrativa de la MCT, de 2 de marzo de 1928, configura este órgano "usando la facultad establecida en el artículo 6 del Estatuto Municipal”, así como de acuerdo con lo establecido en el Reglamento sobre Términos y Población municipal de 2 de julio del mismo año.

La Mancomunidad, sin embargo, adopta una forma jurídica distinta con la Ley de 27 de Abril de 1946, donde se configura como un organismo delegado del Ministerio de Obras Públicas. Posteriormente, el organismo se adaptará a una más moderna caracterización administrativa de la Administración institucional del Estado, bajo la categoría de Organismo autónomo grupo B (Decreto 1348/1962); La Ley 11/1977, General Presupuestaria, le concederá la calificación de organismo autónomo de carácter comercial, y la disposición adicional cuadragésimo primera de la Ley 50/1998, de 30 de diciembre, de Medidas Fiscales, Administrativas y del Orden Social, reclasificará a la Institución bajo la categoría de organismo autónomo, de los previstos en el artículo 43.1 de la Ley 6/1997 de 14 de abril, de organización y funcionamiento de la Administración General del Estado (LOFAGE).

La LOFAGE, sin embargo, ha sido derogada, con efectos 2 de octubre de 2016, por la Ley 40/2015, de 1 de octubre, de Régimen Jurídico del Sector Público. Nada cambiará sin embargo en cuanto a la naturaleza jurídica de la Mancomunidad, que seguirá siendo un organismo autónomo estatal, ahora de los previstos en los artículos 98 y siguientes de esta Ley, así como en el artículo 2.2.a).1o de la Ley 47/2003, de 26 de noviembre, General Presupuestaria. De acuerdo con su definición legal, "Los organismos autónomos son entidades de derecho público, con personalidad jurídica propia, tesorería y patrimonio propios y autonomía en su gestión, que desarrollan actividades propias de la Administración Pública, tanto actividades de fomento, prestacionales, de gestión de servicios públicos o de producción de bienes de interés público, susceptibles de contraprestación, en calidad de organizaciones instrumentales diferenciadas y dependientes de ésta”. 
La Mancomunidad es, por consiguiente, un organismo público estatal adscrito al Ministerio de Agricultura y Medio Ambiente. Es un claro ejemplo del conjunto de entidades públicas que integran la administración institucional del Estado. Organismos que tienen como finalidad separar de la Administración matriz un conjunto de cometidos específicos, normalmente complejos o con un importante contenido técnico, con la finalidad de gestionar de manera más eficiente una determinada actividad o función administrativa. En este caso, la actividad es la gestión en alta de suministros tanto urbanos como de grandes usuarios, y significativamente de la Base Naval de Cartagena.

El nuevo marco legislativo, conformado por la Ley 40/2015, de 1 de octubre, de Régimen Jurídico del Sector Público, permite ahora la conversión de este tipo de entidades en cualquier otra categoría de organismos públicos, incluidas las siguientes fórmulas: entidad pública empresarial, sociedad mercantil estatal o fundación del sector público institucional. Para ello sería necesario, formalmente, la aprobación de un Real Decreto que reclasificara la naturaleza jurídica de la entidad; materialmente, tendría que elaborarse una memoria justificativa que mostrara la necesidad de tal conversión (art. 87). No hay obstáculo, sin embargo, para que la entidad conserve su configuración jurídica actual como organismo autónomo del Estado.

La estructura jurídico-administrativa y funciones asignadas a la MCT se circunscriben a la organización del servicio de suministro de agua en alta. No se plantea por tanto una gestión integrada del recurso, mediante un sistema más globalizador, que articule las fases de abastecimiento en baja, depuración y saneamiento. Esta caracterización distingue a la Mancomunidad de otros organismos o empresas públicas con fines similares, tal como el Canal de Isabel II en Madrid, que al pasar a ser empresa pública en 1977, posteriormente adscrita a la Comunidad de Madrid, asumió nuevas funciones junto al abastecimiento en baja, como es el saneamiento, o la creación y gestión de infraestructuras higiénicosanitarias, a petición de los ayuntamientos (Valenzuela, 1987).

\section{4.- Organización: especial referencia a la representación de la provincia de Alicante en los órganos de gobierno de la MCT.}

La Mancomunidad, pese a ser un organismo formalmente independiente, con personalidad jurídica y autonomía financiera propia, está sujeta a la tutela de la Administración General del Estado, a la que corresponde su dirección estratégica, la evaluación de los resultados de su actividad, y el control de la eficacia de su desempeño. Para alcanzar sus fines, dispone de un patrimonio propio, distinto del de la Administración matriz, del que forman parte los bienes y derechos de los que sea titular. La Mancomunidad forma parte del conjunto de entidades integrantes del sector público institucional estatal. 
La Mancomunidad se estructura internamente en diversos órganos, donde se ubican funcionalmente tanto el staff directivo como técnico. A continuación podemos observar, en la figura 13, correspondiente al organigrama de 2014, el conjunto de órganos unipersonales que conforman la estructura orgánica de funcionamiento.

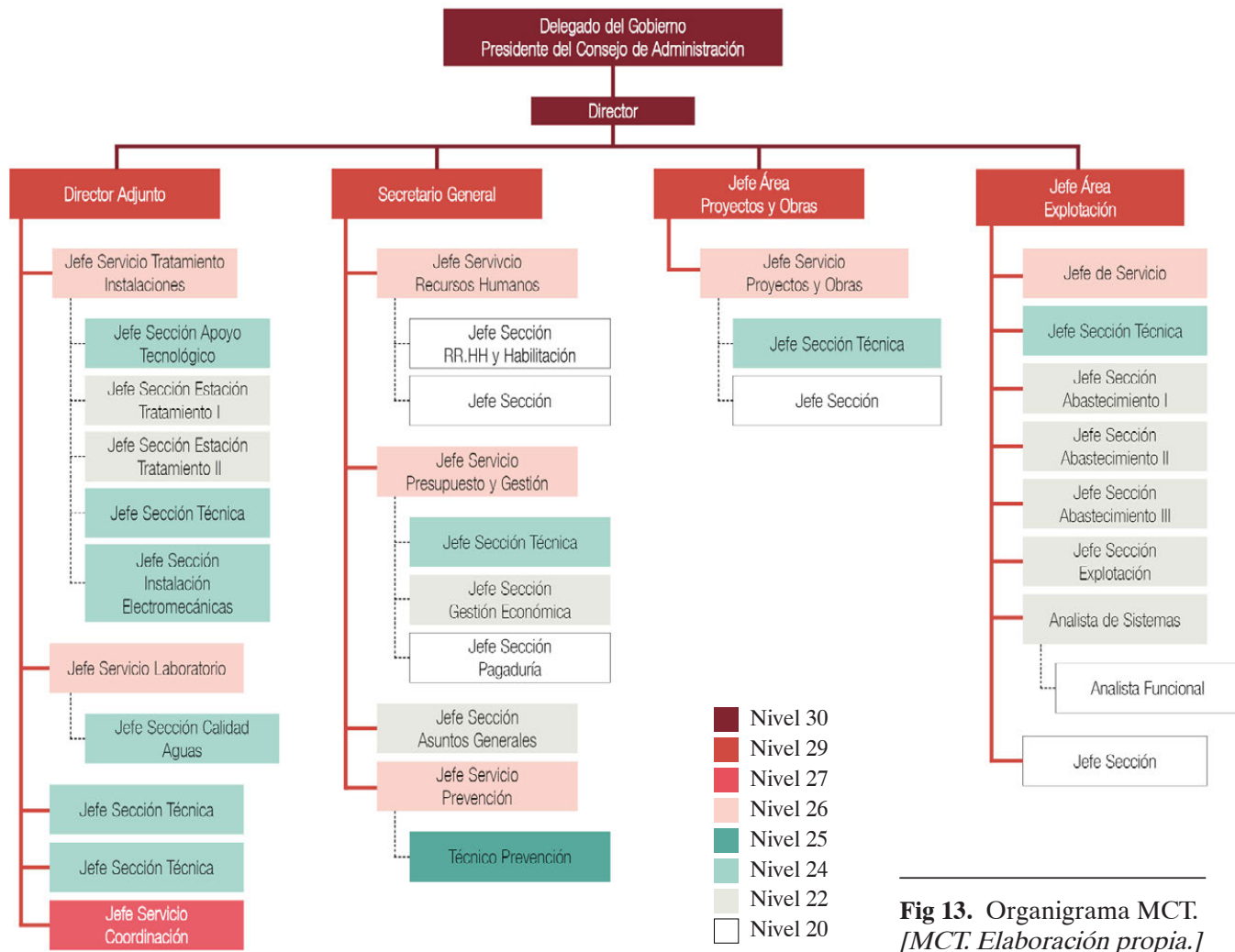

Junto a estos órganos unipersonales y unidades administrativas o técnicas, la Mancomunidad dispone de varios órganos colegiados cuya intervención resulta fundamental en el gobierno de la entidad. Se trata del Consejo de Administración y del Comité Ejecutivo.

El artículo 2 de la Ley de 27 de Abril de 1946, recoge la definición, funciones y caracterización del Consejo de Administración. Interpretando este precepto conforme a la configuración actual de la Ley del Sector Público Estatal de 2015, el Consejo de Administración es un órgano administrativo colegiado del organismo, y en consecuencia, no ostenta personalidad jurídica propia. Es la Mancomunidad la que disfruta de tal condición. Por otra parte, ni el Consejo ni la propia Mancomunidad están exentos del 
control financiero del Estado, aunque la Entidad tiene autonomía financiera y presupuesto propio. En la figura 14 se expone la estructura del Consejo de Administración.

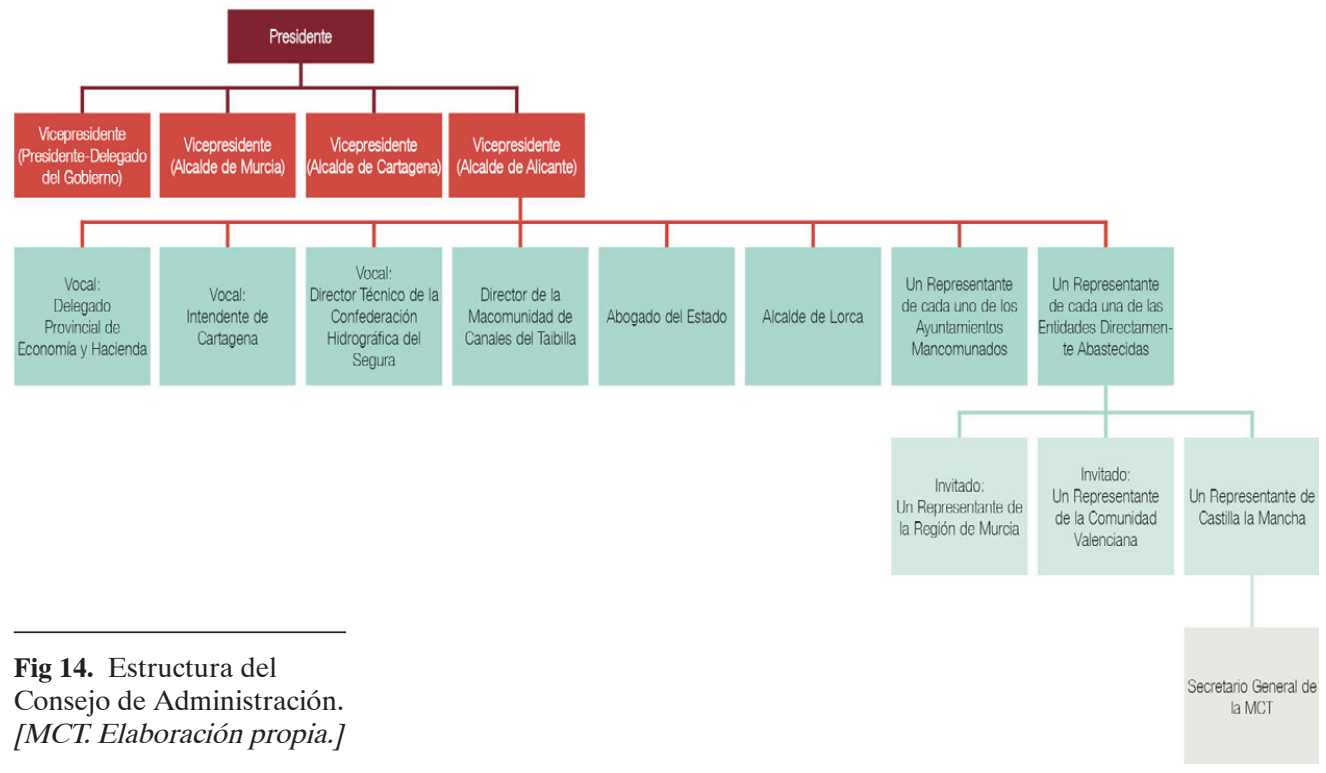

Entre los Vicepresidentes del Consejo figura el Alcalde de Alicante. Además, cada Ayuntamiento alicantino integrado en la Mancomunidad cuenta con un vocal en el órgano, como miembro de pleno derecho; por otra parte, participa en los debates un representante de la Comunidad Valenciana, bajo la condición de invitado.

Por delegación del Consejo actúa un Comité Ejecutivo constituido por los representantes oficiales de la Administración del Estado, los alcaldes de Murcia, Alicante, Cartagena, Lorca, y dos de los representantes de los demás Ayuntamientos. El órgano está presidido por el Delegado del Gobierno.

Fig 15. Estructura del

Consejo Ejecutivo.

[MCT. Elaboración propia.]

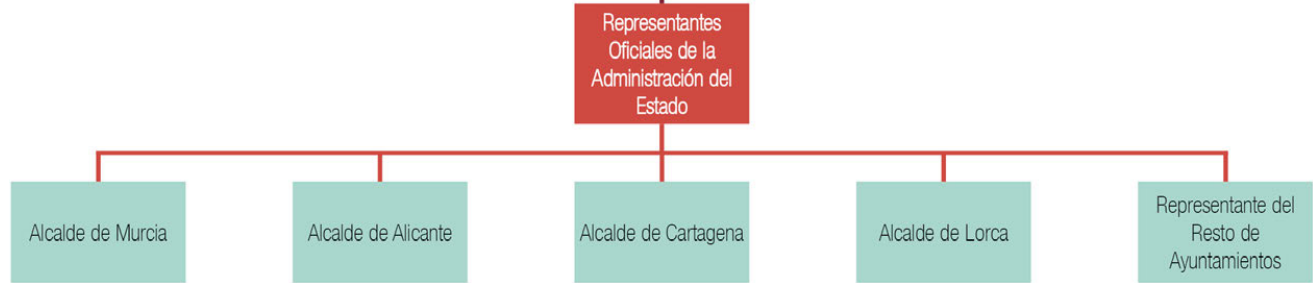




\section{4.- INCORPORACIÓN DE MUNICIPIOS Y LLEGADA DE CAUDALES DE LA MCT A LOS MUNICIPIOS ALICANTINOS.}

\section{1.- Incorporación formal de los municipios alicantinos.}

El contexto geofísico y climático del sureste español no resulta en absoluto favorecedor del crecimiento demográfico y socioeconómico del territorio, lo que contrasta vivamente con la realidad actual. Si observamos esta situación desde una perspectiva histórica, se hace preciso resaltar una circunstancia singular, que motivó una pronta reacción gubernativa dirigida a resolver las limitaciones derivadas de la escasez de agua: la existencia de la Base Naval de Cartagena. La existencia de la Base militar, y la necesidad de asegurar su abastecimiento (se le asignaron $50 \mathrm{l} / \mathrm{seg}$ en origen), constituye el fundamento de la creación de la MCT (CEMCT 30/7/1928).

En 1913 se hizo un primer estudio para abastecer a Cartagena y su Base Naval, con unas necesidades estimadas de 500 1/seg. Por primera vez, aparece la solución río Taibilla para resolver dicho problema. Entre los años 1914 y 1917 se estudió la posible solución del abastecimiento a la Base Naval, Murcia y Cartagena, con agua procedente de los Chorros del río Mundo, solución que fue abandonada al año siguiente debido a la insuficiencia de sus caudales. En 1925 el Ingeniero de Caminos José Eugenio Ribera redactó un anteproyecto en el que la fuente de suministro era el río Taibilla. En 1926, Cartagena acusó un grave problema de falta de agua que puso al borde del desabastecimiento a la población civil, a la guarnición militar y los buques y dependencias de la Armada (Gil y Rico, 2008).

Con base en dicho Anteproyecto, en 1927 el Conde de Guadalhorce impulsa la creación de una mancomunidad de municipios de usuarios de aguas para abastecimiento, ordenando la redacción del proyecto de abastecimiento definitivo. Para dar cumplimiento a dicho objetivo, la Mancomunidad de Canales del Taibilla se constituye mediante Decreto Ley de 4 de octubre de 1927, lo que pondrá las bases para que unos años después, en 1945, lleguen las aguas a Cartagena y a su Base militar a través de más de 200 km de canalizaciones en su canal principal.

Desde agosto de 1928 hasta marzo de 1929, se trabaja en la redacción del Proyecto de Bases o Plan General de Obras. Este Plan modifica el anterior, proyecto Rivera. El Plan General prescinde de regar y utiliza secciones cerradas para mantener las condiciones físico-químicas de las aguas. El proyecto Ribera, contemplaba únicamente el abastecimiento de la Base Naval y las poblaciones de Murcia y Cartagena o alguna otra próxima al trazado. El Plan General amplía el área a abastecer, al incluir las poblaciones situadas en el cuadrilátero de vértices Mula, Lorca, Cartagena y Alicante. Propone el abastecimiento de las siguientes poblaciones en la provincia de Alicante: Orihuela, 
Benferri, Redován, Callosa del Segura, Almoradí, Cox, Albatera, Catral, Dolores, Santa Pola, Crevillente, Elche y Alicante (Nieto Llobet, 2012).

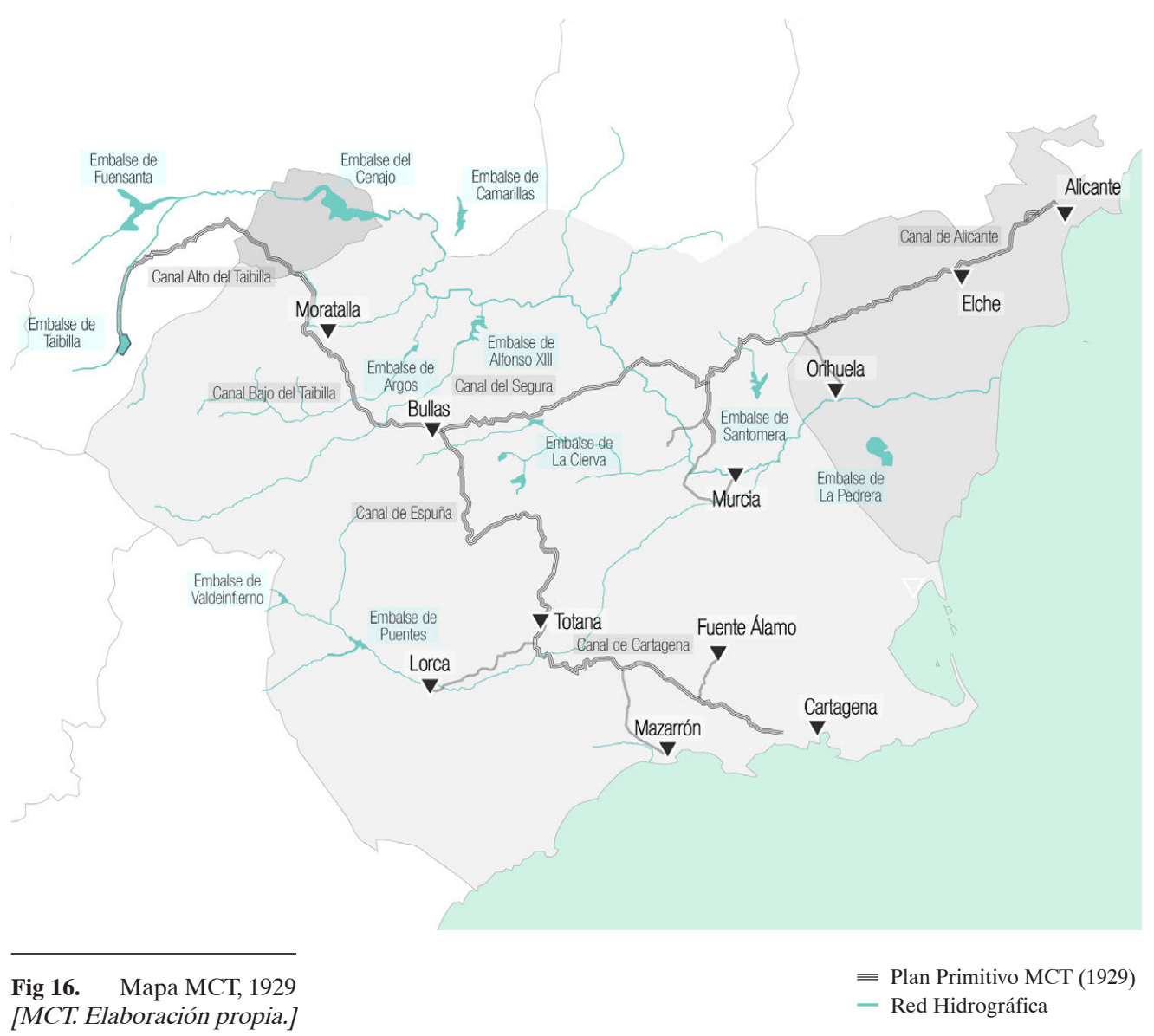

En 1927 se crea la Mancomunidad. Culmina la etapa de gestación y se inicia la de constitución y puesta en marcha. El número de sus municipios ascendía a 35 en 1930. Tras la llegada de la Segunda República se llegó incluso a plantear la disolución de la Mancomunidad (CEMCT, 30/10/1931). La crisis política y económica afectó desfavorablemente al Organismo, y el Real Decreto-Ley de 1 de agosto de 1930 trató de superar esta situación sustituyendo la financiación por cuenta exclusiva del Estado en concepto de anticipo reintegrable en cincuenta años, que había sido la fórmula inicial de financiación, por una subvención anual de dos millones de pesetas durante diez años, y la contratación de empréstitos avalados por los Ayuntamientos. Las obras, comenzadas en 1932, tuvieron que atemperar su desarrollo a la subvención estatal, dado que los Ayuntamientos carecían de capacidad para obtener los avales requeridos, y quedaron paralizadas durante la Guerra Civil (Memoria MCT, 2009). 
El 21 de diciembre de 1928, Alicante solicita su ingreso en la MCT, con el mismo criterio que los ayuntamientos de Orihuela, Elche, Crevillente y Santa Pola, acogiéndose al artículo 34 del Reglamento aprobado por RD de 2 de marzo de 1928, para ser abastecidos por las aguas del Taibilla. En el caso de Santa Pola, la solicitud de incorporación se realizó el 30 de abril de 1928, Crevillente hizo lo propio en junio de ese mismo año (CEMCT 30/5/1928 y 30/6/1928). Santa Pola contaba con más de 4000 habitantes según informó el 4/1/1929 y las embarcaciones de cabotaje tenían que ser abastecidas (más de 300 anuales), así como las embarcaciones de pesca, industria muy importante para Santa Pola. El 28/3/1930, se acepta por la MCT la incorporación.

Elche es uno de los municipios fundadores de la MCT, pero no hay ningún documento en su expediente relativo a su incorporación. Lo primero que consta es la designación de representantes en el Consejo de Administración de la Mancomunidad en 1928. El 23 de agosto de 1946 el municipio acordó por unanimidad ratificar su compromiso de pertenencia a la MCT, solicitando el abastecimiento exclusivamente del casco urbano de la población, al que posteriormente se incorporarán varios grupos del extrarradio: Altabix, Huertos y Molinos, Carrús y Llano de San José. (Acta MCT 26 de agosto de 1946). Orihuela solicitó la ratificación de su permanencia en la MCT el 28 de agosto de 1946.

Crevillente debía haber pertenecido a la Mancomunidad desde su origen, pero una serie de malentendidos y de trabas burocráticas lo impidieron. El Ayuntamiento acudió a varias instancias para solucionarlo y al final se resolvió su incorporación el 31 de octubre de 1928. En esa fecha, la MCT comunica al ayuntamiento de Crevillente que "S.M el REY (q.D.g.) ha tenido a bien disponer que se considere incluido en la Mancomunidad de los Canales del Taivilla al ayuntamiento de Crevillente" (Acta MCT, 31/10/1928). Posteriormente, en 1946 realizaron los trámites propios de la ratificación de su deseo de pertenecer al organismo.

En 1930 se incorporan a la MCT: Benferri (26/3/1930) Redován (16/8/1930), Jacarilla (25/8/1946), Albatera y Catral (1/9/1930). Catral es un caso particular, ya que solicitó su admisión el 7 mayo de 1930, aprobándose su ingreso por el Consejo de Administración el 1 de septiembre de 1930; en mayo de 1932, intentó su separación de la MCT debido a la lentitud con que se estaban desarrollando las obras del Plan General, y los problemas sanitarios que afectaban al municipio. No obstante, en 1946 Catral y Redován reafirmaron su deseo de permanencia (Acta MCT 19/6/1946).

La Mancomunidad experimenta fases inversoras expansivas hasta 1930 y desde 1939, con una etapa de paralización por razones económicas, y por el advenimiento de la Guerra Civil. La Guerra generó importantes tensiones en el seno de la MCT, cuyo ingeniero director manifestaba en julio de 1936, días después del levantamiento militar del 18 de 
julio, que: "el Organismo ha estado, está y estará siempre al lado del poder constituido" (CEMCT 30/7/1936). En el Comité Ejecutivo de Octubre de ese mismo año informó de la muerte del ingeniero director, Agustín Martín-Montalvo y Gurrea "expresando su sentimiento por las circunstancias que le han llevado a tan triste desenlace". El ingeniero director accidental, Rafael de la Cerda y de las Bárcenas, que pronuncia dichas palabras, se refiere eufemísticamente al fusilamiento de su predecesor (CEMCT 30/10/1936). En la Memoria de la MCT de 1945 se hace referencia a este suceso en los siguientes términos: "en 1936, al principio de la dominación roja, fueron encarcelados todos los ingenieros, y el Sr. Martín Montalvo fue asesinado, cayendo por Dios y por España el 18 de octubre, por el sólo crimen de su entusiasta labor al frente de estas obras. La necesidad de mantener medio escondidos en el campo a los ingenieros para evitar que corrieran la misma suerte, fue aprovechada por los ingenieros Sanz Gómez, Cuadrado y Vidal-Abarca, con el que suscribe (De la Cerda) para hacer todos los trabajos de campo que faltaban del Canal Taibilla-Cartagena" (Memoria MCT, 1945).

Debido a las circunstancias de escasez motivadas por la Guerra, la Institución declaró el carácter apolítico del organismo: "queda acordado unánimemente que la Mancomunidad, como organismo de carácter esencialmente administrativo, de interés nacional, y ajeno a todo partido político, sancionará rigurosamente por medio de sus órganos competentes a los funcionarios que individual o colectivamente recurran a los partidos o sindicatos a que pertenezcan para conseguir mejoras o beneficios de clase alguna" (CEMCT, 28/6/1937).

Con el final de la contienda, las obras se reactivan con financiación íntegramente pública, y la construcción de canales e infraestructuras necesarias para abastecer a Cartagena y su Base Naval finalizan en 1945. En concreto, se completan las obras del primitivo canal del Taibilla, de $214 \mathrm{~km}$. En este periodo entran en servicio las obras de la rama Occidental, Presa de Toma, Canales Alto y Bajo de Taibilla, Canal de Espuña y Canal de Cartagena.

El Canal Taibilla-Cartagena, parte de la presa de toma $\left(1 \mathrm{hm}^{3}\right)$, que fue finalizada en 1955; ésta se encuentra a su vez $7 \mathrm{~km}$ aguas abajo del Embalse del Taibilla $\left(9 \mathrm{hm}^{3}\right)$ finalizado en 1979 en el municipio de Nerpio (Albacete). Desde la toma del Taibilla, hasta el depósito regulador de Tentegorra (Cartagena), el canal se dividió en 4 tramos (Canal Alto, Canal Bajo, Canal de Espuña y Canal de Cartagena), que convertían esta conducción en el abastecimiento cubierto más largo de Europa (Rico, 2014). Sin embargo, los planes de abastecimiento incluían además los municipios establecidos en el eje del río Segura, hasta Murcia y buen número de los municipios de la Vega Baja, hasta Alicante. Estas poblaciones tuvieron que esperar a que el panorama jurídico y financiero de la Mancomunidad se clarificara. A partir de 1945, se aborda la construcción de la rama Oriental -los Canales del Segura y Alicante- y los ramales y depósitos del 
resto de poblaciones incluidas en el Plan General de Obras, de 2 agosto 1930. Para ello fue necesario buscar financiación complementaria a la del Estado. En este sentido, resultó fundamental la aprobación de la Ley de 27 de abril de 1946, que transformó la Mancomunidad en un Organismo Estatal, especificó sus funciones, su estructura organizativa, y los recursos financieros para su funcionamiento. Esta legislación posibilitó además que otros ayuntamientos y entidades públicas fueran incorporándose al sistema de explotación de la MCT, en un proceso prácticamente ininterrumpido desde la segunda mitad del Siglo XX. Este marco legal favorecerá la entrada de los municipios alicantinos en el sistema.

En el Decreto de 28 de junio de 1946 se define el concepto de zona geográfica abastecida por el Taibilla, en él se relacionan los 57 ayuntamientos mancomunados hasta esa fecha. El Comité Ejecutivo de la MCT (CEMCT) propuso en 1955 que se modificara dicho Decreto para que se incluyera en la zona geográfica de la MCT a los siguientes ayuntamientos alicantinos: San Miguel de Salinas, Torrevieja y Santa Pola. (CEMCT, 29/12/1955).

Conforme se iban incorporando al abastecimiento las poblaciones, el fantasma de la escasez de agua aparecía en el horizonte, con tintes de gravedad a medio plazo. Los problemas de la Mancomunidad ya no se centran únicamente en la financiación de las inversiones, sino que resulta imprescindible disponer de asignación de agua suficiente para garantizar el abastecimiento de la totalidad de municipios. Desde 1939 a 1945 el problema era aportar, cuanto antes, agua a Cartagena y la Base Naval; a partir de 1946, al desaparecer el importante esfuerzo inversor del Estado destinado a aquellos objetivos, para poder continuar el Plan General el dinero había que buscarlo en los mercados de capitales, y las dificultades de obtenerlos trajeron notables retrasos en las obras; finalmente, en los años sesenta, con la red básica de canales ya construidos, el principal asunto a considerar no será tanto financiero sino dar solución a la insuficiencia de recursos hídricos (Nieto Llobet, 2013).

La relación entre la Mancomunidad y la Base Naval era tan estrecha que las reuniones de los órganos directivos de la Mancomunidad se realizaban en las dependencias de la Capitanía General, hasta que, en 1946, se adjudican las obras de construcción de la sede permanente del Organismo. Se presentaron seis propuestas a concurso, de entre las cuales se acordó adjudicar a Entrecanales y Távora S.A. el contrato, por la cantidad de 1.273.529, 58 pesetas (CEMCT, 26/10/1946).

El artículo 3 de la Ley de 27 de abril de 1946 establecía que los municipios situados en la zona geográfica que podía ser abastecida por los Canales podrían ingresar en la Mancomunidad si dentro del plazo de 4 meses, contados a partir de la publicación de la Ley, lo solicitaban al Ministerio de Obras Públicas, el cual, previo informe de la MCT, resolvería respecto de su admisión, determinando las condiciones a las que hubieran de someterse. 
Las dotaciones de agua a los municipios y su sistema de asignación reciben una nueva regulación con la aprobación por parte del Ministerio de Obras Públicas, del Decreto de 28 de junio de 1946. Las dotaciones las decidirá directamente el Ministerio con una periodicidad de diez años, manteniendo invariable el número de litros por habitante y día. El Decreto define lo que debe entenderse como "zona geofráfica propia de la MCT", siendo ésta la comprendida en una franja de diez kilómetros de ancho a ambos lados del eje del Canal. Fuera de esta zona, las poblaciones podrían ser abastecidas en la medida en que se comprometieran a asumir el exceso de gasto que supusiese la parte de la conducción que rebasara dicha zona.

La Orden Ministerial de 26 septiembre 1946 fijó las condiciones a los ayuntamientos para que pudieran pasar a formar parte de la MCT. La norma, además, relacionaba los municipios integrados en el Organismo. Pertenecen 2 a la provincia de Albacete, 17 a la provincia de Alicante (Albatera, Benejúzar, Benferri, Bigastro, Catral, Crevillente, Dolores, Guadamar del Segura, Jacarilla, Orihuela, Redován, San Miguel de Salinas, Santa Pola, Torrevieja, Alicante, Callosa del Segura y Elche) y 38 a la provincia de Murcia. En esta última disposición, se fijan igualmente para cada municipio las pedanías y núcleos de población con derecho a agua y los volúmenes anuales totales asignados.

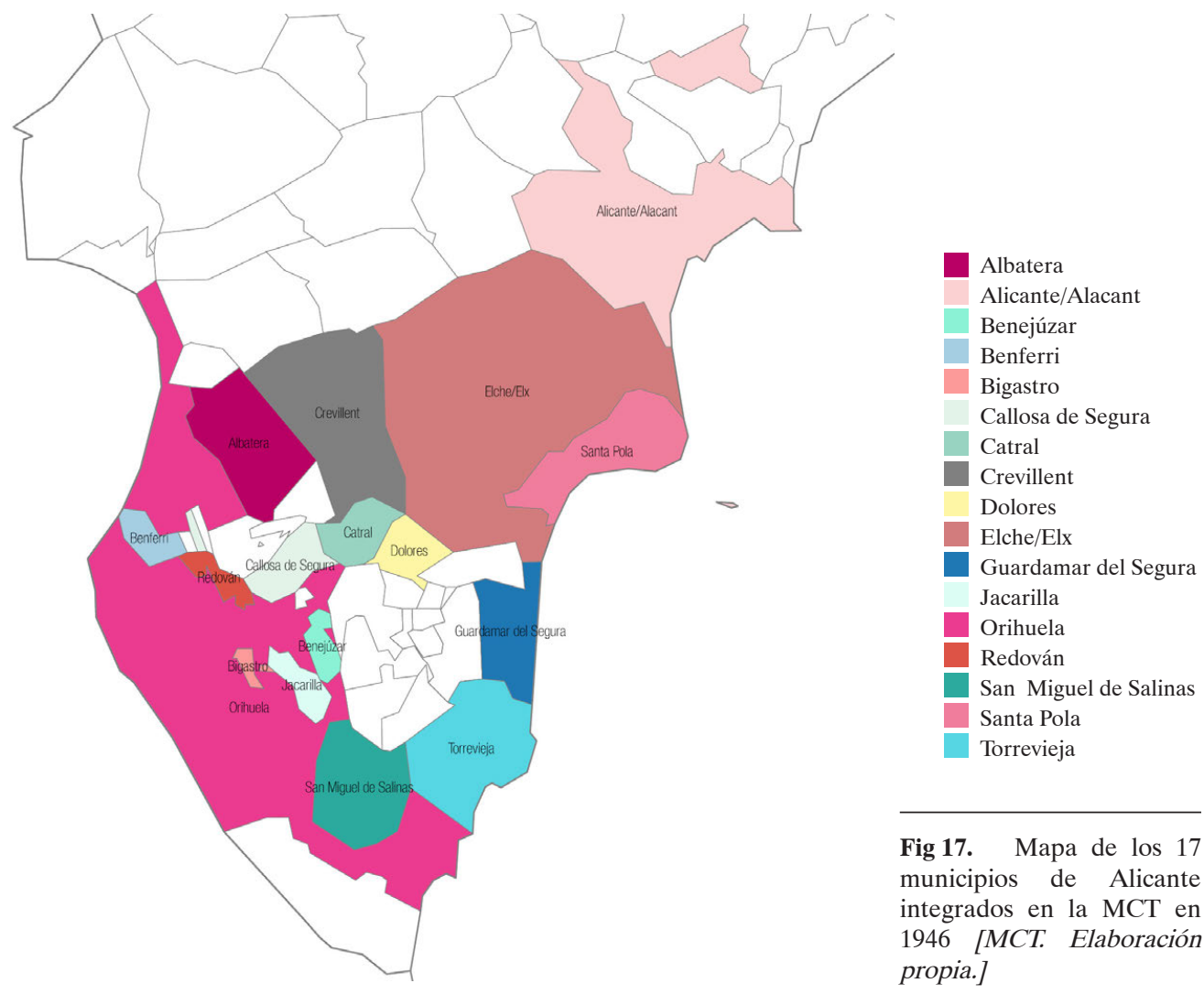


Los Municipios de San Vicente del Raspeig y San Juan de Alicante solicitaron su incorporación en octubre de 1946, pero su petición fue desestimada por haberse realizado fuera del plazo establecido por la Ley. El Alcalde de Alicante, en sesión del Consejo Ejecutivo, manifestó que "le consta que los dos ayuntamientos no solicitaron la incorporación a la MCT por no suponer sus Corporaciones que pudieran quedar enclavadas dentro de la zona geográfica" (CEMCT, 17 de octubre de 1946).

No obstante el plazo limitativo señalado en el referido artículo 3 de la Ley, la Orden Ministerial de 23 de febrero de 1950 dispuso el ingreso de otros cinco Ayuntamientos. Igualmente, la Orden Ministerial de 2 de octubre de ese mismo año autorizó la incorporación de 11 municipios (todos ellos en la Vega Baja, Alicante). La realización del Canal del Segura, y su prolongación a través del Canal de Alicante, permitió la incorporación del grupo inicial de municipios, que constituyen las áreas poblacionales más importantes de la provincia.

Al comienzo de los años sesenta, se confirma la preocupante situación de escasez de recursos hídricos disponible. Los canales principales ya están construidos y buen número de poblaciones se encuentran abastecidas, con lo cual son necesarios volúmenes de agua cercanos a los 50-60 hm³/año, mientras que las disponibilidades en el río Taibilla, apenas alcanzan dicha cifra. Además, aún quedan por abastecer buena parte de municipios del eje del Segura y de la costa, presionados estos últimos por una creciente demanda turística. La toma de agua en el río Segura, en Ojós, salva la situación, pero a largo plazo sería insuficiente.
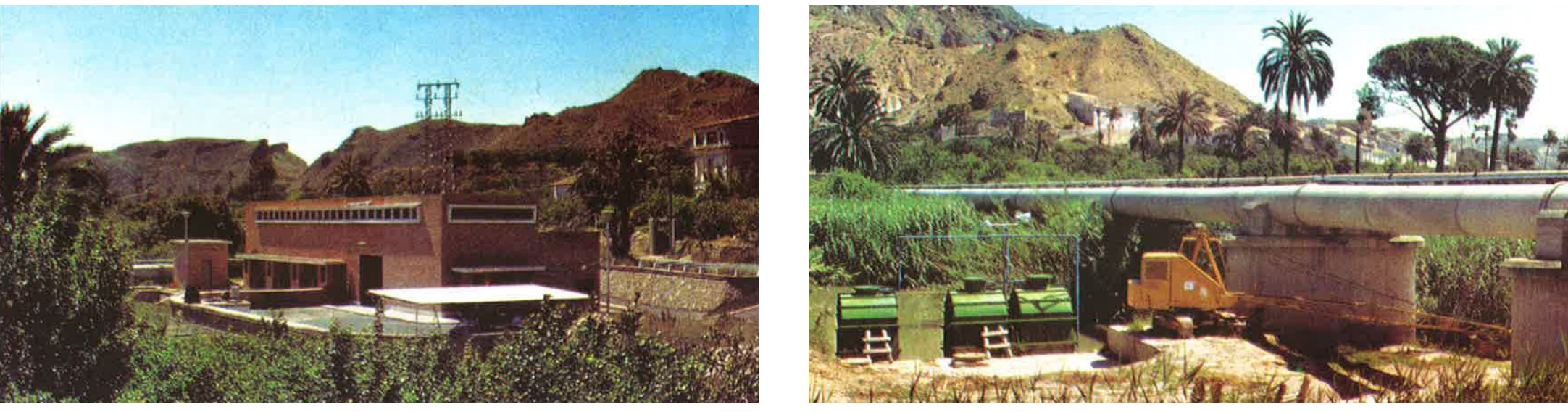

Fig 18. Toma de agua en el río Segura, Ojós (Murcia) [MCT.] 
Torrevieja pidió su adhesión a la MCT el 5 marzo de 1942 dado que uno de los principales problemas que afectaba a esta localidad era el deficiente abastecimiento de aguas potables y alcantarillado, mejoras que no habían podido abordarse por la carencia de aguas. Esta solicitud no surtió efecto porque el marco legal no lo permitía. Torrevieja hubo de volver a solicitar la incorporación en 1946. Benejuzar solicita su incorporación por unanimidad el 21 de julio de 1946, sólo para su casco urbano. Bigastro hará lo propio el 23 de octubre del mismo año, así como San Miguel de Salinas, por estar totalmente desabastecida su población (Acta 27/8/1946. AMCT).

Callosa de Segura se incorporó a la Mancomunidad en junio de 1946, sin embargo, en 1947 quiso separarse; cuando ya estaba informada favorablemente su separación, y se encontraba en la Dirección General de Obras Hidráulicas, en 1948 se retractaron y decidieron permanecer finalmente en la Mancomunidad. Las dudas de Callosa, respondían a si tenían que pagar o no antes de que llegara el agua, a lo que la MCT manifestó que: "no será objeto de imposición de cuota alguna hasta tanto las aguas del Taibilla viertan en los depósitos de las aguas potables de Callosa, en su caso se satisfará la cantidad correspondiente al consumo de agua que se realice, a un precio calculado como máximo de $0,60 \mathrm{ptas} / \mathrm{m}^{3}$." Una vez aclarado este extremo, se formalizó el ingreso el 26 de septiembre de 1946. El Ayuntamiento consideraba que el sacrificio económico que se pedía no era de pequeñas proporciones, ya que un gravamen de un $15 \%$ sobre la Contribución Territorial representaba una cantidad anual de unas 50.000 ptas. Además, el gravamen no resultaba equitativo, pues recaía sobre una clase determinada de contribuyentes, muchos de los cuales ni siquiera residen en Callosa." (Acta de petición de salida de la MCT, 18 de septiembre de 1947. AMCT). También se justificó la petición de salida de la MCT en base a los siguientes argumentos: "debido al duro estiaje del pasado año 1946 y contando esta población con una instalación completa de aguas potables, pero cuyo manantial era de escaso rendimiento, se intentó por medio de nuevas explotaciones en el pozo que abastece a la población el hallazgo de nuevos veneros para resolver el problema gravísimo planteado, teniendo en cuenta que las aguas del Taibilla, tardarían algunos años en llegar (...) se consiguió un abundante alumbramiento de aguas de excelente potabilidad, que resuelven el problema (...) se adoptó por unanimidad el dejar de pertenecer a la MCT (Acta 10 de junio, 1947. AMCT). Finalmente, el 11 de noviembre de 1948 piden la reincorporación a la MCT, y retira "ipso facto" las peticiones anteriores de salida.

Dolores se incorporó también en el año 1946. El municipio carecía de agua potable, y el abastecimiento se realizaba "con las mayores dificultades y gastos de los vecinos; por medio de aljibes que recogen las aguas pluviales y de vendedores que las traen de diferentes caudales". (Acta de solicitud de ingreso, 8 de agosto 1946). Guardamar solicitó en 1946, acogiéndose a la Ley, incorporarse a la Mancomunidad, pero al año siguiente 
quiso separarse. El Consejo de Administración admitió el desistimiento, pero al dilatarse la resolución del expediente en el Ministerio, el 16 de marzo de 1957 el Municipio decidió pedir su reincorporación. Como no había sido dado de baja formalmente todavía, se decidió archivar el expediente y considerar reestablecida la situación activa de dicho municipio, siempre y cuando se comprometiese a cumplir las obligaciones fijadas por la Ley. La MCT acordó restablecer la situación de Guardamar el 27 de marzo de 1957, con la obligación de satisfacer a la MCT el 15\% de las cuotas del Tesoro de la Contribución Rústica y Urbana correspondiente a las fincas sitas en su término municipal, con relación a cada uno de los 10 años comprendidos entre 1948 y 1957, ambos inclusive. Es decir, el municipio tuvo que asumir retroactivamente las cargas tributarias correspondientes a los años en que su incorporación había quedado suspendida. Al igual que los restantes municipios que integran la MCT, Guardamar vendrá obligado a asumir solidariamente con la MCT las obligaciones que ésta hubiere contraído con el Banco de Crédito Local de España en relación con los préstamos escriturados hasta la fecha, en los que tal garantía se estipuló (Acta 22 de octubre de 1957, MCT).

En este proceso de incorporación cabe destacar que, conforme establecía la Orden Ministerial del MOPU de 29 de abril de 1950, se recogía la gratuidad del agua suministrada por a MCT para el municipio durante un año, que podía fragmentarse en varias anualidades. En el caso de la ciudad de Alicante, el año de gratuidad quedó diferido en cuatro anualidades contando a partir del 1 de octubre de 1959 con una minoración en la tarifa. En el caso de Santa Pola, que también se benefició del año de gratuidad a partir del 1 de julio de 1959, no se acordó dicho fraccionamiento. En Crevillente, el año de gratuidad se inició a partir del 1 de septiembre de 1961, con la salvedad de que este municipio hubo de pagar la energía consumida en la elevación de los caudales (CEMCT 10/10/1959; 18/10/1960).

En virtud de la Orden Ministerial de 23-2-1950 y previa la aceptación de las condiciones por ella fijadas, se pusieron las bases para la posible admisión en la Mancomunidad de los municipios de San Vicente del Raspeig y San Juan (CEMCT. 10-3-1950). En el Comité Ejecutivo de 6-5-1950 se informa de que conforme a las certificaciones recibidas, el municipio de San Vicente del Raspeig había aceptado las condiciones impuestas para ingresar en la MCT. Sin embargo, el municipio de San Juan no lo había hecho, por lo que se acordó elevar al Ministerio informe favorable en el caso de San Vicente y desfavorable para San Juan. En septiembre de 1950 se informa al municipio de San Vicente que había sido admitido, y el 26 de septiembre de 1950, el Ayuntamiento acuerda su integración en la MCT, pagando 39.658 ptas, que se correspondían con el 15\% de las cuotas del Tesoro en la contribución Rústica y Urbana de los años 1948, 1949 y 1950.

A partir de la aprobación del Anteproyecto del trasvase Tajo-Segura (1968) se incluían entre las demandas a satisfacer, las correspondientes a la totalidad de municipios del área 
geográfica de la Mancomunidad. El contar con nuevos recursos procedentes del Trasvase posibilitaba incorporar otros núcleos de población no mancomunados que lo solicitaran, lo cual podía hacerse al no lesionar intereses de los mancomunados, como sería el caso de tener que repartir el agua disponible del río Taibilla. (Nieto Llobet, 2014)

El Anteproyecto incluyó entre las demandas a satisfacer las correspondientes a la totalidad de municipios del área geográfica dominada por Mancomunidad. Once municipios de la Vega Baja -Algorfa, Almoradí, Benijofar, Cox, Daya Nueva, Daya Vieja, Formentera, Granja de Rocamora, Rafal, Rojales y San Fulgencio- plantearon integrarse en Mancomunidad. La propuesta, con informe favorable del Organismo, fue elevada al Ministerio condicionada a que se realizasen las obras con financiación conjunta adelantada por los propios ayuntamientos. Por resolución de 2-10-1976, del Ministerio de Obras Públicas, se dio a estos municipios el plazo de un mes para que remitieran las certificaciones de los acuerdos de los plenos municipales aprobando las condiciones impuestas, y los distintos ayuntamientos las enviaron. La Dirección General de Obras Hidráulicas notificó su admisión y las condiciones que debían cumplir.

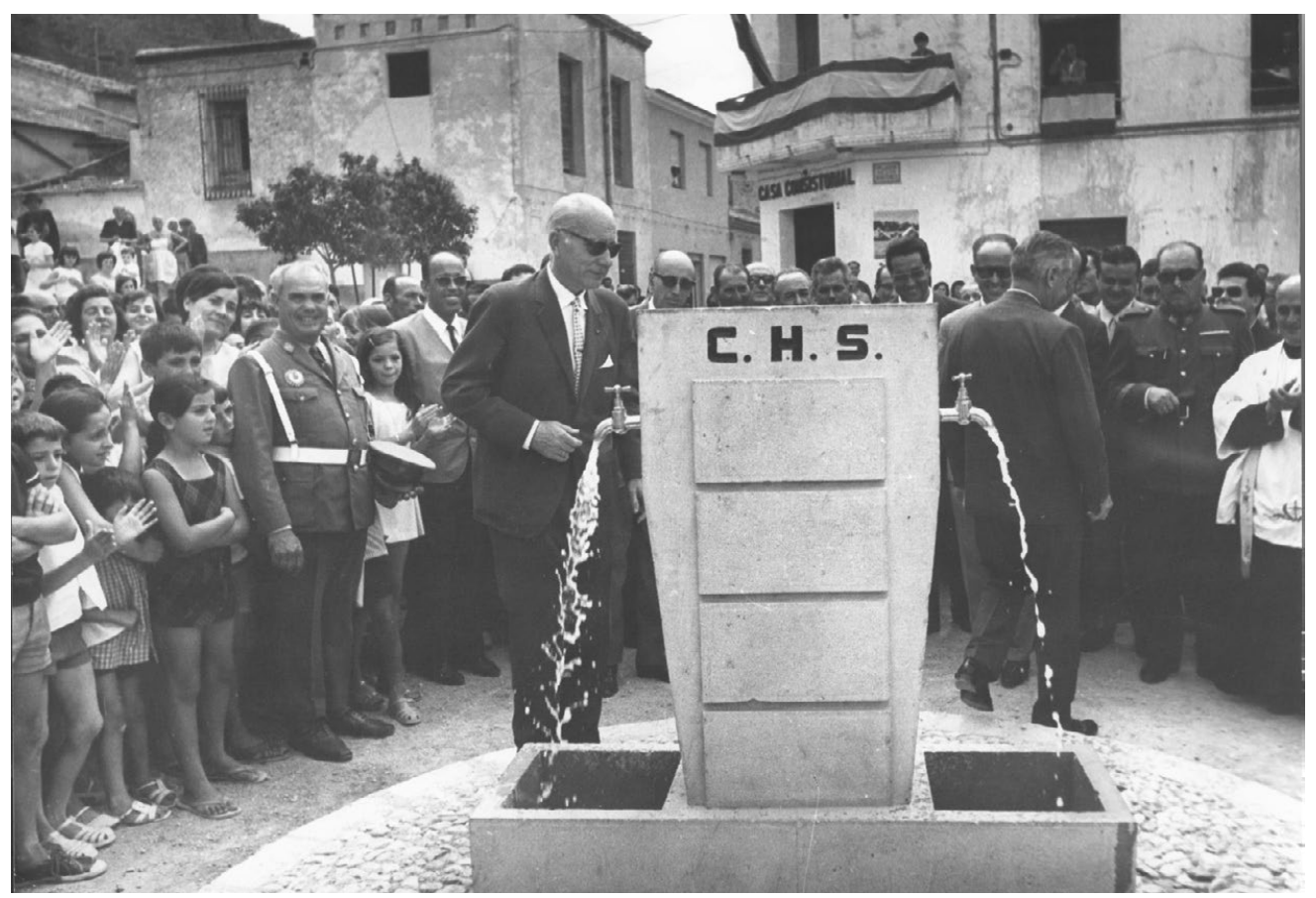

Fig 19. Inauguración de fuente pública en la Vega Baja, julio 1969 [MCT. Archivo histórico.] 
Granja de Rocamora solicitó su ingreso el 6 de junio de 1960, como consecuencia de que los canales de distribución pasaban a escasa distancia del pueblo. El 21 de julio de 1960 responde la MCT que de acuerdo con lo establecido en la ley de 27 de abril de 1946, que definía el ámbito geográfico de la MCT, y daba un plazo de 4 meses para solicitar el ingreso, no existía posibilidad de admitir nuevos municipios que pudieran disfrutar de este beneficio. La OM de 26 de septiembre de 1946 fijaba los Municipios que formaban parte de la Mancomunidad, entre los cuales se repartió la concesión asignada a este Organismo. El municipio reiteró posteriormente esta petición el 10 de diciembre de 1963, sin éxito.

Rafal solicito su ingreso el 21 de julio de 1971, al enterarse que el Ministerio el 10 de julio de 1971 había aprobado el Anteproyecto de ampliación de la red de distribución de la MCT, con la finalidad de no iniciar unas obras para traer agua de pozos desde Callosa de Segura. La respuesta fue similar a la recibida por el municipio de Granja de Rocamora. En ambos casos se evidencia el temprano interés de estos municipios por incorporarse a la red de agua potable del Organismo.

La Orden Ministerial de 16 de octubre de 1971 aprobó el Anteproyecto Modificado de Ampliación de los Abastecimientos, en el cual fueron tenidas en cuenta las necesidades de los ayuntamientos que ahora solicitaban su incorporación a la MCT. Estos municipios tuvieron que aceptar determinadas cargas económicas para entrar en igualdad de condiciones con respecto al resto de los municipios anteriormente mancomunados. Así pues, debieron contribuir a la financiación del Sistema con un recargo en la contribución rústica y urbana, aportando garantías frente a la Banca oficial para responder de los empréstitos, y adelantando parte de la inversión necesaria para ejecutar las infraestructuras de conexión. En cualquier caso, las tarifas que se les aplicarían serían las mismas que al resto de municipios (CEMCT 22/471976). El recargo se venía cobrando desde el 1 de enero de 1948.

El 2 de octubre de 1976 el Ministerio autorizó la incorporación de los once municipios de la Vega Baja a la MCT, lo que tuvo lugar en 1978, iniciándose el abastecimiento en 1984, una vez realizadas las obras, que habían pagado los municipios. La compensación de los anticipos realizados por los ayuntamientos se hizo por la MCT descontando a los ayuntamientos $7 \mathrm{ptas} / \mathrm{m}^{3}$ en las facturas de agua suministrada en los años siguientes. En la tabla 3 se muestran los datos de población de los municipios de la Vega Baja que entran en este periodo, a los que se asignó una dotación de 200 1/hab/día.

El esquema definitivo de las obras a realizar, para asegurar el suministro de agua potable tanto a las poblaciones ya abastecidas como a las de nueva incorporación se recogió en el Anteproyecto Modificado de Ampliación de los Abastecimientos, redactado y aprobado en 1971 (Memoria MCT, 1976). Las infraestructuras existentes resultaban 


\begin{tabular}{|c|c|c|}
\hline Municipio & Habitantes & $\%$ \\
\hline Almoradí & 9.965 & 34 \\
\hline Cox & 4.381 & 14,95 \\
\hline Rojales & 4.083 & 13,93 \\
\hline Rafal & 2.137 & 7,29 \\
\hline $\begin{array}{c}\text { Formentera } \\
\text { del Segura }\end{array}$ & 1.886 & 6,43 \\
\hline $\begin{array}{c}\text { Granja de } \\
\text { Rocamora }\end{array}$ & 1.737 & 5,93 \\
\hline $\begin{array}{c}\text { San } \\
\text { Fulgencio }\end{array}$ & 1.512 & 5,16 \\
\hline Daya Nueva & 1.199 & 4,09 \\
\hline Benijófar & 1.168 & 3,98 \\
\hline Algorfa & 959 & 3,27 \\
\hline Daya Vieja & 283 & 0,97 \\
\hline
\end{tabular}

suficientes para transportar los caudales del río Taibilla, pero la incorporación de nuevos caudales procedentes del trasvase Tajo-Segura exigía nuevas instalaciones. Dado que los núcleos de máxima demanda serían Murcia, Alicante y Cartagena, y aprovechando el Canal de la margen izquierda del post-trasvase Tajo-Segura, se fijaron tres puntos de toma en dicho Canal. Próximo al Canal de Murcia se construyó el nuevo Canal de Murcia; en Torre alta (Orihuela) se inicia el Nuevo Canal de Alicante y en el embalse de la Pedrera el Nuevo Canal de Cartagena.

En 1978 se finalizan los Nuevos Canales de Murcia y Alicante, que ampliaron hasta tres veces la capacidad de las canalizaciones anteriores. Gracias a ello en 1979 la MCT estaba en condiciones de extender el suministro a los nuevos municipios del núcleo central de la Vega Baja del Segura. En marzo de 1981, se inauguró el Canal de Cartagena, que discurre paralelo a la costa, dotando de

Tabla 03. Incorporación de municipios de la Vega Baja en 1978 a la MCT [MCT. Elaboración propia.]

Fig 20. Nuevos Canales de Murcia, Cartagena y Alicante [Memoria MCT, 1976. Elaboración propia.]

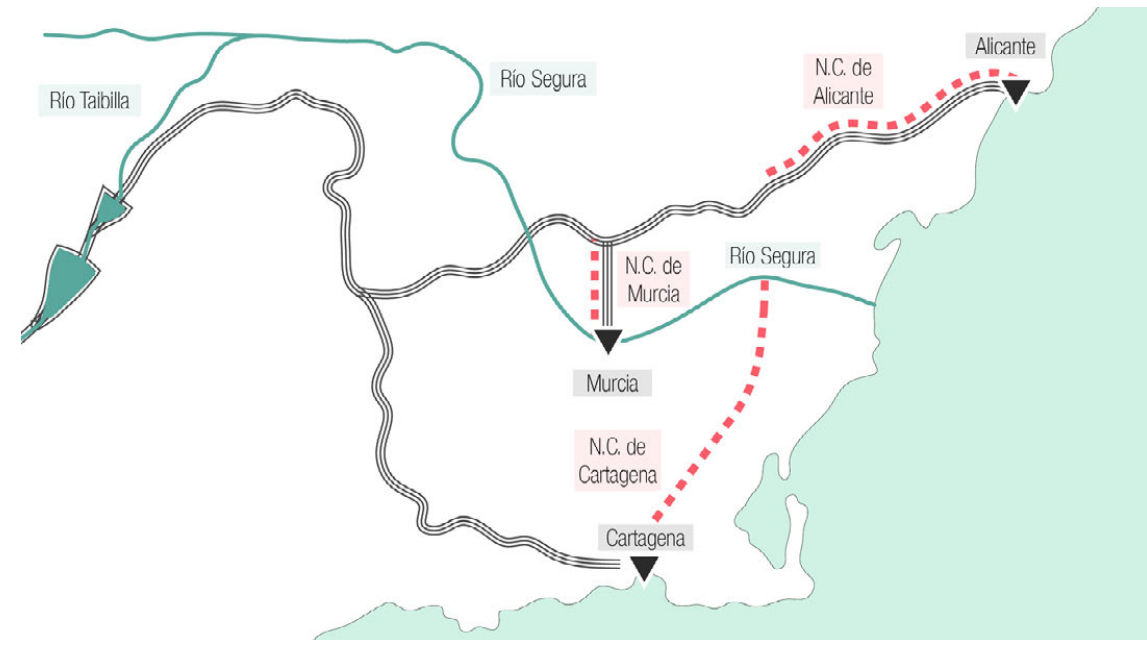


un suministro de mayor capacidad a los núcleos litorales desde Guardamar hasta el límite sur de la provincia de Alicante, continuando hasta Cartagena (Morales Gil, A. y Vera Rebollo, J. F. 1989). En la figura 21 se observa la progresiva incorporación de los municipios alicantinos a la MCT.

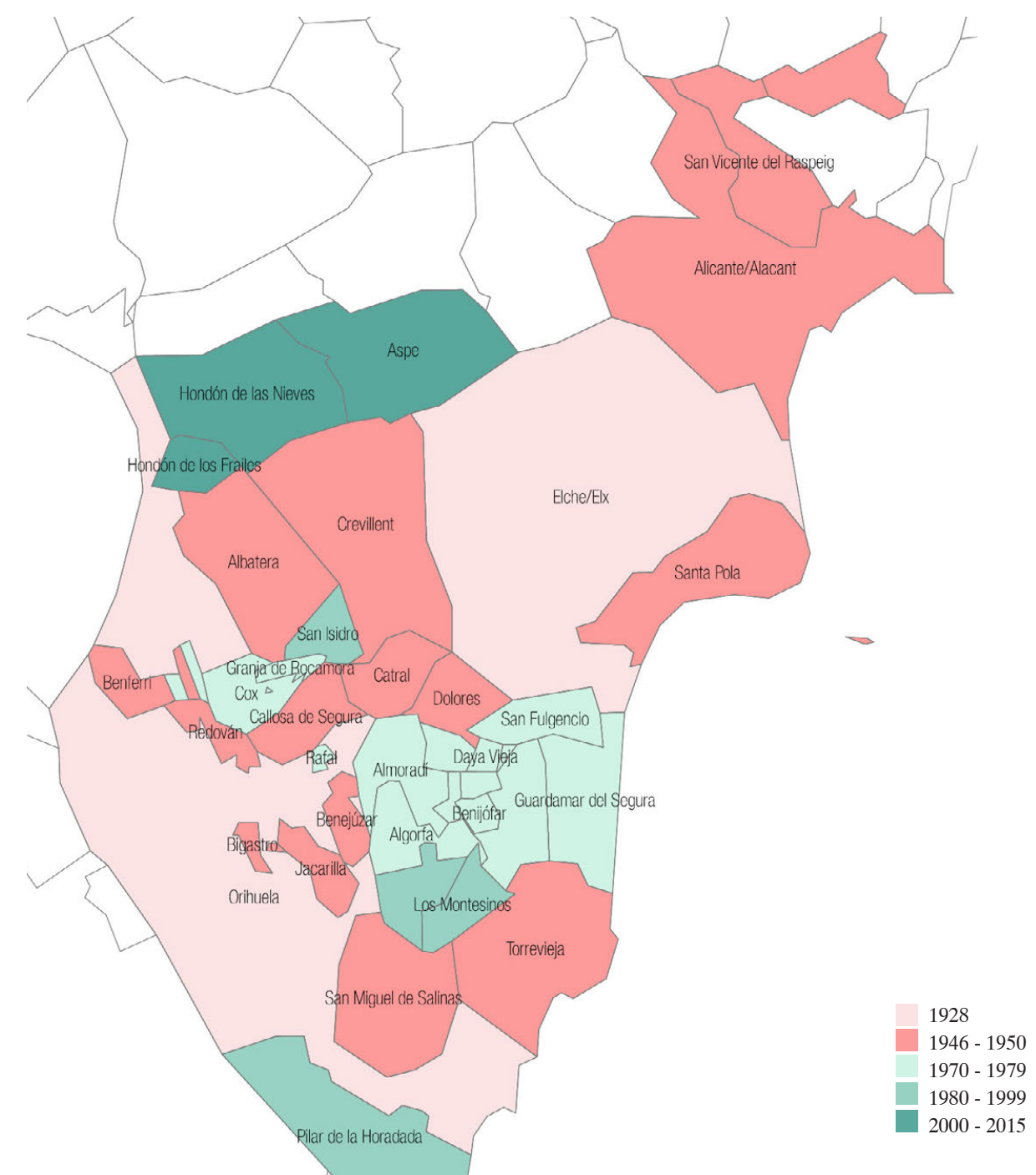

Fig 21. Incorporación de los municipios de la provincia de Alicante a la MCT [MCT. Memoria 2009. Elaboración propia.] 
La adhesión de los municipios alicantinos produce un gran impacto en la MCT, puesto que supone un extraordinario y continuo incremento de la población abastecida a través del sistema, como puede observarse en las figuras 22 y 23.

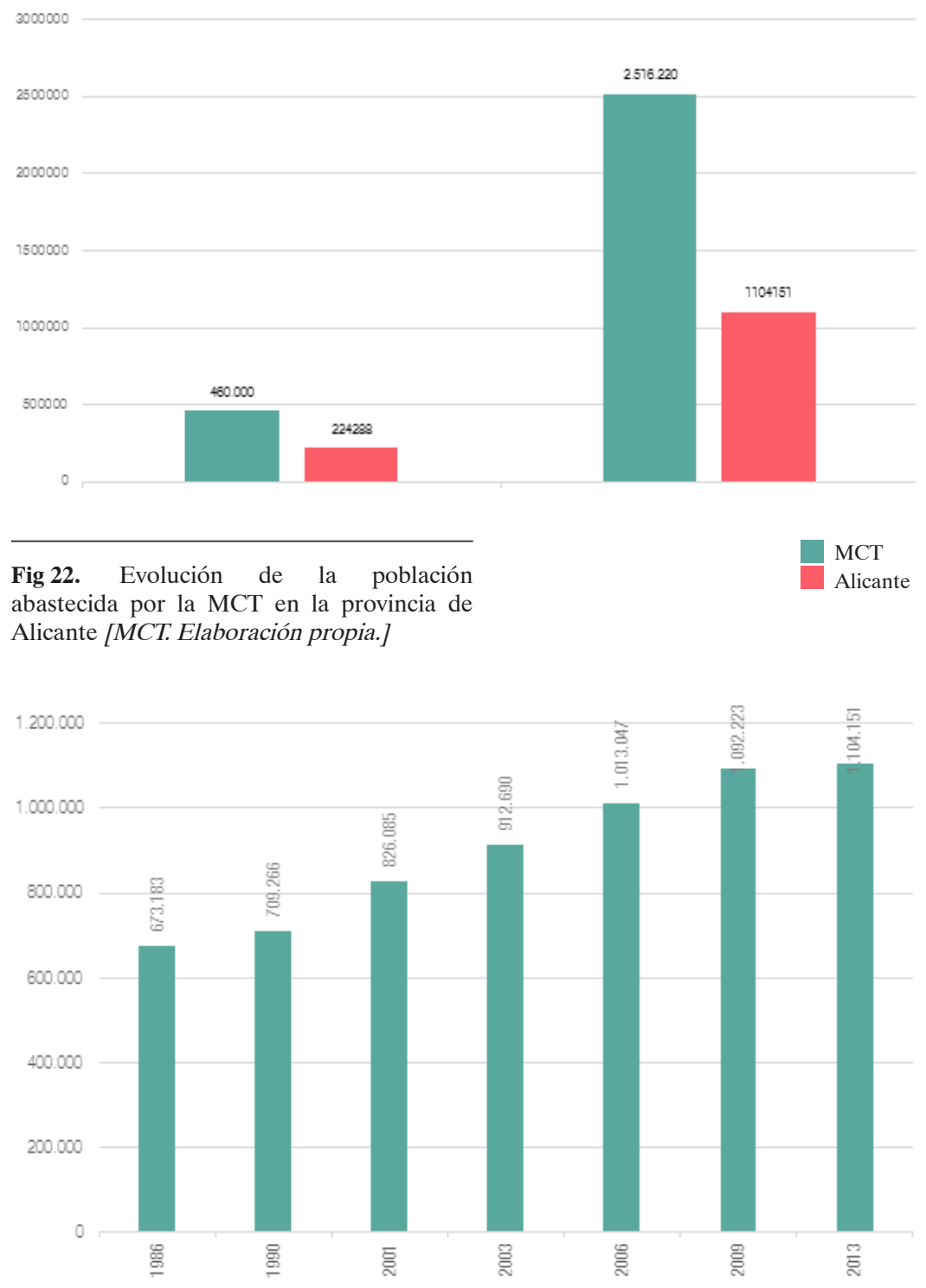

Fig 23. Evolución de la población abastecida por la MCT en la provincia de Alicante (1960-2013) [MCT. Elaboración propia.] 
Desde el punto de vista de las fuentes de suministro, todo este proceso de incorporaciones vino necesariamente acompañado de la aportación al sistema de caudales de diferentes procedencias, siendo las fuentes más antiguas las correspondientes al río Taibilla, totalmente insuficientes para acoger las nuevas demandas. En 1966 se da entrada a los caudales del río Segura (elevación de Ojós), y un año después, a diversos aprovechamientos de aguas subterráneas de la cuenca. La llegada de las aguas del trasvase Tajo-Segura será sin embargo la que permita consolidar el crecimiento de la MCT en Alicante.

El resto de incorporaciones son más bien el resultado de procesos de dinámica municipal, que se corresponden con territorios ya suministrados por la MCT, a través de los Municipios a los que ciertos núcleos poblacionales pertenecían antes de su segregación y constitución en Ayuntamientos independientes. Se trata de Los Montesinos y San Isidro. En el caso de El Pilar de la Horadada, que formaba parte de Orihuela, dispondrá de la conexión física al sistema de la MCT gracias a la extensión del ramal de Torrevieja hacia el sur. Esta población se independizó de Orihuela por Decreto 100/1986 de 30 de julio del Consell de la Generalitat Valenciana. El 18 de diciembre de 1986 la Comisión Gestora Municipal acordó solicitar su incorporación como miembro derecho de la MCT, que fue aceptada sin impedimentos económicos o legales al tratarse de una segregación (CEMCT, 5/371987). A partir del 1 de enero de 1987 comienzan a girarse los recibos a este Ayuntamiento. Los Montesinos se adhiere a la MCT el 30 de noviembre de 1990, dado que este municipio de reciente creación, tras su segregación de Almoradí (Decreto 140/1990 de 30 de julio del Consell de la Generalitat Valenciana) se hace cargo a partir del 1 de enero de 1991 del servicio de abastecimiento urbano de agua potable (CEMCT 19/12/1990). San Isidro solicitó su integración en Sesión Ordinaria del Ayuntamiento de 7/9/1993, por segregación del municipio de Albatera, que fue aceptada por la MCT el 15 de noviembre de 1993.

Las últimas incorporaciones, de Aspe, Hondón de las Nieves y Hondón de los Frailes, se producen por la mala calidad y agotamiento de los recursos subterráneos que abastecían tradicionalmente a estas localidades. La declaración de sobreexplotación del acuífero de la Sierra de Crevillente en 1986, desde donde se suministraban los caudales, comprometía seriamente la seguridad de estos abastecimientos, que encuentran una solución definitiva con la llegada provisional de aguas de la MCT en 1989. En 2005, los dos primeros municipios se integran con pleno derecho al sistema de la MCT, mientras que Hondón de los Frailes lo hará en 2013.

El 5 de marzo de 1986, Aspe solicitó una dotación de refuerzo para mejorar la calidad de sus propias aguas a la MCT, que el Ministerio autorizó en mayo de ese mismo año con una dotación máxima de $0,8 \mathrm{hm}^{3} /$ año, o un caudal continuo de entre 15 y $20 \mathrm{l} / \mathrm{s}$, para reducir hasta límites tolerables el contenido en cloruros de las aguas propias de su 
abastecimiento. El Ayuntamiento se hacía cargo de las obras de conexión con el Canal de Alicante, y se justificaba su petición por el estado de "agotamiento y salinización del acuífero que históricamente había proporcionado los recursos hídricos precisos para el abastecimiento de la población" (CEMCT 3/5/1989 y 15/12/2005).

En 1986, tras el agravamiento de la situación de escasez de suministro de agua potable que venía padeciendo Aspe, se iniciaron los trámites para conseguir la integración en la MCT (Pleno del Ayuntamiento de 22 de mayo de 1986). El Pleno fue convocado de urgencia con un único punto del orden del día: solicitud de integración en la MCT y toma de medidas urgentes para el abastecimiento de agua potable. En ese momento no fue posible la integración, ya que el marco legal que regulaba la MCT no lo permitía, pero se consiguió el suministro de un caudal extraordinario con carácter de emergencia, que desde aquella fecha, y una vez finalizada la conducción necesaria para su traída desde el depósito regulador de Crevillente, abastecía de forma casi exclusiva a Aspe.

La Ley de 1946 limitaba la incorporación de nuevos municipios, como se evidencia ante las diferentes denegaciones que se sucedieron. Así, por ejemplo, en el año 1981 se denegó al Ayuntamiento de Aledo (Murcia) su acceso, y unos años después, en 1987, a El Campello (Alicante). La Dirección General de Obras Hidráulicas confeccionó un borrador de Real Decreto para modificar el Decreto de 28 de junio de 1946, con la intención de flexibilizar el sistema de acceso; sin embargo, el Consejo de Estado, en dictamen de 20 de enero de 1983, informó desfavorablemente dicha propuesta, al estimar que la reforma no debía encauzarse mediante reglamento, sino que debía suponer la modificación de la Ley. Como consecuencia de dicho dictamen se confeccionó un proyecto de Real Decreto Ley por el que se modificaba y actualizaba la Ley de 27de abril de 1946, el cual no llegó a ser elevado al Consejo de Ministros. Al no prosperar dicha iniciativa legislativa, los Municipios de Hondón de las Nieves, Aspe, cuyos expedientes de incorporación estaban en suspenso, así como El Campello, que había solicitado su incorporación en 1987, no pudieron acceder a la MCT por no ser posible conforme al marco legal en ese momento vigente.

El Consejo de Administración de la MCT, en sesión celebrada el 21 de diciembre de 1987, a propuesta del Comité Ejecutivo, adoptó el acuerdo de "Propuesta de reforma de determinados preceptos de la Ley de 27 de abril de 1946", en la que, entre otras, se proponía la modificación del artículo 3 , "en el sentido de que todas las entidades y municipios situados en la zona geográfica que puede ser abastecida por la Mancomunidad podrán solicitar su ingreso en la misma del Ministerio de Obras Públicas y Urbanismo, el cual, previo informe de aquella, resolverá respecto a su admisión, determinando las condiciones a que han de someterse; las entidades y municipios actualmente abastecidos o en curso de serlo como consecuencia de autorización ministerial previa se considerarán miembros de plano derecho de la Mancomunidad" (CEMCT, 25/10/1990). 
La Disposición Adicional cuadragésima primera de la Ley 50/1998, de 30 de diciembre, de Medidas Fiscales, Administrativas y del Orden Social modificó finalmente los artículos 1 y 3 de la Ley de 1946, conforme al proyecto elaborado en 1989 por la Dirección General de Obras Hidráulicas, y prácticamente con la misma redacción propuesta. Esta reforma pudo ver la luz gracias a que era previsible la próxima obtención de nuevos recursos hidráulicos procedentes de la desalinización de agua de mar, lo que hacía posible la incorporación de los tres municipios alicantinos que venían solicitando su ingreso: Hondón de las Nieves, Aspe y Hondón de Los Frailes. El nuevo artículo 3 quedó redactado como sigue: "Todos los municipios situados en la zona geográfica que pueda ser abastecida por la Mancomunidad podrán solicitar su ingreso en la misma al Ministerio de Medio Ambiente, el cual, previo informe de aquélla, resolverá respecto a su admisión determinando las condiciones a que han de someterse. Los municipios y Entidades actualmente abastecidos como consecuencia de autorización ministerial previa se considerarán miembros de pleno derecho de la Mancomunidad”.

El 18 de diciembre de 2003, el Pleno del Ayuntamiento de Aspe, ante el cambio de la norma por la Ley 50/1998, solicitó de nuevo la integración en la MCT. Las razones de dicha petición se sustentaban en la situación de precariedad del suministro que condicionaba gravemente su futuro. La evidencia de la regularidad y realidad del suministro de caudales de la MCT desde hacía ya casi 20 años, y la no necesidad de grandes inversiones gracias a la colaboración de la Generalitat Valenciana, apoyaban esta petición. El escrupuloso cumplimiento de las instrucciones acerca del ahorro del agua que habían sido emitidas por la MCT, favoreció igualmente la petición. Tras las inversiones realizadas, el rendimiento de la red de agua potable está próximo al 90\%. Por otra parte, el Ayuntamiento reiteró su disposición para someterse a las condiciones que le fueran impuestas en la Resolución de integración a la MCT, así como a realizar cuantos trámites sean necesarios para la cesión de las instalaciones de alta de la conducción del agua potable, desde la toma de Crevillente, hasta el depósito regulador de las Amoladeras inclusive. Aspe solicitó su ingreso de nuevo el 24 de noviembre de 2005.

Mediante acuerdo del Pleno del Ayuntamiento de 16 de mayo de 1986, Hondón de las Nieves solicitó suministros de caudales de emergencia a la MCT para solucionar el problema de calidad y salinización del agua de la que se abastecía, debido a la explotación intensiva y descenso de nivel del acuífero y a la sequía que venía sufriendo durante los diez años anteriores. La solicitud se fundamentaba en la posibilidad de aprovechar las infraestructuras que realizaría Aspe para disponer de los caudales, con una mínima derivación hasta la localidad. La distancia entre las instalaciones del Hondón y de la MCT no superaba los $5 \mathrm{~km}$, lo cual abarataría las obras de infraestructura, que se ofreció a financiar el propio municipio (finalmente las financiará la Generalitat Valenciana). El volumen solicitado ascendía a un caudal medio cifrado entre 3 y $5 \mathrm{l} / \mathrm{s}$, un total de 0,1 
$\mathrm{hm}^{3}$ /año para una población de 1600 habitantes. La conexión con la MCT garantizaría la continuidad y salubridad del suministro urbano a la población. Por último, el Ayuntamiento manifestó la ausencia de alternativas de suministro en el entorno inmediato de la población (CEMCT 9/7/1986 y 15/12/2005).

En ese momento no fue posible la integración ya que la norma legal que regulaba la MCT no lo permitía, pero si que se consiguió el abastecimiento de un caudal extraordinario con carácter de emergencia que, desde esa fecha y una vez finalizada la conducción necesaria para su traída desde el depósito regulador de Crevillente, es el que viene abasteciendo de forma casi exclusiva a Hondón de las Nieves. El suministro provisional se habilitó mediante la ejecución de las obras de conexión del Canal de Alicante con los depósitos reguladores de ambos Municipios, mediante una impulsión de $6.8 \mathrm{~km}$ de longitud. Estas obras fueron realizadas con la colaboración de la Generalitat Valenciana, y el suministro, derivado de una resolución ministerial de 19 de junio de 1986, se mantuvo sin interrupción hasta la definitiva incorporación en 2005. El Ayuntamiento de Hondón de las Nieves reiteró su aspiración de incorporarse como miembro de pleno derecho a la MCT (Acta 13 de enero de 2004). Mediante la O.M. de 20 de diciembre de 2005 el Ministerio de Medio Ambiente resolvió la incorporación al Organismo de Aspe y Hondón de las Nieves. El 13 de diciembre 2013 el Comité Ejecutivo de la MCT, inició el expediente de incorporación de Hondón de los Frailes, que permitió su posterior acceso a la Mancomunidad.

En este proceso histórico se puede apreciar la progresiva importancia de la MCT en el suministro de los municipios alicantinos, llegando incluso, aunque sea de manera circunstancial, a áreas muy alejadas del ámbito originario de la institución. Es evidente que sin la MCT, sus recursos e infraestructuras, hubiera sido imposible sustentar el crecimiento socioeconómico de la provincia, así como garantizar un suministro de agua de calidad, con la debida continuidad, regularidad y calidad sanitaria. El desarrollo turístico residencial, en particular, es directamente tributario de este sistema, sin cuya existencia sencillamente no habría sido posible. La MCT es por ello una entidad imprescindible para entender las dinámicas territoriales de las últimas décadas en el Sureste de España. En la figura 24 se aprecia el proceso de integración de los municipios del área abastecida por la MCT desde su creación.

En este proceso, por diferentes causas, no todos los municipios interesados en acceder a la MCT pudieron culminar sus peticiones de integración. El Campello solicitó ingresar en la MCT en 1987, debido a la mala calidad y escasez de los recursos propios. Se pretendía obtener un trato similar al dado a Hondón de las Nieves y a Aspe. Sin embargo, se estimó que la situación no era equivalente, puesto que la MCT entendía que este municipio debía contar con agua procedente del embalse de Alarcón facilitada por la Confederación del Júcar (CEMCT 22/7/1987). Unos años después, el municipio de 


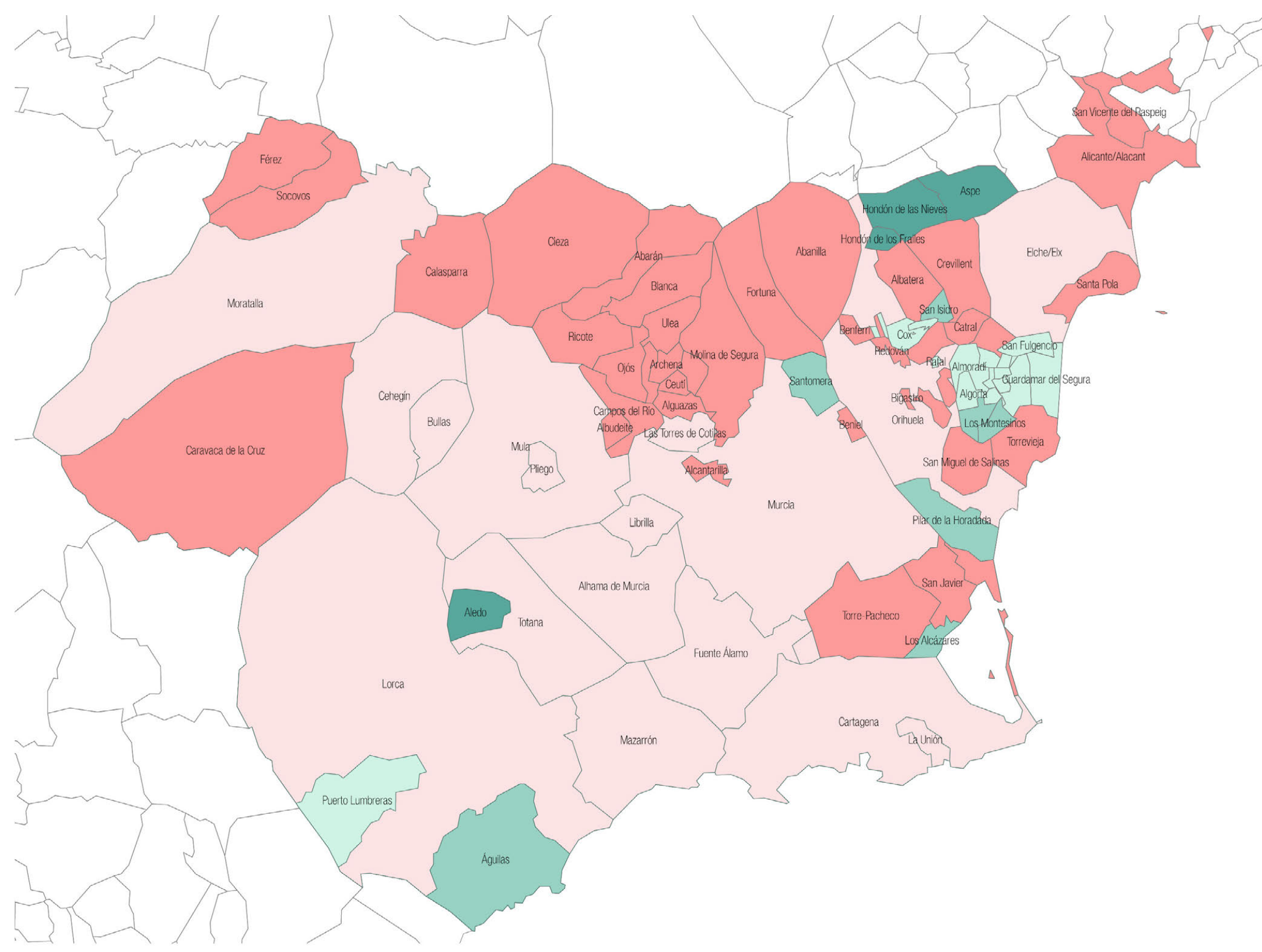

Fig 24. Síntesis del proceso de integración de los municipios en la MCT (1928-2015) [MCT.

Elaboración propia.] 
Xixona/Jijona solicitó también su incorporación (13 de enero de 1999), solicitud que fue rechazada dado que este municipio disponía de alternativas de suministro procedentes de la transferencia Júcar-Vinalopó, según informó la Confederación Hidrográfica del Júcar (informe de 21 de diciembre de 1999), a diferencia de Aspe y Hondón de las Nieves, que carecían de recursos próximos (CEMCT, 15/12/2005). Pinoso solicitó su admisión el 10 de enero de 1995, en previsión de una futura carencia de agua potable como consecuencia de la sobreexplotación de los acuíferos (CEMCT 28/2/1995). Este municipio no accederá a la MCT debido a las dificultades que representa elevar los caudales a la cota 450 metros a la que está situada la población.

Por último, hay que destacar la construcción en 1998 de un ramal de $48 \mathrm{~km}$ de extensión, realizado con carácter de urgencia, para conectar las instalaciones de la MCT con el sistema de explotación de la Marina Baja, a través de la conducción que une los depósitos de Rabasa-Fenollar (Alicante) y el embalse de Amadorio (Villajoyosa). Esta infraestructura permite conectar el sistema de la MCT con el Consorcio de Aguas de la Marina Baja, y en consecuencia, con Benidorm y el resto de municipios turísticos de la Comarca. Gracias a esta canalización es posible movilizar caudales propios de la demarcación del Júcar, depositados en el embalse de Alarcón, así como caudales de los acuíferos alicantinos situados en esta demarcación, y procedentes de las estaciones desalinizadoras, hacia la Marina Baja. El destino principal de esta dotación de emergencia es el municipio de Benidorm. Entre 1999 y 2001 se transfirieron $25,7 \mathrm{hm}^{3}$ para evitar cortes de suministro en el área abastecida por el Consorcio de la Marina Baja (Vera et al., 2009).

Desde 2002 no había vuelto a entrar en servicio esta conducción, sin embargo, el nuevo ciclo de sequía experimentado en los últimos años ha supuesto la necesidad de volver a enviar caudales en el año 2015. En mayo de ese año La Confederación Hidrográfica del Júcar dio el visto bueno al suministro temporal de $5 \mathrm{hm}^{3}$ de agua procedente de la desalinizadora de Mutxamel al Consorcio de la Marina Baja para el abastecimiento, a través de la conducción de Rabasa-Fenollar-Amadorio. Está previsto que la desalinizadora de Mutxamel (18 hm³/año, ampliables a $30 \mathrm{hm}^{3} /$ año en 2025), incluida en el programa AGUA, se conecte a la tubería Fenollar-Amadorio para poder suministrar agua a la Marina Baja en caso de emergencia. 


\section{2.- Llegada de los caudales de la MCT a los municipios alicantinos.}

Es preciso clarificar que las fechas de incorporación formal de los Ayuntamientos alicantinos al sistema de la MCT no coinciden con la llegada efectiva de los caudales suministrados a los distintos municipios. La incorporación de algunos de ellos es de hecho bastante temprana, si bien los caudales llegarán conforme las infraestructuras vayan avanzando y aparezcan nuevos recursos hídricos.

La puesta en funcionamiento de los primeros abastecimientos municipales dependientes de la MCT se produce en los años 40 del pasado siglo, con el municipio de Cartagena y su Base Militar. Pocos años después la MCT fue extendiendo su ámbito de actuación a numerosos municipios murcianos. La provincia de Alicante tuvo que esperar unos años más para que, progresivamente, muchos de sus municipios, entre ellos los más poblados, fueran beneficiándose del sistema de explotación de la Mancomunidad. En esta Institución encontrarían finalmente la garantía y estabilidad a sus suministros, hasta entonces extraordinariamente precarios. El ritmo de llegada de caudales de la MCT a los municipios alicantinos puede verse en la figura 25.

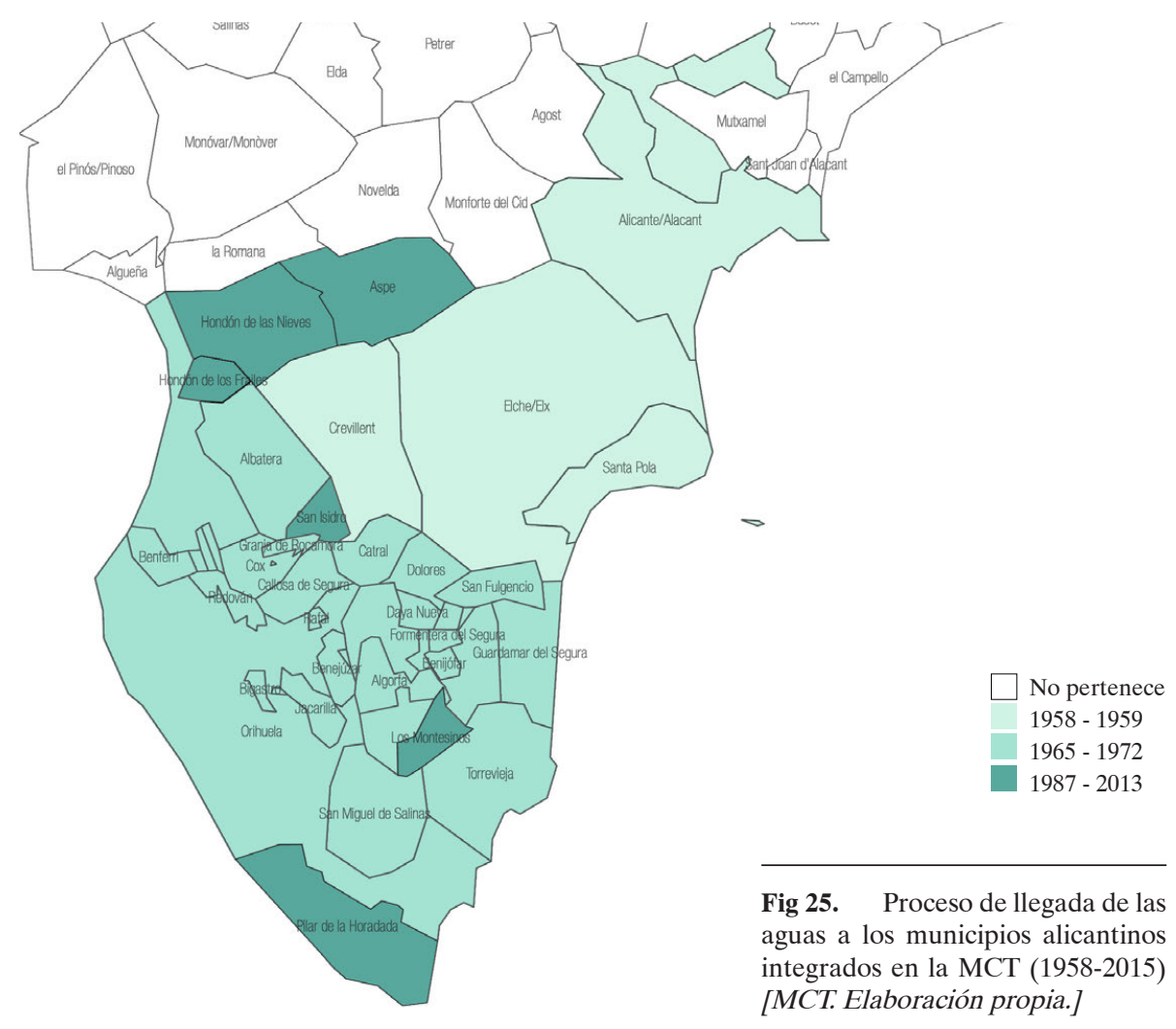


En este mapa puede apreciarse que el mayor ritmo de llegada de caudales a los municipios alicantinos se produce a raíz de la construcción del trasvase Tajo-Segura, y la expectativa que la llegada de nuevos recursos representa. Este es sin duda el factor determinante que permite la ampliación de la MCT en la provincia de Alicante, y la consolidación de los suministros ya existentes. La llegada del agua se realiza a un ritmo relativamente lento, conforme las infraestructuras y los recursos disponibles lo van permitiendo. Las progresivas ampliaciones vienen de la mano no sólo de enormes esfuerzos inversores, sino de la posibilidad de contar con nuevas fuentes de suministro que exceden en mucho las iniciales aportaciones del río Taibilla.

El agua llega a Elche, Crevillente, Alicante, y San Vicente del Raspeig en 1958, culminándose en este año el proceso de construcción y puesta en servicio de los $365 \mathrm{~km}$ de canales principales del primitivo Plan de Obras. El agua llega a Santa Pola en 1959; a Albatera y Catral en 1965; a Benferri, Orihuela, Redován y Dolores en 1966; a Callosa de Segura en 1967; a Bigastro, Jacarilla y Benejúzar en 1969; a San Miguel de Salinas y Guardamar en 1970; a Torrevieja en 1972.

El Ministerio de Obras Públicas aprueba en 1971 el Plan de Ampliación de los Abastecimientos con caudales del trasvase Tajo Segura que posibilitó la integración de nuevos municipios de la Vega Baja del Segura (Algorfa, Almoradí, Benijófar, Cox, Daya Nueva, Daya Vieja, Formentera, Granja de Rocamora, Rafal, Rojales y San Fulgencio). En 1978 se ponen en servicio los Nuevos Canales de Murcia y Alicante con aguas procedentes del Tajo tratadas en las correspondientes potabilizadoras. En marzo de 1981 llegan a los depósitos de Cartagena aguas del mismo origen a través de un nuevo canal que discurre paralelo a la costa redotando a todos los núcleos desde Guardamar a Cartagena. El abastecimiento de los once municipios de la Vega Baja entra en operación en 1984, una vez realizadas las obras.

A partir del año 2000 se inicia el segundo periodo deficitario de recursos por insuficiencia de los caudales del río Taibilla y la dotación legal máxima del trasvase Tajo-Segura para atender la creciente demanda originada por el desarrollo económico e incremento demográfico (la población estable abastecida pasa de un millón de habitantes en 1975 a dos millones en el año 2000). Se hacen precisas aportaciones extraordinarias de las cuencas del Segura (pozos de reserva del Sinclinal de Calasparra) y del Júcar (embalse de Alarcón) proporcionales a los volúmenes suministrados a sus núcleos de población (78\% y 22\%, respectivamente) y el otorgamiento ministerial de las concesiones de las plantas desalinizadoras de Alicante I y San Pedro del Pinatar I (año 2000), previstas, así como sus futuras ampliaciones, en el Plan Hidrológico de la cuenca del Segura (1998) y el Plan Hidrológico Nacional, 2001 (PHN). 
para el desarrollo económico y social de la provincia alicantina, al ofrecer unos recursos de gran calidad para los abastecimientos, en condiciones de seguridad, calidad sanitaria garantizada, continuidad y regularidad.

La llegada de caudales de la MCT a los municipios alicantinos a la MCT experimenta numerosas vicisitudes a lo largo del tiempo.

a.- Llegada de los caudales a los primeros municipios a finales de los años 50 del Siglo

$X X$.

Según la Orden del Ministerio de Fomento, Dirección General de Obras Hidráulicas, de 26 de Septiembre de 1946, se fijaron condiciones a 54 Ayuntamientos para que, una vez cumplidas, pudieran formar parte de la Mancomunidad. Entre ellos figuraban algunos alicantinos. Esta disposición consideró "definitivamente comprendidas en la zona geográfica fijada en la Ley", sin perjuicio de su posible modificación futura, conforme se fueran modificando los trazados de los canales, a los siguientes municipios de la provincia: Alicante, Benferri, Bigastro, Callosa de Segura, Catral, Crevillente, Dolores, Elche, Jacarilla, Orihuela, Redován. La integración del resto quedaba diferida a su futura inclusión en la zona geográfica, en tanto en cuanto quedaran establecidos los trazados definitivos de los canales.

La culminación de las obras del canal del Segura y su continuación a través del de Alicante, con la llegada del agua a esta capital, supone la finalización de la red básica de abastecimiento. En la figura 27 se aprecia con claridad la localización y fechas de llegada de caudales a los municipios alicantinos integrados en la MCT en este periodo inicial.

En el caso del municipio de Alicante, tradicionalmente, la escasez de agua constituyó un problema de vital importancia, que ha influido negativamente en el desarrollo socioeconómico de la ciudad. No existen en el término municipal redes fluviales, ni grandes reservas superficiales o subterráneas de agua. La solución a este déficit natural ha pasado por la captación de reservas fuera del municipio. A partir de 1860, prácticamente se encontraban agotados los manantiales tradicionales de la ciudad. En 1879, incluso se contrató con una empresa británica, Normandy, máquinas destiladoras de agua de mar, cuyo coste era elevado y la cantidad de agua producida poco significativa, entre medio y dos litros de agua por persona y día; pero la escasez era tal que cualquier cantidad de agua era bienvenida. Estas aguas fueron conducidas a dos fuentes situadas en las plazas de Alfonso XII y la Constitución (AMAEM, 2009).

De todos los intentos para atraer agua a Alicante, destaca el de La Alcoraya, en cuya partida era propietario de unos pozos Francisco Riera Alted, que comercializaba sus aguas mediante la venta ambulante con carros y aguadores. La traída del agua se 


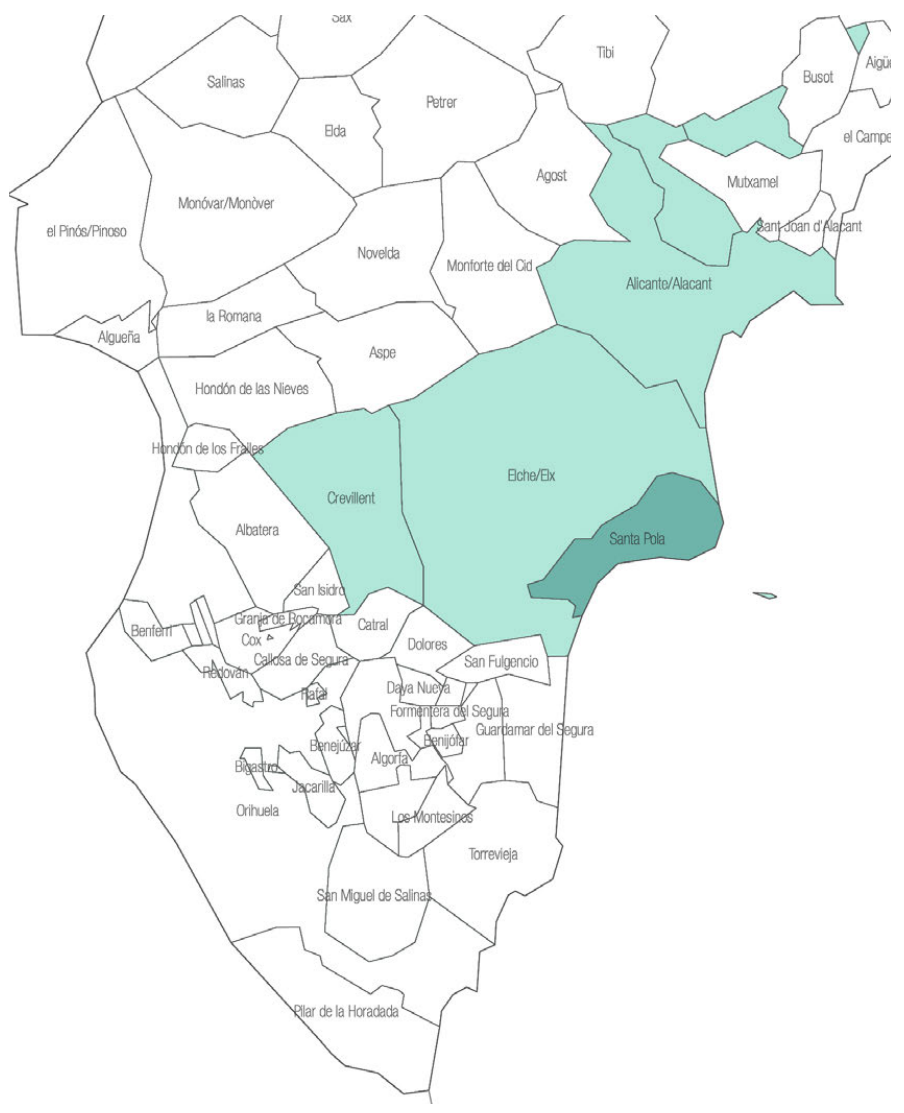

Fig 27. Incorporación de los primeros municipios alicantinos a la MCT (19581959) [MCT. Elaboración propia.]

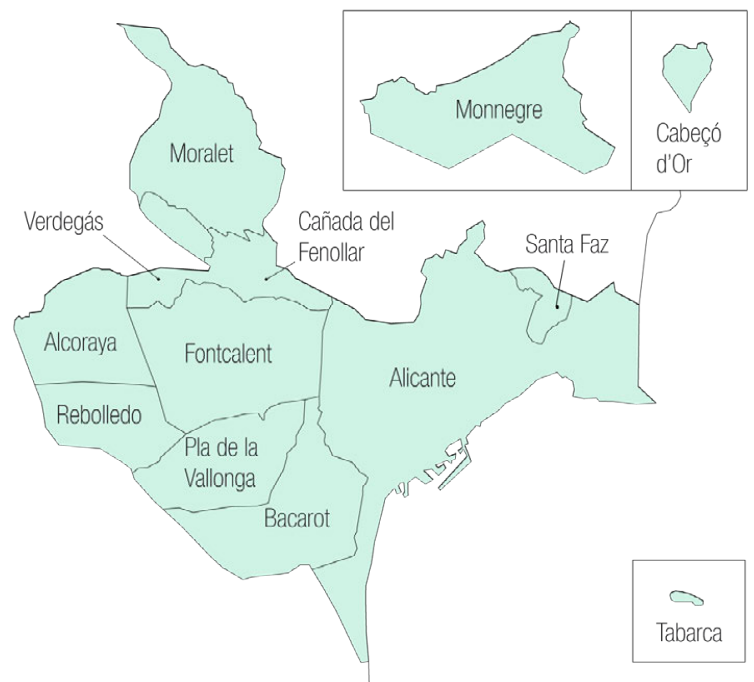

Fig 28. Entidades de población del término municipal de Alicante [Ayuntamiento de Alicante.] 
llevó a cabo por José Carlos Aguilera y Aguilera, Marqués de Benalúa, con autorización municipal y un proyecto redactado por el ingeniero Pascual Pardo Jimeno. En 1881, las aguas llegaban a cinco fuentes (Constitución, San Francisco, Quijano, Muelle de Costa y Puerta de la Reina) y se suministraban al precio de cinco céntimos cada dos cántaros y gratis para los pobres en Puerta de la Reina.

También, se utilizaba un servicio de aguadores a domicilio, a razón de cinco céntimos el cántaro. Los aguadores continuaron prestando dicho servicio hasta el año 1920. El proyecto de La Alcoraya tenía carácter de provisional, en tanto se buscaban otros recursos para el abastecimiento de la ciudad (producía tan solo cuatro litros por habitante y día, para una población de unos 30.000 habitantes). El Marqués de Benalúa vendió sus derechos sobre las aguas de La Alcoraya a la Sociedad Británica "The Alicante Water Work Limited".

En 1871, surgió un nuevo proyecto, el ayuntamiento de Alicante adoptó el primer acuerdo para suscribir un contrato con la sociedad "Canal de Alicante", con el fin de abastecer a la ciudad desde pozos artesianos situados en el término municipal de Sax, a $48 \mathrm{~km}$ de la ciudad. En 1879, se disolvió la citada Sociedad y los pozos fueron comprados por Juan Leach Giró, quien en 1884 solicitó al Consejo de Alicante la utilidad pública de las aguas para abastecer la ciudad. En 1885, consiguió autorización del Gobierno Civil para realizar las obras necesarias del denominado "Canal del Cid". En 1891, Juan Leach Giró vendió los pozos a Enrique Caucourte y Joulliot, quien presentó en el Ayuntamiento el proyecto de abastecimiento que fue aprobado en mayo de 1892. El concurso-subasta le fue adjudicado, firmándose en fecha de 11 de julio de 1893 la escritura de la concesión administrativa, en régimen de exclusividad, "para abastecimiento de aguas a la ciudad de Alicante", por un plazo de sesenta años.

El 17 de febrero de 1897, Caucourte cedió todos los derechos y acciones a un concesionario del abastecimiento de aguas, la sociedad belga "Compagnie Générale de Conduits d'Eaux" de Lieja, y el 3 de agosto de 1898 se constituyó la "Societé Anonyme des Eaux d'Alicante", aportando la "Compagnie Générale de Conduits d'Eaux" al capital de la nueva sociedad, entre otros, la Concesión para el abastecimiento de aguas a la ciudad de Alicante. Esta empresa fue la encargada de realizar el Canal del Cid, que posibilitó que el agua llegara a Alicante el 16 de octubre de 1898, inaugurándose el servicio en las fuentes públicas, celebrándose con toda solemnidad en la fuente de la Plaza de Isabel II, actual plaza de Gabriel Miró. A partir de entonces, se inició la ampliación del servicio. El 1 de enero de 1899 la "Compagnie Générale de Conduits d'Eaux", cedió todos sus poderes, instalaciones y competencias a la nueva compañía Sociedad de Aguas de Alicante. Desde ese momento se establecieron veinte fuentes de hierro y se comenzó a generar la red para el abastecimiento a domicilio, desapareciendo todas las fuentes privadas. Se retiraron los kioscos y todas las conducciones anteriores (AMAEM, 2009). 

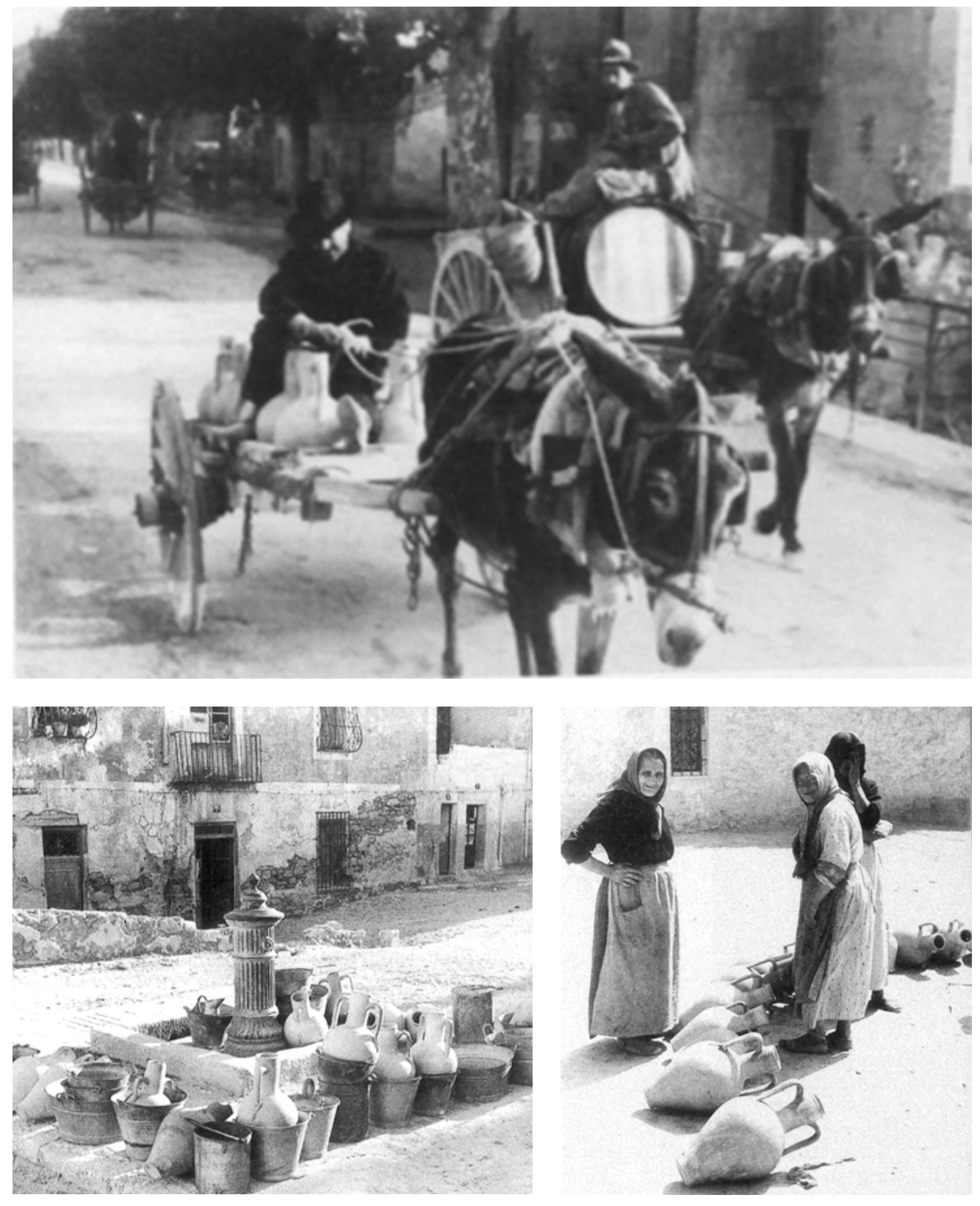

Fig 29. Fotografía de aguadores en Alicante finales del S. XIX [Archivo Municipal de Alicante (AMA). (AMAEM, 2009).]

Fig 30. Fuente de la Plaza del Puente, 1952 (Alicante) [Francisco Sánchez, AMA. (AMAEM, 2009).]

Fig 31. "A por agua", 1944. Alicante [Francisco Sánchez, AMA. (AMAEM, 2009).] 
En 1921, la "Societé Anonyme des Eaux d'Alicante" trasladó su domicilio social a Alicante, en el actual edificio de la calle Alona y, desde entonces, la Sociedad General Aguas de Barcelona, S.A. adquirió más del $90 \%$ del capital social de esta Sociedad, que siguió operando con el nombre de Aguas de Alicante, S.A.

Estando cerca de la finalización del plazo de concesión (sesenta años), y de resolver el problema de abastecimiento, el Ayuntamiento de Alicante, en sesión del Pleno Municipal de 30 de septiembre de 1952, acordó la creación de una comisión para el estudio de la municipalización del servicio en régimen de monopolio. Tras la tramitación del correspondiente expediente, el 17 de septiembre de 1953, se constituyó la Sociedad "Aguas Municipalizadas de Alicante, Empresa Mixta" (AMAEM), entre el Ayuntamiento de Alicante y la Sociedad Mercantil Aguas de Alicante, S.A., desembolsando cada uno de ellos el $50 \%$ del capital social.

El abastecimiento hasta finales de los años 50 seguía proviniendo exclusivamente de los pozos de Sax y Villena, pero ya no resultaba suficiente para Alicante, sobre todo teniendo en cuenta el incipiente desarrollo de la Albufereta y la Playa de San Juan. Alicante recibió agua de la Mancomunidad por primera vez en 1958, lo que permitió el desarrollo urbanístico de la Playa de San Juan, a partir de 1961.

El 22 de junio de 1958, el periódico Información titulaba "Alicante ha comenzado a beneficiarse de las aguas del Taibilla. Queda asegurado así el normal suministro a la población durante el verano". Alicante venía sufriendo restricciones que impedían la expansión de los espacios verdes y que obligaban permanentemente a sistemáticos cortes en el suministro durante el verano (ABC, 24/6/1958). De momento, el agua del Taibilla se mezclaba con la procedente de los pozos de Santa Eulalia en Sax, que hasta ese año eran los que abastecían a la ciudad de Alicante. Una vez concluidas las obras, Alicante dispuso de $47.500 \mathrm{~m}^{3} /$ día procedente de la MCT, y $20.000 \mathrm{~m}^{3}$ de Sax, lo que permitió un consumo diario por habitante de 500 litros, situando a Alicante entre las ciudades mejor abastecidas de España.

A diferencia del tratamiento recibido por los usos turísticos, que se benefician de las aguas de la MCT por formar parte de la categoría de abastecimiento a poblaciones, el suministro a los polígonos industriales se vio dificultado al tratarse de usos de menor rango. El Polígono industrial de Las Atalayas solicitó agua a la MCT en 1970 y no se autorizó por "falta de caudales y porque existe la preferencia del abastecimiento a la población humana frente a las industrias" (CEMCT, 18/5/1970). Ante esta negativa, la empresa TERRAPLAN, encargada de la redacción del proyecto de abastecimiento para el polígono industrial, reformuló su petición en 1971 para hacerla progresiva, solicitando $1000 \mathrm{~m}^{3} /$ día desde 1973, hasta $10.000 \mathrm{~m}^{3} /$ día en 1980. La MCT, sin embargo, denegó de nuevo la petición ya que la situación no difería de la que existía el año anterior; las 

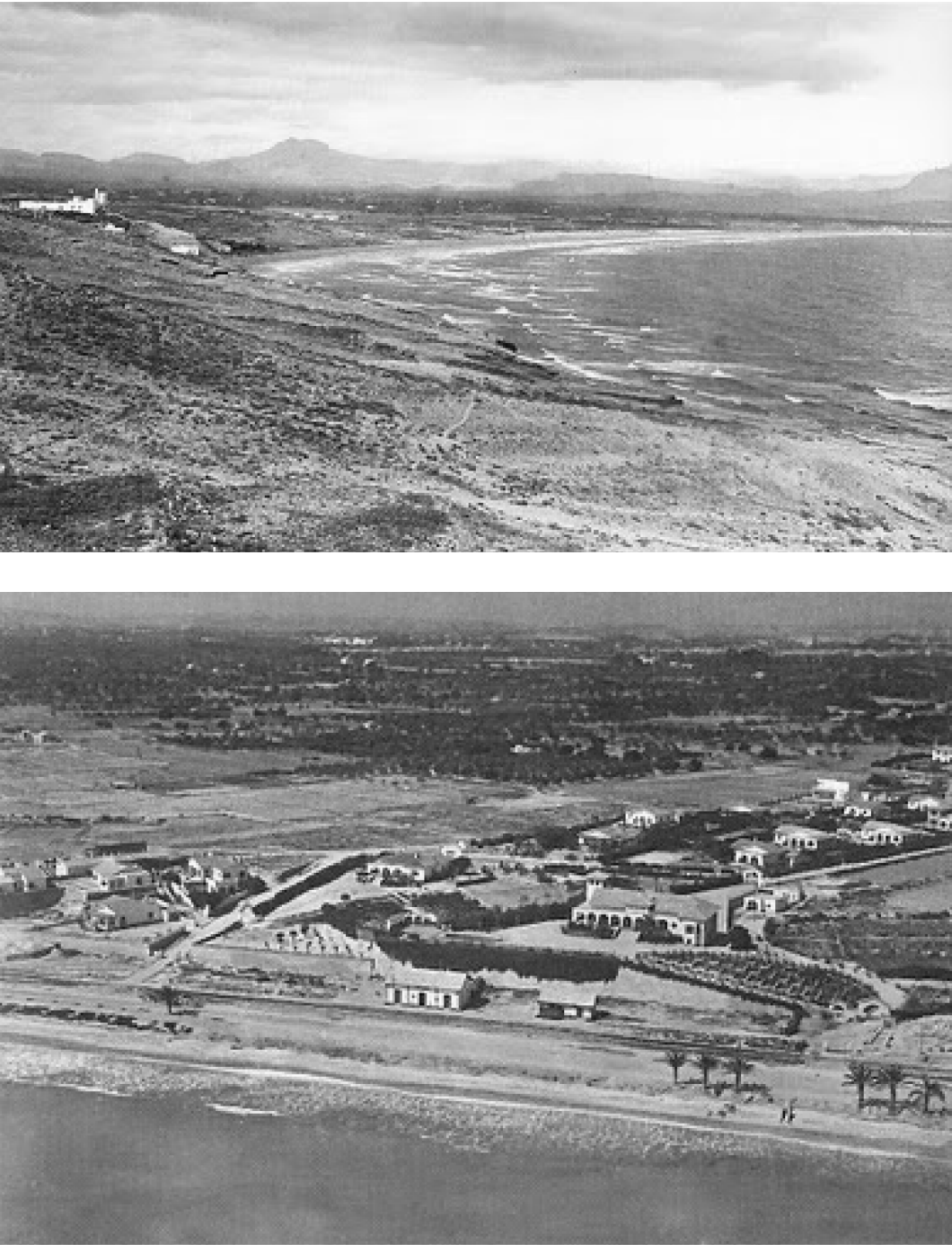


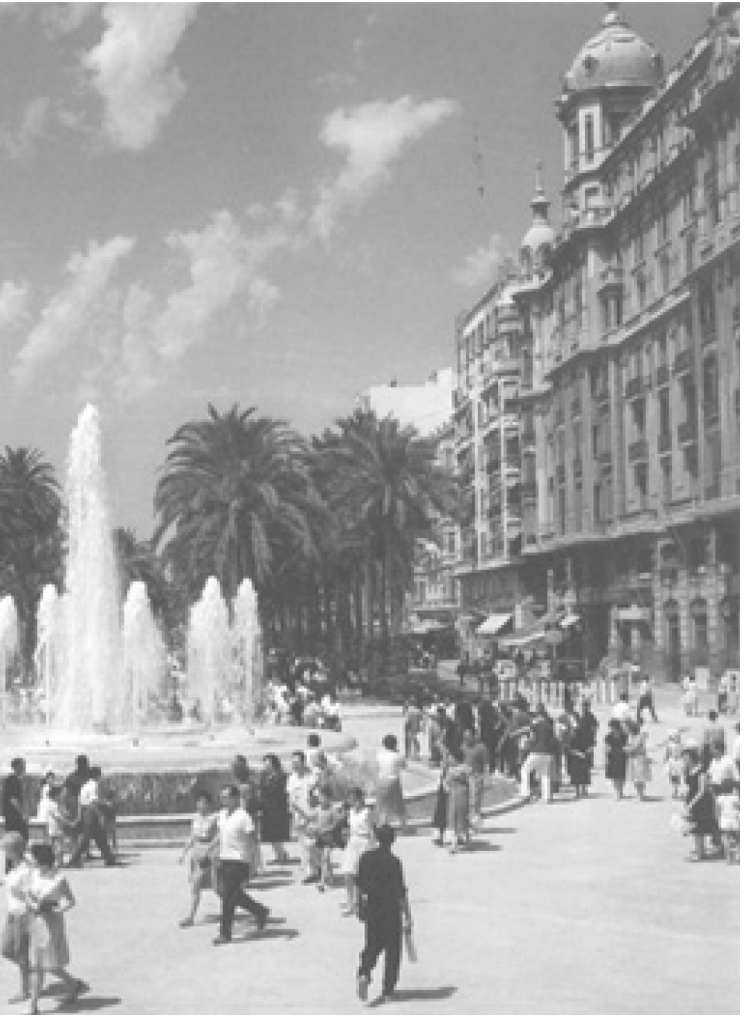

Fig 33. Plaza del Mar, 1960 [Francisco Sánchez, AMA. (AMAEM, 2009).]

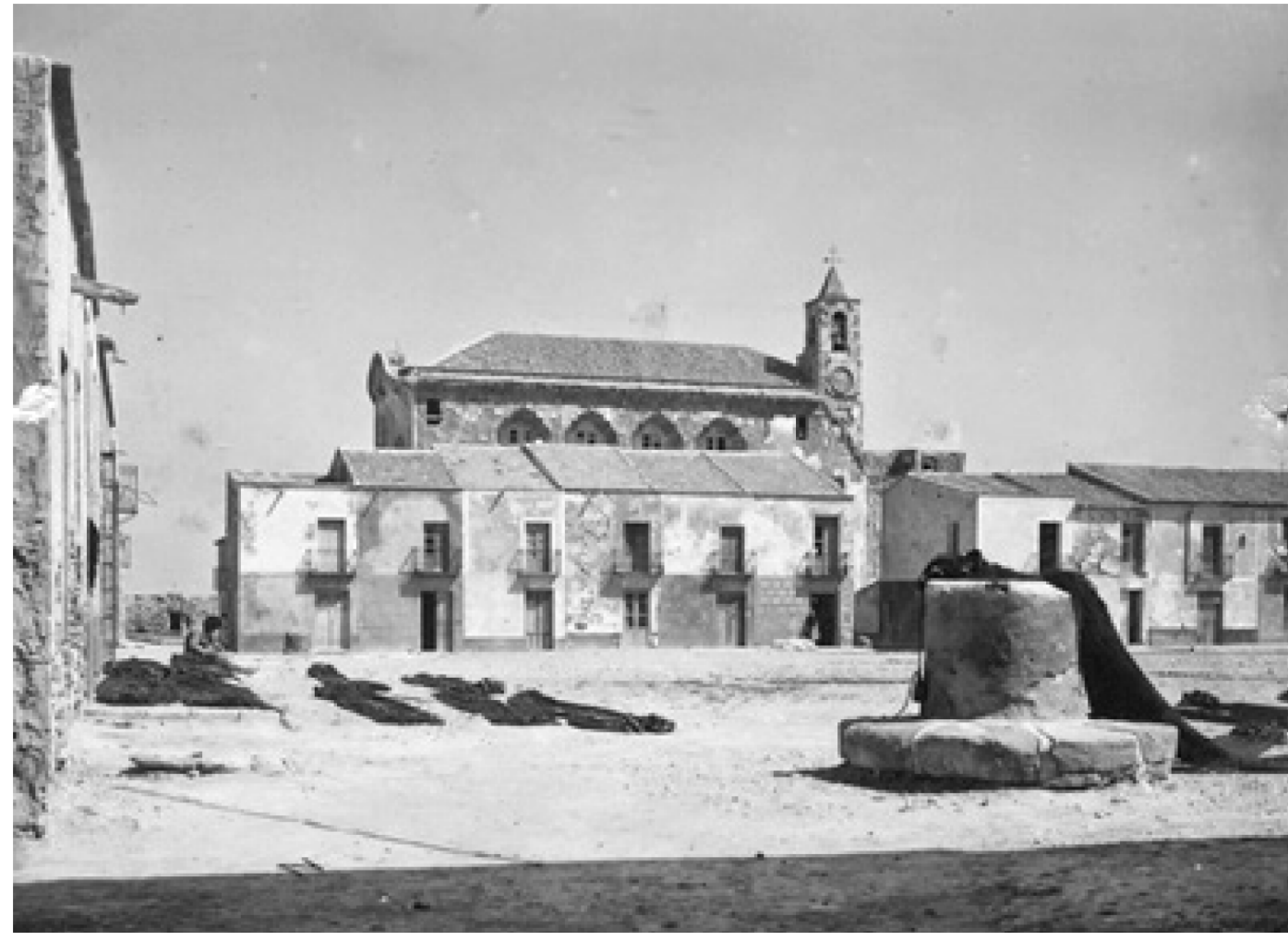

Fig 34. Aljibe público Tabarca.

Años 50 (Alicante) [http://

lafogueradetabarca.blogspot.com.

es/2014/06/el-historico-problema-delagua-y-la.html] 
nuevas dotaciones que se esperaban del trasvase Tajo-Segura estaban asignadas a los abastecimientos, no contemplando en ese momento el suministro a grandes centros o polígonos industriales, "que caen fuera de la competencia de la MCT" (CEMCT 6/3/1971).

No obstante, otros usos diferentes al suministro a poblaciones si fueron autorizados por la MCT, pese no contar con dicho rango. Es el caso de la autorización de $100 \mathrm{~m}^{3} / \mathrm{dia}$ para el nuevo vertedero de Alicante, situado en la finca "Lo Bolini", dicha autorización fue otorgada en precario, con la condición de que se garantizara que no habría problemas sanitarios en el embalse de Fontcalent (CEMCT, 31/7/1972).

En 1984 se inauguró la conducción submarina, de 5 km de longitud, para el suministro de agua potable a la isla de Tabarca, siendo así la única isla del litoral español que se abastece con este procedimiento. Hasta ese momento el abastecimiento se realizaba desde los aljibes públicos y en los momentos críticos con barco-aljibe, al menos desde 1930 hasta 1984.

En Elche, a finales del siglo XIX, el suministro de agua procedía de las fuentes de Barrenas Romero y las del Planet, que resultaban insuficientes para cubrir las necesidades de la población; la falta de caudal, sumada al pésimo estado de las cañerías por las que circulaba el agua, obligaba a seguir buscando otras fuentes fuera del término municipal. Pedro Ibarra, en su libro Estudio acerca de la institución del riego en El Elche, afirmaba: “... hemos llegado al siglo XX, la época en que todo el mundo comarcano se ha formado ya su caudalito de agua potable y para riego de sus términos, y nosotros, que somos los más antiguos en la comarca, que fuimos los más grandes, fuertes y ricos, nos hemos quedado atrás", refriéndose a la escasez y falta de calidad de las aguas con las que se abastecía Elche.

El 24 de abril de 1900 se constituyó la Compañía "The Elche Waterworks Company Limited" en Londres, cuyos propietarios eran John Soane Austin y Laurence Richard Philipps; se nombró como gerente de la sociedad en España a Juan Llacera Garrido. La Sociedad se creó con la finalidad de conducir aguas desde la Alcoraya (Alicante) hasta la ciudad de Elche. Llacera otorgó poderes para representar a la Compañía en Elche a Andrés Tarí Sánchez.

En enero de 1899, se procedió al corte de suministro de agua a la ciudad de Alicante procedente de la Alcoraya, y se comenzó a trabajar para conducir el agua hasta Elche. El 15 de agosto de 1901 llegaron las aguas de La Alcoraya a la plaza de la Merced. En agosto de 1910 se tienen noticias de que la Compañía solicita al Ayuntamiento que se abstenga de regar las plazas de la Glorieta y La Merced debido a la escasez de agua y asegurar el suministro a los abonados. 

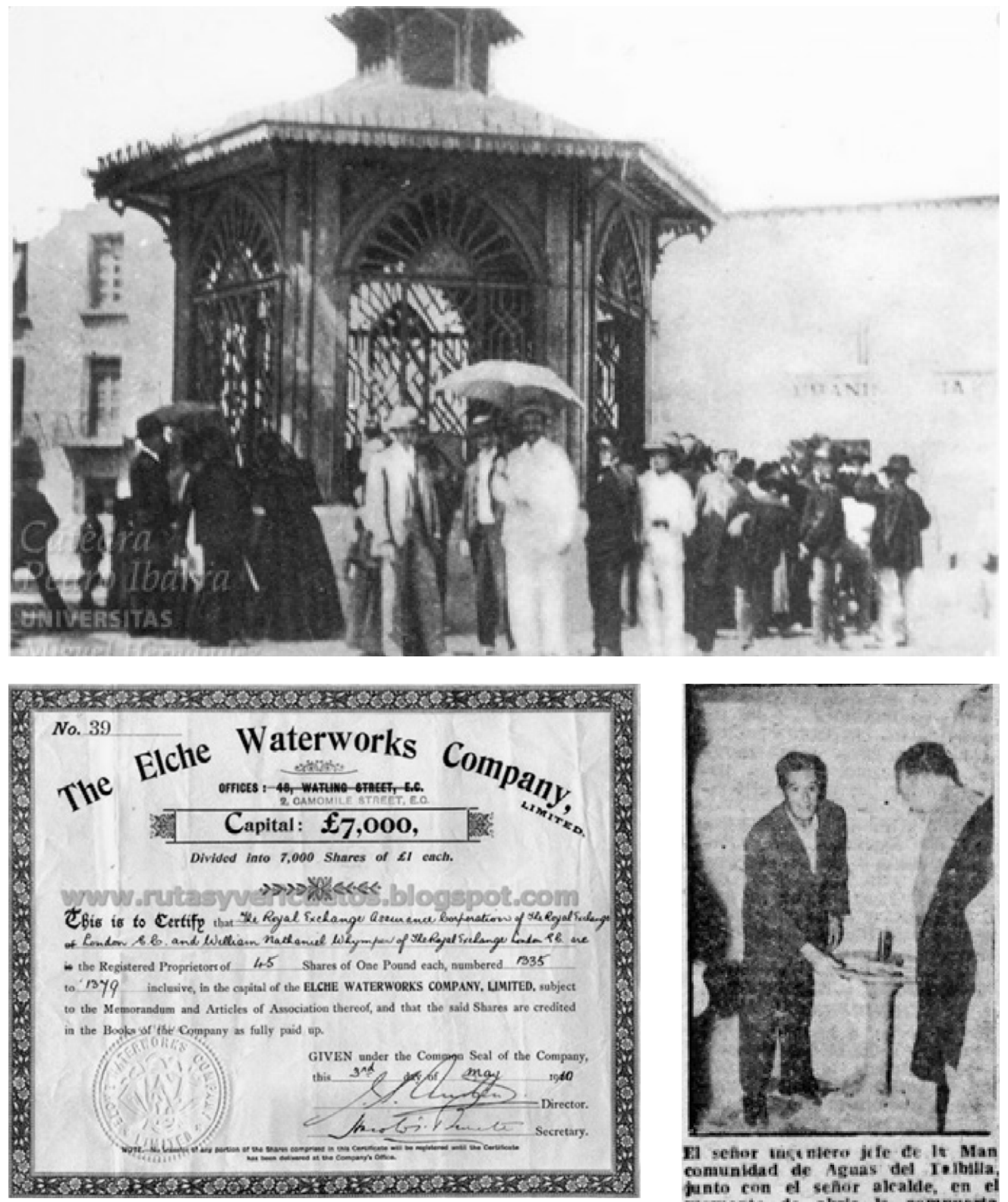

Q sefor tascontere jife de It Man comunidad de Asuas det Io ithlla tuato con el sehor alcalde, en el momento de alorir ia compuerta de las agias ot novierit-

Fig 35. Fuente de la Glorieta en Elche [Cátedra Pedro Ibarra Ruiz. Universidad Miguel Hernández http:// www.elche.me/taxonomy/]

Fig 36. Certificación de titularidad del capital social de la compañía por acciones: The Elche Waterworks Company [Cátedra Pedro Ibarra Ruiz. Universidad Miguel Hernández http://www.elche.me/taxonomy/]

Fig 37. Inauguración llegada de las aguas de la MCT a Elche [Diario Información , 25/6/1958] 
En 1915 el negocio de las aguas de la Alcoraya dejó de ser rentable para la Compañía The Elche Waterworks y anuncia su venta. En marzo del mismo año el Ayuntamiento aprueba adquirir la propiedad de las aguas, para lo cual emitió 500 obligaciones de 250 ptas cada una, que representó un empréstito de 125.000 ptas (González Sevila, 2013).

En 1946 Elche ratifica su solicitud de ingreso en la MCT. En ese momento el municipio estaba ejecutando las obras de alcantarillado, red de distribución interior y abastecimento de aguas desde unos pozos situados en la ciudad de Villena; pero como este abastecimiento era insuficiente, por no disponerse más que de unos tres mil metros cúbicos diarios, se solicitó de la MCT una dotación complementaria de cuatro mil metros cúbicos, cubriéndose con la suma de ambas la dotación fijada en la normativa, toda vez que correspondiendo a cada habitante $200 \mathrm{l} / \mathrm{d}$, se necesitaban para los 34.294 habitantes, $6.890 \mathrm{~m}^{3} / \mathrm{d}$, habiendo pues un exceso de $120 \mathrm{~m}^{3} / \mathrm{d}$ sobre el mínimo obligatorio. (Acta $26 \mathrm{de}$ agosto de 1946, AMCT).

Antes de que llegara el agua del Taibilla a Elche, la ciudad pasó por una gran carestía. El canal de Villena, aunque de caudal abundante, era insuficiente para cubrir las necesidades de la población; durante los veranos se producían cortes de suministro para que diera tiempo a que el depósito se recargara para almacenar agua suficiente para el día siguiente (La Verdad, 30/4/1966). Las aguas del Taibilla (50 1/seg) llegaron a Elche el 24 de junio de 1958, mezclándose con las procedentes de Villena (48 l/seg). Se hizo una ceremonia de bienvenida al agua con unos cohetes-bomba que anunciaron al vecindario la grata nueva (Información, 25/6/1958).

Aigües i Sanejament d'Elx es la empresa mixta que gestiona el ciclo integral del agua en el término municipal de Elche desde el 1 de julio de 2001. En año 2014, y a través de $1230 \mathrm{~km}$. de red de agua potable, suministró agua a una población de 222.000 habitantes, que en los meses estivales ascendió a 233.000, distribuidos en diez núcleos de población. El consumo total de agua para ese año fue de 13,92 $\mathrm{hm}^{3}$. El agua procede en su mayor parte de la MCT. La Mancomunidad suministra anualmente entre el $90 \%$ y el 95\% del total de agua. Otra fuente de suministro tiene su origen en aguas subterráneas captadas en el acuífero de Villena, concretamente en unos sondeos ubicados en una finca denominada Los Frutales, que aportan entre el 10\% y el 5\% del agua, en función de los excedentes disponibles.

Santa Pola contaba para el suministro de su población, desde el S. XVIII, con los tres Aljibes del Massapá, depósitos destinados a guardar agua potable procedente de la lluvia, conducida a través de canalizaciones. Ante el poblamiento de la villa, motivado por la riqueza creada por la sal y la pesca, fue necesario dotar a la población de puntos de abastecimiento de agua mediante depósitos subterráneos, para recoger y almacenar agua de lluvia procedente de las laderas de la Sierra de Santa Pola, vendiéndola posteriormente 
por las calles en tinajas transportadas por carros. En la primera mitad del siglo XX todos los aljibes estaban en funcionamiento, pero con la posguerra, la elevada emigración conllevó el abandono de la agricultura y la desaparición de la cultura hidráulica tradicional.

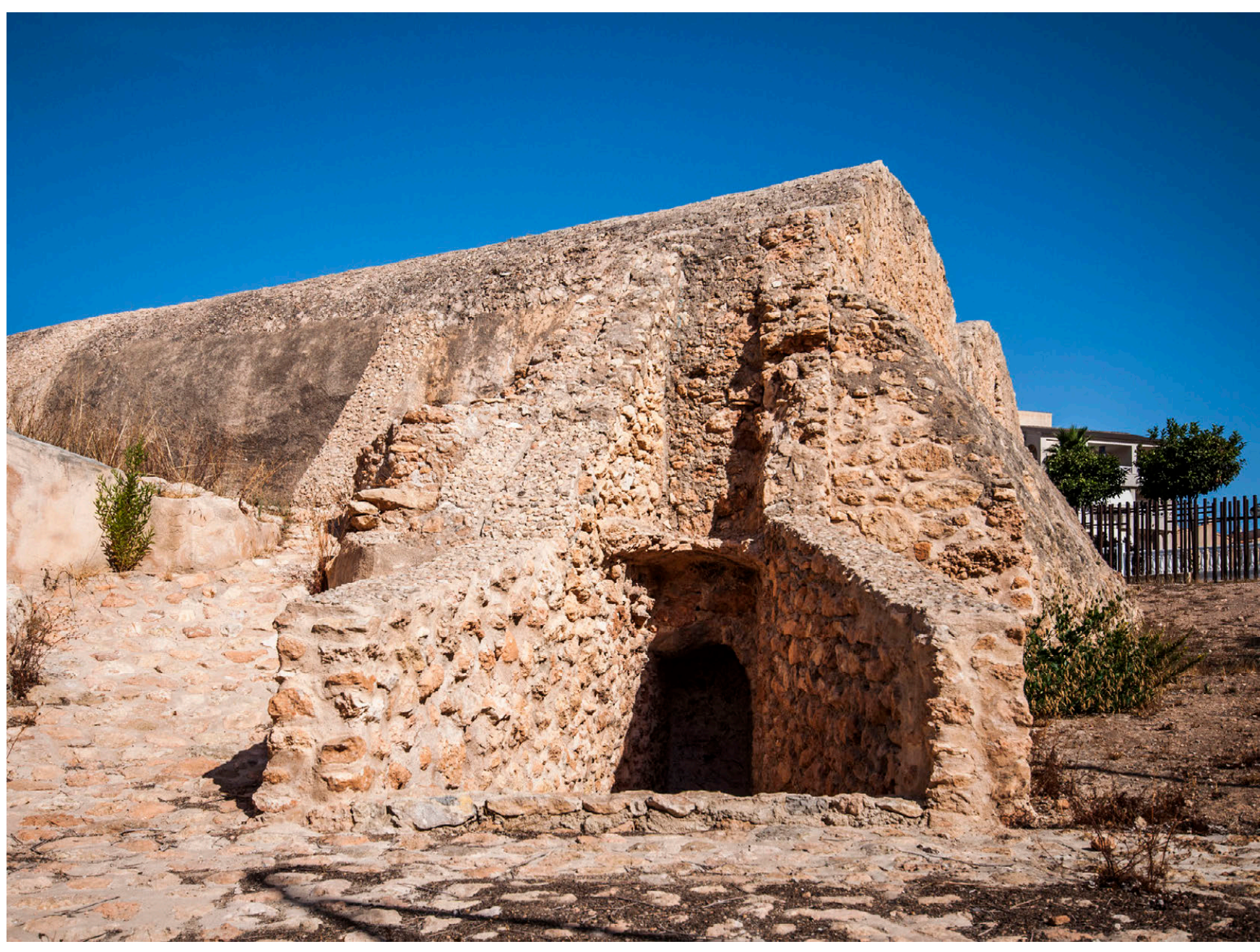

Fig 38. Depósitos de agua de Massapa, Santa Pola. [Rafael Zarza García]

La llegada de las aguas del Tabilla supuso la superación de un suministro ciertamente precario en el municipio. 
Tras la construcción del Canal de Alicante se inicia una nueva fase para la MCT que se caracteriza por la ampliación de los abastecimientos, a partir de la red básica. Los fondos del MOP (Decreto 3.418/63 de 12 de diciembre) permitirán ir financiando estas ampliaciones. En el área suministrada se está experimentando en estos años un claro despegue industrial y un significativo crecimiento poblacional, lo que incrementa las demandas de agua y las nuevas peticiones para acceder al suministro de la MCT.

El Taibilla era ya insuficiente, pese a que había venido suministrando alrededor de $47 \mathrm{hm} 3$ /año. Desde 1959, se evidenciaron restricciones al suministro en los meses de verano, situación que se agravó en 1962, obligando a declarar un estado de emergencia. Los pozos y manantiales que complementaban el suministro en algunas localidades no podían dar respuesta a estas demandas, por lo que se recurrió a caudales del río Segura en 1966. La Mancomunidad fue autorizada a derivar del río, cada año, un volumen igual a la aportación media que el Taibilla realizaba al Segura, incluidas las aguas residuales depuradas. El Ministerio de Obras Públicas llegó a plantear por primera vez en este año la posibilidad de potabilizar aguas del mar (Morales Gil, 2002)

En esta nueva fase, se evidencia un importante incremento del consumo en toda la red oriental del sistema, en la provincia de Alicante, debido a la incorporación de la mayoría de los municipios de la Vega Baja, lo que contribuirá al desequilibrio entre las demandas y los recursos disponibles. Albatera y Catral reciben las aguas de la MCT en 1965, Orihuela, Redován y Dolores en 1966, en 1967 lo hará Callosa de Segura, en 1969, Bigastro, Jacarilla, Benejúzar. San Miguel de Salinas y Guardamar en 1970. En 1972 llegan las aguas a Torrevieja

Con la expectativa de la llegada de nuevos recursos procedentes del trasvase TajoSegura, en 1971, los once municipios de la Vega Baja (Algorfa, Almoradí, Benijófar, Cox, Daya Nueva, Daya Vieja, Formentera, Granja de Rocamora, Rafal, Rojales, San Fulgencio) ingresarán en la MCT (plan de ampliación de los abastecimientos con caudales del ATS), y las aguas llegarán definitivamente a dichos municipios partir de 1984. En la figura 39 se observan los municipios alicantinos que reciben los caudales de la MCT durante este periodo, salvo los once de la Vega Baja, que los recibirán más tarde.

Numerosos municipios de la Vega Baja, debido a la situación de penuria por la que estaban atravesando, solicitaron a la MCT que de forma provisional se les habilitara una fuente pública para contribuir al abastecimiento de la población, como fue el caso de los municipios de Albatera y Catral (CEMCT, 23/6/1964 y 28/7/1965). 


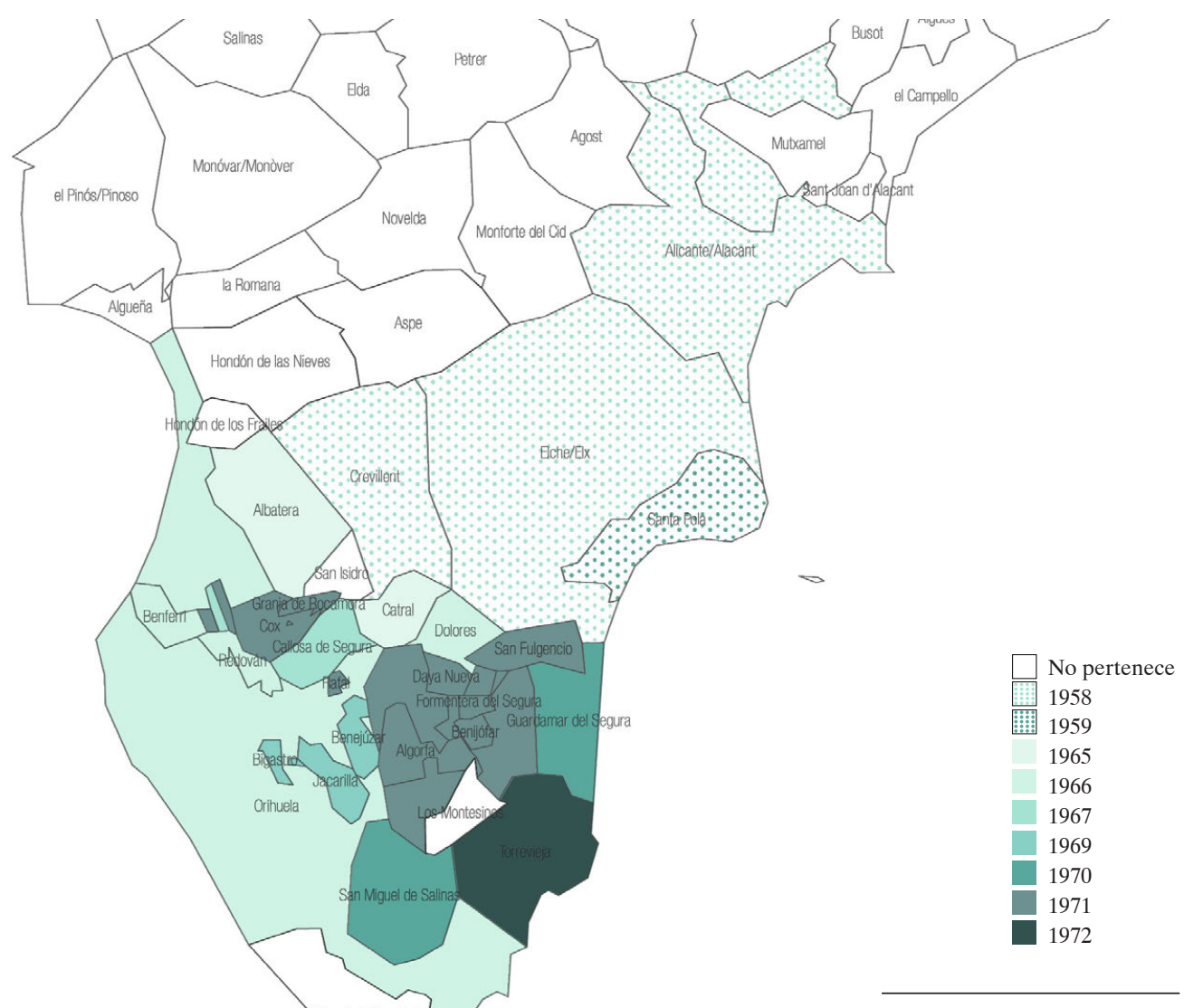

Fig 39. Llegada de las aguas de la MCT a los municipios de Alicante hasta 1972 [MCT.
[MT Elaboración propia.]

* A los once municipios de la Vega Baja, integrados en la MCT en 1971, el agua llegó en 1984

Antes de la llegada de las aguas de la MCT en 1966 a Orihuela, este municipio se venía abasteciendo en parte de los llamados "Pozos de Cremós".

En el año 1936, el Ayuntamiento se interesó por controlar estos abastecimientos, que en principio se desarrollaban de manera privada. Los pozos fueron incautados durante la Guerra, asumiendo la Corporación los créditos pendientes de pago que había contraído el propietario de los mismos para desarrollar el servicio.

Los pozos fueron posteriormente devueltos a su propietario, planteándose la duda sobre los saldos devengados durante el periodo de incautación. 


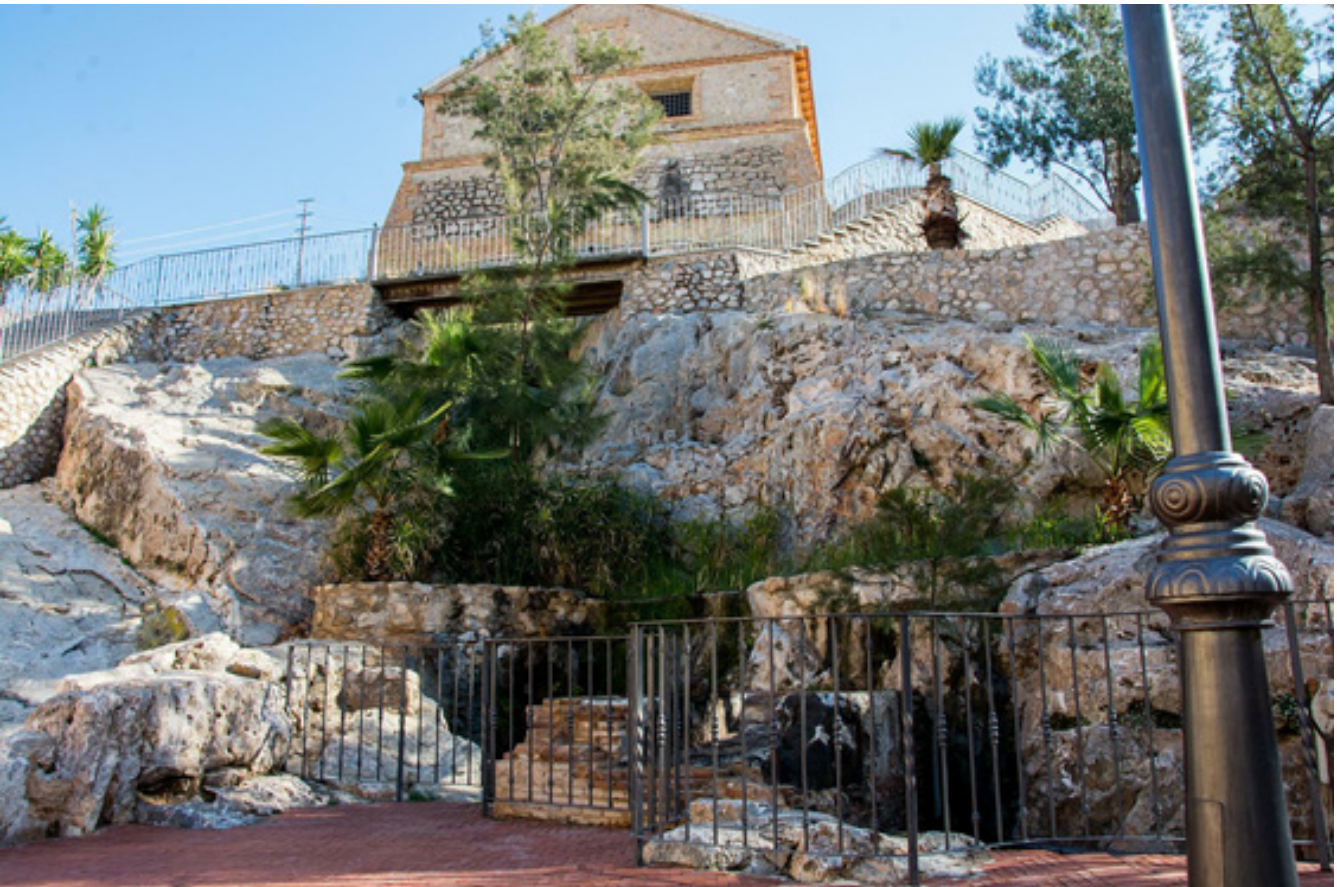

\section{Ayuntamiento de Oríbuela}

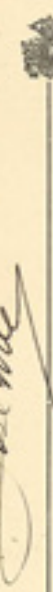

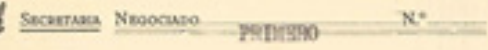

I s syantaniento de ni prosidencis on seaín oolobrads ol din 6 de los earrientes acordo desiganrle s 7. aoso nienbro de in Corporneibn parn quo se ocupe de is inspoceifn del absateciniento do Acras Totables do la pobinelía que explota el sr. Cronóa por haberas inonutalo ol tunieipio te dicho aegocio .

Lo que le partielpo pors ma conocinisnte $y$ denín efoeton, rogusiole firme ol duplicaco adfanto en pruebs do haber rooibieo esta cosualescion,

Solud $y$ tieposilios.

Orihaela 9 de Oetabre de 1936. II Aloside

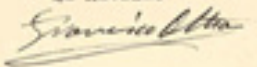

Sr. D. Joeé Irlos tndirou.

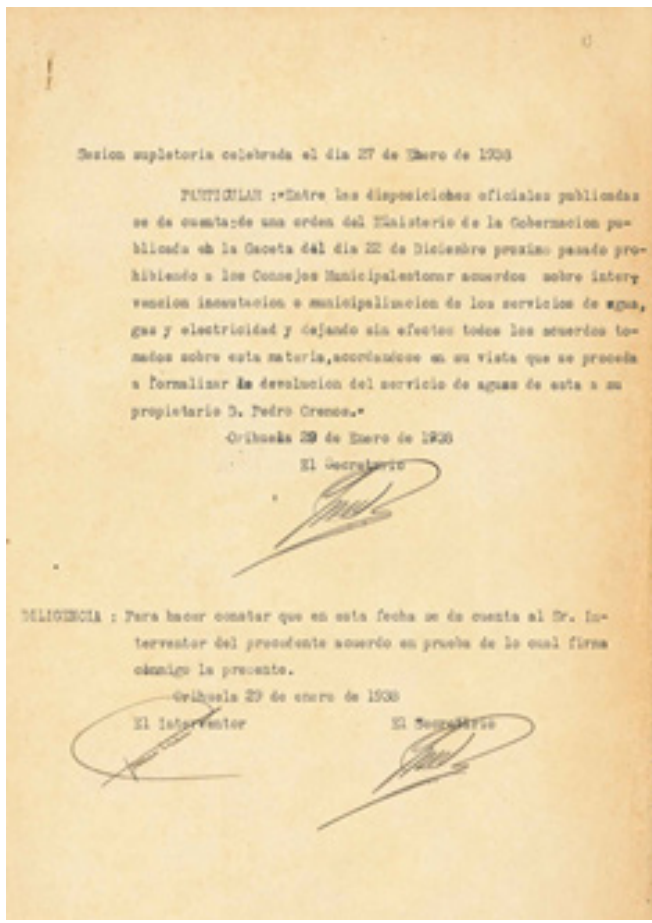

Fig 41. D o c u m e n t o histórico de devolución de los pozos de Cremós (1938) [Archivo Histórico de Orihuela.]

Fig 42. D o c u m e $\mathrm{nt}$ histórico de devolución de los pozos de Cremós (1938) [Archivo Histórico de Orihuela.] 
En 1963, la precariedad del suministro seguía siendo una realidad. El municipio todavía completaba su suministro mediante "aguadores", que distribuían el agua a domicilio en cantaros a "precios prohibitivos para la clase modesta" (Diario Información, 15/6/1963).

Para resolver el problema del estado precario del abastecimiento, el Ayuntamiento de Orihuela solicitó en 1961 a la MCT la ejecución con urgencia de las infraestructuras necesarias para dotar al municipio de un suministro suficiente. Las obras habían sido adjudicadas a Uralita S.A. y a Constructoras Orcelitanas S.A.

La respuesta del Organismo a esta petición fue que "las necesidades y apremios eran los mismos que para otros ayuntamientos, pero los problemas económicos de la MCT impedían llevar a la práctica los planes de abastecimiento con la celeridad deseada" (CEMCT, 14/4/1961).

El 18 de julio de 1966 se inauguró la llegada del agua del Taibilla a Orihuela, con una fuente conmemorativa. Decía la prensa de la época: "En Orihuela se inauguró ayer la red de distribución del agua del Taibilla” (Diario Información, 19/7/1966).
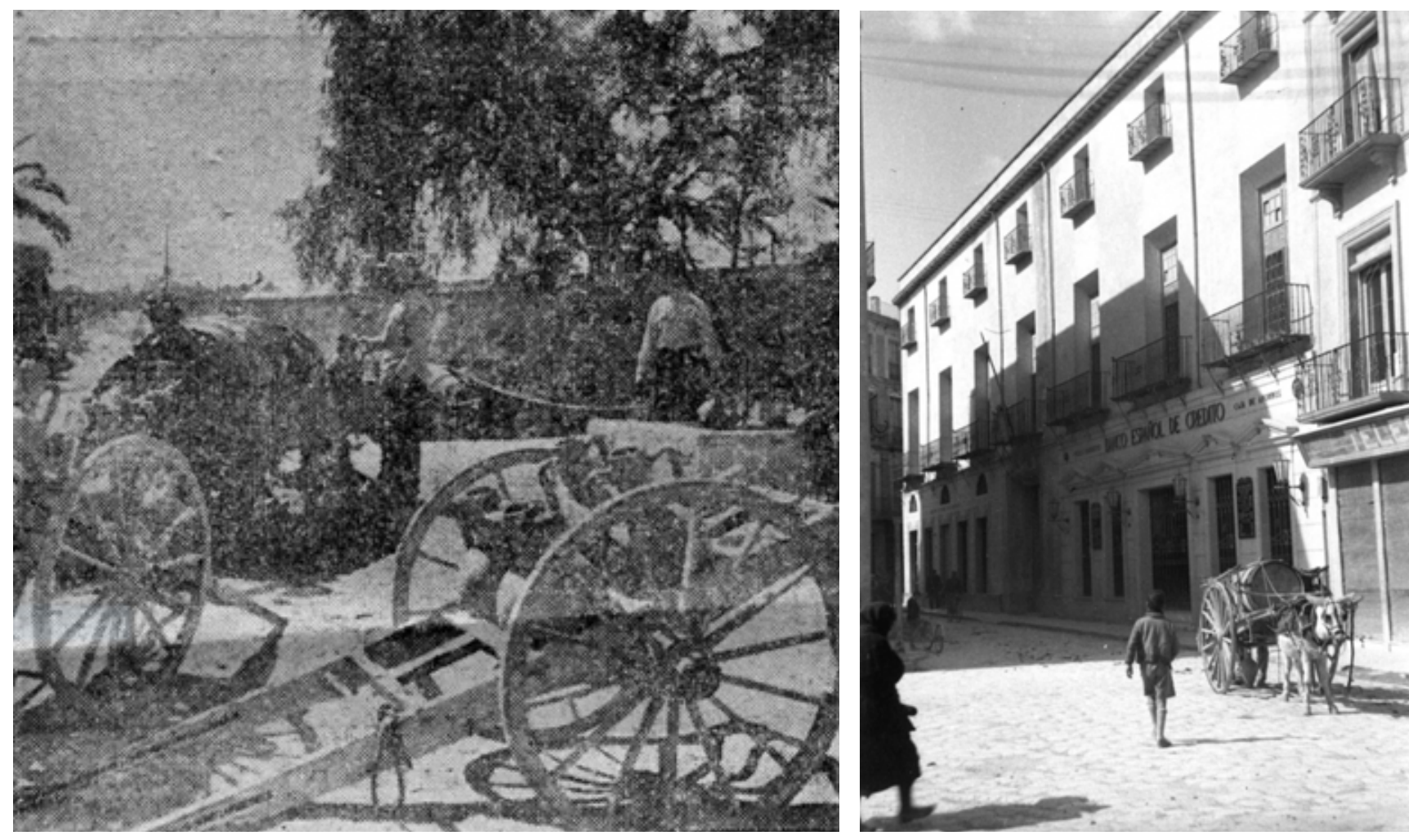

Fig 43. Carros de aguadores en Orihuela [Diario Información 16/6/1963.]

Fig 44. Carro de aguador (1948) [Aguadores Orihuela http://www.minutocero.es/galeria. php?tipo $=$ foto\&id $=342]$ 
Desde el siglo XVII y hasta muy avanzado el siglo XX, Torrevieja se abastecía del agua que se extraía de los aljibes. En los periodos de sequía se recurría a los "aguaores", que con sus carros traían las aguas en tinajas y orzas desde los pozos existentes en las cercanías de la Mata y de la Ceñuela.

Las primeras canalizaciones de abastecimiento de agua datan de 1891, y un año más tarde el agua llegaba hasta las tres primeras fuentes públicas. En Torrevieja se inauguró el servicio municipal de agua potable el 23 de diciembre de 1892. El abastecimiento se realizaba gracias a la traída de aguas pertenecientes a Unión Salinera de España S.A., del manantial llamado Aguas de la Mata, distante $5 \mathrm{~km}$ de la población, de mala calidad y escaso rendimiento; su producción alcanzaba los 288 hectólitros/hora, pudiendo con ello suministrarse a unos 1.500 habitantes; el resto, es decir, 7.899 de los 9.399 habitantes que tenía Torrevieja, se abastecían indistintamente de aguas de aljibe en aquellas viviendas que lo tenían, y el resto, de aguas de pozo suministradas por carros, procedimiento rudimentario y anticuado" ( Acta Archivo MCT, 31/7/1946)

En 1965, debido al auge turístico se agudizan los problemas de abastecimiento de la población. Para intentar solucionarlos se crea la "Comisión Administrativa para el Abastecimiento de Aguas a Torrevieja", bajo cuyos auspicios se realizan las obras de captación, ampliación de redes y depósitos necesarios para asegurar el suministro de los más de 1.000 abonados que había en ese momento. Cinco años más tarde, en 1970, comienza la construcción de la red de alcantarillado. Las viviendas que históricamente venían usando pozos negros van efectuando sus acometidas a la red pública.

En 1970 la llegada del agua a Torrevieja sufrió cierto retraso debido a la quiebra del contratista, lo que suscitó una gran preocupación a las autoridades municipales, quienes pusieron de manifiesto que "por la especiales circunstancias de ser un núcleo eminentemente veraniego la necesidad de agua se hace patente especialmente en la época estival" (CEMCT, 15/10/1970).

En 1971, Torrevieja tenía 10.000 habitantes que en verano ascendían a 60.000. Decía la prensa de la época que cuando "tengamos alcantarillado y agua Torrevieja se convertirá en la Perla del Mediterráneo” (La Verdad, 10/8/1971). En 1972 se esperaba recibir 140.000 $\mathrm{m}^{3}$ de agua del Taibilla, cantidad que se consideraba suficiente para cubrir las necesidades del turismo. Gracias a que estas previsiones se hicieron realidad, Torrevieja se incorporó definitivamente al progreso turístico (Diario Información, 27/2/1972).

El auge del turismo ha sido el motor del desarrollo de la ciudad en las décadas pasadas, siendo, probablemente, la población española que más ha crecido en los últimos años. Actualmente hay censados más de 100.000 habitantes, pero en realidad residen habitualmente más de 175.000 personas, llegando en época punta a las 400.000 . 


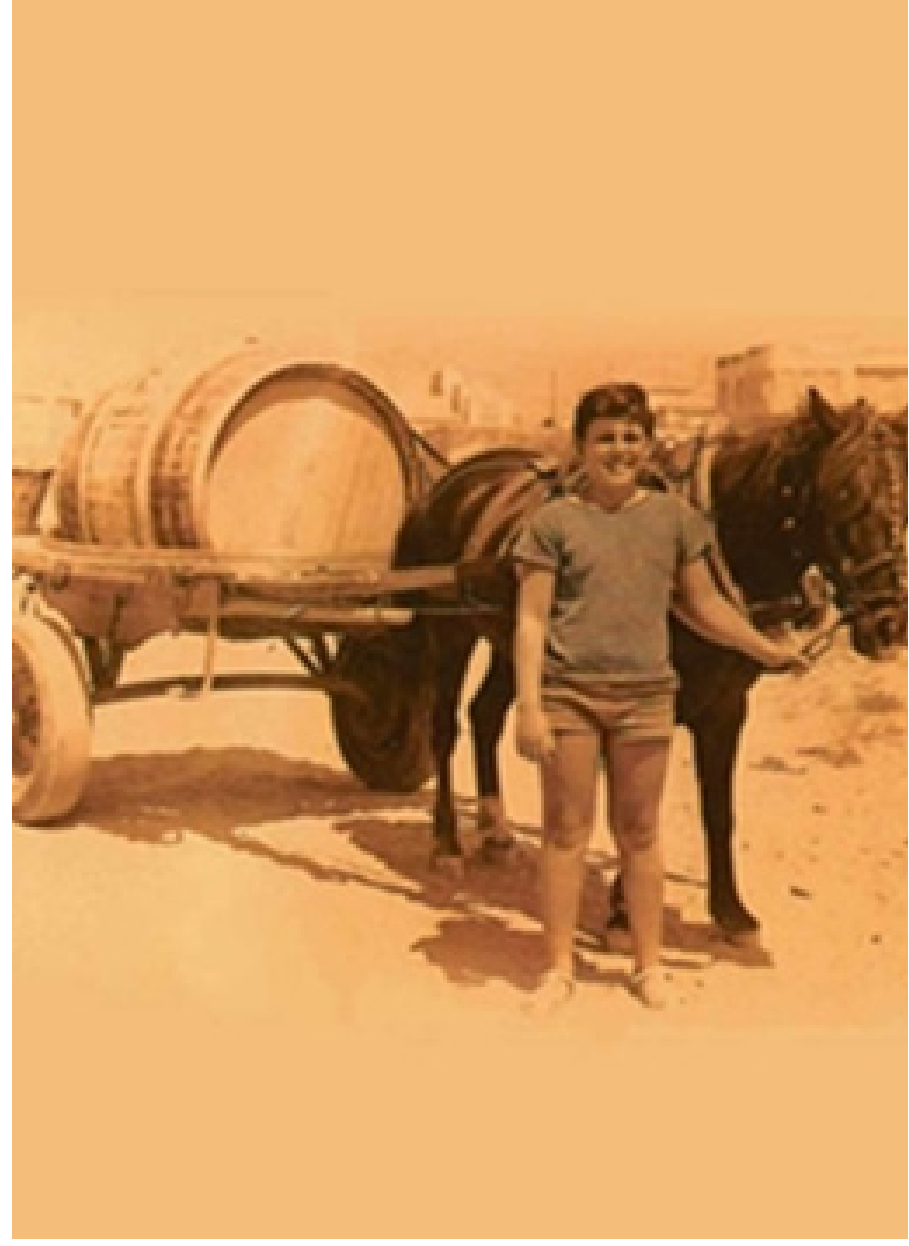

Fig 45. "Aguaores" en Torrevieja, 1960

c.- Ampliación del número de municipios por segregación y consolidación de abastecimientos provisionales (1987-2013).

Determinados municipios suministrados actualmente por la MCT se crean por segregación a partir de otros que ya estaban integrados en el Organismo con anterioridad; salvo en el caso de Pilar de la Horadada, ya contaban con caudales de la MCT antes de su segregación. El caso del Pilar de la Horadada es distinto, puesto que su localización en la costa, a bastante distancia del núcleo principal del municipio originario (Orihuela), hizo que esta parte del entonces término municipal oriolano no contara con suministros de la MCT. Sólo cuando la ampliación de los canales permitió llevar aguas a esta localidad pudo completarse su integración efectiva en 1987, ya como municipio independiente. En 1994, dos nuevos municipios también segregados, Los Montesinos (antes en Almoradí) y San Isidro (antes en Albatera) reciben las aguas de la MCT en las mismas condiciones.

La disposición adicional cuadragésima primera de la Ley 50/1998, de 30 de diciembre, de Medidas Fiscales, Administrativas y del Orden Social, flexibilizó el régimen de acceso a la MCT, autorizando a los municipios situados en la zona geográfica que pudiera ser abastecida por la Mancomunidad a solicitar su ingreso en la misma al Ministerio de Medio Ambiente. Aspe y Hondón de las Nieves se benefician de esta circunstancia, si bien con anterioridad ya recibían caudales de la MCT en virtud de una autorización 
ministerial provisional concedida para paliar la salinidad de las aguas subterráneas de las que captaban sus recursos.

Las poblaciones de Aspe y Hondón de las Nieves se abastecen de una toma en los canales de Alicante, cerca de la presa de Crevillente perteneciente a la Mancomunidad de los Canales del Taibilla. Las instalaciones de transporte a partir de este punto hasta los depósitos reguladores de ambos municipios ya no pertenecen a la MCT, sino a los propios ayuntamientos y son explotadas en la actualidad por la empresa Aguas de Valencia. La realización del Proyecto 05/13 de mejora del abastecimiento a Aspe y Hondón de las Nieves (AL/Varios t.m.) 2013, permitió a estos municipios recibir el agua suministrada por la MCT, y adecuar el sistema a las condiciones de calidad, seguridad y durabilidad exigidos por el Organismo.

El último de los municipios en incorporarse a la MCT ha sido Hondón de los Frailes. Antes de la llegada de los caudales de la Mancomunidad, el abastecimiento del municipio se realizaba mediante captaciones del acuífero de Crevillente cuyas características principales son la salinidad del agua (conductividades entre 2500-3000 $\mu \mathrm{S} / \mathrm{cm}$ ) y la importante profundidad de captación (más de 400 metros).

La captación se realizaba de dos formas, por un lado, mediante una toma de la Galería de los Suizos, y otra con un pozo directamente del acuífero (Pozos de Galiana). Tras la captación se trasportaba a una estación de tratamiento por osmosis inversa (desalobradora), y era conducida hasta el depósito de cabecera del municipio de $1000 \mathrm{~m}^{3}$ de capacidad desde el que se distribuye a todo el municipio ya en baja.

Las principales deficiencias del sistema se derivaban del tipo de agua y su captación. Desde la puesta en explotación del acuífero de Crevillente en los años 60 con la construcción de la Galería (con una longitud de 2360 metros), el descenso de los niveles ha sido continuo. De hecho, tras la terminación de la Galería en el año 1964 dejó de manar agua por la despresurización de la franja superior del túnel, y fue necesario instalar en su interior hasta 12 captaciones, que se iniciaron a 10 metros de profundidad y en la actualidad sobrepasan los 300 metros. De igual forma, la mineralización del agua ha ido aumentando con la profundidad hasta situarse en valores de $600 \mathrm{mg} / \mathrm{l}$. En los últimos años estos valores se habían estabilizado debido a la disminución de las extracciones ante la falta de rentabilidad para la agricultura.

En estas condiciones el abastecimiento de Hondón de los Frailes presentaba una gran vulnerabilidad y elevado coste por las profundidades de captación y el coste de los tratamientos de potabilización. Tras la petición municipal de incorporación a la MCT, en Junio de 2011 se realizó un estudio de alternativas para resolver el abastecimiento desde sus instalaciones. Dicho estudio concluía en plantear el abastecimiento al municipio 
desde el depósito proyectado para Hondón de las Nieves, el cual se abastece desde los Canales de Alicante a través de diversos bombeos. La actuación parte del depósito de la MCT en Hondón de las Nieves, y mediante una estación de impulsión y una tubería se trasporta el agua hasta el depósito de cabecera de Hondón de los Frailes, el cual fue cedido a la MCT para su explotación, adecuando ésta sus instalaciones.

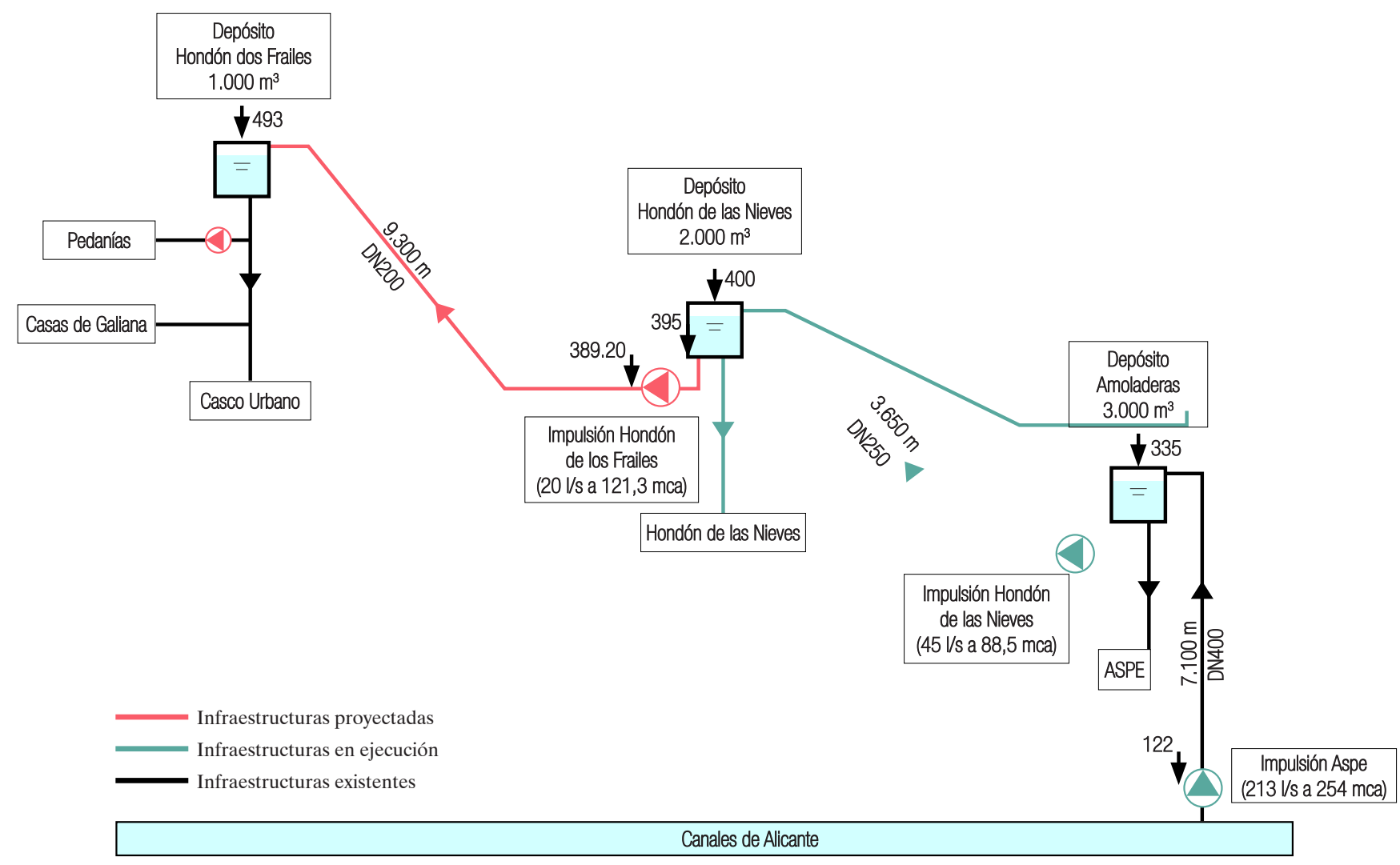

Fig 46. Conexión de Hondón de los Frailes con la MCT [MCT, Proyecto 12/13 de Abastecimiento a Hondón de los Frailes (AC/Hondón de los Frailes). 2014] 
En resumen, en 2016 la provincia de Alicante cuenta con 35 municipios integrados y abastecidos por la MCT. En la figura 47 pueden observarse la totalidad de municipios atendiendo a las fechas en que reciben los caudales.

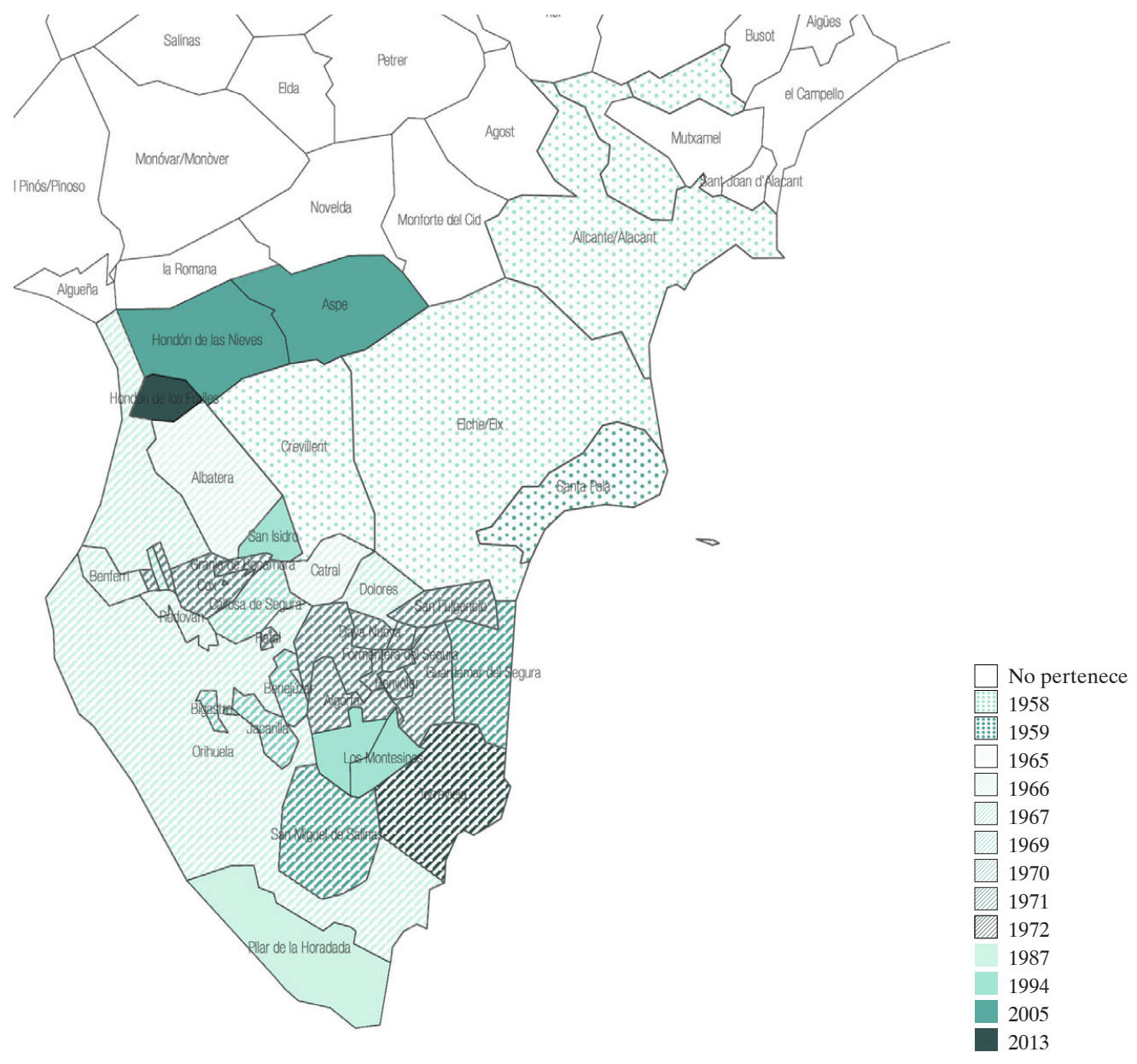

Fig 47. Dinámica de llegada de los caudales de la MCT a los municipios alicantinos [MCT. Elaboración propia.] 
Los municipios abastecidos tienen características poblacionales muy diversas, contando con varias localidades de gran población, por encima de los 100.000 habitantes, numerosos municipios de población intermedia, y pequeños municipios.

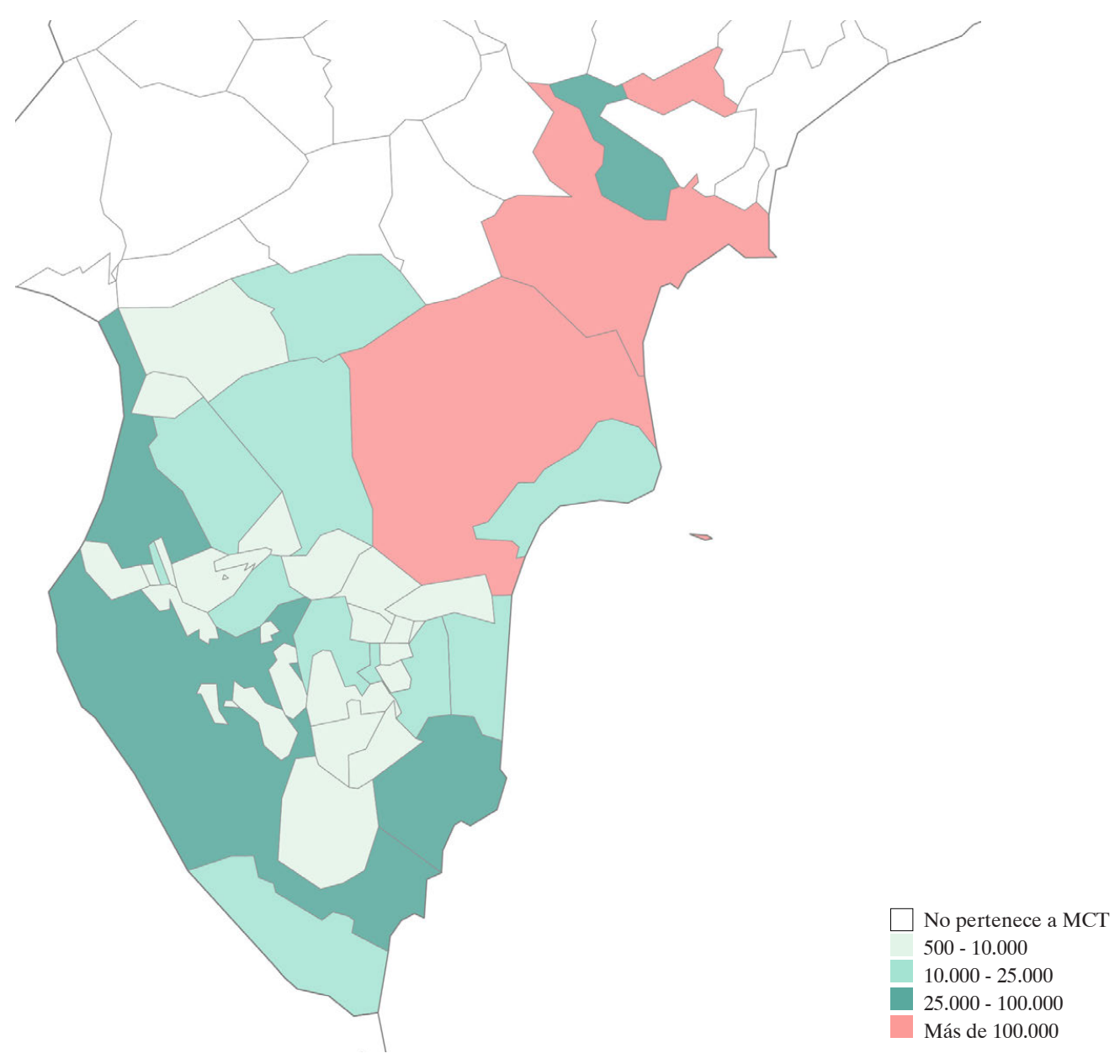

Fig 48. Clasificación de los municipios alicantinos abastecidos por la MCT en función del número de habitantes [MCT. Elaboración propia.] 
Por otra parte, es preciso señalar que junto a los municipios alicantinos indicados, la MCT suministra recursos a una importante entidad en la Provincia, como es el Aeropuerto de Alicante-Elche (AENA). El suministro a esta instalación estratégica se realizó como entidad independiente entre 1979 y 2009, si bien en la actualidad el Aeropuerto recibe los caudales a través del municipio de Elche. Esta instalación llegó a consumir directamente de la MCT hasta $180.000 \mathrm{~m}^{3}$ en el año 1992.

Finalmente, la Mancomunidad ha realizado suministros puntuales al Consorcio de Aguas de la Marina Baja, a través de la conducción Rabassa-Fenollar-Amadorio (Alicante-Benidorm), elevando caudales procedentes de la demarcación Júcar (Melgarejo et al., 2015). La Marina Baja constituye, en términos hidrológicos, una subcuenca independiente sin conexión física con el río Júcar, si bien está adscrita provisionalmente a dicha demarcación conforme establece el Real Decreto 125/2007, de 2 de febrero, por el que se fija el ámbito territorial de las demarcaciones hidrográficas, y confirma la disposición final tercera del Real Decreto 255/2013, de 12 de abril, por el que se establece la composición, estructura y funcionamiento del Consejo del Agua de la Demarcación Hidrográfica del Júcar, y por el que se modifican diversas normas relativas al ámbito y constitución de dicha demarcación y de la Confederación Hidrográfica del Júcar (Melgarejo et al., 2005).

En la Marina Baja se ha alcanzado un elevado grado de suficiencia en el uso integral de los recursos propios gracias al sistema de gobernanza generado por el Consorcio, que articula un sistema de permutas de aguas subterráneas concedidas a los agricultores de la zona a cambio de aguas residuales regeneradas procedentes básicamente de las EDAR de Benidorm y Villajoyosa.

Este modelo de intercambios ha garantizado la suficiencia de los suministros de estas localidades. Sin embargo, dado que se trata de un sistema cerrado, en situaciones de elevado estrés hídrico, producido por sequías extraordinarias, los recursos disponibles pueden no alcanzar a abastecer la totalidad de las demandas, que por otra parte, son elevadas, dado el gran desarrollo turístico, residencial, y la presencia de instalaciones altamente demandantes de agua como son los campos de golf o parques temáticos.

Para resolver esta problemática se construyó una conducción que, desde el término municipal de Alicante, conecta las instalaciones de la MCT con el embalse de Amadorio, ya en la Marina Baja, y por tanto, con las instalaciones gestionadas por el Consorcio. Esta interconectividad ha permitido en situaciones puntuales elevar a la Marina Baja caudales procedentes de la misma demarcación Júcar, sin constituir por ello jurídicamente un trasvase, utilizando las infraestructuras del trasvase Tajo-Segura, 
incluidas las que gestiona la MCT. En puridad, la MCT ha contribuido activamente a paliar estos problemas de abastecimiento facilitando el transporte de recursos desde el embalse de Alarcón al Amadorio, a través de sus propias redes. Se trata por tanto de un ejemplo destacado de buena gobernanza y colaboración institucional entre la MCT, las autoridades ministeriales, los organismos de cuenca implicados, y el Consorcio de Aguas de la Marina Baja. 


\section{5.- LOS RECURSOS HIDRÁULICOS SUMINISTRADOS POR LA MANCOMUNIDAD EN LA PROVINCIA DE ALICANTE}

\section{1.- Integración de caudales de diversa naturaleza y procedencia en el sistema de la MCT.}

Los recursos disponibles, estructuralmente escasos en la zona de suministro, han condicionado el desarrollo histórico de la MCT. Tanto los Planes de Obras como el desarrollo de las infraestructuras han tratado de responder a una doble problemática: por un lado, la creciente demanda de municipios para incorporarse al sistema, y por otro, la insuficiencia de los recursos disponibles para atender dichas demandas. La evolución de las fuentes de suministro parte así de los exiguos caudales del río Taibilla, para ir enriqueciéndose con nuevas fuentes, que desembocan, como último hito, en la reciente incorporación de las aguas desalinizadas.

Precisamente, lo que caracteriza a la MCT, y la convierte además en un modelo prácticamente único de gobernanza de agua, es que para afrontar las demandas viene manejando casi desde sus orígenes caudales de las más diversas procedencias, incluyendo los superficiales, subterráneos, trasvasados, y procedentes de desalinización (Melgarejo et al., 2016). Los Planes de Obras y las infraestructuras básicas han sido concebidos y realizados precisamente con el objeto de dar entrada a los diferentes tipos de agua.

Primero fueron los aprovechamientos de agua superficial, desde el río Taibilla, afluente del Segura, una fuente limitada de recursos pero de buena calidad y en una cantidad inicialmente suficiente para el objeto originario de la MCT, el abastecimiento de Cartagena y su Base Militar. Estos recursos fueron complementados con caudales procedentes del Segura, ya en los años 60, ante la primera crisis de recursos que tuvo que afrontar el Organismo. Las demandas superaban la oferta disponible, y fue necesario ampliar el abanico de recursos disponibles.

Desde 1945, primer año que llegan las aguas del río Taibilla a Cartagena, el número de municipios o entidades abastecidas, la población suministrada y el consumo agregado en salida de depósito, crecieron significativamente; así, se pasó de una única entidad abastecida, con unos 45.000 habitantes, y un consumo de $1 \mathrm{hm}^{3} /$ año en 1945 , a 28 entidades, 500.000 habitantes, y $46 \mathrm{hm}^{3} /$ año en 1962.

A comienzos de los años 60, aún estaba pendiente de abastecer una población próxima a 250-300.000 habitantes, y además se estaba produciendo un importante desarrollo turístico, con notable repercusión sobre la demanda en los municipios costeros. El riesgo de la insuficiencia de recursos empezaba a vislumbrarse a corto plazo. Las demandas se situaron entre 60 y $65 \mathrm{hm}^{3}$, lo cual obligaba a tener en servicio el embalse de regulación 
(anual) en el río Taibilla, para intentar sostener con las aportaciones medias $\left(60-70 \mathrm{hm}^{3} /\right.$ año), y siempre que no fuese un año seco, las demandas previstas. Se evidenciaba que, de continuar la tendencia de incremento de los consumos, no solo el gran problema sería la disponibilidad de agua, sino también que las capacidades de las conducciones serían insuficientes; un Nuevo Plan de Obras, ampliando las existentes, debía ponerse en marcha. El Plan General (1930) proponía el abastecimiento de 41 municipios, mientras que los abastecidos por el Plan Antiguo, a su terminación, eran 58. Aún siendo mayor el número de municipios abastecidos, el área geográfica dominada por la Mancomunidad era sensiblemente la misma (Nieto Llobet, 2013).

En definitiva, se convirtió en perentoria la construcción del embalse de regulación a la entrada del Estrecho del Aire, así como conseguir la asignación de nuevos recursos hídricos que complementasen los del río Taibilla. Durante el verano de 1962 hubo restricciones en el suministro, habida cuenta los reducidos caudales de estiaje que se dieron en el río. Con urgencia, se autorizaron obras provisionales de captación en el río Segura, en Ojós, y la consecuente planta de tratamiento de Sierra de la Espada para potabilizar la mezcla de las aguas del Segura con las del Taibilla.

La Orden Ministerial de 8 de noviembre de 1961 evalúa las necesidades y planes de obra tanto de los abastecimientos como de la ordenación de los regadíos de la cuenca del Segura, con la misión de redactar un Anteproyecto que recogiese las obras necesarias, así como su financiación y reajuste de concesiones de aguas públicas. Se pretendía con ello reconducir lo establecido en el Decreto y Orden Ministerial de 25 de abril de 1953, que había distribuido los recursos hídricos de la cuenca regulados por los embalses del Cenajo y Camarillas exclusivamente para riegos, ignorando las futuras necesidades de los abastecimientos. A finales de 1962 se puso en marcha la "solución provisional de abastecimiento en estiaje de la MCT", para suprimir las restricciones que se venían produciendo durante los últimos veranos por la escasez de las aportaciones del río Taibilla. Suponía la toma de agua del río Segura en Ojós y la construcción de la ETAP de Sierra de la Espada.

La autorización para tomar agua del Segura se estableció sobre la base de la resolución del Ministerio de Obras Públicas de 4 de marzo de 1963, corregida por otra de 12 de abril de 1966 que, con carácter provisional, permitía aumentar a la MCT la toma de agua del río en el equivalente al volumen medio de aguas residuales que eran vertidas al río Segura o cauces de regadío (Ezcurra, 2002).

Las aportaciones de recursos propios del Segura a los embalses de cabecera de la cuenca han experimentado una reducción muy importante en los últimos años. En los primeros 50 años hidrológicos de los que se tiene información histórica documentada en la Confederación Hidrográfica del Segura, 1931-1980, la aportación media de recursos 
hídricos propios a los embalses de cabecera superaba los $570 \mathrm{hm}^{3}$; pero, por contra, entre 1981-2000 se limitaron a unos $314 \mathrm{hm}^{3}$, cuando sólo la demanda de agua estricta de las concesiones de riego del río Segura vigentes llegaba a los $380 \mathrm{hm}^{3}$. De haber continuado la MCT tomando agua de recursos propios del Segura, se hubiese originado una situación muy difícil de sostener a partir de 1980. El trasvase Tajo-Segura será la solución a este problema, dotando de recursos adicionales a la MCT para completar los suyos propios, lo que permitirá no padecer restricciones de agua potable; como valor indicativo, en los últimos 35 años la MCT ha consumido de media casi $114 \mathrm{hm}^{3} /$ anuales de agua del Trasvase, mientras que las aportaciones de recursos propios del Segura a los embalses de cabecera de la cuenca han tenido una reducción muy importante (Ezcurra 2002).

El Anteproyecto del trasvase Tajo-Segura salió a exposición pública en 1968, personándose la Mancomunidad en el proceso, solicitando la reserva de $144 \mathrm{hm}^{3}$ anuales, en función de los cálculos que se habían realizado en el Plan Nacional de Abastecimientos, que tenía como horizonte 1985 (CEMCT, 16/4/1968). Las aguas del trasvase Tajo-Segura proceden de los pantanos de la cabecera del Tajo, Entrepeñas y Buendía.

La dotación asignada a los abastecimientos, en la distribución que se hace de los 600 $\mathrm{hm}^{3} /$ año de la 1a Fase del Trasvase, alcanza $110 \mathrm{hm}^{3} /$ año, al estimar unas pérdidas en transporte y distribución del 15\%. La inicial petición de 155 hm³/año, se redujo al verse incrementados los volúmenes destinados a regadíos. Posteriormente, una valoración más real de pérdidas, del 10\%, posibilitó asignar $15 \mathrm{hm}^{3} / \mathrm{año}$ a la provincia de Almería. Por tanto, el volumen final resultante para los abastecimientos, (pérdidas estimadas del $10 \%$ ), fue de $125 \mathrm{hm}^{3} /$ año, al restar a $540 \mathrm{hm}^{3}$ netos, 400 destinados a regadío y 15 para la provincia de Almería (Nieto Llobet, 2014).

El Centro de Estudios Hidrográficos (CEH), elaboró en abril de 1988 el "Estudio de Determinación de pérdidas de agua en el trasvase Tajo-Segura", que obtuvo unas pérdidas a considerar próximas al $10 \%$ en toda la conducción del Trasvase desde origen hasta las tomas en los canales principales (Ezcurra, 2002). La Comisión Central de Explotación del trasvase Tajo-Segura decidió en 1988 que el 70\% de los recursos imputados a menores pérdidas se adjudicaran a la MCT, lo que representaba un volumen aproximado de $14 \mathrm{hm}^{3}$ / año (CEMCT, 19/7/1988). En 2001, el Centro de Estudios y Experimentación de Obras Públicas (CEDEX), a través del CEH, elaboró un informe técnico sobre la "Estimación actualizada de las pérdidas de agua en el Trasvase Tajo-Segura", que en sus conclusiones recogía: "que todas las medias móviles de los últimos quinquenios, indican porcentajes de pérdidas ligeramente inferiores al 10\%, tal como se había estimado en el informe anterior" (Ezcurra, 2002). 
En 1977, el Delegado del Gobierno y Presidente del Comité Ejecutivo de la MCT informaba de la grave situación y de las restricciones que se podían producir en caso de que se paralizara o retrasara la ejecución de las obras del Trasvase: "desde hace cinco años, y dado el déficit de recursos existentes, la MCT ha venido adquiriendo caudales procedentes de pozos que, por su elevada salinidad, han ido deteriorando las características del agua suministrada a diversas poblaciones (...) además, se crearía una grave situación financiera al Organismo, ya que la falta de rentabilidad impediría hacer frente a los compromisos de amortización de las operaciones de crédito hasta el momento comprometidas" (CEMCT, 27/10/1977). Ante la eventual dilación de la llegada de las aguas del Trasvase, la MCT licitó la adquisición de caudales procedentes de pozos con un precio máximo de $6 \mathrm{ptas} / \mathrm{m}^{3}$ y un volumen de $4 \mathrm{hm}^{3}$ (CEMCT 16/2/1978). De todo ello se deduce la perentoria necesidad de nuevos recursos que mejoraran tanto la calidad del agua suministrada como la financiación del Sistema.

La aportación del Trasvase, a partir de 1979, permitió alcanzar la suficiencia de nuevo en las dotaciones de abastecimiento de los municipios ya dependientes de la MCT, y permitió su ampliación a otras áreas deficitarias y en crecimiento del Sureste de España; en particular, estos aportes permitieron consolidar los suministros de localidades como Torrevieja en 1972, adscrita a la MCT unos años antes, y con un crecimiento turístico que de otra manera, sin dichos recursos, hubiera sido imposible.

No obstante, en la década de los setenta no resultaba previsible el extraordinario crecimiento que tendrían en los años siguientes las principales ciudades abastecidas (Murcia, Alicante, Elche, Cartagena), así como la franja litoral (Torrevieja, Orihuela, Santa Pola, Guardamar, entre otros). Las previsiones quedaron claramente desbordadas y la competencia por el control de las aguas del trasvase comenzó a ser cada vez más acusada. En la Memoria anual de 1986 ya se advertía de esta circunstancia, llamando la atención sobre la necesidad de obtener recursos adicionales a los del Taibilla y del Trasvase.

Pese a la llegada de los caudales del trasvase Tajo-Segura, el fantasma de la escasez, agravado por la sequía que se produjo en los primeros años 80, tanto en la cuenca del Segura como en la Cabecera del Tajo, llevó a que la MCT tuviera que adoptar medidas de carácter restrictivo desde comienzos del verano de 1983, con cortes nocturnos y reducción de presiones en la red que permitieron un ahorro próximo al 15\% respecto al año anterior. Esto supuso la petición de recursos adicionales del Trasvase para cubrir las necesidades de ese año (CEMCT 22/9/1983). Un año después, en 1984, se llegó a declarar la "alerta azul" (restricciones imperativas, a diferencia de la "alerta verde", que supone restricciones voluntarias) en la zona abastecida por la MCT, y al mismo tiempo se aprobó un plan de restricciones con el fin de conseguir un ahorro en el consumo de agua del $30 \%$. Entre las medidas que se adoptaron fueron cortes diarios entre las 19:00 y las 7:00 horas (CEMCT 28/2/1984). 
Dada esta experiencia, la MCT definió un protocolo de actuación que fue muy útil para la gestión del recurso. Es relativamente fácil conseguir ahorros en el consumo del $10 \%$ con campañas adecuadas de concienciación a la población sobre vigilancia y cuidado en el uso del agua. Los cortes nocturnos en el suministro, perturban escasamente a las poblaciones, permiten disminuir presiones en redes, pérdidas o fugas, añaden entre un 5 y un $7 \%$ al ahorro anterior; cortes de 8 horas (de 23 a 7 horas) en las poblaciones pueden suponer un ahorro conjunto entre el 15 y el 17\%. Para obtener ahorros de un $25 \%$ es imprescindible cortar a media tarde, a las 19:00 horas, y mantener desabastecida la red durante 12 horas, lo que produce trastornos reales sobre la población, creando problemas que hay que resolver mediante cortes alternativos por razones o medidas selectivas de suministro. Este último escenario se produjo durante muy escaso tiempo (CEMCT 22/6/1984).

En el inicio de la década de los 90, la sequía provocó una mayor disminución de los aportes del Taibilla, que pasa de suministrar 72,5 hm en 1990 a tan solo $50 \mathrm{hm}^{3}$ en 1996 . Esta merma se compensó con caudales adicionales del Tajo, la apertura de pozos de sequía, y el aporte de recursos propios de algunos Ayuntamientos mediante adquisiciones de agua o utilización de reservas de agua subterránea. Esta situación se mantuvo sin cambios sustanciales hasta el año 2000 (Morales, 2002).

En los últimos años el abanico de recursos disponibles se ha incrementado con la incorporación de las aguas de mar desalinizadas, actividad que se inicia a partir de 2003. La provincia de Alicante adquiere un gran protagonismo en este campo, puesto que es la dasalinizadora del Canal (Alicante I) la primera en aportar este tipo de caudales al balance hídrico de la MCT. A partir de ese momento, y con el impulso del programa A.G.U.A, esta nueva fuente de recursos ha contribuido a garantizar las demandas en un contexto, además, en el que las aportaciones tradicionales del Taibilla se han reducido, y las tensiones sobre la continuidad del trasvase Tajo-Segura han sido continuas.

En el periodo 1998-2005, el consumo global en el ámbito de la MCT evolucionó con valores acordes con las previsiones del Plan Hidrológico de la Cuenca del Segura (Real Decreto 1664/1998, de 24 de julio), en el que evaluaron las demandas para un primer horizonte (10 años) y un segundo horizonte (20 años). Desde 1999, en que comienza un periodo de aportaciones mínimas históricas del río Taibilla, el balance demanda-recursos asignados fue claramente deficitario y requirió la aportación de recursos extraordinarios por parte de las Confederaciones Hidrográficas del Segura y del Júcar. La MCT reclamó a la Confederación Hidrográfica del Júcar que asumiera la responsabilidad del suministro a los municipios alicantinos que geográfica y administrativamente pertenecen a su cuenca y que, históricamente, no sufren restricciones al consumir agua del Tajo-Segura. Se reclamó que desde el Júcar se aportaran todos los años entre 15 y $20 \mathrm{hm}^{3}$ para completar el abastecimiento de Alicante, Elche, Santa Pola, Crevillente, San Vicente del Raspéig, Aspe, y Hondón de las Nieves, cuya población se aproxima al millón de personas. 
El programa A.G.U.A. derivado de la promulgación del Real Decreto Ley 2/2004, de 18 de junio, por el que se modifica la Ley 10/2001 del Plan Hidrológico Nacional, que en su Anexo IV incluye un grupo de "actuaciones prioritarias y urgentes", es el origen de un ambicioso programa de inversiones del Organismo para el incremento de caudales (plantas desalinizadoras) y mejora de su gestión (conexión de plantas desalinizadoras a canales principales y centros de demanda, entre otras). Su ejecución preveía el empleo de volúmenes crecientes de agua desalinizada ( $116 \mathrm{hm}^{3}$ anuales desde finales de 2007), que contribuirían a eliminar a partir del año hidrológico 2006/2007 el déficit de agua, garantizando, junto a los recursos del río Taibilla y del trasvase Tajo-Segura, el suministro a corto y medio plazo de la zona geográfica abastecida.

Varios municipios complementan con aguas propias los suministros del Organismo, destacando Murcia (toma del río Segura en la Contraparada), Elche y Alicante (agua procedente del acuífero de Villena). La demanda global requirió en 2005 un volumen de agua de $238,3 \mathrm{hm}^{3}$, de los que 227,3 correspondían al Organismo y 11,0 a recursos propios municipales.

La extraordinaria sequía del río Taibilla en 2005, con aportaciones de $39 \mathrm{hm}^{3}$, prácticamente iguales al mínimo histórico correspondiente al año $\left.2008(36 \mathrm{hm})^{3}\right)$, y el moderado incremento de la demanda, elevaron hasta $63,5 \mathrm{hm}^{3}$ las necesidades de recursos hídricos adicionales para atenderla, lo que fue resuelto mediante $21,8 \mathrm{hm}^{3}$ procedentes de la desalinización (Alicante I y parcialmente San Pedro del Pinatar I), y $41,7 \mathrm{hm}^{3}$ procedentes de recursos extraordinarios, esencialmente, de las cuencas del Segura (pozos de reserva del Sinclinal de Calasparra) y Júcar (embalse de Alarcón).

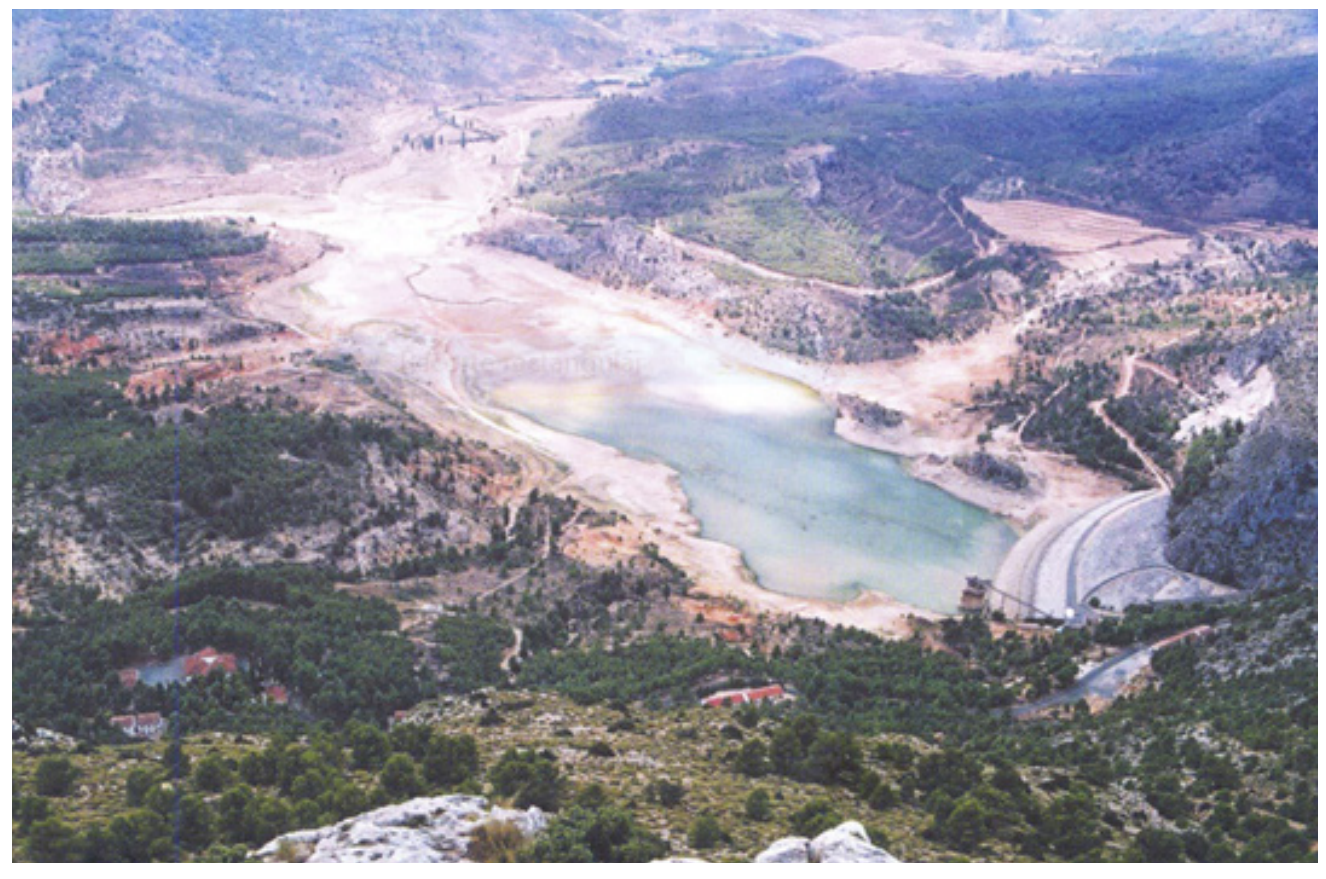

Fig 50. Situación del Embalse del Taibilla a 3 de septiembre de 2003 (Nerpio) [Memoria MCT, 2003.] 
Ante el nuevo período de extraordinaria sequía en las cuencas hidrográficas conectadas con nuestro sistema hidráulico, el correspondiente déficit recursos, y la obligación establecida en la Ley 10/2001, del Plan Hidrológico Nacional, de disponer de un Plan de Emergencia ante situaciones de sequía, que debía estar elaborado en julio de 2003, se elaboró un Protocolo ante Situaciones de Sequía, entretanto se elaboraran los Planes Especiales de las cuencas del Segura y del Júcar. El Protocolo consideraba un Sistema Global de Explotación y el Subsistema de Explotación "TAIBILLA", constituido por los 20 municipios solamente abastecidos con aguas del río Taibilla.

La situación de alerta de sequía de 2006 motivó la aplicación de las medidas contempladas en el Protocolo ante situaciones de sequía de la MCT. En su desarrollo se adoptaron las siguientes medidas excepcionales (Memoria MCT, 2006):

a. Contrato de cesión inter-cuencas (MCT-CR. Canal de las Aves, 35,5hm³).

b. Cesión de derechos intracuenca (MCT-CCRR de Hellín y Moratalla, 1,2hm³).

c. Aportación de 7,5 hm³ del Río Júcar (Embalse de Alarcón) para completar el abastecimiento de Alicante, Santa Pola, San Vicente del Raspeig, Aspe y Hondón de las Nieves.

d. 22,1 $\mathrm{hm}^{3}$ procedentes de acumulación de las campañas de extracción subterránea, durante $2006\left(13,1 \mathrm{hm}^{3}\right)$ y $2007\left(9 \mathrm{hm}^{3}\right)$, del Sinclinal de Calasparra.

e. Convenio de encomienda de gestión con la Confederación Hidrográfica del Segura, suscrito el 26 de diciembre de 2006, para la extracción de 13,8 $8 \mathrm{hm}^{3}$ de aguas subterráneas, procedentes del pozo "Collado de la Reina" y de 5 pozos más en Orihuela, que fueron explotados por la empresa Fejima S.A., por 326.618 euros (CEMCT, 11/12/2007).

La sequía, junto a la paralización del trasvase del Ebro, contemplado en el PHN, conllevó que se aprobara mediante resolución de 17 de febrero de 2005 la ejecución por emergencia de la desalinizadora de San Pedro del Pinatar II, así como la tramitación de urgencia de todas las actuaciones gestionadas por la Mancomunidad contempladas en el Programa A.G.U.A., y la formulación durante el año de todas sus Declaraciones de Impacto Ambiental.

El elevado coste de producción de las aguas desalinizadas ha repercutido directamente sobre las tarifas que la MCT cobra a los distintos operadores en baja; de ahí que, en la medida de lo posible, debido a la existencia de recursos más económicos, y atendiendo al comportamiento meteorológico e hidrológico dentro del ámbito de actuación de la MCT, la producción de estos recursos se ha limitado a la estrictamente necesaria para garantizar el correcto mantenimiento de las instalaciones. 
En el balance hídrico de la MCT son también importantes las aportaciones recursos de origen subterráneo, cuyas concesiones tienen algunos ayuntamientos, quienes en ocasiones los ceden a la MCT; de especial importancia son los recursos procedentes del acuífero del Sinclinal de Calasparra (río Segura), que se utiliza en momentos de sequía o necesidad, como "aportes extraordinarios". La Mancomunidad ha solicitado en varios años la explotación de dichos pozos para atender los abastecimientos con carácter excepcional (CEMCT 25/7/2000).

Para garantizar la llegada de recursos a través del acueducto Tajo-Segura, la MCT ha utilizado los contratos de cesión de derechos de aprovechamiento, figura incorporada en la reforma de la Ley de Aguas de 1985, mediante Ley 46/1999, y que aparece ahora en los artículos 67 y siguientes del texto refundido de 2001 (Melgarejo et al., 2005). La MCT ha realizado contratos de cesión con regantes de Castilla-La Mancha, así como con usuarios del propio territorio de la cuenca del Segura. Con ello se han constituido reservas estratégicas de agua con el objeto de evitar medidas drásticas de reducción de volúmenes de agua a los municipios y entidades mancomunadas.

Puntualmente, se han movilizado caudales desde la cuenca del Júcar, y más en concreto, desde la presa de Alarcón, para canalizar volúmenes a través de las instalaciones del acueducto Tajo-Segura con destino a los suministros alicantinos de la demarcación del Júcar integrados en la MCT. No se trata, por tanto, de trasvases entre las demarcaciones Júcar y Segura, lo que sólo sería posible si así lo permitiera el Plan Hidrológico Nacional, sino cesiones entre sistemas de explotación de la misma demarcación: Júcar.

En resumen, la MCT organiza el suministro a partir de los siguientes recursos:

a. RIO TAIBILLA: Fuente original, de elevada calidad, y cantidad suficiente para las demandas existentes a principios del siglo XX. Estos recursos permitieron la creación de la MCT y el abastecimiento de los primeros núcleos, en particular, Cartagena y su Base Naval. Las aportaciones totales anuales del río Taibilla, son muy variables, y presentan un mínimo histórico de $36 \mathrm{hm}^{3}$ en el año hidrológico 2007/2008, y un máximo de 99 hm³ en 1973.

b. RIO SEGURA: Los recursos procedentes del río permiten superar en los años 60 la primera crisis de suministro que afronta la MCT, como consecuencia del incremento de las demandas, muy por encima de los recursos disponibles.

c. RECURSOS EXTRAORDINARIOS. En situaciones de escasez, donde el resto de recursos disponibles no son suficientes para atender las necesidades del sistema, la MCT ha acudido a recursos subterráneos de diferente tipología y procedencia en la cuenca del Segura, destacando los recursos obtenidos del Sinclinal de Calasparra. 
d. TRASVASE TAJO-SEGURA. Entra en funcionamiento en 1979 y permitió superar la segunda gran crisis de suministro, derivada de la incorporación de nuevos municipios y del incremento de la población, de la actividad económica, y sobre todo, del extraordinario desarrollo del turismo.

e. AGUAS PROPIAS DE MUNICIPIOS MANCOMUNADOS: Se cuenta con aguas subterráneas propias de los municipios prácticamente desde los primeros tiempos de la MCT. Son, sin embargo, muy poco relevantes en términos cuantitativos en el conjunto del Sistema. Funcionan como un complemento en poblaciones concretas. En la actualidad son varios los municipios que aportan aguas propias, destacando Murcia (toma del río Segura en la Contraparada), Elche y Alicante (aguas procedentes del acuífero de Villena). La última información disponible, obtenida de la Memoria 2013 de la MCT, confirma que parte de la demanda total ha sido cubierta con recursos propios de los Ayuntamientos de Alicante $\left(5,1 \mathrm{hm}^{3}\right)$ y Elche $\left(2,2 \mathrm{hm}^{3}\right)$ principalmente. Estas cifras dependen de la pluviometría de cada año hidrológico, que exige contar con las diferentes fuentes de aprovisionamiento en cantidad variable para mantener la regularidad del abastecimiento.

f. MERCADOS DE AGUA. Estos recursos, procedentes de contratos de cesión suscritos con regantes de la cuenca del Tajo, aportaron alrededor de $36 \mathrm{hm}^{3} /$ año durante la pasada sequía (2005-2009).

g. DESALINIZACIÓN: Estos recursos no convencionales entran en el sistema de la MCT en el año 2003, con la inauguración de la desalinizadora del Canal de Alicante. El Comité Ejecutivo de la MCT, desde muy pronto, expresaba la conveniencia de contar con este tipo de recursos: "la razón fundamental de la construcción de las desalinizadoras era la de garantizar los abastecimientos en época de sequía, tan frecuente en el Sureste español”. Se pretendía asegurar los suministros y sus ampliaciones, así como garantizar los desarrollos turísticos (CEMCT 21/11/1996). A partir de la construcción de las primeras desalinizadoras se modifica el modelo de suministro tradicional basado en fuentes convencionales y se incorpora, por tanto, la desalinización y los mercados de agua. Ese cambio de modelo vino precedido por un fuerte incremento del consumo de agua potable provocado por la expansión de nuevas áreas de uso urbano-turísticas propiciadas por el boom inmobiliario (Morote, 2014). Debido a la intensa sequía de 2005-2009, las fuentes de agua convencionales llegaron al límite de su capacidad de oferta, lo que favoreció la incorporación de la desalinización de agua marina al sistema global de suministro de la MCT, incluyendo los recursos adquiridos a través de los mercados de agua a regantes de la cuenca Tajo (Rico, 2014). Desde entonces, se han aportado recursos de buena calidad y en cantidad cada vez más significativa. 
En la tabla 04 se muestran las desalinizadoras propias de la MCT, así como las que gestiona AQUAMED, incluidos los datos de producción máxima anual en $\mathrm{hm}^{3}$ :

\begin{tabular}{|c|c|c|c|}
\hline \multicolumn{2}{|c|}{ Instalaciones de la MCT } & \multicolumn{2}{|c|}{ Instalaciones de AQUAMED } \\
\hline Alicante I (concesión) & 21 & Valdelentisco & 20 \\
\hline $\begin{array}{c}\text { Antonio León. San Pedro del Pinatar I } \\
\text { (concesión) }\end{array}$ & 24 & Torrevieja & 80 \\
\hline San Pedro del Pinatar II & 24 & Águilas & 10 \\
\hline Alicante II & 24 & & \\
\hline Total & $\mathbf{9 3}$ & Total & $\mathbf{7 0}$ \\
\hline
\end{tabular}

Tabla 04. Producción máxima anual de las desalinizadoras que aportan caudales a la MCT [MCT. Elaboración propia.]

Entre los años 2003 y 2008 la entidad construyó dos desalinizadoras en San Pedro del Pinatar y otras dos en Alicante, que suman una capacidad total de producción de $96 \mathrm{hm}^{3} /$ año (en el caso de que plantas funcionaran a pleno rendimiento). A pesar de ello, a partir de 2005, con la ejecución del plan de desalinizadoras del Programa A.G.U.A. (Rico, 2010; Swyngedouw, 2013; March et al., 2014), el Organismo ha suscrito tres convenios con Acuamed para aprovechar otros $70 \mathrm{hm}^{3} /$ año proporcionados por las plantas de Valdelentisco, Águilas y Torrevieja. Entre ellos, el convenio de Torrevieja supone un caudal máximo de $40 \mathrm{hm}^{3} /$ año (CEMCT 14/7/2006). En suma, el sistema global de suministro de la MCT podría llegar a disponer de unos $160 \mathrm{hm}^{3} /$ año de aguas desalinizadas.

Las desalinizadoras están distribuidas por todo el territorio suministrado por la MCT, y pueden conectarse a las canalizaciones del sistema para garantizar la distribución de los caudales generados, mezclándolos con el resto de los recursos del Sistema. Esta circunstancia puede contribuir a que los costes finales de suministro diluyan en parte los importantes gastos que comporta la producción de este tipo de aguas. En la figura 51 se aprecian las previsiones existentes para ordenar la producción, transporte, almacenamiento y posterior consumo de estos caudales. 


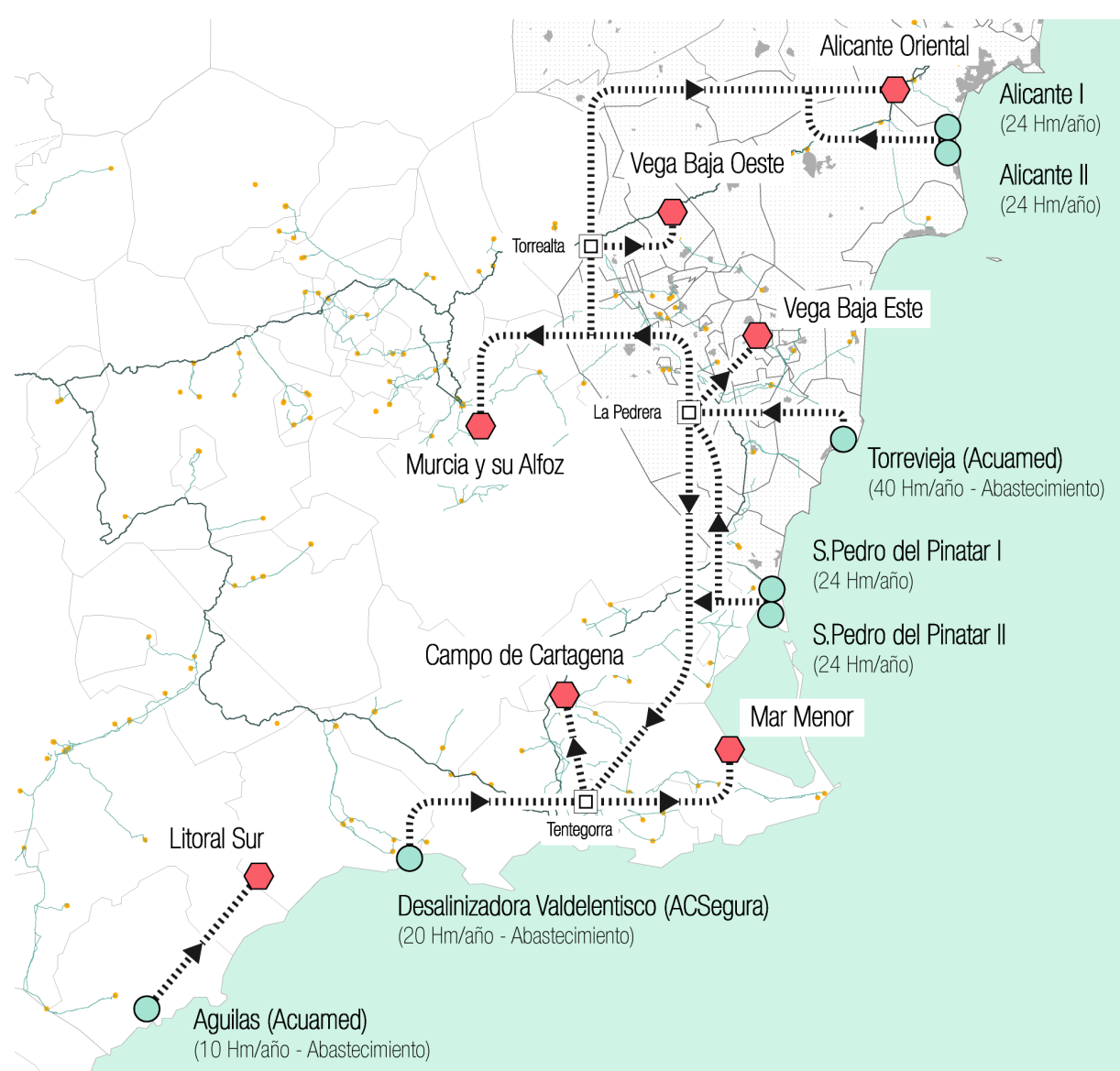

Fig 51. Esquema previsto producción-consumo [MCT. Elaboración propia.]

En las gráficas que siguen a continuación se observa la evolución de los recursos utilizados por la MCT, según su procedencia, entre 1975 y 2015, con una cadencia temporal de cinco años. Permiten claramente observar el cambio en las pautas de oferta, con unos recursos del Taibilla que evolucionan en sentido decreciente tanto en términos absolutos como relativos, unos aportes más estables del trasvase Tajo-Segura, una aportación discontinua tanto de recursos subterráneos de emergencia como propios de algunos municipios, y la irrupción cada vez más importante de las aguas desaladas. 


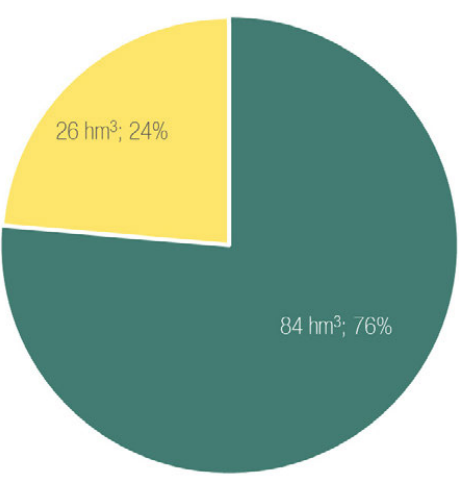

1975

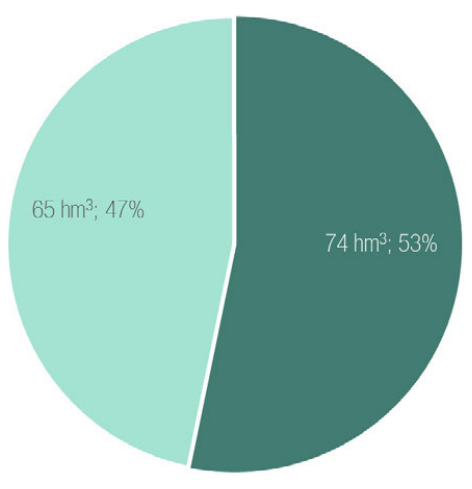

1990

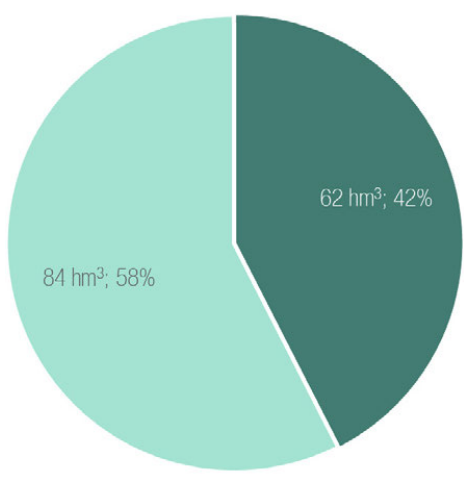

2005

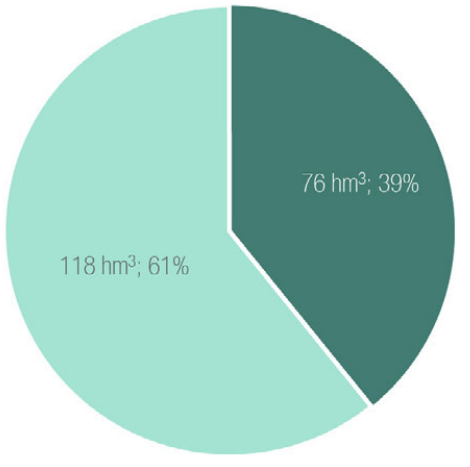

1980

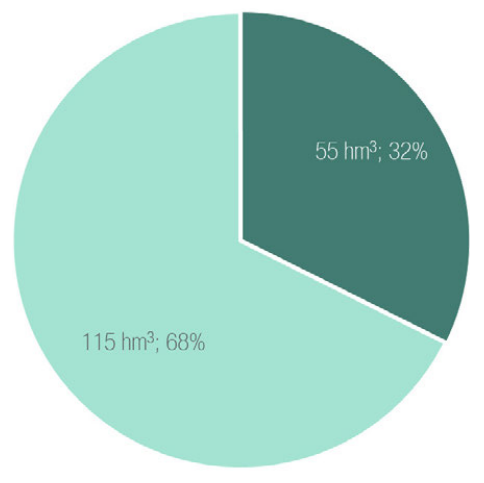

1995

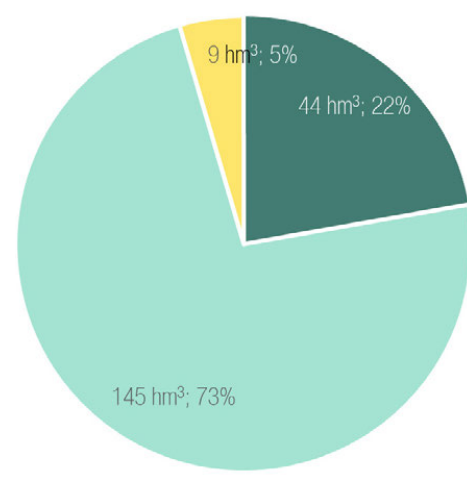

2010

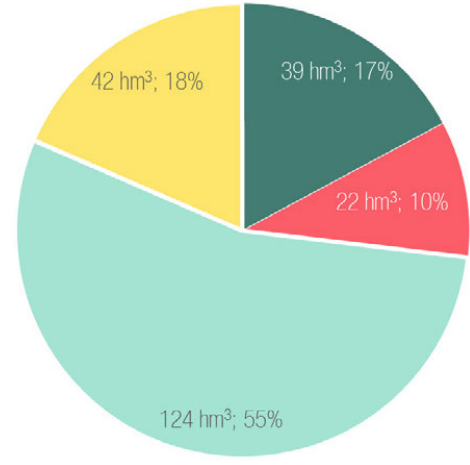

1985

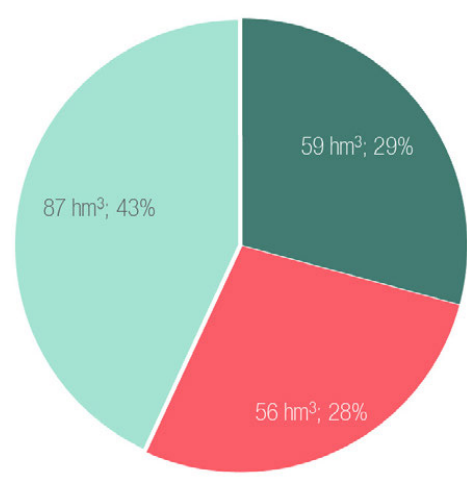

2000

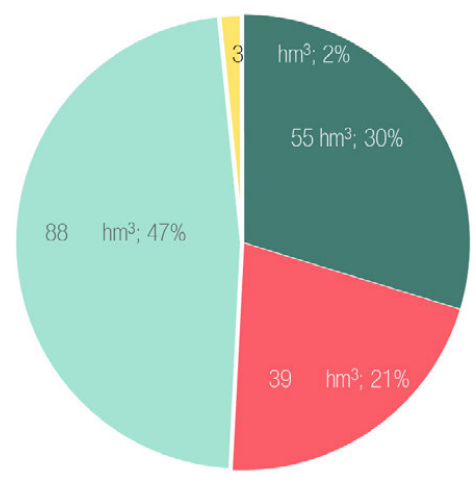

2015

Fig 52. Procedencia de los recursos suministrados por la MCT en diferentes años [MCT. Elaboración propia.]

Taibilla

Desalinización

Trasvase

Extraordinarios 
De todos los recursos disponibles en el sistema de la MCT, el mayor aporte, actualmente, sigue correspondiéndose con los caudales procedentes del Trasvase Tajo-Segura, que ofrece más del $50 \%$ del total disponible. Su continuidad, por tanto, es imprescindible para la sostenibilididad del sistema y de los abastecimientos vinculados al mismo. Los recursos aportados por el Trasvase, no obstante, se han reducido significativamente con respecto a los que se llegaron a trasvasar en la primera década de 2000, que superaban los $120 \mathrm{hm}^{3}$ anuales. En la actualidad, los recursos aportados por el ATS, con datos de 2015, se sitúan en $84 \mathrm{hm}^{3} /$ año, número similar al existente en 1985. Esto es debido, sin duda, a la progresiva mayor aportación de recursos procedentes de la desalación, que en 2015 ascendieron a $39 \mathrm{hm}^{3}$.

También es constatable la constante reducción tanto en términos absolutos como relativos de los recursos procedentes del Taibilla. Los recursos subterráneos del sinclinal de Calasparra, que se utilizan para afrontar situaciones de sequía, son también significativos desde 1998. La siguiente figura permite considerar el conjunto de fuentes de suministro y su evolución en un marco temporal más amplio.

El Plan hidrológico de la demarcación del Segura (2015-2021), establece una previsión de asignación de recursos para usos y demandas actuales y futuras, para abastecimiento, servicios e industrias conectadas a redes municipales, que se corresponde con los siguientes escenarios: a) la totalidad de los recursos propios del río Taibilla, estimados en $35 \mathrm{hm}^{3} /$ año medios interanuales hasta la presa de toma, y $14 \mathrm{hm}^{3} /$ año entre la presa de toma y el río Segura, b) volumen máximo de recursos desalados de $45 \mathrm{hm}^{3} /$ año procedentes de las desalinizadoras de Alicante I y II, $48 \mathrm{hm}^{3} /$ año procedentes de San Pedro de Pinatar I y II. Adicionalmente, se asignan los volúmenes convenidos con la Mancomunidad que sean generados para el abastecimiento de dichos municipios en las desalinizadoras de Valdelentisco, Torrevieja y Águilas-Acuamed, c) Volumen máximo en destino de 110 hm³/ año procedentes del Trasvase Tajo-Segura.

Las demandas de agua potable, en cambio, no se han incrementado como se preveía, y lejos de alcanzarse los $340 \mathrm{hm}^{3} /$ año previstos para la presente década, el volumen suministrado en alta por la Mancomunidad de los Canales del Taibilla, por ejemplo, en el año 2013 fue de $183 \mathrm{hm}^{3}$, frente a los $227 \mathrm{hm}^{3}$ distribuidos en 2005, lo que representa una reducción superior al $19 \%$. 


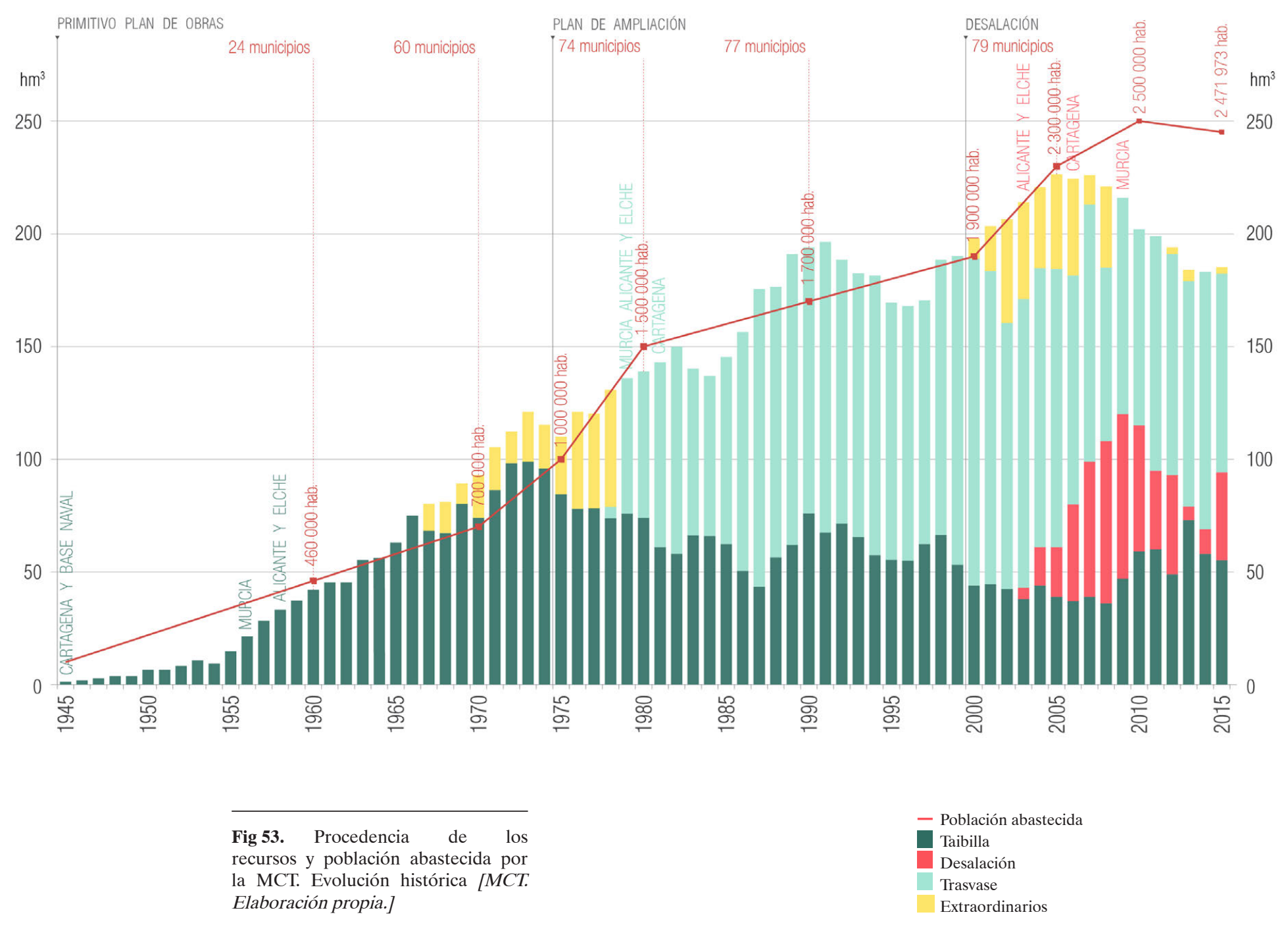




\section{2.- Caudales procedentes del río Taibilla.}

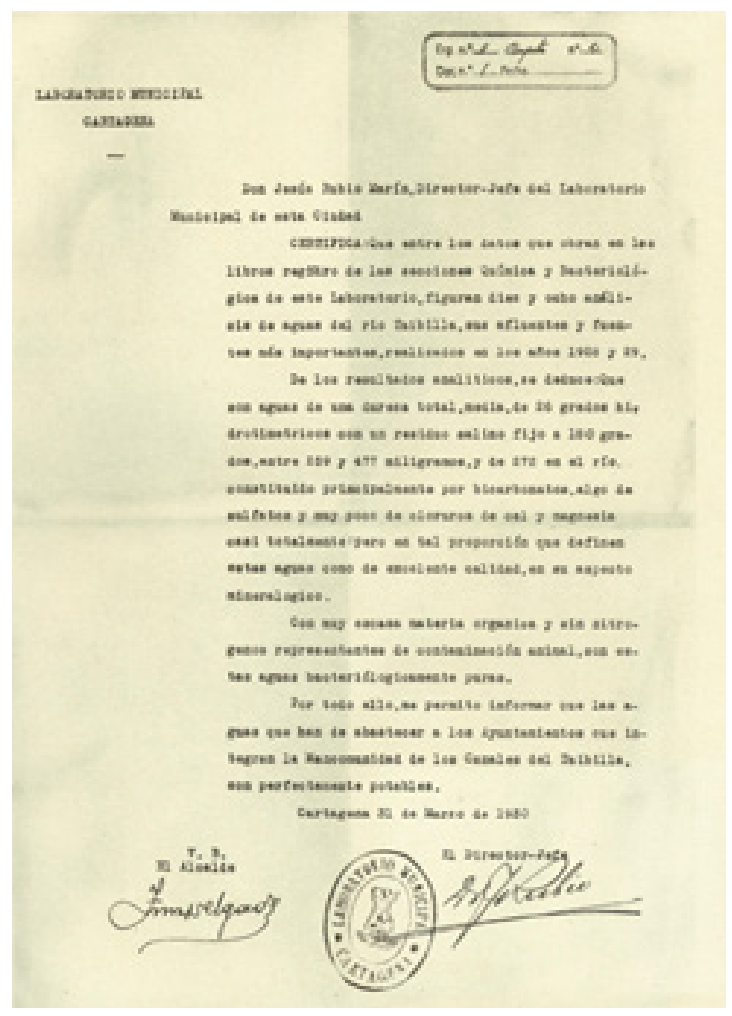

Fig 54. Certificación de calidad del agua del río Taibilla (1930) [Memoria MCT, 1945.]
La fuente originaria de recursos de la MCT son los caudales procedentes del río Taibilla, que sirvieron paragarantizar el suministro de Cartagena y su Base Naval, así como las primeras ampliaciones a municipios murcianos. Siguen en la actualidad siendo un aporte relevante en el conjunto de recursos disponibles del Sistema, aunque han venido reduciéndose en los últimos años como consecuencia de la sequía. Desde 1945 hasta 1964, el agua suministrada por la MCT procedía exclusivamente de esta fuente de elevada calidad, por su limpieza y aislamiento de la zona de captación, que sólo precisaba de un tratamiento de esterilización mediante cloro para asegurar su potabilidad.

En la figura 55 se observa cómo han evolucionado dichos caudales en la serie histórica que abarca el periodo 1945-2015, así como su posición relativa respecto del total de recursos suministrados.

La situación hidrológica de este río hace presumir que los aportes que pueda ofrecer en el futuro se situarán entre los 30 y los $50 \mathrm{hm}^{3} /$ anuales, debido a las presiones actuales que presenta y a los posibles efectos del cambio climático. 


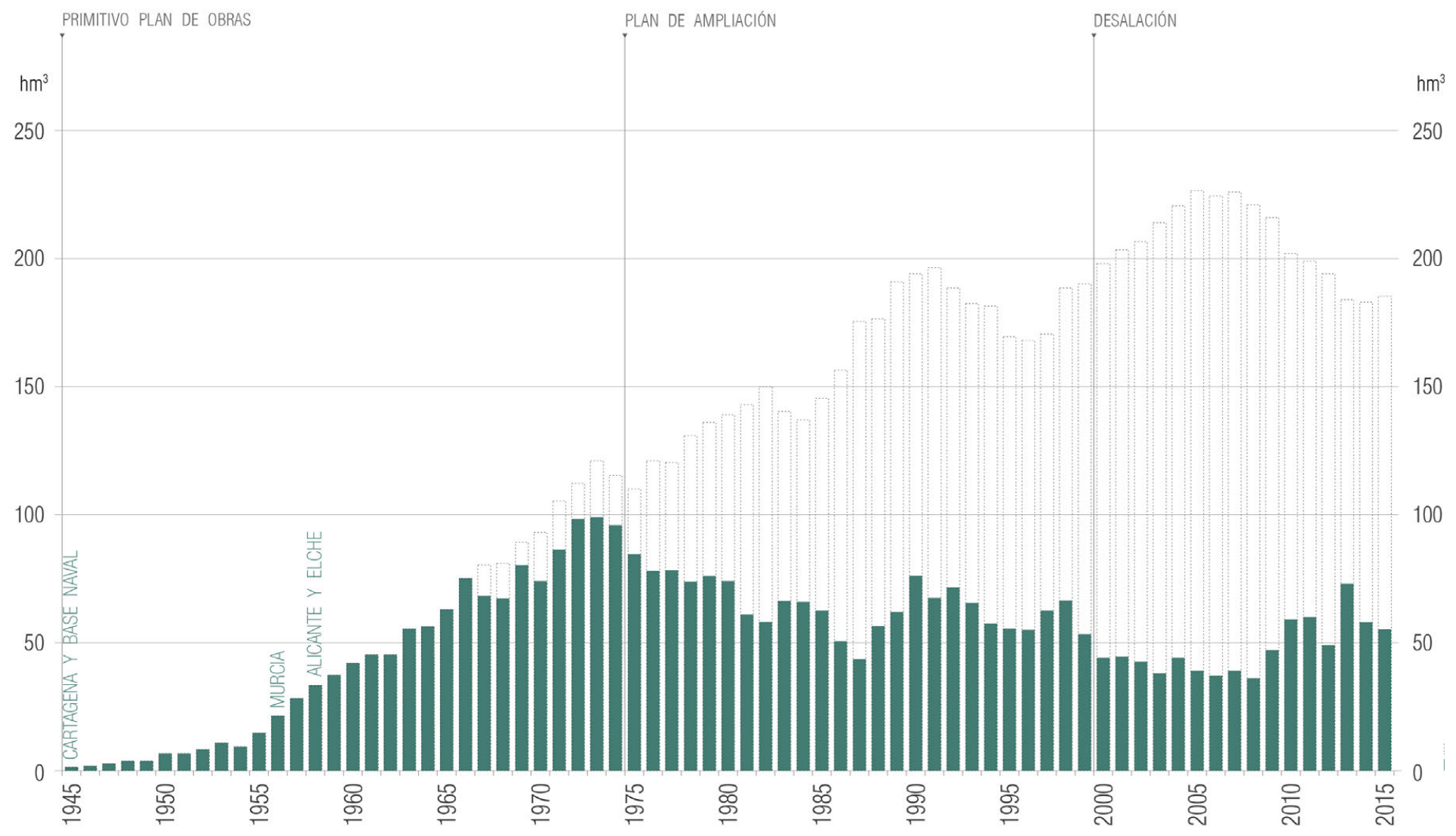

Fig 55. C a u d a 1 e $\mathrm{s}$ procedentes del río Taibilla y su posición relativa en el Taibilla

conjunto del sistema MCT [MCT. Elaboración propia] 


\section{3.- Caudales procedentes del trasvase Tajo Segura.}

El Acueducto Tajo-Segura es el resultado de una política de transformación agrícola de primer orden en el sudeste de España, que además ha permitido asegurar el suministro urbano a un conjunto de importantes municipios en continuo crecimiento (Melgarejo, et al., 2009; Melgarejo et al., 2010). Pasa por ser, en consecuencia, una de las obras hidráulicas europeas de mayor importancia, tanto para uso agrícola como urbano (Fanlo, 2008).

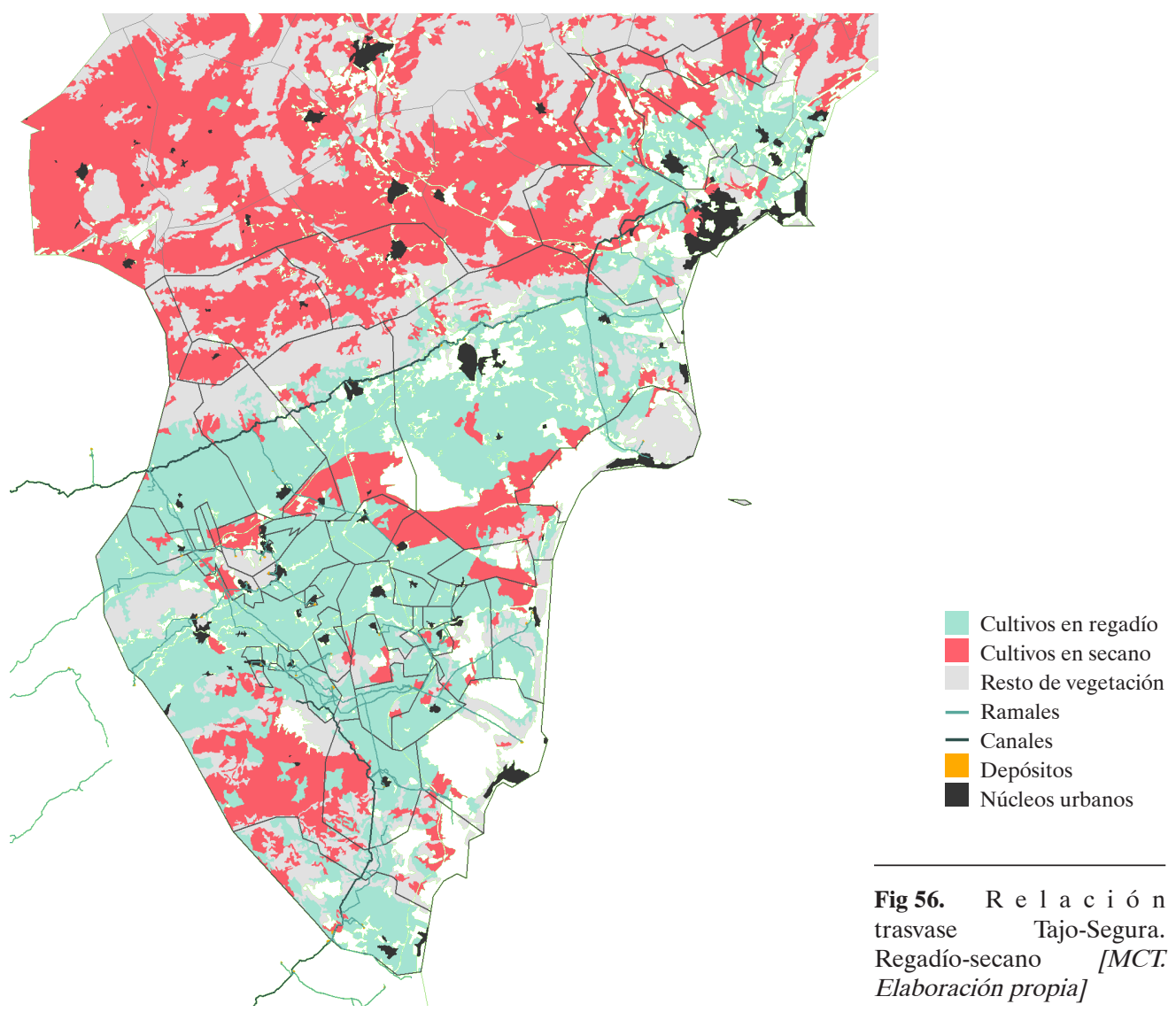


Se compone de un conjunto de infraestructuras que se sitúan a lo largo de un canal de 286 kilómetros de longitud, con capacidad para trasladar unos $33 \mathrm{~m}^{3} / \mathrm{s}$ desde el pantano de Bolarque $\left(35 \mathrm{hm}^{3}\right)$, situado en el curso del río Tajo, aguas abajo de los hiperembalses de Entrepeñas $\left(804 \mathrm{hm}^{3}\right)$, también sobre el Tajo, y Buendía $\left(1.638 \mathrm{hm}^{3}\right)$, sobre el Guadiela. Desde Bolarque, tras la impulsión de Altomira, el agua es depositada en el embalse de la Bujeda (884 m. de altitud), desde donde parte un canal hacia el hiperembalse de Alarcón, sobre el río Júcar. Desde allí, las aguas se conducen al embalse de Talave, en el río Mundo, principal afluente del Segura.
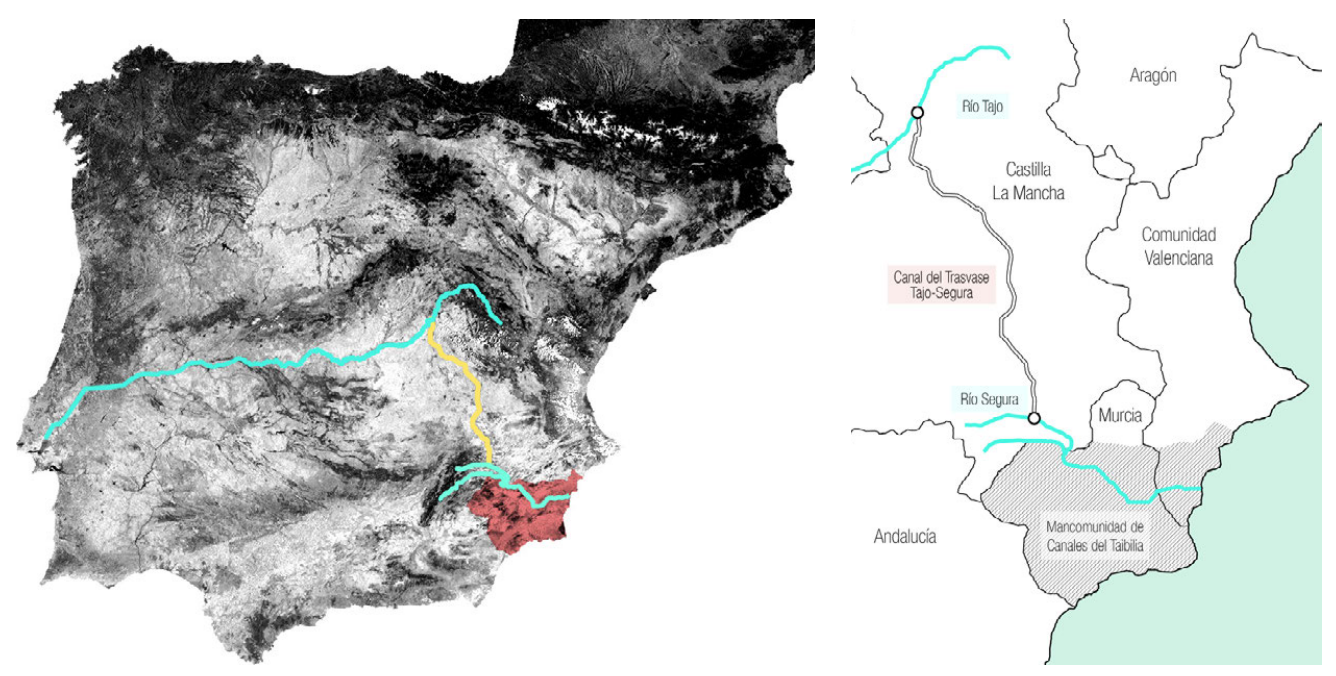

Fig 57. Mapas geofísicos cuencas del Tajo, Segura, acueducto y área de la MCT [Elaboración propia]

Fig 58. Trazado del trasvase Tajo-Segura y zona de influencia de la MCT [Elaboración propia]

Los caudales trasvasados, por tanto, circulan a través de tres demarcaciones hidrográficas distintas, una de origen, el Tajo, otra de tránsito, el Júcar, y otra de destino, la demarcación del Segura. El volumen total de caudal de agua enviado para regadíos y abastecimientos, entre los años 1979 y 2014, ha ido evolucionando con una cierta discontinuidad como se aprecia en la figura 59. 


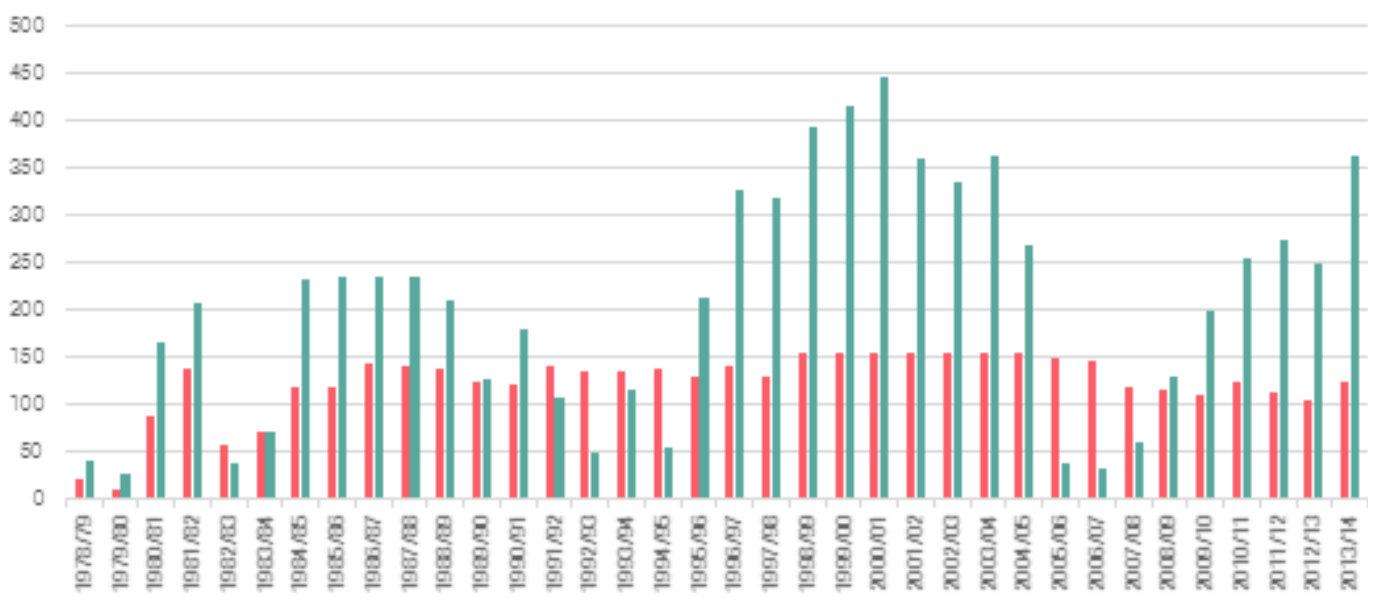

Fig 59. Destino del agua del Tajo-Segura (1979-2014) [Sindicato Central de Regantes del Acueducto Tajo-Segura. Elaboración propia.]

El agua destinada a abastecimiento, y por tanto entregada a la MCT, presenta no obstante una estabilidad relativa, siempre entre los 100 y los $150 \mathrm{hm}^{3} /$ año, salvo en el periodo 1978-1984. Las mayores discontinuidades se presentan en los caudales destinados a regadíos, que presentan al menos tres periodos de crecimiento que se alternan con otros tres de extraordinaria depresión. En algunos años, de hecho, los caudales destinados para este fin ni siquiera superaron los $50 \mathrm{hm}^{3} /$ año o lo hicieron muy ligeramente (2005-2008).

El Trasvase tiene unas sólidas bases normativas. Su disposición reguladora originaria, vigente en la actualidad, es la Ley 21/1971, de 19 de Junio, sobre el aprovechamiento conjunto Tajo-Segura, donde se recogió una dotación anual de $600 \mathrm{hm}^{3}$ para la primera fase del trasvase, que podía elevarse, en una segunda fase, hasta los $1000 \mathrm{hm}^{3}$. El régimen económico y financiero de la infraestructura, se ordena a través de la Ley 52/1980, de 16 de Octubre, de regulación del régimen económico de la explotación del acueducto TajoSegura (Melgarejo, 2010).

Este marco legal básico ha sido posteriormente desarrollado por algunas disposiciones legales que han adaptado su configuración inicial. Así, a finales de los años ochenta, la Ley 13/1987 de 17 de julio, de derivación de volúmenes de agua de la cuenca del Tajo, a través del Acueducto Tajo Segura, autorizó un volumen máximo de $60 \mathrm{hm}^{3}$ a distribuir en los tres años siguientes, con carácter experimental, con destino al Parque Nacional de las Tablas del Daimiel. Esta disposición, inicialmente de carácter temporal, se prorrogó hasta 1995 mediante dos Reales Decretos-leyes, y fue finalmente consolidada por el Real Decreto Ley 8/1995, que otorgó esta dotación con carácter permanente. 
Algunos Decretos, basados en la necesidad de afrontar situaciones de sequía, han venido estableciendo condiciones especiales para la explotación de la infraestructura, incluyendo trasvases extraordinarios, reducciones transitorias del caudal circulante en el Tajo, promoción de contratos de cesión, o la activación de la producción y suministro de caudales desalados, entre otras medidas. El artículo 58 del vigente Texto Refundido de la Ley de Aguas, aprobado por el Real Decreto Legislativo 1/2001, de 20 de julio, faculta al Gobierno para adoptar, mediante real decreto y en circunstancias de sequías extraordinarias, las medidas que sean precisas en relación con la utilización del dominio público hidráulico, aun cuando hubiese sido objeto de concesión, para la superación de circunstancias de necesidad, urgencia, anómalas o excepcionales (Melgarejo, 2009).

Recientemente, el gobierno tuvo que aprobar, ante la persistencia de la situación de sequía, el Real Decreto 356/2015, de 8 de mayo, por el que se declara la situación de sequía en el ámbito territorial de la Confederación Hidrográfica del Segura, y se adoptan medidas excepcionales para la gestión de los recursos hídricos, el cual ha sido prorrogado por el Real Decreto 817/2015, de 11 de septiembre, por el que se establecen los criterios de seguimiento y evaluación del estado de las aguas superficiales, y las normas de calidad ambiental.

Al margen de este funcionamiento excepcional, la Ley 10/2001 de 5 de julio, del Plan hidrológico Nacional, consideraba aguas excedentarias en la cabecera del Tajo las existencias embalsadas en el sistema Entrepeñas-Buendía que superen los $240 \mathrm{hm}^{3}$, y recogía el carácter preferente de los aprovechamientos de dicha Demarcación. La cuestión de las aguas excedentarias fue resuelta en el artículo 23 del Plan hidrológico del Tajo, aprobado mediante Real Decreto 1664/1998 de 24 de julio, que ha estado vigente hasta 2014. Este plan identificaba el umbral mínimo de no trasvase cuando las reservas en los embalses de Entrepeñas y Buendía no superaran los indicados $240 \mathrm{hm}^{3}$, y además definía las "condiciones hidrológicas excepcionales" a que se refiere el artículo 1 del Real Decreto 2530/1985.

La determinación de este umbral vino acompañada de la elaboración de la "Regla para la programación de Trasvases", aprobada por la Comisión Central de Explotación en 1997, que contribuyó a objetivar las decisiones de trasvase. Pese a la mejora que supuso la aplicación de estos criterios y sistema de gestión, las autorizaciones de trasvase no estuvieron exentas de litigiosidad y grandes presiones políticas.

Por otra parte, el PHN derogó el artículo segundo de la Ley 21/1971, actualizando así el mecanismo de regulación de los volúmenes del trasvase depositados en el embalse de Alarcón. Se establecieron para ello una serie de condiciones entre las que destaca la preferencia de las aguas del Júcar para ser embalsadas en el pantano, la garantía de que los desembalses al Acueducto Tajo-Segura procedan realmente de aguas procedentes del 
Tajo, así como otras medidas relacionadas con las pérdidas por evaporación, vertidos, y la contribución de los usuarios del Acueducto al sostenimiento de los gastos del embalse de Alarcón.

A partir de la derogación de parte del Plan hidrológico Nacional, mediante Decreto Ley 2/2004 de 18 de junio, entramos en una fase crítica para la continuidad del trasvase, que afortunadamente será superada unos años más tarde. Este Decreto Ley fue tramitado como proyecto de Ley, para especificar su contenido, y fruto de este segundo impulso legislativo se incorporó una cláusula que podía haber sido letal para la continuidad del Trasvase. En efecto, la disposición adicional primera de esta Ley establece: "el volumen trasvasable desde la cabecera del Tajo se revisará en el futuro, oídas las Comunidades Autónomas afectadas, a medida que el Gobierno lleve a cabo las inversiones precisas para que resulten adecuadamente satisfechas las necesidades de la cuenca del Segura”. En otras palabras, una vez las inversiones del Programa AGUA, consistentes básicamente en la ejecución de desalinizadoras de agua de mar y la reutilización, se fueran poniendo en funcionamiento, se irían reduciendo los caudales trasvasables. Es decir, se pretendía sustituir unas aguas por otras (Melgarejo et al., 2014).

Además de este planteamiento, se inició un proceso de reforma del Estatuto de Castilla la Mancha (BOCG, 11 de abril de 2008), que contenía la derogación explícita del Trasvase en 2015, así como la reducción progresiva de los caudales transferibles mediante el incremento de reservas en el Alto Tajo. La propuesta establecía así mismo diversos mecanismos de obstaculización del trasvase, como la introducción de trabas procedimentales. Junto a ello, en 2010 se aprobó el Esquema de Temas Importantes del Plan Hidrológico del Tajo (ETI-Tajo), donde se fijaban unos caudales ecológicos para el tramo del Tajo en Aranjuez, que de hecho producirían la imposibilidad física de buena parte de las actuales transferencias. Se llegaron a proponer 10,86 m³ $/ \mathrm{s}$ en Aranjuez, 14,1 $\mathrm{m}^{3} / \mathrm{s}$ en Toledo y $15,9 \mathrm{~m}^{3} / \mathrm{s}$ en Talavera. Ninguna de las dos iniciativas prosperó, puesto que el Estatuto, aun habiendo sido aprobado en las Cortes de Castilla-La Mancha, nunca fue aprobado por el Congreso de los Diputados, y la ETI-Tajo finalmente no condujo a la elevación de los caudales ecológicos propuestos gracias a la irrupción del Memorándum del Tajo.

La Ley 21/2013, de 9 de diciembre, de Evaluación Ambiental (LEA) ha dotado a la infraestructura de un marco legal mucho más estable, con mayor seguridad jurídica. No sin perjudicar, eso sí, a los abastecimientos a favor de los regadíos, que reciben una mayor dotación. Con todo, la continuidad de régimen jurídico resulta fundamental para garantizar el sistema de gobernanza y gestión del agua de la MCT. EL Organismo ha manifestado reiteradamente su preocupación por la continuidad del Trasvase (Memorias MCT, 2009, 2010 y 2013). 
El 9 de abril de 2013 se firmó en Madrid el "Memorándum" de entendimiento entre el Secretario de Estado de Medio Ambiente, el Consejero de Agricultura y Agua de la Región de Murcia, y el Vicepresidente del Consell de la Generalitat Valenciana y Conseller de Presidencia y Agricultura, Pesca, Alimentación y Agua; es decir, estaban presentes dos de las Comunidades receptoras del agua del trasvase Tajo-Segura, y la Administración Central, competente para la gestión de las aguas que discurren por más de una comunidad autónoma en España.

Este acuerdo se alcanzó ante la inminente aprobación del Plan Hidrológico del Tajo, que estaba llamado a establecer una nueva ordenación de los caudales excedentarios, y podía alterar el régimen vigente del Trasvase. El Memorándum recoge la necesidad de mantener el trasvase Tajo-Segura dotándole de toda una serie de garantías técnicas y jurídicas, que deben ayudar a su efectiva consolidación y mejora sobre unas bases de consenso.

De acuerdo con lo establecido en el Memorandum, la MCT participa en el agua del Trasvase con un mínimo de $7,5 \mathrm{hm}^{3}$ al mes, que suponen $90 \mathrm{hm}^{3}$ anuales, mientras que las "menores pérdidas" pasan a contemplarse como un derecho de los regantes y para el abastecimiento a Almería; esto supone un menor volumen adjudicado a la Mancomunidad con lo que, en su caso, habría que recurrir al incremento del agua desalada. El Comité Ejecutivo de la MCT manifestó que este extremo era perfectamente asumible por el Organismo a cambio de la firma del "Memorandum" (CEMCT, 24/10/2013).

La tramitación de la LEA sirvió de vehículo para adoptar con rango legal parte de las observaciones y recomendaciones que se habían plasmado en el Memorándum. Se utilizó para ello la fase de introducción de enmiendas en el debate parlamentario de la Ley. En la exposición de motivos de la LEA se recomienda que la regulación de los trasvases entre ámbitos territoriales de distintos planes hidrológicos de cuenca se incorpore al PHN, tal y como dispone el propio Texto Refundido de la Ley de Aguas. Se pretende con ello volver a disponer en el PHN de una regulación integrada y armonizada, incluso con un alcance más ambicioso del que tuvo la Ley de 2001, en cuanto se puedan integrar en un único bloque normativo todas las disposiciones actualmente dispersas en materia de trasvases (Molina, 2010).

El número uno de la disposición final tercera de la LEA da una nueva redacción a la disposición adicional tercera del PHN, de modo que se elevan las reservas a efectos de la estimación de las "aguas excedentarias", a partir ahora de $400 \mathrm{hm}^{3}$ en el conjunto de Entrepeñas-Buendía. Se recuerda que por debajo de esta cifra no se podrán efectuar trasvases en ningún caso, y que dicho volumen podrá revisarse conforme a las variaciones que experimenten las demandas de la cuenca del Tajo, de acuerdo con los principios de eficiencia y sostenibilidad, garantizando su carácter preferente. 
La Ley otorga una mayor seguridad jurídica al sistema y establece un mecanismo de estabilidad técnica, sin dejar a un lado su necesaria adaptación, al ordenar al Gobierno la actualización mediante real decreto de las magnitudes determinantes de la Regla de Explotación del Trasvase. Ello resulta necesario para adecuar de forma flexible estas magnitudes a las variaciones hidrológicas observadas en los últimos años, y para disponer de instrumentos ágiles de adaptación a posibles efectos de alteración hidrológica como los inducidos por el cambio climático.

Un eje fundamental es la modificación parcial del artículo 72 del Texto Refundido de la Ley de Aguas para dotar de mayor eficacia el régimen de cesión de derechos. El objetivo es flexibilizar su régimen jurídico sin perjuicio de la regulación específica de cada uno de los trasvases. Por otra parte, la Disposición adicional primera de la Ley 11/2005, de 22 de julio queda derogada por su manifiesta inviabilidad técnica. La sustitución de caudales desalados por trasvasados no es posible, dado que las redes de distribución de ambos recursos no se superponen ni proporcionan la cobertura necesaria para el intercambio de agua. Junto a ello, el régimen jurídico de los recursos trasvasados y los no convencionales es completamente distinto, no admitiendo el cambio de toma ordinario previsto para las concesiones en la legislación de aguas. Además, el régimen económico es también distinto, con diferencias de costes muy notorias, que impiden la mera sustitución de un recurso por otro.

Absolutamente fundamentales son los cambios en las hasta entonces vigentes reglas de explotación del Trasvase, que se modifican conforme la disposición adicional decimoquinta de la LEA. Las reglas de explotación se crearon con el objetivo de proporcionar pautas para reducir la discrecionalidad en la toma de decisiones sobre los desembalses. Sin embargo, su indefinición fue fuente de continuas controversias. En la figura 60 se muestra la Regla de Explotación en su versión de 1997, que estuvo vigente hasta el 30 de septiembre de 2014.

En la LEA los antiguos tres niveles de decisión quedan redistribuidos en cuatro, con importantes modificaciones, y siempre atendiendo al máximo total trasvasable en cada año hidrológico de $650 \mathrm{hm}^{3}$ (600 para el Segura y 50 para el Guadiana). Se contempla asimismo la posibilidad de que mediante real decreto se puedan modificar los volúmenes de existencias y de aportaciones del Nivel 1, los volúmenes de trasvase mensual de los Niveles 1, 2 y 3, así como los volúmenes de existencias para el Nivel 3. Todo ello al objeto de facilitar la posible modificación de estos valores si en el futuro se estimara necesario técnicamente, y sin tener que acudir para ello a una más complicada modificación legal. De hecho, así ha sido, ya que estos niveles fueron reestructurados por el Real Decreto 773/2014, de 12 de septiembre. En el artículo 1 del Decreto se recogen las nuevas Reglas de explotación del Trasvase (Figura 61). 

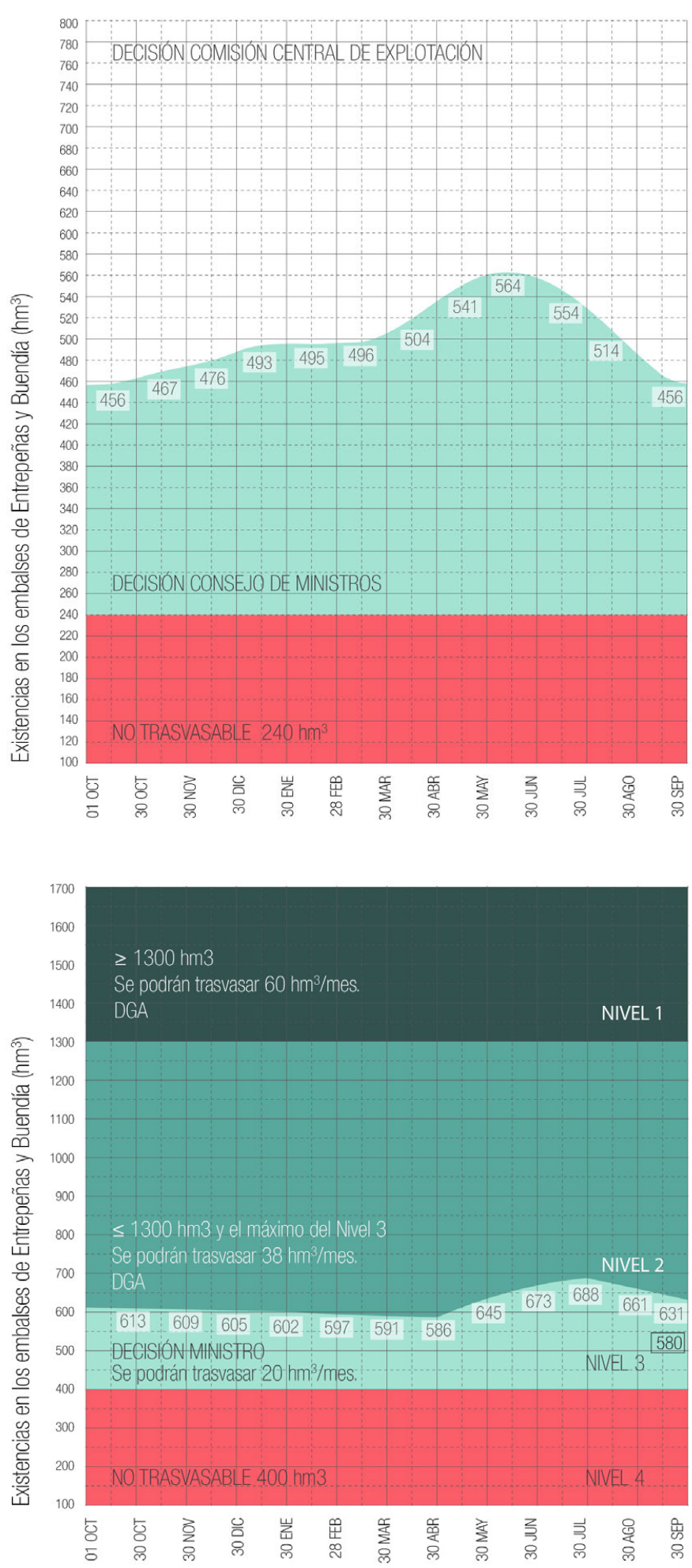

Fig 60. Regla de Gestión del TTS (1997-2014) [Melgarejo, 2009. Elaboración propia.]
Fig 61. Reglas de Explotación del Trasvase Tajo-Segura, 2014 [Melgarejo et al., 2014. Elaboración propia.] 
En la nueva Regla se observan algunas diferencias entre los volúmenes previstos a trasvasar para los distintos niveles aprobados en la LEA y el Real Decreto 773/2014. En primer término, tanto en el Nivel 1 como 2 hay alteraciones en el volumen de existencias conjuntas en los embalses de cabecera y el volumen de las entradas. Respecto a las existencias, de $1.500 \mathrm{hm}^{3}$ pasamos a $1.300 \mathrm{hm}^{3}$, lo que resulta más favorecedor del trasvase. Sin embargo, las aportaciones requeridas para que se den ambos niveles suben desde los $1.000 \mathrm{hm}^{3}$ de la Ley a los $1.200 \mathrm{hm}^{3}$ del Decreto, lo que resulta algo más restrictivo. En cuanto a las cantidades a trasvasar en cada nivel, se opta por reducir en el Nivel 1 los $68 \mathrm{hm}^{3}$ mensuales previstos en la LEA hasta los $60 \mathrm{hm}^{3}$, manteniéndose la misma cantidad $\left(38 \mathrm{hm}^{3}\right)$ en el nivel 2. El agua que se puede trasvasar en cada Nivel no sólo no ha aumentado, sino más bien se ha reducido en uno de los niveles, aunque sin demasiada trascendencia práctica.

En ningún caso, además, se pueden superar los $650 \mathrm{hm}^{3}$ en cada año hidrológico. Para mayor claridad, veamos con detalle cómo quedan definidos ambos niveles:

Nivel 1. Se dará cuando las existencias conjuntas en Entrepeñas y Buendía sean iguales o mayores que $1.300 \mathrm{hm}^{3}$, o cuando las aportaciones conjuntas entrantes a estos embalses en los últimos doce meses sean iguales o mayores que $1.200 \mathrm{hm}^{3}$. En este caso el órgano competente autorizará un trasvase mensual de $60 \mathrm{hm}^{3}$, hasta el máximo anual antes referido.

Nivel 2. Se dará cuando las existencias conjuntas de Entrepeñas y Buendía sean inferiores a $1.300 \mathrm{hm}^{3}$, sin llegar a los volúmenes previstos en el Nivel 3, y las aportaciones conjuntas registradas en los últimos doce meses sean inferiores a $1.200 \mathrm{hm}^{3}$. En este caso el órgano competente autorizará un trasvase mensual de $38 \mathrm{hm}^{3}$, hasta el máximo anual antes referido.

En la concreción de los volúmenes a trasvasar en este segundo nivel fue donde se vivieron los momentos más tensos de la negociación. Se preveía en un principio una reducción de 38 a $32 \mathrm{hm}^{3} /$ mes con respecto a lo previsto en la LEA, es decir un descenso anual de $72 \mathrm{hm}^{3}$, cantidad inaceptable para la cuenca receptora en su conjunto, que hizo que las negociaciones estuvieran a punto de fracasar. Finalmente fue rectificado en las horas previas a su aprobación por el Consejo Nacional del Agua manteniendo las cantidades previstas en la Ley, y por tanto el envío de $38 \mathrm{hm} 3 /$ mes para el Nivel 2.

Se consagra en los Niveles 1 y 2 un auténtico derecho al trasvase, lo que presenta una gran trascendencia y un cambio radical en la situación jurídica de los usuarios, al establecerse que, cuando concurran las condiciones hidrológicas fijadas para cada uno de ellos, deberá trasvasarse un volumen mensual determinado para los niveles 1 y 2 siempre con el máximo de los $600 \mathrm{hm}^{3}$ anuales. El envío de esos recursos es imperativo en la Ley, 
a diferencia de lo que ocurría en las anteriores Reglas de Explotación, donde la expresión utilizada: "se podrá autorizar", llevó al Tribunal Supremo a negar un auténtico derecho al trasvase (STS 27-01-2009), quedando el mismo como una simple expectativa a merced de la discrecionalidad del órgano decisorio.

Nivel 3. Se dará cuando las existencias conjuntas en Entrepeñas y Buendía no superen, a comienzos de cada mes, los valores mostrados en la siguiente tabla (valores en $\mathrm{hm}^{3}$ ):

\begin{tabular}{|l|l|l|l|l|l|l|l|l|l|l|l|}
\hline Oct & Nov & Dic & Ene & Feb & Mar & Abr & May & Jun & Jul & Ago & Sep \\
\hline 613 & 609 & 605 & 602 & 597 & 591 & 586 & 645 & 673 & 688 & 661 & 631 \\
\hline
\end{tabular}

Tabla 05. Indicadores de valores mínimos para Nivel 3 [MCT. Elaboración propia.]

Este segmento es calificado por la ley bajo el rótulo de "situaciones hidrológicas excepcionales", y tendrá lugar cuando las existencias conjuntas en los embalses de Entrepeñas y Buendía no superen, a comienzos de cada mes, los valores que se determinen por el Plan Hidrológico del Tajo vigente (2014).

En este nivel, el órgano competente podrá autorizar discrecionalmente y de forma motivada un trasvase de hasta $20 \mathrm{hm}^{3} /$ mes. La concreción de una cantidad máxima contribuye a reducir la discrecionalidad en este segmento. Sin embargo, aquí se ha producido una diferencia significativa, ya que de acuerdo con la LEA se podía llegar a trasvasar hasta $23 \mathrm{hm}^{3} / \mathrm{mes}$, mientras que el Decreto reduce esta cantidad en $3 \mathrm{hm}^{3} / \mathrm{mes}$, lo que supone una reducción total de $36 \mathrm{hm}^{3} /$ año.

El órgano competente para decidir los trasvases en esta situación ya no será, como hasta ahora, el Consejo de Ministros, sino el Ministro de Agricultura, o el que en el futuro tenga la competencia sobre aguas. Además, podrá actuar con un amplio margen de discrecionalidad, mediante una decisión motivada y fundada en los informes técnicos correspondientes, dada la situación excepcional de las reservas. Los acuerdos de trasvase, en el caso de los Niveles 1 y 2, se realizarán preferentemente por semestres, mientras que en el caso del Nivel 3 lo serán preferentemente por trimestres, salvo que el órgano competente justifique la utilización de plazos distintos. Con ello se ha pretendido lograr una mayor previsibilidad en la planificación. 
Nivel 4. Se dará esta situación cuando las existencias conjuntas en Entrepeñas y Buendía sean inferiores a $400 \mathrm{hm}^{3}$, en cuyo caso no cabe aprobar trasvase alguno salvo que una norma legal de urgencia, un real decreto-ley, lo autorizase de forma excepcional, como ya ocurrió en 1995. El nuevo umbral de aguas no trasvasables pretende garantizar, en el horizonte temporal de la planificación hidrológica, las demandas actuales y futuras de todos los usos y aprovechamientos de la cuenca cedente, incluidos los requerimientos y restricciones medioambientales, dependientes del sistema de la cabecera del Tajo. La garantía es extensible a los caudales ambientales que deben asegurar el buen estado de las aguas en cumplimiento de la Directiva Marco del Agua.

Los volúmenes cuyo trasvase haya sido autorizado se distribuirán entre abastecimientos y regadíos, en la proporción de un $25 \%$ para abastecimiento y el $75 \%$ restante para regadío, hasta el máximo de sus dotaciones anuales, y asegurando siempre al menos 7,5 $\mathrm{hm}^{3} / \mathrm{mes}\left(90 \mathrm{hm}^{3} /\right.$ año $)$ para los abastecimientos urbanos. Esta medida da satisfacción al apartado $3^{\mathrm{o}}$ de la cláusula segunda del Memorándum: "Revisión de la cuestión de las menores pérdidas y de su regulación jurídica, considerando su posible asignación parcial o total a los regadíos ante las nuevas circunstancias de abastecimiento urbano, y la posible proporcionalidad en la asignación a los usos". Se trata de una conquista de los regantes, ya que hasta este momento la MCT percibía en cualquier caso $110 \mathrm{hm}^{3} /$ año del Trasvase, como mínimo, como consecuencia de que el abastecimiento es prioritario en nuestro ordenamiento (Melgarejo et al., 2014).

Es conveniente recordar aquí que la primera fase del Trasvase, preveía unos volúmenes a trasvasar de hasta un máximo de $600 \mathrm{hm}^{3} /$ año, de los cuales 400 eran para el regadío, 110 para abastecimiento y 90 que se imputaban a perdidas. Desde este momento, las potenciales reducciones de pérdidas no benefician al abastecimiento, sino que en la proporción antes descrita, los principalmente favorecidos serán los regadíos. Las menores pérdidas se distribuyen en un $70 \%$ para riego en todas las zonas y $30 \%$ que irá a abastecimientos en Almería.

La Ley 52/1980 de 16 de octubre contempló unas pérdidas de agua del 15\%, que posteriormente se comprobó que eran en realidad del $10 \%$, por lo que existe una diferencia del 5\%, $30 \mathrm{hm}^{3}$, que antes se asignaban exclusivamente para abastecimiento. Desde 1987 se entregaba al Organismo hasta el 70\% de los excedentes producidos en destino por pérdidas inferiores a las previstas en la Ley de 1980, lo que representaba entorno al 3,5\% del total trasvasado cada año, es decir, un volumen de entre 12 y $14 \mathrm{hm}^{3} /$ año (CEMCT 19/12/1990). En la actualidad, de esas menores pérdidas, la LEA asigna 21 $\mathrm{hm}^{3}$ en origen para riego, quedando los $9 \mathrm{hm}^{3}$ restantes para abastecimiento en Almería. La MCT ya no cuenta con estos caudales. 
Un aspecto fundamental en el precio del agua de la MCT se deriva de las tarifas aplicadas al trasvase Tajo-Segura. La tarifa de los abastecimientos sufrió inicialmente un incremento de dos pesetas por metro cúbico, como resultado de aplicar los criterios de estimación y reparto de cargas entre usos, regadíos y abastecimientos, establecidos en la normativa económica del Trasvase. Ello se debió a que en la hipótesis supuesta en el Anteproyecto del Trasvase los abastecimientos deberían pagar el agua al doble que los regadíos. Sin embargo, en una tarifa cuyos costes de explotación, energéticos esencialmente, y conservación, eran importantes en comparación con los de aportación al coste de las obras, resultaba muy difícil admitir esa dualidad en el coste cuando se podían destinar los caudales indistintamente a uno u otro uso. De acuerdo con las primeras estimaciones de coste, las tarifas se establecieron en 4 y 6 ptas $/ \mathrm{m}^{3}$, según fuesen de regadío o abastecimiento. El planteamiento, totalmente arbitrario, fue rechazado por la Mancomunidad, comprometiéndose el Ministerio a revisar el precio relativo de la tarifa de abastecimiento.

Para el sistema de la MCT, en definitiva, los aportes del Trasvase han resultado fundamentales para equilibrar el balance entre las disponibilidades y las crecientes demandas. Dentro del esquema de fuentes de recursos para su distribución por parte de la MCT, el trasvase Tajo-Segura constituye, desde su integración en el sistema, un pilar básico en el funcionamiento de la entidad. Su incorporación ha hecho que la MCT aumente significativamente su alcance y relevancia en los suministros del Sureste peninsular, al haber permitido una continua ampliación del área abastecida.

Estos recursos suponen en la actualidad la mayor aportación al sistema, situándose alrededor del $60 \%$ del volumen total suministrado, con picos máximos que pueden llegar hasta el $75 \%$ del agua trasvasada, en aquellas épocas de especial sequía, en las que las aportaciones del río Taibilla disminuyen drásticamente, como se deduce de la figura 62 . Estos caudales, además, permiten mejorar sustancialmente la calidad del agua aportada y garantizan un abastecimiento continuo y con la debida regularidad.

La continuidad del Trasvase Tajo-Segura no está ni mucho menos garantizada. La infraestructura soporta periódicamente los efectos de un debate político-territorial poco constructivo. En los últimos años la Comunidad de Castilla La Mancha ha elevado el nivel de litigiosidad contra las decisiones de trasvase de la Comisión Central de Explotación, y ha llegado incluso a aprobar normativas que o bien dificultaban la continuidad efectiva del trasvase, o directamente planteaban su extinción en un horizonte temporal próximo. 


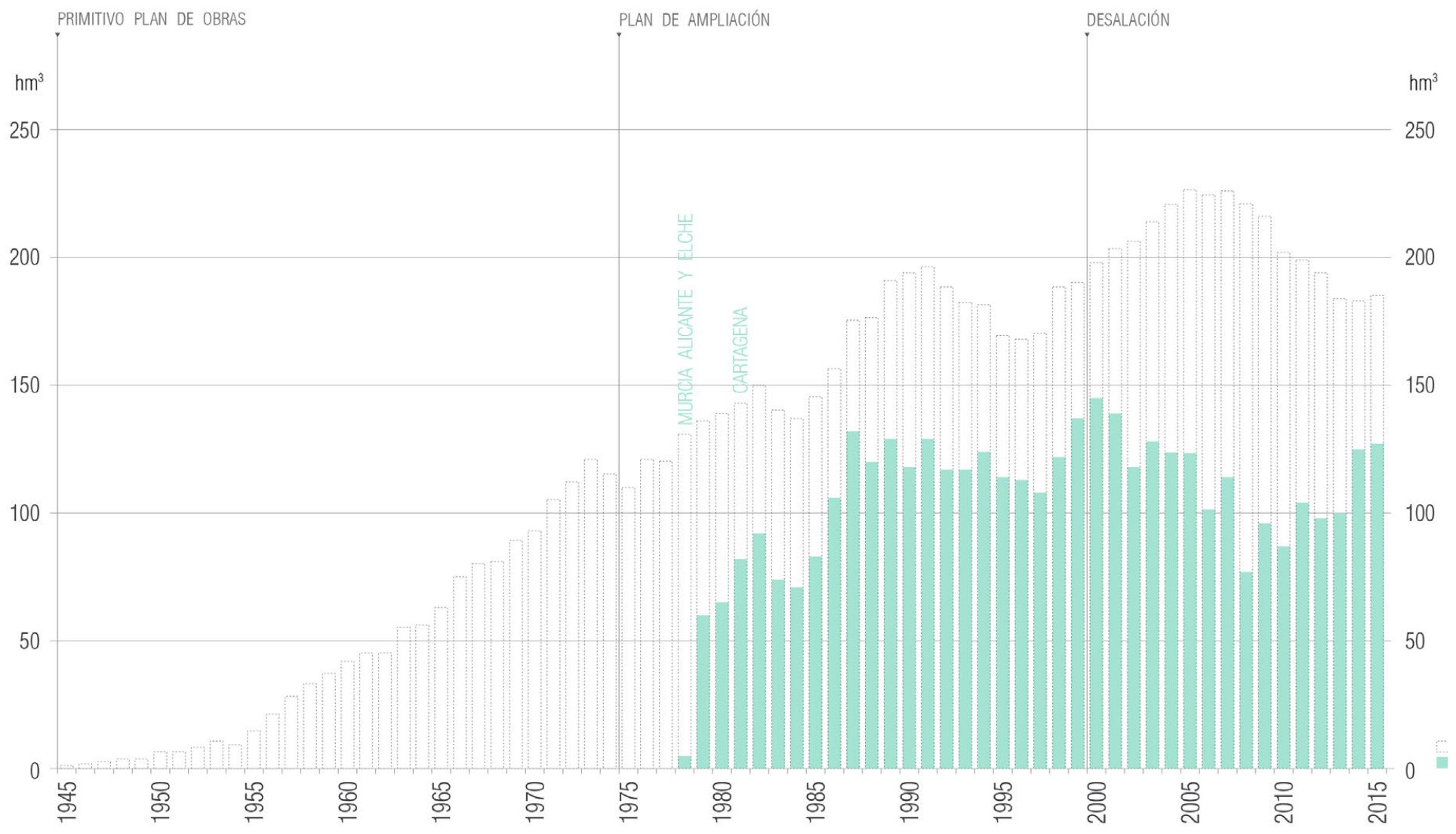

Fig 62. Aportaciones del ATS y peso relativo en el sistema MCT [MCT. Elaboración propia.] 


\section{4.- Caudales procedentes de contratos de cesión a través del Acueducto Tajo- Segura (ATS).}

En 1999 se introducen en nuestro ordenamiento jurídico, mediante una importante reforma de la Ley de Aguas de 1985, dos instrumentos novedosos: los contratos de cesión de derechos de aprovechamiento y los centros de intercambio. La reasignación de caudales inicialmente concedidos a determinados usos, mediante la revisión de los títulos concesionales, es en el plano teórico el instrumento jurídico que permite priorizar la adjudicación del recurso a aquellos usos que se consideren preferentes, y en el primer nivel de preferencia está el abastecimiento humano. Sin embargo, este tipo de procedimientos de revisión son extraordinariamente complejos, y encierran una elevada litigiosidad potencial. Dada la ineficacia real de estos procesos, se incorpora a nuestro ordenamiento un sistema que permite movilizar de manera temporal caudales ya concedidos entre los propios usuarios del agua, sobre la base de acuerdos sujetos a la supervisión o incluso impulso de la Administración hidráulica.

El contrato de cesión, en particular, permite a dos concesionarios o usuarios de agua con título legal de aprovechamiento llegar a un acuerdo por el que se entregan recursos a cambio de un precio pactado. El Organismo de Cuenca competente debe autorizar este contrato, que además debe cumplir con una serie de condiciones establecidas en la Ley de Aguas: cesiones a titulares de igual o superior rango, identificación de los predios a regar con menor dotación, o a los que se renuncia a regar, acreditación de la no afectación negativa al régimen de explotación de los recursos en la cuenca, a los derechos de terceros, a los caudales medioambientales, al estado o conservación de los ecosistemas acuáticos entre otros aspectos (Melgarejo et al., 2005).

La MCT ha utilizado este instrumento en varias ocasiones, alcanzando para ello acuerdos con regantes de la cuenca del Tajo o del propio territorio de la cuenca del Segura, que se han materializado en contratos de cesión de derechos de agua. Estos contratos han contribuido a evitar medidas drásticas de reducción de los volúmenes de agua que se suministran a los municipios y entidades beneficiarias del Sistema (Melgarejo et al, 2008).

En 2004, el Organismo manifestó su voluntad de suscribir contratos de cesión con titulares o concesionarios de derechos al uso privativo de las aguas (BOE 6/1/2004), sin que se recibiera oferta alguna (CEMCT 29/12/2004). Por otra parte, mediante Acuerdo del Consejo de Ministros del 15 de octubre de 2004, se constituyeron los Centros de Intercambio de Derechos al Uso del Agua (CIDUAs), en las Confederaciones del Segura, Júcar y Guadiana (CEMCT, 29/12/2004), aunque no se obtuvieron finalmente caudales por esta vía. 
Durante el trienio 2006-2008 se hizo necesaria la constitución por parte de la Mancomunidad de reservas estratégicas anuales en la cabecera del Tajo, mediante contratos de cesión de derechos con la Comunidad de Regantes del Canal de las Aves (Aranjuez) por un volumen total de $108 \mathrm{hm}^{3}$. En concreto, en 2006, se llevaron a cabo suscripciones de contratos de cesión de derechos de agua $\left(35,5 \mathrm{hm}^{3}\right)$ del río Tajo con la Comunidad de Regantes del Canal de las Aves (Aranjuez) por un importe de 10,2 millones de euros, así como otro contrato de cesión de derechos de agua del río Segura con regantes de zonas de arrozales de Hellín y Moratalla, para un volumen de agua de 1,2 $\mathrm{hm}^{3}$, a un precio de 0,30 euros $/ \mathrm{m}^{3}$ (CEMCT 14/7/2006). En las dos anualidades siguientes se realizaron operaciones similares por la MCT.

\begin{tabular}{|c|c|c|c|c|c|}
\hline Comprador & Cedente & $\begin{array}{c}\text { Año } \\
\text { hidrológico }\end{array}$ & $\begin{array}{c}\text { Volumen en } \\
\text { origen }\left(\mathrm{hm}^{3}\right)\end{array}$ & $\begin{array}{c}\text { Precio } \\
\left(€ / \mathrm{m}^{3}\right)\end{array}$ & $\begin{array}{c}\text { Compensación } \\
(€)\end{array}$ \\
\hline & & $2005-2006$ & 35,52 & 0,2885 & 10.247 .520 \\
\hline \multirow{2}{*}{ MCT } & $\begin{array}{c}\text { C.R Canal } \\
\text { de las Aves }\end{array}$ & $2006-2007$ & 36,03 & 0,2364 & 8.517 .492 \\
\cline { 3 - 6 } & & $2007-2008$ & 36,94 & 0,3130 & 11.562 .220 \\
\hline
\end{tabular}

Tabla 06. Contratos de cesión inter-cuencas entre la MCT y la CR. Canal de las Aves [Calatrava et al., 2016]

Estos contratos contaron con financiación procedente mayoritariamente de la exención de los conceptos b) y c) de la tarifa del trasvase Tajo-Segura, establecida en el Real Decreto Ley 8/2008 de 24 de octubre (Memoria MCT. 2008).

La capacidad de la MCT para poder participar en estos contratos ha sido puesta en cuestión por razones jurídicas, si bien la jurisprudencia es clara al considerar que la entidad está perfectamente legitimada para adquirir recursos a través de esta fórmula. Las dudas se derivaban del hecho de que el artículo 67 del TRLA permite a los "concesionarios" o "titulares de algún derecho de uso privativo de las aguas", ceder caudales con carácter temporal a otro "concesionario o titular de derecho de igual o mayor rango", según el orden de preferencia establecido en la planificación hidrológica. La mención a la categoría de concesionario o titular de otro derecho de igual o mayor rango podría plantear dudas en cuanto a la integración subjetiva de estos contratos. 
Sin embargo, estas limitaciones no operan en la medida en que existe un marco legal específico que autoriza la participación de la MCT en este tipo de contratos. (Sentencia del Tribunal Supremo de 24 de julio de 2012, así como otras posteriores: STS de 26 de junio de 2015, STS de 18 de diciembre de 2015). Señala el Tribunal Supremo en estas Sentencias que "en lo que aquí interesa, el artículo 2 del Real Decreto Ley 15/2015, de 16 de diciembre, de medidas urgentes para la regulación de las transacciones de derechos al aprovechamiento de agua, permite que los titulares de derecho al uso de agua adscritos a las zonas regables de iniciativa pública, cuyas dotaciones brutas máximas figuren en los planes hidrológicos de cuenca puedan, previo informe del Ministerio de Agricultura, Pesca y Alimentación, celebrar los contratos de cesión a los que se refiere el artículo 67.1 del TRLA, sin perjuicio de las formalidades exigidas en el artículo 68.2, posibilidad que se amplía específicamente a la MCT en la disposición adicional primera del Real Decreto Ley".

En definitiva, de acuerdo con esta doctrina jurisprudencial, siempre que las cesiones se celebren en el marco delimitado por una situación de urgente necesidad, que justifique la aprobación de un decreto ley en los términos indicados, la MCT puede perfectamente utilizar esta vía para obtener recursos adicionales.

Cuando las cesiones conciernen a demarcaciones diferentes, y en consecuencia es necesario utilizar infraestructuras de trasvase, el artículo 72 del TRLA, en su redacción resultante de la disposición final cuarta de la LEA, dispone que: "La Dirección General del Agua podrá autorizar la cesión de derechos, a que se refiere esta sección, que implique el uso de infraestructuras que interconectan territorios de distintos Planes Hidrológicos de cuenca, esta autorización conlleva la de uso de las infraestructuras de interconexión. Se entenderán desestimadas las solicitudes de cesión una vez transcurridos los plazos previstos sin haberse notificado la resolución administrativa”. Estas transferencias no afectan al régimen económico financiero establecido en las normas del Trasvase, ni alteran lo establecido en las reglas de explotación.

De hecho, según el Tribunal Supremo (Sentencia de 26 de junio de 2015), es necesario diferenciar, en términos jurídicos, entre lo que es una cesión de derechos de uso del agua, tal como se define en el TRLA, de lo que es propiamente un trasvase, ya que los límites y condicionantes que operan para los trasvases, entre ellos los que establece la Disposición Adicional primera de la Ley 52/1980, de 16 de octubre, de regulación del régimen económico de la explotación del acueducto Tajo-Segura, no entran en juego en este caso. La normativa del trasvase no resulta por tanto aplicable, sino la establecida en los artículos 67 y siguientes del TRLA, que regulan los contratos de cesión, su objeto, formalización y registro, así como la utilización de infraestructuras de conexión intercuencas. La versatilidad del Acueducto Tajo-Segura permite asegurar la eficacia de este tipo de transferencias (Navarro, 2008, 2010). 
El modelo de los centros de intercambio de derechos de agua presenta igualmente una gran potencialidad, aunque no se ha utilizado todavía por parte de la MCT. El Consejo de Ministros es el que, mediante Acuerdo, a propuesta del Ministerio con competencias en medio ambiente, puede acordar poner en marcha este mecanismo, autorizando a las confederaciones hidrográficas a realizar una oferta pública de adquisición de derechos de uso, a la que los usuarios pueden concurrir. Realizado el pago de dichos caudales, estos serán ofrecidos a otros usuarios que precisen incrementar sus disponibilidades, al precio que establezca la confederación.

Los procedimientos de selección deben regularse por vía reglamentaria, así como las causas que pueden justificar el uso de este instrumento. La ausencia de esta regulación ha limitado sensiblemente la constitución de centros de intercambio. Son sin embargo una fórmula muy interesante para reasignar caudales de una manera no traumática, y además bajo el impulso, control y supervisión de la Administración hidráulica. La MCT podría concurrir a este tipo de operaciones en el caso de que se decidieran activar por parte de las autoridades competentes. 


\section{5.- Caudales procedentes de la Cuenca del Júcar (embalse de Alarcón) para los municipios alicantinos integrados en dicha Demarcación.}

\subsection{1.- MCT-Municipios abastecidos por el Consorcio de Aguas de la Marina Baja \\ (CAMB) (Alicante).}

El embalse de Alarcón, aun formando parte de la Demarcación del Júcar, es parte sustancial del sistema de infraestructuras del Acueducto Tajo-Segura, para el que actúa como embalse regulador en el que se mezclan los recursos del trasvase con los propios de la demarcación a la que pertenece. A su vez, dicha característica hace perfectamente posible derivar caudales del Júcar a través del Acueducto, el cual, gracias a las infraestructuras de la MCT, hace posible que dichos caudales lleguen a los municipios alicantinos situados en la demarcación Júcar, y en particular a los Municipios de la Marina Baja a través de la conducción Rabassa-Fenollar-Amadorio (Alicante-Benidorm). (Figura 63).

El Consejo de Ministros acordó la realización de una obra de emergencia para solucionar el problema de abastecimiento de varios municipios de la Marina Baja, que habían llegado a una situación crítica. Esta obra es parte del proyecto de trasvase de recursos hídricos del río Júcar al río Vinalopó, pensada para solucionar definitivamente los abastecimientos de dicha zona, y consiste en una conducción Alicante (Rabasa)Embalse de Amadorio. La solución provisional requería la derivación de aguas del Júcar desde el pantano de Alarcón, por las instalaciones del trasvase Tajo-Segura, hasta la elevación de Torrealta (Orihuela), ya en la MCT. Desde este punto, una vez potabilizadas en la estación de tratamiento, las aguas discurrirán por el Canal de Alicante hasta el punto de entronque con dicha obra de emergencia.

El 21 de noviembre de 1996 y el 16 de febrero de 1997 se informó favorablemente para que la MCT facilitara sus infraestructuras para llevar $2 \mathrm{hm}^{3}$ a la Marina Baja. La derivación se debería realizar entre los meses de diciembre de 1996 a marzo de 1997, meses de consumo inferior a la media anual de los volúmenes suministrados por la MCT, cuyas necesidades habían de ser prioritarias en todo momento. Dado el aforo de los canales, la incorporación de caudales adicionales en los meses de máxima demanda podría haber comprometido la capacidad de transporte de la infraestructura (CEMCT 21/11/1996).

El Consorcio de Aguas de la Marina Baja, el 4 de marzo de 1997 solicitó utilizar las infraestructuras de la MCT para transportar $5 \mathrm{hm}^{3}$. La tarifa propuesta desde el Organismo fue de 23,34 ptas $/ \mathrm{m}^{3}$. La Confederación Hidrográfica del Júcar aportaría los volúmenes, procedentes de sus recursos regulados, para garantizar con carácter excepcional y de emergencia el abastecimiento de agua potable a los municipios de la 


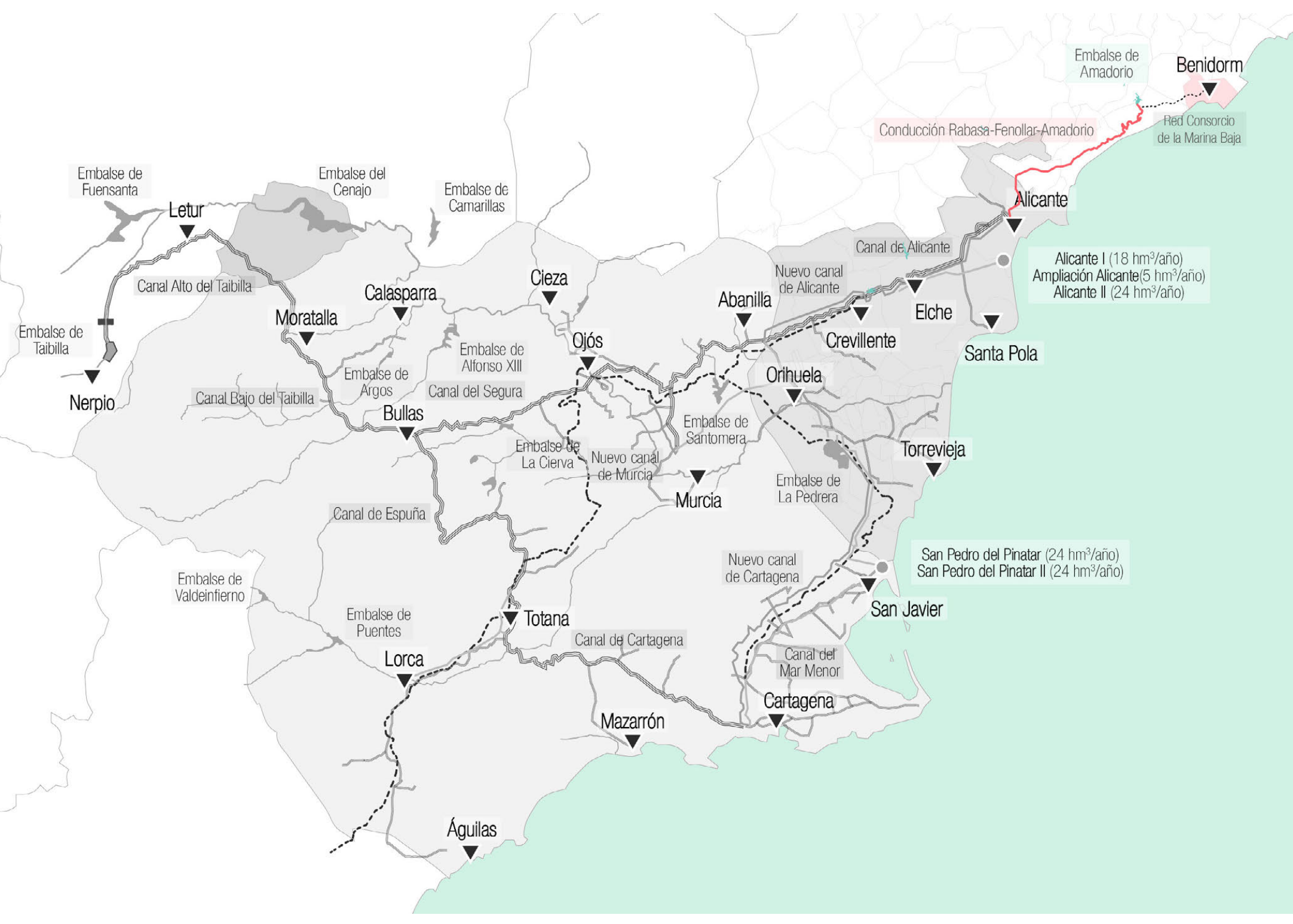

Fig 63. Conducción Rabassa-

Fenollar-Amadorio (AlicanteBenidorm) [MCT. Elaboración propia.] 
Comarca de la Marina Baja. Esta propuesta fue aprobada por unanimidad por el Comité Ejecutivo de la MCT (CEMCT 25/3/1999). En el año 2000 se enviaron un total de $8,8 \mathrm{hm}^{3}$ utilizando las infraestructuras del trasvase Tajo-Segura y de la MCT a la Marina Baja (CEMCT 13/12/2000).

La articulación jurídica de este instrumento precisó modificar el artículo 10 de la Ley 52/1980, de 16 de octubre, de regulación del régimen económico de la explotación del Acueducto Tajo-Segura, que impedía el uso de las infraestructuras del Trasvase para estos fines. El Real Decreto Ley 8/1999, de 7 de mayo, modificó dicho precepto, admitiendo la utilización de las infraestructuras del trasvase para transportar y distribuir recursos propios de las demarcaciones hidrográficas del Júcar, Segura o Sur, para ser utilizados exclusivamente en el ámbito de cada una de ellas. Se trata con ello de la utilización instrumental de las infraestructuras del trasvase sin modificar ni las asignaciones ni las reservas propias del sistema Tajo-Segura. Esos recursos quedan subordinados al cumplimiento de los fines prioritarios de la Ley de 1980, y sujetos a la tarifa de conducción de agua que corresponda en el momento en que se realizan las transferencias.

El Decreto Ley se aprobó para afrontar la importante sequía que se venía sufriendo ante la carencia de precipitaciones durante el otoño de 1998 y el invierno de 1999. Esta situación había agravado significativamente la sobreexplotación de los acuíferos alicantinos, con una drástica disminución de las reservas de los embalses de Guadalest y Amadorio. Por ello se optó por un instrumento legal de urgencia, como es el Decreto Ley, para habilitar de manera inmediata la transferencia de caudales desde Alarcón hasta los municipios de la Marina Baja.

Resuelta la cuestión relativa al uso de infraestructuras, quedaba por articular el mecanismo de redistribución de los caudales, inicialmente asignados a determinados usos, y que en estos casos serían objeto de cesión temporal a los abastecimientos de la Marina Baja. Para ello, el artículo 55 del TRLA, que regula las facultades de los Organismos de cuenca en relación con el aprovechamiento y control de los caudales concedidos, en su apartado 2, precisa que la Confederación: "con carácter temporal, podrá también condicionar o limitar el uso del dominio público hidráulico para garantizar su explotación racional". Conforme a este precepto, las Confederaciones pueden reordenar de manera temporal los aprovechamientos cuando sea necesario para garantizar una explotación racional de los recursos disponibles.

El Plan Hidrológico del Júcar, aprobado por Real Decreto 1664/1998, de 24 de julio, establecía que una vez satisfechas las necesidades del sistema del Júcar, podrán aprovecharse recursos sobrantes en actuaciones generales de mejora medioambiental o para paliar déficit coyunturales de abastecimiento en la cuenca. Este marco regulador abría la posibilidad para derivar caudales con la finalidad de redotar, de manera 
coyuntural, derechos de aprovechamiento previamente concedidos en la demarcación, para afrontar situaciones puntuales de extrema necesidad.

La utilización de estos caudales se realiza previo el abono por parte de los beneficiarios de las compensaciones económicas pertinentes, incluidas las indemnizaciones a los usuarios industriales (hidroeléctricas), que puedan resultar por la reducción en la producción de energía eléctrica causada por la detracción de los caudales. El inciso final del apartado segundo del artículo 55 del TRLA dispone a este respecto que: "cuando por ello se ocasione una modificación de caudales que genere perjuicios a unos aprovechamientos en favor de otros, los titulares beneficiados deberán satisfacer la oportuna indemnización, correspondiendo al organismo de cuenca, en defecto de acuerdo entre las partes, la determinación de su cuantía".

El Tribunal Superior de Justicia de la Comunidad Valenciana (Sentencias 194/2010 de 19 de febrero y 356/2009 de 12 de marzo), ha interpretado que estas compensaciones, al presentar una naturaleza de indemnizaciones, en vez de prestaciones patrimoniales públicas, no comportan infracción alguna del principio de legalidad tributaria. Además, el Tribunal considera que estas compensaciones no presentarían un carácter coactivo, ya que son el resultado de una acción voluntaria tanto en la petición de la autorización de utilización temporal como en el uso efectivo de los caudales autorizados.

Otra de las cuestiones problemáticas que resuelve la jurisprudencia tiene que ver con las dudas suscitadas por la Sentencia del Tribunal Supremo de 20 de octubre de 2004, que anuló parte del Plan Hidrológico de Cuenca del Júcar, por considerar que éste había regulado cuencas internas de la Comunidad Valenciana, incluidas las del Vinalopó y Marina Baja, entre otras, sin tener capacidad para ello. Esta Sentencia partía de la idea de que siendo cuencas internas, debían contar con su propia planificación hidrológica, de ámbito autonómico, y que por tanto, el plan del Júcar no debía regularlas (Melgarejo et al., 2005).

Pues bien, la Sentencia del Tribunal Superior de la Comunidad Valenciana de 2010 mantiene que, aun aceptando como hipótesis dialéctica la afectación de cauces intracomunitarios por parte del Plan del Júcar, el Real Decreto 125/2007 de 2 de febrero, por el que se fija la competencia territorial de las demarcaciones hidrográficas, superaría esta controversia, toda vez que su disposición transitoria única, bajo la rúbrica: "adscripción provisional de las cuencas no traspasadas", establece que este tipo de cuencas intracomunitarias quedan provisionalmente adscritas a la Confederación hidrográfica correspondiente. Es decir, aquellas Comunidades Autónomas que no han asumido de forma real y efectiva las competencias sobre sus cuencas internas, no pueden regularlas, por lo que es el Estado, a través de los Organismos de Cuenca, el que está llamado a organizar sus aprovechamientos. 
El artículo 23 del Anexo XI (disposiciones normativas del Plan Hidrológico de la Demarcación Hidrográfica del Júcar (2015-2021), que regula el sistema de explotación Marina Baja, establece: "Con el objetivo de mejorar la garantía del abastecimiento del Consorcio de Aguas de la Marina Baja, la conducción Rabasa-Fenollar-Amadorio podrá aportar recursos externos hasta un máximo de $11,5 \mathrm{hm}^{3} /$ año, que podrán proceder del sistema Júcar, de los recursos aportados por la transferencia Júcar Vinalopó Marina Baja y de la desalinizadora de Mutxamel, y preferentemente se podrán transferir en condiciones de sequía, de acuerdo a lo que se estipule en las normas de explotación del sistema”. Desde la desalinizadora de Mutxamel se han conducido $5 \mathrm{hm}^{3}$ en 2015, y otros 5 están previstos para 2016 con destino al embalse del Amadorio, con una tarifa similar a la de la MCT, es decir, $0,69 \mathrm{c} € / \mathrm{m}^{3}$.

\subsection{2.- MCT-Otros municipios alicantinos de la Demarcación del Júcar.}

El artículo 24 del Anexo XI (disposiciones normativas del Plan Hidrológico de la Demarcación Hidrográfica del Júcar (2015-2021), que regula las asignaciones de recursos en la demarcación, determina: "En cuanto a los recursos externos al sistema de explotación, éstos tendrán la siguiente procedencia: a) Los recursos transferidos para el abastecimiento urbano en el ámbito de la MCT, en concreto para el abastecimiento de Alicante, Elche y su zona de influencia, en un volumen estimado de $50 \mathrm{hm}^{3} / \mathrm{año}$. b) Los volúmenes transferidos desde el río Júcar". Como se puede observar, los caudales que pueden eventualmente transferirse desde Alarcón a la Marina Baja no quedan cuantificados en el Plan, por lo que deberán establecerse caso por caso. Dicho artículo dispone también que "El volumen máximo de $18 \mathrm{hm}^{3} /$ año procedente de la desalinizadora de Mutxamel se utilizará para la sustitución de bombeos para uso urbano en masas de agua subterránea en mal estado cuantitativo y para futuros crecimientos urbanos, con prioridad para atender las demandas de las poblaciones de Alicante, Sant Joan d'Alacant, San Vicente del Raspeig, Mutxamel y el Campello y, en periodos de sequía, los abastecimientos del Consorcio de Abastecimiento de la Marina Baja"

A finales de los años 90 se produjo una acusada reducción de los aportes del río Taibilla, y un ininterrumpido aumento del consumo, lo que generó un déficit significativo de recursos hidráulicos que pudo ser atendido mediante reservas del trasvase TajoSegura, generadas por volúmenes no utilizados en años anteriores, y aportaciones extraordinarias de las confederaciones hidrográficas del Segura y del Júcar. El déficit de demanda, que se cifró en $20 \mathrm{hm}^{3}$, se debió a razones climáticas (altas temperaturas, y escasas precipitaciones), así como al incremento del consumo derivado del desarrollo económico de la zona abastecida. 
Los volúmenes suministrados por el Organismo a Alicante, Elche, Santa Pola, San Vicente del Raspeig y Aspe representaban aproximadamente el 20\% del total suministrado por la MCT, por lo que el déficit de recursos correspondientes a dichos municipios, unos $4 \mathrm{hm}^{3}$, se obtiene aplicando dicho porcentaje al mínimo total previsto. Dichos recursos podrían ser aportados, como se hizo en el anterior año hidrológico, por el sistema Júcar, utilizando el acueducto Tajo-Segura hasta la toma en la potabilizadora de Torrealta, origen del Canal de Alicante; considerando las pérdidas en el transporte, el volumen necesario ascendía a $4.5 \mathrm{hm}^{3}$. Estos recursos fueron transferidos para garantizar el suministro de estas poblaciones durante los años hidrológicos: 1997-98 y 1999-2000 (CEMCT 25/7/2000).

En 2006, el Comité Ejecutivo acordó la indemnización a los regadíos tradicionales de la Ribera (Confederación Hidrográfica del Júcar) de 0,28 euros $/ \mathrm{m}^{3}$ por la utilización de $4,1 \mathrm{hm}^{3}$ de agua del Júcar con destino a los abastecimientos de los Ayuntamientos integrados en la MCT que están situados en el ámbito de la cuenca del Júcar (CEMCT 14/7/2006). En 2015, la Mancomunidad de Canales del Taibilla ha recurrido de nuevo a solicitar agua a la cuenca del Júcar para garantizar el suministro a la población. Se solicitaron $4 \mathrm{hm}^{3}$ para el primer trimestre (CEMCT, 18/12/2015).

\section{6.- Caudales propios de los municipios alicantinos integrados en el Organismo.}

Los aportes de agua en el área de suministro de la MCT se incrementan en algo más de $35 \mathrm{hm}^{3} /$ año a partir de aguas procedentes de acuíferos subterráneos. Se trata de caudales con los que cuentan algunos de los municipios del Sistema, y que vienen a complementar los recursos que se reciben desde la entidad. Alicante y Elche, como se observa en la figura 64, son los principales municipios que cuentan con este tipo de recursos, aunque existe un buen número de ellos en el límite sur de la provincia.

En orden de magnitud, la importancia de estos recursos propios en un año medio (2004), tanto en volumen global, como en porcentaje, alcanzó prácticamente el 10,7\% de las necesidades hídricas globales del conjunto de abastecimientos de la MCT en la provincia de Alicante, representando alrededor de $10 \mathrm{hm}^{3}$; un volumen importante pero porcentualmente poco determinante. 


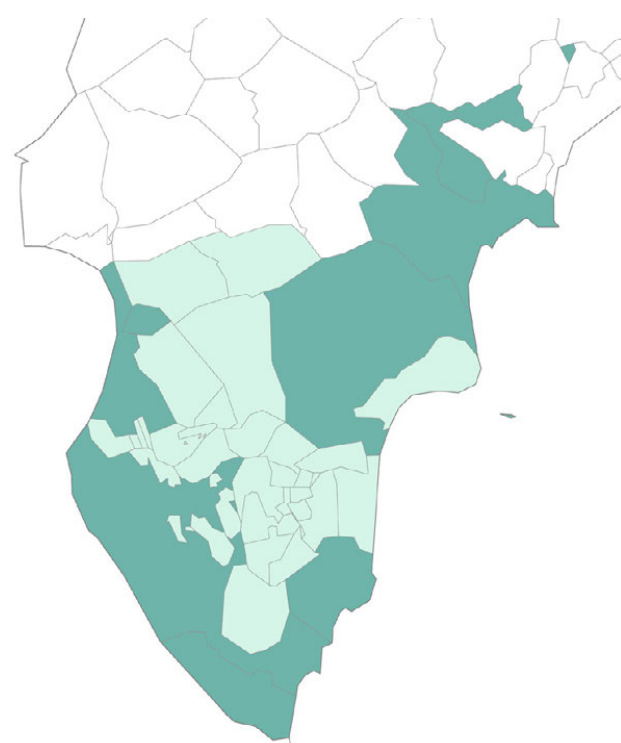

No abastecido por la MCT

Municipio sin recursos propios

Municipio con recursos propios

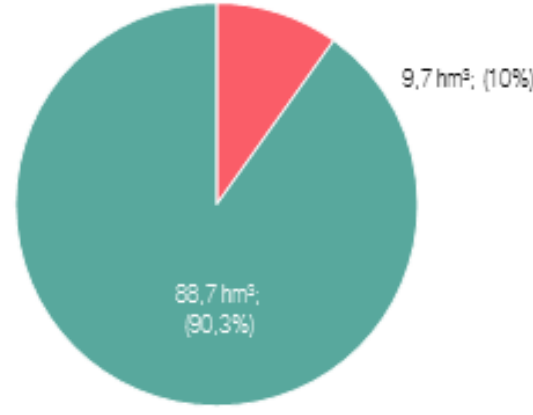

Recursos propios MCT
Fig 64. Poblaciones que cuentan con recursos propios en el ámbito de la MCT en la provincia de Alicante [MCT. Elaboración propia.]

Fig 65. Recursos propios en volumen y porcentaje (2004) [MCT. Elaboración propia.]

En el caso de la ciudad de Alicante, el acuífero de Jumilla-Yecla-Villena aporta del orden de $20 \mathrm{hm}^{3} /$ año a los municipios del Campo de Alicante, utilizando para ello el ramal de la Huerta y las infraestructuras de Aguas Municipalizadas de Alicante (AMAEM). Elche, por su parte, recibe unos $2 \mathrm{hm}^{3}$ del Vinalopó Medio (Morales, 2002). Estas aportaciones, que han sido gráficamente descritas como "los viajes del agua", vienen siendo realizadas desde finales del Siglo XIX (Rico, 2007).

La empresa AMAEM, creada en 1898, ha sido tradicionalmente la encargada de traer estos recursos hídricos a través, en un primer momento, del denominado Canal del Cid. En la actualidad, la empresa gestiona los suministros de Petrer, Monforte del Cid, San Juan y Campello, que no dependen de la MCT, así como los abastecimientos de San Vicente del Raspeig y Alicante, que si son beneficiarios del Sistema. En la figura 66 se muestran los recursos propios de la ciudad de Alicante.

En el caso de Elche, los recursos son aportados por la sociedad "Los Frutales" para el abastecimiento de agua potable. En la figura 67 se muestran los recursos propios de esta población. 


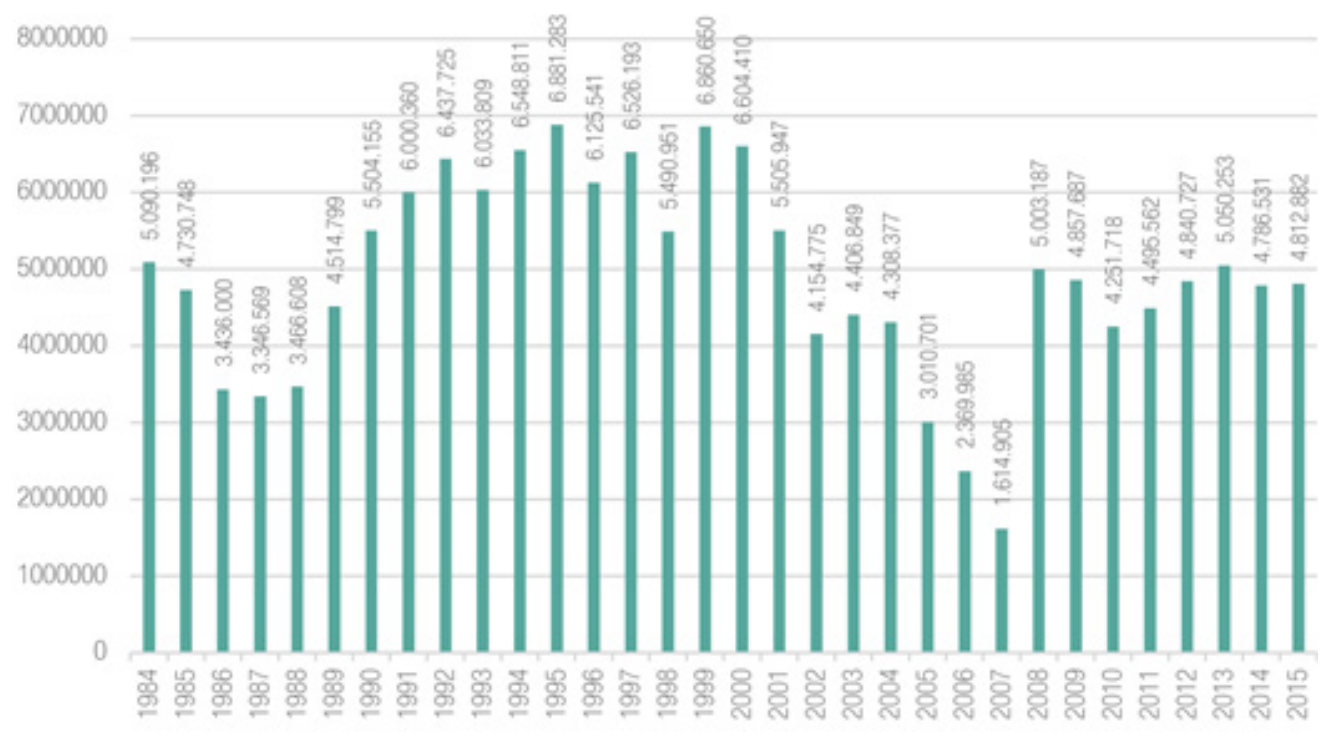

Fig 66. Recursos propios de la ciudad de Alicante (1984-2015) [MCT. Elaboración propia.]

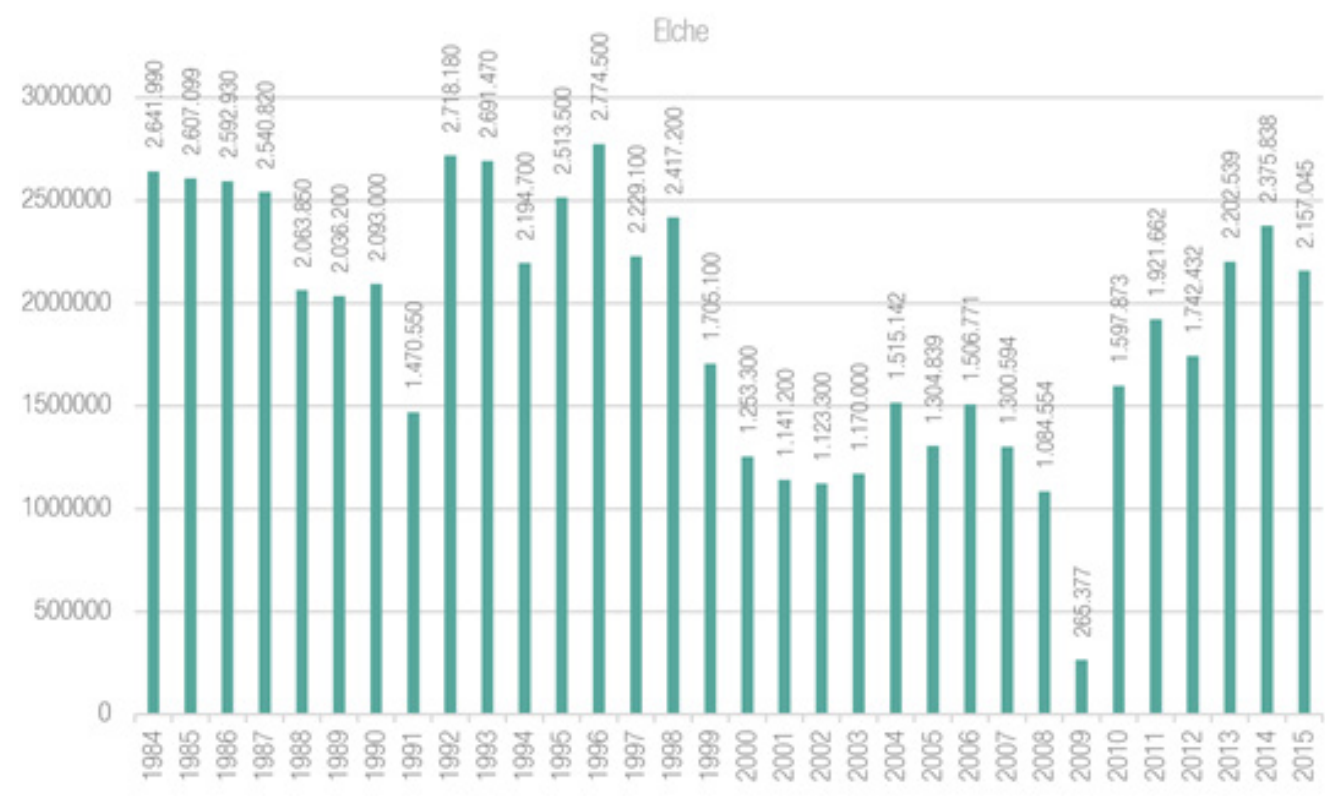

Fig 67. Recursos propios

de Elche (1984-2015)

[MCT. Elaboración propia.] 


\section{7.- Recursos subterráneos extraordinarios.}

A lo largo de la explotación del sistema de la MCT se han ido produciendo momentos en los que ha habido que recurrir a recursos extraordinarios, es decir, inicialmente no concedidos a la MCT. Se trata de caudales procedentes de aprovechamientos de agua subterránea de la cuenca del Segura.

Un antecedente de especial interés fue el suministro de 100 1/seg. en el Partidor de Orihuela en 1972. El Consejo de Ministros de 23 de junio de 1972 autorizó con carácter de urgencia la celebración de un "concurso epigrafiado", al que sólo se presentó la propuesta de Agustín María Serna, quien ofreció estos caudales por el precio de $2.70 \mathrm{ptas} / \mathrm{m}^{3}$, cantidad coincidente con el tope fijado en las bases del concurso. Ofrecía dos pozos, el $\mathrm{n}^{\underline{0}}$ 1, denominado Santa Isabel, con un caudal aforado de 100,20 1/seg, y el no 2, denominado Santa Cruz, con 162,25 1/seg, cuyas características de potabilidad se correspondían con las requeridas por el Ministerio. El Comité Ejecutivo de la MCT adjudicó el concurso y fue aprobado por unanimidad (CEMCT, 31/7/1972). En 1977 terminó el contrato anterior, firmado en 1974, para el suministro a la MCT de un volumen en el Canal de Alicante de hasta $2 \mathrm{hm}^{3} / \mathrm{año}$. Ante las posibles incidencias en la llegada de caudales del trasvase Tajo-Segura, se aconsejó licitar nuevamente la adquisición de caudales complementarios a los de la MCT, ya que en otro caso podrían producirse situaciones de restricción del suministro en diversos municipios. Por ello se propuso sacar a concurso un volumen total de $4 \mathrm{hm}^{3}$ como máximo, a suministrar en dos años. El precio máximo de la oferta fue de 6 $\mathrm{ptas} / \mathrm{m}^{3}$ (CEMCT, 16/2/1978). La mayor parte de caudales extraordinarios, sin embargo, provienen del Sinclinal de Calasparra. Las extracciones (una decena), se ejecutaron por la CHS a primeros de los años 90, junto al río Segura en Los Almadenes (Cieza, Murcia). Aportan recursos al Sistema de la MCT desde el año 2000.

Según la CHS la tarifa de utilización de agua de los pozos de reserva del Sinclinal de Calasparra es la que podemos ver en la tabla 7. 


\begin{tabular}{|c|c|c|}
\hline Año & Riego €/m & Abastecimiento \\
\hline $\mathbf{2 0 0 0}$ & 0,08 & 0,09 \\
\hline $\mathbf{2 0 0 1}$ & 0,15 & 0,17 \\
\hline $\mathbf{2 0 0 2}$ & - & 0,13 \\
\hline $\mathbf{2 0 0 3}$ & - & - \\
\hline $\mathbf{2 0 0 4}$ & - & 0,109 \\
\hline $\mathbf{2 0 0 5}$ & - & 0,0806 \\
\hline $\mathbf{2 0 0 6}$ & - & 0,1007 \\
\hline $\mathbf{2 0 0 7}$ & $-\left(^{*}\right)$ & $-\left(^{*}\right)$ \\
\hline $\mathbf{2 0 0 8}$ & $-\left(^{*}\right)$ & $-\left(^{*}\right)$ \\
\hline $\mathbf{2 0 0 9}$ & $-\left(^{*}\right)$ & $-\left(^{*}\right)$ \\
\hline $\mathbf{2 0 1 0}$ & $-\left(^{*}\right)$ & $-\left(^{*}\right)$ \\
\hline $\mathbf{2 0 1 1}$ & $-\left(^{*}\right)$ & $-\left(^{*}\right)$ \\
\hline
\end{tabular}

Tabla 07. Tarifa de utilización de agua de los pozos de reserva del Sinclinal de Calasparra (2000-2011) [CHS.] (*) En los años 2007, 2008, 2009, 2010 y 2011 no se utilizaron los pozos de sereserva de Sinclinal de Calasparra [CHS] 


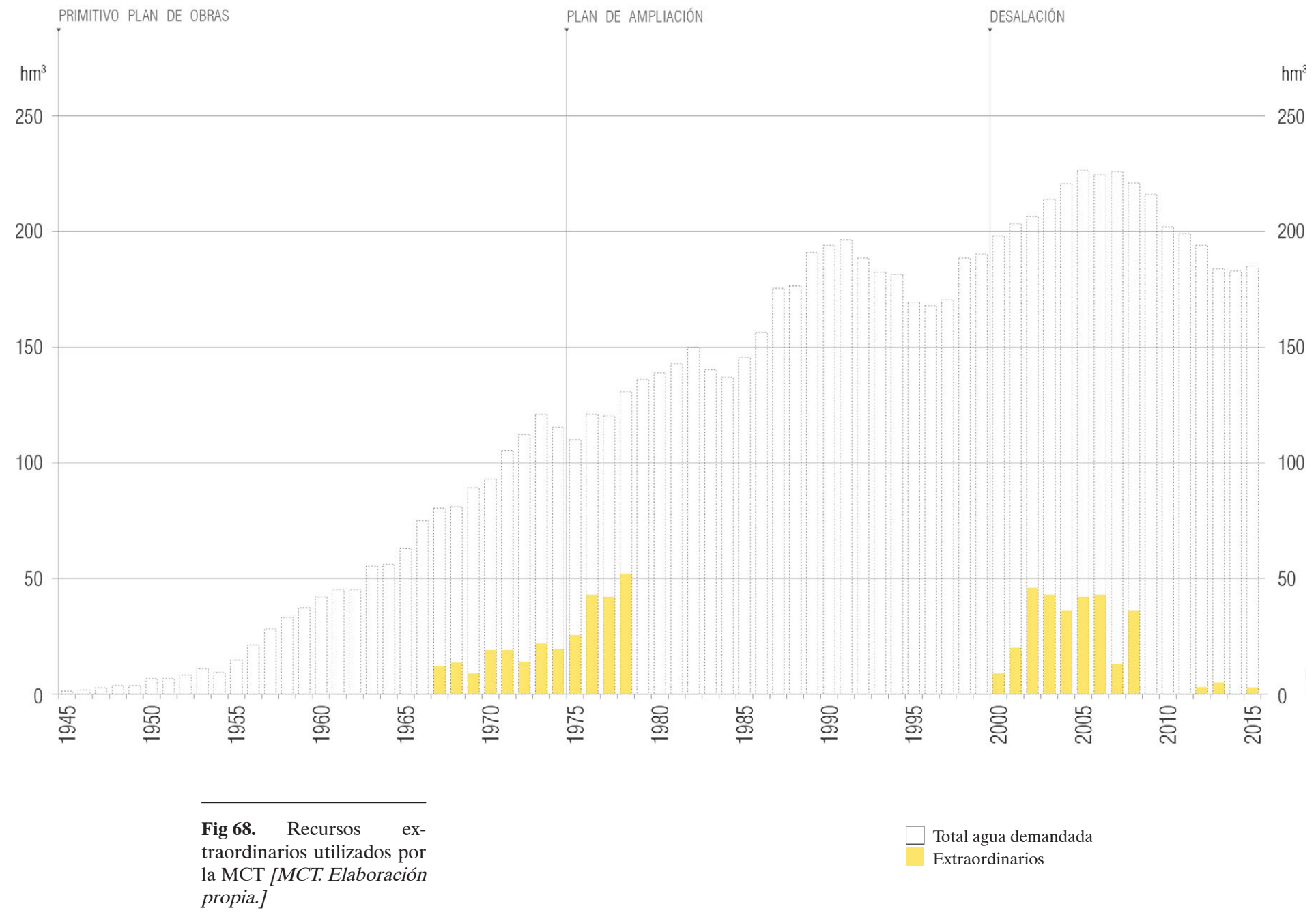




\section{8.- Recursos procedentes de la desalinización con aprovechamiento en la provincia de Alicante.}

La primera vez que se anuncia la conveniencia de contar con una planta desalinizadora marina como apoyo a los caudales disponibles data de 1966, antes de la aprobación del proyecto del trasvase Tajo-Segura (Morales et al., 1989). La desalación, como complemento de los caudales convencionales de la MCT, se contempla de nuevo antes de la derogación del trasvase del Ebro y su consiguiente sustitución por el Programa A.G.U.A (Real Decreto Ley 2/2004, de 18 de junio). En concreto, el Ministerio de Medio Ambiente tenía previsto ejecutar un plan de actuaciones de desalación para garantizar el suministro de la Mancomunidad, que se concretaba en la construcción de 4 plantas desalinizadoras.

En el año 2000 la Secretaría de Estado de Agua y Costas adjudicó el contrato de concesión de las desalinizadoras del Nuevo Canal de Cartagena y Nuevo Canal de Alicante, "que aportarán los recursos hidráulicos precisos para eliminar la actual situación de déficit en que se encuentra el Organismo". Los contratos contemplaban financiación tarifaria de la inversión en la parte no cubierta por el Fondo de Cohesión (CEMCT 13/12/2000).

Fruto de ello fue la ejecución de la desalinizadora de Alicante, inaugurada en el verano de 2003, y la de San Pedro del Pinatar, en 2005. La primera se diseñó con una capacidad inicial de desalación de $18 \mathrm{hm}^{3}$, ampliada a $21 \mathrm{hm}^{3}$ (2006), mientras que la segunda cuenta con una capacidad de desalación de $24 \mathrm{hm}^{3}$. Estaba previsto que en 2007 se alcanzara una capacidad instalada de desalación de $80 \mathrm{hm} 3 /$ año, lo que hacía necesario ampliar las plantas citadas, y construir una nueva en el Campo de Cartagena (Valdelentisco).

Con la aprobación del Programa A.G.U.A., el Ministerio de Medio Ambiente cambió totalmente la política hidráulica española, optando por abandonar la política de trasvases, e incrementar el peso de las desalinizadoras. Fruto de ello, en el ámbito de la Mancomunidad, será la construcción de la desalinizadora de Torrevieja $\left(80 \mathrm{hm}^{3}\right)$ por Acuamed, así como San Pedro del Pinatar II (2006, 24 hm³), y Alicante II $\left(2008,24 \mathrm{hm}^{3}\right)$, por parte de la MCT. Estaba previsto que en 2008 la producción conjunta de todas estas instalaciones alcanzara los $146 \mathrm{hm}^{3} / \mathrm{año}$ (Rico, 2007).

La realidad, sin embargo, demuestra que las expectativas creadas por el programa AGUA no se han llegado a cumplir. En la figura 69 se aprecia que las aportaciones de las desalinizadoras al sistema de la MCT, en 2015, no llegaron a alcanzar los $40 \mathrm{hm}^{3}$, siendo entre los años 2007 y 2010 cuando se alcanzan las mayores aportaciones de aguas desaladas, en el entorno de $\operatorname{los} 60 \mathrm{hm}^{3} /$ año. 


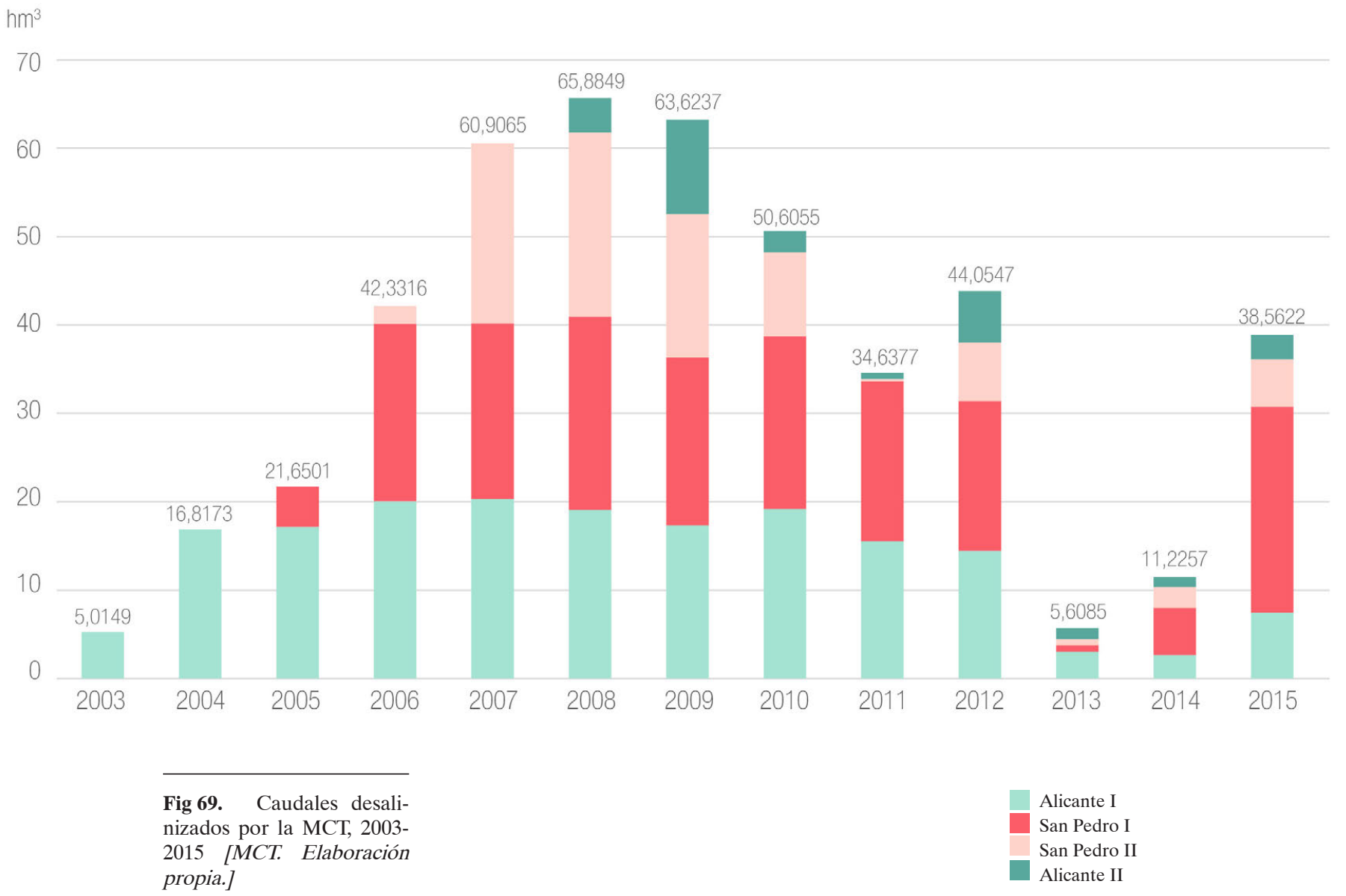


No obstante, en el conjunto del sistema MCT los caudales desalinizados representan un volumen relevante y variable en función de la evolución del resto de fuentes de suministro, sobre todo del comportamiento del río Taibilla, y de los caudales trasvasados, como se observa en la figura 70 .

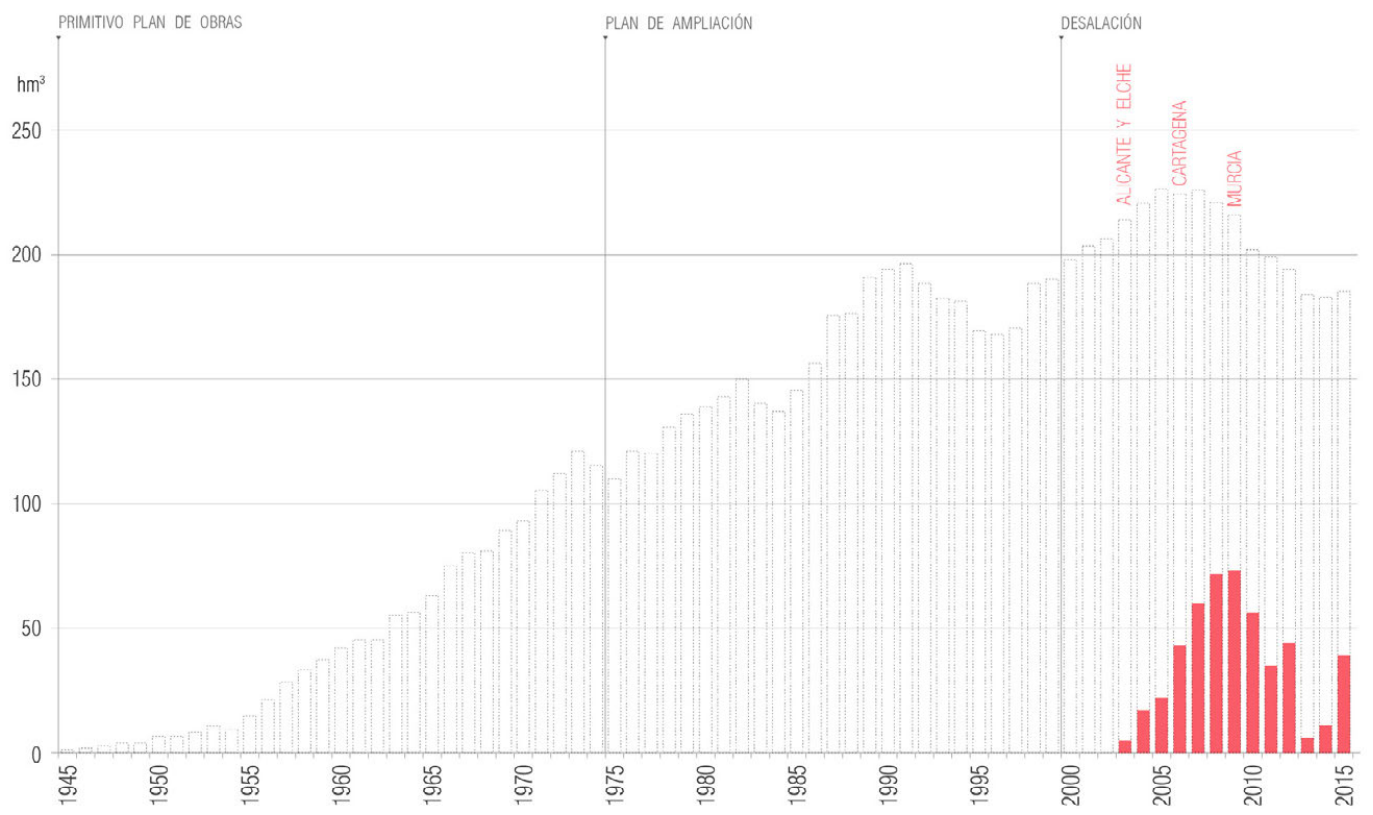

Fig 70. Aportación de caudales desalinizados en el conjunto de la MCT [MCT. Elaboración propia.]

La primera de las desalinizadoras construidas por la MCT, Alicante I, contó con una inversión de 55 millones de euros. Está situada en el paraje de Aguamarga, en el término municipal de Alicante. Los caudales aportados sirven al Nuevo Canal de Alicante. La planta entró en servicio en 2003, y fue ampliada en el 2006. La desalinizadora consta de: toma de agua de mar, planta desalinizadora, impulsión de agua desalinizada, depósito regulador, conexión al canal de alicante y vertido de agua de rechazo y efluentes. El proceso del agua en la planta es común a todas las desalinizadoras de la MCT. 


\begin{tabular}{|c|c|}
\hline Producción máxima & $50.000 \mathrm{~m}^{3}$ /día \\
\hline Proceso de desalación & Osmosis Inversa \\
\hline № de bastidores de Osmosis Inversa & 7 unidades \\
\hline № de trenes de alta presión & 7 unidades \\
\hline Tipo de captación & Batería de 18 pozos playeros \\
\hline Bombeo agua desalada & 4 unidades \\
\hline Conducción de impulsión & $\begin{array}{l}8.300 \mathrm{~m} \text { en } \varnothing 1.100 \\
13.625 \mathrm{~m} \text { en } \varnothing 700\end{array}$ \\
\hline Conducción de vertido & $1.070 \mathrm{~m}$ en $\varnothing 1.800$ \\
\hline Depósito regulador & $50.000 \mathrm{~m}^{3}$ \\
\hline Potencia total instalada & $14 \mathrm{MW}$ \\
\hline Plazo de la concesión & 15 años \\
\hline Inversión realizada & 55 millones de euros \\
\hline Financiación del Fondo de Cohesión & $85 \%$ \\
\hline
\end{tabular}

Tabla 08. Características principales de la desalinizadora Alicante I [MCT.]

Entre los años 2004 y 2012 Alicante I funcionó en valores próximos a su máximo rendimiento de diseño, en especial en los años 2006-2008 y 2010. Sin embargo, sus aportaciones en 2013 y 2014 fueron prácticamente testimoniales, situándose en 2015 en el entorno de los $7 \mathrm{hm}^{3}$, una tercera parte de su capacidad. 


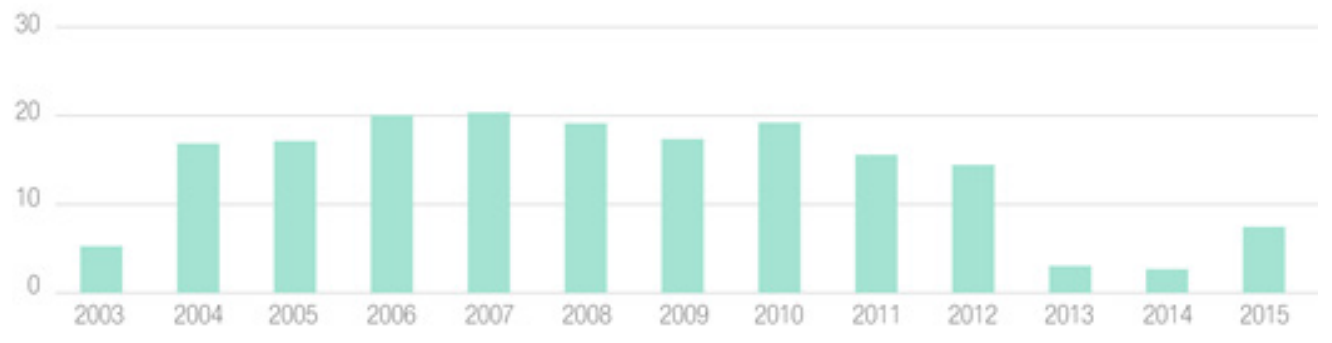

Fig 71. Aportación de aguas desaladas al sistema de la MCT por la IDAM Alicante I [MCT. Elaboración propia.]

En la misma localización, unos años después, en 2008, entró en funcionamiento una segunda planta desalinizadora de agua de mar, con una capacidad de producción algo superior a la anterior: Alicante II, con una inversión de 109,4 millones de euros. Esta estación venía a duplicar la capacidad de producción para complementar los caudales destinados al área de la capital provincial. Sin embargo, la producción real se ha situado muy por debajo de su capacidad potencial en toda la serie histórica, como se observa en la figura 72. La desalinizadora de Alicante II sólo alcanzó aproximadamente la mitad de su capacidad de producción en 2009, presentando aportaciones bastante escasas en el resto de años; en 2015, apenas transformó unos $2 \mathrm{hm}^{3}$ de agua de mar.

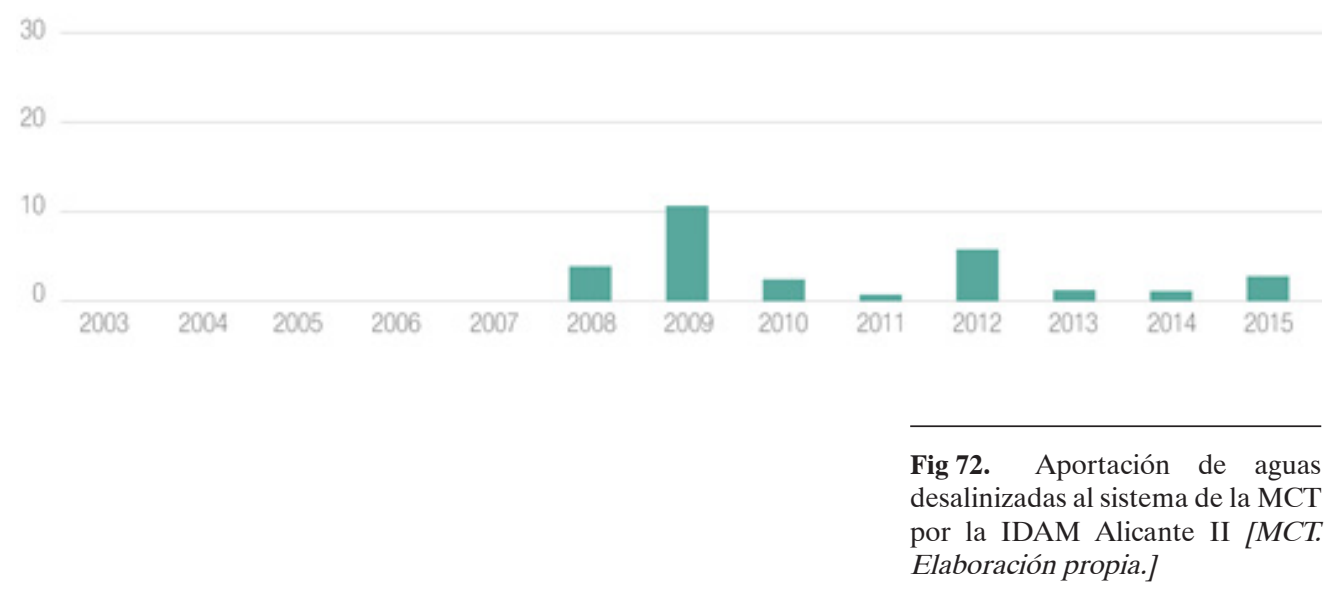




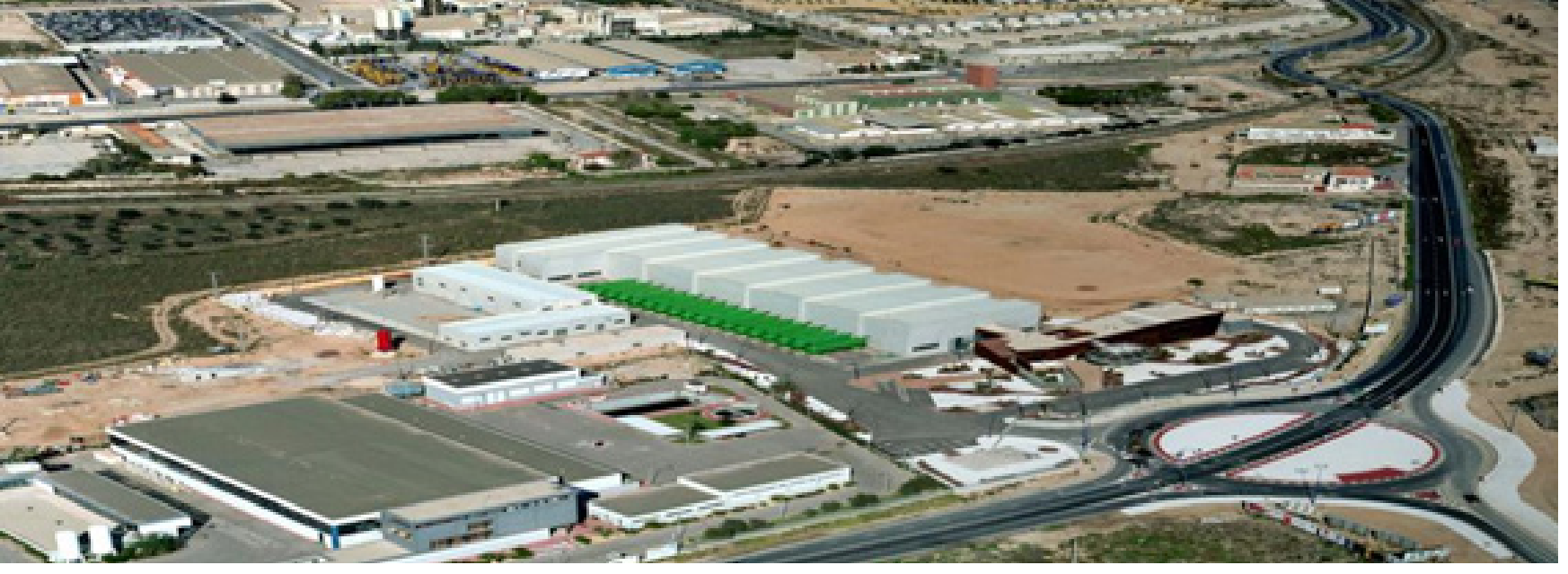

Fig 73. Desalinizadoras de Alicante I y II [MCT.]

Esta planta cuenta con el mismo tipo de instalaciones que Alicante I, es decir, toma de agua de mar, planta desalinizadora, impulsión de agua desalinizada, depósito regulador, conexión al Canal de Alicante y vertido de agua de rechazo y efluentes. Las características principales de la instalación pueden verse en la tabla 9.

\begin{tabular}{|c|c|}
\hline Producción diaria & $65.000 \mathrm{~m}^{3}$ \\
\hline Proceso de desalinización & Ósmosis inversa \\
\hline № de líneas de proceso & 9 unidades \\
\hline Tipo de captación & Toma abierta de agua de mar \\
\hline Vertido del agua de rechazo & Emisario de $5.800 \mathrm{~m}(1.400 \mathrm{~mm} \varnothing)$ \\
\hline Potencia total instalada & $15 \mathrm{mva}$ \\
\hline Consumo energético & $3,8 \mathrm{kwh} / \mathrm{m}^{3}$ \\
\hline Conducción de impulsión & $8.000 \mathrm{~m}(1.100 \mathrm{~mm} \varnothing)$ \\
\hline Depósito regulador & $65.000 \mathrm{~m}^{3}$ \\
\hline
\end{tabular}

Tabla 09. Datos planta desalinizadora Alicante II [MCT. Elaboración propia.] 
A diferencia de las anteriores, la desalinizadora de San Pedro, que también aporta recursos con destino, parcialmente, a la provincia de Alicante, ha venido funcionando casi a pleno rendimiento desde 2006, con las excepciones de 2013, cuando estuvo prácticamente parada, y 2014, cuando recuperó ligeramente su producción hasta cerca de los $5 \mathrm{hm}^{3}$; en 2015, como se aprecia en la figura 74, la desalinizadora ha vuelto a situarse en máximos de rendimiento, por encima de los $20 \mathrm{hm}^{3}$.

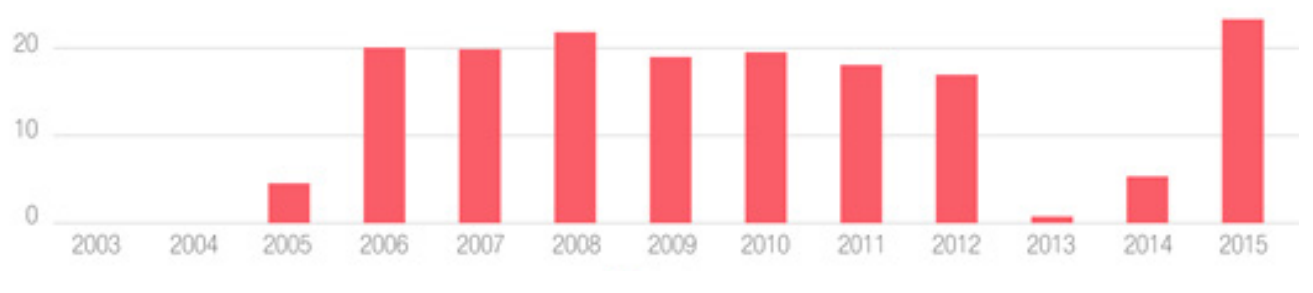

Fig 74. Aportación de aguas desaladas al sistema de la MCT por la IDAM San Pedro del Pinatar [MCT. Elaboración propia.]

La planta, cuya inversión ascendió a 72 millones de euros, está situada en el paraje del Mojón, en las inmediaciones de las Salinas y Arenales de San Pedro del Pinatar. Sus caudales se entregan al Nuevo Canal de Cartagena y a la conexión con la Vega Baja del Segura. Dispone de una toma de agua de mar que conduce las aguas a la planta desalinizadora. Sus características principales pueden verse en la tabla 10.

\begin{tabular}{|c|c|}
\hline Producción diaria & $65.000 \mathrm{~m}^{3}$ \\
\hline Proceso de desalinización & Ósmosis inversa \\
\hline № de líneas de proceso & 9 unidades \\
\hline Tipo de captación & 20 drenes horizontales \\
\hline Vertido del agua de rechazo & Emisario de $5.800 \mathrm{~m}(1.400 \mathrm{~mm} \varnothing)$ \\
\hline Potencia total instalada & $15 \mathrm{mva}$ \\
\hline Consumo energético & $3,75 \mathrm{kwh} / \mathrm{m}^{3}$ \\
\hline Conducción de impulsión & $7.500 \mathrm{~m}(800 \mathrm{~mm} \varnothing)$ \\
\hline Depósito regulador & $65.000 \mathrm{~m}^{3}$ \\
\hline
\end{tabular}

Tabla 10. Datos desalinizadora San Pedro I (Antonio León Martínez Campos) [MCT. Elaboración propia.] 
Finalmente la desalinizadora de San Pedro II, cuya inversión alcanzó los 89 millones de euros, se situó en valores próximos a su máxima capacidad de producción entre los años 2007 y 2009, presentando varios años donde la generación de agua fue prácticamente inexistente tal como se observa en la Figura 75. En 2005 esta desalinizadora aportó unos $5 \mathrm{hm}^{3}$ al sistema de la MCT.

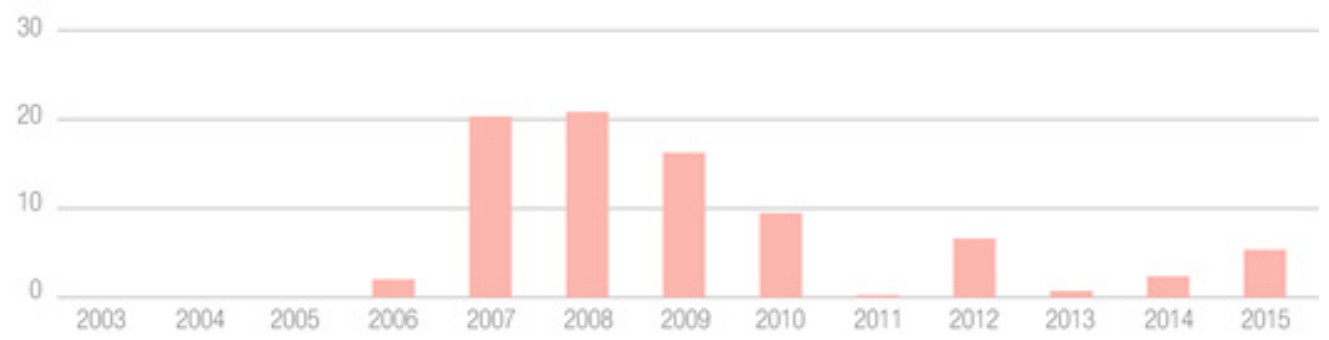

Fig 75. Aportación de aguas desaladas al sistema de la MCT por la IDAM San Pedro II [MCT. Elaboración propia.]

Esta desalinizadora está situada junto a San Pedro I, y sus caudales, al igual que aquélla, son entregados al Nuevo Canal de Cartagena y a la Conexión con la Vega Baja del Segura. Sus características pueden apreciarse en la tabla 11.

\begin{tabular}{|c|c|}
\hline Producción diaria & $65.000 \mathrm{~m}^{3}$ \\
\hline Proceso de desalinización & Ósmosis inversa \\
\hline № de líneas de proceso & 9 unidades \\
\hline Tipo de captación & Toma abierta de agua de mar \\
\hline Vertido del agua de rechazo & Emisario de $5.800 \mathrm{~m}(1.400 \mathrm{~mm} \varnothing)$ \\
\hline Potencia total instalada & $15 \mathrm{mva}$ \\
\hline Consumo energético & $3,75 \mathrm{kwh} / \mathrm{m}^{3}$ \\
\hline Conducción de impulsión & $8.000 \mathrm{~m}(1.100 \mathrm{~mm} \varnothing)$ \\
\hline Depósito regulador & $65.000 \mathrm{~m}^{3}$ \\
\hline
\end{tabular}

Tabla 11. Datos desalinizadora San Pedro II [MCT. Elaboración propia.] 
En la figura 76 puede observarse la localización de las desalinizadoras que incorporan caudales al sistema de la MCT, y su relación con las canalizaciones y resto de infraestructuras del Organismo.

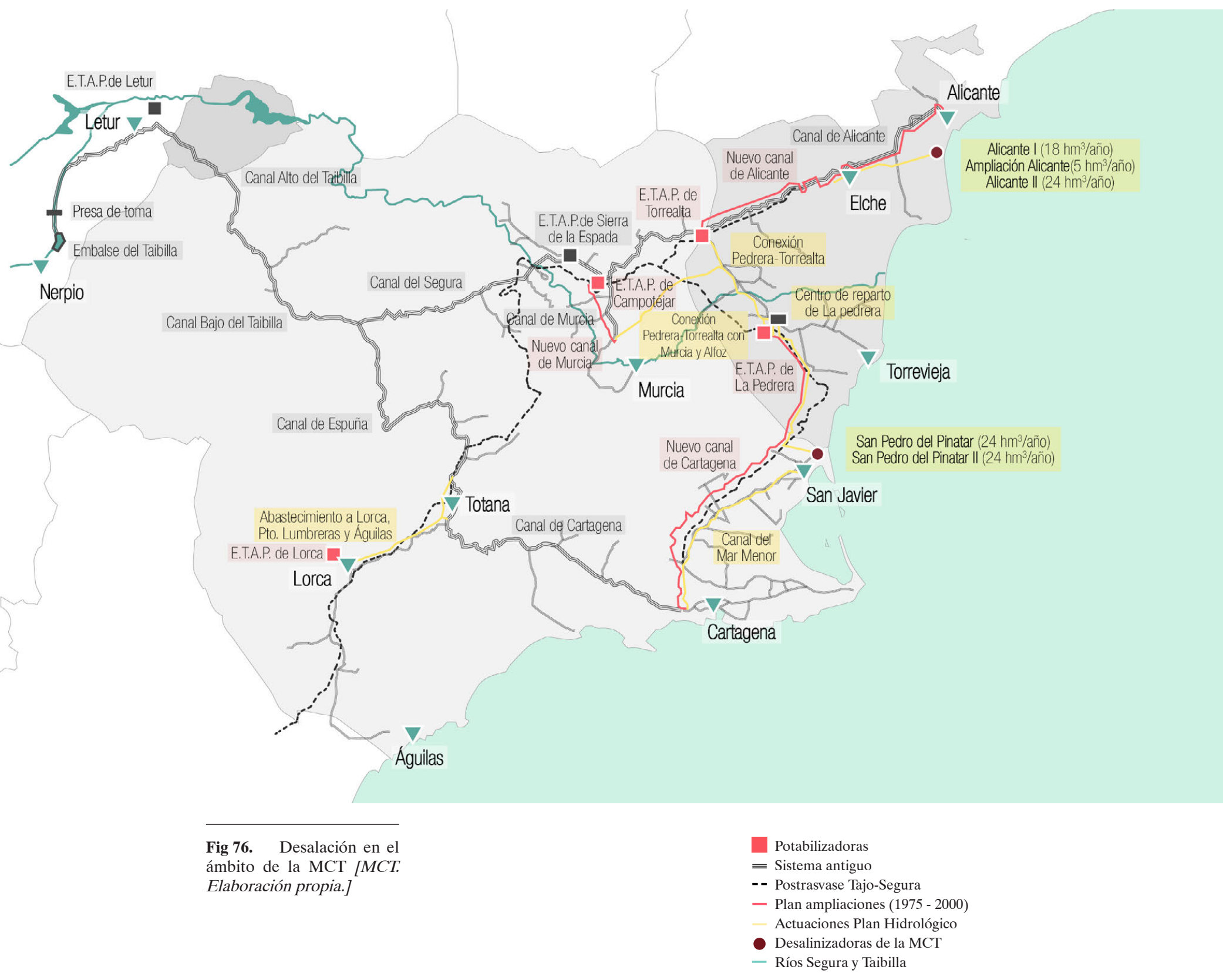


Una de las mayores preocupaciones es el coste de generación de estos caudales, que pueden incidir de manera sustancial en los precios del agua suministrada por la MCT. En las siguientes figuras se observa la evolución de las tarifas de las desalinizadoras gestionadas por la MCT entre 2005 y 2008.
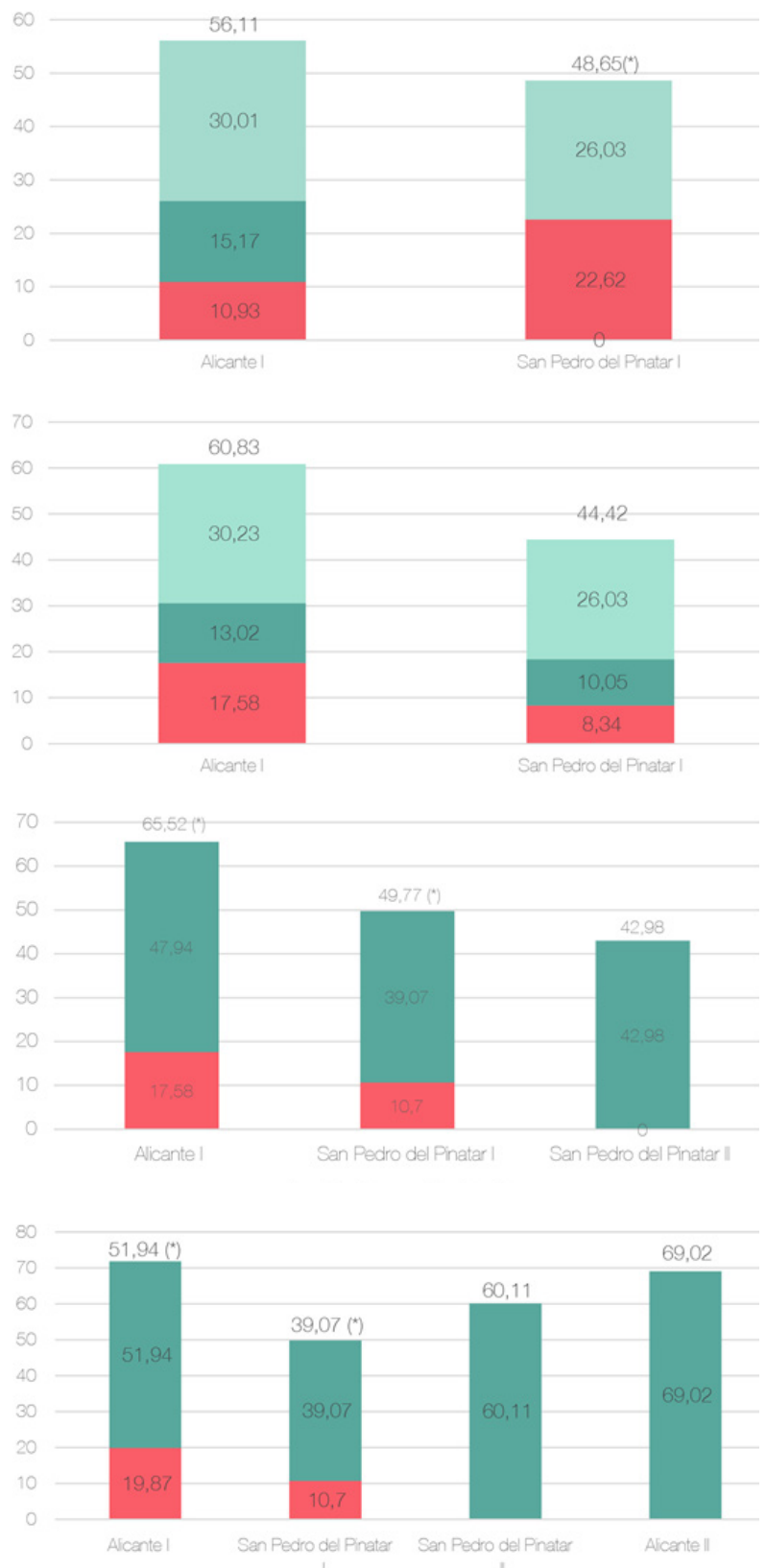

Amortización

Explotación (F)

Explotación (V)

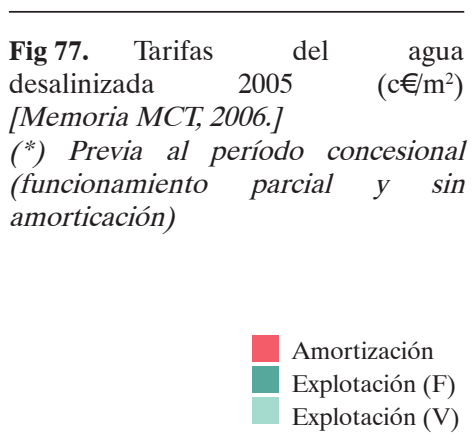

Fig 78. Tarifas del agua desalinizada $2006\left(\mathrm{c} € / \mathrm{m}^{2}\right)$ [Memoria MCT, 2007.] (*) Desalinizadora ampliada (**) Provisional

Amortización

Explotación (F)

Explotación (V)

Fig 79. Tarifas del agua desalinizada $2007\left(\mathrm{c} € / \mathrm{m}^{2}\right)$ [Memoria MCT, 2008.] (*) Tarifa concesional

Amortización

Explotación (F)

Explotación (V)

Fig 80. Tarifas del agua desalinizada $2008\left(\mathrm{c} € / \mathrm{m}^{2}\right)$ [Memoria MCT, 2009.] (*) Tarifa concesional 
En las siguientes figuras pueden apreciarse los valores actualizados a 2015, donde además se desagregan el conjunto de costes fijos y variables, así como los de amortización de las instalaciones.

\begin{tabular}{|c|c|c|c|}
\hline & \multicolumn{3}{|c|}{ IVA incluido } \\
\cline { 2 - 4 } & $\begin{array}{c}\text { Coste fijo } \\
\text { explotación anual } \\
\text { total }(\boldsymbol{(})\end{array}$ & $\begin{array}{c}\text { Coste amortización } \\
\text { anual }(\boldsymbol{(})\end{array}$ & $\begin{array}{c}\text { Tarifa variable } \\
\text { total }(\boldsymbol{€} / \mathbf{m} \mathbf{)})\end{array}$ \\
\hline Alicante I & $3.646 .719,13$ & $3.897 .689,37$ & 0,3583 \\
\hline San Pedro I & $3.005 .623,94$ & $2.280 .945,62$ & 0,3031 \\
\hline Alicante II & $2.406 .390,42$ & & 0,3304 \\
\hline San Pedro II & $2.222 .695,05$ & & 0,3374 \\
\hline
\end{tabular}

\begin{tabular}{|c|c|c|c|c|c|c|c|c|c|}
\hline & \multicolumn{9}{|c|}{ Tarifas desglosadas y actualizadas (Costes desaladoras 2015 rev.1) } \\
\hline & \multirow{3}{*}{$\begin{array}{c}\text { Amortización } \\
\qquad\left(€ / \mathbf{m}^{3}\right)\end{array}$} & \multicolumn{5}{|c|}{ Explotación $\left(€ / \mathbf{m}^{3}\right)$} & \multirow{3}{*}{$\begin{array}{l}\text { Producción } \\
\text { nominal } \\
\left(\mathbf{m}^{3}\right)\end{array}$} & \multirow{2}{*}{\multicolumn{2}{|c|}{$\begin{array}{c}\text { Importes fijos } \\
\text { Coste fijo anual }(€)\end{array}$}} \\
\hline & & \multicolumn{2}{|c|}{ Energéticos } & \multicolumn{2}{|c|}{ No energéticos } & \multirow[b]{2}{*}{$\begin{array}{c}\text { Total } \\
\text { explotación }\end{array}$} & & & \\
\hline & & Fijos & Variable & Fijos & Variable & & & Energético & $\begin{array}{c}\text { No } \\
\text { energéticos }\end{array}$ \\
\hline $\begin{array}{l}\text { Alicante } \\
\text { I }\end{array}$ & 0,1857 & 0,0950 & 0,2834 & 0,0787 & 0,0749 & 0,5320 & 20.987 .500 & $1.994 .208,22$ & $1.652 .510,91$ \\
\hline $\begin{array}{c}\text { San } \\
\text { Pedro I }\end{array}$ & 0,1000 & 0,0775 & 0,2250 & 0,0542 & 0,0781 & 0,4348 & 22.815 .000 & $1.768 .415,86$ & 1.237.208,08 \\
\hline $\begin{array}{c}\text { Alicante } \\
\text { II }\end{array}$ & & 0,0580 & 0,3027 & 0,0455 & 0,0277 & 0,4359 & 22.815 .000 & $1.323 .403,32$ & $1.082 .987,10$ \\
\hline $\begin{array}{c}\text { San } \\
\text { Pedro II }\end{array}$ & & 0,0327 & 0,3078 & 0,0405 & 0,0296 & 0,4379 & 22.815 .000 & $745.981,44$ & \\
\hline
\end{tabular}

Tabla 12. Tarifas de las desalinizadoras gestionadas por la MCT, 2015 [MCT. Elaboración propia.] 
En el componente tarifario los costes energéticos son los más determinantes para el precio final del agua producida como se observa en la tabla 13.

\begin{tabular}{|c|c|c|c|c|c|}
\hline Planta & $\begin{array}{c}\text { Bombeo } \\
\text { hasta } \\
\text { filtros }\end{array}$ & Turbobombas & $\begin{array}{l}\text { Bombeo } \\
\text { Producto }\end{array}$ & $\begin{array}{c}\text { Tratamiento } \\
\text { y S.A. }\end{array}$ & $\begin{array}{c}\sum \text { Total de } \\
\text { Procesos } \\
\mathbf{k W h} / \mathbf{m}^{3}\end{array}$ \\
\hline Alicante I & 0,892292 & 3,482022 & 0,648673 & 0,122435 & 5,145423 \\
\hline $\begin{array}{c}\text { San Pedro } \\
\text { I }\end{array}$ & 0,4118035 & 3,09459568 & 0,39547927 & 0,041451 & 3,943629 \\
\hline $\begin{array}{c}\text { San Pedro } \\
\text { II }\end{array}$ & 0,3797953 & 3,086668 & 0,34190166 & 0,163435 & 3,971800 \\
\hline
\end{tabular}

Tabla 13. Consumos $(\mathrm{kWh} /$

$\mathrm{m}^{3}$ ) en desalinizadoras del área de influencia MCT [MCT. Elaboración propia.]

Las aportaciones de la desalación de agua de mar han cobrado una importancia decisiva en los últimos años en el global de los caudales suministrados por la MCT. Destaca que en el año hidrológico 2008-2009, donde se produjo la mayor aportación de recursos del río Taibilla del último decenio, el funcionamiento de las cinco desalinizadoras posibilitó la superación del periodo deficitario de recursos hidráulicos, por lo que se pudo atender todas las demandas hídricas de cualquier tipo, urbanísticas, industriales etc (Memoria MCT, 2009). 


\section{6.- POBLACIÓN ABASTECIDA Y VOLÚMENES SUMINISTRADOS POR LA MCT EN LA PROVINCIA DE ALICANTE.}

\section{1.- Datos generales.}

La población de la provincia de Alicante presenta dinámicas de crecimiento muy acusadas, como se puede observar en la figura 81 .

La dotación media en litros por habitante y año para un año medio, como 2004, varía en la provincia de Alicante según las diferentes comarcas, como se puede observar en la figura 82 .

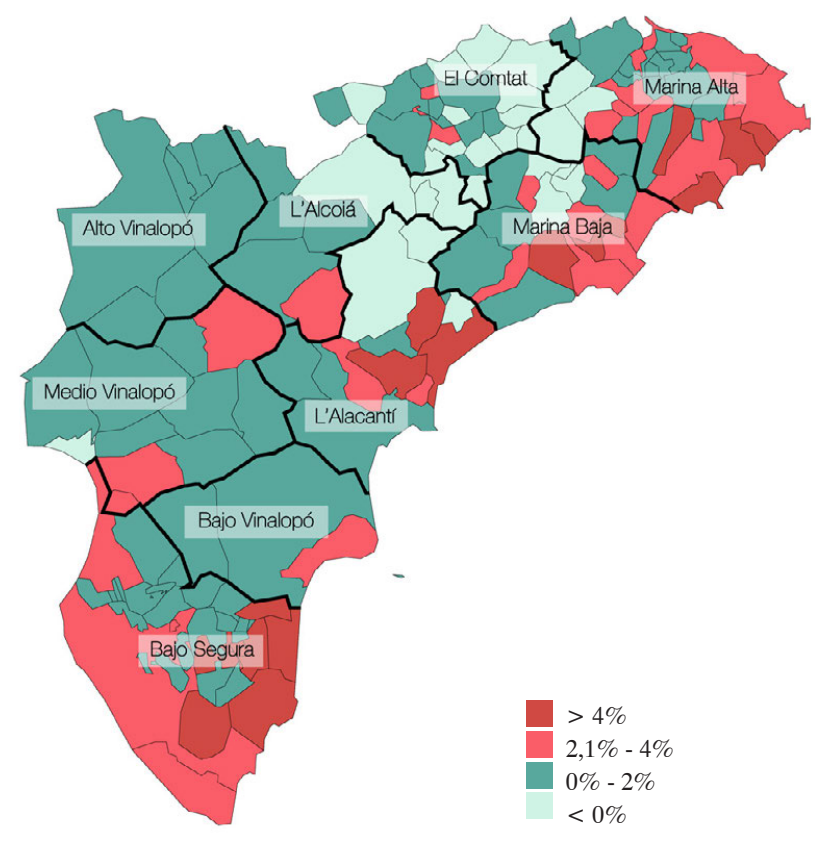

Fig 81. Dinámica de crecimiento de la población en la provincia de Alicante [Diputación de Alicante. Elaboración propia.]

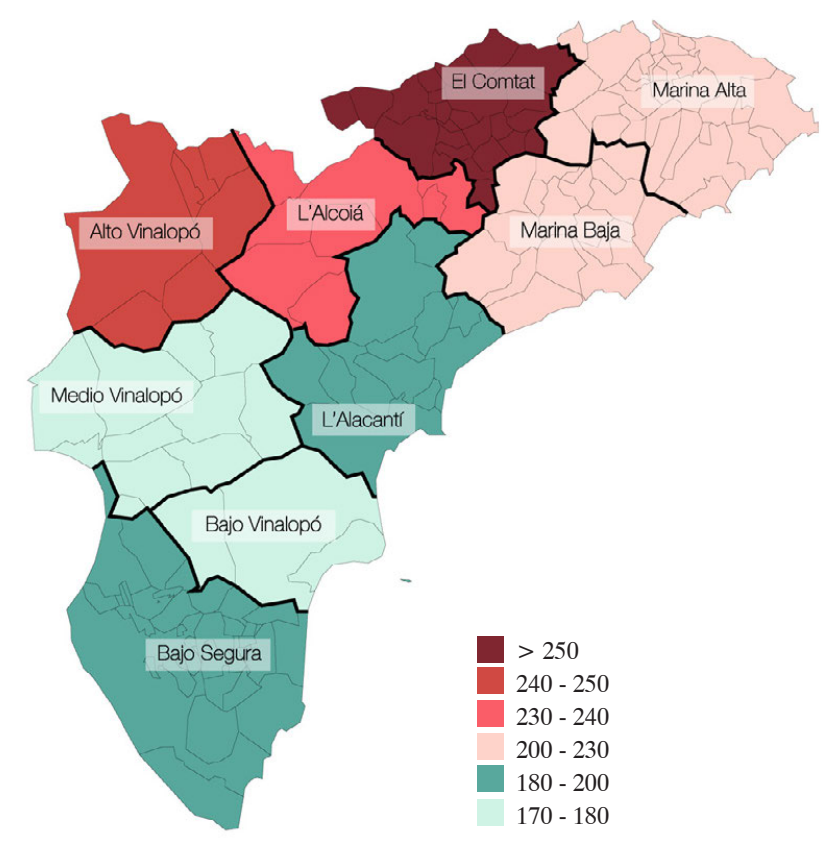

Fig 82. Dotación real (l/h/día) año 2004 [Diputación de Alicante. Elaboración propia.]

La MCT suministra agua a un total de 2.400 .000 habitantes, aproximadamente, de los que un $42 \%$, unos 1.008 .000 habitantes, residen en Alicante. 


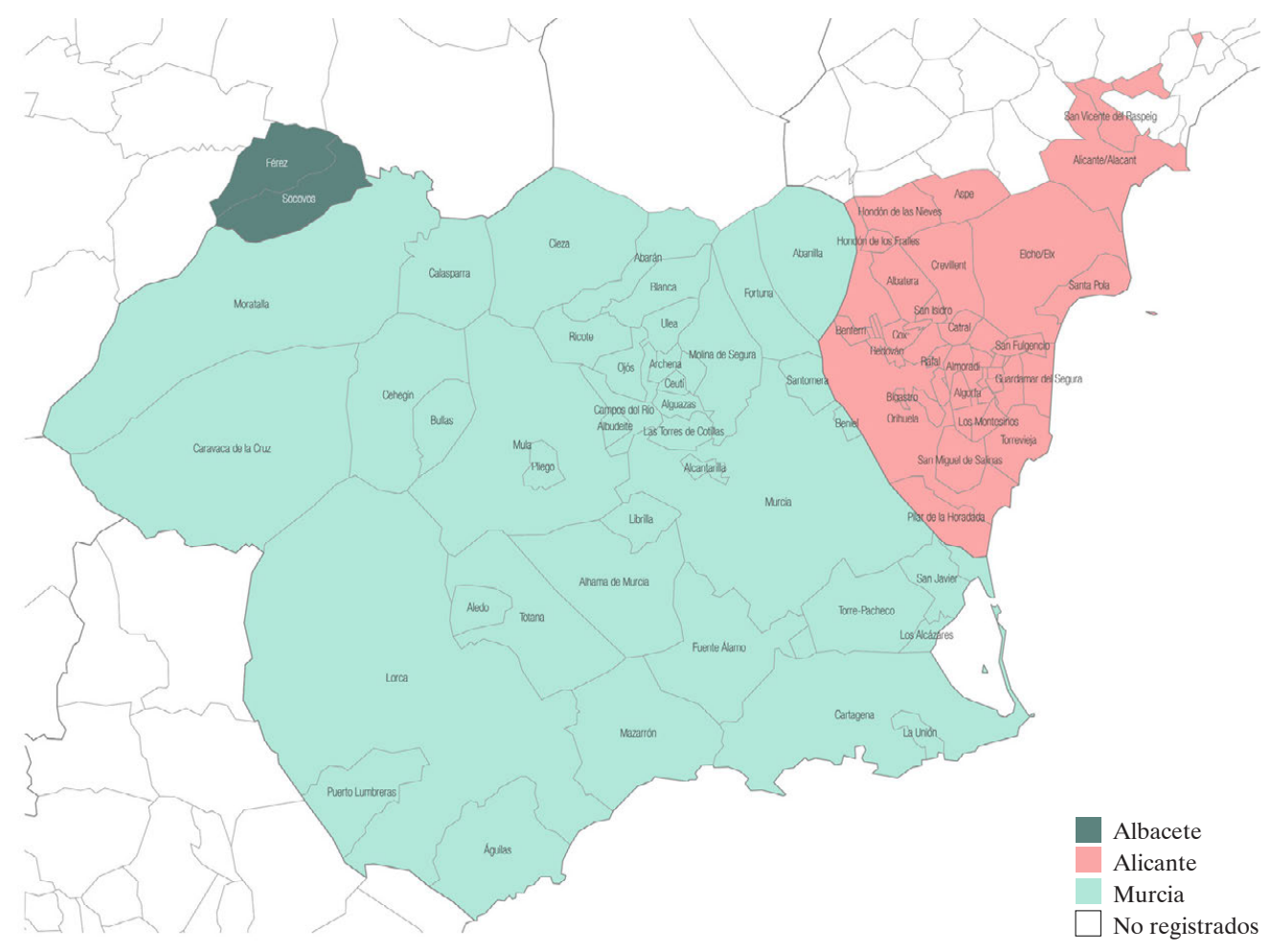

Fig 83. Municipios abastecidos por la MCT por provincias [MCT. Elaboración propia.]

La figura 83 refleja el dominio en cuanto a territorio de los abastecimientos correspondientes a la provincia de Murcia, seguidos por los de la provincia de Alicante, y por último los correspondientes a la provincia de Albacete. El predominio territorial murciano viene acompañado de una mayor importancia en el reparto de los volúmenes medios utilizados para abastecimiento. En el periodo 1989/2005, prácticamente el 62\% de los recursos suministrados correspondieron a municipios pertenecientes a la Región de Murcia. El suministro a poblaciones de la provincia de Albacete es prácticamente testimonial, con un $0,11 \%$.

Del total poblacional de la provincia de Alicante, los habitantes servidos gracias a las aguas suministradas en alta por la MCT se aproximan en el año 2015 al $40 \%$ de la población total de la provincia, como puede observarse en la figura 84 . 


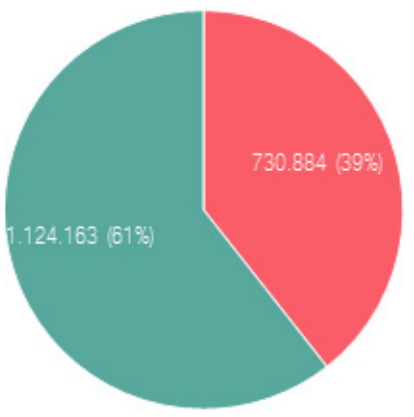

Fig 84. Población de Derecho abastecida en Alicante según suministrador en alta en número de habitantes y porcentaje sobre el total [INE. 2015. Elaboración propia.]

Este porcentaje es una clara muestra de la importancia de este Organismo para el sostenimiento de las demandas de agua urbana en la provincia. El abastecimiento en alta, especialmente en el ámbito costero, que es el que presenta un mayor desarrollo socioeconómico e incremento poblacional, se circunscribe a cinco grandes entidades, entre las cuales la MCT es proporcionalmente la más relevante, seguida por los Consorcios de Aguas de la Marina Baja y la Marina Alta, y por los Canales de la Huerta y Del Cid. En la figura 85 se aprecia la distribución territorial del ámbito respectivo de dichas entidades.

El consumo de agua en la provincia de Alicante, en especial en la zona sureste, se ha venido incrementando progresivamente en los últimos años, planteando continuamente nuevas demandas. No obstante, dicho crecimiento no ha sido tan exponencial como podría esperarse atendiendo al notable desarrollo socioeconómico de esta zona, sobre todo por el crecimiento del turismo residencial. Y ello no ha sido así debido al incremento en la eficiencia de los abastecimientos en baja.

En efecto, Desde el año $1984\left(131,2 \mathrm{hm}^{3}\right)$ a $1991\left(191,3 \mathrm{hm}^{3}\right)$ se observa un fuerte incremento del consumo en la provincia. Sin embargo, a partir de este año, la sequía de la primera mitad de los años noventa se deja sentir en el volumen distribuido por la Mancomunidad, que se reduce progresivamente, hasta alcanzar los $167 \mathrm{hm}^{3}$ en 1996. A partir de entonces, se produce de nuevo una recuperación del consumo de agua potable en todo su ámbito. La expansión de nuevas zonas residenciales en municipios interiores y, sobre todo, en los costeros, explicaría este segundo ciclo de fuerte expansión del consumo, que se inició a partir de $1997\left(168 \mathrm{hm}^{3}\right)$ y que continuó hasta $\left.2006(217 \mathrm{hm})^{3}\right)$. Torrevieja, por ejemplo, incrementó su consumo de agua en alta desde $6,2 \mathrm{hm}^{3}$ en 1994, a 10,3 hm en 2001 , es decir, un $65 \%$. 


\begin{tabular}{|c|c|}
\hline RECURSOS 2004-2005 & $\mathbf{H m}^{\mathbf{3}}$ \\
\hline Río Taibilla & 42 \\
\hline Trasvase Tajo-Segura & 126 \\
\hline Desalación & 23 \\
\hline Extraordinarios & 32 \\
\hline TOTAL & 223 \\
\hline
\end{tabular}

\begin{tabular}{|c|c|}
\hline RECURSOS 2005-2006 & $\mathbf{H m}^{\mathbf{3}}$ \\
\hline Río Taibilla & 37,9 \\
\hline Trasvase Tajo-Segura & 120,1 \\
\hline Desalación & 35,09 \\
\hline Extraordinarios & 30,9 \\
\hline TOTAL & 223,9 \\
\hline
\end{tabular}

Tabla 14. Recursos según procedencia de la MCT años hidrológicos de 2004-2005 [MCT. Elaboración propia.]

Tabla 15. Recursos según procedencia de la MCT años hidrológicos de 2005-2006 [MCT. Elaboración propia.]

En los años hidrológicos de 2004-2005, y 2005-2006, el volumen total utilizado por la MCT alcanzó los 223 y $223,9 \mathrm{hm}^{3}$ respectivamente, contando con caudales de diversa procedencia como se observa en las tablas 14 y 15 .

A partir de 2006, sin embargo, las dinámicas se invierten, y observamos reducciones significativas en las demandas de muchos municipios. Destaca la menor demanda de los tres ayuntamientos más importantes, Murcia, Alicante y Elche, que en el año hidrológico 2008-2009 fue un 11\% inferior a la prevista (Memoria MCT, 2009). En 2006 el consumo de la ciudad de Torrevieja descendió hasta $9,7 \mathrm{hm}^{3}$, gracias a las mejoras en la red de distribución en baja (Rico, 2007). En 2013, la demanda total de agua de la Mancomunidad se situó en $183,9 \mathrm{hm}^{3}$, de los que 74,1 $\mathrm{hm}^{3}$ corresponden a la provincia de Alicante, un $40,3 \%$ del total. Las tendencias de consumo se han contenido en términos generales gracias al control de fugas, del subcontaje y de la reducción de la morosidad. Los niveles de eficiencia son ya muy elevados, por lo que los márgenes de mejora en este terreno son limitados. En el siguiente mapa se puede observar la evolución del consumo de agua potable en los Municipios abastecidos por la MCT en el sur de la provincia de Alicante.

En la figura 86 se observa cómo en los últimos años el agua suministrada se ha contenido e incluso reducido significativamente, por efecto, como hemos señalado, de la sequía y de la mejora de los rendimientos técnicos. Los efectos de la crisis económica iniciada en 2008 también se han hecho sentir en dicha reducción de los consumos. 
En localidades como Alicante o Torrevieja, el volumen de agua suministrado en alta ha descendido entre el 11 y 5\% entre 2011 y 2013, y el consumo doméstico de agua un $20 \%$ desde principios de la década del 2000 (Gil et al., 2015).

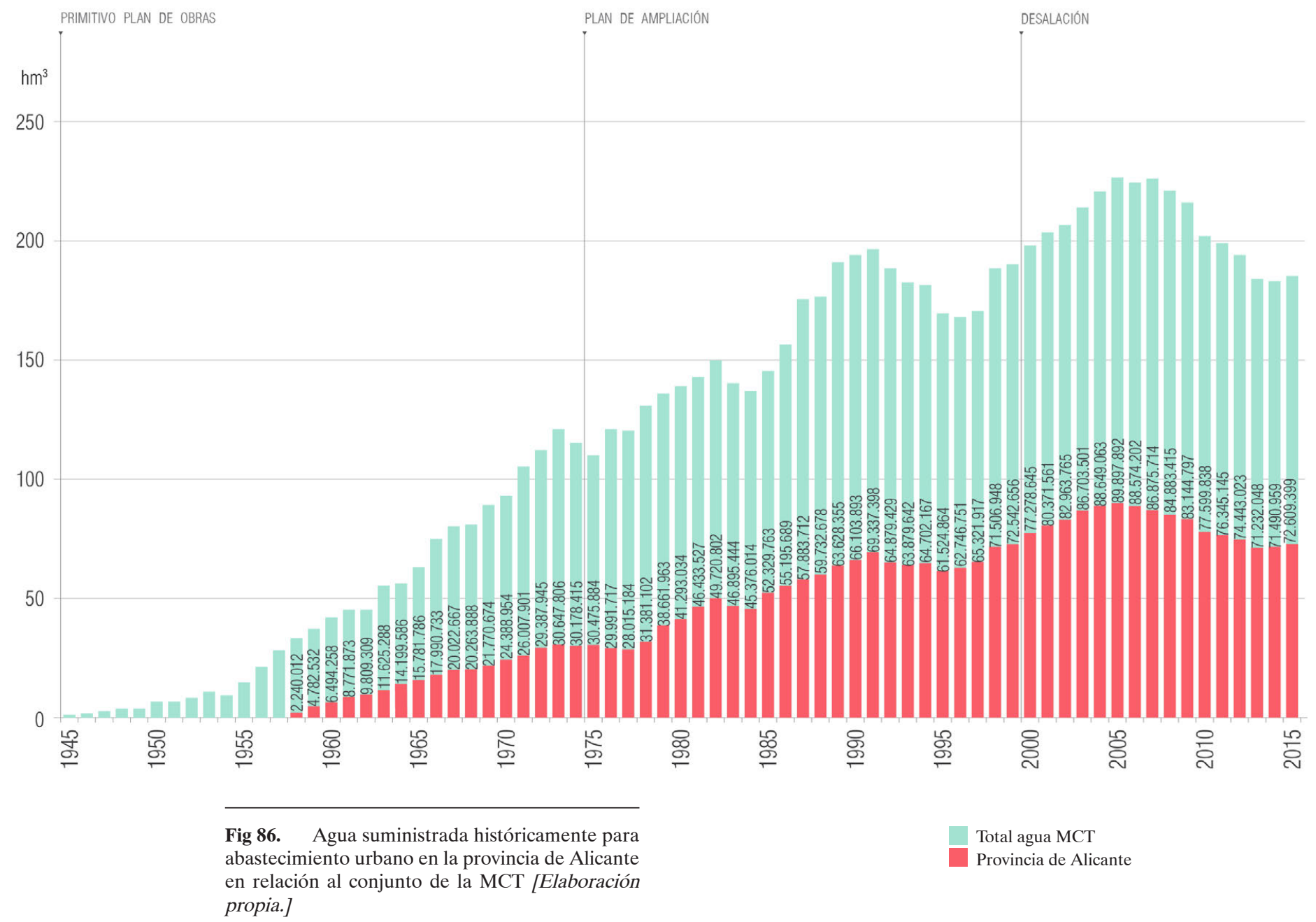

En el caso de los recursos suministrados por la MCT, las tendencias son equivalentes a las observadas analizando los consumos totales, tal como se representa en la figura 87. En este caso hay además que tener en cuenta el incremento poblacional experimentado por estos municipios, el desarrollo de nuevas actividades económicas demandantes de agua, y la incorporación de nuevos municipios alicantinos al Sistema. Con todo, la reducción de consumos se evidencia también en estos municipios después de 2006. 


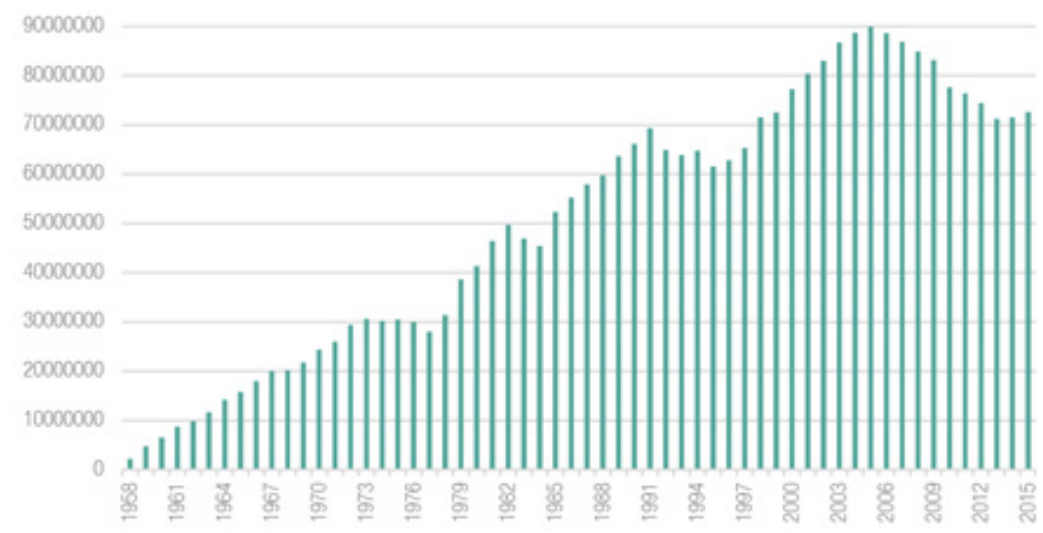

Fig 87. Evolución del agua distribuida por la MCT a los municipios abastecidos de la provincia de Alicante [MCT. Elaboración propia.]

La importancia de la provincia de Alicante en la MCT, en cuanto a los volúmenes demandados, es creciente.

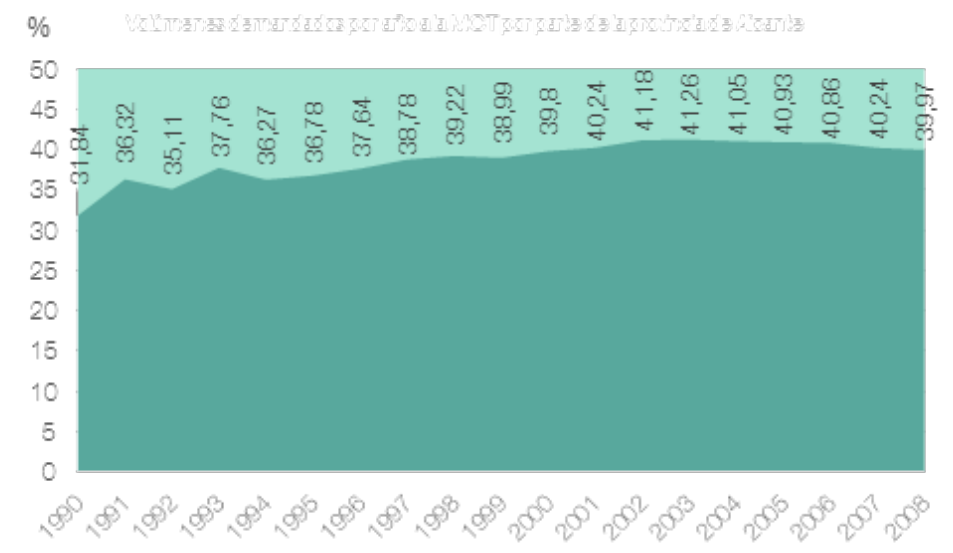

Fig 88. Volúmenes demandados por año a la MCT en la provincia de Alicante [MCT. Elaboración propia.]

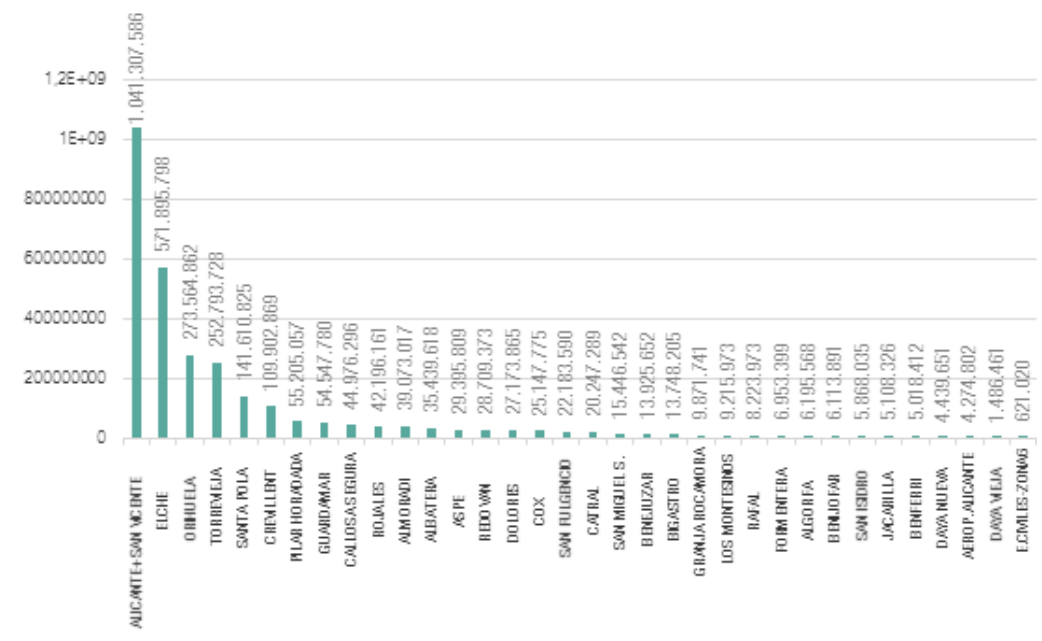

Fig 89. Consumos agregados por municipios desde la llegada de caudales en la provincia de Alicante [MCT. Elaboración propia.] 


\begin{tabular}{|c|c|c|c|c|c|c|}
\hline Municpios MCTA & 1994 & 2007 & 2015 & (1994-2007) & (1994-2015) & $(2007-2015)$ \\
\hline Albatera & 811.298 & 922.770 & 736.693 & 13,74 & $-9,20$ & $-20,17$ \\
\hline Algorfa & 89.380 & 429.000 & 339.777 & 379,97 & 280,15 & $-20,80$ \\
\hline Alicante & 18.926 .444 & 22.375 .995 & 18.525 .785 & 18,23 & $-2,12$ & $-17,21$ \\
\hline Almoradí & 948.090 & 1.218 .220 & 1.075 .114 & 28,49 & 13,40 & $-11,75$ \\
\hline Aspe & 920.750 & 1.280 .290 & 1.150 .930 & 39,05 & 25,00 & $-10,10$ \\
\hline Benejúzar & 344.390 & 437.250 & 399.500 & 26,96 & 16,00 & $-8,63$ \\
\hline Benferri & 127.270 & 202.220 & 160.330 & 58,89 & 25,98 & $-20,72$ \\
\hline Benijófar & 127.970 & 272.330 & 224.940 & 112,81 & 75,78 & $-17,40$ \\
\hline Bigastro & 313.670 & 477.860 & 359.180 & 52,34 & 14,51 & $-24,84$ \\
\hline Callosa de Segura & 868.170 & 1.288 .247 & 760.700 & 48,39 & $-12,38$ & $-40,95$ \\
\hline Catral & 490.510 & 735.917 & 633.150 & 50,03 & 29,08 & $-13,96$ \\
\hline Cox & 751.570 & 933.790 & 607.002 & 24,25 & $-19,24$ & $-35,00$ \\
\hline Crevillente & 3.197 .461 & 2.214 .490 & 1.857 .661 & $-30,74$ & $-41,90$ & $-16,11$ \\
\hline Daya Nueva & 122.200 & 171.350 & 128.172 & 40,22 & 4,89 & $-25,20$ \\
\hline Daya Vieja & 28.210 & 85.630 & 75.498 & 203,54 & 167,63 & $-11,83$ \\
\hline Dolores & 543.840 & 644.286 & 537.870 & 18,47 & $-1,10$ & $-16,52$ \\
\hline Elche & 14.032 .054 & 14.311 .142 & 12.063 .246 & 1,99 & $-14,03$ & $-15,71$ \\
\hline Formentera & 196.080 & 296.520 & 223.580 & 51,22 & 14,02 & $-24,60$ \\
\hline Granja de Rocamora & 277.150 & 494.030 & 313.880 & 78,25 & 13,25 & $-36,47$ \\
\hline Guardamar del Segura & 1.275 .961 & 1.951 .990 & 1.670 .394 & 52,98 & 30,91 & $-14,43$ \\
\hline Jacarilla & 116.090 & 185.800 & 137.850 & 60,05 & 18,74 & $-25,81$ \\
\hline Orihuela & 5.192 .801 & 10.466 .158 & 9.337 .841 & 101,55 & 79,82 & $-10,78$ \\
\hline Rafal & 243.010 & 247.480 & 202.920 & 1,84 & $-16,50$ & $-18,01$ \\
\hline Redován & 831.290 & 880.590 & 782.400 & 5,93 & $-5,88$ & $-11,15$ \\
\hline Rojales & 975.384 & 2.098 .900 & 1.788 .335 & 115,19 & 83,35 & $-14,80$ \\
\hline San Fulgencio & 576.300 & 1.012 .267 & 814.570 & 75,65 & 41,34 & $-19,53$ \\
\hline San Miguel de Salinas & 361.098 & 556.910 & 525.873 & 54,23 & 45,63 & $-5,57$ \\
\hline San Vicente del Raspeig & 793.273 & 3.333 .370 & 2.415 .100 & 320,20 & 204,45 & $-27,55$ \\
\hline Santa Pola & 3.391 .012 & 3.887 .370 & 3.388 .900 & 14,64 & $-0,06$ & $-12,82$ \\
\hline Torrevieja & 6.288 .842 & 9.756 .192 & 8.509 .609 & 55,13 & 35,31 & $-12,78$ \\
\hline Pilar Horadada & 1.156 .879 & 2.657 .740 & 2.187 .512 & 129,73 & 89,09 & $-17,69$ \\
\hline Los Montesinos & 241.160 & 571.560 & 334.261 & 137,00 & 38,61 & $-41,52$ \\
\hline San Isidro & 142.560 & 478.050 & 340.826 & 235,33 & 139,08 & $-28,70$ \\
\hline Total MCTA & 64.702 .167 & 86.875 .714 & 72.609 .399 & 34,27 & 12,22 & $-16,42$ \\
\hline
\end{tabular}

Tabla 16. Evolución del consumo de agua potable en los municipios de la provincia de Alicante atendidos por la MCTA, excepto Hondón de las Nieves [MCT. Elaboración propia.] 
De todo ello se deduce la decisiva importancia de la MCT en el abastecimiento de agua potable en la provincia de Alicante, que garantiza el suministro de numerosas poblaciones que carecen de fuentes propias, o en las que éstas son absolutamente insuficientes para garantizar sus demandas.

La aportación de prácticamente el $60 \%$ de los recursos disponibles por caudales procedentes del ATS da una idea por otra parte de la importancia de esta fuente de suministro para la provincia de Alicante. En el global de la Provincia, estos recursos representan el 20,4\% del total de la demanda, pudiéndose cuantificar en algo más de $43,67 \mathrm{hm}^{3}$, para un año medio como 2004.

El impacto de la MCT en el poblamiento de Alicante, considerando tanto la población abastecida como el número total de viviendas, es elevado, sobre todo si lo comparamos con los datos correspondientes al conjunto de la Comunidad Valenciana, tal como se aprecia en la figura 90 .

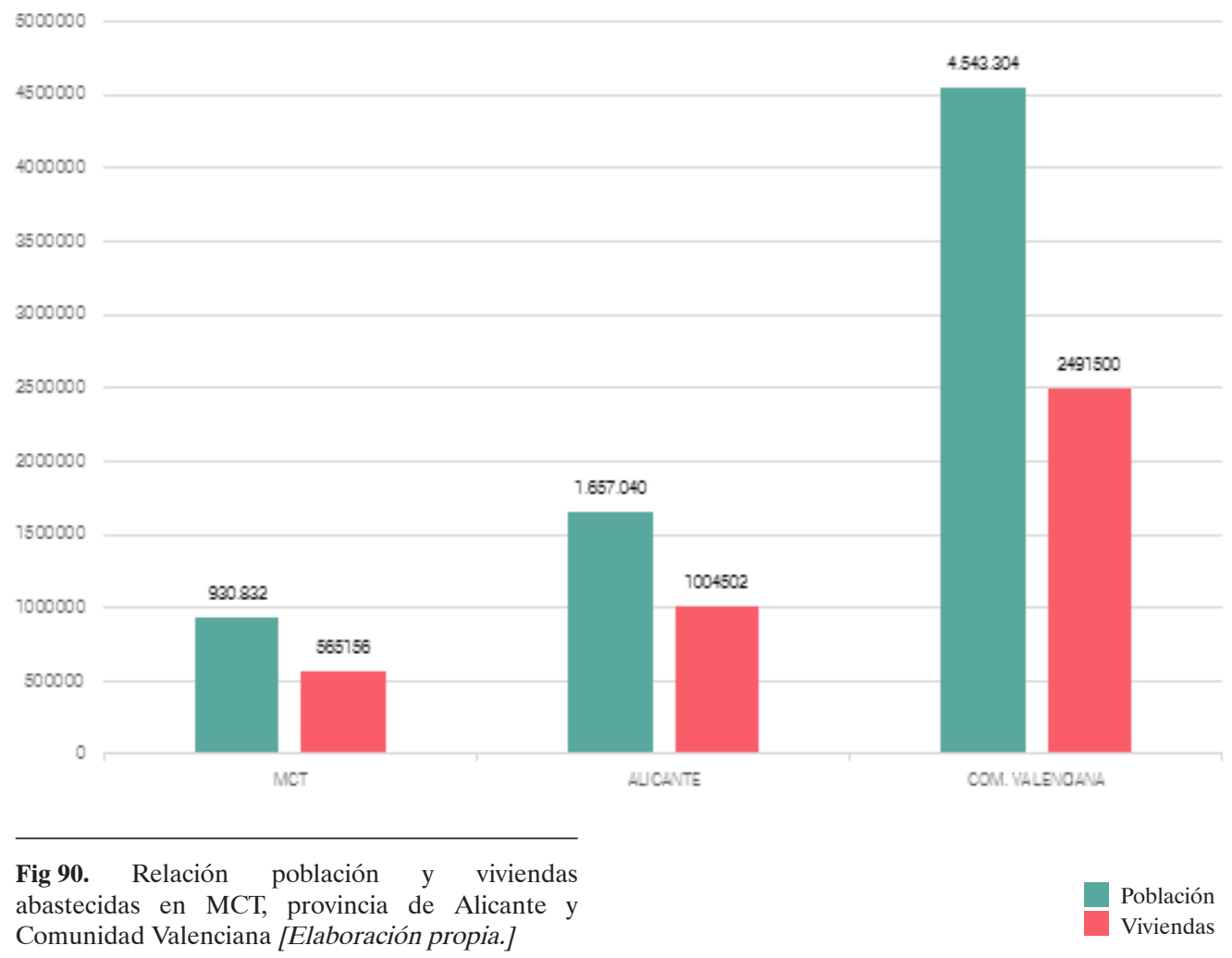




\subsection{Evolución de los consumos en los municipios alicantinos del sistema MCT.}

Las aportaciones de la MCT en los municipios de la provincia de Alicante han evolucionado de manera particular en cada caso, atendiendo a la problemática que presenta cada uno de ellos. Existen patrones comunes, que hemos señalado en el apartado anterior, pero conviene desagregar dichos patrones en cada municipio abastecido para advertir sus particularidades. Agruparemos los municipios en varias categorías debido a sus características homogéneas, en primer término, los grandes municipios, menos afectados por el crecimiento del turismo residencial: Alicante, Elche y Orihuela, en segundo término, los municipios del litoral; tercero, los del prelitoral; cuarto, los del interior; y finalmente, los del Medio Vinalopó (Aspe, Hondón de las Nieves y Hondón de los Frailes). Además, se han diferenciado el Aeropuerto de Alicante-Elche y la llamada Zona $6^{\mathrm{a}}$.

El carácter temporal de las prácticas turísticas influye en el consumo estacional que se realiza del agua, de manera que deben conjugarse momentos de gran punta en el suministro con periodos de mínimos definidos por los consumos exclusivamente residenciales. El consumo atribuible a la población estacional se estima en unos 51,5 $\mathrm{hm}^{3} /$ año, prácticamente el $25 \%$ del consumo total provincial. La mayor parte de ese $25 \%$ se consume en el área de la MCT. La dotación bruta, para un año medio, como 2004, alcanza en la provincia de Alicante los 336 1/hab./día. Las comarcas marcadamente turísticas presentan dotaciones sensiblemente mayores debido a la importante población estacional. Teniendo en cuenta esta particularidad, y si se realizan los cálculos de dotación compensado el consumo de este tipo de demanda, nos encontramos con una drástica reducción en las dotaciones, situándose la media provincial en Alicante, cercana a los 250 1/hab./día, cifra ciertamente ajustada, si tenemos en cuenta las pérdidas por distribución en la red de suministro, que en esta provincia, se habían contabilizado en un $22 \%$, lo que sitúa la media provincial en aproximadamente 195 l/hab/día en 2004 (Plaza et al., 2009). Los datos de dotación real de la provincia de Alicante se aproximan la media de la Comunidad Valenciana (186 1/hab./día en 2007), si bien, son sensiblemente superiores a los de la Región de Murcia (166 1/hab./día en 2007), y sobre todo a la media nacional, que se sitúa en 157 1/hab./día. En ello han influido las campañas de sensibilización y programas educativos, así como la mayor conciencia sobre el problema de la sequía, de modo que parece observarse una tendencia clara a la reducción de consumos. 
Prueba de esta tendencia la observamos en el municipio de Alicante, en donde la dotación por abonado descendió por encima de un $41 \%$ en el periodo que va desde 1991 a 2008, manteniéndose el rendimiento hidráulico de las redes de distribución prácticamente invariable, cercano al $85 \%$ de media, al igual que el agua potable suministrada en dicho lapso de tiempo, situándose esta, incluso por debajo de los niveles de inicio. A partir de 2008 a estos factores se ha añadido la reducción de los consumos como consecuencia de la crisis económica, que ha afectado al turismo, la industria, y a ciertos patrones de consumo.

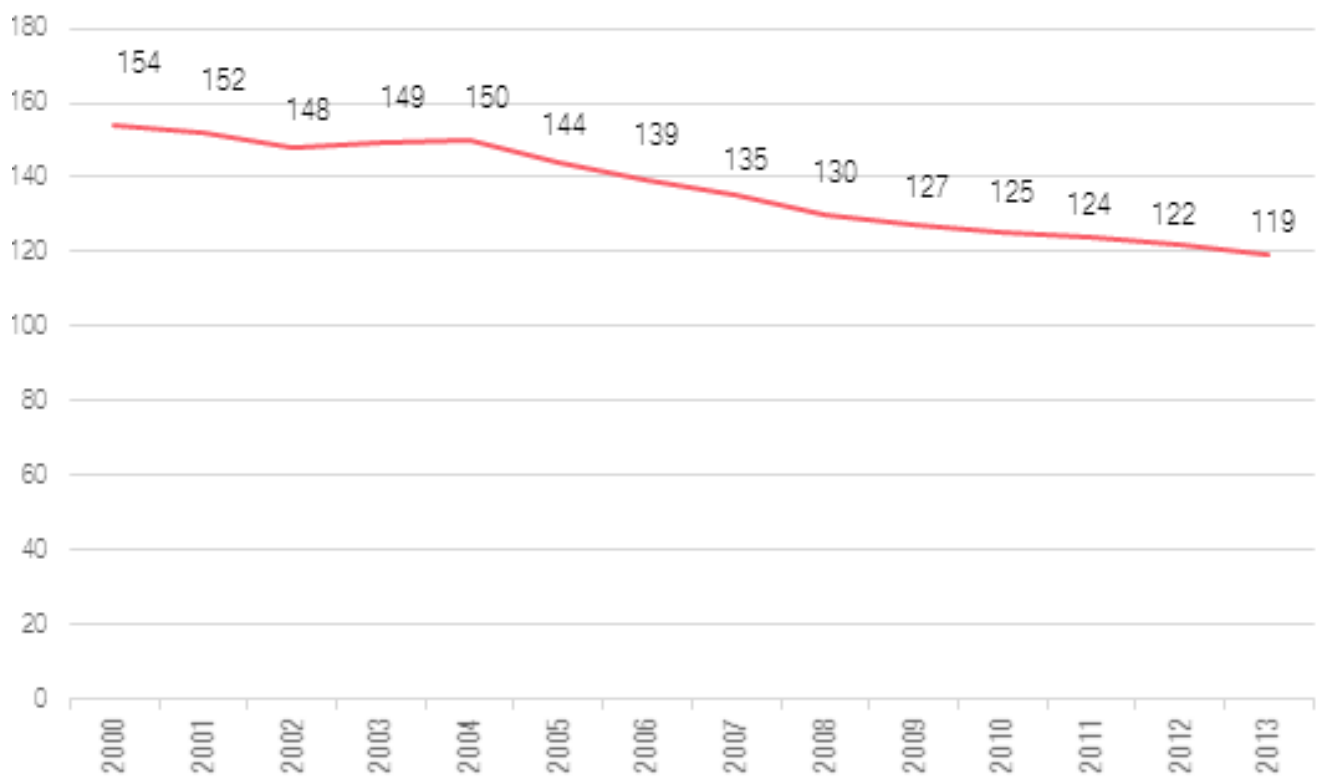

Fig 91. Evolución anual del consumo doméstico (1/hab/día) en la ciudad de Alicante, 2000-2013 [Albiol et al., 2014.]

Desde el punto de vista del abastecimiento de agua, se debe gestionar la irregularidad de las demandas y el mantenimiento de infraestructuras de abastecimiento y distribución sobredimensionadas (Morote, 2015). De ahí la conveniencia de mostrar gráficamente, y de acuerdo con diferentes cortes temporales, la evolución de los consumos mensuales de los municipios abastecidos por la MCT que tienen actividades turísticas en la provincia de Alicante. En las figuras que se muestran a continuación se observa cómo los volúmenes de consumo se elevan especialmente durante los periodos estivales. 
Alicante contaba con una población en 1960, dos años después de la llegada de las aguas de la MCT, de 121.832 habitantes. En 2015, su población ascendió a 328.648 habitantes (INE), es el segundo municipio más poblado de la Comunidad Valenciana y el undécimo de España. Es una ciudad eminentemente turística y de servicios.

Durante los años 1990 a 1997, la evolución del consumo en la ciudad de Alicante se mantuvo estable en el entorno del 11 y $12 \%$ del total suministrado por la MCT.

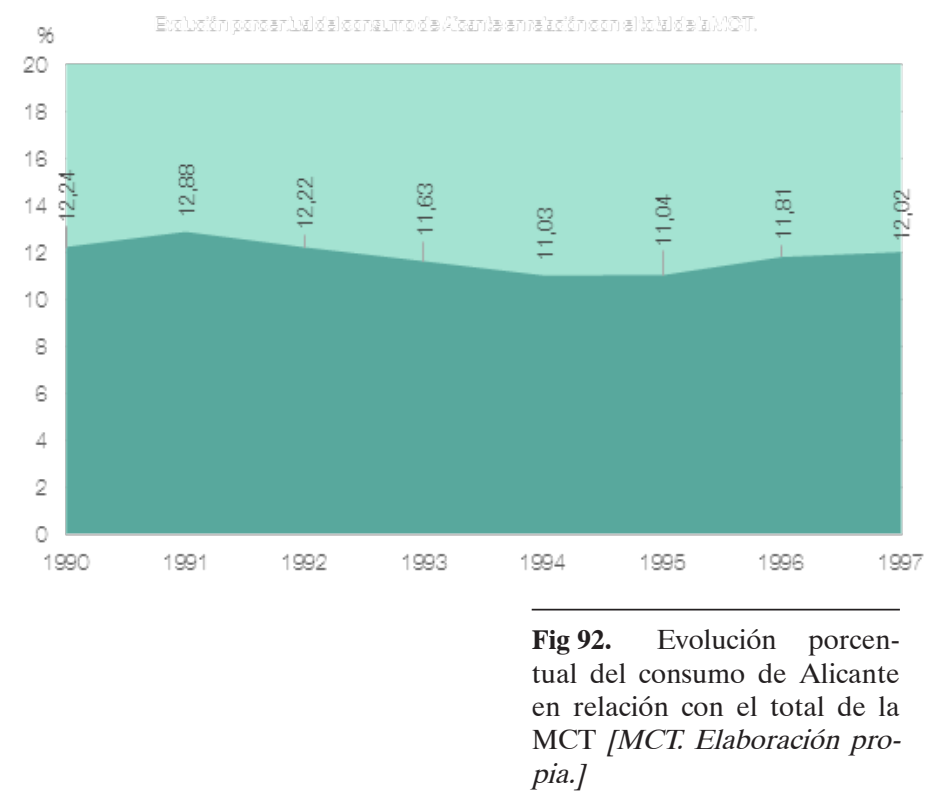

La ciudad de Alicante incrementó su consumo de agua de $19,3 \mathrm{hm}^{3}$ en 1984 a 24,6 $\mathrm{hm}^{3}$ en 1991, si bien posteriormente experimentó importantes descensos hasta situarse de nuevo en el entorno de los $19 \mathrm{hm}^{3}$ en 1995. Desde ese momento, los consumos vuelven a incrementarse hasta superar los $25 \mathrm{hm}^{3}$ en 2006, aunque este dato está ciertamente distorsionado al incluir los consumos de San Vicente del Raspeig, que representaron en dicho año un volumen de $3,4 \mathrm{hm}^{3}$. A partir de entonces, y hasta 2012 el consumo se estabiliza, reduciéndose significativamente entre los años 2013 y 2015. 


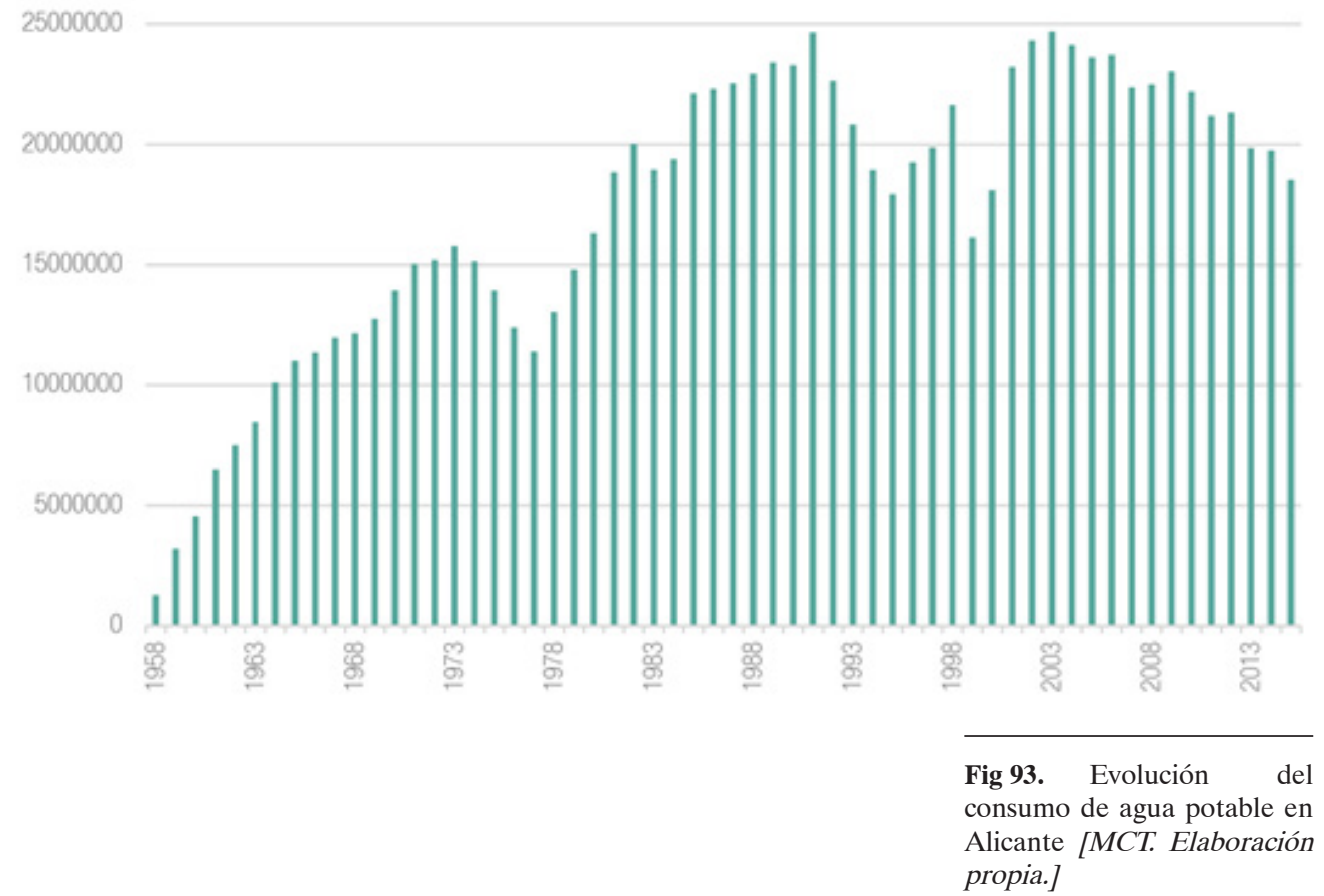

El rendimiento técnico de la red, en la ciudad de Alicante, supera el $90 \%$ del caudal inyectado en la red. A los recursos que facilita la MCT se suman las aguas subterráneas de varios acuíferos del Alto Vinalopó, que son aprovechados por la capital provincial desde 1898 (Rico, 2007). El consumo de agua en la ciudad presenta importantes variaciones mensuales, acusándose más, como es natural, en los meses más calurosos y secos del año (junio, julio y agosto).

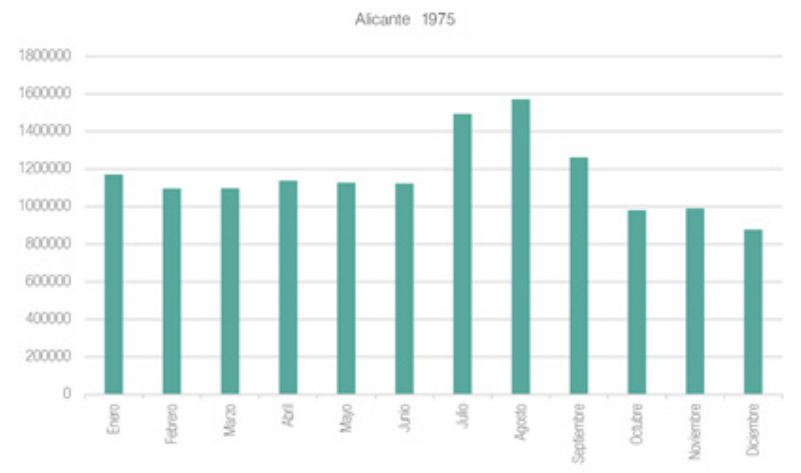


Alcante 1985

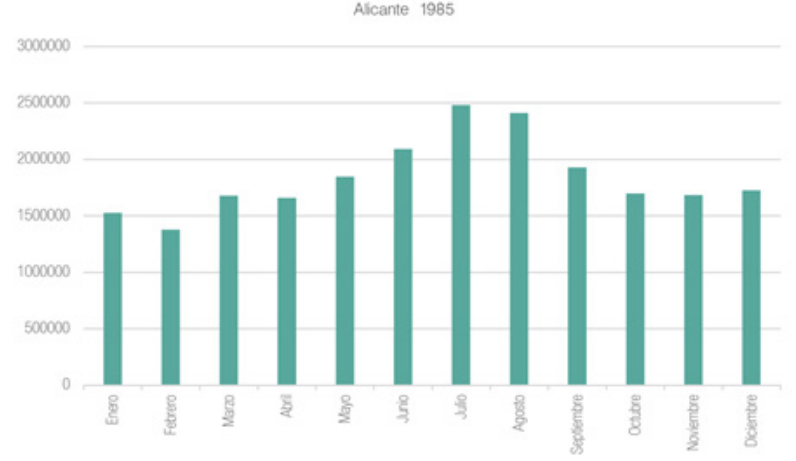

Alicante 1995

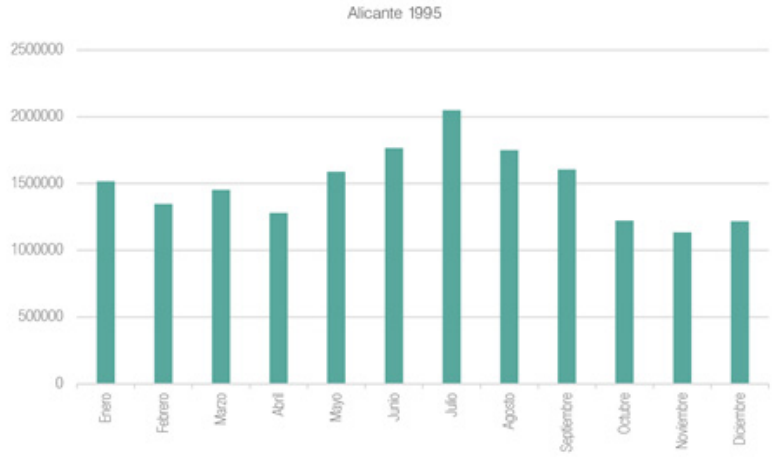

Alcante 2005

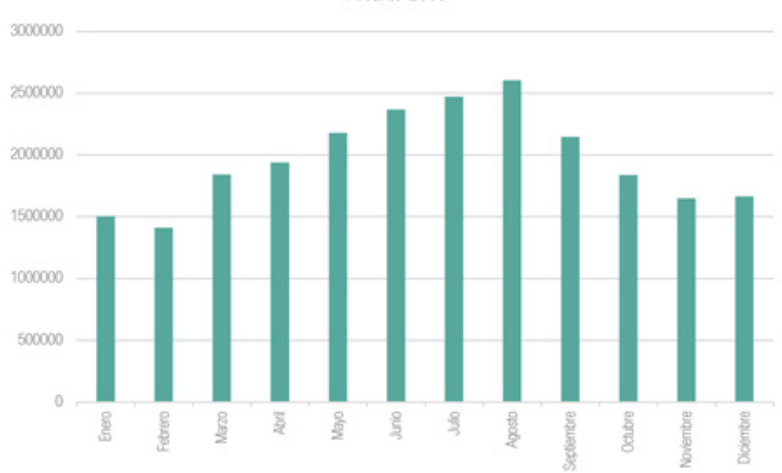

Alicante 2015

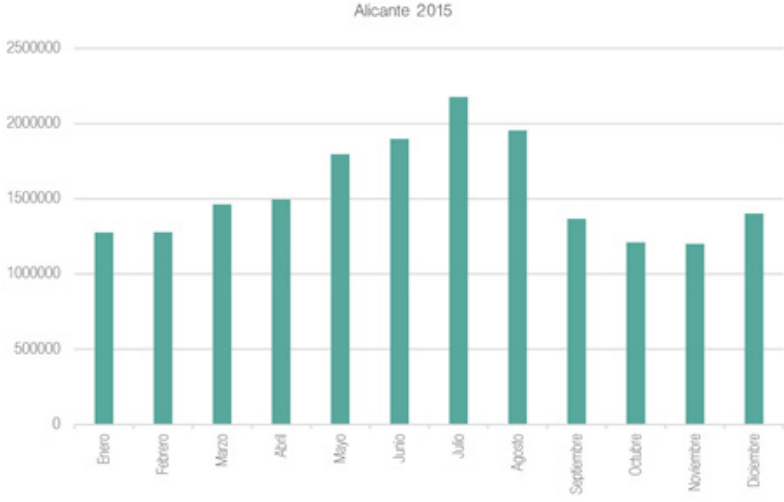

Fig 94. Distribución mensual del consumo de agua potable en Alicante $(1975,1985,1995$, 2005, 2015) [MCT. Elaboración propia.] 
La Relación entre los caudales suministrados por la MCT y los recursos propios del municipio se aprecia en las figuras 95 y 96.

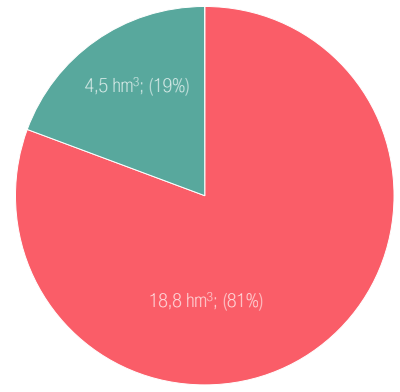

Fig 95. Volúmenes según procedencia en Alicante 2011 [AMAEM. Elaboración propia.]

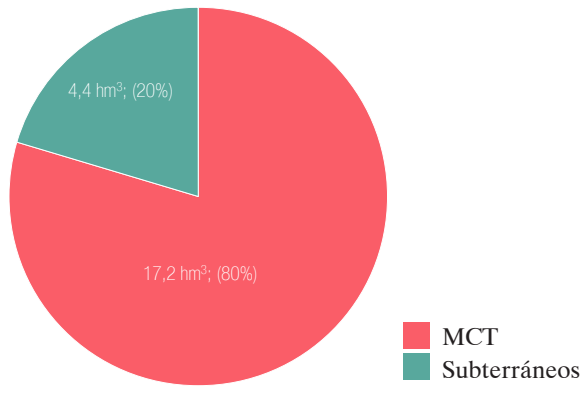

Fig 96. Volúmenes según procedencia en Alicante 2015 [AMAEM. Elaboración propia.]

En la comarca del Campo de Alicante se precisan alrededor de $45 \mathrm{hm}^{3} /$ año para atender a una población que, durante el verano, puede superar los 600.000 habitantes.

Junto al municipio de Alicante, la Mancomunidad también facilita el abastecimiento en alta del municipio de San Vicente del Raspeig desde 1993 de forma desagregada de Alicante. En 1991 contaba con 30.119 habitantes, dos años antes de recibir agua directa y diferenciadamente desde la MCT; en 2015, tenía 56.302 habitantes (INE). (Figura 97).

La economía de San Vicente se basa principalmente, por un lado, en la industria con todo tipo de empresas acogidas en los varios polígonos que hay en la localidad, y por otro, en su faceta de ciudad residencial del área metropolitana de Alicante, a lo que hay que sumar el peso de albergar la sede de la Universidad de Alicante, considerada como un ente de gran consumo de agua potable. (Figuras 98 y 99).

En la figura 100 se muestran los caudales agregados de Alicante y San Vicente del Raspeig, dado que la MCT no diferenciaba dichos volúmenes hasta 1994. 


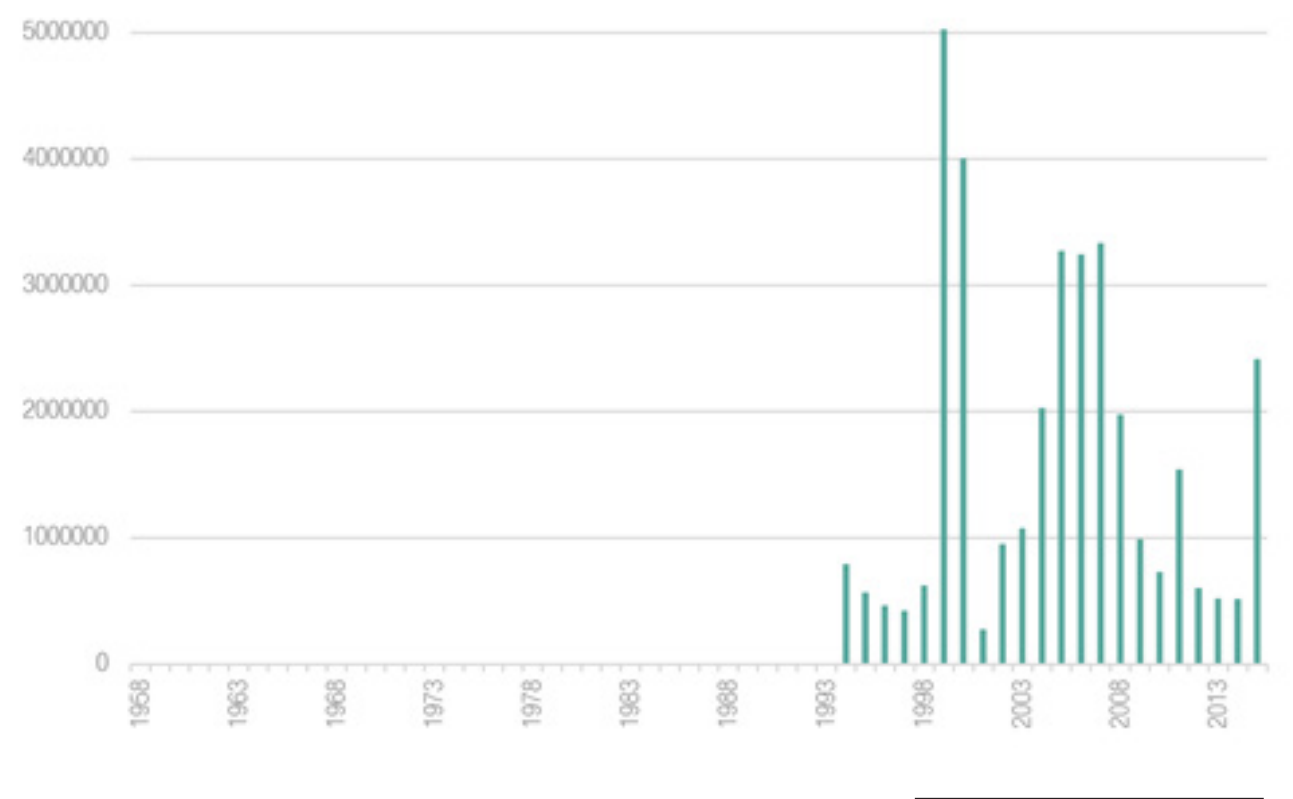

Fig 97. Agua suministrada por la MCT a San Vicente del Raspeig (1993-2015) [MCT. Elaboración propia.]

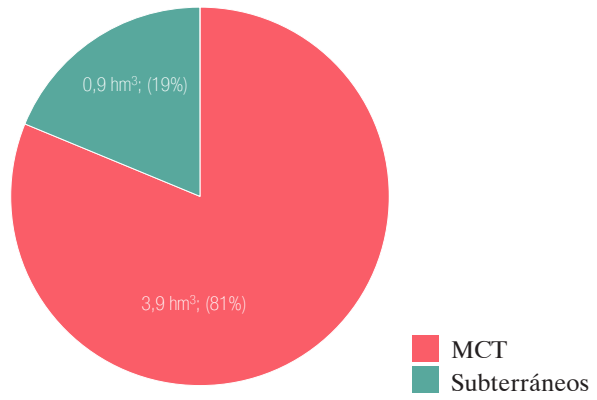

Fig 98. Volúmenes según procedencia en San Vicente 2011 [AMAEM. Elaboración propia.]

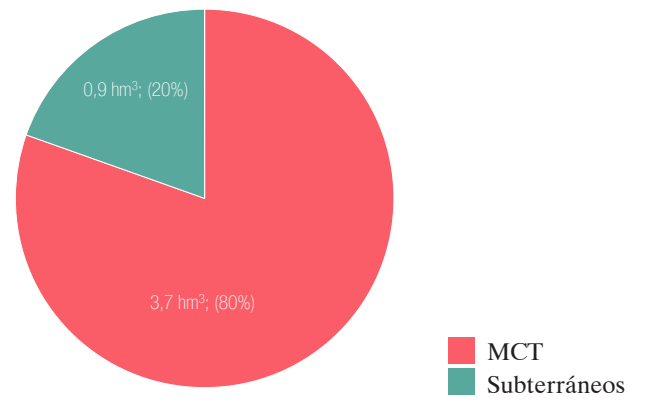

Fig 99. Volúmenes según procedencia en San Vicente 2015 [AMAEM. Elaboración propia.] 


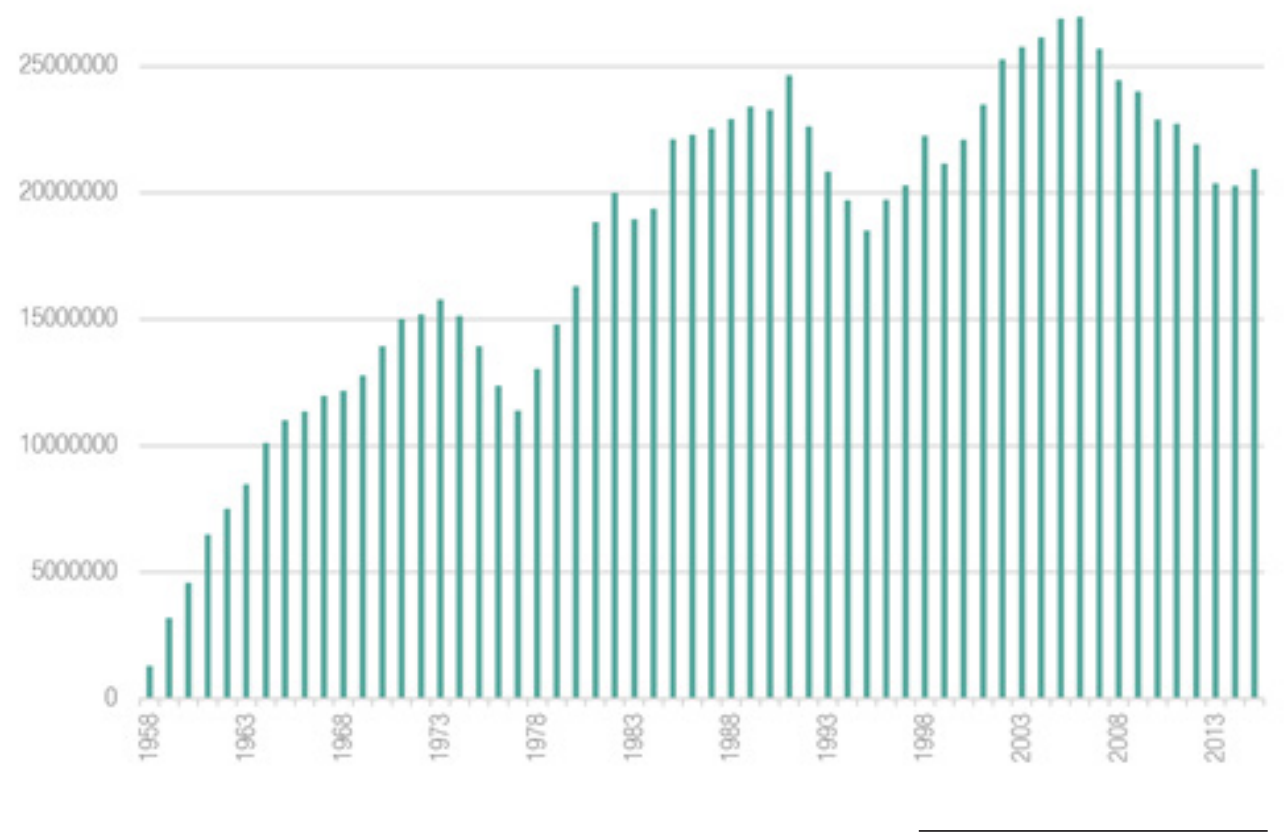

Fig 100. Caudales agregados de Alicante y San Vicente del Raspeig [MCT. Elaboración propia.]

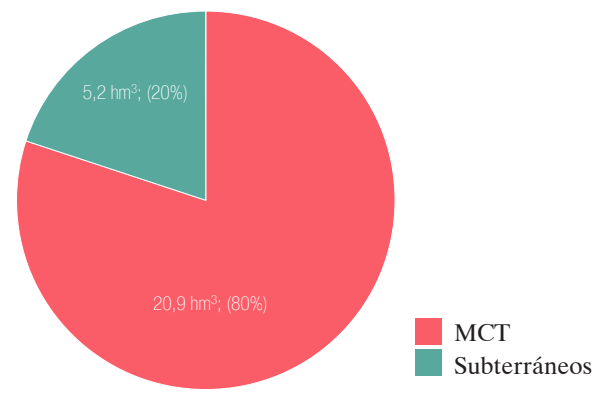

Fig 101. Volúmenes según procedencia en Alicante + San Vicente 2011. [AMAEM. Elaboración propia.]

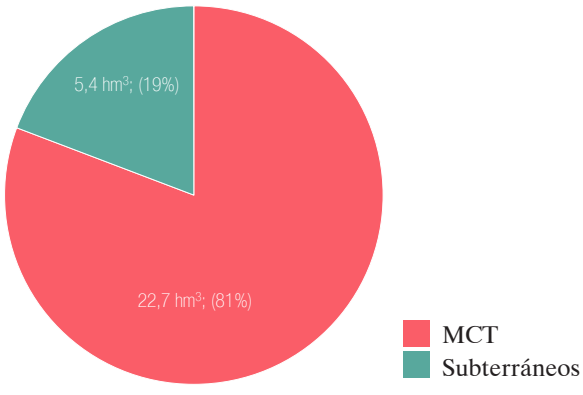

Fig 102. Volúmenes según procedencia en Alicante + San Vicente 2015. [AMAEM. Elaboración propia.] 
En 1960, dos años después de la llegada de las aguas de la MCT, Elche tenía 75.720 habitantes. El fuerte proceso de desarrollo industrial y más recientemente de los servicios y el turismo ha hecho que la población total en el municipio alcanzase en 2015 los 227.312 habitantes; mientras que la población del casco urbano fue de 187.135 (INE 2015). Elche cuenta con diversos núcleos de población (20), algunos de ellos con un número muy relevante de habitantes, en 2013, entre éstos destaca Torrellano con 7.308, El Altet 5.530, Las Bayas 2.747, Altabix 2.780, La Hoya 2070, Matola 2.634, La Marina 2.307, Llano de San José 2.236, Valverde 1.792, Los Arenales del Sol 1.195. Algunos de estos con grandes desarrollos turístico-residencial como La Marina, Arenales del Sol o El Altet.

Durante los años 1990 a 1997, la evolución del consumo en la ciudad de Elche se mantuvo estable en el entorno del 7 y $8 \%$ del total suministrado por la MCT.

El aumento de consumo de agua de Elche durante los últimos años ha sido moderado, apenas un $1 \%$ entre 1994 y $2006\left(14 \mathrm{hm}^{3}\right.$ a $\left.14,3 \mathrm{hm}^{3}\right)$. En este caso, el mayor aumento

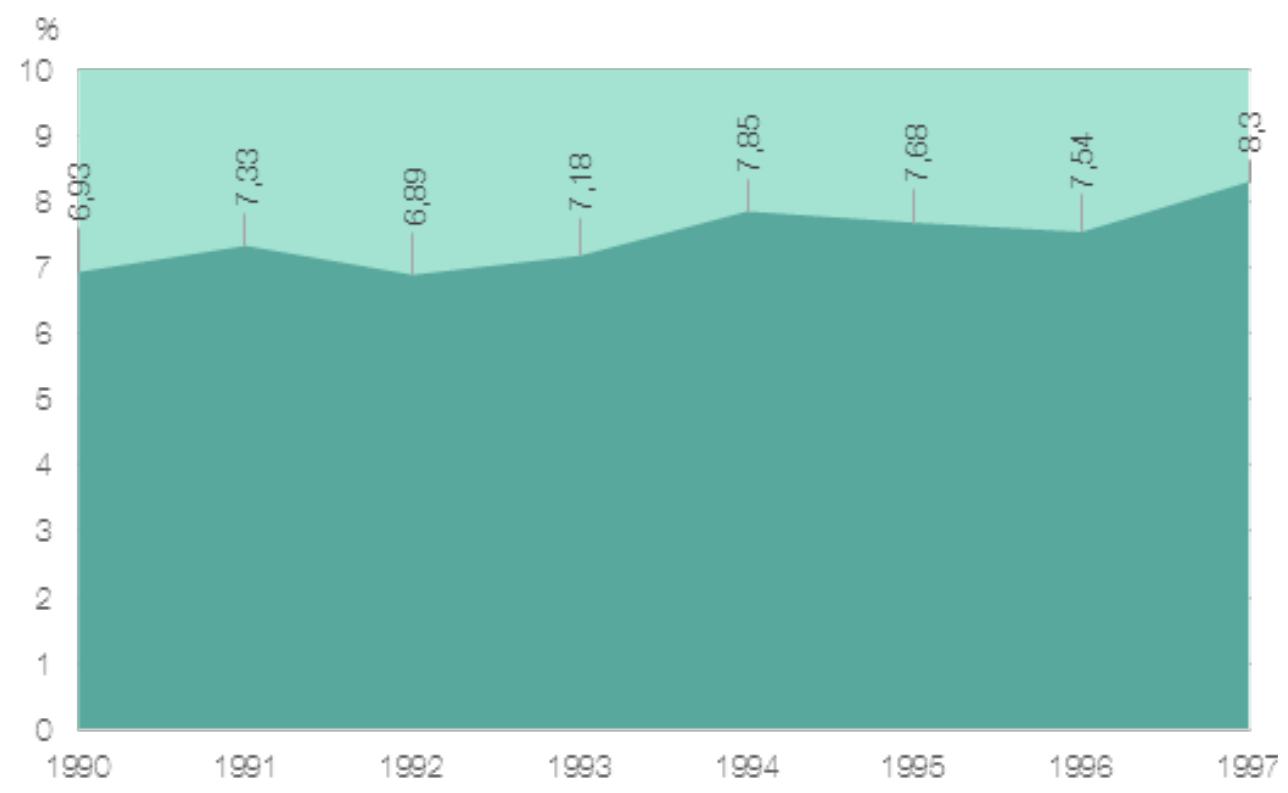

Fig 103. Evolución porcentual del consumo de Elche en relación con el total de la MCT [MCT. Elaboración propia.] 
de consumo tuvo lugar entre 1984 y 1994 cuando el suministro de agua en alta llevado a cabo por la MCT pasó de 7,4 $\mathrm{hm}^{3}$ a $14 \mathrm{hm}^{3}$, momento en el que tiene lugar el desarrollo de Los Arenales del Sol y la proliferación de segundas residencias en el campo ilicitano. Las mejoras en la red de distribución llevadas a cabo en los últimos años permiten comprender la contención en las cifras de incrementos de consumo de este período.

En este municipio se dispone de caudales propios, que complementan los suministrados por la MCT, aunque en una reducida cantidad. Así, por ejemplo, en 2006 el municipio recibió un caudal total de $16,4 \mathrm{hm}^{3}$, de los que unos $14,6 \mathrm{hm}^{3}$ fueron facilitados por la MCT; el resto, $1,8 \mathrm{hm}^{3}$, procedieron de captaciones de pozos situados en Villena.

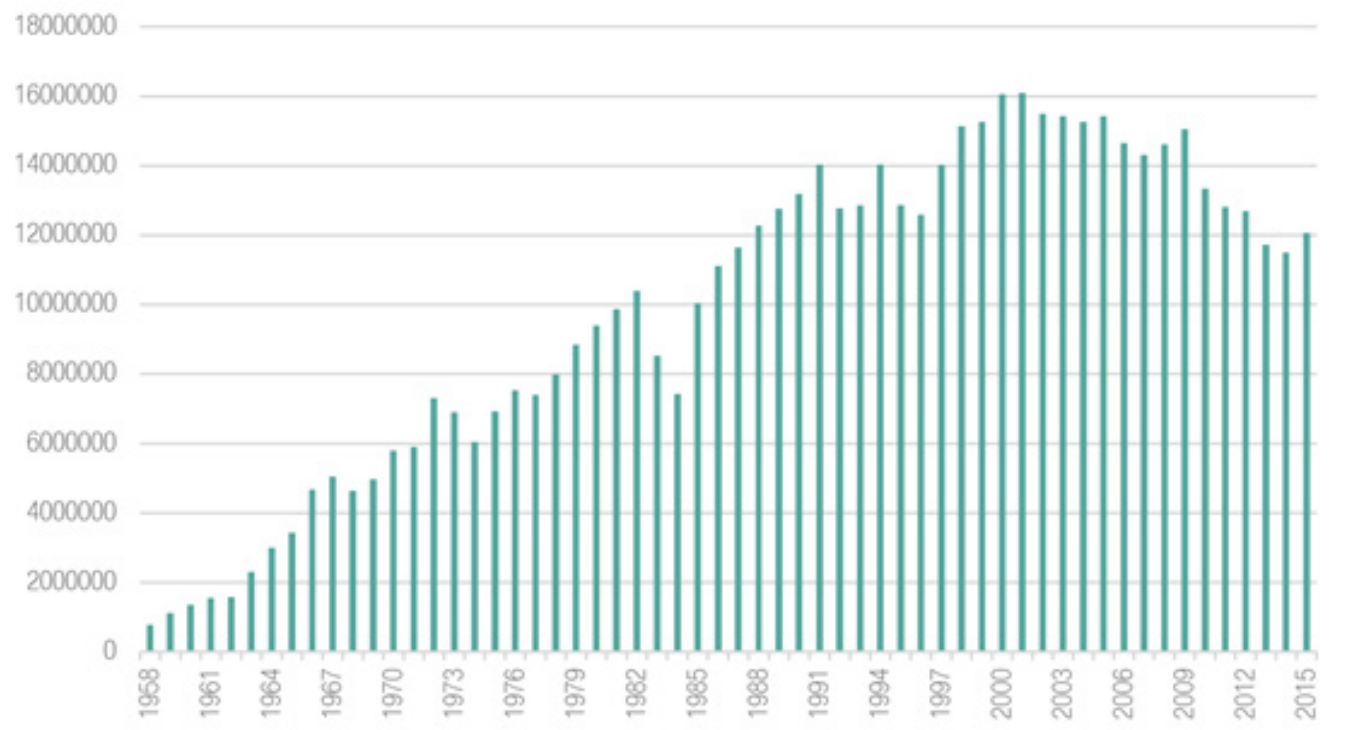

Fig 104. Evolución del consumo de agua potable en Elche (1958-2015) [MCT. Elaboración propia.] 
Elche 1975

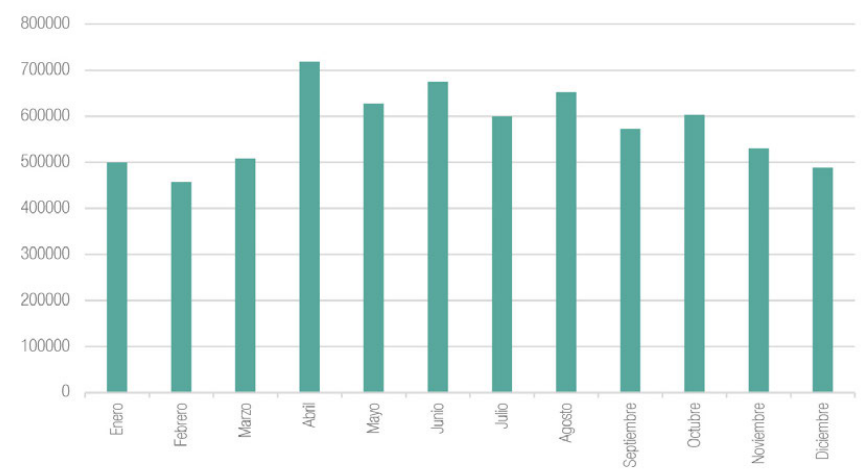

Elche 1995

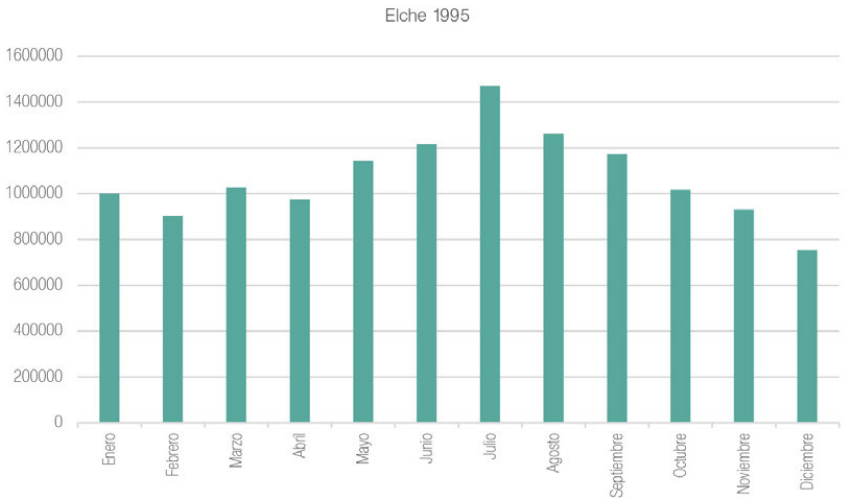

Elche 2015

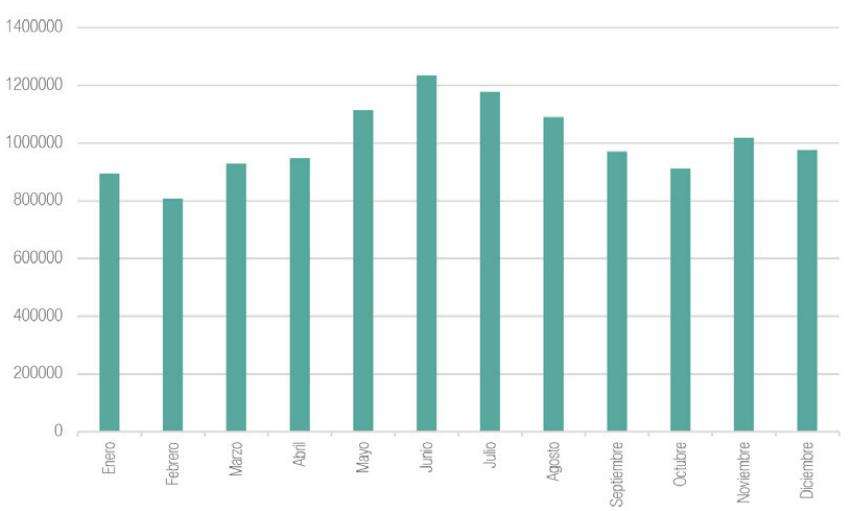

Elche 1985

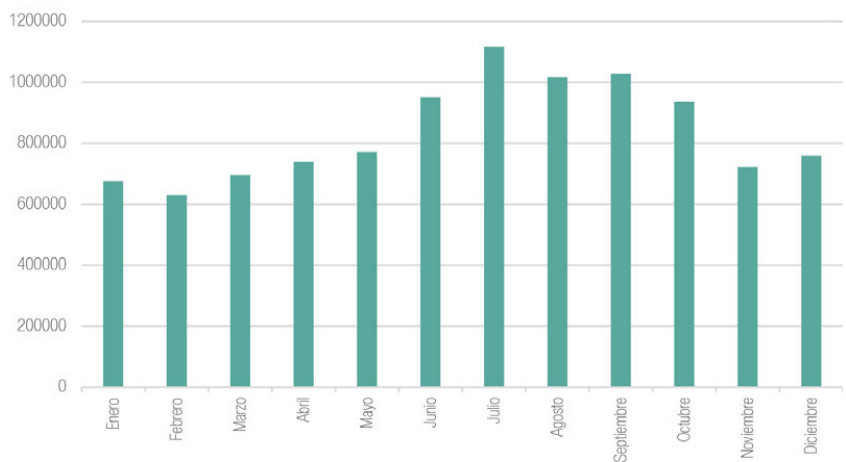

Elche 2005

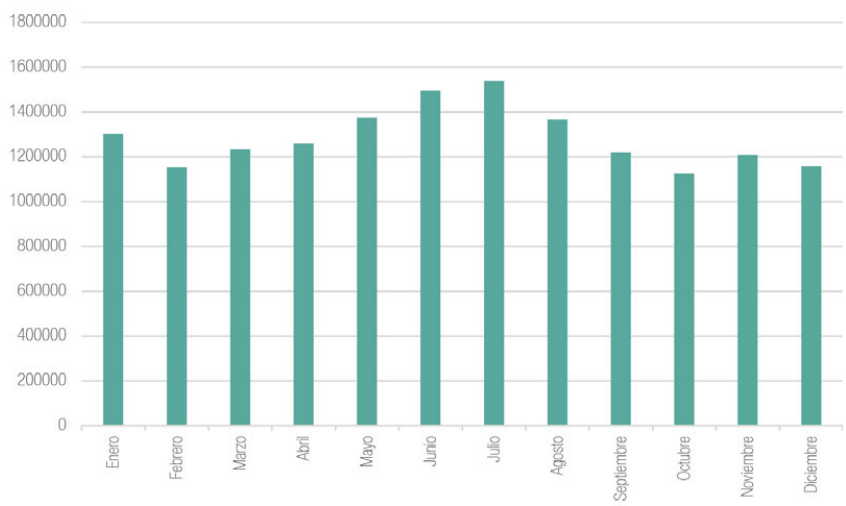

Fig 105. Distribución mensual del consumo de agua potable en Elche (1975, 1985, 1995, 2005, 2015) [MCT. Elaboración propia.] 
En 2013 Orihuela contaba con 91.260 habitantes (INE), de los cuales 32.609 residían en el casco urbano de la ciudad. En 2015 la población total fue de 82.675 habitantes. El municipio posee numerosas poblaciones en su término teniendo algunas de ellas una población de miles de habitantes.

En la actualidad las pedanías de Orihuela son: Arneva (1.229), Barbarroja, Camino de Beniel (772), Camino Viejo de Callosa (470), Correntías Altas, Correntías Medias (994), Correntías Bajas, El Escorratel (916), El Mudamiento, Hurchillo (963), La Aparecida (1.970), La Campaneta (1.200), La Murada (3.093), Las Norias (1014), Desamparados, Los Huertos, Media Legua, Molino de la Ciudad, Molins (1.433), La Matanza (978), Raiguero de Bonanza (1346), San Bartolomé (2.419) y Torremendo (1.649).

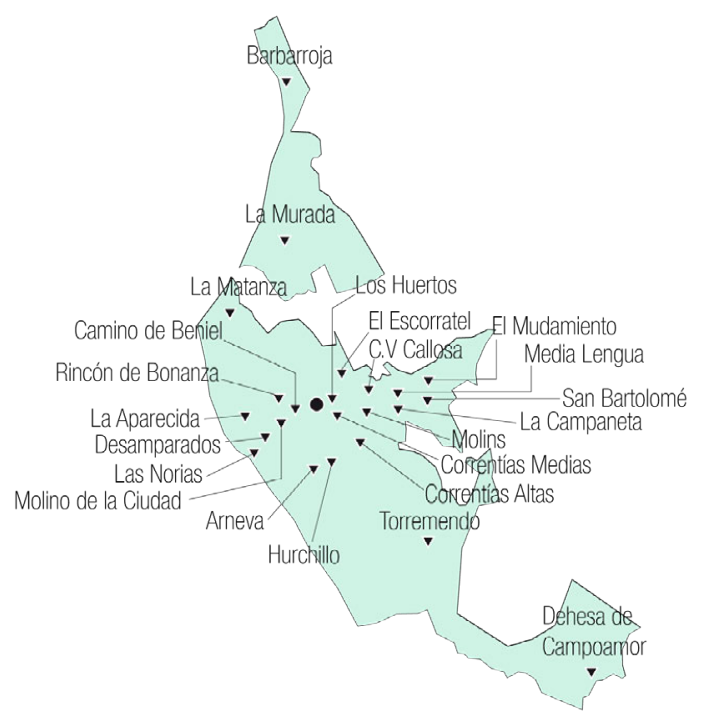

Fig 106. Término municipal de Orihuela y sus pedanías [Ayuntamiento de Orihuela. Elaboración propia.]
Esta distribución de la población junto con el tamaño del término municipal $\left(365 \mathrm{~km}^{2}\right)$, condiciona extraordinariamente el abastecimiento urbano de agua potable.

La economía de Orihuela se ha basado tradicionalmente en la agricultura. Actualmente, en torno al $9 \%$ de la población trabaja en el sector primario, el $12 \%$ en el sector secundario, y el restante $79 \%$ de la población trabaja en el sector terciario.

Orihuela ha experimentado un aumento importante de consumo de agua debido casi en exclusiva al extraordinario desarrollo turístico e inmobiliario que ha experimentado su franja litoral, entre La Zenia y Campoamor (24.126 habitantes, en 2007). Junto a Torrevieja y Guardamar del Segura es el municipio que mayor promoción inmobiliaria ha presentado en el ámbito de la MCT en la provincia de Alicante. 
El Plan de Ampliación de los Abastecimientos del Organismo, aprobado por el MOPU el 16 de octubre de 1971, contemplaba el abastecimiento de toda la zona costera del término de Orihuela, como centro de consumo estacional (La Zenia, $n^{\circ}$ 6, Cabo Roig, $n^{\underline{0}}$ 7, Campoamor, no 8 y Pilar de la Horadada, no 9), con una población conjunta en 1985 de 56.600 habitantes, y un consumo total de $11.320 \mathrm{~m}^{3} /$ día, equivalente a una dotación de 200 1/hab/día. Las necesidades de agua se evaluaron en 1,1 hm³/año, resultado de considerar una duración de suministro de 100 días al año como consecuencia de su carácter estacional. El abastecimiento habría de derivarse del Nuevo Canal de Cartagena, y la financiación de las obras no correspondería al Organismo al tratarse de nuevos asentamientos en vez de pedanías. Estos lugares, aun estando contemplados en el Plan de Abastecimientos, eran los únicos que todavía carecían de conexión con el Sistema de la MCT, debido a que contaban con aguas subterráneas. La deficiente calidad y sobreexplotación de las mismas aconsejaba sin embargo su sustitución por nuevos caudales suministrados por el Organismo, para lo que éste exigió al ayuntamiento de Orihuela la puesta al día de sus obligaciones económicas con la MCT, así como la financiación de las redes e instalaciones necesarias para la conexión con el Nuevo Canal de Cartagena (CEMCT, 22/2/1989).

En la época de mayor crecimiento, el consumo pasó de 5,2 hm en 1994 a 10,4 hm en 2007, lo que supuso un incremento del $100 \%$. A partir de este año, los consumos se estabilizan e incluso decrecen significativamente a partir de 2009 y hasta la actualidad.

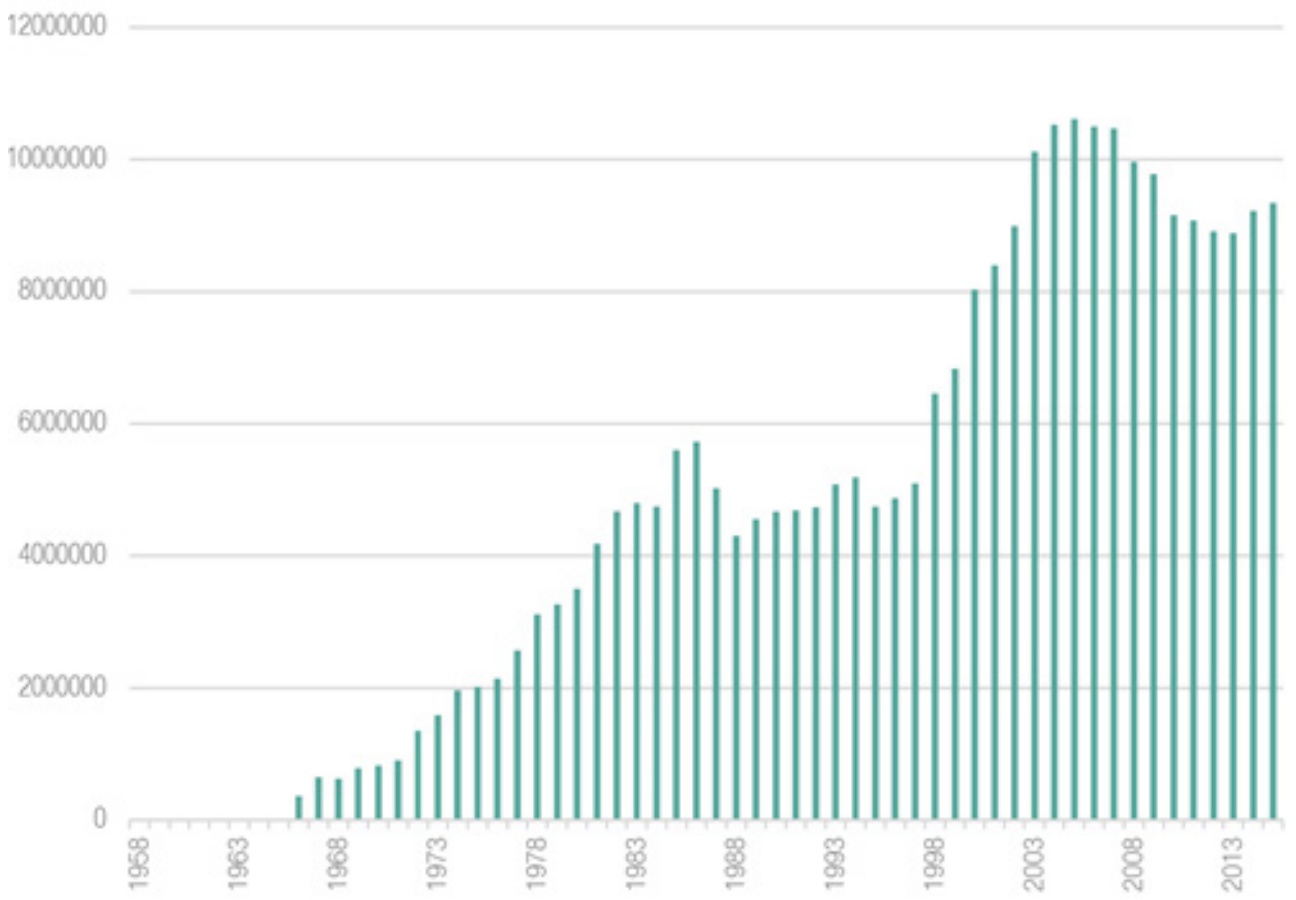

Fig 107. Evolución del consumo de agua potable en Orihuela [MCT. Elaboración propia.] 
Orihuela 1975

250000

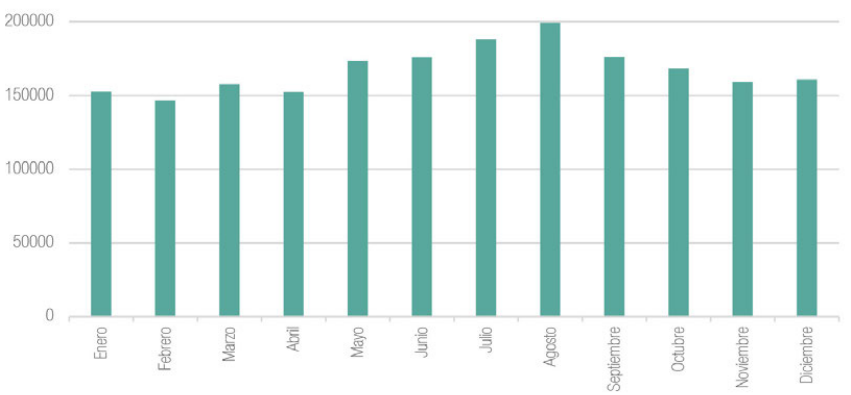

Orihuela 1995

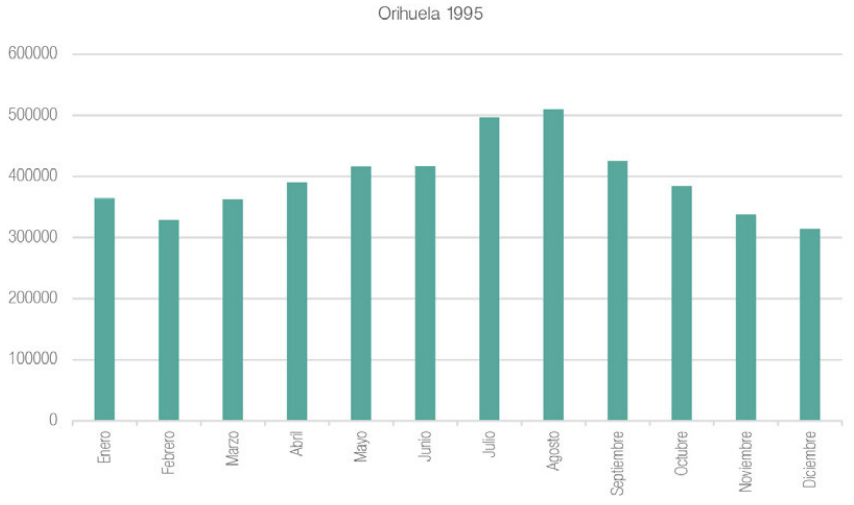

Orihuela 2015

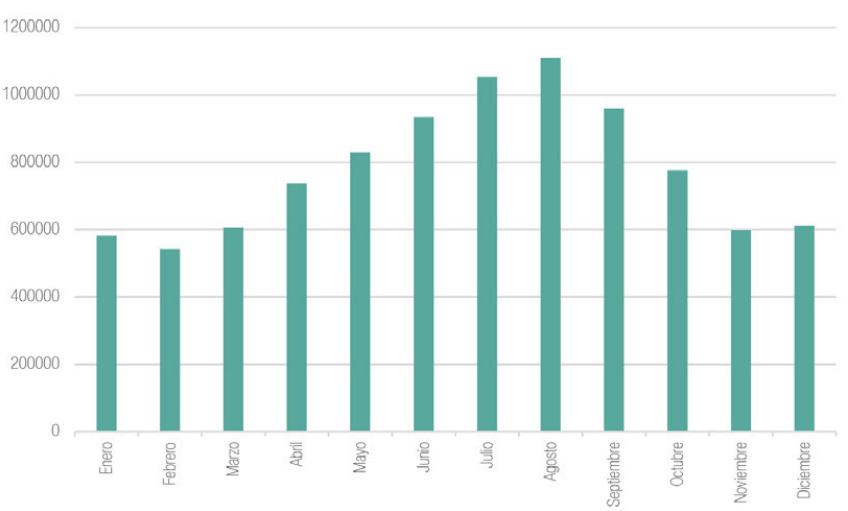

Orihuela 1985

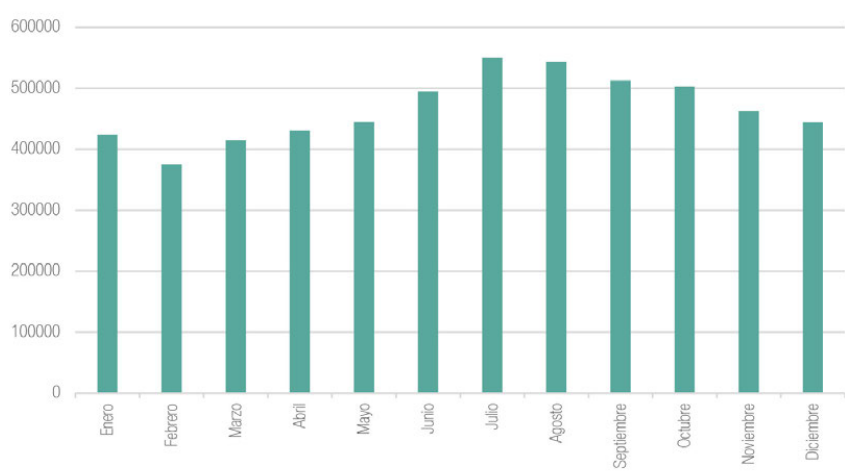

Orihuela 2005

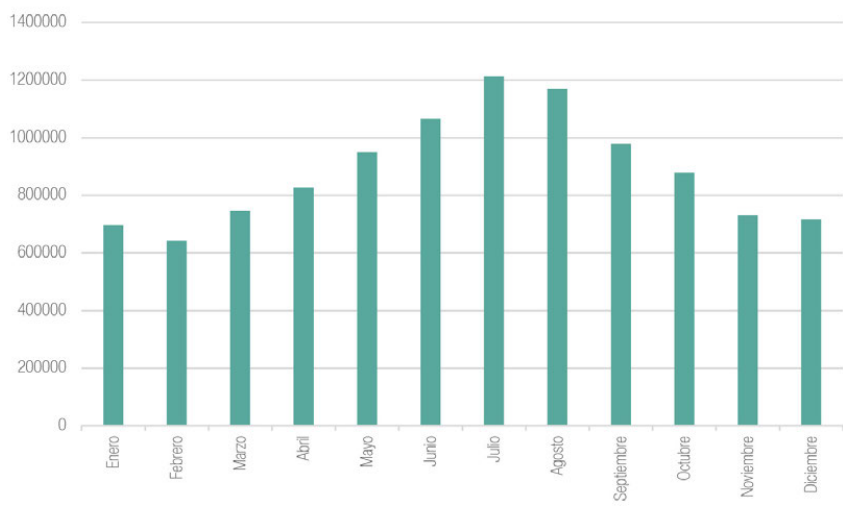

Fig 108. Distribución mensual del consumo de agua potable en Orihuela (1975, 1985, 1995, 2005, 2015) [MCT. Elaboración propia.] 
En los municipios considerados hasta ahora, que se corresponden con los mayores núcleos urbanos suministrados por la MCT en la provincia de Alicante, a excepción de Torrevieja, el grado de estacionalidad del suministro es bajo salvo en Orihuela. En todos ellos, los meses centrales del verano (julio y agosto) registran un lógico incremento de consumo respecto a los meses de invierno, pero esta situación es mucho más acusada en el caso de Orihuela. En este municipio la estacionalidad es mayor porque en los meses de verano recibe la mayor concentración de visitantes a lo largo del año.

La valoración del índice de estacionalidad es importante, puesto que refleja la diferente intensidad de la actividad turística, y en particular, del turismo residencial, mucho más acusado en el municipio oriolano. Los asentamientos turístico-residenciales en ese término municipal son mucho más intensos en su franja litoral, donde nos encontramos con grandes urbanizaciones como Playa Flamenca, La Zenia, Cabo Roig, La Regia, Dehesa de Campoamor. También el prelitoral del municipio presenta un importante grado de desarrollo turístico, entorno a actuaciones turístico-residenciales ligadas a la oferta de campos de golf (Villamartín, Campoamor, Las Ramblas) (Baños et al., 2010).

Las ciudades consideradas, Alicante, Elche y Orihuela, suman más de 650.000 habitantes permanentes, lo que explica que el agua facturada por la MCT alcance casi una cuarta parte de los consumos dependientes de la Mancomunidad. Entre 1994 y 2009, el consumo pasó de $39 \mathrm{hm}^{3}$ a $48,8 \mathrm{hm}^{3}$, con una de variación del $20 \%$. Es, por tanto, el grupo que menos crece en términos relativos ya que en 2005 el consumo seguía una tendencia todavía creciente $52,9 \mathrm{hm}^{3}$, que luego comenzó a disminuir, lo que da idea de los esfuerzos y resultados conseguidos en la gestión de eficiente de las redes, que ha podido compensar, al menos en parte, el crecimiento urbano y turístico. (Baños et al, 2010). 
Por población y relevancia, deberíamos incluir a esta localidad entre los grandes municipios de la provincia de Alicante suministrados por la MCT. Sin embargo, su comportamiento y dinámica de consumo de agua es más propio de los municpios englobados en este apartado.

La población de Torrevieja ha tenido un comportamiento de crecimiento extraordinario desde la llegada de las aguas de la MCT en 1972. Así, en 1970 los habitantes del municipio ascendían a 9.735; en 1991 eran 25.890; en 200050.189 y en 2010 101.191.

La crisis económica y en especial la relacionada con el sector inmobiliario ha hecho que la población oficial en 2015 pase a ser de 88.447 habitantes; son 2.968 menos que el año anterior y 16.758 menos que en 2013. Estas fuertes caídas de la población se deben, en su mayor parte, al estallido de la "burbuja Inmobiliaria". Con información a 4 de julio de 2016, según el padrón municipal, la población de Torrevieja es de 97.548, lo que supone un notable crecimiento, que se aproxíma al máximo alcanzado en 2010.

En Torrevieja el consumo de agua en alta se incrementó desde los $6,2 \mathrm{hm}^{3}$ registrados en 1994, hasta superar los $10 \mathrm{hm}^{3}$ suministrados en 2003. Este caudal se vio posteriormente reducido, en el año 2006, a 9,7 hm³ , gracias a las mejoras en la gestión del suministro urbano (rendimientos técnicos superiores a $85 \%$ ). En 2010 se registra otra reducción importante del consumo hasta situarse escasamente por encima de $\operatorname{los} 8 \mathrm{hm}^{3}$ por el efecto de la crisis económica general e inmobiliaria en particular.

El extraordinario crecimiento en los consumos experimentado desde 1972 se explica teniendo en cuenta que este municipio ha generado más de 2.500 ha de suelo urbano, con una elevada densidad edificatoria y fuerte grado de estacionalidad. Existen más de 240.000 plazas en viviendas, que contrastan con una planta hotelera relativamente modesta (alrededor de 1.700 plazas).

La potencia del turismo residencial, por tanto, es importantísima, y ha tirado fuertemente de los consumos. En el mes de agosto, la población abastecida puede superar los 400.000 habitantes (Vera Rebollo, J.F., 2002). 


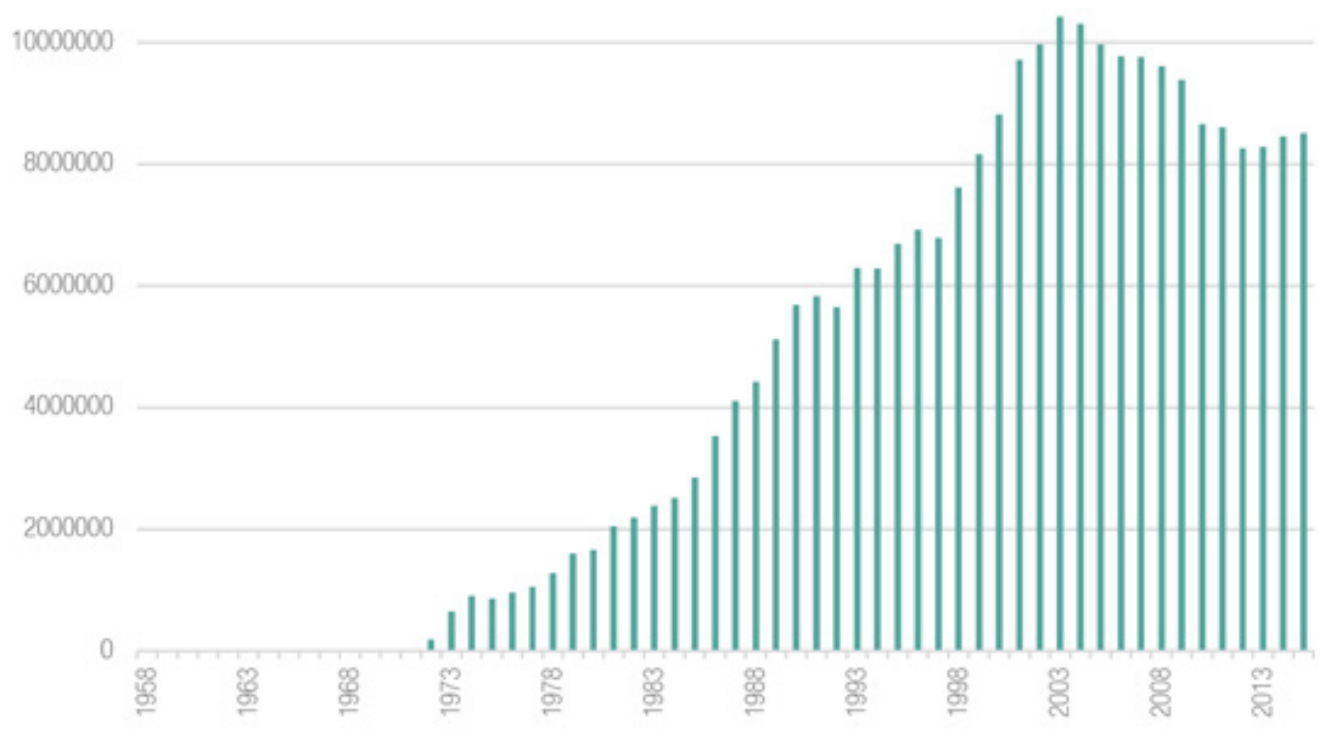

Fig 109. Consumo de agua potable en Torrevieja (19722015) [MCT. Elaboración propia.] 
Torrevieja 1975

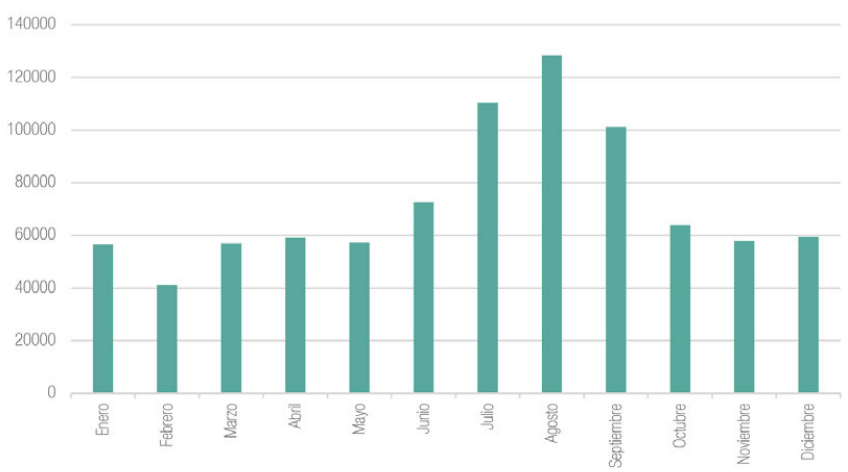

Torrevieja 1995

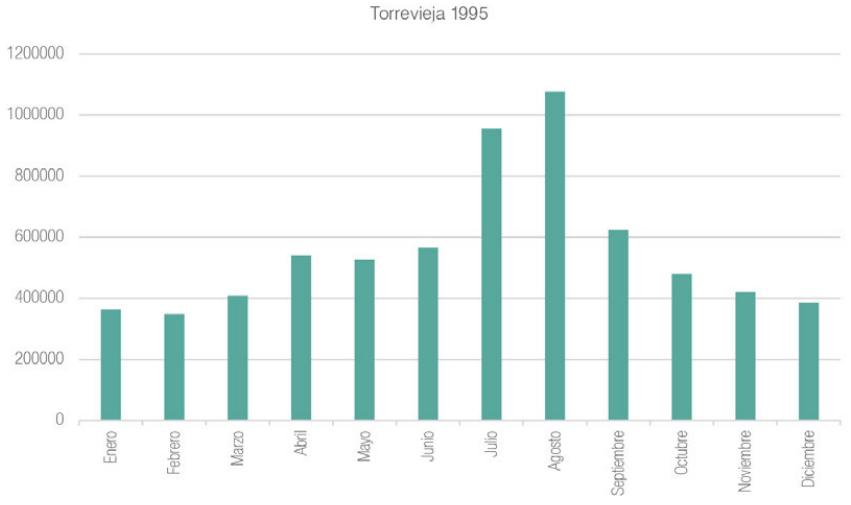

Torrevieja 2015

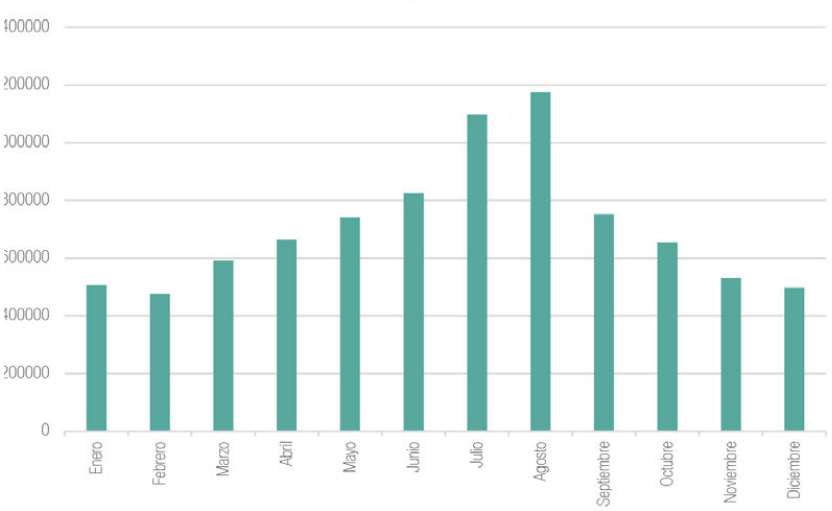

Torrevieja 1985

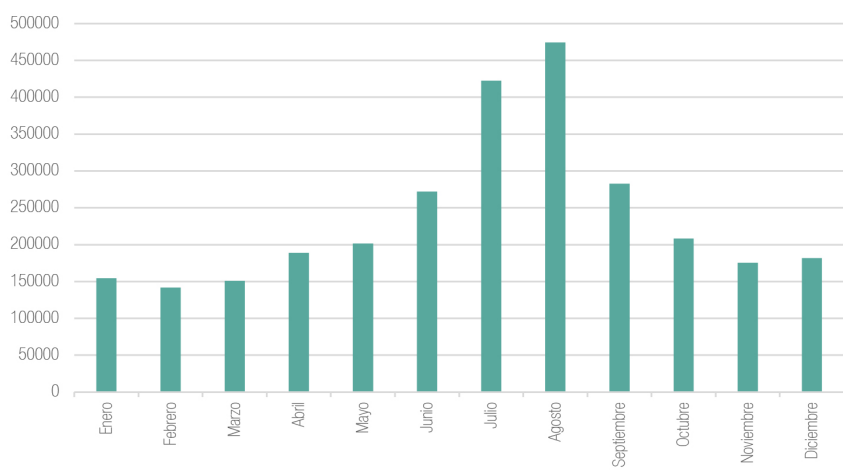

Torrevieja 2005

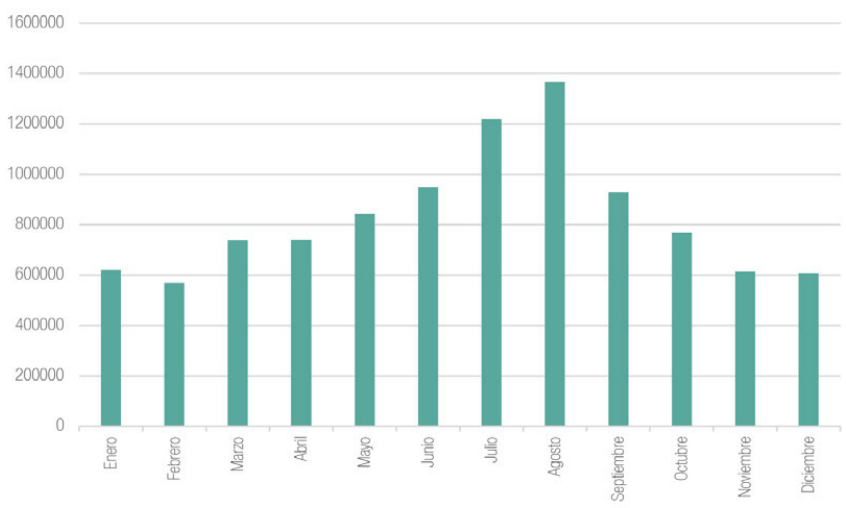

Fig 110. Distribución mensual del consumo de agua potable en Torrevieja (1975, 1985, 1995, 2005, 2015) [MCT. Elaboración propia.] 
En 1960, el municipio contaba con 6.443 habitantes; en 2000 con 18.922. En 2007 tenía 29.221, de los cuales 21.416 vivían en Santa Pola ciudad. Otro núcleo poblacional importante es Gran Alacant, que contaba con 7.336 habitantes en ese año. La totalidad de la población de Santa Pola en 2015 ascendió a 31.657 habitantes.

Santa Pola ha tenido una progresión similar a Elche, habiendo incrementado el consumo de agua potable de 2,3 $\mathrm{hm}^{3}$, en 1984, a 3,9 hm³ , en 2006. Posteriormente, los consumos decrecen excepto en el año 2008, en el que se observa la punta de mayor consumo histórico de la población de aguas procedentes de la MCT.

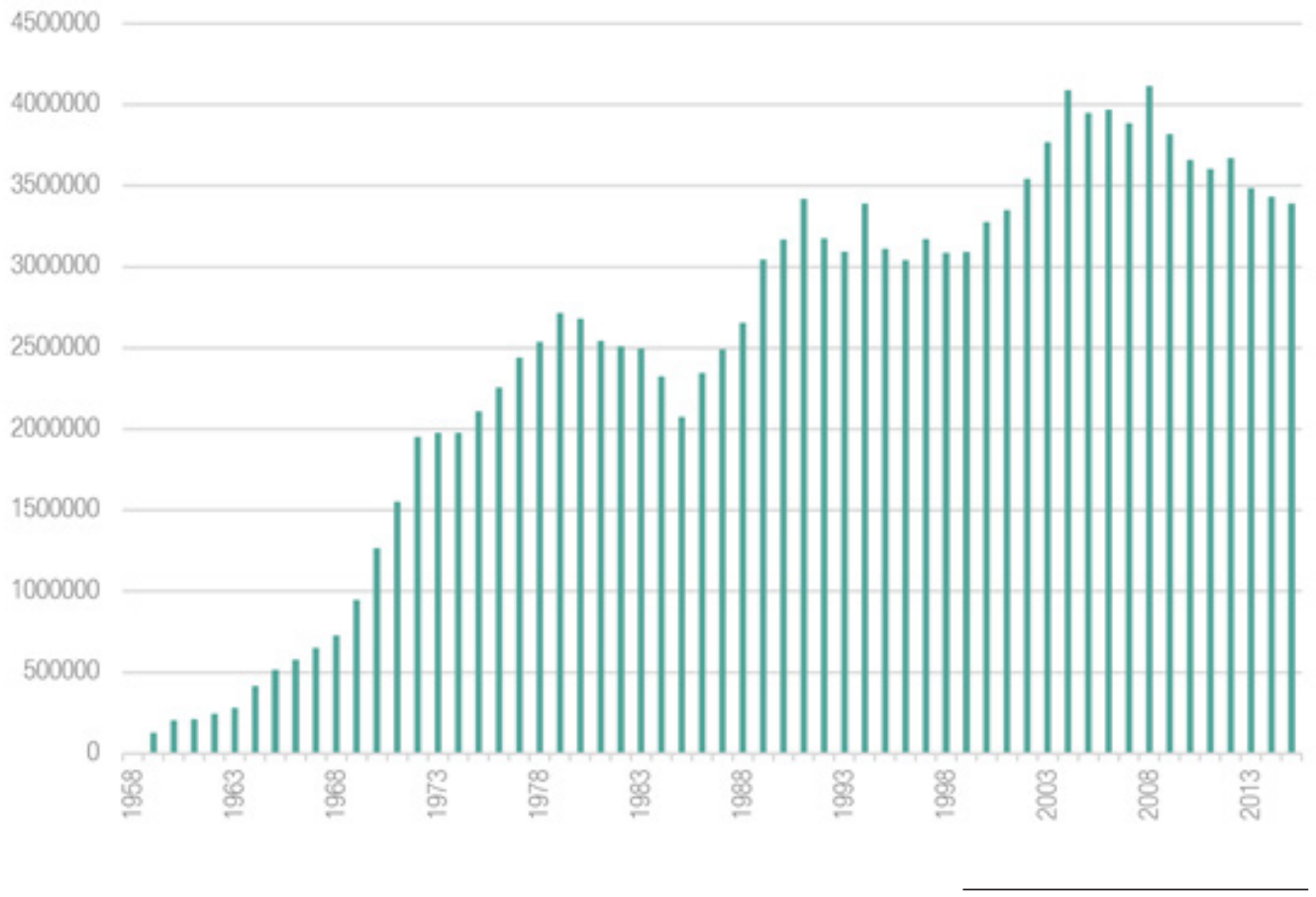

Fig 111. Consumo de agua potable en Santa Pola (19582015) [MCT. Elaboración propia.] 
Santa Pola 1975

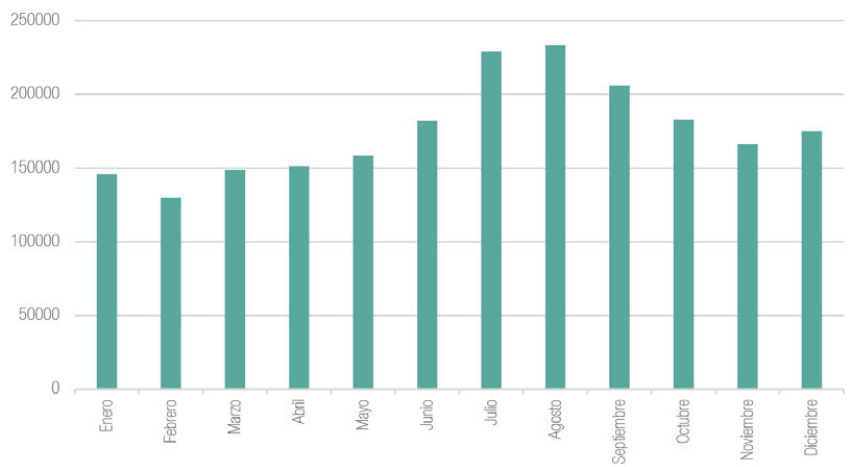

Santa Pola 1995

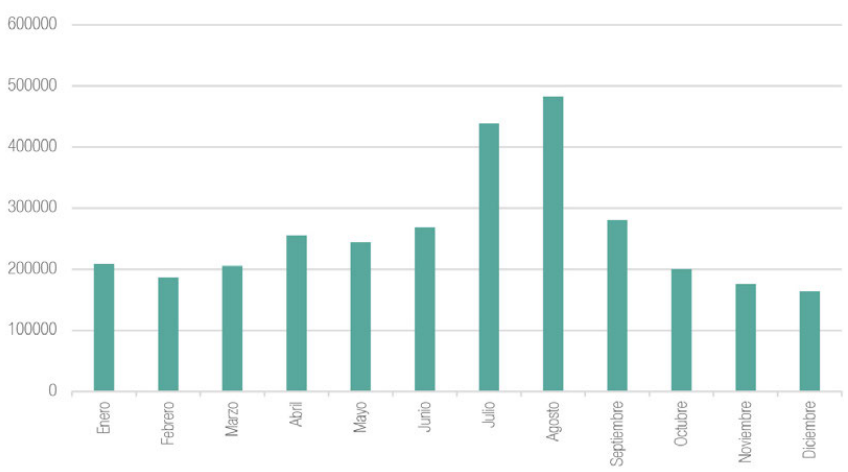

Santa Pola 2015

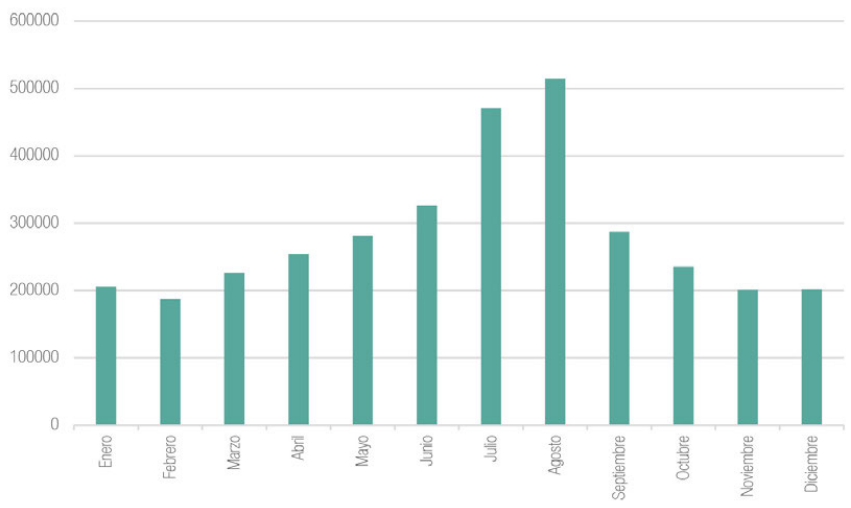

Santa Pola 1985

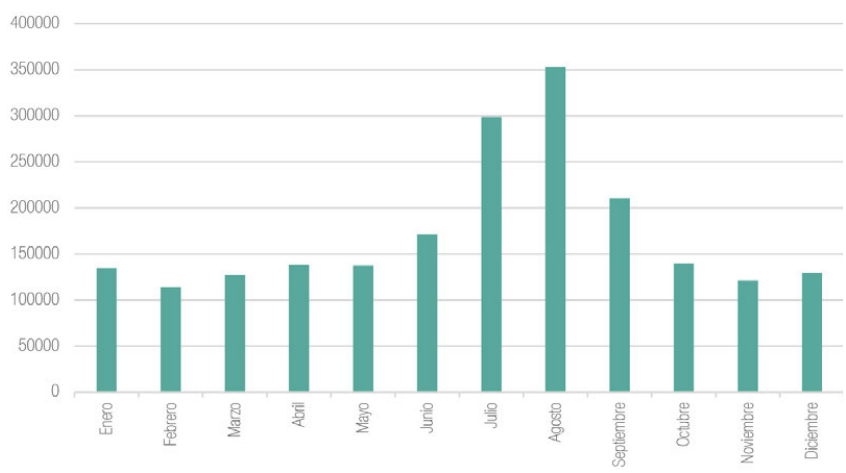

Santa Pola 2005

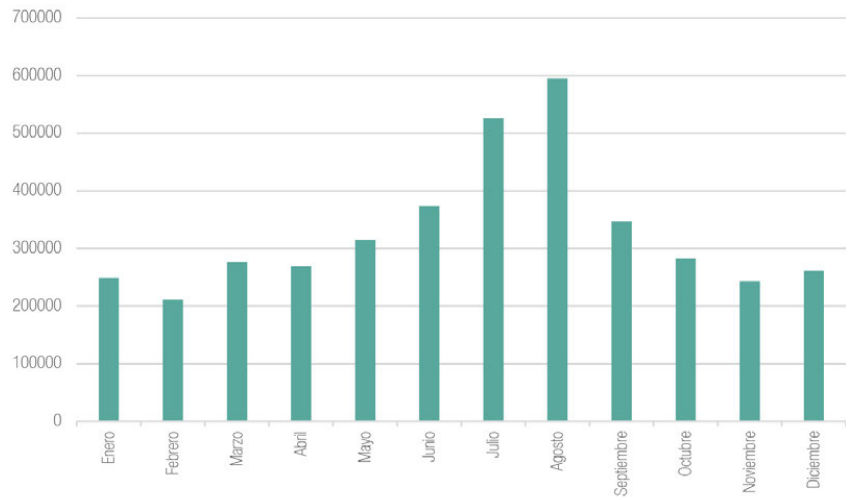

Fig 112. Distribución mensual del consumo de agua potable en Santa Pola (1975, 1985, 1995, 2005, 2015) [MCT. Elaboración propia.] 


\section{c.- Guardamar.}

Guardamar presenta un fuerte crecimiento demográfico desde los años ochenta, alcanzando los 16.863 habitantes en 2011 (INE, 2011). El 40,4\% de sus habitantes es de nacionalidad extranjera, principalmente procedentes de otros países europeos. Los consumos de agua del municipio se representan en la figura 113.

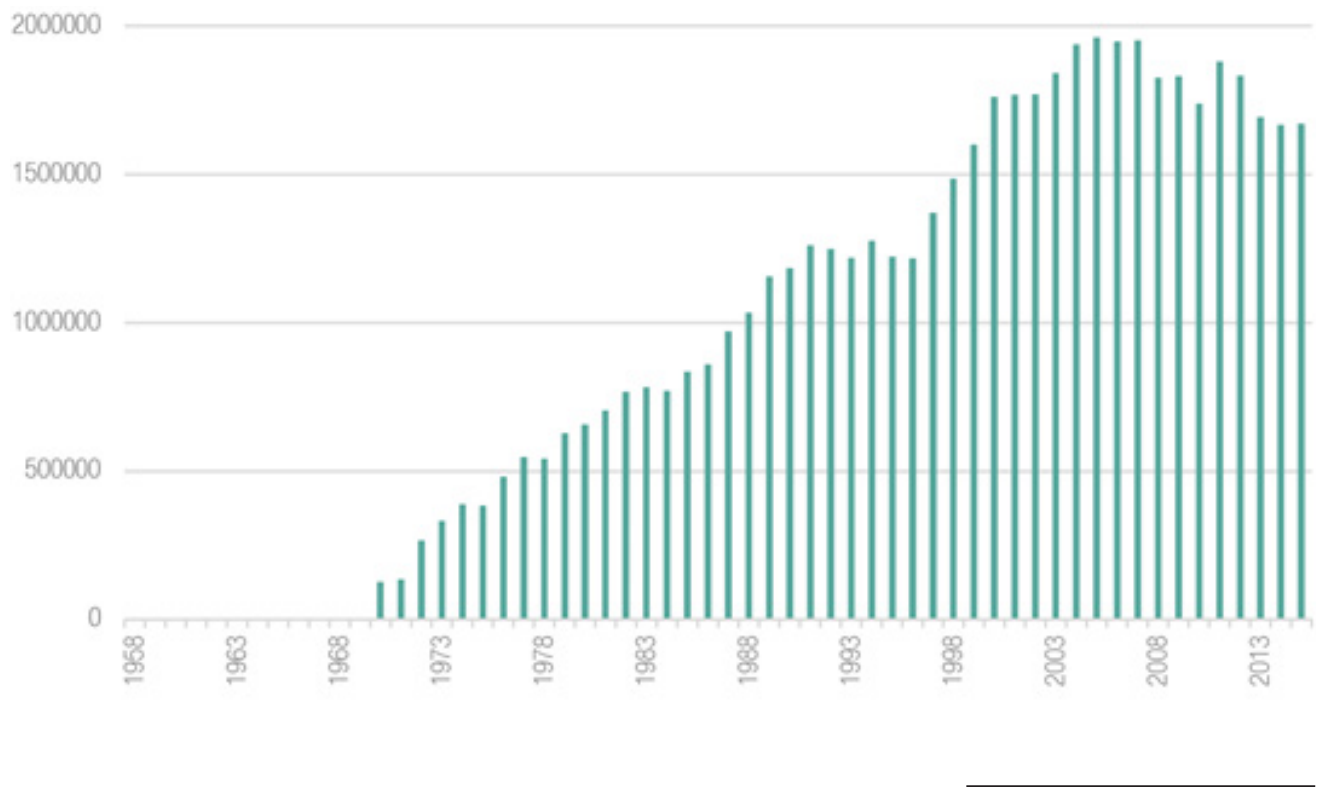

Fig 113. Consumos de agua de Guardamar (1969-2015) [MCT. Elaboración propia.]

La gráfica muestra para el caso de Guardamar unas tendencias similares a las observadas en el municipio de Santa Pola. 
Guardamar 1975

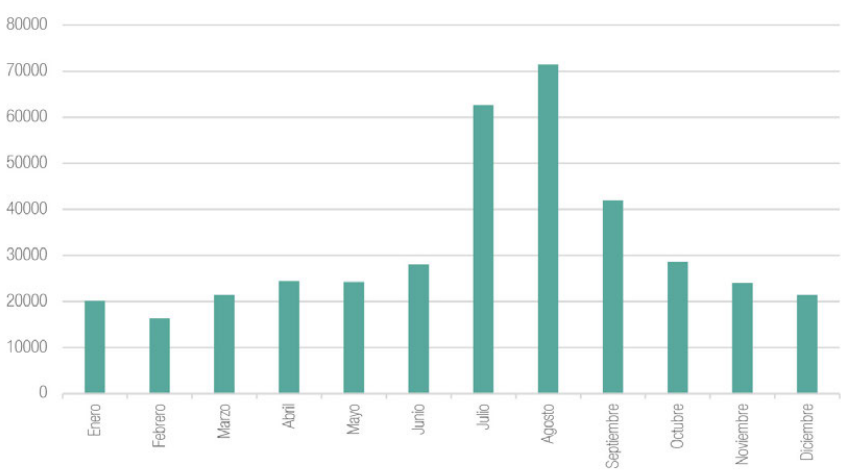

Guardamar 1995

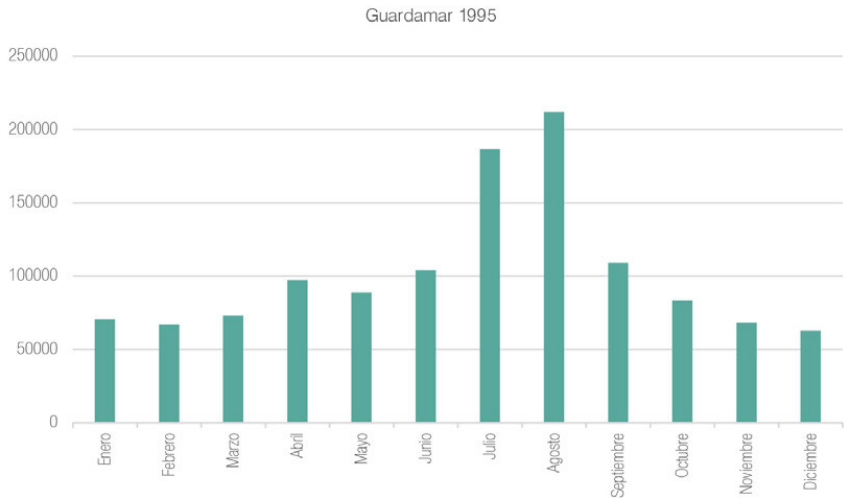

Guardamar 2015

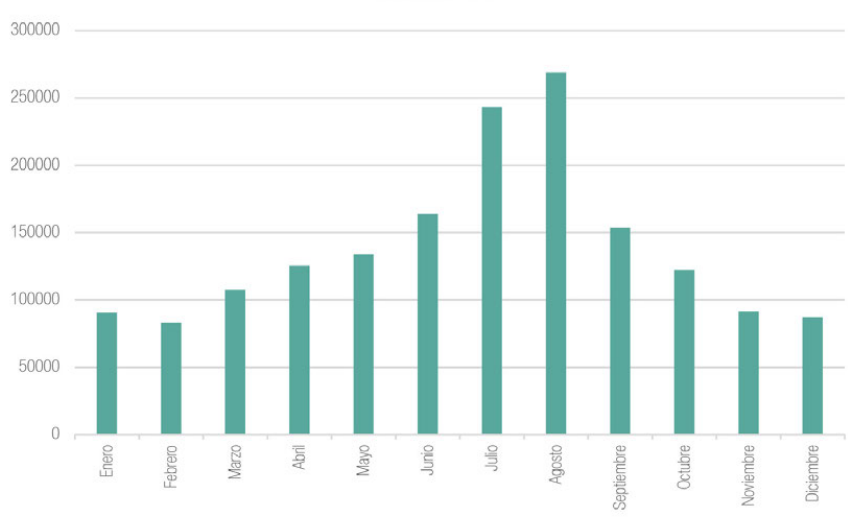

Guardamar 1985

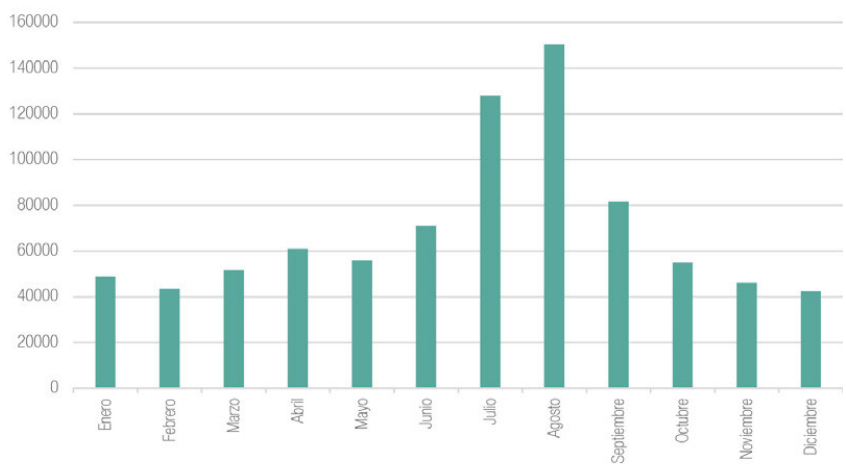

Guardamar 2005

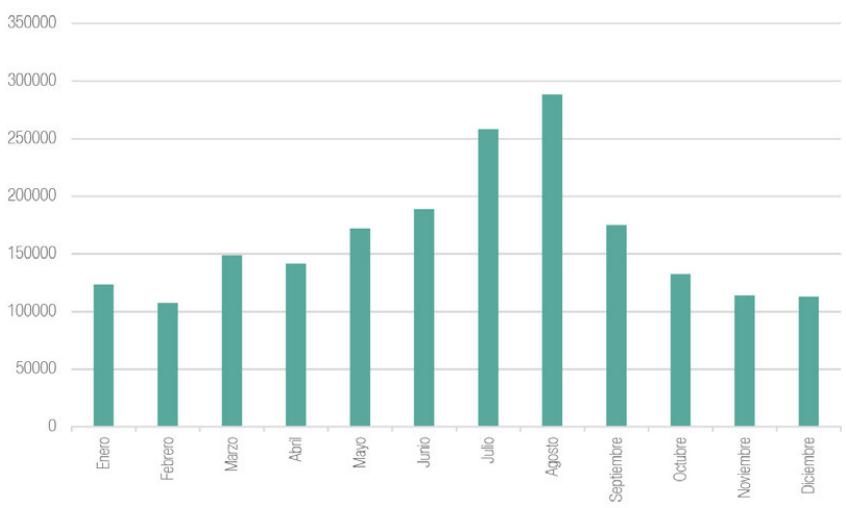

Fig 114. Distribución mensual del consumo de agua potable en Guardamar del Segura (1975, 1985, 1995, 2005, 2015) [MCT. Elaboración propia.] 
Esta localidad está situada a $36 \mathrm{~km}$ de Orihuela, municipio del que formó parte hasta su segregación el 30 de julio de 1986. Contaba en 2015 con una población de 21.629 habitantes, mientras que en 1986 contaba con 6.509. En los años 1996 y 2000 incrementó su población en el 27 y $22 \%$ respectivamente. En 2014 llegó incluso a perder el 8,79\% de la población, estabilizándose este saldo en 2015 (INE, 2016).

3000000

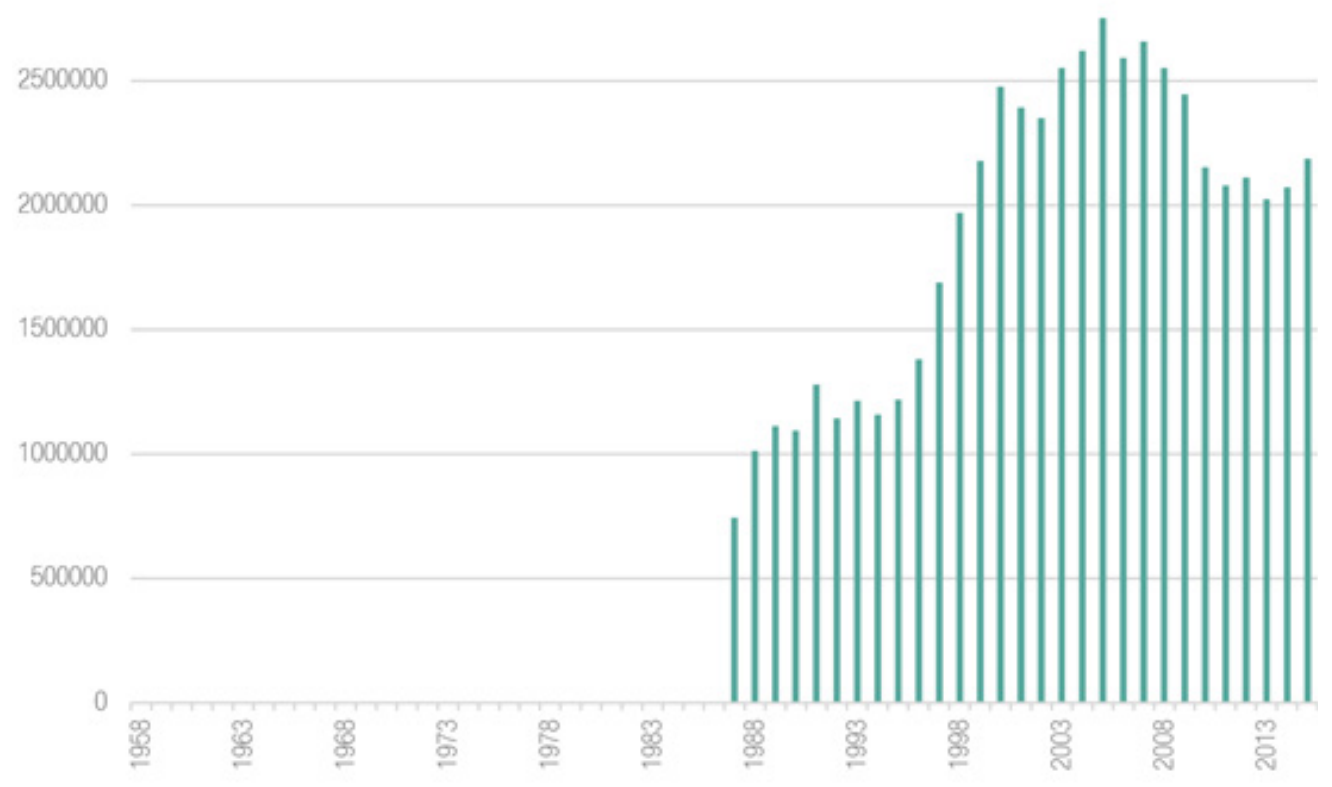

Fig 115. Consumo de agua potable en Pilar de la Horadada (1987-2015) [MCT. Elaboración propia.] 
Puer de la Horadada 1995

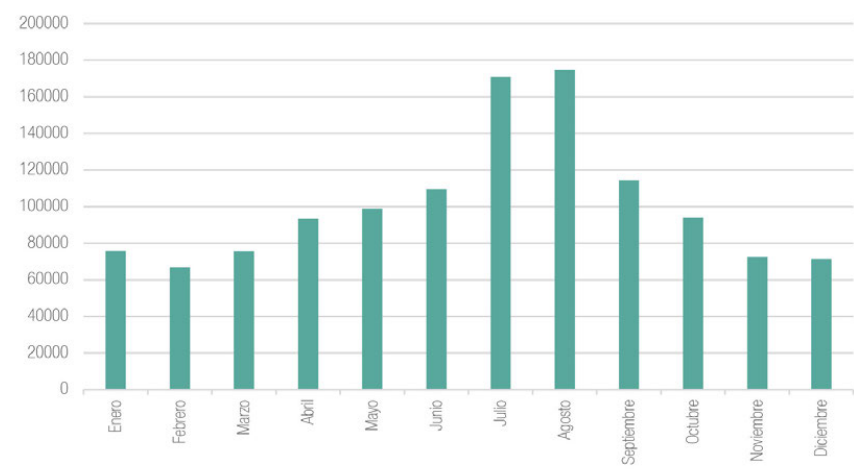

Plar de la Horadada 2005

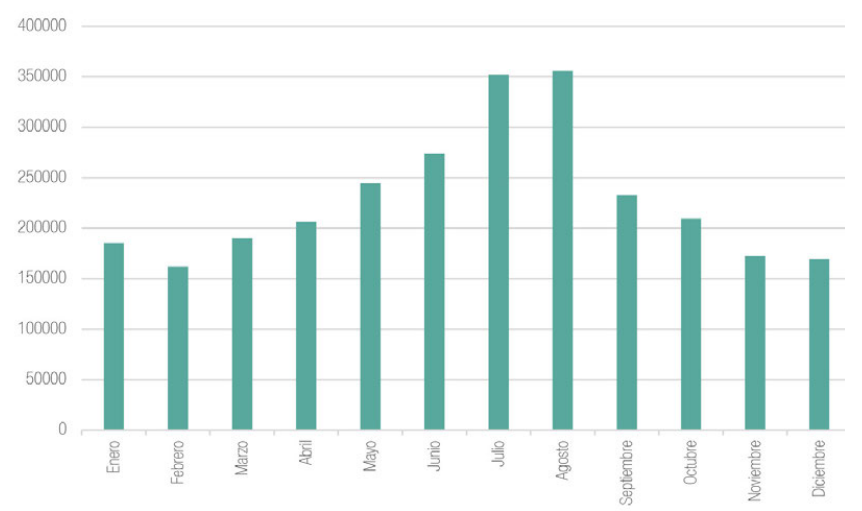

Plar de la Horadada 2015

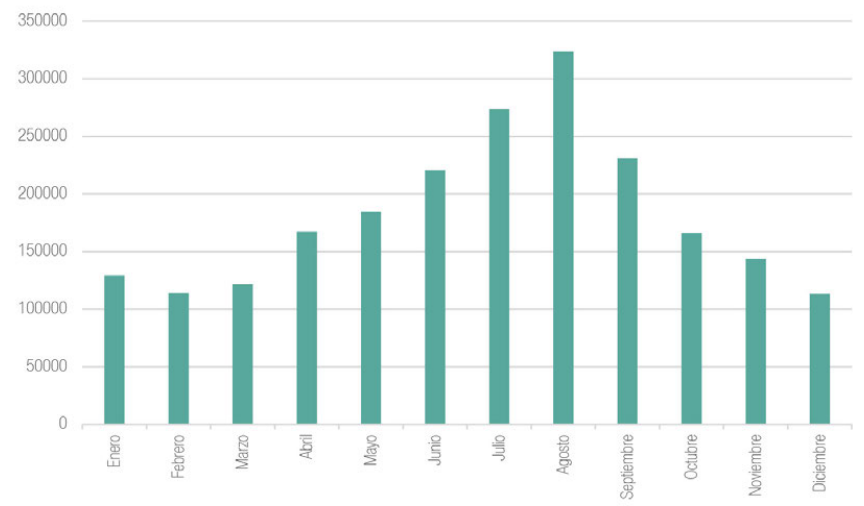

Fig 116. D is tribu c ión mensual del consumo de agua potable en Pilar de la Horadada (1995, 2005, 2015) [MCT. Elaboración propia.] 
Las intensas dinámicas inmobiliarias en este grupo de municipios costeros alicantinos, y sus efectos sobre el incremento de las unidades de vivienda de uso vacacional, han tenido una notable repercusión sobre los consumos hídricos de estos destinos. Los incrementos en los consumos registrados desde al menos mitad de los años noventa resultan indicativos del proceso de construcción de nuevas unidades urbanas en relación con demandas de tipo residencial y turístico, especialmente en el municipio de Torrevieja. (Baños et al., 2010)

En los núcleos turísticos costeros la estacionalidad estival del consumo es acusada, aunque Torrevieja ha ido equilibrando sus consumos a lo largo del año, reduciendo las discontinuidades en los volúmenes consumidos entre los meses de invierno y verano; y ello debido a la progresiva transformación del municipio de núcleo urbano a espacio residencial. Guardamar del Segura y Santa Pola tienen un incremento muy importante del consumo en los meses de julio y agosto, lo que obliga a tener sobredimensionados tanto los depósitos como las redes de distribución durante buena parte del año. En algunos casos, la atracción generada sobre determinados mercados de demanda — tercera edad, razones laborales - ha supuesto la suavización de los índices de estacionalidad (Baños et al., 2010).

\subsection{3.- Municipios del área pre-litoral.}

En los municipios del prelitoral el incremento en el consumo de agua es muy significativo en términos generales, ante la gran expansión residencial-turística. De hecho, este grupo de municipios presenta el crecimiento más acelerado en los consumos hídricos dentro del área MCT en la provincia de Alicante, debido a la gran actividad inmobiliaria.

Pasan de consumir 4,5 hm $\mathrm{hm}^{3}$ en 1994 a 10,1 en 2009. Es decir, la tasa de variación media alcanza el 122\%, con casos espectaculares como el de Algorfa que en ese periodo triplica los consumos. En este caso, las actuaciones inmobiliarias surgidas en torno a campos de golf contribuyen al incremento.

A partir de 2009, sin embargo, los consumos se han atenuado, lo que de hecho ha venido ocurriendo en el resto de municipios desde inicio o mediados del 2000. El fenómeno se manifiesta aquí, por tanto, de manera algo más tardía. En los gráficos siguientes se pueden observar los consumos hídricos de los destinos vacacionales prelitorales del área MCT hasta 2015. 
a.- Rojales.

Rojales es un municipio ribereño del Segura, cuya población supera en la actualidad los 22.000 habitantes, de los que 5.200 son de origen español; el resto conforman un conglomerado internacional de 74 nacionalidades. Su estructura urbana está formada por dos grandes bloques: el centro histórico y las urbanizaciones. El crecimiento de su población ha sido extraordinario, ya que en 1981 contaba con 4.117 habitantes, lo que explica el gran incremento en el consumo de agua, especialmente a partir de 1988.

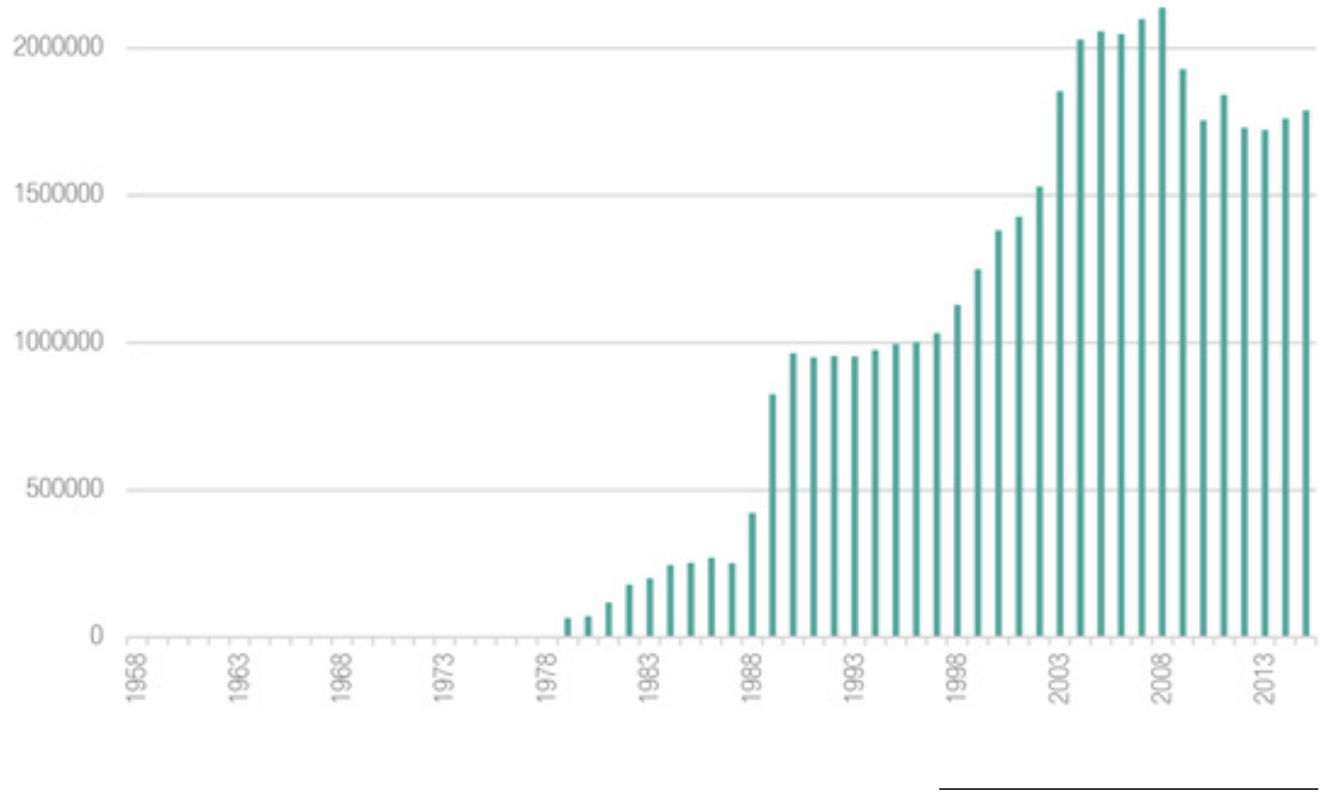

Fig 117. Consumo de agua potable en Rojales (1979-2015) [MCT. Elaboración propia.] 
La actividad económica tradicional de San Fulgencio ha sido tradicionalmente la agricultura, sin embargo, la localidad experimentó un crecimiento fortísimo y constante debido al turismo, dada su situación junto a los enclaves costeros de La Marina (Elche) y Guardamar del Segura. Además del núcleo principal, se han construido nuevas urbanizaciones próximas al litoral, la mayor de las cuales es la Urbanización La Marina, iniciada a finales de los años 80. La repercusión de estas dinámicas en la población residente es extraordinaria, en 1981 la localidad contaba con 1.549 habitantes, que en 2011 ascendieron a 12.354, muchos de nacionalidad extranjera.

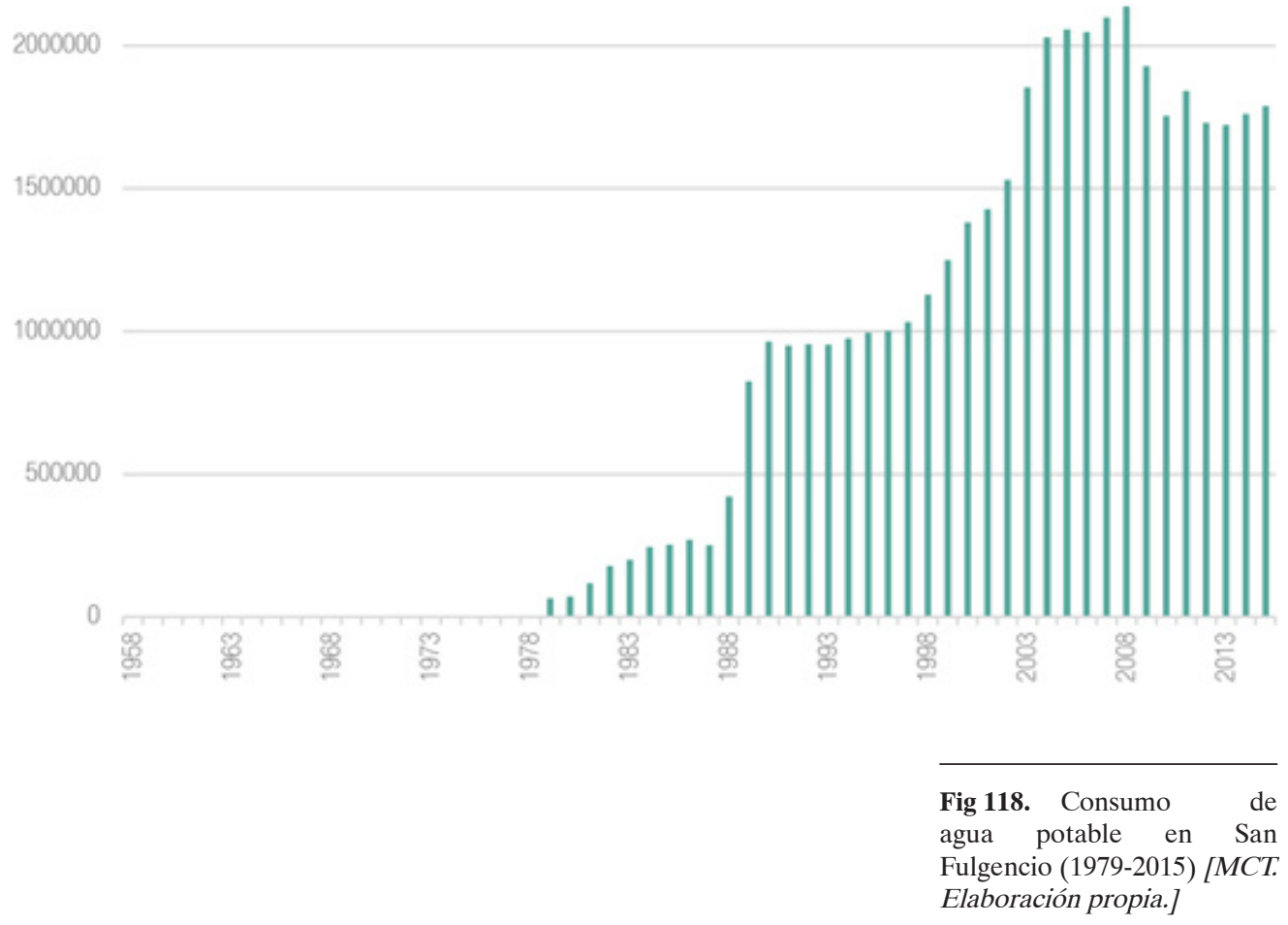


San Fulgencio 1985

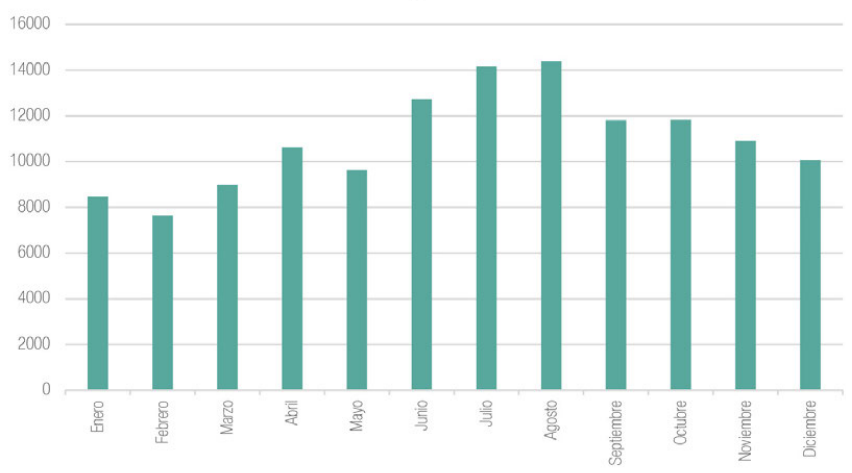

San Fulgencio 2005

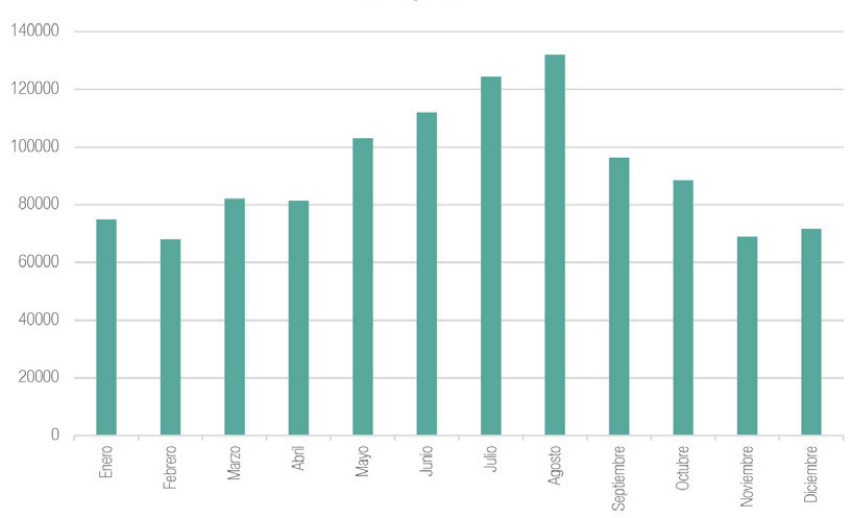

San Fulgencio 1995

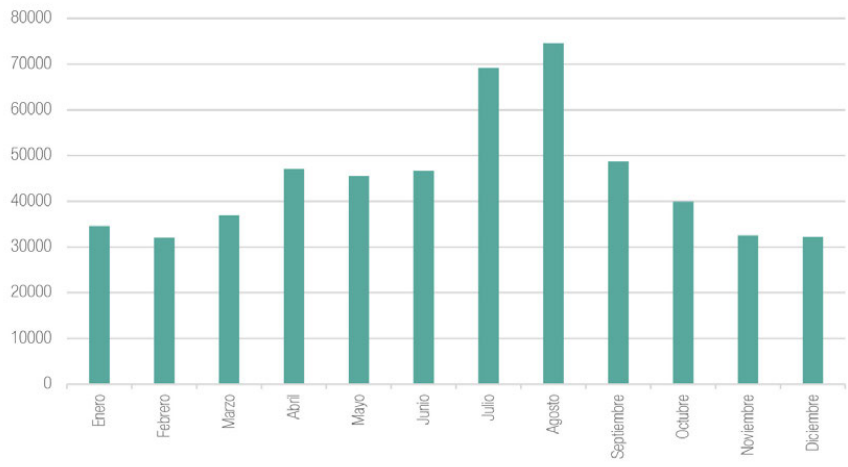

San Fulgencio 2015

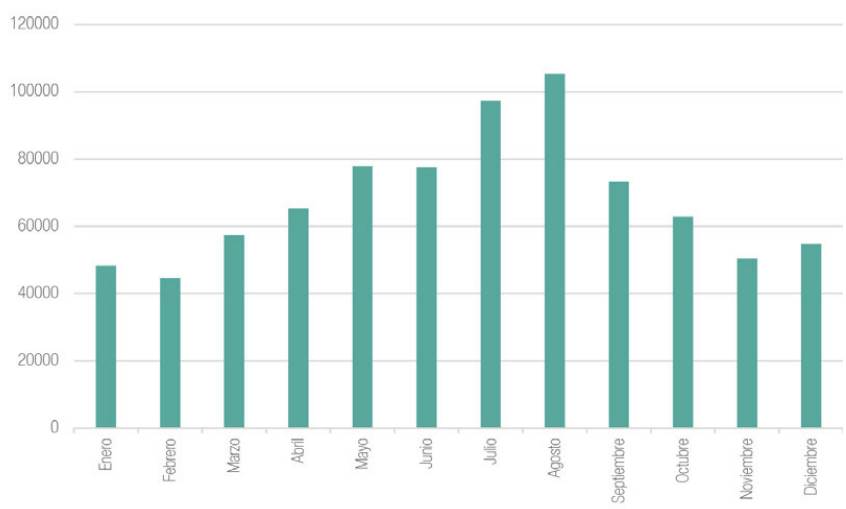

Fig 119. D i s t r i b u c i ón mensual del consumo de agua potable en San Fulgencio (1985, 1995, 2005, 2015) [MCT. Elaboración propia.] 
Esta localidad contaba en 1981 con 2301 habitantes, creciendo dicha cifra hasta los 8.057 en 2010, de los cuales unos 5.200 eran extranjeros.

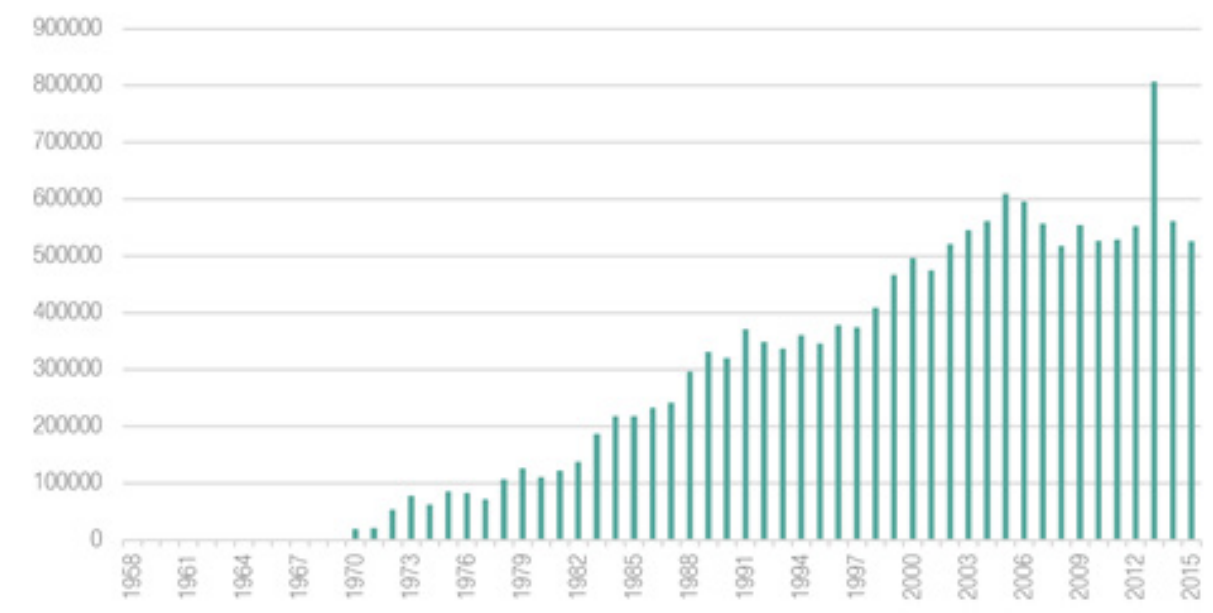

Fig 120. Consumo de agua potable en San Miguel de Salinas (1979-2015) [MCT. Elaboración propia.]

$$
\text { d.- Algorfa. }
$$

Este municipio contaba en 1981 con una población de 1.068 personas, en 2011 ascendieron a 4.625 , de las cuales el $65 \%$ eran extranjeras.

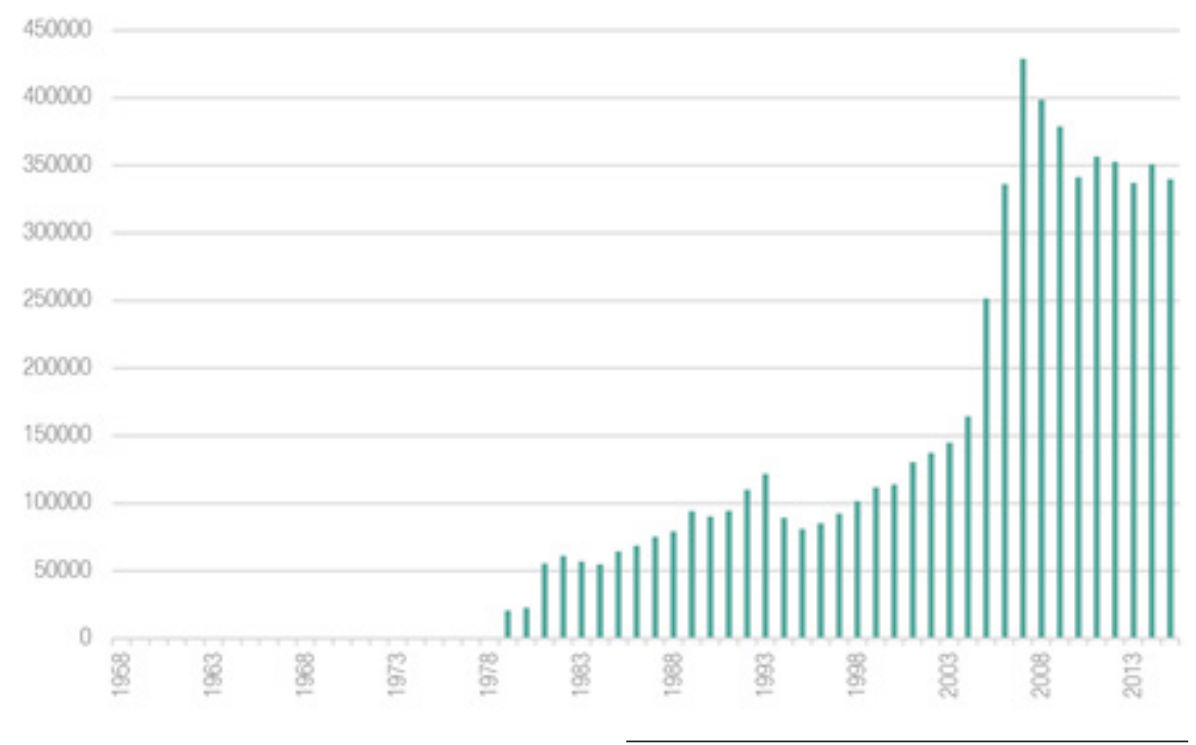

Fig 121. Consumo de agua potable en Algorfa (1979-2015) [MCT. Elaboración propia.] 
En estos municipios la estacionalidad del consumo es importante en los meses centrales del verano, aunque dicha característica se ve atenuada en algunas localidades como Rojales o San Fulgencio, en los que las residencias están ocupadas durante buena parte del año.

Otros, sin embargo, siguen la pauta de mayor estacionalidad, como ocurre en el caso de Pilar de la Horadada, donde la ocupación de apartamentos sólo durante el periodo estival es mucho más acusada. Ello conduce a un incremento mayor de los consumos que se producen en esta época respecto al resto de meses del año.

\subsection{4.- Municipios de interior.}

En las localidades situadas más al interior, predominan las actuaciones turístico residenciales dispersas. Son municipios en los que el paisaje tradicional se ha visto fuertemente transformado en los últimos años, con un desarrollo inmobiliario incluso más intenso que en el resto de municipios del sur de la provincia de Alicante. Ello ha dado lugar a que se observen incrementos de consumo incluso superiores al $50 \%$ entre 1994 y 2007. Es el caso de Catral, o de Granja de Rocamora.

En algunos casos, incluso, se ha duplicado o triplicado el consumo de agua. Así ha ocurrido en Daya Vieja o San Isidro, que no obstante partían de consumos muy bajos en 1994. Albatera, Benejuzar, Cox, Daya Nueva, Rafal o Redován, no han experimentado sin embargo estas alzas de consumo, dado que las actuaciones urbanísticas son de menor entidad.

Con todo, estas localidades también incrementan sus consumos en el periodo 19942007, aunque en porcentajes inferiores al 30\%. La estacionalidad no es acusada, dado que la demanda es estable a lo largo de todo el año, e incluso puede reducirse en verano debido al traslado de parte de su población a segundas residencias situadas en la costa durante la época estival. 
El crecimiento poblacional de este municipio ha sido menos acentuado que en el grupo de municipios del pre-litoral, pasando de 14.183 habitantes en 1981 a 18.034 en 2012.

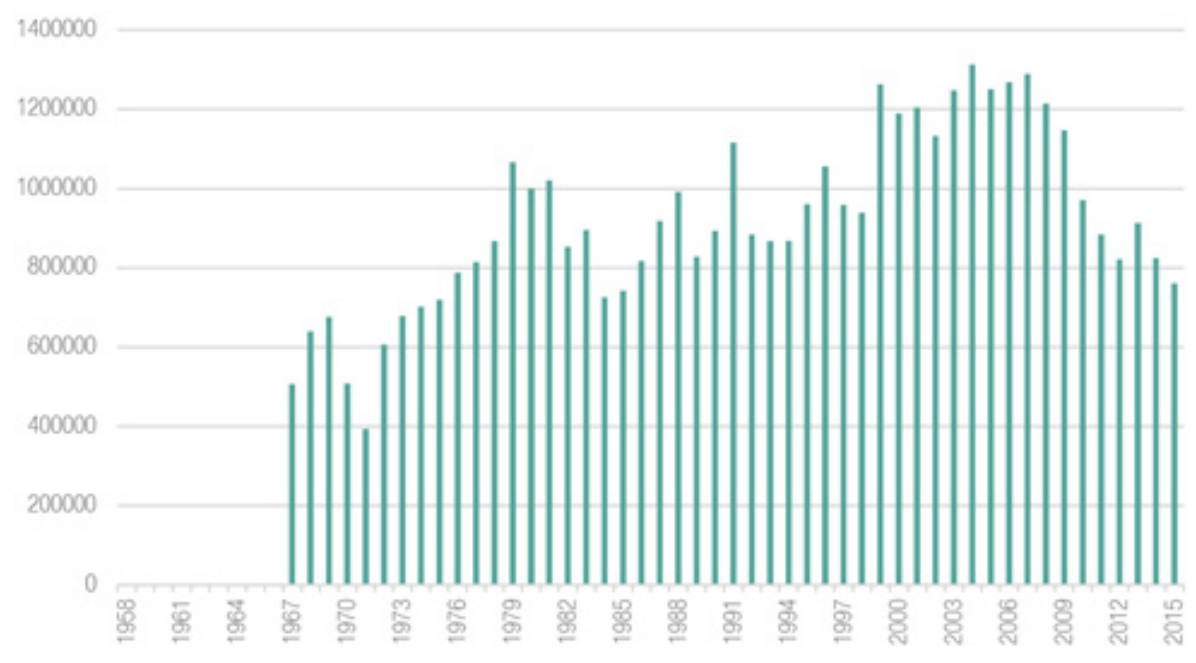

Fig 122. Consumo de agua potable en Callosa del Segura (1966-2015) [MCT. Elaboración propia.]

b.- Catral.

Este municipio tiene un comportamiento turístico diferenciado con respecto a los municipios costeros. En él predominan las viviendas de huerta diseminadas. La población ha pasado de 4.209 personas censadas en 1981 a 8.663 en 2014.

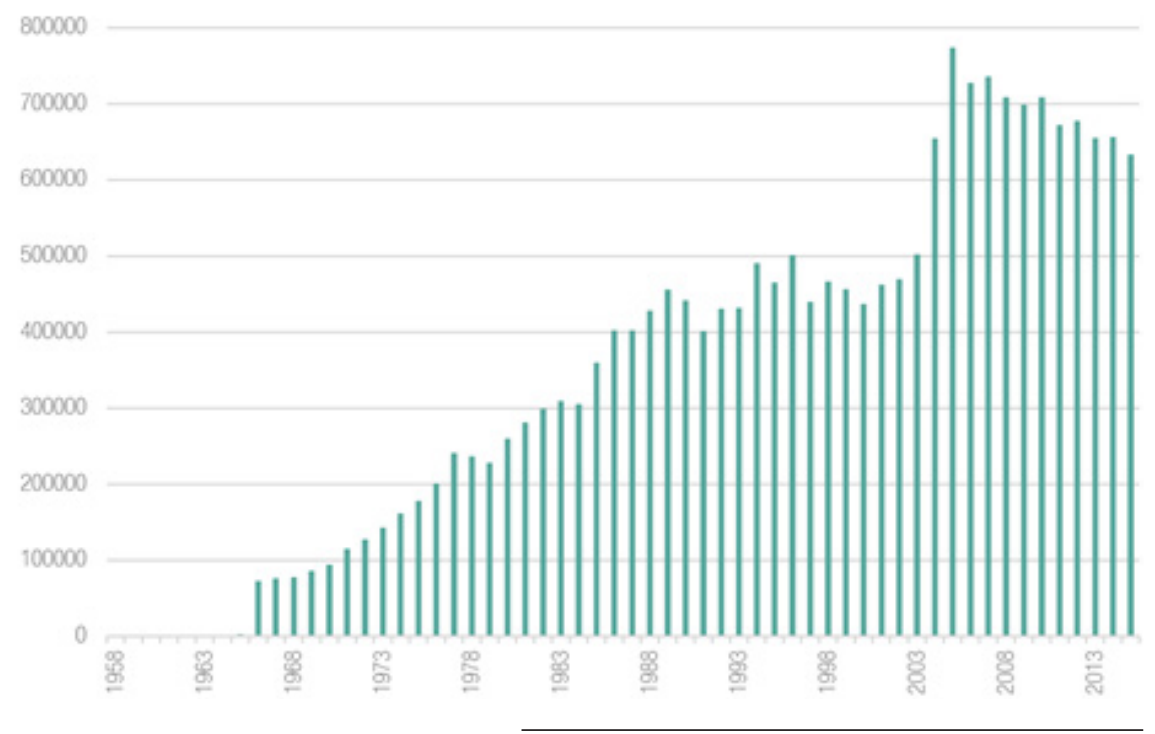

Fig 123. Consumo de agua potable en Catral (1966-2015) [MCT. Elaboración propia.] 
Municipio eminentemente agrícola, con una población en 2010 de 1.951 personas que no ha experimentado fuertes crecimientos demográficos.

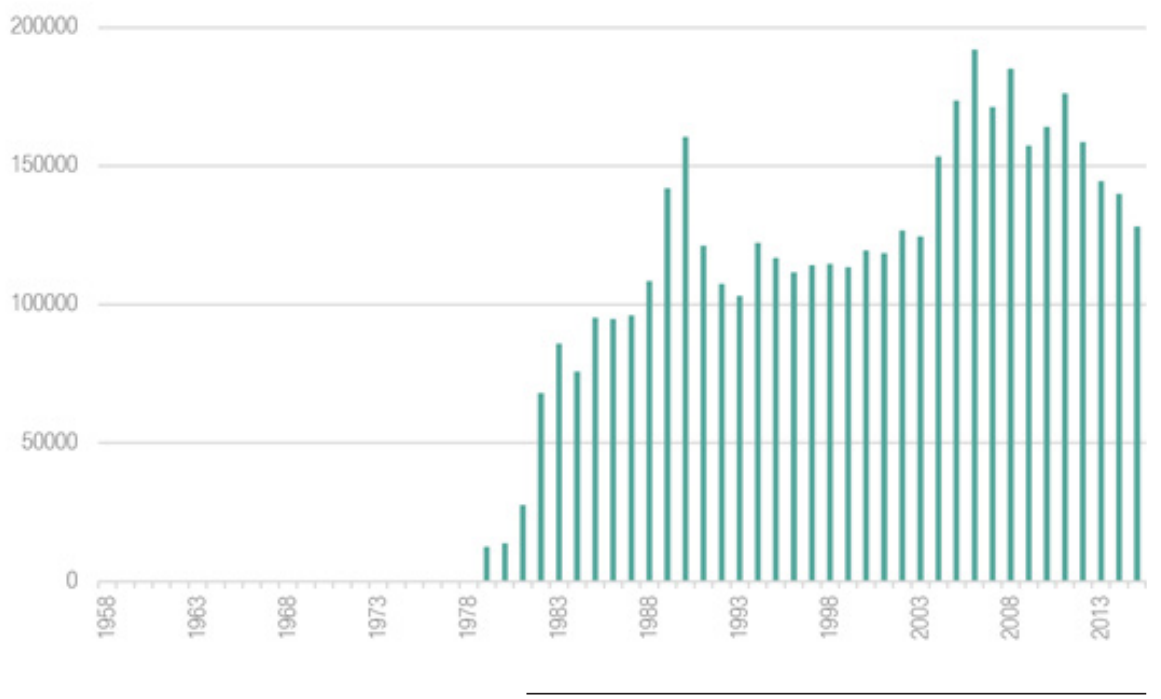

Fig 124. Consumo de agua potable en Daya Nueva (1979-2015) [MCT. Elaboración propia.]

d.- Daya Vieja.

Este municipio, dedicado básicamente a la agricultura, contaba en 2011 con 726 habitantes (INE).

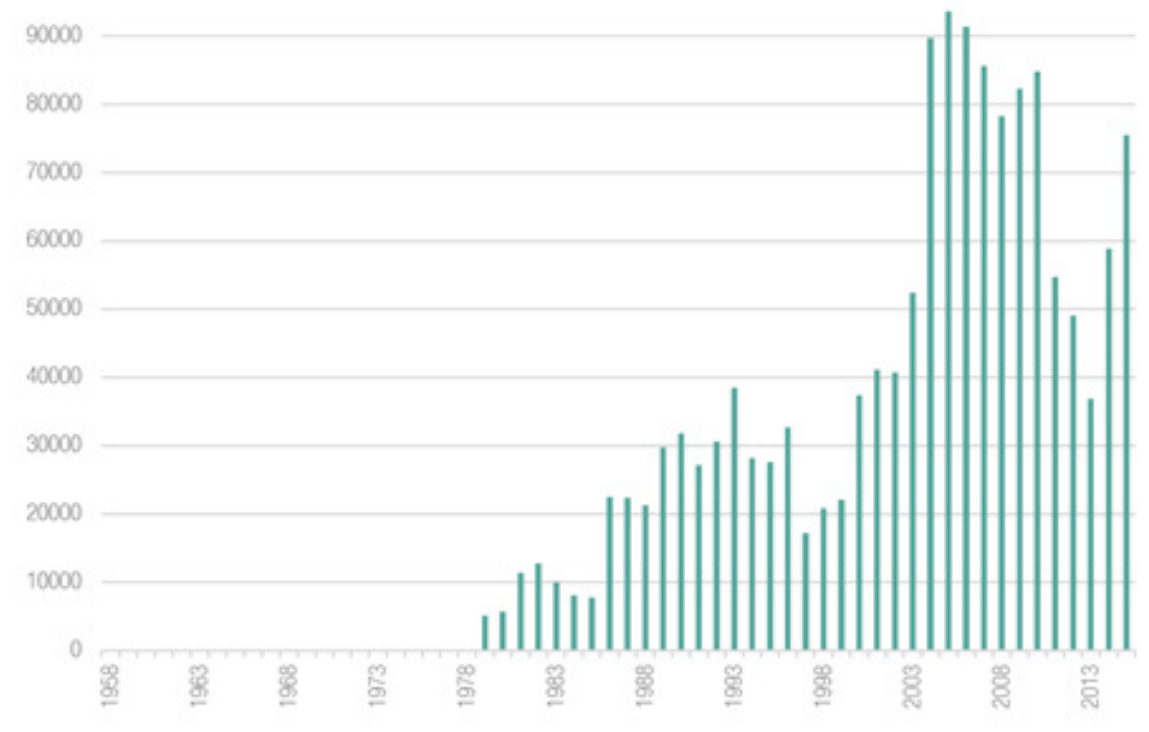

Fig 125. Consumo de agua potable en Daya Vieja (1979-2015) [MCT. Elaboración propia.] 
Municipio agrícola con una población en 1981 de 909 habitantes, que en 2015 ascendió a 1.899 personas (INE).

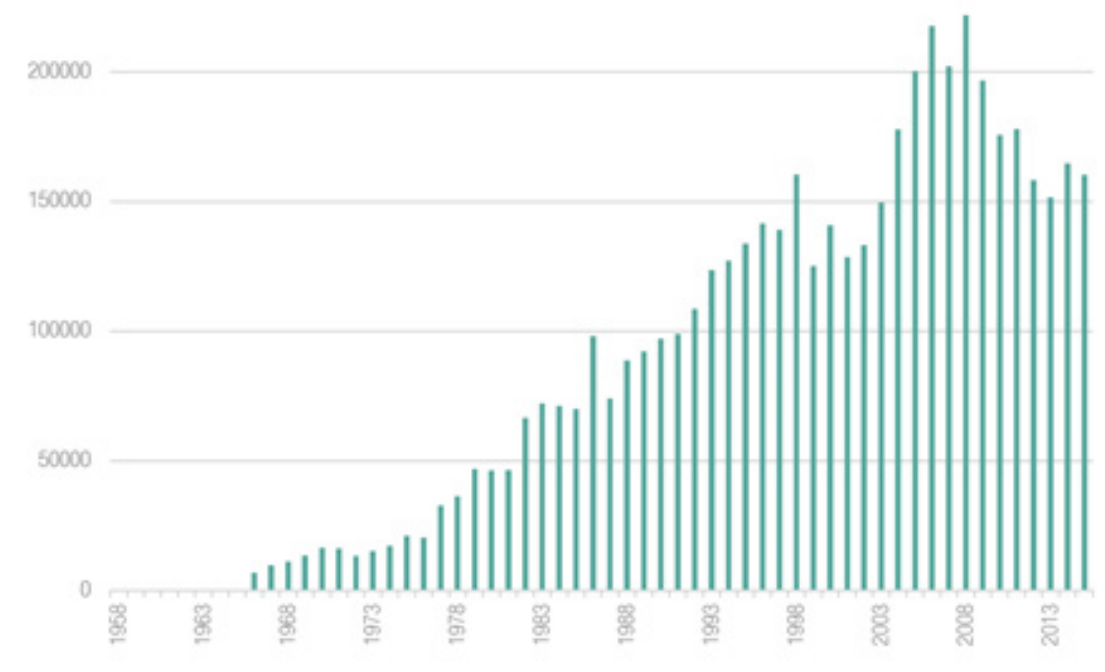

Fig 126. Consumo de agua potable en Benferri (1966-2015) [MCT. Elaboración propia.]

\section{f.- Albatera.}

La economía de Albatera se ha basado tradicionalmente en la agricultura de regadío, sin embargo, hoy en día esta actividad económica no constituye el sector principal, que ha sido ocupado por el sector servicios en general y el comercio en particular. En 1981 contaba con 8.076 habitantes que han crecido en 2015 hasta los 12.338 .

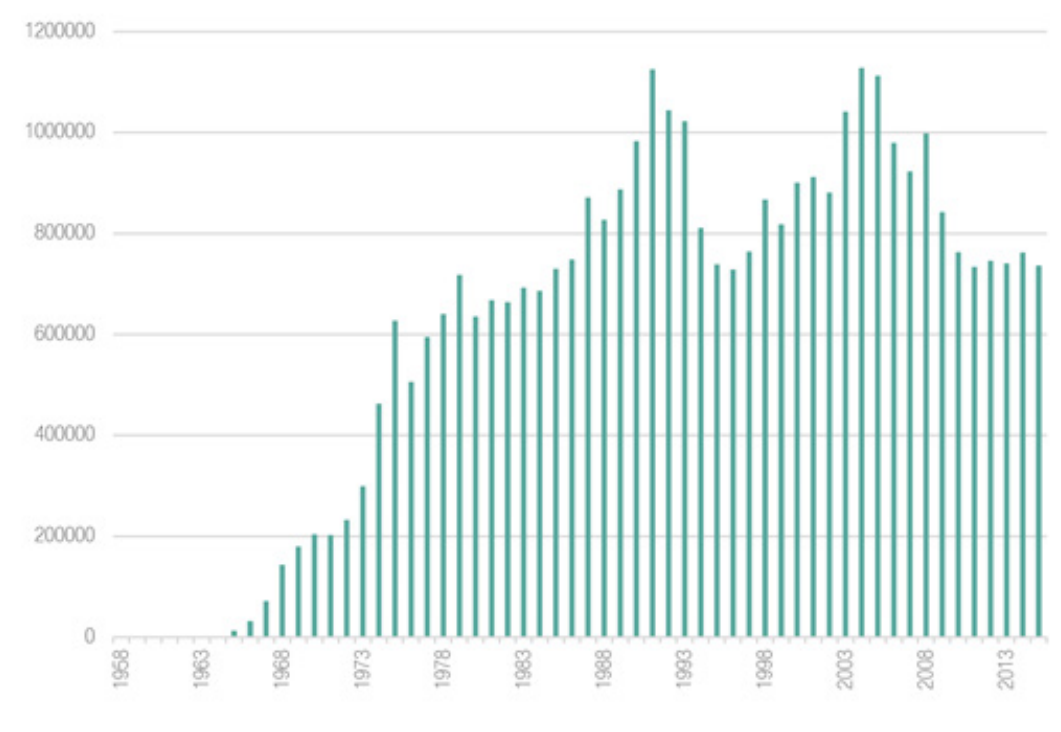

Fig 127. Consumo de agua potable en Albatera (1966-2015) [MCT. Elaboración propia.] 
En 1995, dos años después de su segregación de Albatera, San Isidro tenía 1.185 habitantes, que en 2013 ascendieron a 1901.

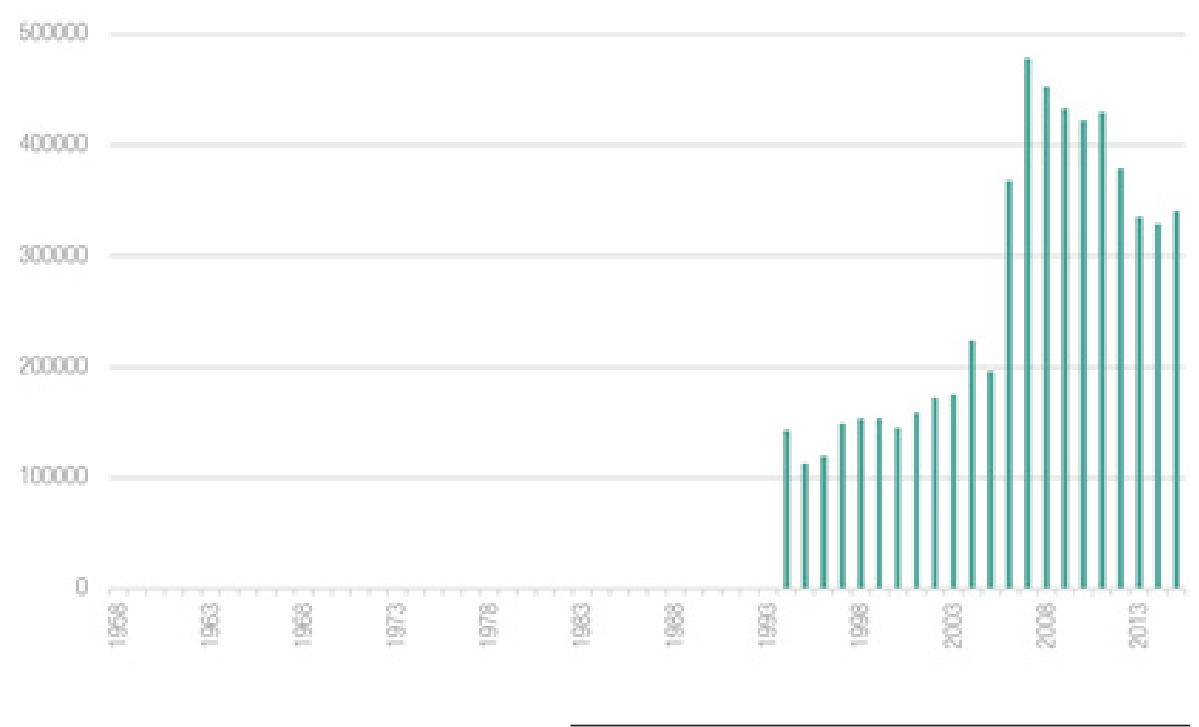

Fig 128. Consumo de agua potable en San Isidro (1995-2015) [MCT. Elaboración propia.]

\section{f.- Redován.}

Este municipio cuenta con un sector económico diferenciado, en el que todos los sectores son relevantes. Contaba en 1981 con 4.391 habitantes, y en 2014 ascendieron a 8.064 (INE).

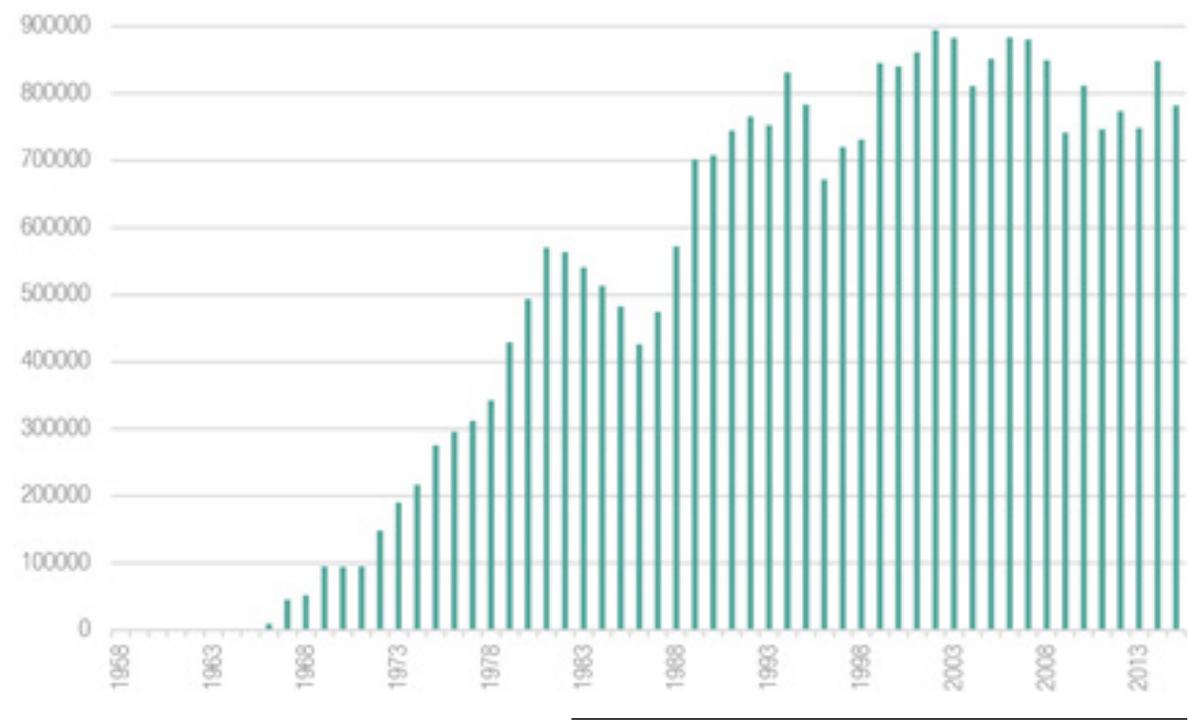

Fig 129. Consumo de agua potable en Redován (1965-2015) [MCT. Elaboración propia.] 
Tiene una economía basada tradicionalmente en la agricultura y en la fabricación de conservas vegetales. Su población en 1981 era de 2.234 personas que en 2007 ascendieron a 3.901 (INE).

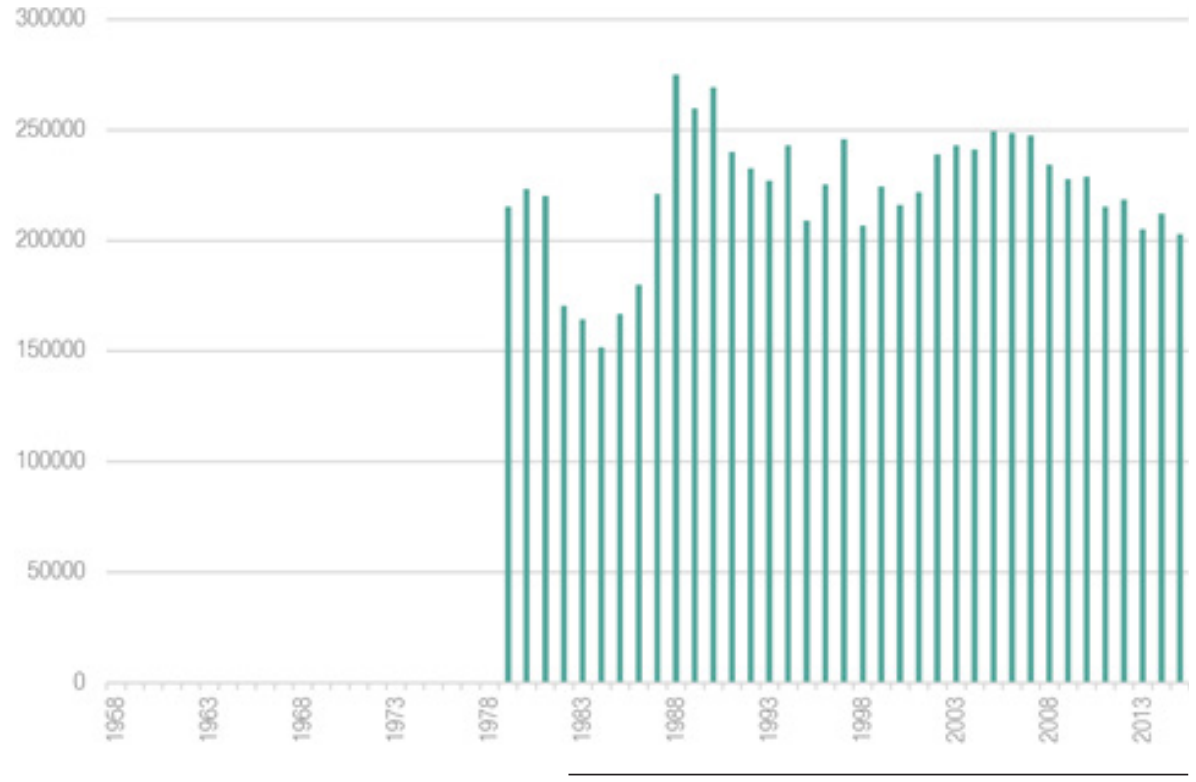

Fig 130. Consumo de agua potable en Rafal (19792015) [MCT. Elaboración propia.]

\section{h.- Los Montesinos.}

Se trata de un municipio en franca expansión, demográfica y económica. Un 32,1\% de su población es de nacionalidad extranjera destacando por su número los británicos y los búlgaros. Mediante Decreto 140/90 del Consell de la Generalitat Valenciana, Los Montesinos se convirtió en municipio independiente (antes formaba parte de Almoradí). En 1991 contaba con 2.232 habitantes que han ascendido en 2015 a 4.921 (INE).

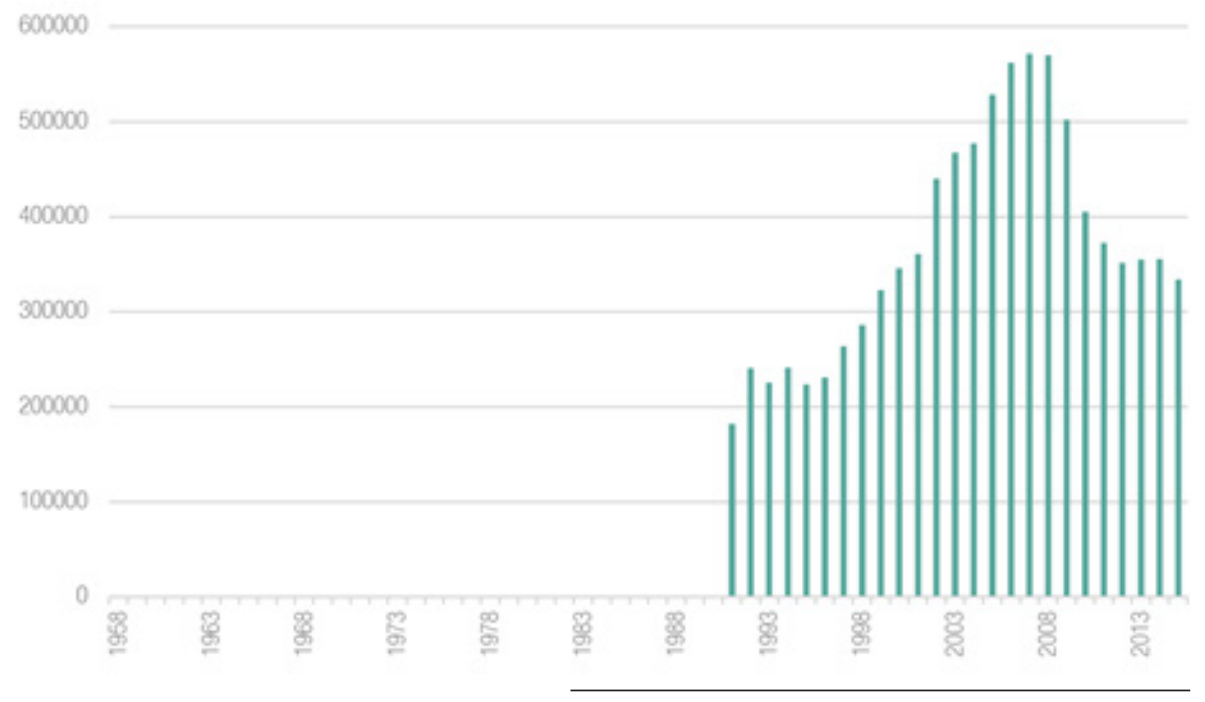

Fig 131. Consumo de agua potable en Los Montesinos (1991-2015) [MCT. Elaboración propia.] 
Jacarilla en 1970 contaba con 1154 habitantes, comenzó a recibir agua de la MCT en 1966; en 2015 tenía 1.930 personas.

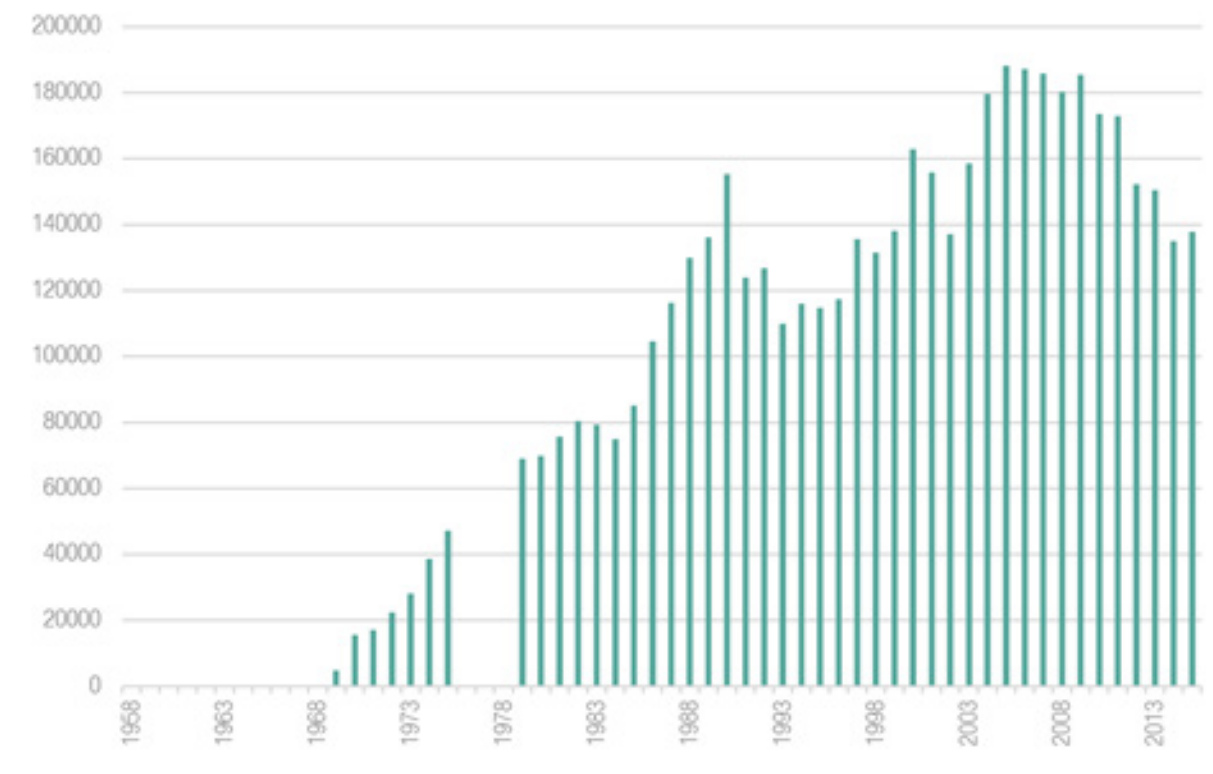

Fig 132. Consumo de agua potable en Jacarilla (1966-2015) [MCT. Elaboración propia.]

i.- Granja de Rocamora.

Su actividad económica primordial es la agricultura. En 2015 su población ascendía a 2.425 habitantes.

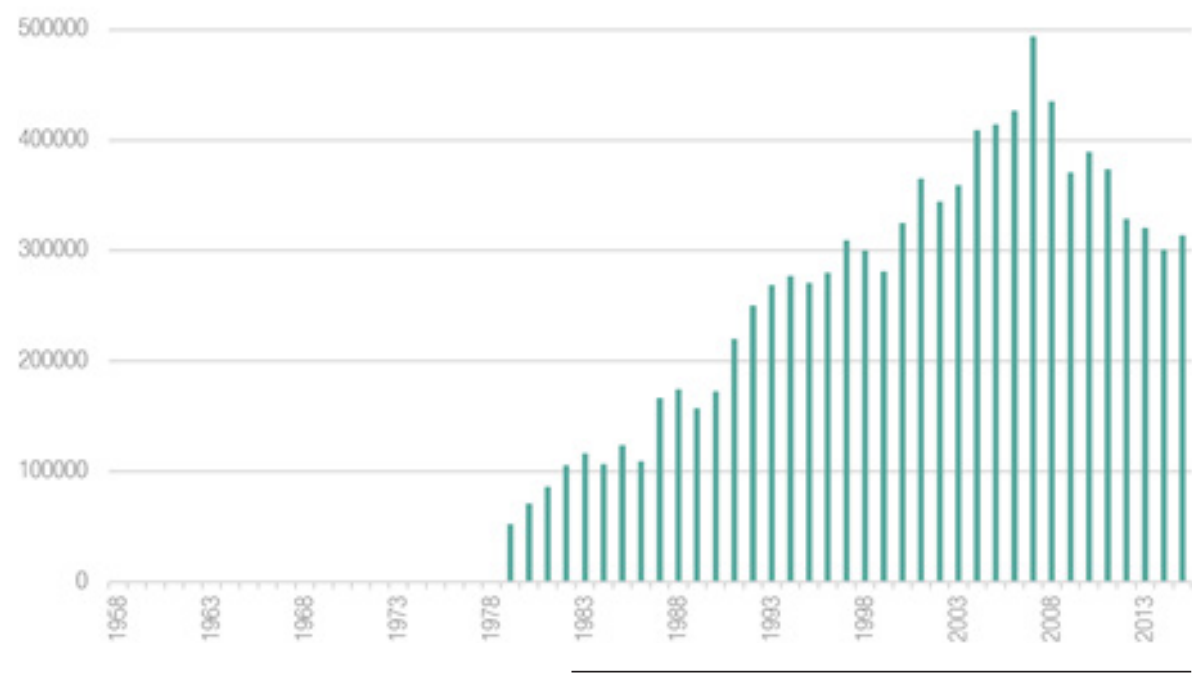

Fig 133. Consumo de agua potable en Granja de Rocamora (1979-2015) [MCT. Elaboración propia.] 
Formentera del Segura contaba con 3.518 habitantes en 2007 (INE). De estos, 1.927 residen en el núcleo de Formentera del Segura, 1.591 en la pedanía de Los Palacios y el resto diseminado por el término municipal. En 2015, su población era de 4.206 habitantes.

El núcleo que más ha crecido en los últimos años ha sido el de Los Palacios, que pasó de 750 habitantes en 2001 a los 1.591 del 2007. Un 36,6\% de la población es, según el censo de 2007, de nacionalidad extranjera, principalmente británicos y, en menor medida, marroquíes, ecuatorianos y nacionales de otros países europeos.

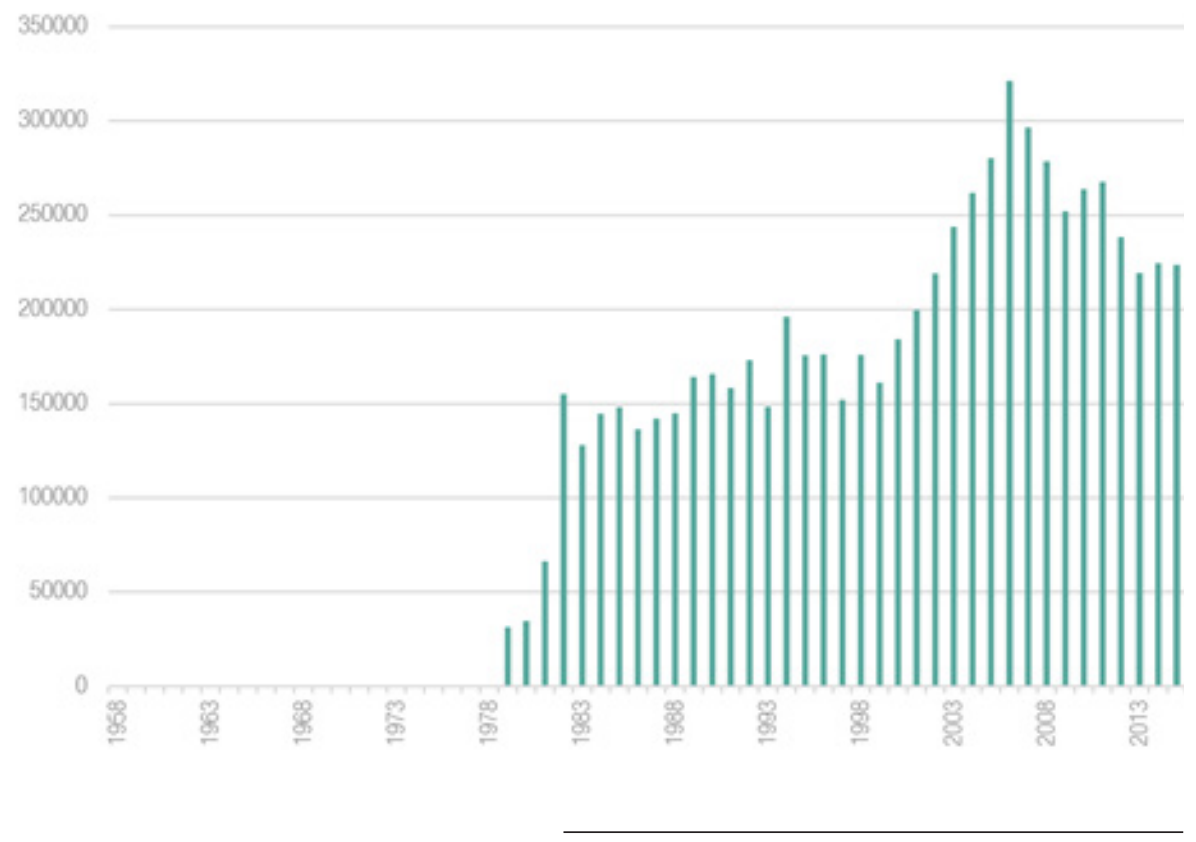

Fig 134. Consumo de agua potable en Formentera (1979-2015) [MCT. Elaboración propia.] 
Las principales actividades económicas son los servicios y la construcción. En 1970 tenía una población de 5.450 personas; en 2015 ascendían a 7.246.

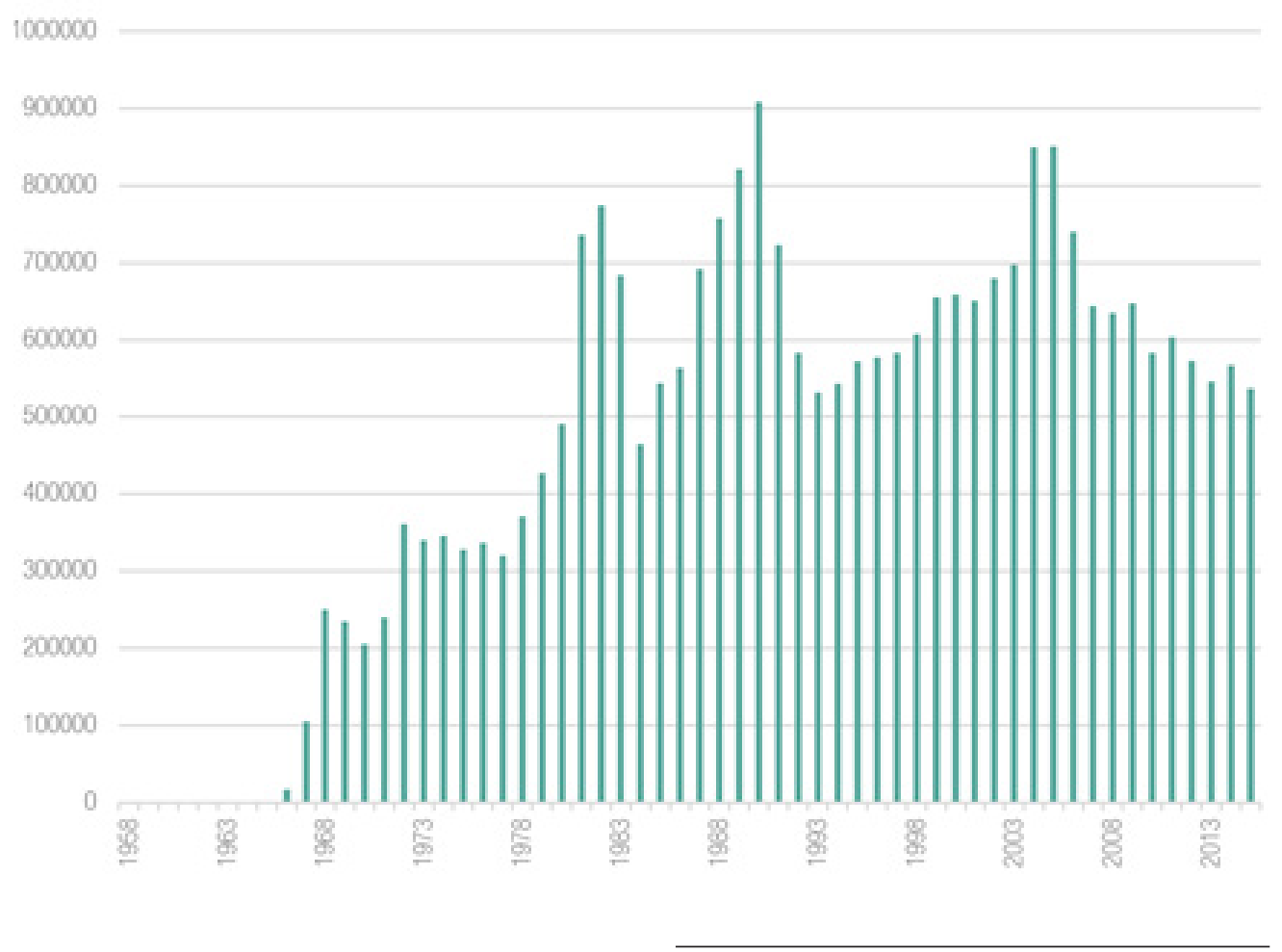

Fig 135. Consumo de agua potable en Dolores (1966-2015) [MCT. Elaboración propia.]

\section{1.- Crevillente/ Crevillent.}

Crevillente contaba con 16.901 habitantes en 1970; en 2010 (INE) con 28.738. En 2015 los habitantes se encuentran repartidos por los diferentes núcleos de población del término: El núcleo urbano de Crevillente (28.465 habitantes). El Barrio de la Estación (68). El Rincón de los Pablos (26). Las Casicas (105). El Realengo (340) y San Felipe Neri (412). La industria textil, en concreto la alfombra ha sido la principal actividad económica de Crevillente. 


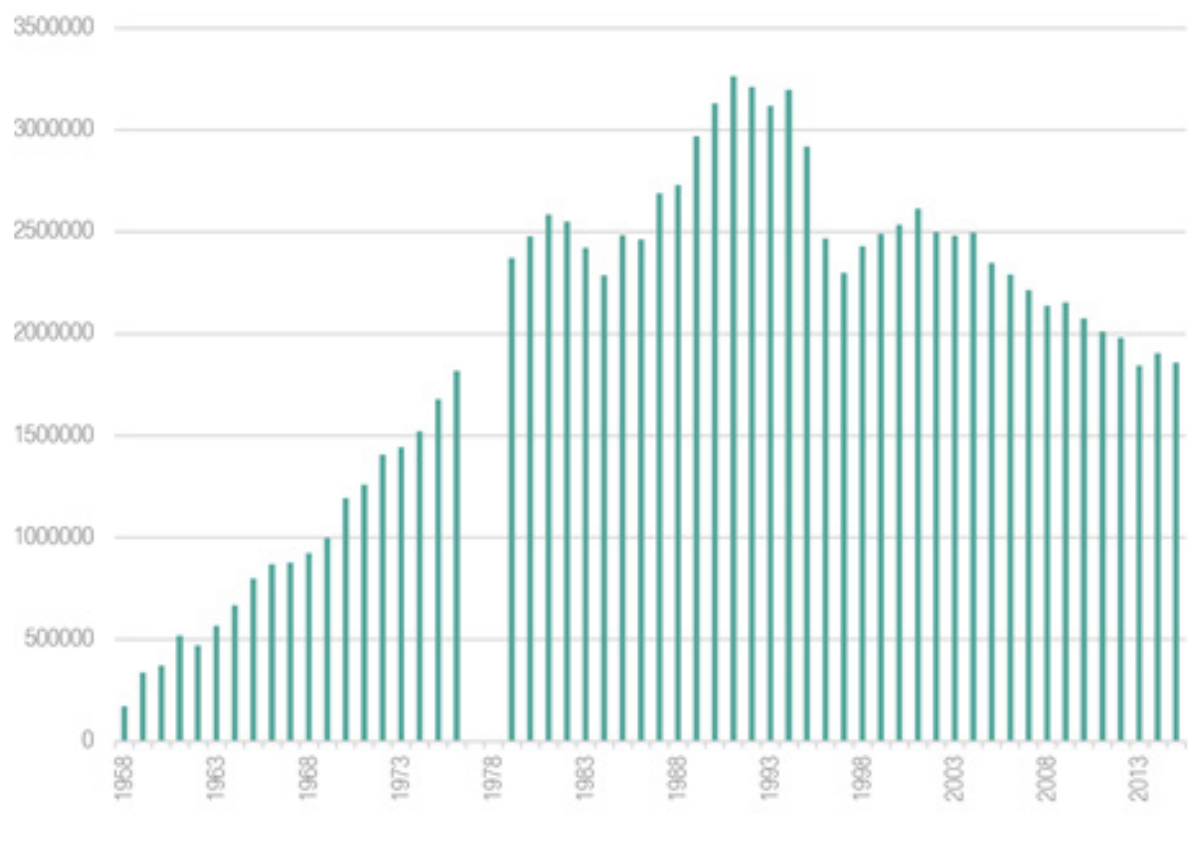

Fig 136. Consumo de agua potable en Crevillente (1958-2015) [MCT. Elaboración propia.]

m.- Cox.

Cox es uno de los municipios más dinámicos de la Vega Baja, tiene un pujante comercio de frutas y hortalizas. Además, se han desarrollado otras industrias de fabricación de calzado, textiles, redes y derivados de la construcción que se alojan en los dos polígonos industriales de la localidad. En 2015 contaba con 7.229 habitantes.

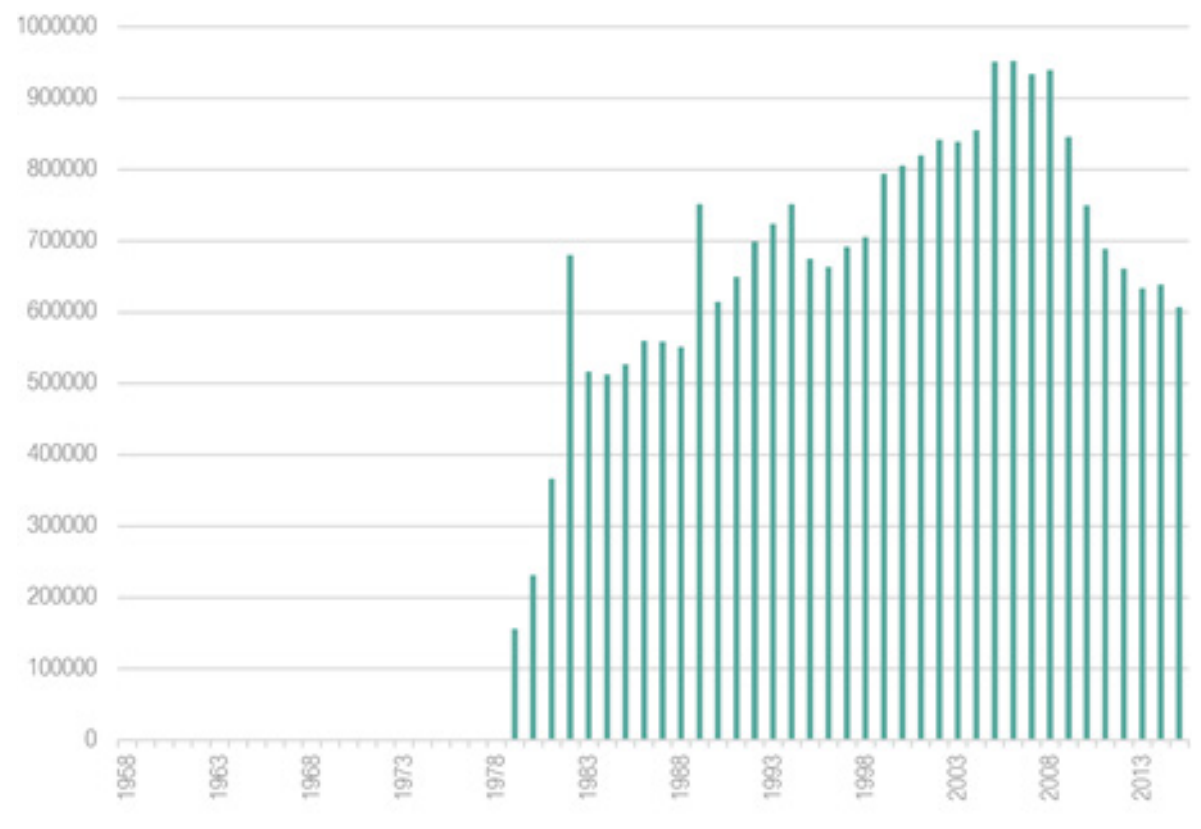

Fig 137. Consumo de agua potable en Cox (19792015) [MCT. Elaboración propia.] 
n.- Bigastro.

En el año 2009, Bigastro contaba con 6.744 habitantes. En 2007 la cifra de población de nacionalidad extranjera era del 17,5\% de los cuales la mayoría de nacionalidad británica (INE).

600000

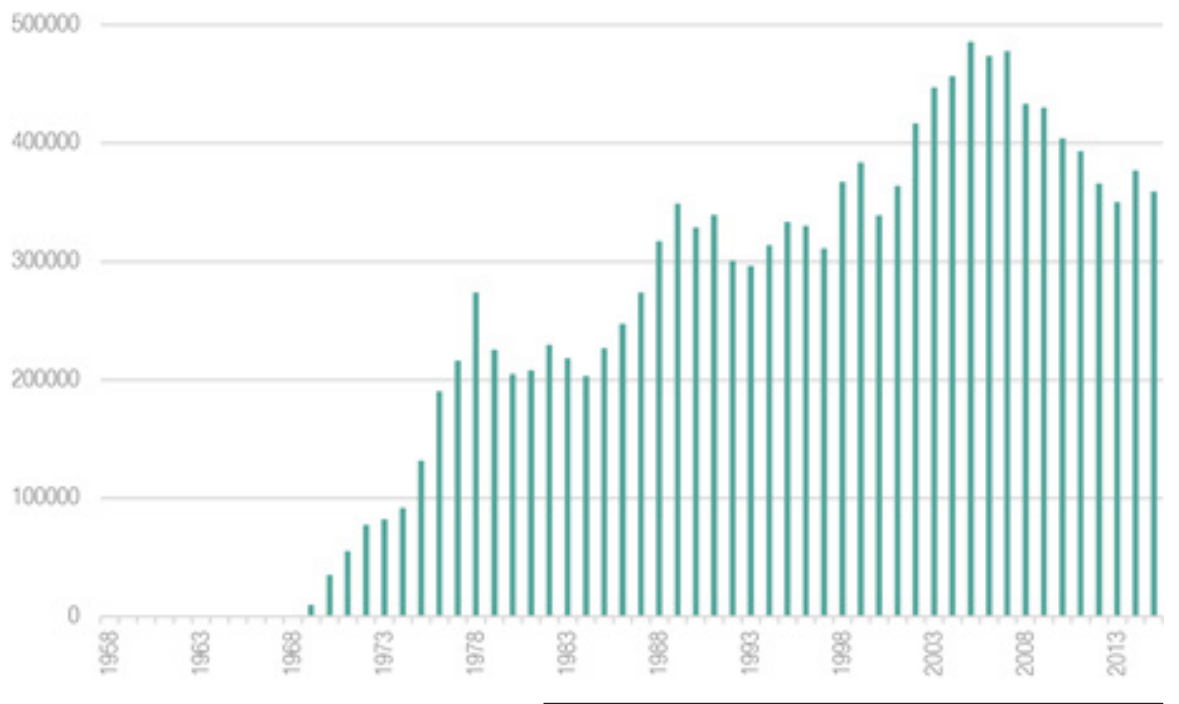

Fig 138. Consumo de agua potable en Bigastro (1969-2015) [MCT. Elaboración propia.]

o.- Benijófar.

En 1981 contaba con 1.344 habitantes; que han pasado a 3655 en 2015 (INE). La actividad dominante es la agricultura de regadío.

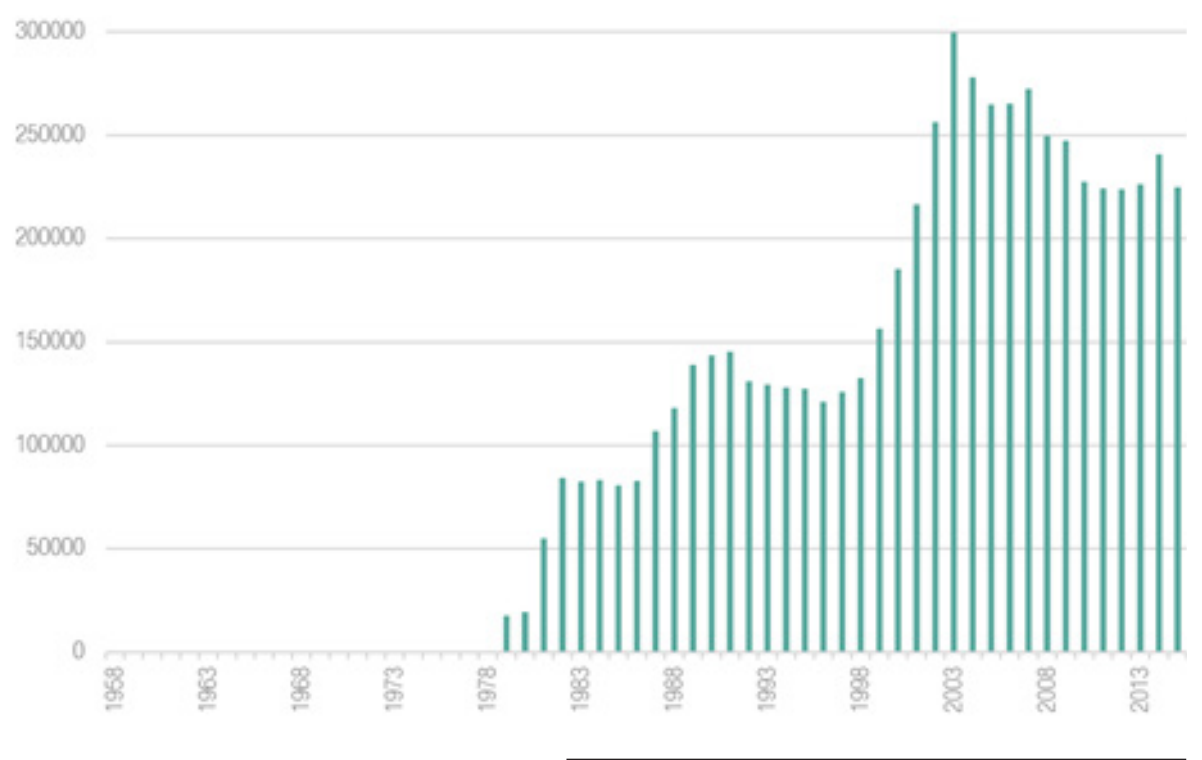

Fig 139. Consumo de agua potable en Benijófar (1979-2015) [MCT. Elaboración propia.] 
Contaba en 1981 con 4.041 habitantes. En 2015 tenía 5.398. Su actividad principal es la agricultura de regadío.

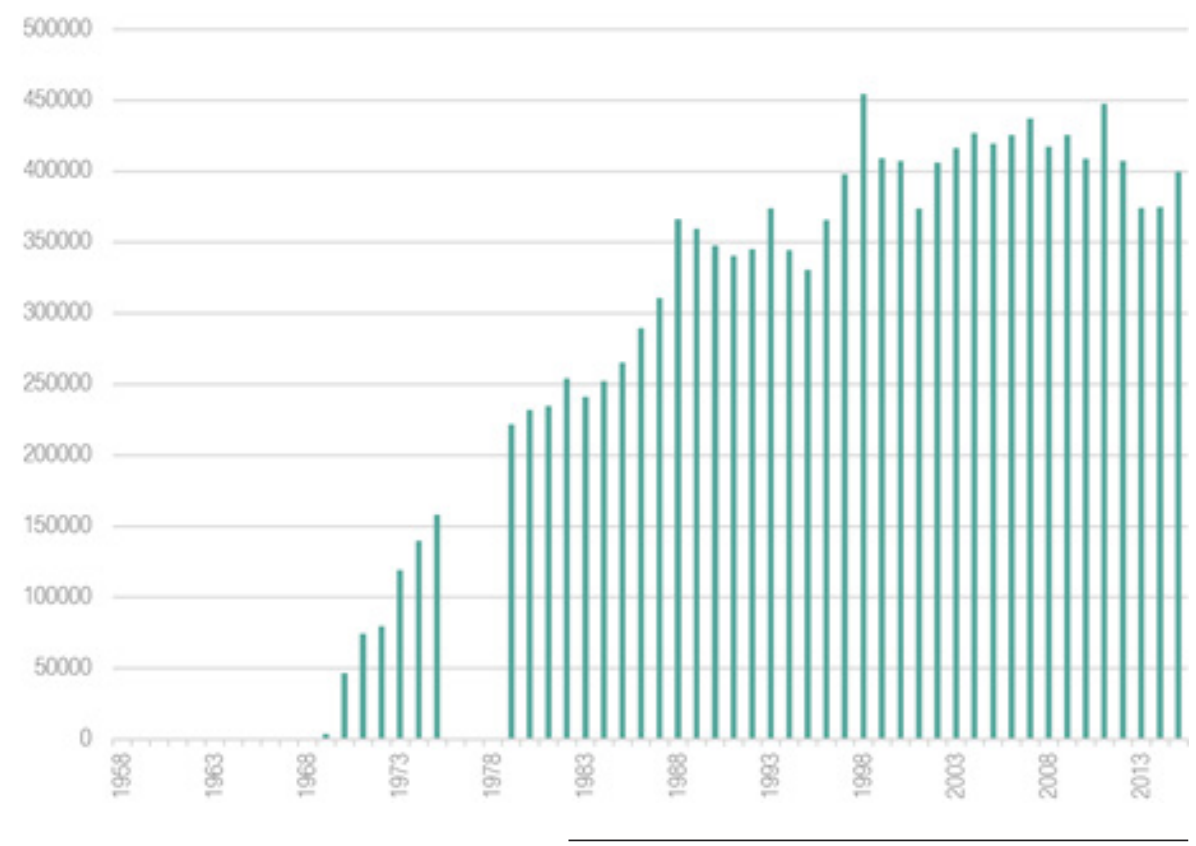

Fig 140. Consumo de agua potable en Benejúzar (1969-2015) [MCT. Elaboración propia.]

q.- Almoradí.

Tiene una población de 19.955 habitantes (INE, 2015). Su economía gira alrededor del comercio y la producción de muebles, así como la agricultura.

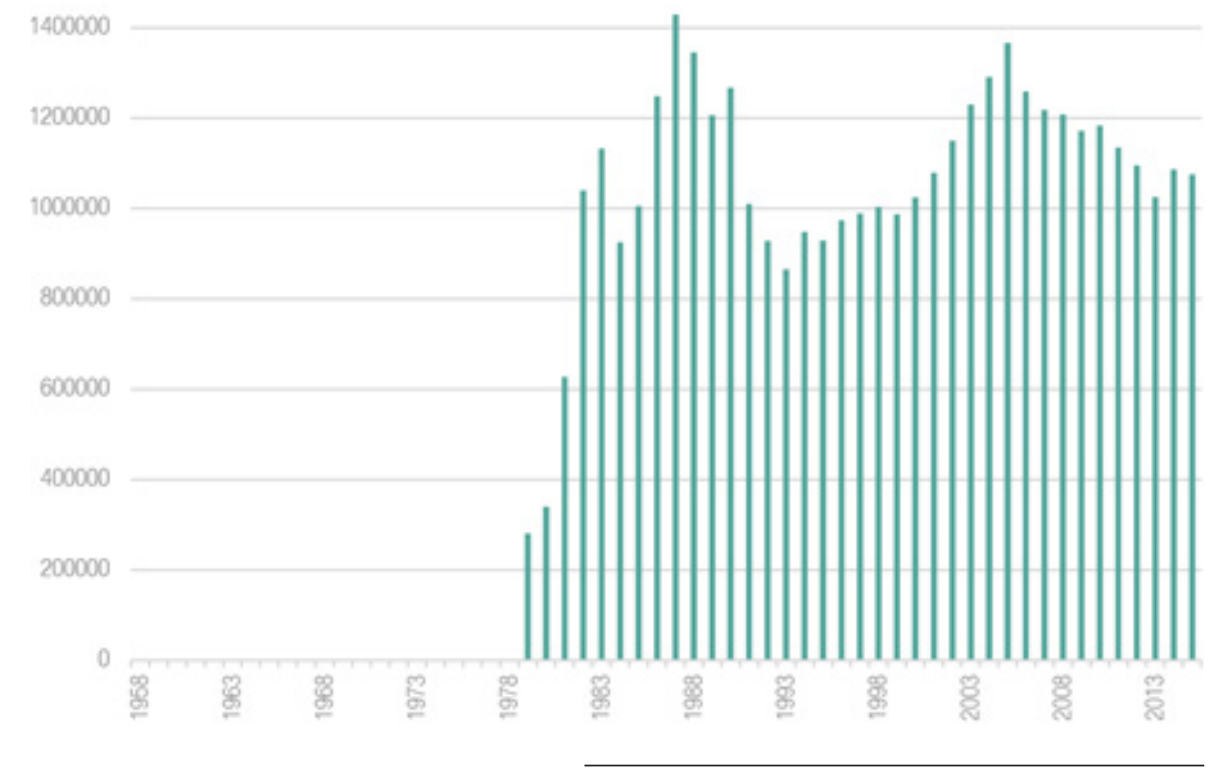

Fig 141. Consumo de agua potable en Almoradí (1979-2015) [MCT. Elaboración propia.] 
Aspe en 1991 contaba con 15.923 habitantes; en 2015 eran 20.406. Su prosperidad se fundamenta principalmente en la agricultura y la industria. Hondón de las Nieves, su economía tradicional agrícola, sustentada en la uva de mesa, se ve hoy en día complementada y superada por los negocios inmobiliarios, ya que cada vez es mayor el número de extranjeros que se instalan en el municipio; en 2015 su población ascendía a 2.583 habitantes. La muy reciente incorporación de Hondón de los Frailes a la MCT, en 2013, complementa este apartado, este municipio tenía en 2001, 622 habitantes que en 2015 casi se han duplicado 1.160, motivado por el incremento de extranjeros que han radicado su domicilio en la localidad.

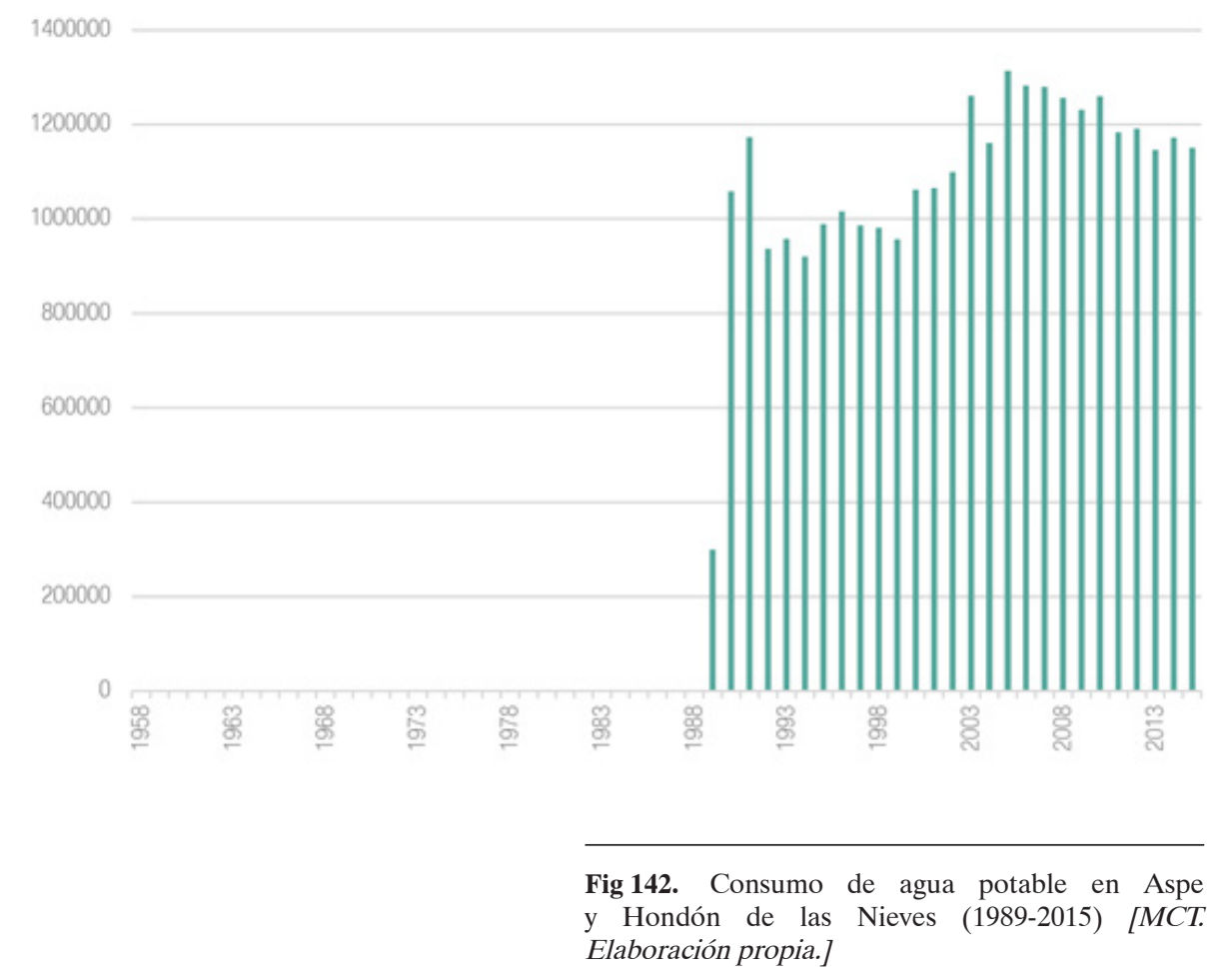


El Aeropuerto de Alicante-Elche, situado en El Altet (Elche), tuvo una toma independiente para su abastecimiento desde 1979 hasta 2008 año en el que se integró en el suministro de la ciudad de Elche. El actual aeropuerto alicantino se abrió al tráfico el 4 de mayo de 1967 con capacidad para un millón de pasajeros. Desde su inauguración, ha favorecido la creación de un modelo turístico y de crecimiento para la provincia de Alicante y todo ello se ha podido en parte consolidar al contar con un abastecimiento en cantidad y calidad suficiente suministrado por la MCT.

El Aeropuerto de Alicante-Elche cerró 2015 con 10.574 .484 pasajeros y registró el mejor año de su historia. Destaca el crecimiento experimentado por el tráfico nacional que aumentó un 9,1\% y registró 1.266 .973 pasajeros. No obstante, el viajero internacional siguió siendo el mayoritario con 9.296.271. Desglosando por nacionalidades el tráfico internacional, los países que más pasajeros contabilizaron durante el año 2015 fueron Reino Unido, con 4.420.453 viajeros; seguido de Alemania, con 742.247; Noruega, con 661.052; Holanda, con 637.573; Bélgica, con 541.831, y Suecia, con 405.175 viajeros.

Podemos afirmar, que tanto la MCT como el Aeropuerto de Alicante-Elche son dos pilares sobre los que se sustenta el desarrollo turístico de la provincia de Alicante; sin los cuales difícilmente podría explicarse el éxito del modelo turístico alicantino.

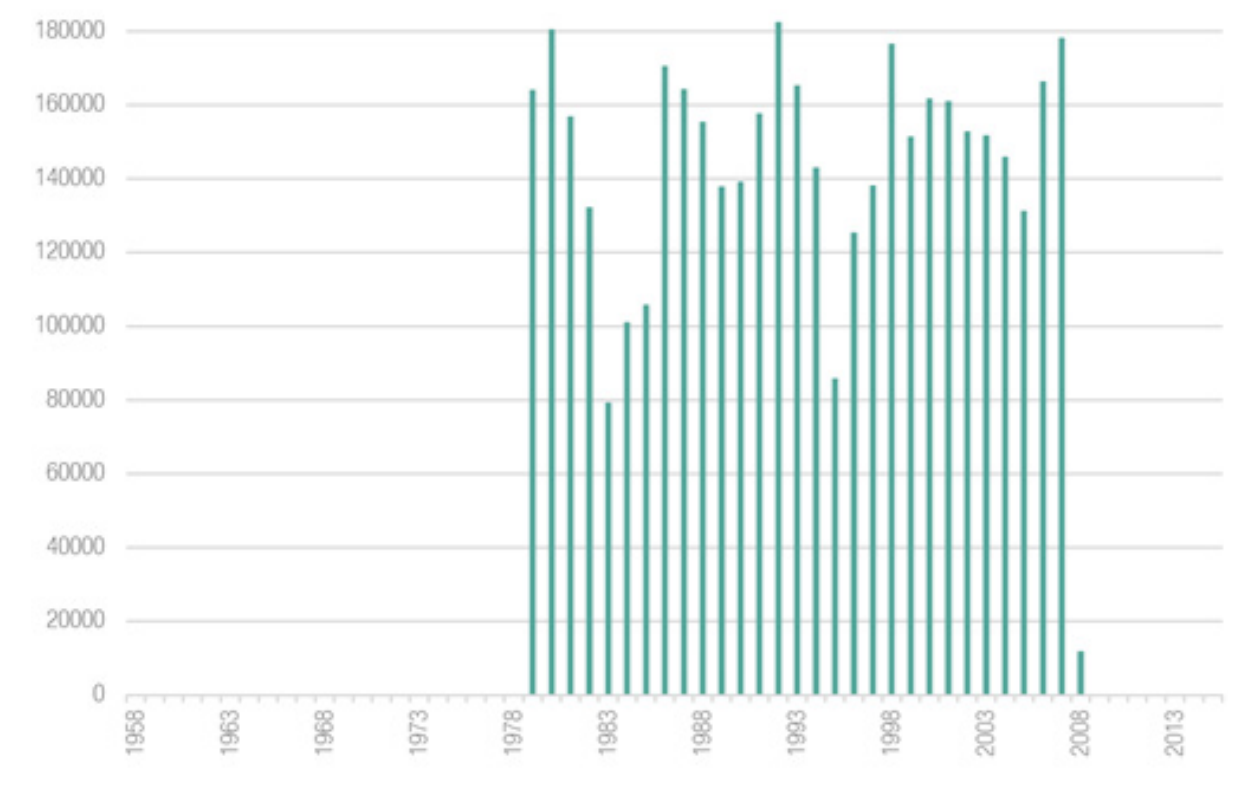

Fig 143. Consumo de agua del Aeropuerto de Alicante-Elche (1979-2008) [MCT. Elaboración propia.] 
6.2.7.- Otros suministros en la Zona 6 de la MCT (Alicante)

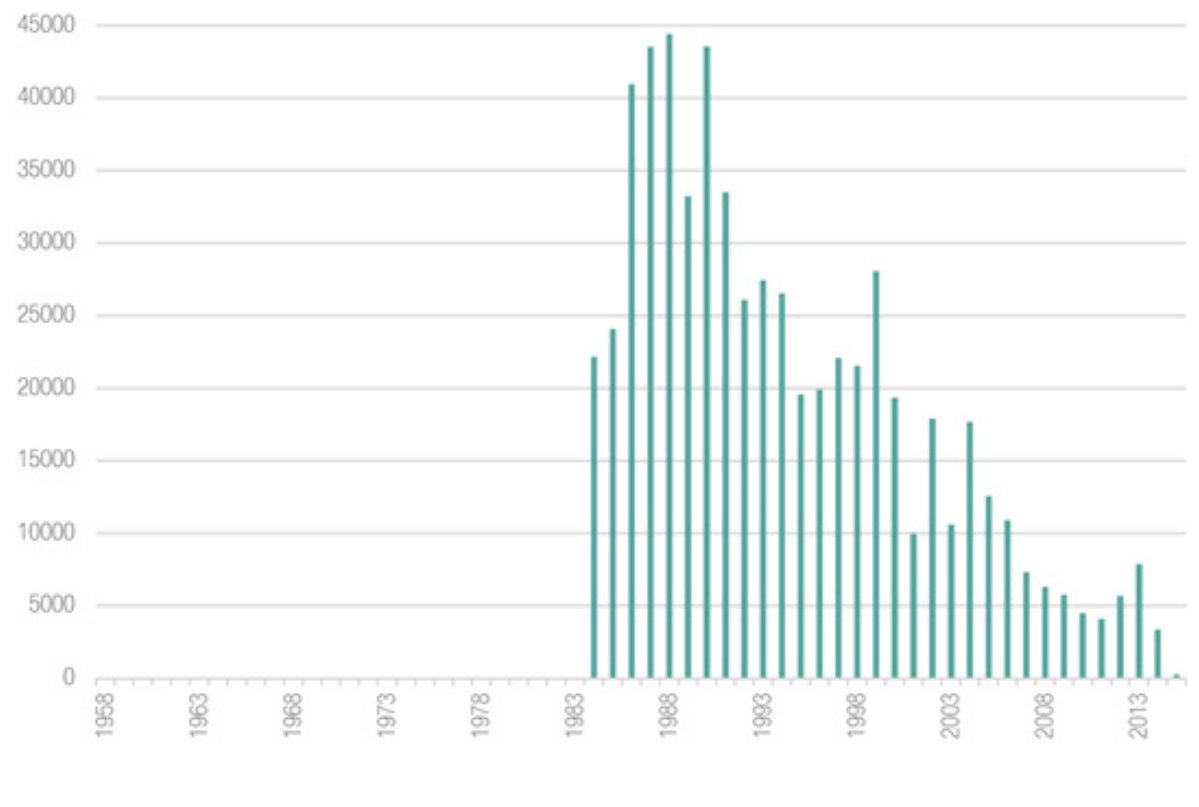

Fig 144. Suministro a Entidades Civiles [MCT. Elaboración propia.] 


\section{7.- INFRAESTRUCTURAS DE DISTRIBUCIÓN Y POTABILIZACIÓN DEL AGUA EN ALTA DE LA MCT EN LA PROVINCIA DE ALICANTE.}

\section{1.- Transporte del agua: canales.}

El área de suministro de la MCT se extiende a lo largo de más de $11.000 \mathrm{~km}^{2}$, gracias a una amplia red de canales y conducciones que suman más de $1.400 \mathrm{~km}$ (más de $500 \mathrm{~km}$ de canales cubiertos y unos 800 de conducciones forzadas), así como unos $3.000 \mathrm{~km}$ de ramales, a los que hay que añadir más de un centenar de depósitos de reserva (unos 137 con una capacidad de más de $800.000 \mathrm{~m}^{3}$ ), diez grandes estaciones de bombeo, media docena de plantas potabilizadoras, sifones, estaciones de elevación, rápidos, centrales eléctricas, obras de regulación y reserva. Este complejo sistema se articula bajo la supervisión automatizada de un centro de control de explotación situado en Cartagena (Grindlay et al 2008). Para circular los caudales a través de estas redes, así como para el resto de la demanda energética de las infraestructuras de la MCT, se cuenta con una potencia instalada de $50 \mathrm{Mw}$.

En lo que se refiere a la provincia de Alicante, cabe reseñar que, para junio de 1958, fecha en que se iniciaba el abastecimiento de Alicante, se habían terminado los canales y arterias principales de la red básica de abastecimiento. Durante los años 1957 y 1958 se trabajó activamente en la construcción del Canal de Alicante, eje hidráulico desde el que derivaría el abastecimiento de los municipios mancomunados de la provincia de Alicante. Al entrar en servicio el Canal de Alicante, en el transcurso de 1958, se incorporaron al abastecimiento los municipios de Alicante, Elche y Crevillente; un año más tarde, lo haría Santa Pola 1959. El Canal de Alicante tiene una longitud de $53,7 \mathrm{~km}$ y una capacidad de entre 1,3 y $0,9 \mathrm{~m}^{3} / \mathrm{s}$. La sección es ovoide, similar al Canal de Espuña, con dimensiones 1,40x1,05 m, y pendientes variables entre 7 y 4 diezmilésimas, según tramos. El canal, ya en Alicante, vierte a un depósito de reserva y regulación de $40.000 \mathrm{~m}^{3}$ de capacidad, del que parte la red de distribución a la ciudad.

Durante la década de los sesenta, terminados los canales principales, el Organismo va realizando la red de ramales y depósitos para dotar de agua a la totalidad de municipios mancomunados, incluyendo zonas costeras de indudable vocación turística, incipientemente pobladas. Se construyen los ramales de Torrevieja y de Albatera, y de ellos parten los sub-ramales a los núcleos mancomunados de la Vega Baja y la costa alicantina. Del ramal de Torrevieja se abastece: Benferri, Cox, Callosa, Redován, Rafal, Orihuela, Beniel, Bigastro, Jacarilla, Benejúzar, San Miguel de Salinas, Algorfa, Benijófar, 
Torrevieja y Guardamar y del de Albatera: Catral, Dolores y Albatera, municipios que se incorporan al abastecimiento entre los años 1965 y 1972.

En este periodo se da por prácticamente finalizado el Plan General de 1930, completando el abastecimiento de los municipios que se incorporaron en su momento al Organismo. Tan sólo quedaba pendiente la ejecución de la presa de embalse para llevar a cabo la regulación anual del río Taibilla y la ETAP de Letur, instalación obligada al derivar aguas de embalse que necesitan ser tratadas por su turbidez y materia en suspensión. Ambas obras se realizan a comienzos de los años setenta.

El comienzo de los años setenta se caracteriza por la terminación de los ramales de Cieza y Torrevieja, además de las obras de la presa de embalse y la ETAP de Letur.

Una segunda etapa (comprendida entre 1965 y 1979), se corresponde con la aportación de las aguas del río Segura al sistema del Taibilla. El plan de ampliaciones de 1971, desarrollado tres años después, permitió la incorporación de 11 nuevos municipios a la MCT, ubicados en la Vega Baja. La Orden Ministerial de 23 de diciembre de 1970 estableció las siguientes reglas: "10- Ordenar a la Mancomunidad de los Canales del Taibilla, de acuerdo con la Confederación Hidrográfica del Segura, la redacción del Anteproyecto o Anteproyectos Modificados, necesarios para el abastecimiento de los pueblos integrados en la Mancomunidad con aguas procedentes del aprovechamiento conjunto Tajo-Segura. La capacidad de los canales principales se proyecta acorde con los consumos del día punta de verano del año 2000 (horizonte 30 años), mientras que la de los ramales, para las necesidades del día punta de 1985 (horizonte 15 años). Los depósitos de reserva en las poblaciones almacenarán el consumo del día punta de 1985.

El Organismo abastecerá a todos los núcleos mancomunados más los nuevos núcleos con población superior a los 1.000 habitantes. No obstante, se dimensionarán las obras para las necesidades de abastecimiento de la totalidad de la zona dominada por la red de conducciones. Es claro que esta apertura a incorporar nuevos núcleos no mancomunados es consecuencia de la nueva asignación de agua procedente del Trasvase y el deseo de regularizar situaciones excluyentes. Finalmente, se anuncian medidas transitorias como forma de sostener la demanda de los abastecimientos, en tanto llegue el Trasvase a la cuenca del Segura. Tales son: compra de agua para incorporar al Canal de Alicante, la construcción del embalse de Fontcalent en cola de ese canal, y la puesta en funcionamiento de la ETAP existente en Murcia, adecuadamente modernizada con cargo a la Mancomunidad (Nieto Llobet, 2014).

El comienzo de la década de los sesenta obligó a replantear los recursos hidráulicos necesarios para hacer frente a las demandas futuras de los abastecimientos, debido al notable aumento del nivel de vida y la espectacular eclosión del turismo en el ámbito de 
la MCT. Se autoriza inicialmente la captación de recursos del río Segura y a finales de 1970 la Dirección General de Obras Hidráulicas ordena a la Mancomunidad la redacción del Anteproyecto de Ampliación de sus abastecimientos con aguas procedentes del aprovechamiento conjunto Tajo-Segura (155 $\mathrm{hm}^{3}$ anuales) y con capacidad suficiente de las obras para poder tratar y distribuir, no sólo los recursos hidráulicos atribuidos al Organismo en la primera fase del trasvase Tajo-Segura, sino también los de la segunda fase del mismo.

Dicho Anteproyecto fue aprobado por el Ministerio de Obras Públicas y Urbanismo en 16 de octubre de 1971 y es la base del Plan de Ampliación de los Abastecimientos, que ha presidido la acción inversora del Organismo desde 1973. Las hipótesis básicas del Plan fueron: a) Previsión de necesidades de agua con horizonte 1985. b) Dimensionamiento de canales principales (excepto sifones) para el caudal máximo previsible en el año 2000. c) Cálculo de capacidades de Estaciones de Tratamiento y Bombeo en el año 2000.

Para el desarrollo del Plan de Ampliación se establecieron dos etapas de construcción solapadas, correspondiendo a la $1^{\underline{a}}$ Etapa la ampliación y construcción de canales principales, estaciones de tratamiento e instalaciones elevadoras, y a la $2^{2}$ Etapa la ampliación y construcción de ramales y depósitos. Por Decreto 497/1975, 6 de marzo, se dispone la financiación a cargo de la Mancomunidad de las obras de la 1 ${ }^{\text {a }}$ Etapa (culmina en 1981) y con cargo a los Presupuestos Generales del Departamento (hasta el ejercicio 2000) las de la 2 a Etapa, ajustándose el ritmo de las obras a la disponibilidad presupuestaria (Memoria MCT, 2009). El elevado coste de las obras del Plan de Ampliación, imposibles de sufragar con el alza de las tarifas, motivó la aprobación del Decreto de 6 de marzo1975, por el que se fijó el régimen de auxilios del Estado, de manera que las obras de la primera etapa corren con cargo a la MCT (obras principales: canales, depuradoras, estaciones elevadoras), mientras los correspondientes a la segunda fase (ampliación de ramales y depósitos), se realizan con cargo a los presupuestos generales del MOP (Morales, 2002).

La inversión total superó, en valores actualizados, los 370 millones de euros. En el periodo 1990-2001, el Departamento financió las ampliaciones de las grandes instalaciones recogidas en la $1^{\underline{a}}$ Etapa del Plan (Plantas Potabilizadoras de los Nuevos Canales de Murcia, Alicante y Cartagena y Grandes Estaciones de Bombeo). Asimismo, llevó a cabo la cofinanciación con el Fondo de Cohesión de los proyectos de abastecimiento de agua en red primaria incluidos en el Plan Especial para el Desarrollo de Cartagena, con un montante conjunto superior a los 12 millones de euros (Memoria MCT, 2009). 


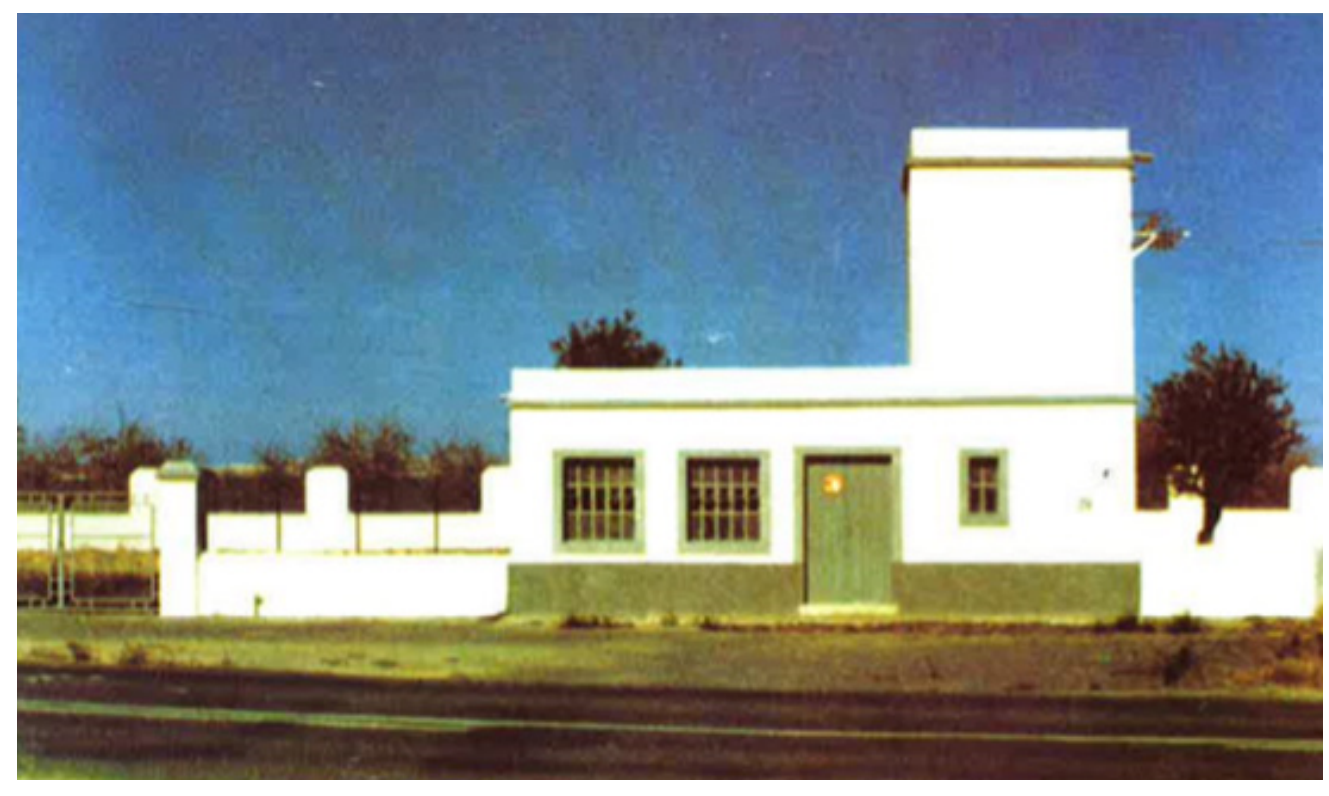

Fig 145. Elevación de San Miguel de Salinas [Memoria MCT, 1976.]

Un tercer período se inicia en 1980, correspondiendo con la llegada de las aguas del trasvase Tajo-Segura, que fueron suministradas mediante cuatro depuradoras a la red de distribución. Este periodo coincide con el incremento de la demanda procedente tanto de las áreas urbanas de Murcia y Alicante, como, especialmente, con las crecientes demandas del litoral sur de la provincia de Alicante, donde la implantación inmobiliarioturística entra en plena expansión.

Las aguas del trasvase Tajo-Segura permitieron aumentar las dotaciones concedidas a la Mancomunidad y, de esta forma, llevar a cabo el Plan de Obras de Ampliaciones de los Abastecimientos. El Real Decreto 798/1989, autorizó un aumento de hasta 25 hm³/año en la dotación inicial del trasvase, que se había establecido por Ley 52/1980 (dotación máxima de $110 \mathrm{hm}^{3}$ /año). Estos nuevos recursos requerían importantes obras de infraestructura para su distribución, lo que se organizó a partir de la localización de los grandes centros consumidores: Murcia, Alicante y Cartagena. De este modo, aprovechando el transporte de agua del trasvase por la margen izquierda del Segura, gracias a la construcción de un nuevo canal para regadío, la MCT estableció tres puntos de toma en el mismo con sus correspondientes depuradoras, que permiten incorporar los caudales a la red de la Mancomunidad: 
a) junto al canal de Murcia, de donde partiría el Nuevo Canal de Murcia;

b) en Torre Alta (Orihuela), de donde partiría el Nuevo Canal de Alicante;

c) en el Embalse de la Pedrera (depuradora de Vistabella, Orihuela), donde tiene su origen el Nuevo Canal de Cartagena.

En los años noventa se ejecuta la Segunda Fase del Plan de Obras de Ampliaciones. De entre las obras ejecutadas, destacan las inversiones realizadas en la franja litoral murciano-alicantina, en respuesta al gran crecimiento de las actuaciones urbanísticas en la zona. El espacio comprendido entre Santa Pola y Águilas es donde se concentra este desarrollo, incluyendo singularmente el litoral de Torrevieja, Orihuela y Pilar de la Horadada. Para suministrar agua en esta franja, así como a la propia ciudad de Alicante, se ejecutan las desalinizadoras de San Pedro del Pinatar y Alicante.

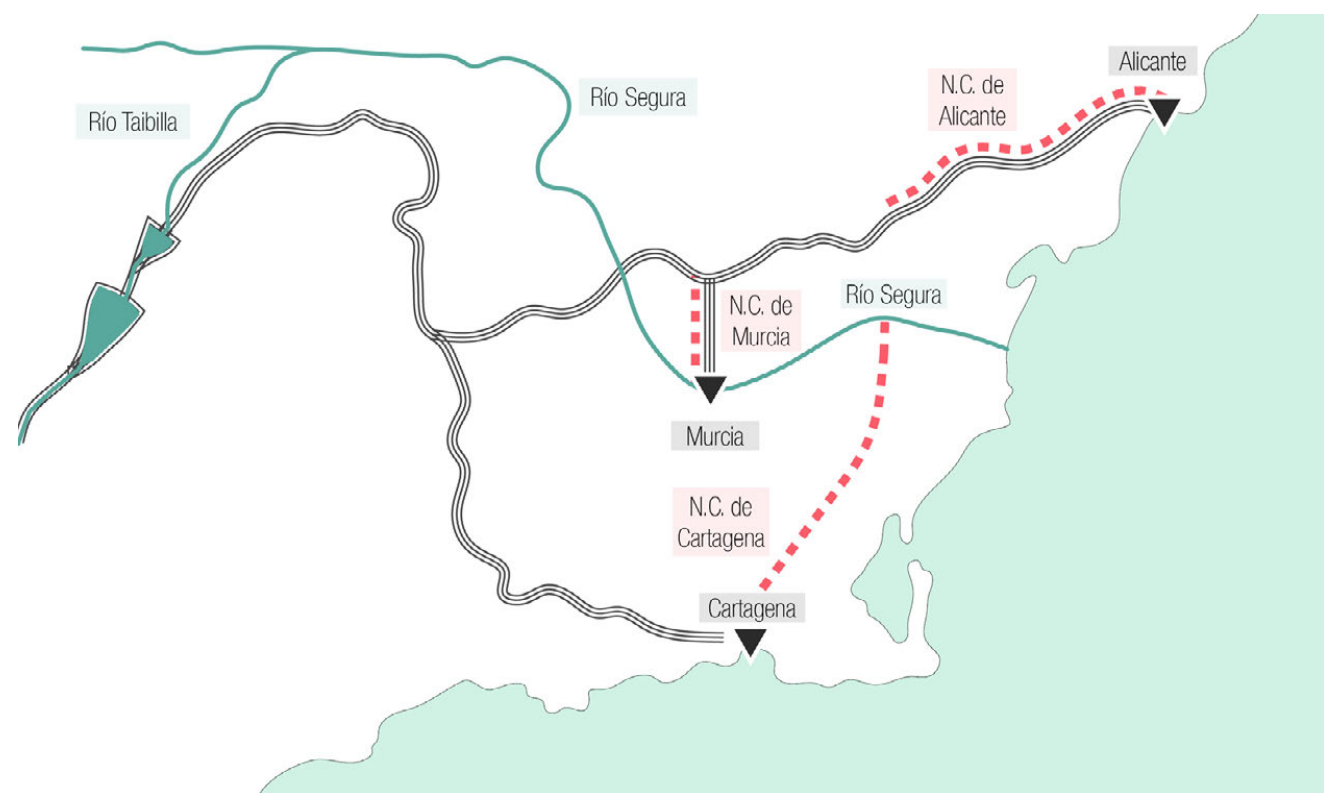

Fig 146. Nuevos Canales de Alicante y Cartagena [Memoria MCT, 1976. Elaboración propia.] 


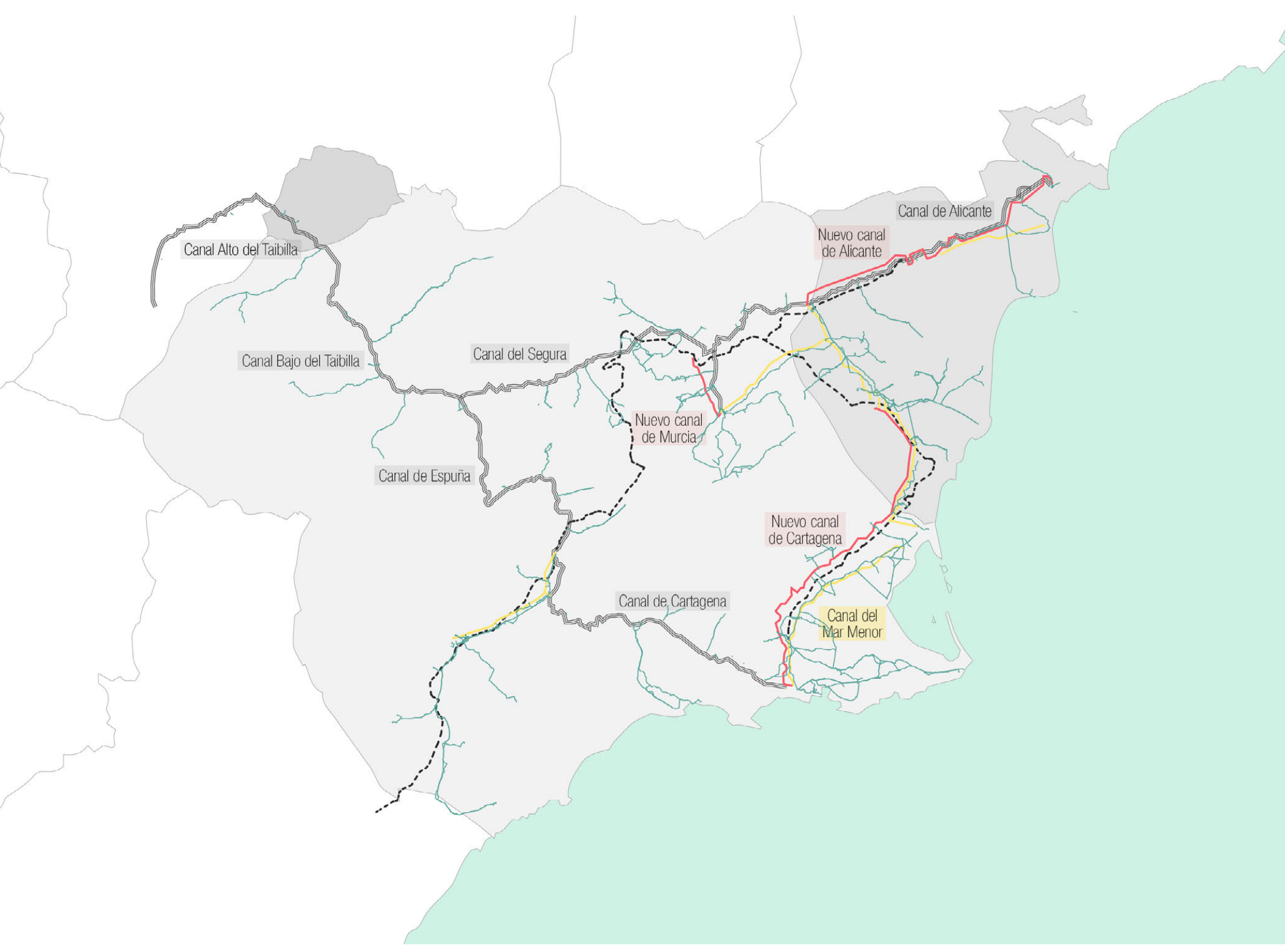

Fig 147. Redes de

canales de la MCT [MCT.

Elaboración propia] $\equiv$ Canal principal de la MCT (1945-1960)

- Ramales de la MCT

- Plan ampliaciones (1975-2000)

- Actuaciones Plan Hidrológico

- - Postrasvase Tajo-Segura 


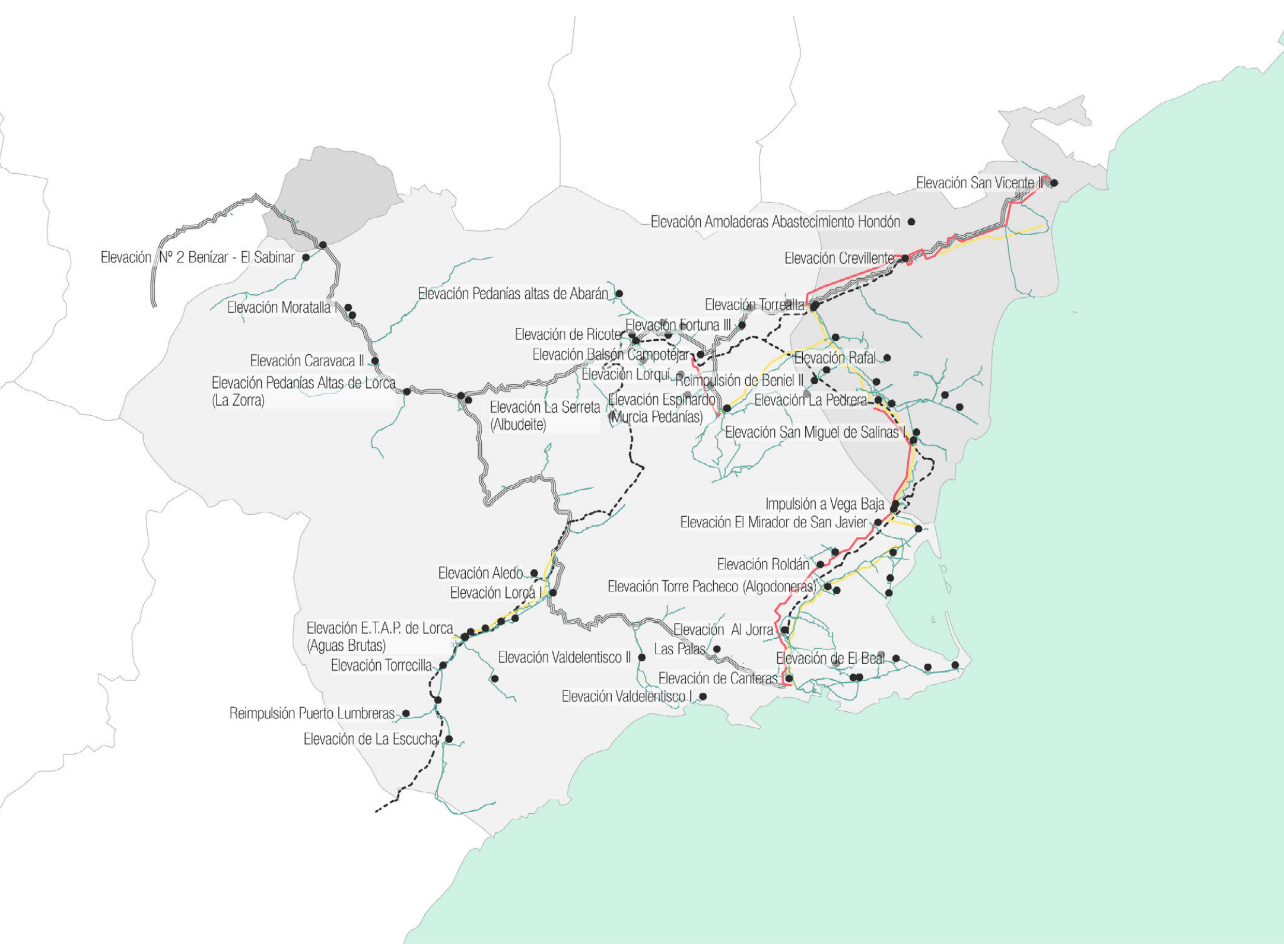

Fig 148. Nuevas elevaciones y canales de la MCT [MCT. Elaboración propia]
Sistemas de elevación de agua

= Canal principal de la MCT (1945-1960)

- Ramales de la MCT

- Plan ampliaciones (1975-2000)

- Actuaciones Plan Hidrológico

- - Postrasvase Tajo-Segura 


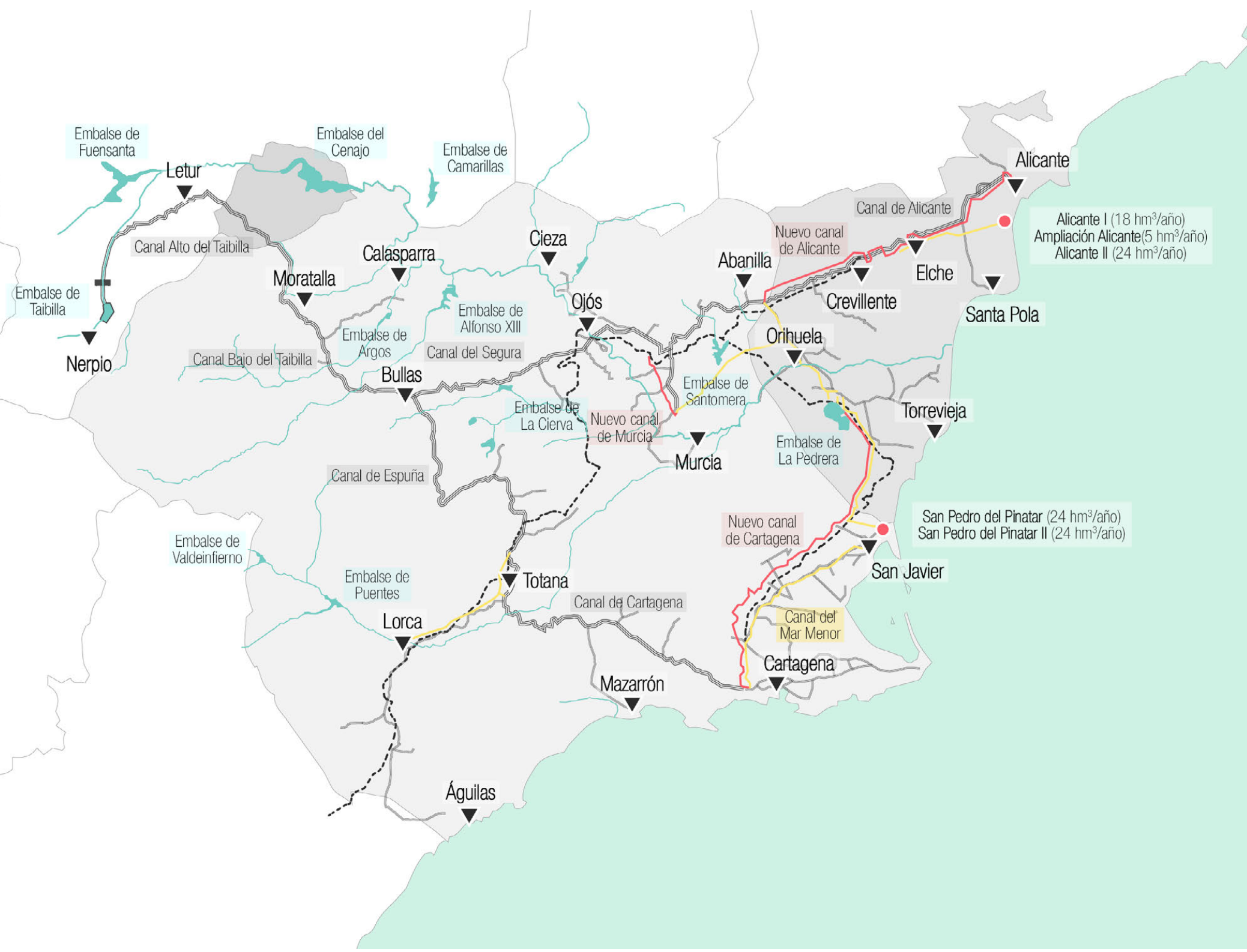

Fig 149. Red de Canales principales en la MCT y canales del postrasvase, sobre los que se han instalado potabilizadoras de agua [MCT. Elaboración propia.]
- Desalinizadora de la MCT

= Canal principal de la MCT (1945-1960)

- Red Hidrográfica

- Plan ampliaciones (1975-2000)

- Actuaciones Plan Hidrológico

-- Postrasvase Tajo-Segura 


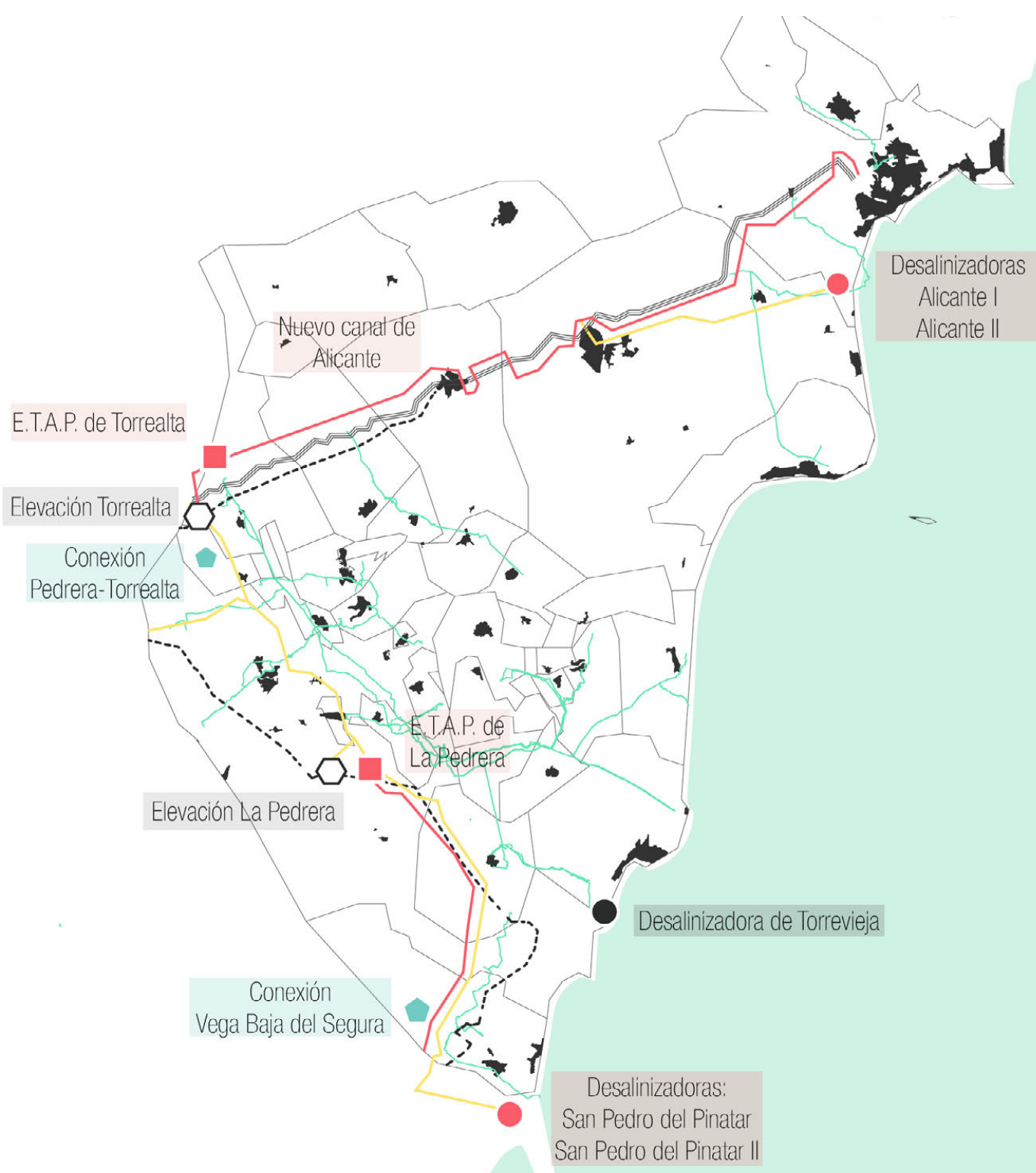

Fig 150. Canales y desalinizadoras en el área de la MCT [MCT. Elaboración propia.]

\footnotetext{
$\square$ Grandes elevaciones

Planta potabilizadora

Desalinizadora de la MCT

= Canal principal de la MCT (1945-1960)

- Red Hidrográfica

- Plan ampliaciones (1975-2000)

Actuaciones Plan Hidrológico

-- Postrasvase Tajo-Segura
} 
En resumen, la provincia de Alicante la MCT cuenta con tres grandes canalizaciones para la distribución de caudales en alta:

Se trata de una continuación del Canal del Segura, que sigue la orientación definida por éste, y finaliza en los depósitos de cabecera de distribución de Alicante. De él parten diversos ramales que derivan parte de las aguas que transporta a los municipios de la provincia de Alicante: Albatera, Alicante, Benejúzar, Benferri, Bigastro, Callosa, Catral, Crevillente, Dolores, Elche, Guardamar, Jacarilla, Orihuela, Redován, San Miguel de Salinas, San Vicente del Raspeig, Santa Pola y Torrevieja. Las características principales de esta infraestructura pueden verse en la tabla 17.

\begin{tabular}{|c|c|}
\hline Longitud & $53,7 \mathrm{~km}$ \\
\hline Capacidad & $1,3 \mathrm{y} 0,9 \mathrm{~m} 3 / \mathrm{seg}$ \\
\hline Pendiente normal & $0,0007 \mathrm{y} 0,0004$ \\
\hline Sección tipo & 1,158 \\
\hline Clase de sección & Ovoide \\
\hline Túneles & $13,8 \mathrm{~km}$ \\
\hline Acueductos & $1,6 \mathrm{~km}$ \\
\hline Sifones & 8,0 \\
\hline
\end{tabular}

Tabla 17. Datos técnicos del Canal de Alicante [MCT. Elaboración propia.]

\section{b. Nuevo canal de Alicante (1978).}

Esta canalización comienza en la nueva potabilizadora de Torrealta, que se alimenta de caudales procedentes del canal del postrasvase. Discurre en paralelo al Canal de Alicante, y finaliza igual que éste en el depósito de Rabasa. Se trata, por tanto, de una infraestructura que permite complementar los caudales suministrados a través del Canal de Alicante. Tiene prácticamente la misma longitud, pero su capacidad es sensiblemente mayor, como puede observarse en la tabla 18. 


\begin{tabular}{|c|c|}
\hline Longitud & $53,3 \mathrm{~km}$ \\
\hline Capacidad & $4,5 \mathrm{y} 2,9 \mathrm{~m} 3 / \mathrm{seg}$ \\
\hline Pendiente normal & $0,0007 \mathrm{y} 0,0004$ \\
\hline Clase de sección & \\
\hline Túneles & $7,3 \mathrm{~km}$ \\
\hline Acueductos & $1,5 \mathrm{~km}$ \\
\hline Sifones & \\
\hline
\end{tabular}

Tabla 18. Datos técnicos del Nuevo Canal de Alicante [MCT. Elaboración propia.]

c.- Conexión entre las potabilizadoras de La Pedrera y Torrealta (2008)

Esta conducción permite conectar ambas potabilizadoras con un canal de casi $26 \mathrm{~km}$, permitiendo además la circulación de los caudales en ambos sentidos, lo que aumenta la versatilidad y garantía de suministro. El canal facilita de esta manera la distribución de los caudales que llegan al centro de reparto de La Pedrera hasta la Vega Baja del Segura, el área metropolitana de Murcia y el bajo Vinalopó. Las características principales de la infraestructura pueden verse en la tabla 19.

\begin{tabular}{|c|c|}
\hline Longitud & $25,9 \mathrm{~km}$ \\
\hline Capacidad & $1,3 \mathrm{~m}^{3} / \mathrm{seg}$ \\
\hline Diámetro & $1.200 \mathrm{y} 1.000 \mathrm{~mm}$ \\
\hline
\end{tabular}

Tabla 19. Datos técnicos de la conexión entre las potabilizadoras de $\mathrm{La}$ Pedrera y Torrealta [MCT. Elaboración propia.] 


\section{2.- Infraestructuras de almacenamiento.}

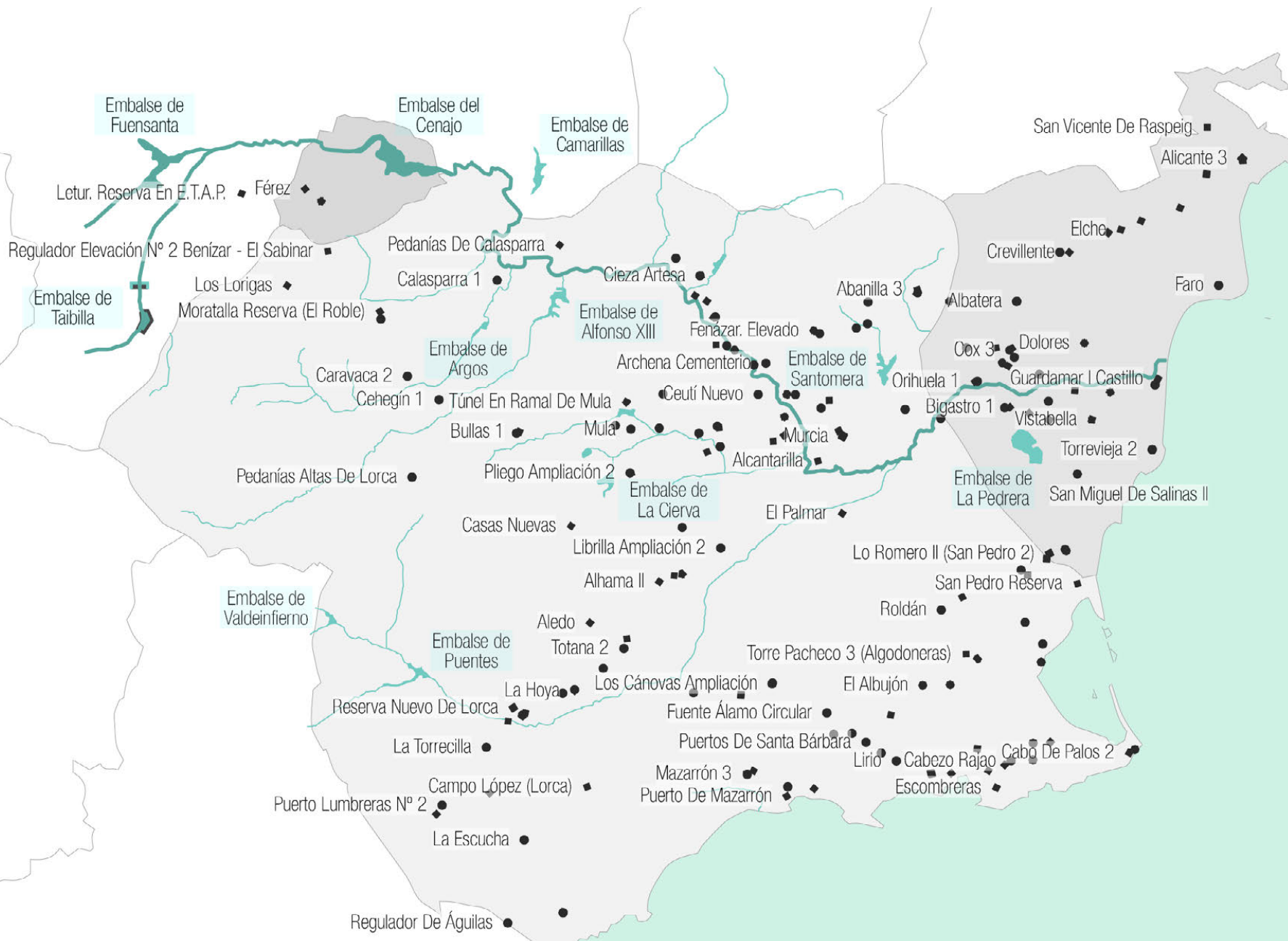

Fig 151. Depósitos

Depósitos de la MCT

- Ríos Segura y Taibilla

n. Embalses 
La MCT cuenta con un total de 2 presas y 176 depósitos. Existen además 4 embalses de seguridad. La denominada "presa de embalse" está situada en la embocadura del Estrecho del Aire, en el río Taibilla, realiza la regulación anual de aportaciones y laminación de crecidas, asegurando unas disponibilidades mínimas anuales de $47 \mathrm{hm}^{3}$. Los caudales medios que regula son aproximadamente el 50\% del total suministrado por el río Taibilla. El otro 50\% nace en los manantiales del Estrecho del Aire, en el tramo de 7,5 km., comprendidos entre la Presa de Embalse y la de Toma. Por otra parte, la denominada "presa de toma" es un Azud aguas abajo del Estrecho del Aire, en el río Taibilla, que actúa como dispositivo de entrada, por aliviadero, al origen del Canal Alto del Taibilla. Al margen de estas presas, como se observa en la figura 151, el sistema de la MCT se beneficia del resto de presas de la Cuenca del Segura, fundamentalmente las vinculadas al trasvase Tajo-Segura como el embalse de La Pedrera.

El depósito de alicante, que estructuralmente se corresponde con el modelo utilizado en Murcia, consta de dos unidades de igual capacidad, de $40.578 \mathrm{~m}^{3}$, que entraron en servicio en 1958 y 1966 respectivamente.

Fig 152. Depósito de cabecera de distribución de la ciudad de Alicante [Memoria MCT, 2007.]

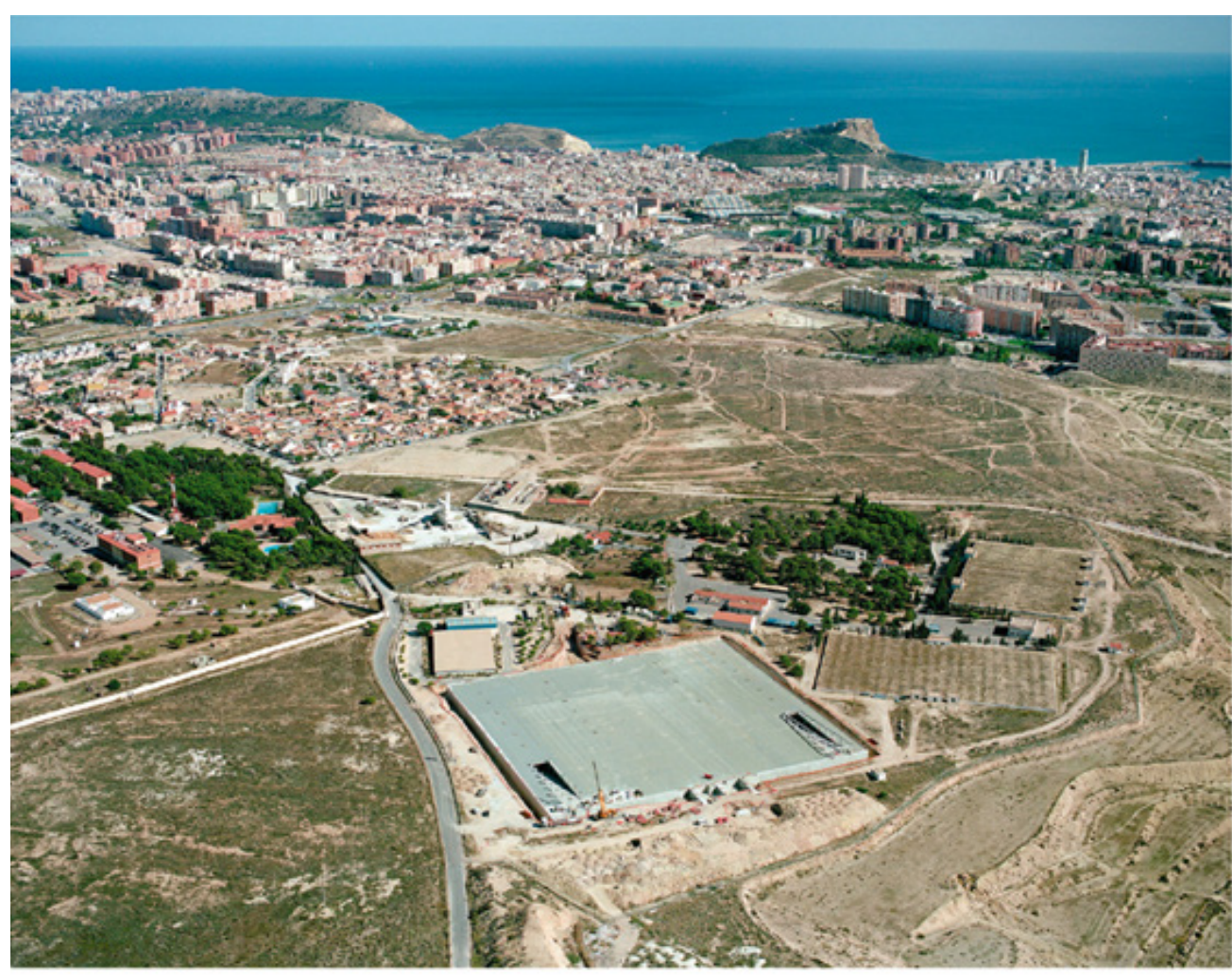




\section{3.- Infraestructuras de potabilización.}

Las plantas potabilizadoras de la MCT son un total de 6, con una capacidad de potabilización total de $18 \mathrm{~m}^{3} / \mathrm{s}$. En la figura 153 se puede apreciar su localización, destacando que dos de ellas, la potabilizadora de la Pedrera y la potabilizadora de Torrealta se sitúan en la provincia de Alicante. La puesta en servicio de la Toma en el río Segura, para garantizar los consumos de la Rama Oriental, llevó aneja la construcción de la estación potabilizadora de la Sierra de la Espada (Molina del Segura, Murcia), para tratar las aguas mezcladas del Taibilla y Segura, ya que las condiciones de éstas últimas requerían un proceso más complejo de depuración que la simple adición de cloro.

La potabilizadora de Sierra de la Espada, aunque está situada en término municipal de Molina de Segura, contribuye también al suministro de la provincia de Alicante, toda vez que entrega las aguas al Canal del Segura.

La ETAP Sierra de la Espada fue puesta en funcionamiento en 1964, aportando caudales captados en el cauce del río Segura a la red de la MCT, con destino a Alicante, así como a las Vegas Media y Baja del Segura. El Ministerio, consciente de la gravedad de la situación a la que se había llegado, por OM de 8 noviembre 1961 decidió constituir la Comisión Segura-Taibilla para el estudio de las necesidades y planes de obra tanto de los abastecimientos como de la ordenación de los regadíos de la cuenca, con la misión de redactar un anteproyecto que recogiese las obras necesarias, su financiación y reajuste de concesiones de aguas públicas, para una vez aprobado técnicamente ser sometido a información pública. Esta Comisión planteó con urgencia lo que se denominará "Solución provisional de abastecimiento en estiaje a la Mancomunidad", para complementar los mermados caudales del río Taibilla durante el verano, mediante la toma de agua en el río Segura, en Ojós, y la planta de tratamiento de Sierra de la Espada. La construcción de esta instalación fue necesaria una vez se incorporaron al sistema las aguas del río Segura, que presentaban turbiedades y condiciones bacteriológicas de obligada corrección. Fue la segunda planta realizada en España con una concepción moderna de tratamiento del agua potable (decantadores de pulsación, filtros rápidos de arena, etc). Las aguas captadas en Ojós, venían a compensar los volúmenes aportados por el río Taibilla al embalse del Cenajo, dado que la concesión otorgada al Organismo era de recursos de dicho río hasta un caudal de $2.500 \mathrm{l} / \mathrm{s}$, volumen que no se alcanzaba en el punto de toma. Desde este punto del río hasta su desembocadura en el Segura, circulaban aguas surgentes y de escorrentías (12-16 hm³/año) de afluentes al Segura, que quedaban almacenadas en el embalse del Cenajo. Ya reguladas, era factible disponer de ellas aguas abajo del embalse, en Ojós (Murcia). Gracias a la puesta en servicio en 1964 de la Toma de Ojós y la ETAP de Sierra de la Espada, pudieron evitarse restricciones en los núcleos abastecidos. 


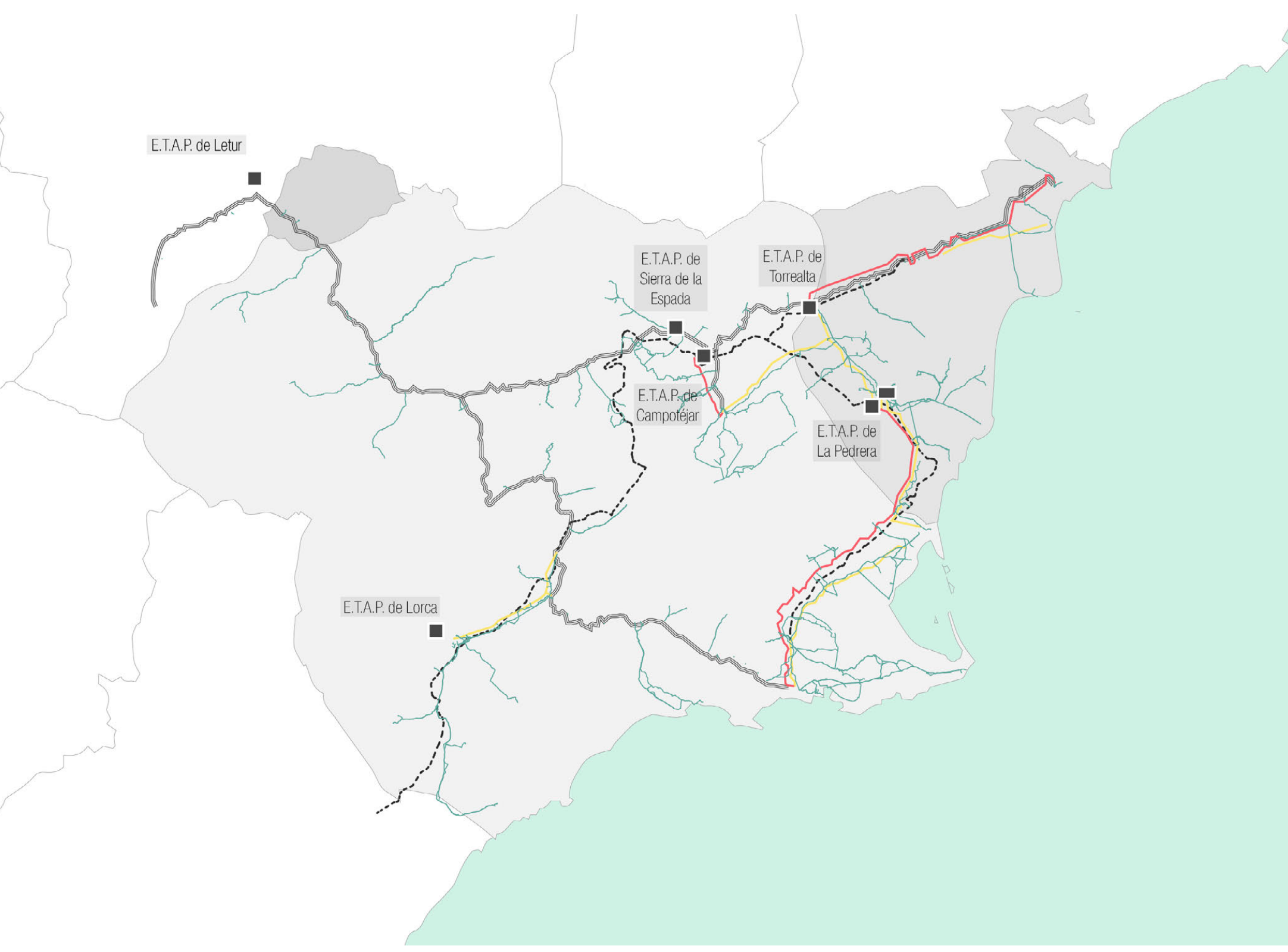

Fig 153. Localización de las ETAP del sistema de la MCT [MCT. Elaboración propia.]

ETAP

$\equiv$ Canal principal de la MCT (1945-1960)

- Red Hidrográfica

- Plan ampliaciones (1975-2000)

- Actuaciones Plan Hidrológico

-- Postrasvase Tajo-Segura 
La potabilizadora de Sierra de la Espada originariamente trataba aguas procedentes de los ríos Segura y Taibilla pero, en la actualidad, trata también aguas procedentes del canal del postrasvase Tajo-Segura. Atiende las necesidades de los municipios de la provincia de Alicante y Vegas Media y Baja del Segura. Fue ampliada en 1974 y mejorada en 2004. Sus características principales vienen especificadas en la tabla 20.

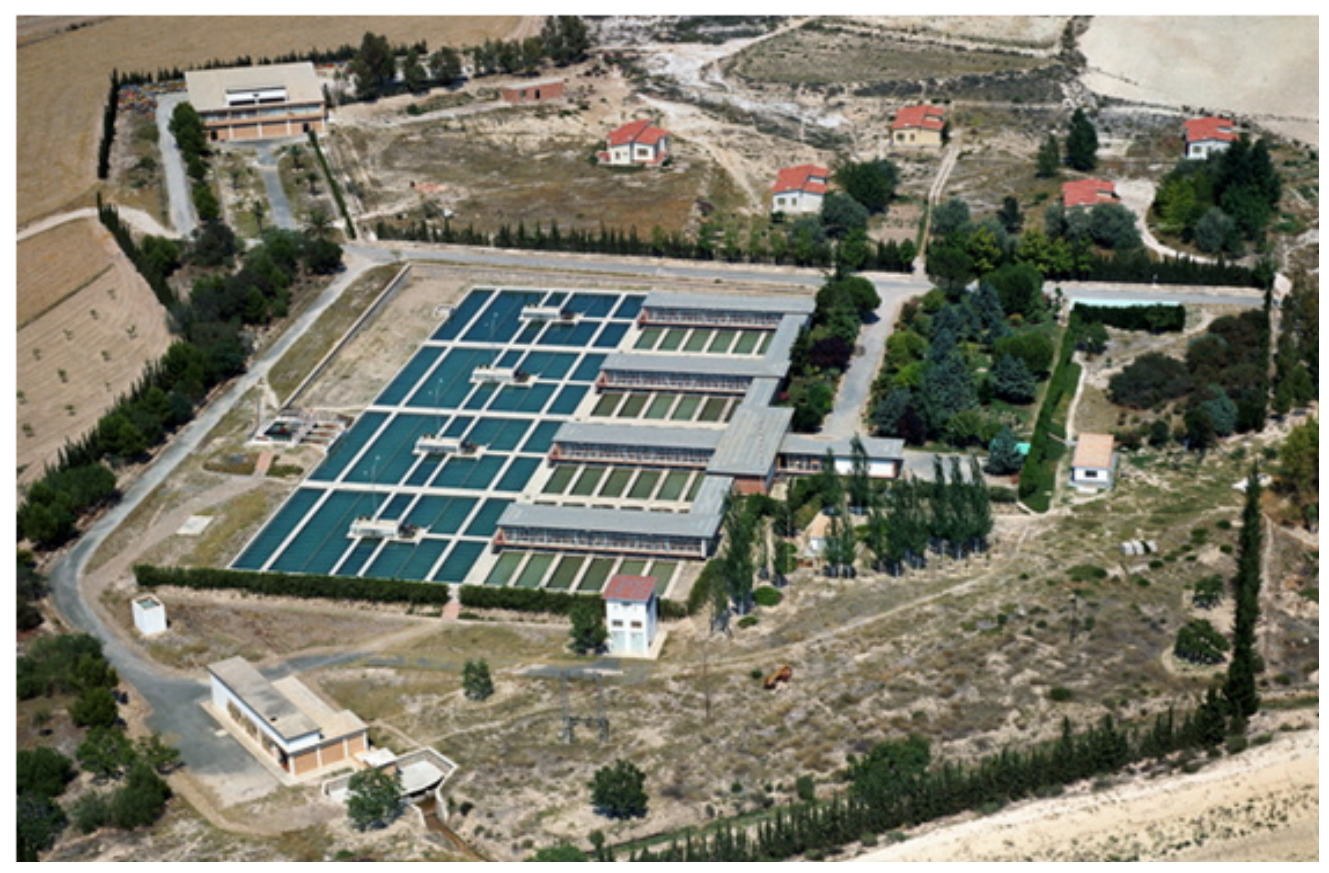

Fig 154. ETAP Sierra de la Espada (Molina del Segura, Murcia) [MCT.]

\begin{tabular}{|c|c|}
\hline Caudal & $2,1 \mathrm{~m}^{3} / \mathrm{seg}$ \\
\hline Decantadores & 4 \\
\hline Filtros & $\begin{array}{c}18 \text { de carbón activo } 6 \mathrm{de} \\
\text { arena silícea }\end{array}$ \\
\hline Potencia instalada & $1.200 \mathrm{Kva}$ \\
\hline
\end{tabular}

Tabla 20. Datos técnicos ETAP Sierra de la Espada [MCT.] 
En los años 70 los aportes del río Taibilla y las captaciones del río Segura resultaban insuficientes para satisfacer el incremento de las demandas resultantes del aumento poblacional, y del crecimiento del turismo residencial especialmente en el litoral sur de la provincia de Alicante.

Para afrontar esta situación, en 1978 estaban ya disponibles los primeros caudales del trasvase, lo que precisó la ampliación de los canales y la construcción de depósitos y potabilizadoras, en un volumen que venía a duplicar las instalaciones existentes. Estas actuaciones se fueron desarrollando desde 1974 en el marco del plan de ampliación y obras del postrasvase, para posibilitar la incorporación de dichos caudales. Para facilitar el tratamiento de estos caudales se construyó la potabilizadora de La Pedrera (1978).

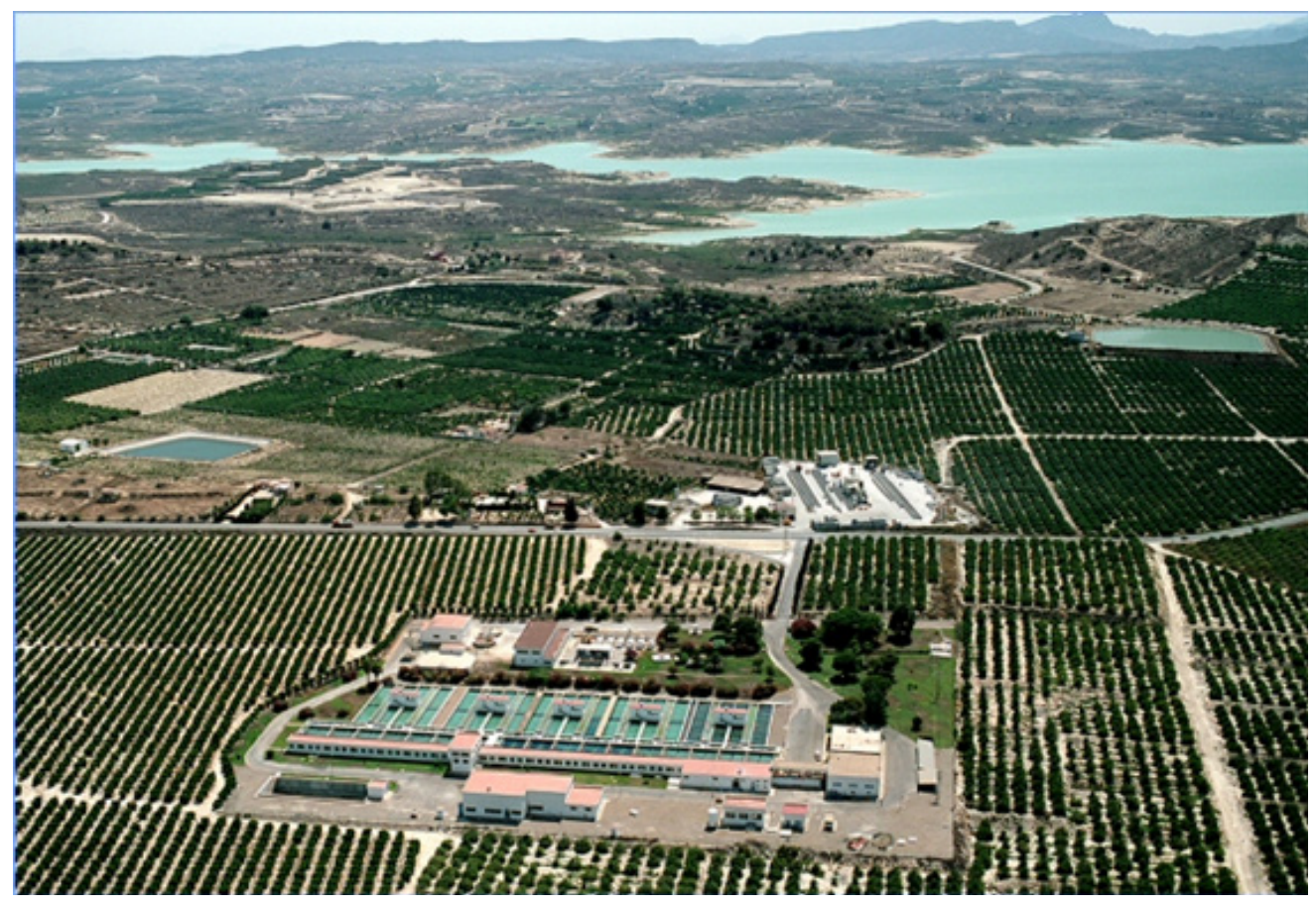

Fig 155. ETAP La Pedrera [MCT.]

Esta instalación está situada en el término municipal de Jacarilla (Alicante), y fue ampliada en 1994. La captación de agua se realiza desde el embalse de La Pedrera, de $250 \mathrm{hm}^{3}$ de capacidad, al cual confluyen las aguas del Canal de la Margen Izquierda del postrasvase Tajo-Segura. Las aguas, una vez potabilizadas, son entregadas al Nuevo 
Canal de Cartagena; ahora bien, parte de las mismas son dirigidas al Canal de Alicante a través de la conducción ejecutada en 2008, que permite, con un funcionamiento reversible, conectar las potabilizadoras de La Pedrera y Torrealta. Sus características técnicas pueden apreciarse en la tabla 21.

\begin{tabular}{|c|c|}
\hline Caudal & $4,2 \mathrm{~m} 3 / \mathrm{seg}$ \\
\hline Decantadores & 1a fase: 3 pulsator 2a fase: 1 pulsator 1 superpulsator \\
\hline Filtros & 1a fase: 12 2a fase: 5 \\
\hline Potencia instalada & \\
\hline
\end{tabular}

Tabla 21. Características técnicas de la potabilizadora de La Pedrera [MCT.]

Junto a la potabilizadora de La Pedrera, la potabilizadora de Torrealta (1978), inyecta al sistema de la MCT importantes caudales potabilizados que sirven a la provincia de Alicante. En la figura 157 se aprecia el esquema de instalaciones de la ETAP Torrealta.

La instalación está situada en el término municipal de Orihuela (Alicante), trata aguas procedentes del Canal de la Margen Izquierda del postrasvase Tajo-Segura. La captación de agua se realiza directamente desde el Canal del postrasvase Tajo-Segura. Sirve al Nuevo Canal de Alicante, y gracias a la conexión con la potabilizadora de La Pedrera permite también la conexión con Murcia y al Nuevo Canal de Cartagena. Fue construida en dos fases, culminando la segunda en 1997.

Sus características técnicas principales son presentadas en la tabla 22.

\begin{tabular}{|c|c|}
\hline Caudal & $5,3 \mathrm{~m}^{3} / \mathrm{seg}$ \\
\hline Decantadores & 1a fase: 3 2a fase: 4 \\
\hline Filtros & 1a fase: 9 2a fase: 12 \\
\hline Potencia instalada & 6.350 Kva \\
\hline
\end{tabular}

Tabla 22. Datos técnicos ETAP de Torrealta [MCT.] 


\section{8.- PRECIOS DEL AGUA}

\section{1.- Cuestiones generales.}

Según el estudio (AEAS-AGA, 2013), el precio medio del agua para uso doméstico en España es de $1,59 € / \mathrm{m}^{3}$, del que $0,92 €$ corresponde al servicio de abastecimiento y 0,67 $€$ al de saneamiento (alcantarillado y depuración de aguas residuales), sin incluir IVA. El consumo doméstico en España (agua para consumo en el hogar, lavarse, ducharse, fregar, inodoro, regar las plantas...) es de 122 litros habitante/día como media.

Los ligeros incrementos en el precio del $\mathrm{m}^{3}$ no han afectado sustancialmente al gasto familiar, ya que los hábitos de consumo más responsable han compensado parte de dichos incrementos. Además, las campañas divulgativas de las operadoras del suministro, el establecimiento de tarifas progresivas, y el esfuerzo por alcanzar mayores niveles de eficiencia, han ayudado a la contención tanto de los consumos como de los precios.

El precio medio indicado, sin embargo, presenta grandes variaciones en las diferentes provincias, (figura 158) y Comunidades Autónomas (figura 159), lo que obedece a diversos factores tales como la disponibilidad, calidad, proximidad de los recursos hídricos, procesos, técnicas y costes necesarios para la potabilización y depuración del agua, así como a la incorporación de los diferentes tributos regionales.

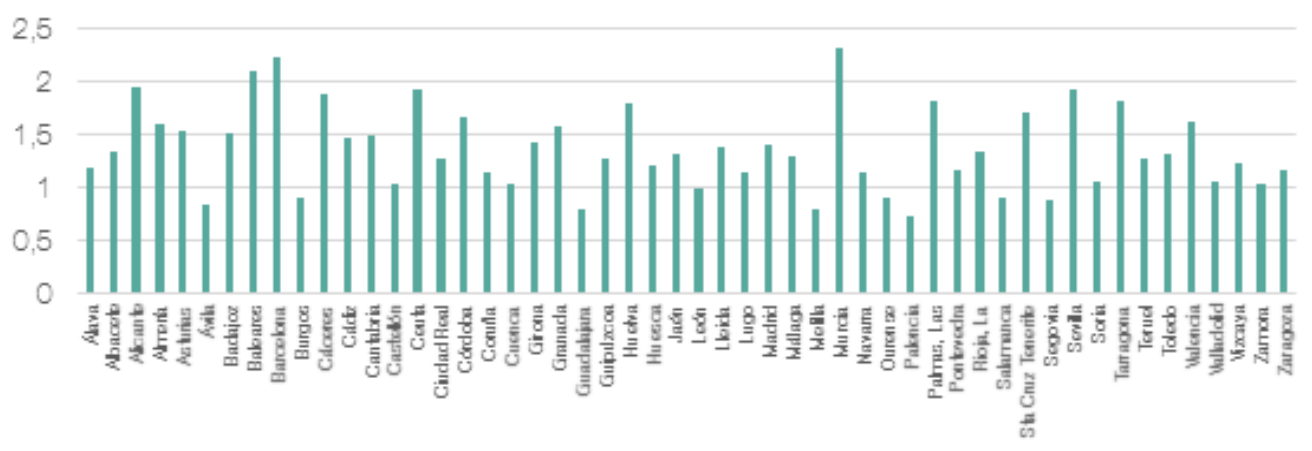

Fig 158. Precio del agua

$\left(€ / \mathrm{m}^{3}\right)$ de uso doméstico en España por provincias $[A E A S$ AGA (2013). Elaboración propia.] 


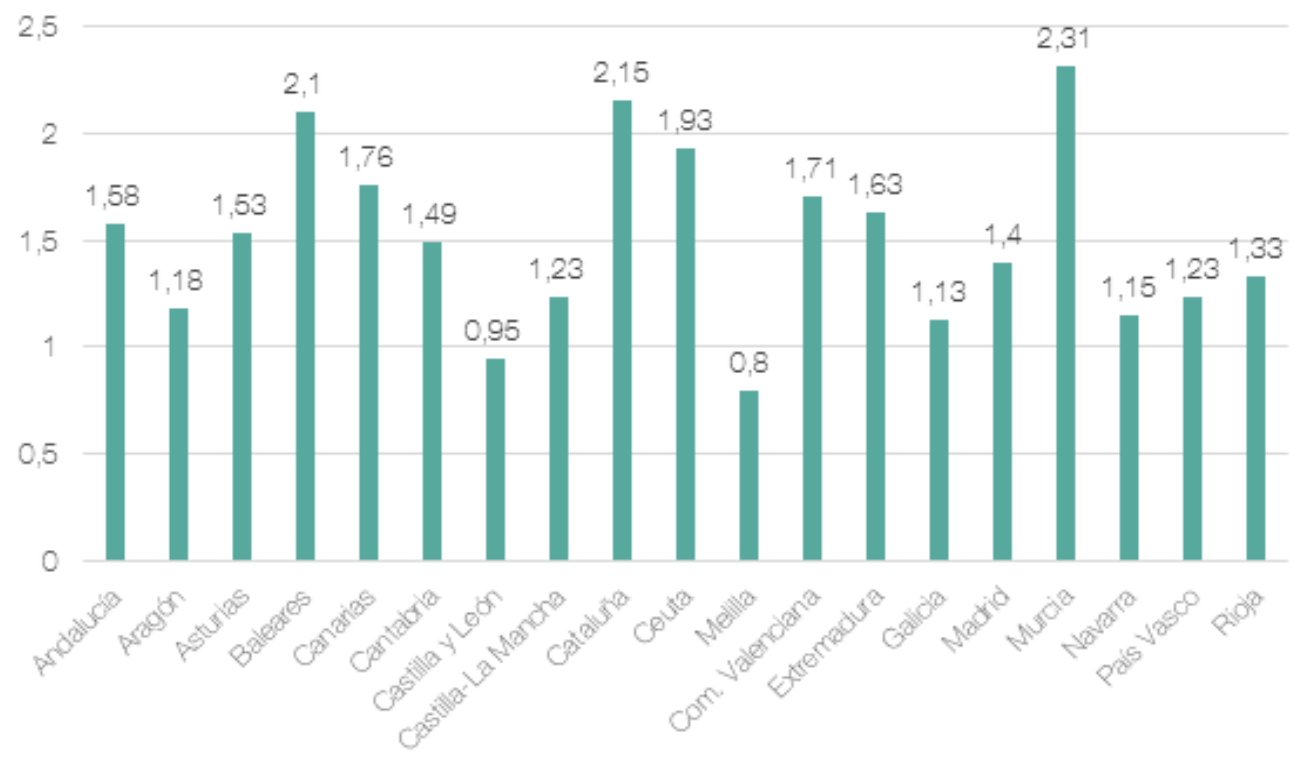

Fig 159. Precio del agua

$\left(€ / \mathrm{m}^{3}\right)$ de uso doméstico en

España por Comunidades Autónomas [AEAS-AGA

(2013). Elaboración propia.]

Es interesante destacar para nuestro caso de estudio que el precio medio pagado en las provincias de Alicante, $1,94 € / \mathrm{m}^{3}$ y en Murcia, 2,31 $€ / \mathrm{m}$, se debe principalmente al uso combinado de aguas de diversa procedencia y coste. La incorporación de aguas desaladas, de hecho, ha supuesto un incremento sustancial del precio medio de provisión del agua, debido al coste energético y a los costes de explotación y mantenimiento. Incremento que, por otra parte, no puede ser compensado mediante subvenciones públicas, toda vez que la Directiva Marco del Agua obliga a repercutir en el usuario todos los costes derivados de la gestión del recurso. La repercusión lineal de estos sobrecostes a todos los municipios, con independencia del grado de eficiencia en la gestión de los recursos, ha generado críticas en algunos de los municipios beneficiarios del sistema.

En esta cuestión existe una tensión entre los principios de eficiencia y equidad. Si la tarifa refleja más el primero de los principios, debe considerar la valoración de todos los costes del recurso, incluidos los ambientales y de gestión. Sin embargo, si se prioriza la equidad, entonces se dan situaciones de precios políticos, puesto que la tarifa no refleja en todos los casos el esfuerzo por alcanzar mejores estándares prestacionales. En un sistema complejo como el de la MCT, donde son muchos los municipios servidos, y con problemáticas y realidades distintas, alcanzar un balance entre ambos principios es ciertamente difícil. 
En la fijación de los precios del agua deben por tanto trasladarse las exigencias de la recuperación de costes, con atención, eso sí, a los efectos sociales, ambientales y económicos, así como a las condiciones geográficas y climáticas. Una aplicación puramente matemática del principio no parece razonable en el ámbito de la MCT. Se precisa, por otra parte, el diseño de estructuras tarifarias que incentiven el uso eficiente, internalizar los costes ambientales en la tarifa, aplicar el principio de transparencia y participación de los usuarios, y tomar en consideración los impactos sociales del precio del agua (Melgarejo et al., 2016).

La Comisión Europea señala que la política de tarificación del agua tiene que reflejar los siguientes costes: Los costes financieros de la prestación de los servicios del agua (costes de explotación, mantenimiento y de capital). Los costes ambientales que suponen los daños al ecosistema y el medio ambiente por los usos del agua. Y, los costes del recurso, representado por el coste de oportunidad para otros usuarios por el agotamiento de los recursos superior al índice de renovación o recarga natural.

\section{2.- Tarifa de la MCT}

La tarifa es una cuestión central en el desarrollo histórico de la Mancomunidad. En el año 1945 se fijó la primera tarifa provisional en $0,60 \mathrm{ptas} / \mathrm{m}^{3}$. Este precio fue cuestionado por el ayuntamiento de Cartagena, que alegó que era preciso tener en cuenta que desde que la Mancomunidad cede el agua en el depósito local hasta llegar ésta al consumidor, se produce una pérdida aproximada del $40 \%$. Esto suponía un coste inicial para el Ayuntamiento de $0,90 \mathrm{ptas} / \mathrm{m}^{3}$, precio que hacía inasumible la utilización del agua en muchas industrias creadas; e impediría a su vez que la clase modesta pudiera consumir el agua necesaria en condiciones higiénicas modernas. Por otra parte, dicho precio se vería incrementado por los gastos de amortización de las obras de distribución y alcantarillado, que el Ayuntamiento debía construir, así como los de conservación y administración, que harían elevar el coste del $\mathrm{m}^{3}$ para el consumidor a una cantidad no inferior a 1,50 - 1,75 $\operatorname{ptas} / \mathrm{m}^{3}$.

La OM de 14 junio de 1946 aprueba provisionalmente la tarifa de $0,60 \mathrm{ptas} / \mathrm{m}^{3}$ y en el Comité Ejecutivo de febrero 1946, nuevamente los alcaldes insisten en proponer como definitiva una más reducida que sería de $0,45 \mathrm{ptas} / \mathrm{m}^{3}$. El Ministerio no admite la propuesta y mantiene el inicial valor de $0,60 \mathrm{ptas} / \mathrm{m}^{3}$ La O.M. de 29 abril 1950, rectificada por la de 23 septiembre del mismo año, aprueba las tarifas por consumo de agua para los municipios y entidades estatales, manteniendo la gratuidad para la Base Naval, 0,60 ptas $/ \mathrm{m}^{3}$ para consumo de ayuntamientos y $0,20 \mathrm{ptas} / \mathrm{m}^{3}$, para consumo de entidades estatales. Se estableció una modalidad como alternativa que fue la de actuar con unos 
volúmenes mínimos de consumo, sobre los que se aplicaría un canon de $0,40 \mathrm{ptas} / \mathrm{m}^{3}$. Los excesos se facturarían a $0,10 \mathrm{ptas} / \mathrm{m}^{3}$, con la finalidad de incentivar el consumo y asegurar unos ingresos fijos. Los mínimos previstos tenían carácter progresivo y las tarifas eran revisables proporcionalmente al coste de la vida.

En 1958, las tarifas experimentaron un incremento del $60 \%$, por lo que el canon sobre los volúmenes mínimos se situaba en $0,64 \mathrm{ptas} / \mathrm{m}^{3}$, y $0,16 \mathrm{ptas} / \mathrm{m}^{3}$ sobre los excesos. En los años 60 el crecimiento de las demandas y el uso abusivo del agua suministrada, propiciado precisamente por unas tarifas que incentivaban el consumo, dio lugar a que la OM del 3 diciembre de 1963 aprobara unas nuevas tarifas en las que se gravaba el consumo excesivo; los consumos que no excedían la dotación normal eran gravados a $1 \mathrm{ptas} / \mathrm{m}^{3}$ a los Ayuntamientos; las entidades estatales pagarán 0,464 y REPESA deberá abonar $1,910 \mathrm{~m}^{3}$. La dotación normal de un municipio se determinaba en función de la población abastecida y era revisada anualmente, con la dotación invariable por habitante concedida por OM de 26 septiembre 1946. Los excesos de consumo sobre la dotación normal, verán incrementada la tarifa proporcionalmente, sin exceder del 50\% de la misma. Las tarifas podían ser revisadas proporcionalmente al coste de la vida, siempre que los resultados económicos lo exigieran, y la variación experimentada fuera mayor de un 10\%”.

En diciembre 1963 se aprueban nuevas tarifas de agua y mediante el Decreto 3418/63 de 12 de diciembre, el Ministerio pretende resolver de una vez por todas, la financiación necesaria para finalizar el Plan de Obras aprobado en 1930. El informe que presenta la Dirección de la Mancomunidad muestra que la inversión realizada a fecha 31 de diciembre de 1962 ascendía a 736,6 millones de pesetas y quedaban por invertir para finalizarlas 606,8 millones. Así se recoge en la OM de 3 diciembre 1963 que aprueba el Plan de terminación, en el plazo de seis años.

La tarifa de $1 \mathrm{pta} / \mathrm{m}^{3}$ estuvo vigente hasta enero de 1973, donde ésta experimentó un importante incremento hasta las $2 \mathrm{ptas} / \mathrm{m}^{3}$. A comienzos de 1974 se produce una nueva subida a 3,80 ptas $/ \mathrm{m}^{3}$, como consecuencia del Plan de Ampliaciones y la necesidad de presentar ingresos consecuentes con el nivel de endeudamiento que se va solicitando. En junio de 1975 la tarifa subió a 5,50 ptas/m³ permaneciendo así hasta finales de 1977. De nuevo, la tarifa sube a $8 \mathrm{ptas} / \mathrm{m}^{3}$ el 1 de enero de 1978 , y en julio 1979 pasa a $9 \mathrm{ptas} / \mathrm{m}^{3}$ (8,50 para las entidades estatales).

La llegada del agua del Trasvase, con un precio para los abastecimientos de $8 \mathrm{ptas} / \mathrm{m}^{3}$, encareció sensiblemente los costes del agua, pues los caudales del Segura que se venían captando en Ojós sin coste alguno de adquisición, debieron sustituirse por un volumen similar procedente del Trasvase. La tarifa ascendió en mayo de 1980 a 11 ptas $/ \mathrm{m}^{3}$, se incrementó en enero de 1981 a 13 ptas/m³ y en julio 1981 a 14 ptas $/ \mathrm{m}^{3}$ (Melgarejo, 2000). 
Téngase en cuenta que, en el año 1980, los volúmenes previstos a tomar del Trasvase hubieran sido de $62 \mathrm{hm}^{3}$ que hubieran importado 496 millones de pesetas a abonar por la Mancomunidad, cantidad que repartida entre los $128 \mathrm{hm}^{3}$ totales suministrados a los abastecimientos, repercutiría en unas $4 \mathrm{ptas} / \mathrm{m}^{3}$, que como mínimo deben añadirse a la tarifa anterior a la llegada del Trasvase. De hecho, el poder captar ese año $35 \mathrm{hm}^{3} \mathrm{de}$ aguas del río Segura, sin coste alguno, supuso poder encajar ese escalón de $11 \mathrm{ptas} / \mathrm{m}^{3} \mathrm{al}$ que antes nos hemos referido.

Los ingresos procedentes de recargos a favor de la MCT en las contribuciones territoriales superaron los 500 millones de pesetas en 1989, último año en el que se percibieron ingresos por este concepto; esta circunstancia motivó que a partir de 1990 se generara un déficit equivalente a esta cantidad en las cuentas de la MCT, lo cual tuvo que ser compensado con un incremento en la tarifa de $3 \mathrm{ptas} / \mathrm{m}^{3}$ (CEMCT, 20/12/1989).

La tarifa de la MCT, en el año 2004, se elevó un 10,6\% con respecto al año anterior, ascendiendo a $12,43 \mathrm{c} € / \mathrm{m}^{3}$ debido al aumento de la tarifa del trasvase Tajo-Segura y a la utilización del agua desalinizada. El 20 de diciembre de 2005 se aprobó la nueva tarifa de suministro de agua potable a municipios y entidades abastecidas, con efectos a partir del 1 de enero de 2006, en $0,3659 € / \mathrm{m}^{3}$. En 2007 la tarifa de la MCT fue de 43,26 c€/m³, ésta sufrió un incremento del 25,9\% en $2008\left(54,46 \mathrm{c} € / \mathrm{m}^{3}\right)$. Esta importante subida se debió a la puesta en servicio de las desalinizadoras de Alicante II y Valdelentisco, que trajeron consigo el incremento de los gastos financieros (Memoria MCT. 2008).

En 2009 el Consejo de Ministros aprobó las nuevas tarifas del trasvase Tajo-Segura, entrando en vigor del día 15 de diciembre, circunstancia que motivó la necesidad de equilibrar los ingresos y gastos para la siguiente anualidad. Se propuso una nueva tarifa de $58,74 \mathrm{c} € / \mathrm{m}^{3}$. Por otra parte, la crisis económica que atravesó España durante este tiempo, 2008-2014, tuvo importantes consecuencias económicas para el equilibrio presupuestario del Organismo, al interrumpir la evolución alcista de la demanda, evidenciándose un menor consumo con respecto a las previsiones del estudio para 2009. La menor facturación de agua supuso un perjuicio económico del orden de 10 millones de euros. Los miembros del Consejo Ejecutivo manifestaron su preocupación por el coste del agua desalada, que año tras año, bien por la inversión realizada o por el incremento de las tarifas eléctricas, siempre traen como consecuencia el aumento de la Tarifa (Memoria MCT, 2009).

En 2013 se manifiesta una vez más la preocupación de los municipios abastecidos por el Organismo por el futuro incremento de la tarifa ante la incorporación de nuevas aguas desaladas, debido a la aplicación de los convenios suscritos, en su día con Acuamed para la participación en las desalinizadoras de Águilas y Torrevieja, y la repercusión que tendrán en la tarifa (CEMCT 24/10/2013). A partir de 2015, la tarifa vigente es de 0,6905 $€ / \mathrm{m}^{3}$ tal y como se muestra en las figuras siguientes. Entre 2005 y 2015 , la tarifa se ha visto incrementada en un $91,7 \%$ para poder lograr el equilibrio financiero. 


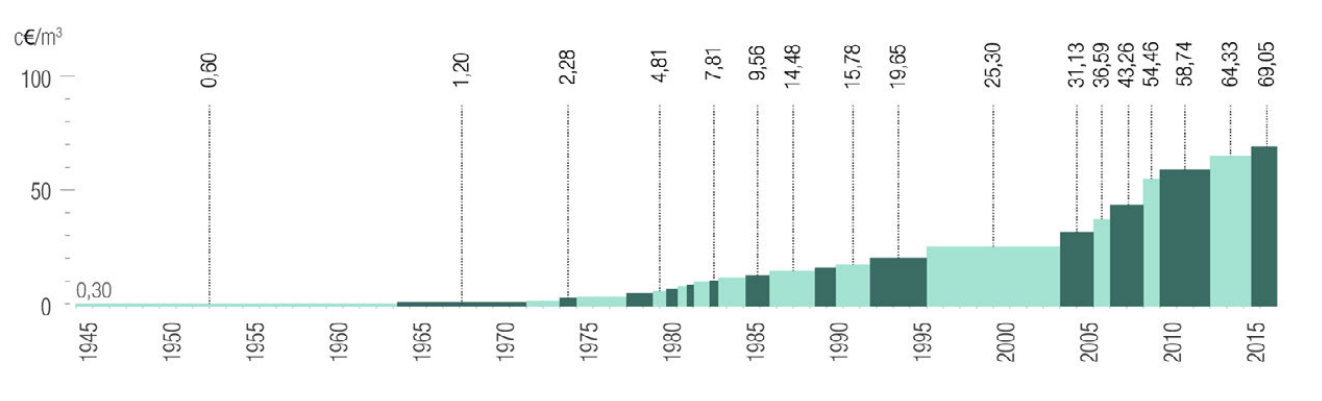

Fig 160. Tarifas del agua de la MCT desde 1945 hasta 2015 [MCT. Elaboración propia.]

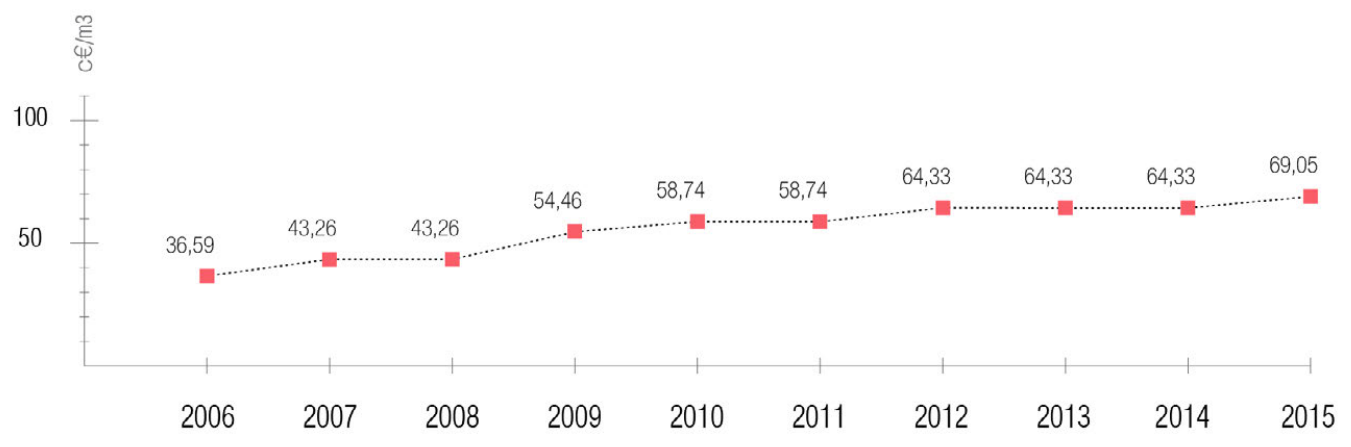

El incremento se debe a factores como la incorporación de las aguas desaladas, pero también por la reducción del consumo experimentada en los últimos años. Esta reducción es la suma de muchos factores, entre los que destaca la influencia de la crisis económica, que a partir de 2007/2008 ha reducido la actividad productiva de forma considerable. Junto a ello, la mayor concienciación social y la evolución tecnológica, con electrodomésticos e instalaciones más eficientes, y la modificación de hábitos de higiene o la sustitución de jardines por elementos menos demandantes de riego, ha contribuido también al menor consumo. En la industria el cambio tecnológico en los sistemas de ahorro de agua y procesos más eficientes es todavía más significativo. 
En los usos domésticos, se estima una tasa interanual de mejora tecnológica comprendida en un rango de 0,5\%-1,75\%. En los usos industriales, la tasa de cambio tecnológico es incluso más variable y de mayor rango, con niveles documentados (dependiendo del tipo de industria) comprendidos entre el 0,5\% y el 6,25\% anual. Este estancamiento en el consumo de agua hace que no sean previsibles mayores ingresos procedentes de aumentos de volúmenes facturados.

En la tabla 23 se aprecian los dos fenómenos apuntados, la presencia cada vez más significativa de recursos más costosos, lo que genera más costes, y la tendencia decreciente del consumo global, lo que reduce la facturación.

\begin{tabular}{|c|c|c|c|c|c|c|c|c|c|}
\hline $\begin{array}{c}\text { Aportaciones } \\
\left(\mathbf{h m}^{\mathbf{3}}\right)\end{array}$ & $\mathbf{2 0 0 5}$ & $\mathbf{2 0 0 6}$ & $\mathbf{2 0 0 7}$ & $\mathbf{2 0 0 8}$ & $\mathbf{2 0 0 9}$ & $\mathbf{2 0 1 0}$ & $\mathbf{2 0 1 1}$ & $\mathbf{2 0 1 2}$ & $\mathbf{2 0 1 3}$ \\
\hline $\begin{array}{c}\text { Aportaciones } \\
\text { Totales }\end{array}$ & 227 & 225 & 226 & 221 & 216 & 202 & 199 & 194 & 184 \\
\hline Rio Taibilla & 39 & 37 & 39 & 36 & 48 & 59 & 60 & 49 & 73 \\
\hline Trasvase & 124 & 103 & 114 & 77 & 95 & 87 & 104 & 98 & 100 \\
\hline Desalación & 22 & 42 & 60 & 72 & 73 & 56 & 35 & 44 & 6 \\
\hline Otras & $\mathbf{4 2}$ & $\mathbf{4 3}$ & $\mathbf{1 3}$ & $\mathbf{3 6}$ & $\mathbf{0}$ & $\mathbf{0}$ & $\mathbf{0}$ & $\mathbf{3}$ & $\mathbf{5}$ \\
\hline
\end{tabular}

Tabla 23. Aportaciones al sistema de la Mancomunidad de los Canales del Taibilla, según procedencia (20052013) [Memorias MCT (Varios años). Elaboración propia.] 


\section{9.- REPERCUSIONES SOCIOECONÓMICAS DE LA MCT EN LA PROVINCIA DE ALICANTE.}

\subsection{Salud pública.}

La escasez de recursos y la mala calidad de los existentes en todo el Sureste peninsular han supuesto tradicionalmente que la franja entre Alicante y Almería haya sufrido de las llamadas enfermedades hídricas, llegando algunas de ellas (tifus, paratíficas) a ser endémicas, y otras (cólera, paludismo) a experimentar frecuentes brotes con gravísimas consecuencias para la población (Grindlay et al, 2008). En Murcia, por ejemplo, se sucedían problemas de salubridad, con tifoideas endémicas, mientras que, en Cartagena o Lorca, los tenían de infradotación y restricciones en el suministro (Morales et al., 1989). Las enfermedades vinculadas a la escasez de agua se propagan en condiciones de escasez de agua dulce y saneamiento deficiente (tracoma, dermatitis de contacto, etc). Estas enfermedades pueden controlarse fácilmente con una mejor higiene, para lo cual es imprescindible disponer de suministros adecuados de agua potable.

Hasta la llegada de las aguas del Taibilla, la región permaneció en un estado sanitario deplorable, con un nulo desarrollo urbano e industrial en una situación de absoluta indigencia hídrica (Carrillo, 2002). La MCT contribuirá decisivamente a solucionar estos problemas con la progresiva incorporación de los municipios de su área de influencia. Con todo, la llegada de las aguas no se tradujo en todos los casos en una incorporación plena de la población al suministro, mediante una red básica de distribución de agua potable, ya que el abastecimiento de determinados municipios quedaba limitado a la construcción de depósitos o fuentes; pese a ello, fue manifiesta la mejora de las condiciones higiénicas y de salubridad que ello significaba por la calidad de las aguas, frente a las que habitualmente se utilizaban, cuyo contenido salino resultaba excesivamente elevado para el consumo, lo que había obligado tradicionalmente a depender de los aljibes que recibían aguas de lluvia, mediante el sistema de boqueras (Morales, 2002).

La población de Elche estuvo afectada por el tracoma de forma endémica. Se trata de una enfermedad asociada a la falta de higiene y, sobre todo, al consumo de agua salobre. Hasta bien entrado el siglo XX era una dolencia muy común en toda la región del sureste peninsular, cuya escasez de agua potable obligaba a la gente a beberla, frecuentemente, con altos contenidos de salinidad.

La precariedad de la calidad de las aguas para abastecimiento se pone de manifiesto en diferentes momentos, así, por ejemplo, en el municipio de Catral de forma temprana aparecen referencias a los problemas de salud pública que sufría la población y que pretendían resolverse con su incorporación al sistema de la MCT: "careciendo de aguas potables, el ayuntamiento en 1930, creyó resolver tan angustiosa situación ingresando 
en la MCT, confiando en que se harían las obras en breve plazo (...) se ha comprobado la lentitud de las obras y las dificultades del Plan General, por lo que para que lleguen las aguas faltan muchos años (...) siendo unánime y constante el clamor del vecindario pidiendo que se le provea de aguas potables en condiciones de salubridad, puesto que las únicas que pueden utilizar y se utilizan, especialmente por la clase proletaria, proceden de la acequia de riegos de este término que las deriva del río Segura en la ciudad de Orihuela, a cuya acequia vierten los retretes de varias casas de las calles de Orihuela, con grave y constante peligro para la salud pública de los habitantes de esta población (...) La Corporación ha acordado por unanimidad separarse de la MCT, para una vez exenta de estas obligaciones, realizar por otros medios más rápidos el abastecimiento de aguas potables procedentes de un manantial abundante que existe en la Sierra de Callosa de Segura" (Acta, 11 de mayo 1932, firma Juan Gómez, alcalde). En similares circunstancias se encontraba el municipio de Jacarilla, que en 1946, antes de su incorporación a la MCT, carecía de agua potable y se abastecía del río Segura y de acequias de riego, con grave riesgo para la salud (Acta de 25 de agosto de 1946). San Miguel de Salinas presentaba una situación similar: "José Andreu Zapata, Alcalde-Delegado Especial, Gestor único de este Ayuntamiento del Gobernador Civil de la provincia de Alicante., solicita el ingreso por estar totalmente desabastecida esta ciudad de 1.475 habitantes, que precisaba de 73.750 1/diarios". (Acta 27 de agosto de 1946).

En informe de la MCT se califican las aguas de consumo de Callosa de Segura como de poca calidad o maléficas. El Ayuntamiento respondió, que no había necesidad de esa sustitución con urgencia, ya que, pese a que sus aguas eran ciertamente deficientes, el problema se encontraba resuelto con la existencia en esta población de 300 aljibes, con una enorme capacidad de agua procedente de lluvia, que se emplean únicamente para beber y una pequeña parte para los trabajos de limpieza e higiene familiar y pública. Además, la salud pública no se había resentido nunca por causa de las aguas, puesto que las enfermedades gástricas no tienen un porcentaje mayor que en cualquier otra población de esta categoría. (Acta de petición de salida de la MCT, 18 de septiembre de 1947. AMCT).

El 10 de diciembre de 1963, el Ayuntamiento de Granja de Rocamora solicitaba de nuevo su ingreso en la MCT al carecer de aguas potables: "La acuciante necesidad de abastecimiento de aguas potables (...) carente este municipio en absoluto de tal beneficio en sus cercanías, cuyo motivo hace que este servicio, deficientemente prestado por algún vecino que no de forma regular se dedica a ello, resulta a veces agobiante por su falta y excesivamente caro por su precio" "se trataría de aliviar en gran parte esta agobiante y costosa situación". 
En el año 1966, el municipio de Dolores informaba a la MCT de las dificultades de calidad del agua por las que atravesaba la población. Para resolver esta situación, solicitó al Organismo, de forma provisional, una toma en la plaza del pueblo, donde ya existía una instalación con contador para el llenado de cubas y su posterior distribución en vehículos. La MCT autorizó al municipio a "una toma de agua para la carga de vehículos destinados al exclusivo abastecimiento del casco de la villa". El número de vehículos asignados a este servicio debía ser el mínimo indispensable y el Ayuntamiento debía remitir una relación detallada de los vehículos utilizados a la MCT para que ésta pudiera efectuar el seguimiento. Este estricto sistema de control pretendía evitar "las cargas clandestinas de vehículos". La MCT se exoneraba de cualquier responsabilidad sobre la calidad sanitaria del agua una vez saliera de la conducción general, debiendo el Ayuntamiento responsabilizarse de su manejo (CEMCT 23/471966).

El 19 de mayo de 1966, desde el Diario Información se hacía un requerimiento a la colaboración ciudadana para evitar las fiebres tifoideas, que parece que provenían de algún agua contaminada del abastecimiento urbano, concretamente se concienciaba a los habitantes que tuvieran sus casas próximas a las conducciones, como los que vivían en los alrededores de la finca El Toribio, en Carrús.

En el verano de 1971 se detectó la presencia de "vibrión colérico" en la cuenca del Segura. Como consecuencia de la mezcla de las aguas del Segura con las del Taibilla a través de la toma de Ojós se comprobó la presencia de esta bacteria en los decantadores de la ETAP de Sierra de la Espada. La crisis hubo de afrontarse incrementando los niveles de seguridad en la cloración de las aguas. A la salida de la planta de tratamiento, se establecieron cuatro puntos adicionales de cloración adecuadamente distanciados, antes de derivación a población alguna, de forma que se disponían cinco pantallas de cloración cuya probabilidad de fallo simultáneo era casi nula. El planteamiento dio resultado gracias a un singular esfuerzo en tomas de muestras, análisis y vigilancia de los dispositivos de cloración, superando así el verano. Pero la tensión de tener el cólera, dentro de las instalaciones, no fue plato de gusto (Nieto Llobet, 2014).

Desde 1979 a la actualidad, la llegada de las aguas del trasvase Tajo-Segura y la conexión de la Mancomunidad a la red del postrasvase de dicho sistema, permitirá ampliar la relación de municipios de la provincia de Alicante que terminan incorporándose a la Mancomunidad. Se producen, así, las últimas incorporaciones, con casuística diversa en este proceso. Es el caso de los municipios del corazón de la Vega Baja (Cox, Rojales, San Fulgencio, Rafal, Granja de Rocamora, Daya Nueva, Daya Vieja, Benijofar, Almoradí, Formentera del Segura y Algorfa), incluidos en el denominado "plan Klokol", del Ministerio de Obras Públicas, cuya finalidad era dotar de agua potable de calidad a los municipios de la Vega Baja ante la psicosis que se había levantado esos años de la posibilidad de desarrollo de un brote de cólera. Todos ellos recibirán aguas de la Mancomunidad en 1979 (Morales y Vera, 1989). 
Hondón de las Nieves, cuando solicita su ingreso en la MCT, en 1986, alude a problemas de salubridad en el suministro, debido a la elevada salinidad de las aguas de que disponían. Las muestras de agua presentaban niveles de cloruros de $600 \mathrm{mg} / \mathrm{l}$, muy superiores al máximo tolerable $(300 \mathrm{mg} / \mathrm{l})$, fijados por la reglamentación técnico sanitaria vigente. El agua estaba clasificada como "no sanitariamente permisible". Por contraste el agua de la MCT, en la rama oriental, presentaba un índice de cloruros que no superaban los $100 \mathrm{mg} / \mathrm{l}$. El municipio, que en un primer momento pretendió un suministro de emergencia, pretendía diluir sus caudales altamente salinizados con los de mayor calidad de la MCT. El Organismo autorizó por unanimidad entre 50 y $80.000 \mathrm{~m}^{3} /$ año para reducir hasta límites tolerables el contenido en sales de las aguas propias de abastecimiento (CEMCT 9/7/1986).

No cabe duda de que el abastecimiento de calidad es un activo fundamental para la salud de los ciudadanos, en ese sentido, en 1990 se estableció la posibilidad de fluorar el agua. Esta es una competencia de las Comunidades Autónomas, sólo la de Murcia, en ese año, tomó la iniciativa de realizar este tipo de tratamiento a su cargo, con un coste de 0,50 $\mathrm{ptas} / \mathrm{m}^{3}$, con una incidencia por habitante abastecido de en torno a 50 ptas/año.

La intervención de la MCT ha permitido superar este tipo de problemas al garantizar un suministro continuo, regular, y con la debida calidad físico química. La labor de la MCT desde sus inicios hasta la actualidad ha sido capital para conseguir que la esperanza y calidad de vida de los ciudadanos por ella abastecidos sea de las más altas del país. Superados los problemas de índole higiénico-sanitarios que afectan a las zonas con escasez y mala calidad de los recursos hídricos, la siguiente conquista fue la del confort, que se manifiesta en la calidad y regularidad del servicio; en este sentido la MCT garantiza el abastecimiento en alta para casi 2.500 .000 personas que en verano sobrepasan los 3.000.000.

\subsection{Turismo.}

El sur de Alicante es una de las áreas más secas de Europa, lo que acentúa el carácter estratégico de los recursos de agua para el desarrollo de la población y de sus actividades económicas. Las condiciones térmicas y de insolación otorgan a este espacio una posición privilegiada para el desarrollo de las actividades turísticas. De este modo, en los últimos treinta y cinco años se ha producido un espectacular crecimiento demográfico y económico basado, en gran medida, en la actividad turístico-residencial. 
Las actividades de ocio, turismo y segundas residencias han adquirido una importancia de primer orden en la evolución de las demandas de agua de muchas regiones españolas, entre las cuales se encuentra la provincia de Alicante (Morote, 2015). La costa alicantina constituye el principal eje de desarrollo territorial de la Comunidad Valenciana con fuerte implantación de actividades turísticas, de ocio y residenciales, directamente condicionadas por la escasez y competencia entre los diferentes usos del agua (Juárez, 2008; Gil, 2010; Piqueras, 2012). La disponibilidad de recursos hídricos en territorios con escasez natural de agua y con procesos de dinámica territorial intensos, justifica la aparición de situaciones de competencia para abastecer usos diversos. Se generan, así, tensiones por la utilización del recurso escaso, que tradicionalmente se han resuelto con medidas de incremento de oferta allí donde era posible. Si esta competencia se establece entre las actividades agrarias y las urbano-turísticas y no es posible aumentar los recursos, la garantía de abastecimiento de las demandas de agua del medio urbano pasa a ser el principal objetivo (Rico et al., 2014).

Los recursos de agua pueden influir en la elección de los destinos turísticos, más aún cuando se dan cita problemas de escasez o mala calidad (Rico, 2007). Para territorios turísticos, la necesidad de planificar los usos actuales y futuros teniendo en cuenta una posible disminución de caudales ha sido puesta de manifiesto por diversos autores en un ensayo sobre las relaciones entre el turismo y el uso del agua (Gössling et al., 2012). El agua es un recurso vital para la actividad turística (Cole, 2012; 2014; Gössling, 2015), fundamental por tanto en el caso de la provincia de Alicante, en especial en el litoral donde se desarrollan las actividades turístico-residenciales, que se caracterizan por una importante demanda de agua (Gil y Morales, 1999; Baños, 2014; Hernández et al., 2015). La escasez de recursos hídricos ha condicionado el desarrollo socio-económico de esta región (Rico; 2007; Rico y Hernández, 2008; Rico et al., 2009; Olcina y Rico, 1999). La provincia es un espacio que integra espacios turísticos emblemáticos, tanto por sus magnitudes de oferta y demanda, como por su imagen y proyección en el mercado nacional y en el exterior (Torres, 1997; Baños et al., 2010).

A la presencia de destinos turísticos costeros en el área de la MCT, como Torrevieja, Santa Pola o Guardamar del Segura, se añade la de entidades localizadas en el espacio prelitoral, dedicadas a la función residencial, especialmente en su vertiente de captación de ciudadanos de origen extranjero, el denominado residencialismo, que suma notables cantidades de unidades urbanas y que justifica la creación de un amplio sistema de servicios (Vera et al., 2009). 


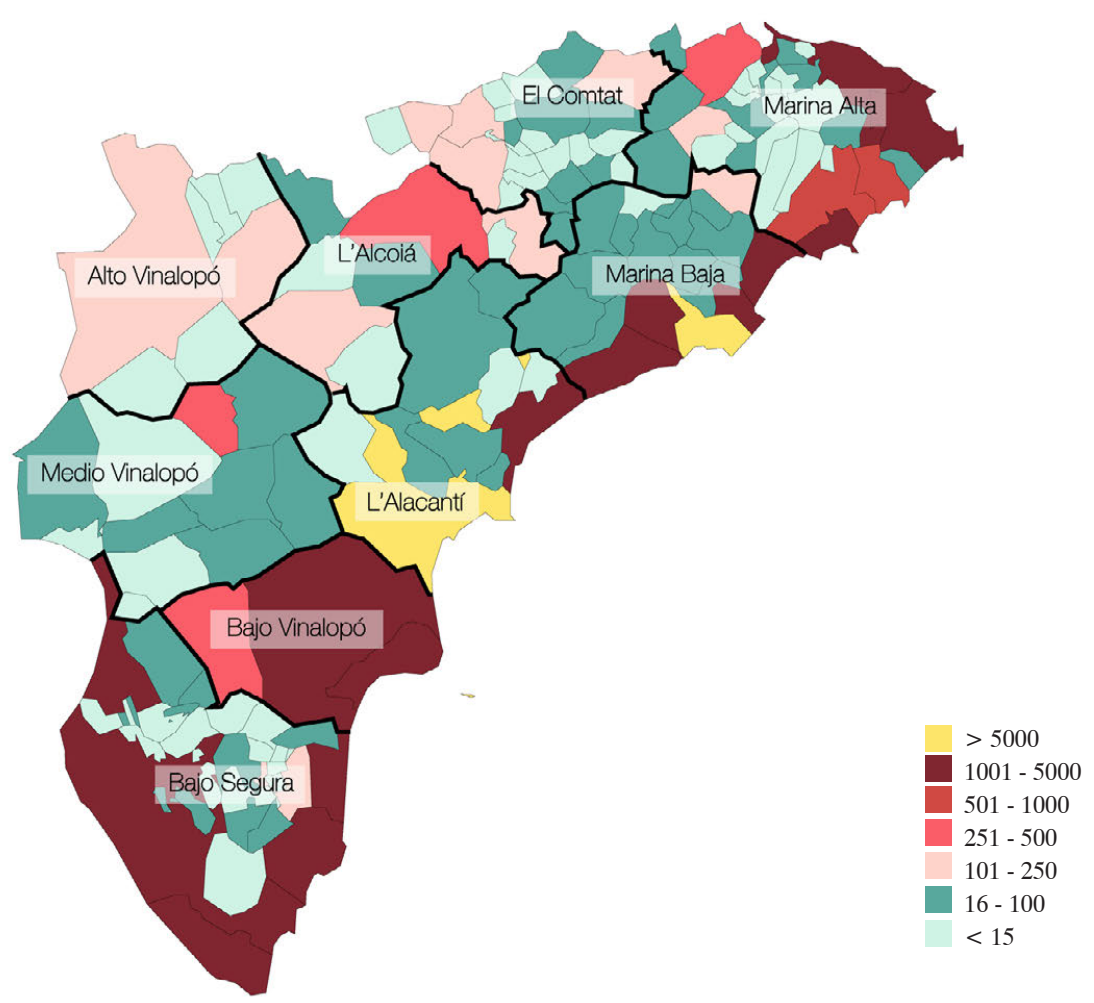

Fig 162. Distribución de plazas turísticas en la provincia de Alicante [Elaboración propia.]

La actividad turística presenta vínculos y relaciones directas con el abastecimiento de agua, dado que éste actúa sobre los destinos como factor condicionante y recurso del que depende la implantación y el desarrollo de la actividad (Saurí, 2003; Vera et al., 2004; Staddon, 2010). Este hecho resulta especialmente notorio en ámbitos como el de Alicante, cuyas condiciones climáticas vienen marcadas por la irregularidad y la consiguiente escasez de agua disponible (Morales, 2001; Morales et al., 2000; Olcina, 2002; Gil y Rico, 2007).

Veinte municipios de la provincia concentran el $75 \%$ de los extranjeros residentes con 288.268 personas de un total de 385.225. En el área de la MCT, Alicante, con 44.901 extranjeros, ocupa el primer lugar desplazando a Torrevieja al segundo puesto con 41.434, manteniéndose Orihuela en el tercer lugar con 31.028 extranjeros. Rojales ha pasado al primer lugar en términos relativos, con 13.669 extranjeros que representan el 72,6\% del total de la población, desplazando a San Fulgencio al tercer lugar con 6.387 extranjeros, 
que representan el $69,1 \%$ de los censados. Rojales se mantiene en primer lugar, con 12.955 vecinos/ extranjeros que representan el 71,5\% del total de la población, habiendo disminuido en 714 personas respecto al año anterior. San Fulgencio cuenta con 6,131 de 9.021 (68,0\%); San Miguel de Salinas con 3.844 de 6.773 (56,8\%); Benijófar con 1.910 de 3.655 (52,3\%); Hondón de los Frailes con 582 de 1.162 (50,2\%). Daya Vieja con 428 de 668 (64,1\%); Algorfa con 2.339 de 3.693 (63,3\%) (SECRETARIADO DIOCESANO DE MIGRACIÓN 2016).

La actividad económica en estos municipios gira, en buena medida, en torno al turismo y los procesos de construcción y promoción de viviendas, asociados tanto a la fijación de población residente, procedente de otros países y regiones, como a la ocupación estacional de los alojamientos. Dependen de estos procesos, en mayor o menor grado, todos los municipios localizados en la franja litoral y en el espacio prelitoral, aunque la dinámica del mercado de trabajo generado por los servicios y la construcción afecta, de modo más o menos directo, a la práctica totalidad de las entidades locales de este espacio. Por tanto, la progresiva integración de las entidades municipales en el gran sistema de abastecimiento de la MCT ha sido clave para el desarrollo territorial. El abastecimiento de las áreas turísticas, como parte del suministro a poblaciones, es casi determinante en la orientación del producto turístico de esta región, centrado de forma básica en la modalidad de sol y playa, en su faceta de alojamiento en asentamientos residenciales surgidos ex novo, o en forma de viviendas vacacionales situadas en los propios núcleos urbanos (Baños et al., 2010).

Desde muy pronto, la MCT cobra conciencia de la importancia que el turismo tendrá en el incremento de los consumos, y en las consiguientes dotaciones gestionadas por el Organismo. El Presidente de la MCT, en 1964, se hace eco y muestra su preocupación por el problema que en un futuro inmediato van a generar los "múltiples complejos turísticos que desde la Playa de San Juan (Alicante) hasta Mazarrón (Murcia) tienen en proyecto empresas inmobiliarias y particulares, que lo hacen sin duda esperanzados en su abastecimiento de agua potable con cargo al Taibilla, que de modo alguno podrán disponer mientras que por medio distinto al que representa la actual concesión de la Mancomunidad puedan ampliarse los abastecimientos. Esto, en casos muy particulares, está produciendo y ha de producir en el futuro una disminución de la dotación individual de los núcleos abastecidos, tiene que plantearse la cuestión, y para evitar las propias consecuencias, impedir así mismo que los ayuntamientos mancomunados hagan 


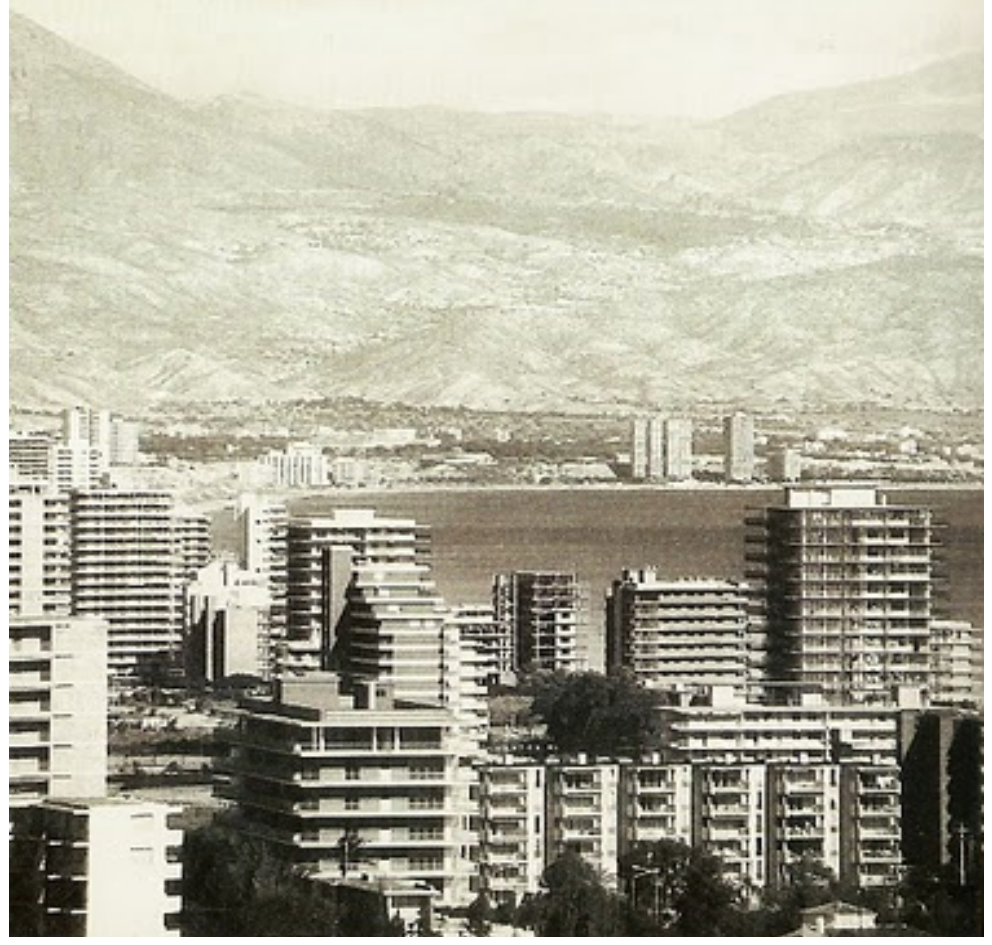

Fig 163. Playa de San Juan (Alicante), años 70 [http:// arquitecturadirecta. blog s pot.com. es/2011/04/algunasfotos-antiguas-de-laplaya-de.html]

concesiones de aguas a empresas industriales, manifestando su deseo de que conste en acta que ni lo uno ni lo otro podrá hacerse sacando más agua del río Segura". Ante esta argumentación del Presidente, se adoptó el acuerdo de: "impedir y perseguir todas las tomas ilegales y oficiar a los gobernadores civiles, delegados provinciales, presidentes de las diputaciones y alcaldes de los municipios mancomunados de territorios limítrofes a la costa mediterránea, para advertirles de la conveniencia de que antes de informar ningún proyecto o plan complejo turístico que tenga por base en su abastecimiento potable las aguas del Taibilla, de que es distribuidora esta Mancomunidad, establezcan contacto con su delegación de gobierno o dirección técnica para que puedan considerarse en informar sobre la conveniencia o inconveniencia del pretendido abastecimiento y evitar que queden aprobados aquellos, en la esperanza de un agua que nunca podrán disfrutar, por ser limitada la capacidad de su concesión, y estar comprometida su distribución por disposiciones legales" (CEMCT, 14/3/1964).

La MCT actúa en un espacio territorial que abarca $1.828 \mathrm{~km}^{2}$, aproximadamente un $31,4 \%$ del espacio que ocupa la provincia de Alicante. En su ámbito se concentra el 20\% de las plazas regladas de oferta turística de la Costa Blanca, con unas 32.000 unidades de alojamiento, y casi el 50\% de la oferta residencial, incluyendo municipios eminentemente turísticos como Torrevieja, Santa Pola o Guardamar del Segura. Junto a ellos, en el contexto prelitoral, proliferan urbanizaciones residenciales en buena medida ocupadas por ciudadanos de otras partes de España y, muy significativamente, de países europeos, que han fijado definitivamente su residencia en nuestra provincia o pasan largas temporadas del año. (Vera et al., 2009). 
La zona abastecida por la MCT en el litoral de Alicante es la siguiente:

-Unidad de Demanda Urbana 4, MCT-Torrealta: se integran aquellos abastecimientos atendidos desde la planta potabilizadora de Torrealta (Orihuela, Santa Pola, Alicante y Elche).

-Unidad de Demanda Urbana 5, MCT-Pedrera: se localizan los municipios atendidos desde la potabilizadora de La Pedrera (Algorfa, Benijófar, Daya Nueva, Daya Vieja, Formentera del Segura, Guardamar del Segura, Rojales, San Fulgencio, San Miguel de Salinas, Torrevieja, Pilar de la Horadada y Los Montesinos).

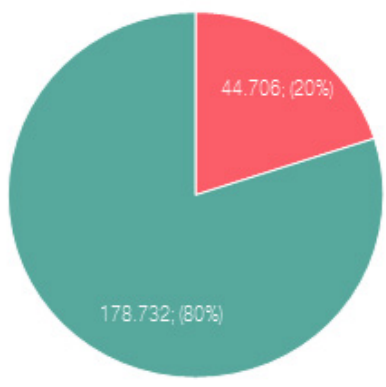

Los destinos turísticos del área abastecida por la MCT en el sur de la provincia de Alicante, aun cuando cuentan con sus particularidades, y responden a una caracterización y dinámica turística diferenciada, tienen como nexo común la seguridad de los suministros de agua en alta, que en todos los casos ha permitido su crecimiento.

Las plazas en hoteles, hostales, apartamentos turísticos, camping, casas rurales y albergues, son una parte minoritaria dentro del conjunto de la oferta del área MCT.

La oferta hotelera, por otra parte, se ve un tanto distorsionada en términos relativos, puesto que existen grandes diferencias entre los diferentes municipios. Como puede verse en la figura 166, sólo los municipios de Alicante y Torrevieja cuentan con una planta hotelera significativa, superior a las 5000 plazas, mientras que más de 10 municipios de interior carecen de esta oferta. 


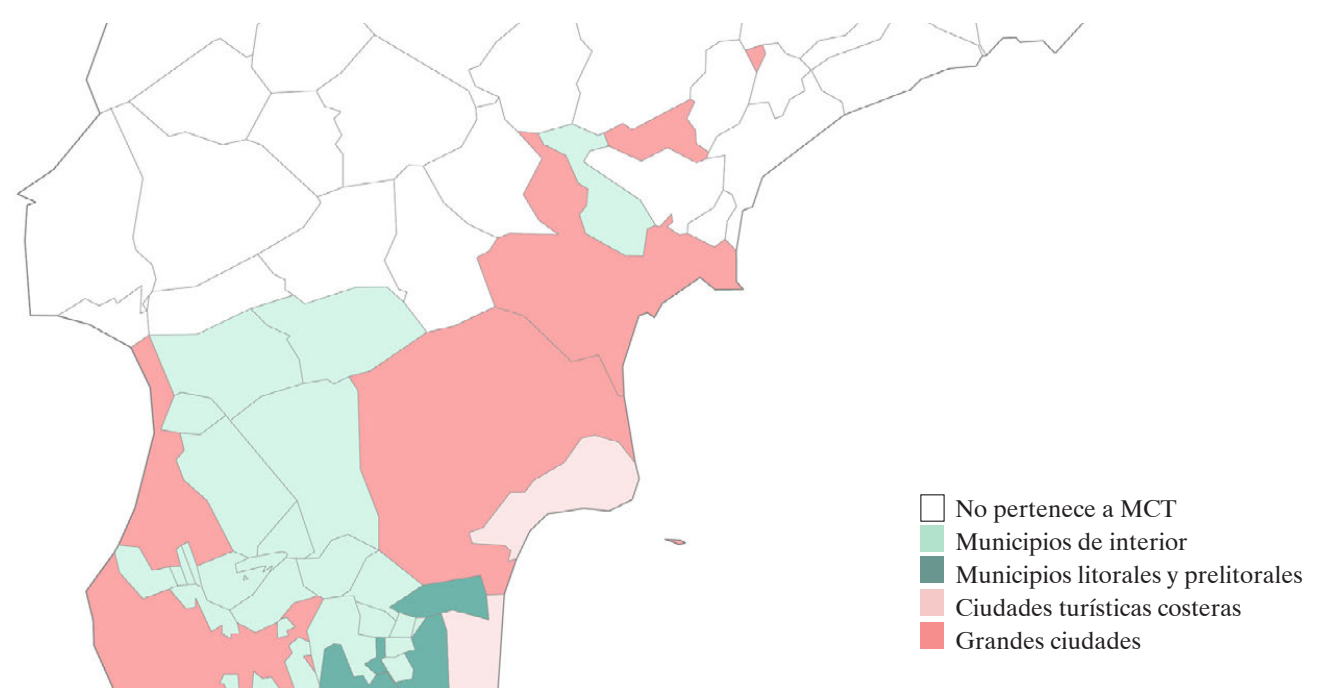

Fig 165. Mapa de tipologías de municipios turísticos en el área alicantina de la MCT [MCT. Elaboración propia.]

120000

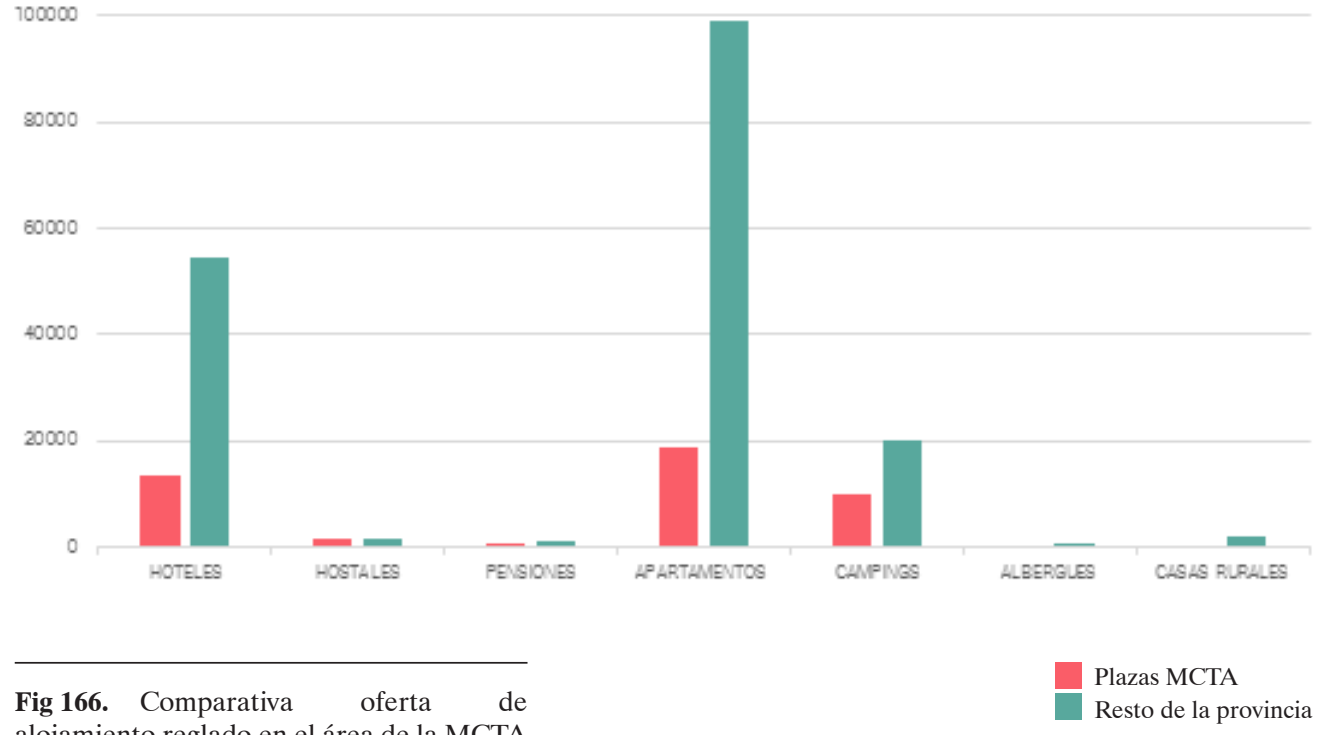

alojamiento reglado en el área de la MCTA

vs. resto de la provincia de Alicante (2015)

[Conselleria de Turismo. Elaboración propia.] 


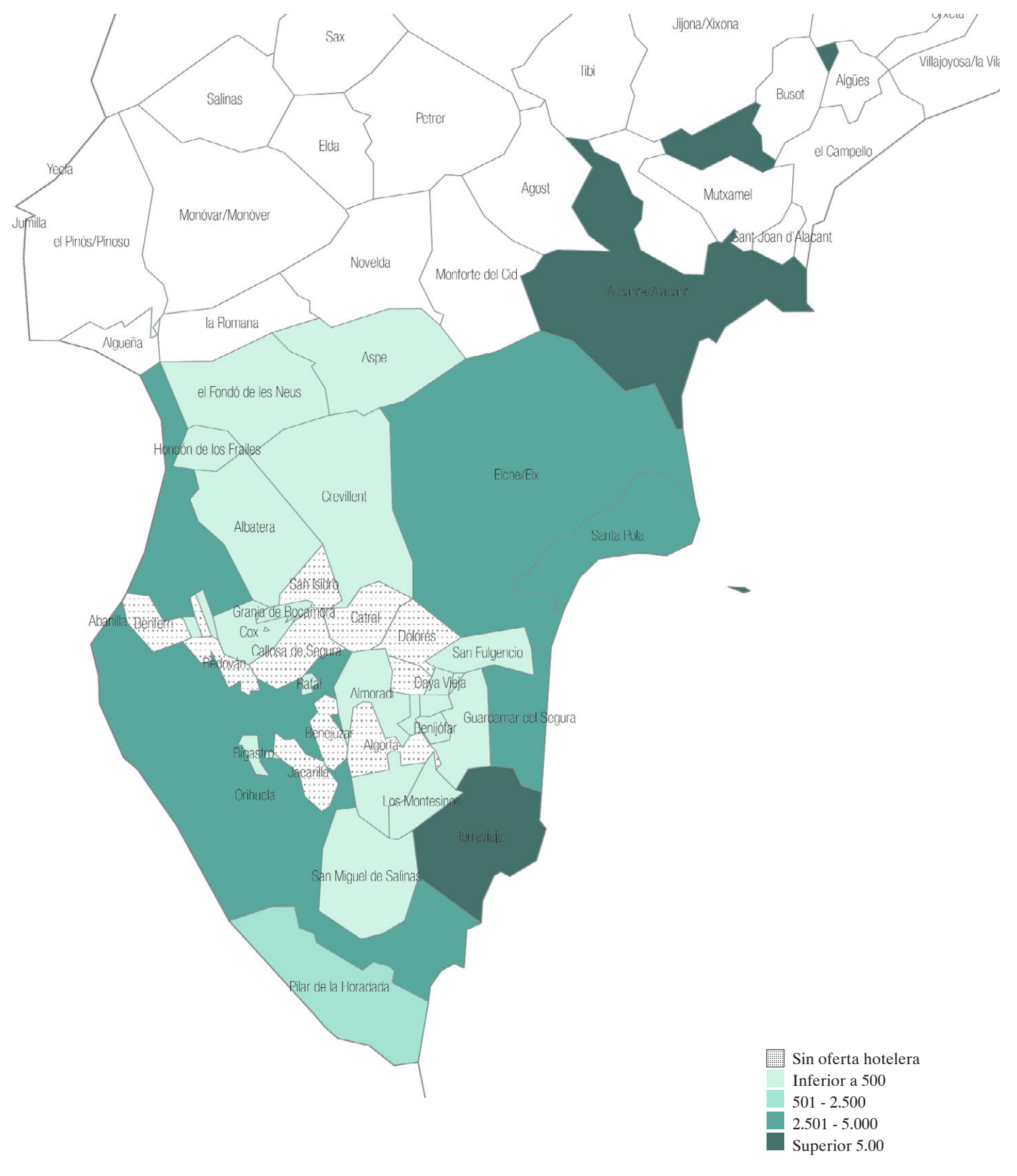

Fig 167. Planta hotelera [Conselleria de Turismo. Elaboración propia.] 
El peso de la ciudad Alicante en este aspecto es particularmente relevante, como se aprecia en la figura 168.

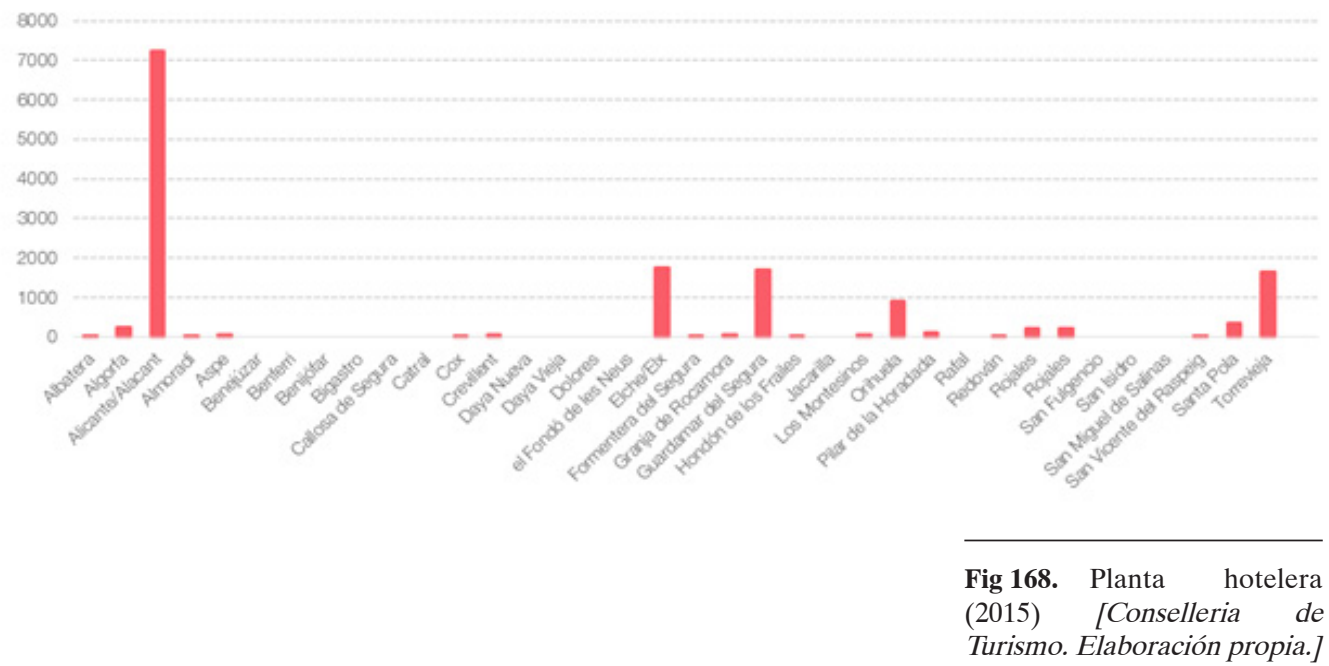

En la siguiente figura, se observa la evolución de la planta hotelera en los municipios en los que esta actividad tiene un peso significativo: Alicante, Elche, Torrevieja, Orihuela y Santa Pola y Guadamar del Segura.

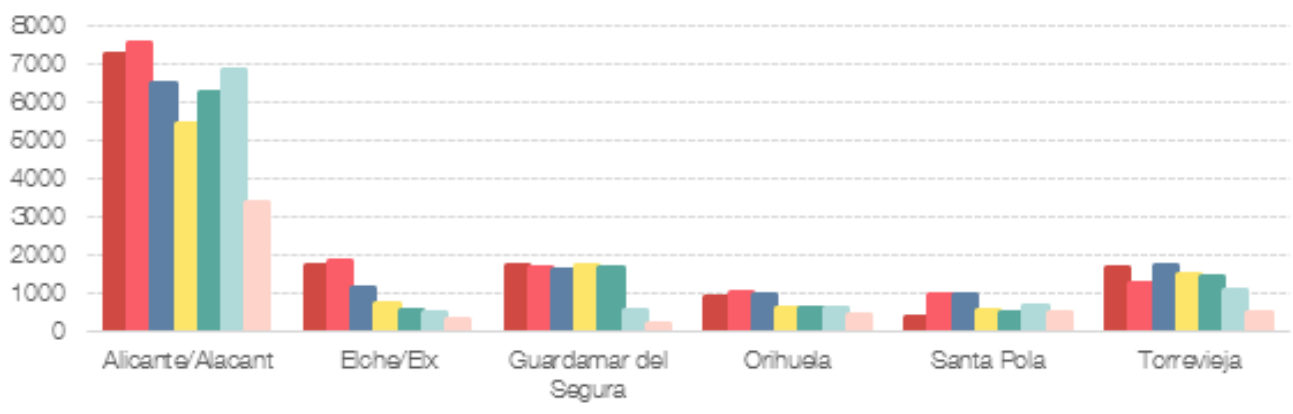

Fig 169. Evolución de la planta hotelera en el ámbito de la MCT (1986-2015) [Conselleria de Turismo. Elaboración propia.] 
Aunque la importancia del alojamiento hotelero en el área suministrada por la MCT es significativa, el factor realmente determinante y caracterizador en esta zona es el alojamiento en unidades residenciales extrahoteleras, verdadero protagonista como puede observarse en el siguiente mapa.

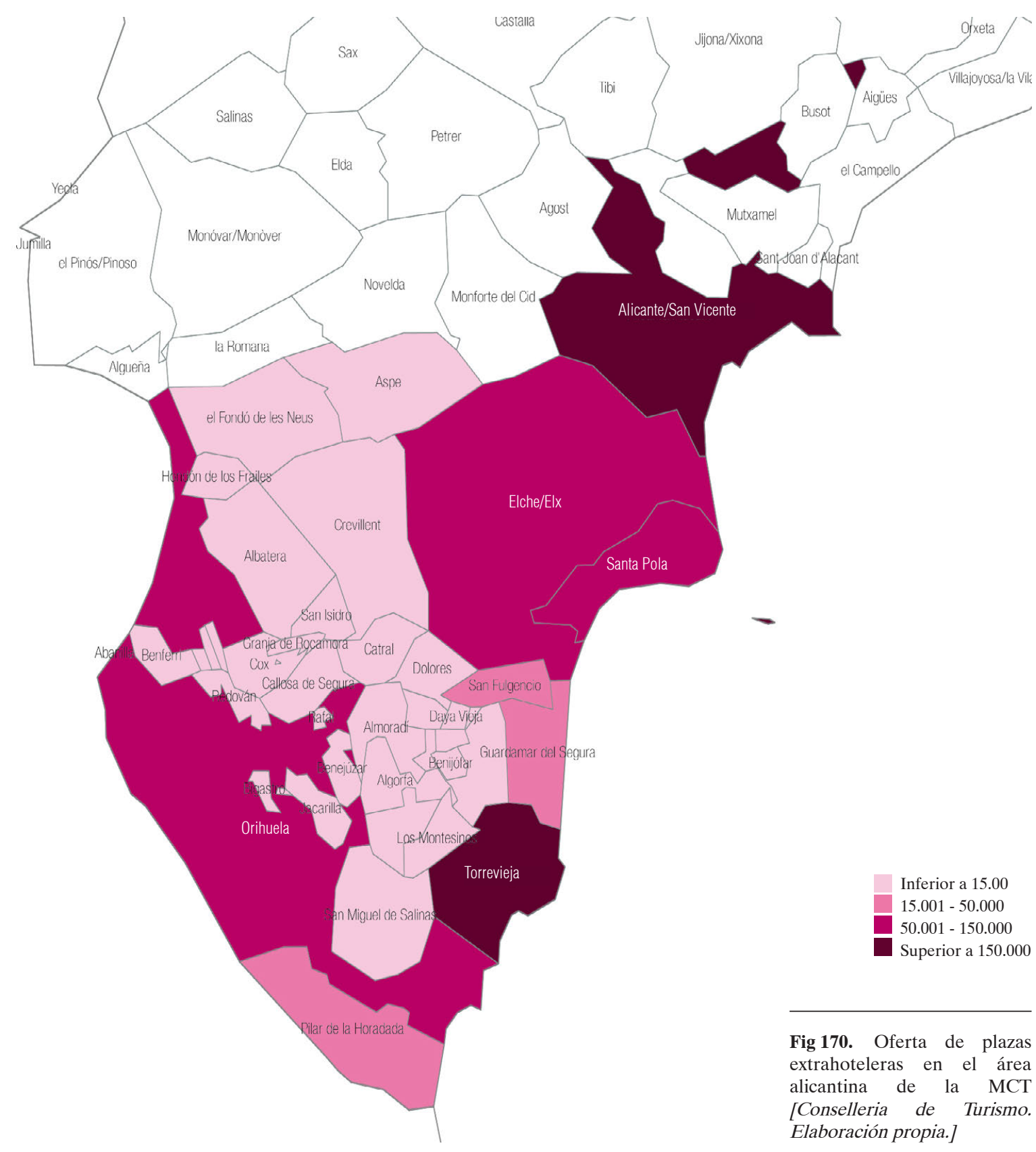


Todo este sistema turístico-residencial sería imposible sin los recursos que aporta el sistema de la MCT, ya que los recursos endógenos son estructuralmente insuficientes para acoger estas demandas crecientes. La relación entre ambos factores, a saber, la incorporación de estos municipios a la MCT, y la explosión de su desarrollo turístico residencial, se observa de manera evidente en localidades como Torrevieja, Rojales, San Fulgencio, Santa Pola, El Pilar de la Horadada, Guardamar del Segura, entre otras. También la propia ciudad de Alicante, y el crecimiento de ámbitos del término municipal de Elche como Arenales del Sol o La Marina, se alinean con la creciente disponibilidad de recursos suministrados por la MCT.

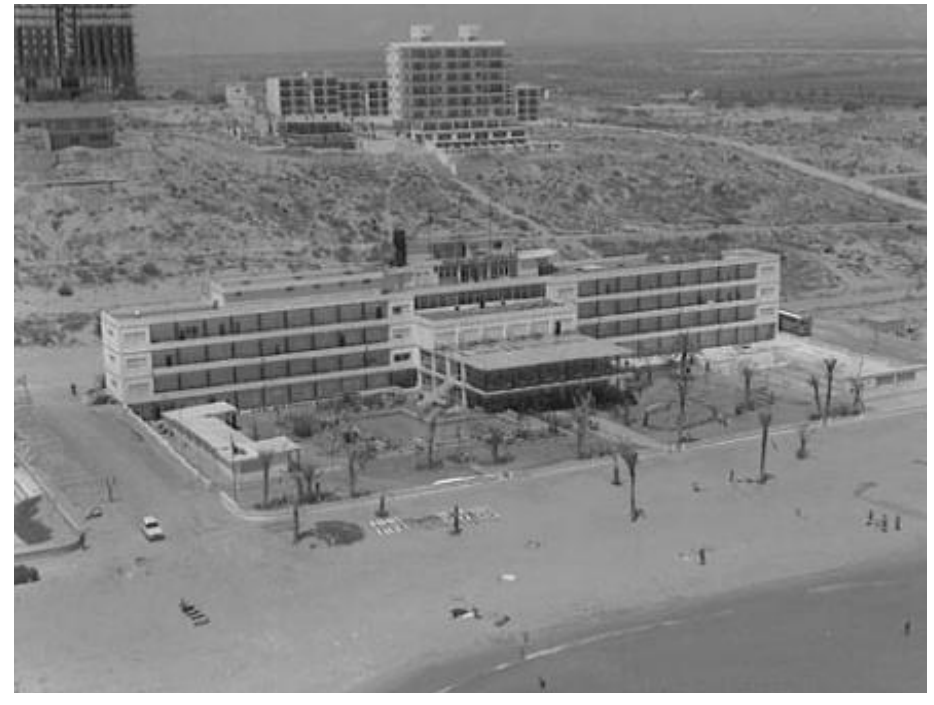

Fig 171. Arenales del Sol, años 70, Elche [http://Www. carabassi.net/fotografias/ antiguas.html]

Entre 1991 y 2007, el número de viviendas de potencial uso turístico creció un 51\% en términos medios, aunque en Torrevieja, Algorfa, Almoradí y Los Montesinos el crecimiento se situó por encima del $100 \%$. En una franja intermedia, Rojales y Pilar de la Horadada, San Miguel de Salinas, Bigastro, Catral, Guardamar del Segura y Orihuela presentan tasas de crecimiento entre el $50 \%$ y el 100\%,. Finalmente, con un crecimiento menor al 50\% tenemos a los municipios de Alicante, Elche, Crevillente, Santa Pola y San Vicente del Raspeig, así como muchos otros pequeños municipios, como Bigastro, Callosa de Segura, Dolores, Jacarilla, Rafal, Granja de Rocamora y Redován, muchos de los cuales ya disponían de un gran número de viviendas secundarias (Vera et al., 2009) 


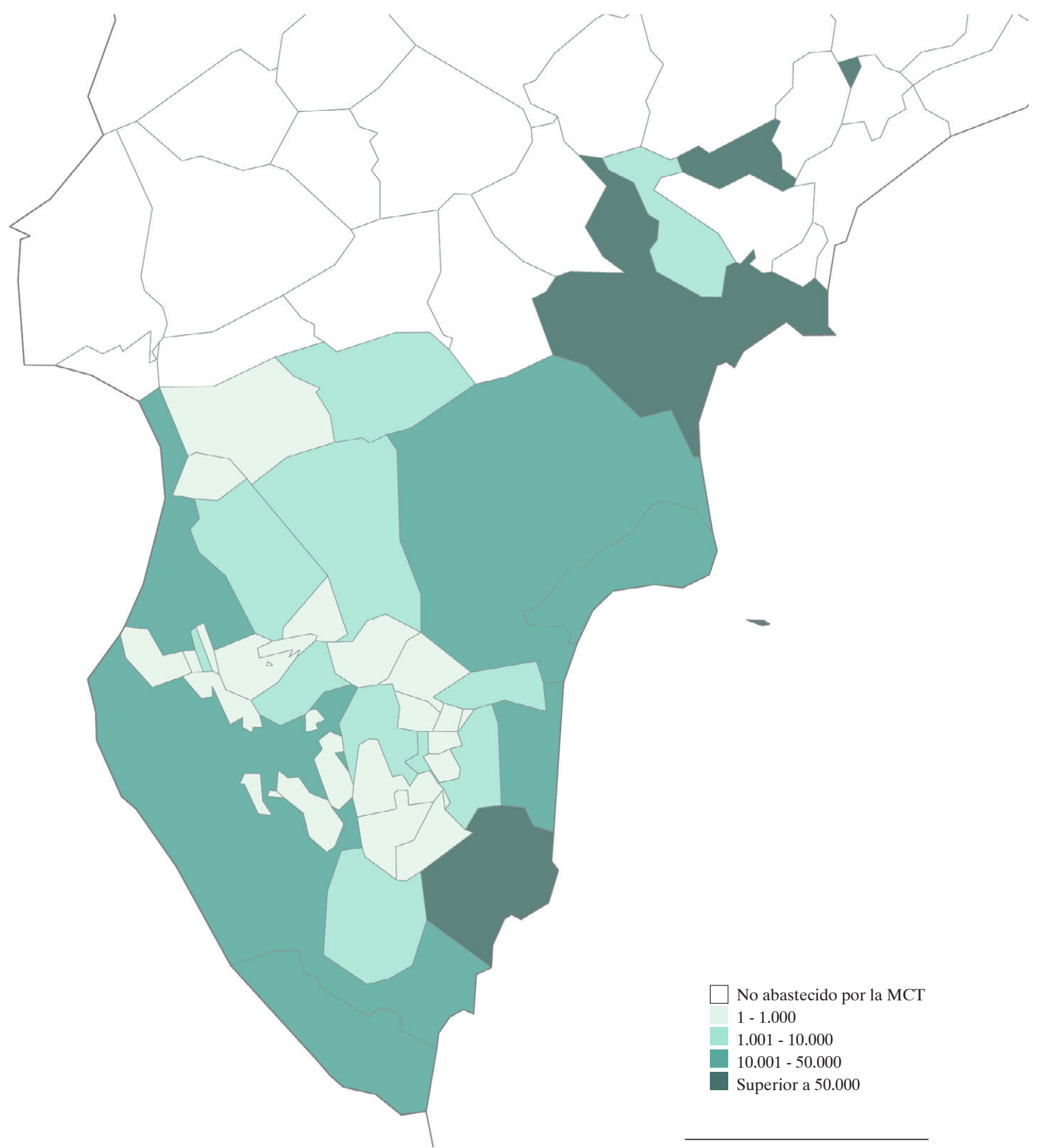

Fig 172. Peso de la Vivienda de Potencial Uso Turístico (VPUT) en el área abastecida por la MCT [INE y Observatorio Valenciano de la Vivienda. Elaboración propia.] 
Sólo en unos pocos municipios se experimentó una reducción de vivienda secundaria, debido a la transformación de muchas de ellas en primeras viviendas, y la ocupación de viviendas vacías, como ocurre en San Fulgencio. En otros casos, simplemente, se trata de municipios con poco atractivo turístico y limitado crecimiento poblacional, como Daya Vieja, Daya Nueva, Benferri, Benejúzar, Cox, Formentera del Segura, Hondón de las Nieves y en menor medida Aspe y Albatera.

El agua es, por otra parte, fundamento de las nuevas orientaciones del modelo turístico, surgidas ante las motivaciones del turista-consumidor, que justifican la creación de productos como el golf, principal reclamo de las nuevas promociones de viviendas vacacionales en este espacio regional. De hecho, en el caso de Murcia y del sur de Alicante, la promoción incorpora los resort-golf como la imagen turística más diferenciada (Baños et al. 2010).

De los 19 campos de golf existentes en la Costa Blanca, el área MCTA concentra 9, es decir, el $45 \%$ del total, una cantidad que unida a la proximidad entre las instalaciones, supone una masa crítica suficiente para organizar el uso conjunto como producto competitivo a escala internacional. Las limitaciones normativas, tanto urbanísticas como de ordenación territorial, condicionan el uso de aguas potables para este tipo de usos, imponiéndose la utilización de recursos alternativos como las aguas regeneradas. La MCT, indirectamente, ayuda a sostener estos consumos, puesto que garantiza el caudal en alta que, una vez utilizado, puede regenerarse para esta actividad.

El Artículo 19 del Plan Hidrológico de la Demarcación del Segura (2015-2021) establece, en cuanto a las dotaciones y demanda de agua para riego de campos de golf y zonas verdes asociadas a urbanizaciones, que: "se establece una dotación máxima neta de $8.000 \mathrm{~m}^{3} / \mathrm{ha} /$ año. Los recursos que permitan su desarrollo se encontrarán en consonancia con la acordado en su declaración de impacto ambiental y procederán de la reutilización de aguas depuradas o desalinización de agua de mar”. Se prohíbe además utilizar volúmenes procedentes del trasvase Tajo-Segura para el riego temporal o definitivo de campos del golf.

La Costa Blanca cuenta con 25 puertos deportivos, de los que el área MCTA suma el $48 \%$, con un total de 12 instalaciones, que se verán incrementadas con una nueva al entrar en funcionamiento la Marina Salinas, en la dársena del puerto de Torrevieja. Otra oferta de ocio que requiere la utilización de aguas potables de la máxima calidad son las actividades de ocio y relax, SPA, balneoterapia, etc. Este tipo de actividades complementan la oferta turística de manera especializada. Junto a ello, es importante el turismo de ocio activo, un producto en crecimiento (deportivo, ecuestre, acuático, etc). Todo ello precisa de una garantía de suministro de agua que sólo la MCT, con la combinación de recursos de diversa procedencia, ha podido garantizar. 


\section{3.- Construcción inmobiliaria.}

El litoral mediterráneo español ha vivido grandes transformaciones territoriales desde los años sesenta y setenta del pasado siglo con la instalación de la actividad turística (Vera, 2006; Hernández, 2013). Una de ellas ha sido el intenso proceso de urbanización que ha repercutido en un espectacular incremento del número de viviendas y población en la franja costera (Morote, 2016).

La expansión residencial acaecida en el litoral español desde 1998 ha tenido notables repercusiones territoriales. El número total de viviendas en España se incrementó en casi cinco millones entre el año 2001 y el 2011 (Ministerio de Fomento). Porcentaje que se concentra mayoritariamente entre 2001 y 2008, coincidiendo con el denominado boom de la construcción. Esta tendencia se ralentiza a partir de 2007, cuando se inicia la crisis inmobiliaria. El intenso desarrollo urbano resultante presenta una marcada concentración territorial, que se acentúa todavía más a escala provincial.

El factor explicativo de la expansión de las funciones residenciales en el litoral mediterráneo es la adquisición de viviendas por población procedente de otras regiones españolas; pero, sobre todo, por la fuerte demanda por parte de inmigrantes europeos, norteafricanos y sudamericanos. Llamativos resultan municipios como Rojales, San Fulgencio o San Miguel de Salinas, en los que el porcentaje de extranjeros ha pasado del 35 al $70 \%$ entre 2001 y 2011, respectivamente; ocupando los primeros puestos del ranking de municipios españoles con mayor número de extranjeros (Hernández, 2013).

La expansión residencial se ha fundamentado en la difusión de nuevos modelos urbanoresidenciales de media y baja densidad, basados en la proliferación de unifamiliares adosadas y viviendas unifamiliares en zonas periurbanas, cuando no en entornos no urbanos hasta entonces, donde los usos exteriores de las viviendas, jardines y piscinas privadas, son uno de sus elementos definidores. La tipología de vivienda unifamiliar en la provincia de Alicante ha registrado una evolución similar a la experimentada en el resto de España (Hernández et al., 2015). Este tipo de modelos conllevan una mayor presencia de zonas verdes tanto públicas como privadas, con elevado consumo de agua. El consumo en zonas urbanas de baja densidad, por ejemplo, es manifiestamente superior al de áreas de alta densidad por la presencia de usos exteriores como jardines y piscinas (Rico, 2002).

La actividad inmobiliaria tiene una relación directa con el suministro y disponibilidad de agua, de manera que no es posible la primera sin tener suficientemente garantizado lo segundo. Hasta tal punto es así que, ante la parquedad de los recursos en la franja costera, se observan correspondencias lineales entre la fecha de la integración de los municipios en la MCT, con la consiguiente garantía de abastecimiento, y el crecimiento de sus licencias de construcción y del espacio urbanizado. Es el caso de Torrevieja, que se incorpora 
al Organismo desde 1972/73, y cuyo crecimiento ha sido espectacular. En general son numerosas poblaciones las que se han apoyado en este factor para su desarrollo turísticoresidencial, Rojales, San Fulgencio, Santa Pola, El Pilar de la Horadada, Guardamar del Segura, incluida la propia capital alicantina (Vera et al., 2009).

La construcción intensifica la presión sobre los recursos hídricos y sobre los sistemas de distribución, tanto en alta como en baja (Rico, 2007). La relación entre la promoción inmobiliaria y el consumo de agua potable da lugar a una gran diversidad de situaciones, si bien todas ellas ofrecen el denominador común de intensificar la presión sobre los recursos hídricos y sobre los sistemas de distribución.

En 2007, los estudios de demanda realizados por la MCT y la Confederación Hidrográfica del Segura, preveían que para el año 2018 se habrían construido 650.000 nuevas viviendas. Teniendo en cuenta esta previsión, el consumo de agua potable se elevaría hasta $340 \mathrm{hm}^{3} /$ año y haría necesario disponer de una capacidad de producción de agua desalinizada superior a $80 \mathrm{hm}^{3} /$ año para completar las fuentes convencionales. Estas previsiones no se han cumplido ya que para 2015 la MCT ha provisionado $185 \mathrm{hm}^{3}$.

Durante los años anteriores a la crisis que se inicia en 2008, la provincia de Alicante experimentó un extraordinario desarrollo de la construcción inmobiliaria, convirtiéndose este sector en el motor económico provincial. La liberalización del proceso urbanizador, originada por la Ley estatal del Suelo de 1998, confirmada por el Real Decreto Legislativo 2/2008, y potenciada en la Comunidad Valenciana por la Ley Reguladora de la Actividad Urbanística de la Comunidad Valenciana de 1994 (derogada por la Ley 16/2005, Urbanística Valenciana), se cuenta como una de las causas directas más importantes de este fenómeno.

El nuevo marco legislativo otorgó un elevado protagonismo a las empresas promotoras, en detrimento de la iniciativa pública y de la participación de los propietarios del suelo. La irrupción de la figura del agente urbanizador propició la presentación de innumerables programas para el desarrollo de actuaciones integradas, que iban acompañados de propuestas de aprobación de planificación urbanística diferida, a menudo modificativa de la planificación general. La relativamente fácil aprobación de planes parciales en el suelo urbanizable, y de reforma interior en el urbano no consolidado, facilitó el desarrollo de numerosas actuaciones urbanísticas muchas de las cuales estaban dirigidas a captar turismo residencial.

Estos procesos no tuvieron en cuenta, en muchos casos, la disponibilidad efectiva de recursos hidráulicos para sostener tales desarrollos. De hecho, pese a que tanto la legislación estatal del suelo como la autonómica valenciana contemplaban la necesidad de un informe de las Confederaciones hidrográficas, como paso previo para la aprobación de 
los planes, muchas veces dicho informe no constaba o, en otros casos, el informe negativo se contrarrestaba con informes favorables aportados por las suministradoras en baja. Estas prácticas fueron cuestionadas por el Tribunal Superior de Justicia de la Comunidad Valenciana en resoluciones ya bastante tardías, coincidentes con el final de la llamada "burbuja inmobiliaria". La falta de certidumbre derivada de la redacción de la normativa, tanto estatal como autonómica, que calificaban al informe de la Confederación como "determinante", rehuyendo la calificación de "vinculante", ayudó a que la disponibilidad de recursos hidráulicos no resultara en la práctica un factor limitante para estos desarrollos (Molina, 2008).

En la tabla 24 se aprecian claramente las consecuencias de estos procesos en la provincia de Alicante, con un ritmo de construcción muy elevado de unidades de vivienda en 2000, que sin embargo empieza a decaer en 2006.

\begin{tabular}{|c|c|c|c|c|c|c|}
\hline & \multicolumn{3}{|c|}{ Año 2000 } & \multicolumn{3}{c|}{ Año 2006 } \\
\cline { 2 - 7 } & Unifamiliar & En bloque & Total & Unifamiliar & En bloque & Total \\
\hline Alicante & 18.215 & 24.021 & 42.236 & 6.657 & 34.939 & 41.596 \\
\hline
\end{tabular}

Tabla 24. Evolución de la construcción de viviendas en las provincias abastecidas por la MCT (2000 y 2006) [Ministerio de Fomento, 2007.]

Un ejemplo muy significativo de estos procesos se observa en el municipio de Orihuela, en el que, gracias a la mayor disponibilidad de recursos hídricos, se ha podido sustentar un crecimiento urbanístico exponencial en los últimos años. El término municipal de Orihuela se configuró históricamente con grandes propiedades agrícolas de secano. Este espacio sufrió un cambio notable, por un lado, con la puesta en riego de numerosos terrenos tras la llegada del trasvase Tajo-Segura y, por otro, al hecho de que al extenderse el desarrollo urbano a la zona litoral, se generaron modernas urbanizaciones y nuevas zonas residenciales.

En las figuras siguientes se observa el cambio en las tipologías de suelo en los planes urbanísticos sucesivos que ha tenido el municipio. El incremento de los tipos de suelo con vocación residencial es extraordinario (suelos urbanos y urbanizables), especialmente en el litoral. 


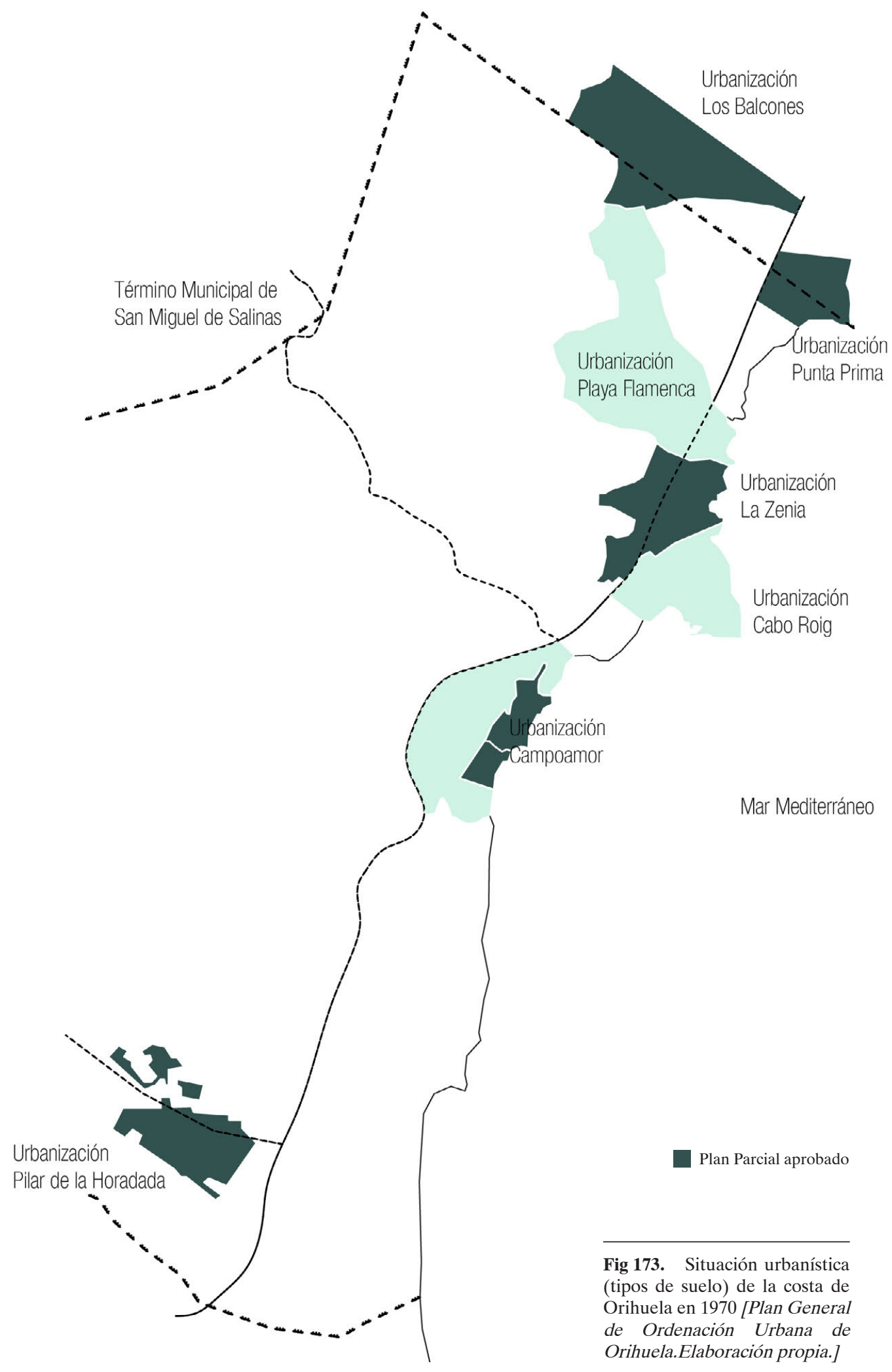




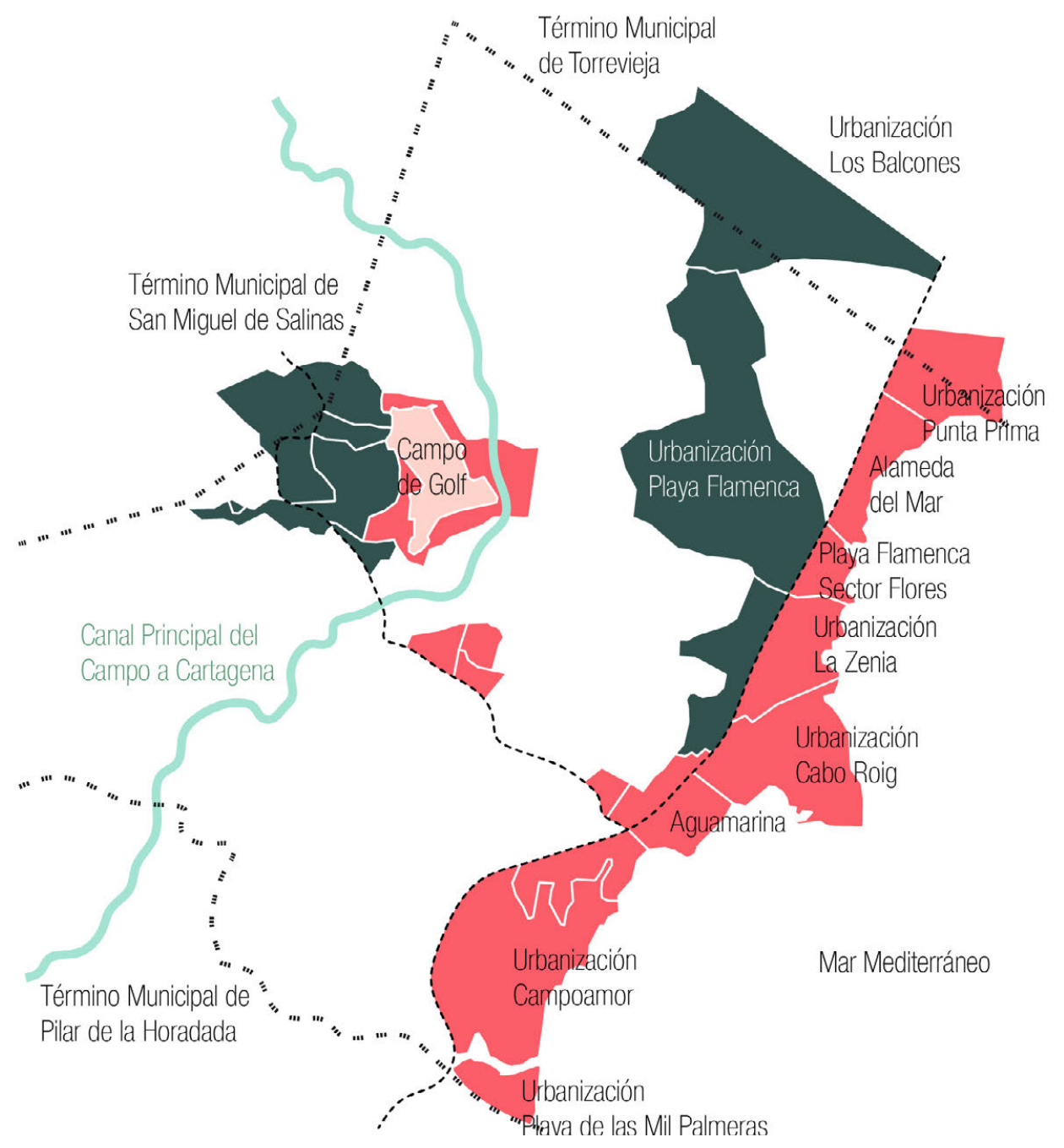

Suelo urbano

Suelo no urbanizable

Fig 174. Situación urbanística (tipos de suelo) de la costa de Orihuela en 1988 [Plan General de Ordenación Urbana de Orihuela.Elaboración propia.] 


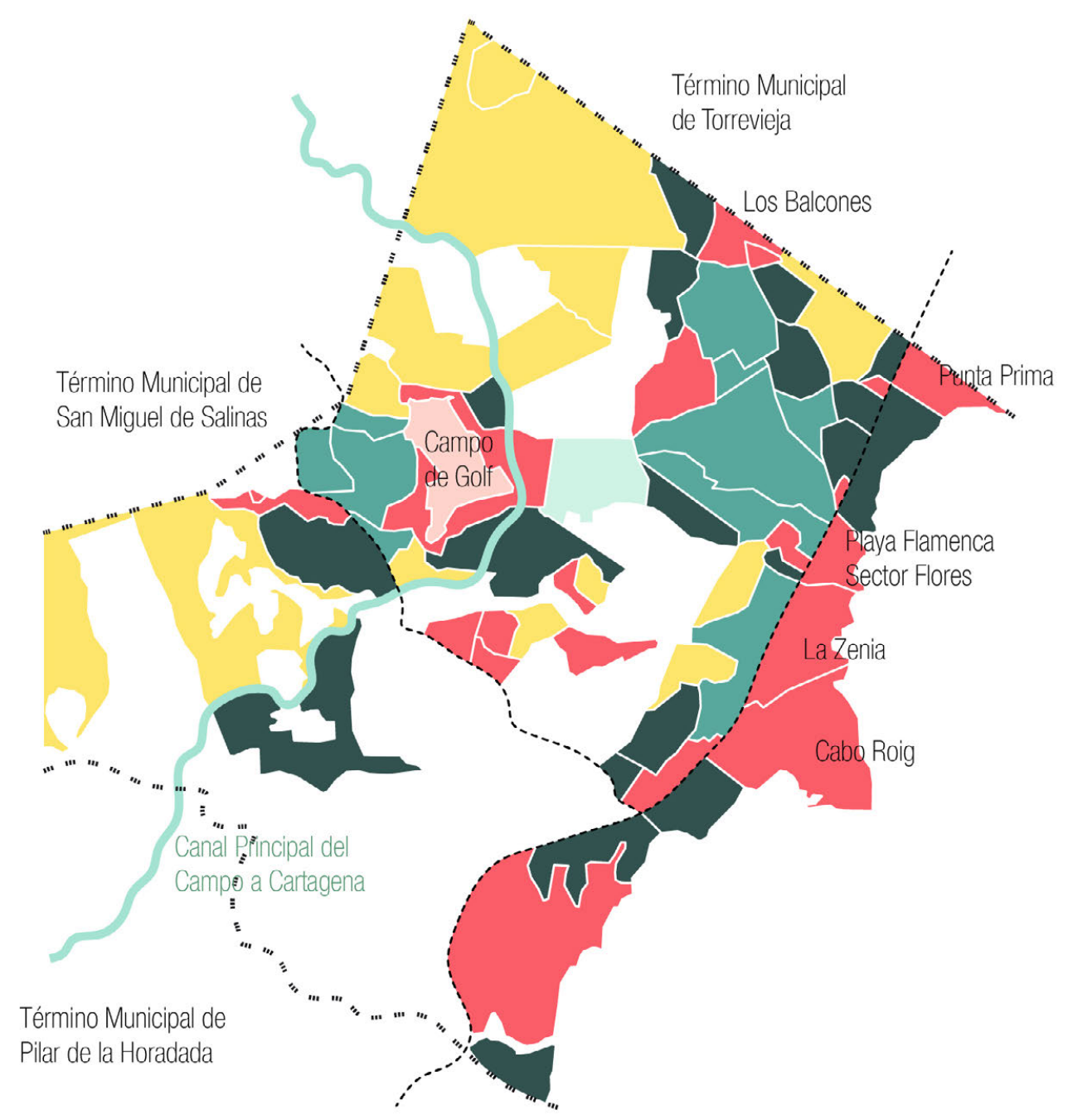

Suelo urbano

Suelo urbano ordenado pormenorizadamente

Con Plan Parcial aprobado

Con modificación de Plan Parcial aprobado antes del P.G. de 1990 Sin Plan Parcial

Suelo urbanizable no ordenado pormenorizadamente

Fig 175. Situación urbanística (tipos de suelo) de la costa de Orihuela en 1995 [Plan General de Ordenación Urbana de Orihuela.Elaboración propia.] 


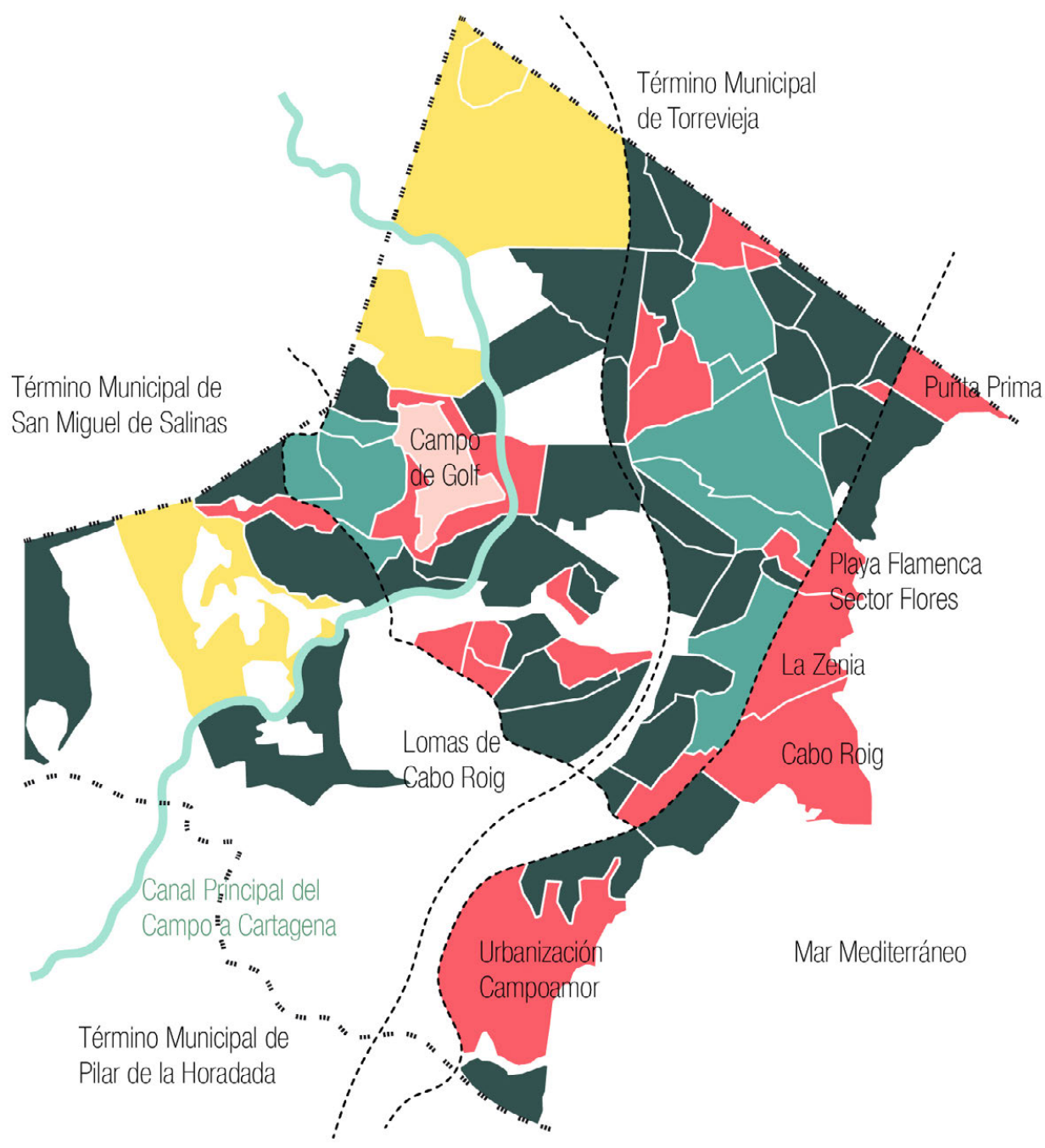

Suelo urbano

Suelo urbano ordenado pormenorizadamente

Con Plan Parcial aprobado

Con modificación de Plan Parcial aprobado antes del P.G. de 1990

Suelo urbanizable no ordenado pormenorizadamente

Fig 176. Situación urbanística (tipos de suelo) de la costa de Orihuela en 1988 [Plan General de Ordenación Urbana de Orihuela.Elaboración propia.] 
En 2011 la costa de Orihuela contaba con 468,25 ha de suelo urbano ordenado y 121,97 ha de suelo urbano sujeto a Plan Especial de Reforma Interior. Con todo, desde 2007, la promoción y el mercado inmobiliario experimentó una caída muy significativa en los ritmos vividos desde mediados de los años noventa del pasado siglo. La coyuntura económica internacional, el encarecimiento del precio del dinero, y las correcciones en la legislación urbanística, así como en su interpretación por los Tribunales, ponen fin al ciclo expansivo.

El escenario futuro hace prever un descenso en el ritmo de creación de nuevas ofertas residenciales, en lo que influye la situación económica global, la caída de ventas y la gran cantidad de viviendas en promociones que no han sido vendidas. Pero, en aras de la propia calidad del destino turístico y de su futura competitividad, habrá que seguir garantizando los abastecimientos actuales, en calidad y cantidad suficientes. Por tanto, aunque es previsible que la situación futura no se caracterice por grandes incrementos del parque de viviendas vacacionales, comparables a los ocurridos en la década anterior, si debe considerarse el efecto de la tendencia hacia un uso más frecuente de estas viviendas, lo que supondrá un incremento del consumo de agua.

A partir de las variables del planeamiento urbanístico vigente, de construcción de vivienda, y de las dinámicas demográficas, se estiman que en el horizonte del año 2025 la demanda podría superar en este espacio de la MCT los $320 \mathrm{hm}^{3} / \mathrm{año}$, frente a los $216 \mathrm{hm}^{3}$ que se suministraban en 2009. Este fuerte incremento del consumo de agua potable vendría motivado por la construcción de nuevas viviendas, destinadas a vivienda principal y segunda residencia. Así, en 2025, a pesar de que la dotación bruta por vivienda descenderá por la mayor eficiencia de la gestión, la Mancomunidad estaría obligada a incrementar las fuentes actuales de suministro en más de $100 \mathrm{hm}^{3} /$ año (Baños et al., 2010). No obstante, a tenor de lo sucedido entre 2010 y 2015, todo parece indicar que tales expectativas resultan de difícil materialización, y por tanto, con alta probabilidad, no se requerirá la totalidad del incremento de consumo señalado. Buena parte del planeamiento urbanístico en base al cual se establecen tales previsiones ha quedado en suspenso y previsible revisión.

En cuanto al desarrollo en el futuro de nuevos desarrollos inmobiliarios que requieran la aportación de nuevos recursos, el Plan hidrológico de la Demarcación del Júcar (20152021) prevé que: "Los incrementos de demanda urbana en el Alacantí y Bajo Vinalopó pueden ser atendidos con la capacidad remanente y con la ampliación de la desalinizadora de Mutxamel, mediante incrementos de aportaciones de la Mancomunidad de los Canales del Taibilla, y por la sustitución de recursos subterráneos utilizados para el riego con aguas procedentes de la reutilización. Los pequeños crecimientos esperados en el Alto y el Medio Vinalopó podrán atenderse con agua subterránea”. Ahora bien, según el artículo 25: "En los sistemas Júcar y Vinalopó-Alacantí no es posible atender con 
los recursos disponibles en la propia demarcación hidrográfica todos los derechos de agua existentes, las redotaciones y los posibles futuros crecimientos de demanda con las adecuadas garantías, y cumplir con el régimen de caudales ecológicos. Los balances realizados de acuerdo con el artículo 21 del Reglamento de la Planificación Hidrológica (RPH), muestran un déficit de $195 \mathrm{hm}^{3} /$ año en el sistema Júcar y de $70 \mathrm{hm}^{3} /$ año en el sistema Vinalopó-Alacantí. El déficit anterior se remite para su estudio y solución al Plan Hidrológico Nacional”.

Respecto a los territorios de la MCT incluidos en la demarcación del Segura, el artículo 14.7 del Plan hidrológico de esta Demarcación (2015-2021) establece: "Todo incremento de demanda urbana que excede el correspondiente al normal crecimiento de la población existente, conforme a las previsiones del INE, o que no pueda ser respaldado por las asignaciones anteriores, deberá ser abastecido mediante nuevos recursos externos o desalinizados. Sólo se admitirá la utilización de nuevos recursos, o la reasignación de recursos procedentes de la modificación de características de aprovechamientos preexistentes de la cuenca del Segura, en aquellos casos en los que no se tenga acceso a recursos externos o desalinizados sin incurrir en costes desproporcionados. Con independencia de la procedencia final del recurso, para estas nuevas demandas de abastecimiento deberá quedar garantizada a largo plazo la sostenibilidad de la explotación, tanto desde un punto de vista cuantitativo como cualitativo, denegándose cualquier solicitud que incumpla este requisito".

\subsection{Actividades industriales}

La provincia de Alicante, además de contar con un sector agrario de gran importancia, donde el regadío cobra un singular protagonismo, especialmente en la zona sur, es también un territorio dinámico en lo que a la actividad industrial se refiere. Industrias que, por otra parte, precisan de una garantía de suministro de agua para sus operaciones habituales, por lo que la MCT cumple un decisivo papel en el mantenimiento y progresión de este tejido productivo del máximo interés estratégico. En la figura 180 se aprecia la importancia de este tipo de actividad en los diferentes municipios del área abastecida por la Mancomunidad en la provincia de Alicante. 


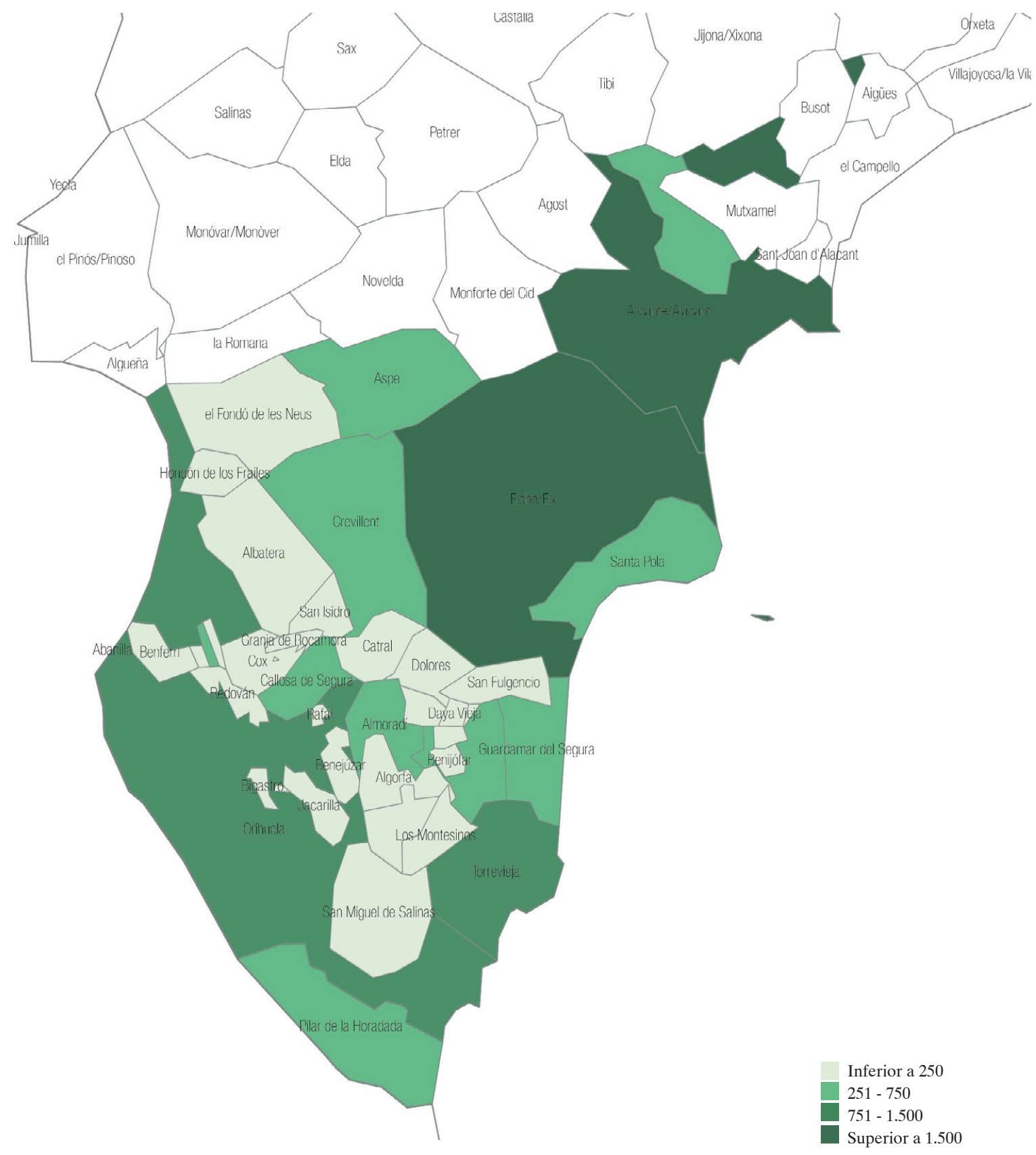

Fig 177. Actividades industriales en los municipios de la MCT [Elaboración propia.] 
Un caso particularmente relevante es el suministro de Elche Parque Empresarial (Torrellano), uno de los más importantes de España. El Proyecto inicial de "Elche, Parque Empresarial" nace a principio de los años noventa, con la intención de desarrollar un área industrial de alta calidad en un lugar estratégico. Fue promovido por el Ayuntamiento de Elche, a través de la empresa pública Promociones e Iniciativas Municipales de Elche, S.A. (PIMESA). Desarrollado en varias fases, ocupa en la actualidad una superficie de $2.700 .000 \mathrm{~m}^{2}$, Cuenta con unas 600 empresas instaladas de diferentes sectores de actividad y 11.000 trabajadores. El diseño urbanístico del Parque responde a las nuevas tendencias del urbanismo, la estructura viaria interna, la gran proporción de espacios abiertos, dotaciones y zonas verdes.

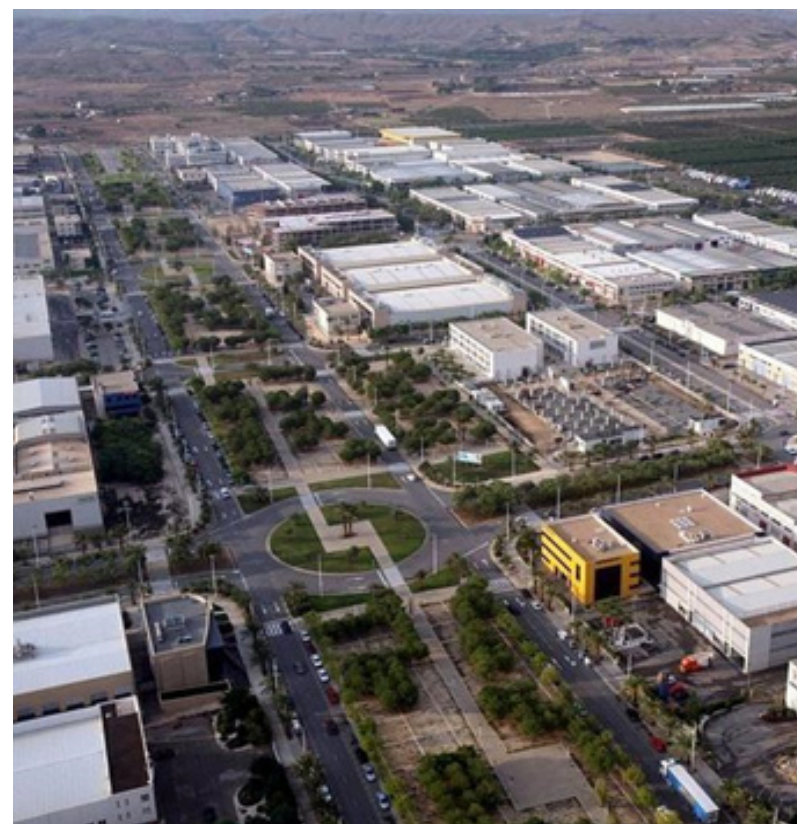

Fig 178. Fotografía aérea de Elche Parque Industrial [Diario La Verdad 7/2/2015.]

\section{5.- Comercio.}

La actividad comercial precisa, como es natural, de un suministro de agua garantizado, tanto para el desarrollo del propio sector como por el efecto de arrastre que produce en el desarrollo de otras actividades directamente relacionadas con la disponibilidad de recursos hídricos. Disponer de agua permite el crecimiento económico, incrementa la población, garantiza el turismo, el desarrollo de la actividad industrial, entre otros aspectos, y todo ello es un motor fundamental para el desarrollo del comercio. Esta actividad es ciertamente importante en los municipios del área de la MCT, con especial intensidad en los Municipios de Alicante y Elche, como se aprecia en la figura 179. 


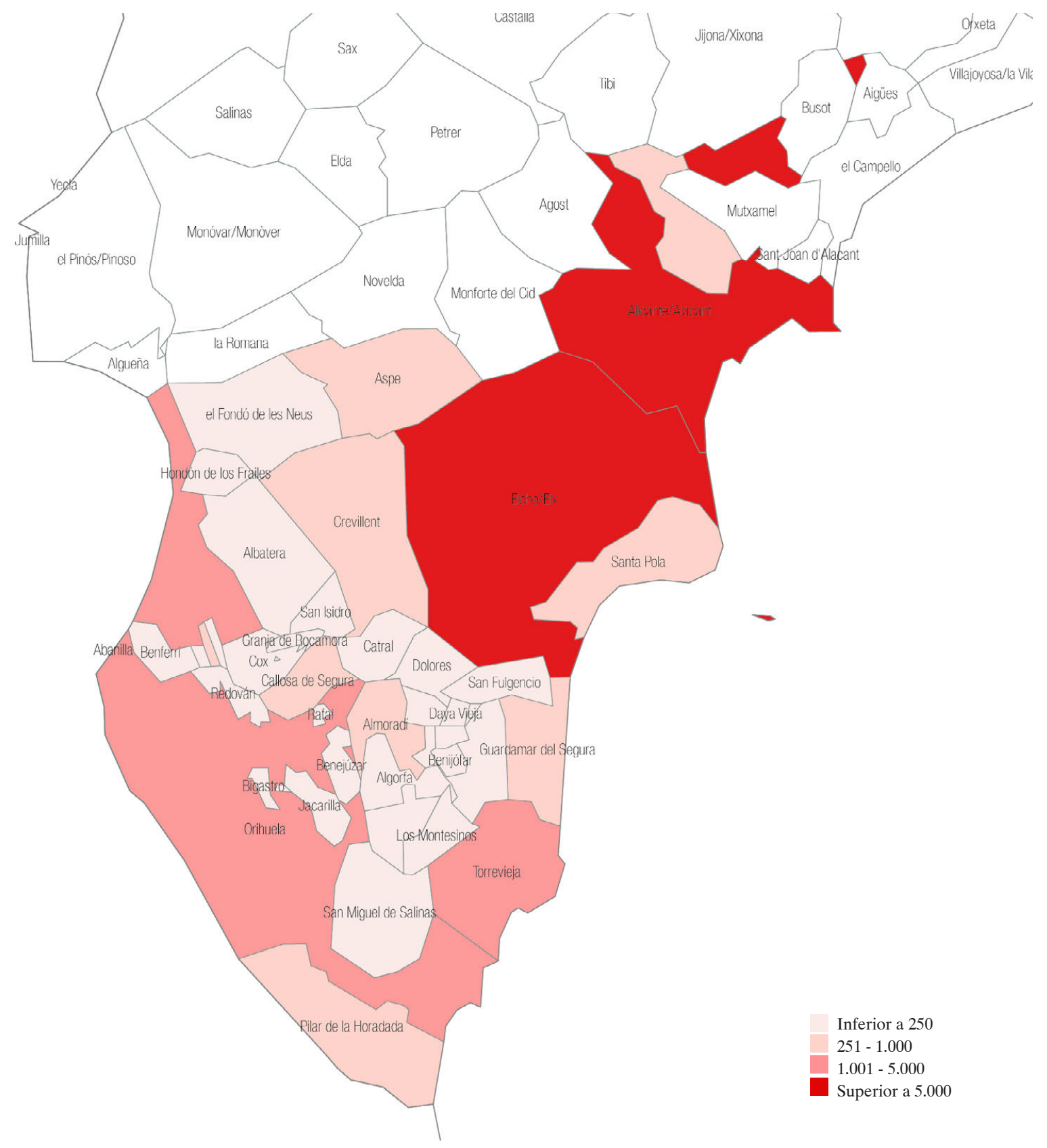

Fig 179. Importancia de las actividades comerciales en el área suministrada por la MCT [Conselleria de Economía Sostenible, Sectores Productivos, Comercio y Trabajo. Elaboración propia.] 


\section{0.- CONCLUSIONES.}

La gobernanza del agua no es otra cosa que la puesta en marcha de mecanismos jurídico-institucionales y económicos que permitan ordenar de manera eficiente la actividad desarrollada por todos los actores implicados en la gestión del agua. La gobernanza del agua precisa disponer de un marco jurídico e institucional acorde con los desafíos.

En este trabajo hemos mostrado una experiencia de gobernanza del mayor interés, puesto que ha permitido resolver las demandas crecientes de una zona extremadamente seca y de gran crecimiento económico, agrario, turístico, e industrial, con una demanda creciente de agua. Además, ha garantizado la calidad y la continuidad del abastecimiento urbano, lo que ha resultado extraordinariamente beneficioso para resolver problemas de índole higiénico-sanitario (algunas enfermedades relacionadas con la escasez y mala calidad del agua) y de confort; pocos bienes y servicios proporcionan tanta satisfacción como la regularidad y calidad del abastecimiento de agua potable, como la suministrada por la MCT.

Este Organismo tuvo en origen la función de garantizar el abastecimiento de la Base Naval de Cartagena, pero su estructura sirvió para asumir un reto mucho más ambicioso como es la distribución de los caudales a más de dos millones y medio de habitantes, que en época estival superan los tres millones de usuarios. Los convenios firmados entre la entidad y los Ayuntamientos de la zona han ido creciendo con el transcurso del tiempo, siendo cada vez más los municipios que han confiado la garantía de su suministro a esta Entidad, dado su buen hacer. La MCT abastece a un total de 79 municipios de las provincias de Albacete, Alicante y Murcia. Este proceso, que se inició en 1927, continúa abierto en la actualidad, ya que son permanentes las peticiones de ingreso, debido a las situaciones de riesgo de escasez o mala calidad que algunos municipios no integrados en el Organismo siguen padeciendo en el Sureste de España.

La Mancomunidad es un Organismo Autónomo del Estado, su naturaleza jurídica y marco institucional permiten abordar la actividad de gestión en alta del suministro. No se aprecian razones que justifiquen un cambio o alteración en dicha naturaleza, ni se han constatado datos que indiquen la conveniencia de procesos de privatización en la gestión de sus actividades, lo que en algún momento se ha planteado. Los Diputación provincial de Alicante y numerosos municipios alicantinos integrados en la MCT, a través de sus órganos representativos, expresaron su apoyo al mantenimiento del actual status jurídico-institucional de la Entidad. 
La eficiencia de la MCT ha permitido garantizar los suministros de agua potable a una región de las de mayor crecimiento, tanto demográfico como económico de España, superando para ello, la escasez endémica de recursos disponibles, el aumento del consumo, e incluso las incidencias negativas de los ciclos de sequía. Para ello se ha apostado por la tecnificación de la gestión de la red, así como por campañas de educación sobre el agua, fomentando la cultura de su uso eficiente.

La figura 180 muestra las variables más relevantes que han caracterizado el devenir de la MCT. Especial atención merece la diferente procedencia de los caudales, ya que, a los iniciales, provenientes del río Taibilla (afluente del Segura) en 1945, se sumaron los recursos llamados extraordinarios, de origen subterráneo, a partir de 1967, que sirvieron para complementar las aguas del Taibilla hasta que llegaron las procedentes del trasvase Tajo-Segura en 1979. Desde ese año, el Trasvase se convirtió en el principal sostén de Sistema, aportando de media entre el 50 y el $60 \%$ de la totalidad de los caudales servidos.

En el año 2000 el Trasvase suministró $145 \mathrm{hm}^{3}$ de los $198 \mathrm{hm}^{3}$ totales $(73,23 \%)$. A partir de ese año, de nuevo hubo que recurrir a los recursos extraordinarios, debido al incremento de la demanda y a la reducción de las aportaciones del Taibilla (el año que menos agua aportó de la serie histórica fue en 2008 con $36 \mathrm{hm}^{3}$ ). En este caso, a los recursos extraordinarios tradicionales, se sumaron los procedentes del Sinclinal de Calasparra (río Segura, Murcia), que en 2004 fueron $46 \mathrm{hm}^{3}$ (22, 12\% del total).

Desde 2003 se incorporan nuevos recursos procedentes de la desalinización de agua de mar, con los que se intentó hacer frente a las reducciones sufridas en el Taibilla, al mantenimiento creciente de la demanda y la reducción de los recursos provenientes del Trasvase, lo que estuvo motivado por la intensa sequía que afectó a la cabecera del Tajo. En 2009 las plantas desalinizadoras suministraron $73 \mathrm{hm}^{3}$ (33,95\%). Cuando el Taibilla se recuperó, como sucedió en 2013, los caudales desalinizados se redujeron a tan solo 6 $\mathrm{hm}^{3}(3,26 \%$ del total $)$.

Por su parte, la población abastecida ha pasado de 460.000 habitantes en 1960, con los municipios de Cartagena y la Base Naval, Alicante y Elche a la cabeza, a más de 2.400.000 en 2005; a los que habría que sumar los turistas y veraneantes sobre todo en época estival, que en ocasiones han superado los 3.000.000 de personas en el ámbito de la MCT.

La inversión acumulada, entre 1945 y 2005, ascendió a un total de 1.709 millones de euros de 2005. Con esta inversión se pudieron llevar a cabo las grandes infraestructuras que dan soporte a la red de la MCT. El Primitivo Plan de Obras que se desarrolló entre 1930 y 1974 requirió de 361 M€; el Plan de Ampliación ejecutado entre 1975 y 1999 precisó de $570 \mathrm{M€}$; por último, las plantas desalinizadoras y sus conexiones han conllevado una inversión de 778 M€ entre el año 2000 y el 2008. 
PRIMITIVO PLAN DE OBRAS

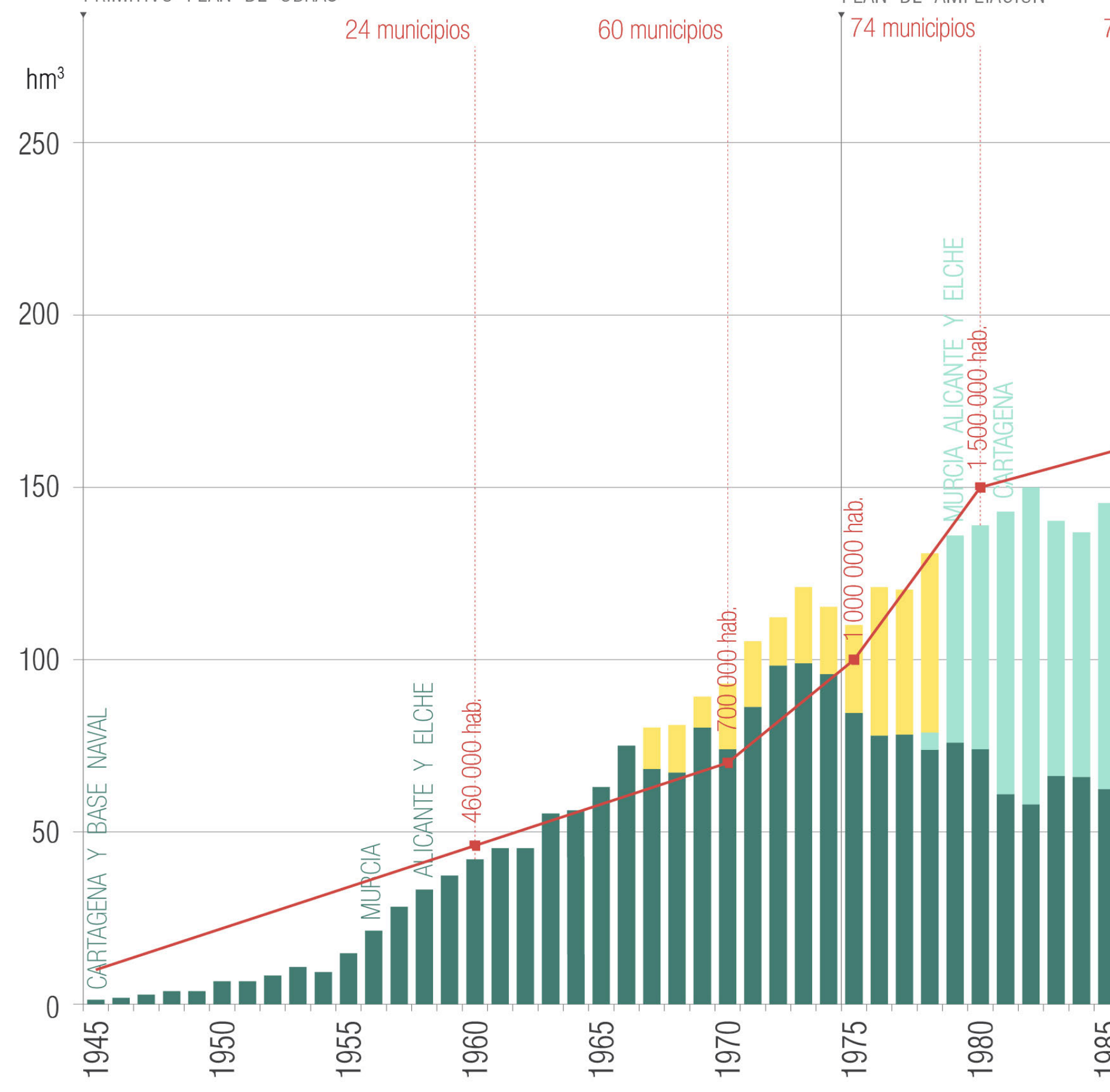




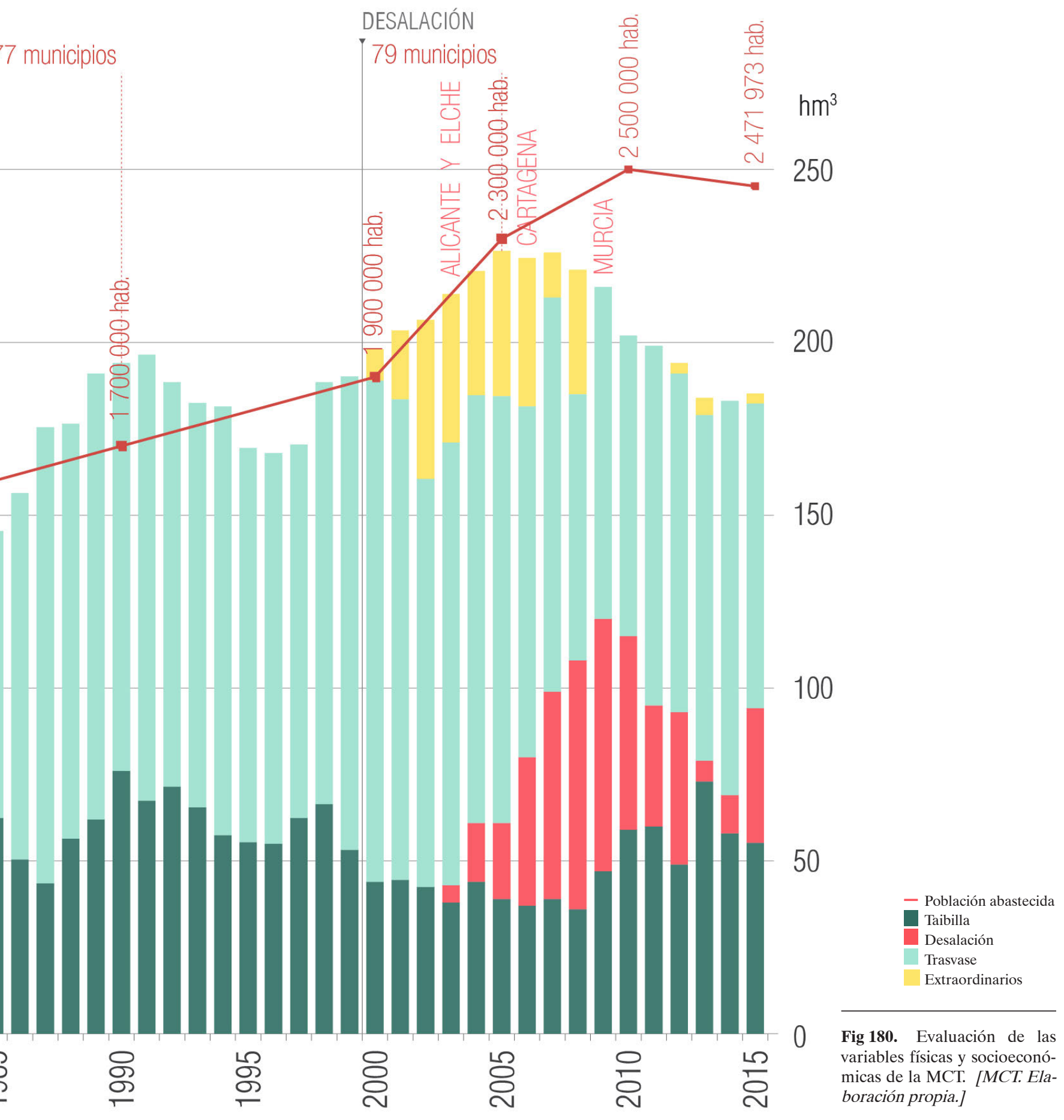


Para poder cumplir con sus cometidos y hacer frente a los gastos que ello suponía, desde muy pronto el Organismo contó con un instrumento económico que le ha posibilitado la búsqueda del equilibrio económico financiero: las tarifas, que consecuentemente han ido creciendo conforme se necesitaban más recursos para financiar los distintos proyectos de ampliación y para cubrir los gastos corrientes de funcionamiento de la MCT. Se ha pasado de una tarifa de $0,30 \mathrm{c} € / \mathrm{m}^{3}$ en 1945 a la actual, establecida en 2013, de 69,05 c€/ $\mathrm{m}^{3}$.

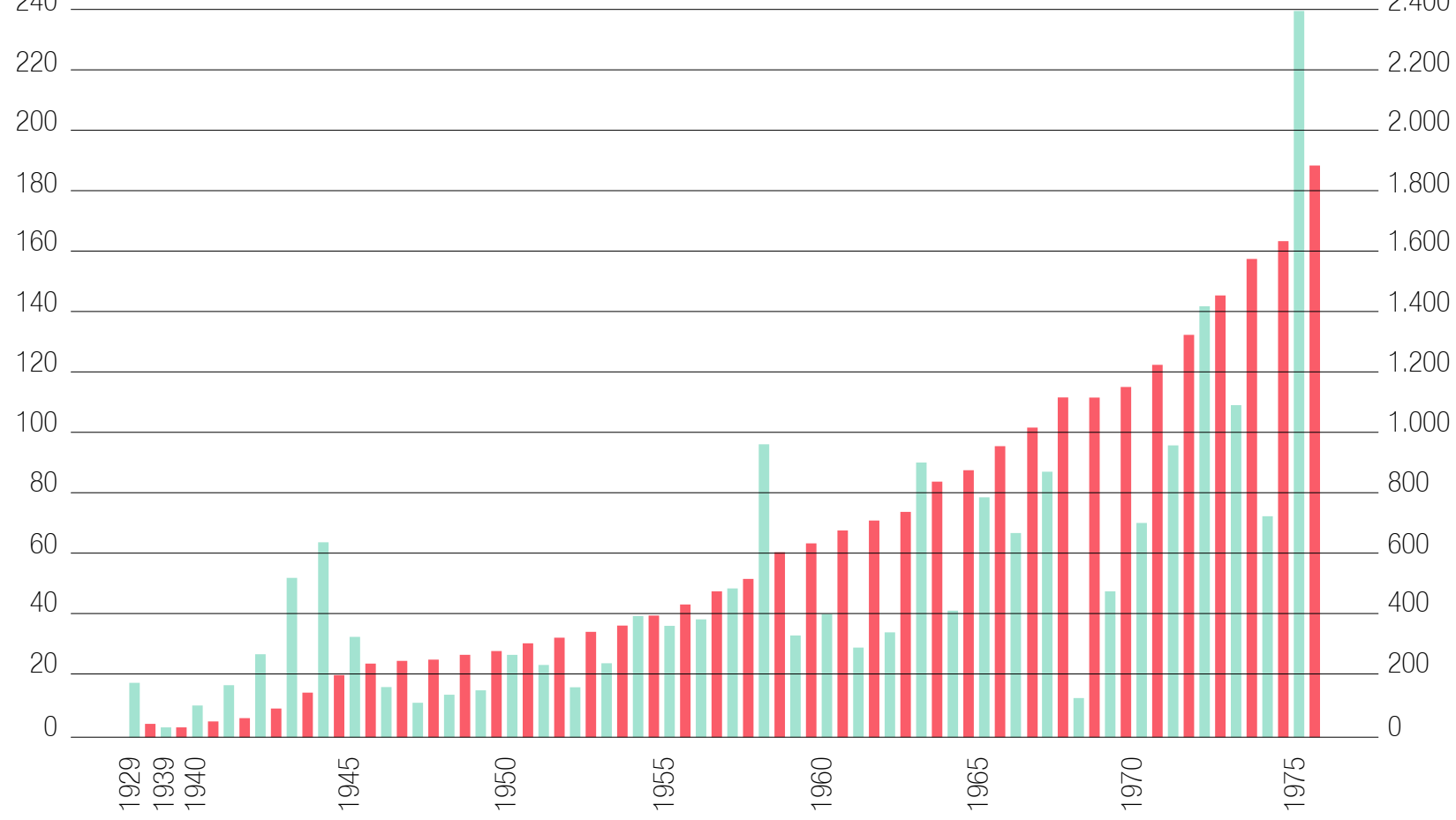

Fig 181. Inversiones reales 1929 - 1975 [Memoria MCT, 


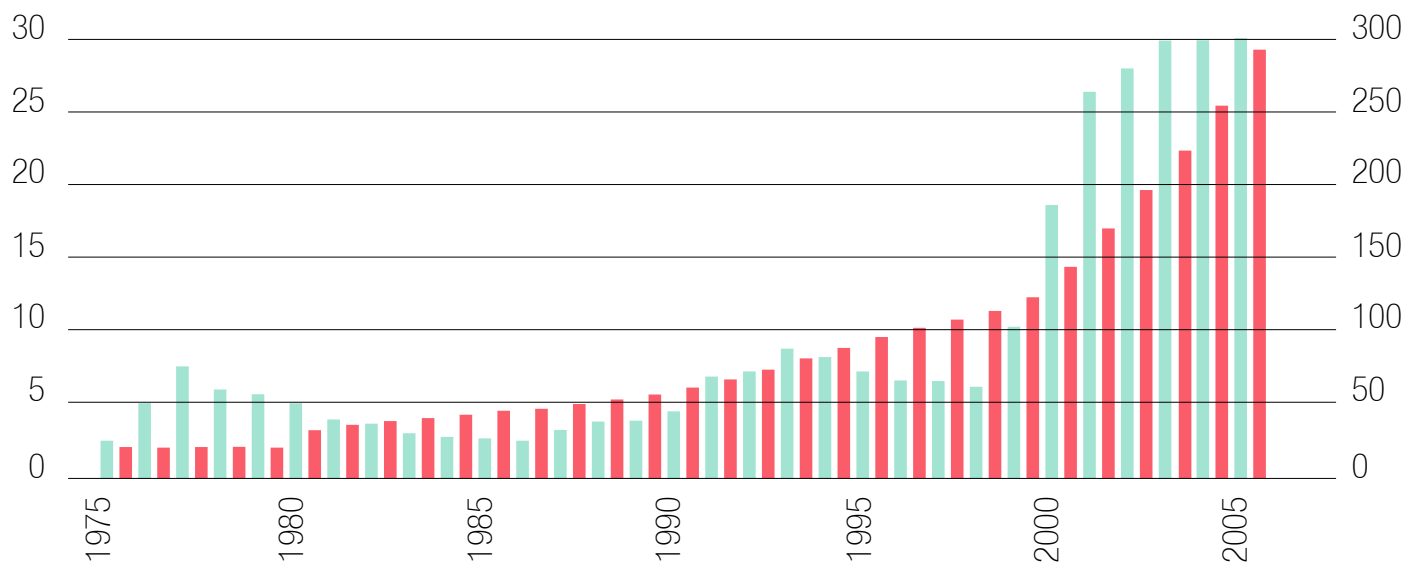

Fig 182. Inversiones reales 1975 - 2005 [Memoria MCT, 2005. Elaboración propia.]

La continuidad del Trasvase Tajo-Segura, que aporta una parte fundamental de los caudales que gestiona la MCT, no está ni mucho menos garantizada. La infraestructura soporta periódicamente los efectos de un debate político-territorial poco constructivo. En esta línea de buena gobernanza hay que destacar el papel del Memorándum del trasvase Tajo-Segura, que ha permitido consolidar el Trasvase sobre la base del acuerdo entre las regiones implicadas. De nada serviría contar con la MCT y su buen hacer si los caudales del Trasvase no llegan a la cuenca receptora. El Memorándum, luego transformado en Ley, ha permitido que todas las partes resultaran satisfechas con las nuevas reglas de explotación del Trasvase, en las que se evidencia la cesión en sus intereses tanto de los representantes de la cuenca receptora como de la emisora. Es de esperar que los conflictos sigan en el futuro encauzándose a través de mecanismos que se fundamenten en el pacto entre las diferentes instituciones políticas y territorios. Sólo así podrán superarse las diferencias dando satisfacción a todas las partes. Los pactos, además, necesitan de un buen marco jurídico e institucional que les de soporte, lo que se ha logrado con el nuevo marco legislativo (LEA), y el mantenimiento de la MCT en la organización de las aguas trasvasadas.

Por otra parte, la flexibilización del marco legal que regula los contratos de cesión y centros de intercambio de derechos de agua constituyó una buena noticia para la MCT, que puede encontrar en estos instrumetnos una fórmula adecuada para complementar las dotaciones en aquellos años en los que, como consecuencia de la sequía, las aportaciones 
de caudales resulten insuficientes. Además, la adquisición de agua suele generar una menor oposición, ya que las compensaciones económicas pueden llegar a ser elevadas. Sería deseable que, junto a los contratos bilaterales, en los que la MCT ya cuenta con una experiencia favorable, la propia Administración hidráulica incentivara la creación de centros de intercambio de derechos, de modo que la Administración dirija el proceso de reasignación de caudales.

El hecho de que algunos municipios importantes integrados en la MCT se encuentran en la Demarcación del Júcar ha hecho que en determinados momentos críticos, y de forma extraordinaria, el Organismo recurriera a la Confederación del Júcar para articular la cesión de caudales de dicha Cuenca desde el embalse de Alarcón hacia estos municipios. Es decir, agua del Júcar, para la Demarcación del Júcar, utilizando la infraestructura de la MCT. Además, en algunos casos ha habido aguas del Júcar para resolver problemas en la Marina Baja, a través de las conducciones de la MCT y del Canal Rabasa-FenollarAmadorio (Alicante-Benidorm).

Desde 2003, los caudales producidos por las desalinizadoras gestionadas por la MCT, Alicante I y II, y San Pedro del Pinatar I y II, han contribuido decisivamente a cubrir el incremento de la demanda en un contexto de reducción de las aportaciones tradicionales de la MCT. Esto ha permitido además la incorporación de nuevos municipios alicantinos al Organismo, como es el caso de Aspe, Hondón de las Nieves y Hondón de los Frailes, así como consolidar las dotaciones del resto de municipios y de sus ampliaciones.

La población abastecida en el área de la MCT de la provincia de Alicante ha crecido exponencialmente por efecto de la entrada de nuevos municipios, el crecimiento demográfico, sustentado en buena medida por el desarrollo de las actividades económicas, la construcción y el turismo. Junto a ello, los nuevos modelos residenciales de baja densidad, presentes en numerosos municipios, han favorecido el incremento de las dotaciones necesarias.

Resulta pertinente agrupar los municipios alicantinos en varias categorías debido a sus características homogéneas, en primer término, los grandes municipios, menos afectados por el crecimiento del turismo residencial: Alicante, Elche y Orihuela, en segundo término, los municipios del litoral; tercero, los del prelitoral; cuarto, los del interior; y finalmente, los del Medio Vinalopó (Aspe, Hondón de las Nieves y Hondón de los Frailes. Del total poblacional de la provincia de Alicante, los habitantes servidos gracias a las aguas suministradas en alta por la MCT se aproximan en el año 2015 al $40 \%$ de la población total de la provincia. Este porcentaje es una clara muestra de la importancia de este Organismo para el sostenimiento de las demandas de agua urbana en la provincia. En 2013, la demanda total de agua de la Mancomunidad se situó en 183,9 $\mathrm{hm}^{3}$, de los que 74,1 $\mathrm{hm}^{3}$ corresponden a la provincia de Alicante, un 40,3\% del total. 
El consumo de agua en la provincia de Alicante, en especial en la zona sureste, se ha venido incrementando progresivamente en los últimos años, planteando continuamente nuevas demandas. No obstante, dicho crecimiento no ha sido tan exponencial como podría esperarse atendiendo al notable desarrollo socioeconómico de esta zona, sobre todo por el crecimiento del turismo residencial. A partir de 2006, las dinámicas se invierten, y observamos reducciones significativas en las demandas de muchos municipios. En los últimos años el agua suministrada por la MCT se ha contenido e incluso reducido significativamente, por efecto de la mejora de los rendimientos técnicos. Los efectos de la crisis económica iniciada en 2008 también se han hecho sentir en dicha reducción de los consumos. En localidades como Alicante o Torrevieja, el volumen de agua suministrado en alta ha descendido entre el 11 y $5 \%$ entre 2011 y 2013, y el consumo doméstico de agua un $20 \%$ desde principios de la década del 2000.

La MCT ha tenido que incrementar la tarifa que cobra a los municipios para mantener su equilibrio financiero tras la entrada en funcionamiento de las desalinizadoras. Estos acuerdos, adoptados por el Consejo de Administración de la Entidad, han contado con la oposición de los representantes de los municipios; un rechazo habitual en los últimos años. Los mayores costes derivados de la producción de estos recursos, a pesar de que la generación de agua ha estado muy por debajo de la capacidad total instalada, han obligado a adoptar esta medida. Conforme estas plantas se vean obligadas a producir más recursos, ante las reducciones de las aportaciones tradicionales y, significativamente, del trasvase Tajo-Segura, cuya regulación tras la LEA ha supuesto una limitación importante de las dotaciones anteriores, es previsible que en los próximos años nos encontremos con sucesivos incrementos en los precios del suministro.

Previo a la llegada de la MCT, el Sureste de España estaba aquejado de graves problemas higiénicos-sanitarios, parte de los cuales se debían a la escasez de recursos hídricos y de infraestructuras (abastecimiento y saneamiento) que posibilitaran la llegada de agua potable a los domicilios. La intervención de la MCT ha permitido superar este tipo de problemas al garantizar un suministro continuo, regular, y con la debida calidad físico-química. La labor de la MCT desde sus inicios hasta la actualidad ha sido capital para conseguir que la esperanza y calidad de vida de los ciudadanos por ella abastecidos sea una de las más altas del país. Superados los problemas de índole higiénico-sanitarios que afectan a las zonas con escasez y mala calidad de los recursos hídricos, la siguiente conquista fue la del confort, que se manifiesta en la calidad y regularidad del servicio.

Podemos afirmar, que tanto la MCT como el Aeropuerto de Alicante-Elche son los dos pilares sobre los que se sustenta el desarrollo turístico de la provincia de Alicante; sin los cuales difícilmente podría explicarse el éxito del modelo turístico alicantino. 
Las actividades de ocio, turismo y segundas residencias han adquirido una importancia de primer orden en la evolución de las demandas de agua. El agua es un recurso vital para la actividad turística, fundamental por tanto en el caso de la provincia de Alicante, en especial en el litoral. En un espacio que abarca $1.828 \mathrm{~km}^{2}$ y que representa el 31,4\% del espacio provincial, se concentra el $20 \%$ de las plazas regladas de oferta turística de la Costa Blanca y casi el 50\% de la oferta residencial. Las plazas en hoteles, hostales, apartamentos turísticos, camping, casas rurales y albergues, son una parte minoritaria dentro del conjunto de la oferta del área MCT. El factor realmente determinante y caracterizador en esta zona es el alojamiento en unidades residenciales extrahoteleras. El área suministrada cuenta por otra parte con 9 campos de golf que favorecen la diversificación de la oferta, y a cuyo mantenimiento la MCT contribuye indirectamente con las aguas en alta que luego son regeneradas para su reutilización.

El abastecimiento de las áreas turísticas, como parte del suministro a poblaciones, es determinante en la orientación del producto turístico de esta región. Desde muy pronto, la MCT cobra conciencia de la importancia que el turismo tendrá en el incremento de los consumos, y de las consiguientes dotaciones gestionadas por el Organismo. Todo este sistema turístico-residencial sería imposible sin los recursos que aporta el sistema de la MCT, ya que los recursos endógenos son estructuralmente insuficientes para acoger estas demandas crecientes. La relación entre ambos factores, a saber, la incorporación de estos municipios a la MCT, y la explosión de su desarrollo turístico residencial, se observa de manera evidente en localidades como Torrevieja, Rojales, San Fulgencio, Santa Pola, El Pilar de la Horadada, Guardamar del Segura, entre otras. También la propia ciudad de Alicante, y el crecimiento de ámbitos del término municipal de Elche como Arenales del Sol o La Marina, se alinean con la creciente disponibilidad de recursos suministrados por la MCT.

El escenario futuro hace prever un descenso en el ritmo de creación de nuevas ofertas residenciales, debido a la situación económica global, la caída de ventas y la gran cantidad de viviendas en promociones que no han sido vendidas. Es previsible que la situación futura no se caracterice por grandes incrementos del parque de viviendas vacacionales, comparables a los ocurridos en la década anterior, pero si debe considerarse la tendencia hacia un uso más frecuente de las viviendas vacacionales, lo que supondrá un incremento del consumo de agua.

A partir del planeamiento urbanístico vigente, y de las dinámicas demográficas, se había estimado que en el horizonte del año 2025 la demanda podría superar en este espacio de la MCT los $320 \mathrm{hm}^{3} /$ año, frente a los $216 \mathrm{hm}^{3}$ que se suministraban en 2009 . No obstante, a tenor de lo sucedido entre 2010 y 2015, todo parece indicar que tales expectativas resultan de difícil materialización, y por tanto, con alta probabilidad, no se requerirá la totalidad del incremento de consumo señalado. Buena parte del planeamiento urbanístico en base al cual se establecen tales previsiones ha quedado en suspenso y previsible revisión. 




\section{BIBLIOGRAFÍA.}

AEAS-AGA (2014). XIII Encuesta de Suministro de Agua Potable y Saneamiento en España.

AGUILAR, G. e IZA, A. (2006) Gobernanza de aguas compartidas: aspectos jurídicos e institucionales. UICN-Mesoamérica. 59 p.

ALBIOL OMELLA, C. Y BRU ANGELATS, A. (2013) Estudio sobre el precio del agua en España, AQUAE-PAPERS, no 1 .

ALBIOL, C. y AGULLÓ, F. (2014) La reducción del consumo de agua en España: causas y tendencias. Aquaepapers, Aquae Fundación, 6, 70 p.

ÁLVAREZ FERNÁNDEZ, M. (2004) El abastecimiento de agua en España, Cívitas. Madrid.

AMAEM (2009) Fuentes públicas de la ciudad de Alicante. 285 p.

AYANZ, J., PLAZA, A. (2009) Importancia del Trasvase Tajo-Segura en el abastecimiento del sureste español. En MELGAREJO, J. (Dir.). El Trasvase Tajo-Segura: repercusiones económicas sociales y ambientales en la cuenca del Segura. Alicante, CAM, 307-343.

BAÑOS CASTIÑEIRA, C.J. (2014) Los espacios del golf en la provincia de Alicante. Entre la diversificación turística y las inercias inmobiliarias. En: Libro jubilar en homenaje al profesor Antonio Gil Olcina. Ed: Olcina Cantos, J. y Rico Amorós, A. Publicaciones de la Universidad de Alicante, 1.301-1.317.

BAÑOS CASTIÑEIRA, C.J.; VERA REBOLLO, J.F. y DÍEZ SANTO, D. (2010) El abastecimiento de agua en los espacios y destinos turísticos de Alicante y Murcia. Investigaciones Geográficas, 51, 81-105.

BRU RONDA, C. (1993) Los recursos de agua. Aprovechamiento y economía en la provincia de Alicante. CAM.

BURRIEL DE ORUETA, E. (2008) La década prodigiosa del urbanismo español (1997-2006). Scripta Nova, vol. XII, 270 (64). Disponible en: http://www.ub.es/geocrit/sn/ sn-270/sn-270-64.htm

CALATRAVA, J; MARTÍNEZ-GRANADOS, D. (2016) La actividad de los mercados formales de agua en la cuenca del Segura. XXXIV Congreso Nacional de Riegos, Sevilla pp 45-459. http://dx.doi.org/10.21151/CNRiegos.2016 
CALVO MIRANDA, J.L. (2010) "Abastecimiento de agua potable y saneamiento de las aguas residuales urbanas en España”. Revista Aragonesa de Administración Pública, no 36 .

CÁNOVAS, J. y MELGAREJO, J. (Coords.) (2002) La Confederación Hidrográfica del Segura 1926-2001. 75 Aniversario. Ministerio de Medio Ambiente. Murcia.

CARRILLO DE LA ORDEN, I. (1995) El abastecimiento urbano. La Mancomunidad de los Canales del Taibilla. En SENENT, M. y CABEZAS, F.: Agua y futuro en la Región de Murcia. Asamblea Regional de Murcia. Murcia. pp. 221-235.

CARRILLO DE LA ORDEN, I. (2002) El abastecimiento urbano. La Mancomunidad de los Canales del Taibilla. En CÁNOVAS, J. y MELGAREJO, J. (Coords.): La Confederación Hidrográfica del Segura (1926-2001), Ministerio de Medio Ambiente, Murcia, 279-289.

CARRILLO DE LA ORDEN, I. y MIRÓN LÓPEZ M. (2004) La Mancomunidad de los Canales del Taibilla. En Gil Olcina, A. (dir): La Cultura del Agua en la Cuenca del Segura. Ed. Cajamurcia. Murcia. pp. 199-220.

COLE, S. (2012) A political ecology of water equity and tourism: a case study from Bali. Annals of Tourism Research, 39, 2, 1.221-1.241.

CUBILlO GONZÁLEZ. F. (2001) Uso y Gestión Eficiente del Agua en Abastecimientos Urbanos. Revista de Obras Públicas, Octubre 2001 № 3.414, pp. 127136.

DIPUTACIÓN DE ALICANTE (2007) Ciclo Hídrico. Mapa del Agua de la Provincia de Alicante. $2^{\underline{a}}$ ed.

EZCURRA CARTAGENA, J. (2002) El trasvase Tajo-Segura. En CÁNOVAS, J. y MELGAREJO, J. (Coords.): La Confederación Hidrográfica del Segura (1926-2001), Ministerio de Medio Ambiente, Murcia, 261-278.

FANLO LORAS, A. (2008) (Coord.) La ordenación jurídica del Trasvase Tajo-Segura. Instituto Euromediterráneo del Agua, Murcia.

FONT, J. y PARRADO, S. (2000) Eligiendo socios en la Administración municipal española: los consorcios y las mancomunidades, Cuadernos de Gobierno y de Administración, núm. 3.

FERNÁNDEZ-MONTES， C.; TORREGROSA，J.; GONZÁLEZ， A. (2004) "Demanda hídrica consolidada y evolución esperada. Abastecimientos e industria". En Melgarejo, J. (Ed.). Repercusiones socioeconómicas del Plan Hidrográfico Nacional en la provincia de Alicante. Alicante. Fundación COEPA, 163-205. 
GIL OLCINA, A.(Dir.) (2000) Cartografía temática de las tierras alicantinas. Instituto Universitario de Geografía. Universidad de Alicante.

GIL OLCINA, A. (2010) Optimización de recursos hídricos y armonización de sus usos: el Consorcio de Aguas de la Marina Baja. Investigaciones Geográficas, 51, 165-183.

GIL OLCINA, A. y MORALES GIL, A. (eds.) (1988) Demanda y economía del agua en España, Caja de Ahorros del Mediterráneo, Alicante, 498 pp.

GIL OLCINA, A. y MORALES GIL, A., (eds.) (1995) Planificación Hidráulica en España. Fundación Caja del Mediterráneo. Alicante. 430 pp.

GIL OLCINA, A. y MORALES GIL, A. (Eds.) (1999) Los usos del agua en España. Alicante, Universidad de Alicante y Caja de Ahorros del Mediterráneo.

GIL OLCINA, A. y RICO AMORÓS, A.M. (2007) El problema del agua en la Comunidad Valenciana. Valencia, Fundación Agua y Progreso de la Comunidad Valenciana.

GIL OLCINA, A. y RICO AMORÓS, A.M. (2008) Políticas del Agua II. Mejora y Ampliación de los Riegos de Levante. ESAMUR y EPSAR, Murcia.

GIL OLCINA, A.; HERNÁNDEZ HERNÁNDEZ, M.; MOROTE SEGUIDO, A.F.; RICO AMORÓS, A.M.; SAURÍ PUJOL, D. y MARCH CORBELLA, H. (2015) Tendencias del consumo de agua por uso doméstico y grandes abonados, entre 2007-2013, en la ciudad de Alicante y Área Metropolitana de Barcelona. HIDRAQUA, Gestión Integral de Aguas de Levante, S.A. y Universidad de Alicante.

GONZÁLEZ GÓMEZ, F. (2005) El precio del agua en las ciudades. Reflexiones y recomendaciones a partir de la Directiva 2000/60/CE. Ciudad y territorio. Estudios Territoriales, XXXVII (144), Ministerio de Vivienda, 305-321.

GONZÁLEZ SEVILA, S. (2013) El agua de La Alcoraya. http://www.elche.me/sites/ default/files/el_agua_de_la_alcoraya_a_elche.pdf

GÖSSLING, S., PEETERS, P. HALL, C.M., CERON J.P. DUBOIS, G., LEHMANN, V., SCOT, D. (2012) Tourism and water use: Supply, demand, and security. An international review, Tourism management, 33, pp. 1-15.

GRINDLAY, A.A., RODRIGUEZ, M.I., MOLERO, F.E. (2008) Infraestructuras de abastecimiento y suburbanización en la cuenca del Segura: la transformación de las huertas tradicionales. Congreso Internacional Paisaje e Infraestructuras, Granada. 
HERNÁNDEZ, M. y MORALES GIL, A. (2008) Trascendencia socio-económica del trasvase Tajo-Segura tras 30 años de su funcionamiento en la provincia de Alicante. Investigaciones Geográficas, 46, 31-48.

HERNÁNDEZ HERNÁNDEZ, M. (2013) Análisis de los procesos de transformación territorial en la provincia de Alicante (1985-2011) y su incidencia en el recurso hídrico a través del estudio bibliográfico, Documents d'Anàlisi Geogràfica, no 59 (1), 105-136.

HERNÁNDEZ, Ma.., SAURI, D. y MORALES, A. (2015) Auge y caída de nuevas naturalezas urbanas: plantas ornamentales y expansión turístico-residencial en Alicante. Boletín de la AGE, pp 129-157.

IBARRA Y RUIZ, P. (1914) Estudio acerca de la institución del riego en Elche. Madrid.

INE (2015). Encuesta sobre el Suministro y Saneamiento del Agua, año 2013.

INTEGRATED WATER RESOURCES MANAGEMENT IN ACTION. WWAP, DHI Water Policy, PNUMA-DHI (2009). Centro para el Agua y el Medio Ambiente.

JUÁREZ SÁNCHEZ-RUBIO, C. (2008) Indicadores hídricos de sostenibilidad y desarrollo turístico y residencial en la Costa Blanca. Boletín de la Asociación de Geógrafos Españoles, 47, 213-243.

MARCH, H.; SAURÍ, D. y RICO, A.M. (2014) The end of scarcity? Water desalination as the new cornucopia for Mediterranean Spain. Journal of Hydrology, 519, 2642-2652.

MATÉS BARCO, J.M (2001) Evolución y cambio en el abastecimiento urbano: del sistema clásico al moderno. Universidad de Jaén.

MATÉS BARCO, J.M. (2008) Las empresas de abastecimiento de agua en la región levantina (1850-1939). IX Congreso de la AEHE, Murcia

MELGAREJO, J. (dir.) (2009) El trasvase Tajo-Segura: repercusiones económicas, sociales y ambientales en la cuenca del Segura. Edición de la Caja de Ahorros del Mediterráneo, Alicante.

MELGAREJO, J., MOLINA, A. (2005) (dir.) Los mercados del agua. Aranzadi, Pamplona.

MELGAREJO, J. MOLINA, A. BLANES, M.A. (2005) Análisis jurídico y económico de la Sentencia del Tribunal Supremo de 20 de octubre de 2004 por la que se anulan diversos artículos del Plan Hidrológico de la cuenca del Júcar. Revista Aranzadi de Derecho Ambiental, pp. 129 - 156. 
MELGAREJO, J.; LÓPEZ ORTIZ, Ma I. (2008).iSon los contratos de cesión de derechos y los bancos de agua instrumentos convenientes para mejorar la gestión del agua?. Tractat de l'aigua, no1, 54-62.

MELGAREJO J. y LÓPEZ, M.I. (2009) Historia del trasvase Tajo-Segura, en Melgarejo J. (Dir.), El trasvase Tajo-Segura: repercusiones económicas, sociales, y ambientales en la cuenca del Segura. Ed. Caja Mediterráneo. Alicante, pp. 37-113.

MELGAREJO J., MOLINA A y DEL VILLAR A. (2009) La responsabilidad patrimonial del Estado ante la hipotética reducción o cancelación del trasvase TajoSegura, Revista Aranzadi de Derecho Ambiental, no 16.

MELGAREJO J., MOLINA A y DEL VILLAR A. (2010) El Valor socioeconómico del Trasvase Tajo-Segura, COEPA/INECA, Alicante.

MELGAREJO, J., MOLINA, A. y LÓPEZ, Mạ. I. (2014) El memorándum sobre el Trasvase Tajo-Segura. Modelo de resolución de conflictos hídricos, Revista Aranzadi de Derecho Ambiental, no 29, septiembre-diciembre.

MELGAREJO, J., MOLINA, A. y LÓPEZ, Mạ. I. (2015) La Mancomunidad de los Canales del Taibilla, MCT. Garantía del abastecimiento en el Sureste de España. En A. ORTUÑ (Eds.), Cómo se gestiona una ciudad. Publicaciones de la Universidad de Alicante, pp. 165-189.

MELGAREJO, J., MOLINA, A. (2017) Gobernanza y sostenibilidad en el abastecimiento urbano. La Mancomunidad de los Canales del Taibilla (MCT), España. En prensa.

MELGAREJO J. y LÓPEZ, M.I. (2016) La economía del ciclo urbano del agua en España. En: Desafíos del Derecho de Aguas (Navarro, T.M., (ed). Aranzadi, pp. 144-182.

MELGAREJO, J., MOLINA, A. (2016) La gestión del agua urbana en España. modelos de éxito en las regiones semiáridas del Sureste peninsular. En: Una mirada multidisciplinar en relación a la presentación de los servicios públicos. Corporación de Estudios y publicaciones, Quito, Ecuador, pp. 57-96.

MIMAM (2010) Libro Blanco del Agua

MINISTERIO DE MEDIO AMBIENTE Y MEDIO RURAL Y MARINO (MMA) (2007) "Precios y Costes de los Servicios de Agua en España. Informe integrado de recuperación de costes de los servicios de agua en España”, Madrid: MMA.

http://hispagua.cedex.es/sites/default/files/especiales/Tarifas_agua/precios_costes_ servicios_\%20agua.pdf 
MOLINA, A. (2008) Comentarios sobre la naturaleza del informe sobre disponibilidad de recursos hidráulicos en actuaciones urbanísticas, a la luz de la jurisprudencia cautelar y sustantiva valenciana. Revista Aranzadi de Derecho Ambiental, no 14.

MOLINA, A. y MELGAREJO, J. (2015) Water policy in Spain: seeking a peaceful balance between transfers, desalination and wastewater reuse. International Journal of Water Resources Development.

MORALES GIL, A. y VERA REBOLLO, J.F. (1989) La Mancomunidad de Canales del Taibilla. Instituto Universitario de Geografía, Universidad de Alicante. Academia Alfonso X El Sabio. Alicante, 132 p.

MORALES GIL, A.; OLCINA CANTOS, J. y RICO AMOROS, A.M. (2000) Diferentes percepciones de la sequía en España: adaptación, catastrofismo e intentos de corrección. Investigaciones Geográficas, 23, 5-46.

MORALES GIL, A. (2001) Un modelo de eficiencia en el abastecimiento urbano de agua: la Mancomunidad de Canales del Taibilla. En CÁNOVAS, J. y MELGAREJO, J. (Coord.): Confederación Hidrográfica del Segura, 1926-2001, 75 aniversario, Ministerio de Medio Ambiente, pp. 292-305.

MORALES GIL, A. (2001) Agua y territorio en la Región de Murcia. Fundación Centro de Estudios Históricos e Investigaciones Locales. Murcia.

MOROTE SEGUIDO, A.F. (2014) Tipologías urbano-residenciales del litoral de Alicante: repercusiones territoriales. Ciudad y Territorio. Estudios Territoriales, vol. XLVI, 181, 431-443.

MOROTE SEGUIDO, A.F. (2015) Los grandes sistemas de abastecimiento de agua en el litoral de Alicante. Anales de Geografía, vol. 35, núm. 2, 97-120

MOROTE SEGUIDO, A.F. (2016) El uso del agua en los jardines de las urbanizaciones del litoral de Alicante. Prácticas de ahorro y sus causas. Investigaciones Geográficas, no 65, pp. $135-152$.

MOROTE, A.F. y HERNÁNDEZ, M. (2016) Urban sprawl and its effects on water demand: A case study of Alicante, Spain. Land Use Policy, 50, pp. 352-362.

NAVARRO, T. M. (2008). Las transacciones de derechos al uso del agua y su transferencia a las cuencas receptoras del Trasvase Tajo-Segura. En, Fanlo, A. (coord). La ordenación jurídica del trasvase Tajo-Segura. Instituto Euromediterráneo del Agua. Murcia. 
NAVARRO, T. M. (2010). Experiencias actuales de los bancos de agua en España. Estudio de los casos del Guadiana, Guadalquivir, Júcar y Segura. Administración de Andalucía, Revista Andaluza de Administración Pública, 76, 349-382.

NIETO LLOBET, A. (2012) Los años turbulentos. Mancomunidad de los Canales del Taibilla, 1927-1939.

NIETO LLOBET, A. (2013) El sueño se hace realidad (1939-1964). MCT, Cartagena.

NIETO LlOBET, A. (2014) El Plan de Ampliaciones. Llegan las aguas del Tajo. La MCT, 1965-1986. MCT, Cartagena.

OLCINA CANTOS, J. (2002) Planificación hidrológica y recursos de agua no convencionales en España. En: Insuficiencia Hídrica y Plan Hidrológico Nacional. Instituto Universitario de Geografía, Universidad de Alicante, Caja de Ahorros del Mediterráneo, 69-130.

OLCINA CANTOS, J. y RICO AMORÓS, A. (1999) Recursos de agua «no convencionales» en España. Depuración y desalación. En: Los usos del agua en España. Eds: Gil Olcina, A. y Morales Gil, A. Instituto Universitario de Geografía y Caja de Ahorros del Mediterráneo, Alicante, 203-252.

OLCINA CANTOS, J. y MOLTÓ MANTERO, E. (2010) "Recursos de agua no convencionales en España: estado de la cuestión”, Investigaciones Geográficas, no ${ }^{\circ}$ 51, Instituto Universitario de Geografía, Universidad de Alicante, pp. 131-163.

OLCINA, J., SAURÍ, D. y VERA, F. (2014) Turismo, cambio climático y agua: Escenarios de adaptación en la costa mediterránea española. En Libro Jubilar en Homenaje al Profesor Antonio Gil Olcina. Servicio de Publicaciones de la Universidad de Alicante, pp. 171-193

OlCINA, A. y RICO AMORÓS, A.M. (2015) Consorcio de Aguas de la Marina Baja. Gestión convenida, integral y sostenible del agua. Instituto Interuniversitario de Geografía, Universidad de Alicante.

PÉREZ BERROCAL, J., LINARES STUTZ, V. y GARCIA NICOLÁS, H. (2012) Adaptación a los regímenes de producción en la gestión de la explotación de las plantas desalinizadoras San Pedro II y Alicante II, Madrid, IX Congreso Internacional de la Asociación Española de Desalación y Reutilización.

PIQUERAS, J. (2012) Geografía del territorio valenciano. Naturaleza, economía y paisaje. Universidad de Valencia. Valencia. 
PLAZA MARTÍNEZ, A. y AYANZ LÓPEZ-CUERVO, J. (2009): Análisis comparativo del uso y gestión del agua en la provincia de Alicante y su entorno competitivo. Gestión eficiente del uso del agua en el ámbito urbano. (mimeo)

RICO AMORÓS, A.M. (2002) «Insuficiencia de recursos hídricos y competencia de usos en la Comunidad Valenciana», Boletín de la Asociación de Geógrafos Españoles, no $33,23-35$.

RICO AMORÓS. A.M. (2004) Sequías y Abastecimientos de Agua Potable en España. Boletín de la A.G.E. № 37 de 2004, pp. 137-181.

RICO AMOROS, A.M. (2007) "Tipologías de Consumo de agua en abastecimientos urbano-turísticos de la Comunidad Valenciana”, Investigaciones Geográficas, no 42, pp. $5-34$.

RICO AMORÓS, A.M. (2010) Plan Hidrológico Nacional y Programa A.G.U.A.: Repercusión en las regiones de Murcia y Valencia. Investigaciones Geográficas, 51, 235 267.

RICO AMOROS, A.M. (2014) La Mancomunidad de los Canales del Taibilla: un modelo de aprovechamiento conjunto de fuentes convencionales y desalinización de agua marina. En: Libro Jubilar en Homenaje al Profesor Antonio Gil Olcina, Servicio de Publicaciones de la Universidad de Alicante, pp. 367-394.

RICO AMORÓS, A.M. y HERNÁNDEZ HERNÁNDEZ, M. (2008) Ordenación del territorio, escasez de recursos hídricos, competencia de usos e intensificación de las demandas urbano-turísticas en la Comunidad Valenciana. Documents d'Anàlisi Geogràfica, 51, 79-109.

RICO AMORÓS, A.M.; OLCINA CANTOS, J. y SAURÍ, D. (2009) Tourist land use patterns and water demand: Evidence from the Western Mediterranean. Land Use Policy, 26, 493-501.

RICO AMORÓS, A.M., OLCINA CANTOS, J., BAÑOS CASTIÑEIRA, C.J. (2014) Competencias por el uso del agua en la provincia de Alicante: experiencias de gestión en la armonización de usos urbano-turísticos y agrícolas. Documents d'Anàlisi Geogràfica , vol. $60 / 3$, p. $523-548$

ROGERS, P. y HALL, A. W. (2003) La Gobernabilidad Efectiva del Agua, Global Water Partnership, GWP. №7.

SAURÍ, D. (2003) Lights and shadows of urban water demand management. The case of the metropolitan region of Barcelona. European Planning Studies, 11, 229-243. 
SECRETARIADO DIOCESANO DE MIGRACIÓN (2016) Aproximación estadística a la población extranjera en la Provincia de Alicante. http://astialicante.org/ wp-content/uploads/2013/05/Informe-estad\%C3\%ADstico-2016.pdf

STADDON, C. (2010) Managing Europe's water resources: 21st century challenges. Farnham: Ashgate.

SWYNGEDOUW, E. (2013) Into the sea: desalination as hydro-social fix in Spain. Annual Association American Geographers. 103 (2), 261-270.

TORRES, F.J.(1997) Ordenación del litoral en la Costa Blanca. Alicante. Publicaciones de la Universidad de Alicante.

VALENZUELA RUBIO, M. (1988) Estructura metropolitana y abastecimiento de agua. En GIL OLCINA, A. Y MORALES GIL, A. (1988): Demanda y economía del agua en España, Caja de Ahorros del Mediterráneo, Alicante, pp. 67-77.

VERA REBOLLO, J.F. (2002) Transferencia de recursos y demandas turísticas. En GIL OLCINA, A. y MORALES GIL, A.(Eds.) Insuficiencias hídricas y Plan hidrológico nacional. CAM e Instituto Universitario de Geografía. Universidad de Alicante, pp. 179200.

VERA REBOLLO, J.F (2005) El auge la función residencial en destinos turísticos del litoral mediterráneo: entre el crecimiento y la renovación. Papers de Turisme, 37-38, pp. 95-114.

VERA REBOLLO, J.F. (2006) Agua y modelos de desarrollo turístico: la necesidad de nuevos criterios para la gestión de los recursos. Boletín de la Asociación de Geógrafos Españoles, 42, 155-178.

VERA, J.F.; CASADO, J. Mํ. y RAMÓN, A. B. (2004) Consideraciones sobre el impacto del Plan Hidrológico Nacional en el sector turístico de la provincia de Alicante. En MELGAREJO MORENO, J. (Dir.) Repercusiones socioeconómicas del Plan Hidrológico Nacional en la provincia de Alicante. Alicante, Fundación COEPA, 205-267.

VERA, J.F.; OLCINA, J.; DÍEZ, D. (2009) Repercusiones del Trasvase Tajo-Segura en el sector turístico de la Región de Murcia». En MELGAREJO MORENO, J. (Dir.). El trasvase Tajo-Segura: repercusiones económicas, sociales y ambientales en la cuenca del Segura. Alicante: CAM, 465-516.

VERA REBOLLO, J.F; BAÑOS CASTINEIRA, C.J. (2010) Renovación y reestructuración de los destinos turísticos consolidados del litoral: las prácticas recreativas en la evolución del espacio turístico. Boletín de la Asociación de Geógrafos Españoles, 53, pp. 329-353. 

Los autores queremos expresar nuestro agradecimiento a aquellas personas que, de manera especial, nos han ayudado a la confección de este trabajo. En particular, a los funcionarios y autoridades de la MCT:

D. Adolfo Gallardo De Marco. Presidente-Delegado del Gobierno de la MCT.

D. Carlos Conradi Monner. Director de la MCT.

D. Antonio Fornet Aguado. Archivero de la MCT

D. Rafael M. Del Baño Zapata. Archivero de la MCT.

D. Fernando Hernández Lorente. MCT.

D. Jesús García Molina. Archivero Ayuntamiento de Orihuela. 


